\title{
Review and Assessment of Neutron Cross Section and Nubar Covariances for Advanced Reactor Systems
}

\author{
VM Maslov ${ }^{1,3}$ P Obložinský' ${ }^{2}$ and M Herman ${ }^{2}$ \\ 1 Joint Institute for Nuclear and Energy Research \\ Krasina Street 99, 220109 Minsk-Sosny, Belarus \\ 2 National Nuclear Data Center, Brookhaven National Laboratory \\ Upton, NY, 11973-5000, USA \\ 3 Guest Scientist at National Nuclear Data Center, Brookhaven National \\ Laboratory, Upton, NY, 11973-5000, USA
}

December 2008

The aim of this report is to review and assess preliminary neutron cross section and nubar covariance data for advanced reactor systems recently produced by the National Nuclear Data Center, BNL. The list of materials includes 19 actinides, the incident neutron energies cover the fast region (above about $1 \mathrm{keV}$ ) up to $20 \mathrm{MeV}$ and include cross sections for elastic, fission, inelastic, capture and $(n, 2 n)$ reaction channels, as well as prompt nubars (average number of emitted neutrons per fission). We focus on the diagonal terms of covariances matrices, that is, on cross section and nubar uncertainties. We found that quite a few of the preliminary BNL uncertainties should be improved and we propose such improved values. We also point out that in several instances, in particular 238-Pu and 242,244-Cm, basic ENDF/B-VII.0 evaluations are fairly poor and should be improved.

\footnotetext{
Notice: This manuscript has been co-authored by employees of Brookhaven Science Associates, LLC under Contract No. DE-AC02-98CH10886 with the U.S. Department of Energy. The publisher by accepting the manuscript for publication acknowledges that the United States Government retains a non-exclusive, paid-up, irrevocable, world-wide license to publish or reproduce the published form of this manuscript, or allow others to do so, for United States Government purposes.
} 


\section{DISCLAIMER}

This report was prepared as an account of work sponsored by an agency of the United States Government. Neither the United States Government nor any agency thereof, nor any of their employees, nor any of their contractors, subcontractors, or their employees, makes any warranty, express or implied, or assumes any legal liability or responsibility for the accuracy, completeness, or any third party's use or the results of such use of any information, apparatus, product, or process disclosed, or represents that its use would not infringe privately owned rights. Reference herein to any specific commercial product, process, or service by trade name, trademark, manufacturer, or otherwise, does not necessarily constitute or imply its endorsement, recommendation, or favoring by the United States Government or any agency thereof or its contractors or subcontractors. The views and opinions of authors expressed herein do not necessarily state or reflect those of the United States Government or any agency thereof. 


\begin{abstract}
In January 2007, the National Nuclear Data Center (NNDC) produced a set of preliminary neutron covariance data for the international project "Nuclear Data Needs for Advanced Reactor Systems". The project was sponsored by the OECD Nuclear Energy Agency (NEA), Paris, under the Subgroup 26 of the International Working Party on Evaluation Cooperation (WPEC). These preliminary covariances are described in two recent BNL reports $[1,2]$. The NNDC used a simplified version of the method developed by BNL and LANL that combines the recent Atlas of Neutron Resonances, the nuclear reaction model code EMPIRE and the Bayesian code KALMAN with the experimental data used as guidance. There are numerous issues involved in these estimates of covariances and it was decided to perform an independent review and assessment of these results so that better covariances can be produced for the revised version in future.

Reviewed and assessed are uncertainties for fission, capture, elastic scattering, inelastic scattering and $(\mathrm{n}, 2 \mathrm{n})$ cross sections as well as prompt nubars for 15 minor actinides $\quad\left({ }^{233,234,236} \mathrm{U}, \quad{ }^{237} \mathrm{~Np}, \quad{ }^{238,240,241,242} \mathrm{Pu}, \quad{ }^{241,242 \mathrm{~m}, 243} \mathrm{Am} \quad\right.$ and $\left.{ }^{242,243,244,245} \mathrm{Cm}\right)$ and 4 major actinides $\left({ }^{232} \mathrm{Th},{ }^{235,}{ }^{238} \mathrm{U}\right.$ and $\left.{ }^{239} \mathrm{Pu}\right)$. We examined available evaluations, performed comparison with experimental data, taken into account uncertainties in model parameterization and made use state-of-the-art nuclear reaction theory to produce the uncertainty assessment.
\end{abstract}





\section{Contents}

1. Introduction.............................................. 1

2. Elastic Scattering........................................ 4 $(\mathrm{n}, \mathrm{el})$ plots for 19 actinides

3. Fission Cross Sections................................... 9

$(\mathrm{n}, \mathrm{f})$ plots for 19 actinides

4. Inelastic Scattering...................................... 15

(n,n') plots for 19 actinides

5. Capture Cross Sections.................................... 18

$(\mathrm{n}, \gamma)$ plots for 19 actinides

6. (n,2n) Cross Sections........................................... 22

$(\mathrm{n}, 2 \mathrm{n})$ plots for 19 actinides

7. Prompt Fission Neutron Multiplicities.................... 25

$v$-bar plots for 19 actinides

8. Conclusions............................................... 29

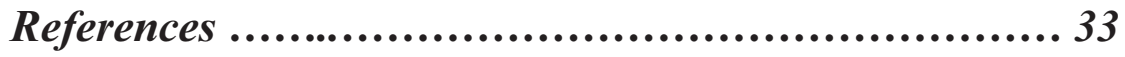

Appendix A: Tables of cross section covariances, from [1,2]

Appendix B: Tables of v-bar covariances, from [1,2] 


\section{List of Figures}

$\begin{array}{ll}2.1 & { }^{232} \mathrm{Th}(\mathrm{n}, \mathrm{el}) \\ 2.2 & { }^{238} \mathrm{U}(\mathrm{n}, \mathrm{el}) \\ 2.3 & { }^{236} \mathrm{U}(\mathrm{n}, \mathrm{el}) \\ 2.4 & { }^{234} \mathrm{U}(\mathrm{n}, \mathrm{el}) \\ 2.5 & { }^{238} \mathrm{Pu}(\mathrm{n}, \mathrm{el}) \\ 2.6 & { }^{240} \mathrm{Pu}(\mathrm{n}, \mathrm{el}) \\ 2.7 & { }^{242} \mathrm{Pu}(\mathrm{n}, \mathrm{el}) \\ 2.8 & { }^{242} \mathrm{Cm}(\mathrm{n}, \mathrm{el}) \\ 2.9 & { }^{244} \mathrm{Cm}(\mathrm{n}, \mathrm{el}) \\ & { }^{235} \mathrm{U}(\mathrm{n}, \mathrm{el}) \\ 2.10 & { }^{233} \mathrm{U}(\mathrm{n}, \mathrm{el}) \\ 2.11 & { }^{239} \mathrm{Pu}(\mathrm{n}, \mathrm{el}) \\ 2.13 & { }^{241} \mathrm{Pu}(\mathrm{n}, \mathrm{el}) \\ 2.14 & { }^{243} \mathrm{Cm}(\mathrm{n}, \mathrm{el}) \\ 2.15 & { }^{245} \mathrm{Cm}(\mathrm{n}, \mathrm{el}) \\ 2.16 & { }^{237} \mathrm{~Np}(\mathrm{n}, \mathrm{el}) \\ 2.17 & { }^{241} \mathrm{Am}(\mathrm{n}, \mathrm{el}) \\ 2.18 & { }^{243} \mathrm{Am}(\mathrm{n}, \mathrm{el}) \\ 2.19 & { }^{242 \mathrm{~m}} \mathrm{Am}(\mathrm{n}, \mathrm{el})\end{array}$

$3.1{ }^{232} \operatorname{Th}(\mathrm{n}, \mathrm{f})$

$3.2{ }^{238} \mathrm{U}(\mathrm{n}, \mathrm{f})$

$3.3{ }^{236} \mathrm{U}(\mathrm{n}, \mathrm{f})$

$3.4 \quad{ }^{234} \mathrm{U}(\mathrm{n}, \mathrm{f})$

$3.5 \quad{ }^{238} \mathrm{Pu}(\mathrm{n}, \mathrm{f})$

3.6 ${ }^{240} \mathrm{Pu}(\mathrm{n}, \mathrm{f})$

$3.7 \quad{ }^{242} \mathrm{Pu}(\mathrm{n}, \mathrm{f})$

$3.8 \quad{ }^{242} \mathrm{Cm}(\mathrm{n}, \mathrm{f})$

$3.9 \quad{ }^{244} \mathrm{Cm}(\mathrm{n}, \mathrm{f})$

$3.10 \quad{ }^{235} \mathrm{U}(\mathrm{n}, \mathrm{f})$

$3.11{ }^{233} \mathrm{U}(\mathrm{n}, \mathrm{f})$

$3.12{ }^{239} \mathrm{Pu}(\mathrm{n}, \mathrm{f})$

$3.13{ }^{241} \mathrm{Pu}(\mathrm{n}, \mathrm{f})$

$3.14{ }^{243} \mathrm{Cm}(\mathrm{n}, \mathrm{f})$

$3.15{ }^{245} \mathrm{Cm}(\mathrm{n}, \mathrm{f})$

$3.16 \quad{ }^{237} \mathrm{~Np}(\mathrm{n}, \mathrm{f})$

$3.17{ }^{241} \mathrm{Am}(\mathrm{n}, \mathrm{f})$

$3.18{ }^{243} \operatorname{Am}(\mathrm{n}, \mathrm{f})$

$3.19{ }^{242 \mathrm{~m}} \mathrm{Am}(\mathrm{n}, \mathrm{f})$
Chapter 2: Elastic Scattering

\section{Chapter 3: Fission Cross Sections}


Chapter 4: Inelastic Scattering

$\begin{array}{ll}4.1 & { }^{232} \mathrm{Th}\left(\mathrm{n}, \mathrm{n}^{\prime}\right. \\ 4.2 & { }^{238} \mathrm{U}\left(\mathrm{n}, \mathrm{n}^{\prime}\right) \\ 4.3 & { }^{236} \mathrm{U}\left(\mathrm{n}, \mathrm{n}^{\prime}\right) \\ 4.4 & { }^{234} \mathrm{U}\left(\mathrm{n}, \mathrm{n}^{\prime}\right) \\ 4.5 & { }^{238} \mathrm{Pu}\left(\mathrm{n}, \mathrm{n}^{\prime}\right) \\ 4.6 & { }^{240} \mathrm{Pu}\left(\mathrm{n}, \mathrm{n}^{\prime}\right) \\ 4.7 & { }^{242} \mathrm{Pu}\left(\mathrm{n}, \mathrm{n}^{\prime}\right) \\ 4.8 & { }^{242} \mathrm{Cm}\left(\mathrm{n}, \mathrm{n}^{\prime}\right) \\ 4.9 & { }^{244} \mathrm{Cm}\left(\mathrm{n}, \mathrm{n}^{\prime}\right) \\ 4.10 & { }^{235} \mathrm{U}\left(\mathrm{n}, \mathrm{n}^{\prime}\right) \\ 4.11 & { }^{233} \mathrm{U}\left(\mathrm{n}, \mathrm{n}^{\prime}\right) \\ 4.12 & { }^{239} \mathrm{Pu}\left(\mathrm{n}, \mathrm{n}^{\prime}\right) \\ 4.13 & { }^{241} \mathrm{Pu}\left(\mathrm{n}, \mathrm{n}^{\prime}\right) \\ 4.14 & { }^{243} \mathrm{Cm}\left(\mathrm{n}, \mathrm{n}^{\prime}\right) \\ 4.15 & { }^{245} \mathrm{Cm}\left(\mathrm{n}, \mathrm{n}^{\prime}\right) \\ 4.16 & { }^{237} \mathrm{~Np}\left(\mathrm{n}, \mathrm{n}^{\prime}\right) \\ 4.17 & { }^{241} \mathrm{Am}\left(\mathrm{n}, \mathrm{n}^{\prime}\right) \\ 4.18 & { }^{243} \mathrm{Am}\left(\mathrm{n}, \mathrm{n}^{\prime}\right) \\ 4.19 & { }^{242 \mathrm{~m}} \mathrm{Am}\left(\mathrm{n}^{\prime}, \mathrm{n}^{\prime}\right)\end{array}$

Chapter 5: Capture Cross Sections

$\begin{array}{ll}5.1 & { }^{232} \mathrm{Th}(\mathrm{n}, \text { gamma }) \\ 5.2 & { }^{238} \mathrm{U}(\mathrm{n}, \text { gamma }) \\ 5.3 & { }^{236} \mathrm{U}(\mathrm{n}, \text { gamma }) \\ 5.4 & { }^{234} \mathrm{U}(\mathrm{n}, \text { gamma }) \\ 5.5 & { }^{238} \mathrm{Pu}(\mathrm{n}, \text { gamma }) \\ 5.6 & { }^{240} \mathrm{Pu}(\mathrm{n}, \text { gamma }) \\ 5.7 & { }^{242} \mathrm{Pu}(\mathrm{n}, \text { gamma }) \\ 5.8 & { }^{242} \mathrm{Cm}(\mathrm{n}, \text { gamma }) \\ 5.9 & { }^{244} \mathrm{Cm}(\mathrm{n}, \text { gamma }) \\ & \\ 5.10 & { }^{235} \mathrm{U}(\mathrm{n}, \text { gamma }) \\ 5.11 & { }^{233} \mathrm{U}(\mathrm{n}, \text { gamma }) \\ 5.12 & { }^{239} \mathrm{Pu}(\mathrm{n}, \text { gamma }) \\ 5.13 & { }^{241} \mathrm{Pu}(\mathrm{n}, \text { gamma }) \\ 5.14 & { }^{243} \mathrm{Cm}(\mathrm{n}, \text { gamma }) \\ 5.15 & { }^{245} \mathrm{Cm}(\mathrm{n}, \text { gamma }) \\ 5.16 & { }^{237} \mathrm{~Np}(\mathrm{n}, \text { gamma }) \\ 5.17 & { }^{241} \mathrm{Am}(\mathrm{n}, \text { gamma }) \\ 5.18 & { }^{243} \mathrm{Am}(\mathrm{n}, \text { gamma }) \\ 5.19 & { }^{242 \mathrm{~m}} \mathrm{Am}(\mathrm{n}, \text { gamma })\end{array}$




$\begin{array}{ll}6.1 & { }^{232} \mathrm{Th}(\mathrm{n}, 2 \mathrm{n}) \\ 6.2 & { }^{238} \mathrm{U}(\mathrm{n}, 2 \mathrm{n}) \\ 6.3 & { }^{236} \mathrm{U}(\mathrm{n}, 2 \mathrm{n}) \\ 6.4 & { }^{234} \mathrm{U}(\mathrm{n}, 2 \mathrm{n}) \\ 6.5 & { }^{238} \mathrm{Pu}(\mathrm{n}, 2 \mathrm{n}) \\ 6.6 & { }^{240} \mathrm{Pu}(\mathrm{n}, 2 \mathrm{n}) \\ 6.7 & { }^{242} \mathrm{Pu}(\mathrm{n}, 2 \mathrm{n}) \\ 6.8 & { }^{242} \mathrm{Cm}(\mathrm{n}, 2 \mathrm{n}) \\ 6.9 & { }^{244} \mathrm{Cm}(\mathrm{n}, 2 \mathrm{n}) \\ & \\ 6.10 & { }^{235} \mathrm{U}(\mathrm{n}, 2 \mathrm{n}) \\ 6.11 & { }^{233} \mathrm{U}(\mathrm{n}, 2 \mathrm{n}) \\ 6.12 & { }^{239} \mathrm{Pu}(\mathrm{n}, 2 \mathrm{n}) \\ 6.13 & { }^{241} \mathrm{Pu}(\mathrm{n}, 2 \mathrm{n}) \\ 6.14 & { }^{243} \mathrm{Cm}(\mathrm{n}, 2 \mathrm{n}) \\ 6.15 & { }^{245} \mathrm{Cm}(\mathrm{n}, 2 \mathrm{n}) \\ 6.16 & { }^{237} \mathrm{~Np}(\mathrm{n}, 2 \mathrm{n}) \\ 6.17 & { }^{241} \mathrm{Am}(\mathrm{n}, 2 \mathrm{n}) \\ 6.18 & { }^{243} \mathrm{Am}(\mathrm{n}, 2 \mathrm{n}) \\ 6.19 & { }^{242 \mathrm{~m}} \mathrm{Am}(\mathrm{n}, 2 \mathrm{n})\end{array}$

Chapter 7: Prompt Fission Neutron Multiplicities

$\begin{array}{ll}7.1 & { }^{232} \mathrm{Th}-\text { nubar } \\ 7.2 & { }^{238} \mathrm{U}-\text { nubar } \\ 7.3 & { }^{236} \mathrm{U}-\text { nubar } \\ 7.4 & { }^{234} \mathrm{U}-\text { nubar } \\ 7.5 & { }^{238} \mathrm{Pu}-\text { nubar } \\ 7.6 & { }^{240} \mathrm{Pu}-\text { nubar } \\ 7.7 & { }^{242} \mathrm{Pu}-\text { nubar } \\ 7.8 & { }^{242} \mathrm{Cm}-\text { nubar } \\ 7.9 & { }^{244} \mathrm{Cm}-\text { nubar } \\ & \\ 7.10 & { }^{235} \mathrm{U}-\text { nubar } \\ 7.11 & { }^{233} \mathrm{U}-\text { nubar } \\ 7.12 & { }^{239} \mathrm{Pu}-\text { nubar } \\ 7.13 & { }^{241} \mathrm{Pu}-\text { nubar } \\ 7.14 & { }^{243} \mathrm{Cm}-\text { nubar } \\ 7.15 & { }^{245} \mathrm{Cm}-\text { nubar } \\ 7.16 & { }^{237} \mathrm{~Np}-\text { nubar } \\ 7.17 & { }^{241} \mathrm{Am}-\text { nubar } \\ 7.18 & { }^{243} \mathrm{Am}-\text { nubar } \\ 7.19 & { }^{242 m} \mathrm{Am}-\text { nubar }\end{array}$




\section{Chapter I}

\section{Introduction}

The NNDC produced preliminary uncertainties and correlation matrices for 15 actinides, including ${ }^{233,234,236} \mathrm{U},{ }^{237} \mathrm{~Np},{ }^{238,240,241,242} \mathrm{Pu},{ }^{241,242 \mathrm{~m}, 243} \mathrm{Am},{ }^{242,243,244,245} \mathrm{Cm}[1,2]$. These results are crosschecked by making comparisons with measured cross section data and newly calculated data for fission, capture, elastic, inelastic, (n,2n) cross sections and neutron multiplicities of major $\left({ }^{232} \mathrm{Th},{ }^{235,238} \mathrm{U},{ }^{239} \mathrm{Pu}\right)$ and minor actinides in the unresolved resonance region (URR) and fast neutron energy region.

Notwithstanding the years of experimental and theoretical efforts, the evaluated capture, $(n, 2 n)$, neutron inelastic and inelastic scattering cross sections of most thoroughly investigated nuclides like ${ }^{232} \mathrm{Th},{ }^{235} \mathrm{U},{ }^{238} \mathrm{U}$ or ${ }^{239} \mathrm{Pu}$ in major data libraries differ a lot. Since these cross sections are obtained (or might be obtained) via Hauser-Feshbach model calculations, the part of the differences might be attributed to the unjustified simplifications in modeling excited nucleus (either composite, compound or residual) energy spectra or neutron-nucleus interactions. For fissile target nuclides ${ }^{235} \mathrm{U}$ or ${ }^{239} \mathrm{Pu}$ the spectroscopic properties of the transition states at inner and outer saddles deformations of fissioning ${ }^{236} \mathrm{U}$ or ${ }^{240} \mathrm{Pu}$ nuclides, respectively, are of key importance. Though the relative contributions of transition states to the fission cross section are much affected by the target spin value $\mathrm{I}^{\pi}=7 / 2^{-}$for ${ }^{235} \mathrm{U}$ and $1 / 2^{+}$for ${ }^{239} \mathrm{Pu}$ and relative heights of the inner and outer fission barrier humps [3, 4, 5], the fair description of ${ }^{235} \mathrm{U}(\mathrm{n}, \mathrm{f})\left(\mathrm{I}^{\pi}=7 / 2^{-}\right)[3],{ }^{237} \mathrm{U}(\mathrm{n}, \mathrm{f})\left(\mathrm{I}^{\pi}=1 / 2^{+}\right)[5],{ }^{233} \mathrm{U}(\mathrm{n}, \mathrm{f})\left(\mathrm{I}^{\pi}=5 / 2^{+}\right)$and ${ }^{239} \mathrm{Pu}(\mathrm{n}, \mathrm{f})\left(\mathrm{I}^{\pi}=1 / 2^{+}\right)$allows to reproduce measured data on capture and inelastic scattering rather reliably. That approach paves the way to prediction of fission, capture, elastic and inelastic scattering cross sections at $1 \mathrm{keV}-5 \mathrm{MeV}$ energy range for fissile minor actinide nuclides.

Major source of discrepancies in case of inelastic scattering on ${ }^{232} \mathrm{Th}$ or ${ }^{238} \mathrm{U}$ targets are the coupling strengths of the deformed optical potential $[6,7]$. Experimental data on inelastic neutron scattering are analyzed in a Hauser-Feshbach-Moldauer approach using a coupled channel estimates of the direct inelastic scattering. For the direct excitation of the ${ }^{238} \mathrm{U}$ ground state rotational band levels with $\mathrm{I}^{\pi}=0_{1}^{+}, 2^{+}, 4^{+}, 6^{+}, 8^{+}$the rigid rotator model was used, whereas for the direct excitation of members of the $\beta-, \gamma-\left(\mathrm{K}^{\pi}=0_{2}{ }^{+}, 0_{2}{ }^{+}, 2_{2}{ }^{+}\right)$and the first octupole band $\mathrm{K}^{\pi}=0^{-}$, a soft-deformable rotator model was used $[6,7]$. Quadrupole, octupole, hexadecapole and gamma-deformation parameters were defined by consistent analysis of excited rotational-vibrational band structures and excitation cross section of the relevant excited levels of ${ }^{232} \mathrm{Th}$ or ${ }^{238} \mathrm{U}$. Structures evident in measured neutron emission 
spectra for En $\sim 1-6 \mathrm{MeV}$ are correlated with excitation of levels of $\mathrm{K}^{\pi}=0^{-}$and $\mathrm{K}^{\pi}=0_{2}{ }^{+}, 0_{2}^{+}, 2_{2}^{+}$bands. That approach was used for the ${ }^{232} \mathrm{Th}$ and ${ }^{238} \mathrm{U}$ inelastic scattering data analysis. Similar quality of inelastic data description was obtained. That means we have a viable tool for inelastic cross section prediction for even-even target nuclides. While compound scattering component is influenced mainly by the fission competition, in case if high fissility $\mathrm{Pu}$ or $\mathrm{Cm}$ nuclides the role of direct excitation of vibrational levels will be much enhanced. That should be taken into account when making the uncertainty estimates of the relevant cross sections.

For neutron capture reactions on even-even $\mathrm{U}, \mathrm{Pu}$ and $\mathrm{Cm}$ nuclei in unresolved resonance and fast neutron energy ranges the methods, proven in case of ${ }^{232} \mathrm{Th}(\mathrm{n}, \gamma)$ and ${ }^{238} \mathrm{U}(\mathrm{n}, \gamma)$ [8, 9] data analysis would be used. Advances of the present approach over previous evaluations are due to precise treatment fission and neutron emission competition, which depends on the $(\mathrm{Z}, \mathrm{N})$-composition of the compound nuclei.

${ }^{235} \mathrm{U}(\mathrm{n}, \mathrm{xn})$ and ${ }^{238} \mathrm{U}(\mathrm{n}, \mathrm{xn})$ reaction cross sections and prompt fission neutron spectra (PFNS) are affected by the emissive fission chances distribution $\beta_{x}=\sigma(n, x n f) / \sigma(n, F)$ of ${ }^{235} U(n, F)[10]$ and ${ }^{238} U(n, F)$ $[11,12,13]$, respectively. In present approach $\beta_{\mathrm{x}}$ are based on consistent description of the cross section database and PFNS, they differ a lot from the evaluations of ENDF/B-VII.0 [14] and JEFF-3.1 [15]. That peculiarity influences most the (n, xn) cross section discrepancies. In case of poorly investigated minor actinides the $\beta_{\mathrm{x}}$ differences defines the $(\mathrm{n}, \mathrm{xn})$ cross section differences and relevant uncertainties.

Recently released ENDF/B-VII.0 evaluated data library [14] much contributed to recognition of the need of re-examining the major principal reactions, such as neutron capture on ${ }^{238} \mathrm{U}$ or inelastic scattering on ${ }^{235} \mathrm{U}$ and ${ }^{239} \mathrm{Pu}$, to tell nothing about prompt fission neutron spectra. The assessment of the preliminary covariance data produced by the NNDC for minor actinides should be based on educated expectations, which are grounded mostly on the accumulated knowledge of major actinide data analyses. It is exemplified in the ENDF/B-VII.0 [14], JENDL-3.3 [16], JEFF-3.1 [15] evaluated data files and data files, produced by Maslov et al. [17-34] (a number of these minor actinide data files are adopted for JENDL-3.3, JEFF-3.1 and ENDF/B-VII.0 data libraries, in case of major fertile nuclides, i.e. ${ }^{238} \mathrm{U}$ and ${ }^{232} \mathrm{Th}$ the evaluations by Maslov et al. [19, 23] were in many respects followed later on in other data libraries) as well as calculations specifically made during that report compilation.

Disentangling of the model deficiencies, when measured data fits are rather poor, and model parameter uncertainties, turned out to be a major problem. The calculations with the EMPIRE code [35], used in [1, 2] were fitted to the evaluated data of ENDF/B-VII.0 [14] data library, except ${ }^{235} \mathrm{U},{ }^{238} \mathrm{U}$ 
and ${ }^{239} \mathrm{Pu}$ nuclides. However, in a number of cases these evaluated data are much different from the newest measured data (stemming from direct neutron or surrogate measurements) or calculations, made with the modern theoretical approaches (see Proceedings of the International Conference on Nuclear Data for Science and Technology, Nice, France, 22-27 April 2007). That happens either for poorly investigated nuclides like ${ }^{242,244} \mathrm{Cm},{ }^{238} \mathrm{Pu}$ or major fissile nuclides like ${ }^{235} \mathrm{U}$ or ${ }^{239} \mathrm{Pu}$. Though in latter case covariance estimates were adopted from JENDL-3.3 data library, the same conclusion applies for JENDL-3.3 library as well. In a number of cases recent ENDF/B-VII.0 evaluations are much different from those of JENDL-3.3. These peculiarities might influence the realistic estimate of covariances, whatever would be the adopted evaluated data file, however, the deficiencies of the models, used for the specific data evaluation, can not be simulated by enlarging the uncertainties of the model parameters.

For actinide nuclides the most important correlation of the parameters, which is frequently ignored, is imposed by the fission cross-section description constraint. One of the purposes of the present analysis is to clear out the cases, when say $\sim 20 \%$ estimate of the relative standard deviations (r.s.d) is claimed for cross sections (or nu-bars), which differ from the experimental data or other evaluations, which seem quite reasonable, by $\sim 50-200 \%$. The important point is that those "other evaluations" are often produced using more refined approaches as compared to those previously used. Similar situation occurs for many minor actinide cross sections. Otherwise, we should assume that r.s.d refers to some virtual "true " cross section. That is the point where the question of model simplification comes into play. For example, there is some systematic for capture cross sections for ${ }^{233} \mathrm{U},{ }^{235} \mathrm{U}$ and ${ }^{237} \mathrm{U}$, which is violated in ENDF/B-VII.0 [14] for ${ }^{237} \mathrm{U}$. Surrogate measurements for ${ }^{237} \mathrm{U}(\mathrm{n}, \gamma)$ and $\left.{ }^{237} \mathrm{U}(\mathrm{n}, 2 \mathrm{n})\right)$ at LLNL, when available, might provide guidance for similar predictions for $\mathrm{Pu}$ and $\mathrm{Cm}$ targets.

The review and assessment of relative standard deviations is provided below for the 15-group representation for fission, capture, elastic, inelastic, $(\mathrm{n}, 2 \mathrm{n})$ cross sections and prompt fission neutron multiplicities. 


\section{Chapter 2}

\section{Elastic scattering}

It was a common practice for major actinides not long ago and it still is for some minor actinides $\left({ }^{244} \mathrm{Cm}\right.$ data file of ENDF/B-VII.0, borrowed from JENDL-3.3, for example) to obtain the elastic cross section as a difference of the total cross section and all partial neutron cross section. In that case the uncertainty of the elastic cross section depends in a rather sophisticated fashion upon the uncertainties of the involved partial cross sections.

In another case, when the elastic scattering cross section is defined as a sum of shape elastic cross section plus a compound elastic scattering cross section, the uncertainty of the evaluated/calculated elastic scattering cross section would be defined by the uncertainties of the calculated elastic cross section and that of the measured elastic scattering data if available. The contribution of the compound elastic scattering cross section much depends on the fissility of the compound nuclides. In case of high fissility $\mathrm{Cm}$ even-odd compound nuclides ${ }^{243,245} \mathrm{Cm}$ the contribution of the compound elastic scattering might be relatively low, but it still will impose rather high uncertainty on the lumped inelastic scattering cross section. In summary, it might be argued there is no justification, that the elastic scattering cross section r.s.d of $\mathrm{U}, \mathrm{Pu}$ of $\mathrm{Cm}$ could be more optimistic than those of ${ }^{238} \mathrm{U}$ or ${ }^{232} \mathrm{Th}$.

${ }^{232}$ Th: Fig. 2.1 shows, that the uncertainty estimate in the $3 \mathrm{~d}$ group (first minimum of the elastic scattering cross section) for the data file adopted for ENDF/B-VII.0 [36] should be decreased to the level of $2 \%$ (similar to adjacent groups) and increased in some lower energy groups due to uncertainty of the total cross section mostly. In fact, in case of ${ }^{232} \mathrm{Th}[19]$ and ${ }^{238} \mathrm{U}$ [23] there is no robust justification to increase the cross section uncertainty at first minimum (see also [37], as predicted in BNL evaluation [1, 2], though the measured data [38-46] scatter a lot (see Fig. 2.1).

${ }^{238} \mathrm{U}$ : Fig. 2.2 shows, that the elastic scattering cross section uncertainty estimate of JENDL-3.3 data file [16] is much higher than that of ${ }^{232} \mathrm{Th}$ data file, adopted for ENDF/B-VII.0 data library. It should be mentioned that the relevant measured data base for these two nuclides, ${ }^{232} \mathrm{Th}[38-46]$ and ${ }^{238} \mathrm{U}$ [46-52] are rather similar. The compound elastic scattering contribution/uncertainty are similar as well. That means we can impose the r.s.d. at incident neutron energy above $2 \mathrm{keV}$ equal to $2 \%$ (see Fig. 2.2).

${ }^{236} \mathbf{U}$ : the r.s.d., shown on the Fig.2.3 gives increased uncertainty in the first minimum around 2 $\mathrm{MeV}$ and in the incident neutron energy range of 200-500 keV. Evidently, the r.s.d should be less optimistic than in case of either ${ }^{238} \mathrm{U}$ or ${ }^{232} \mathrm{Th}$, especially around $100 \mathrm{keV}$ and at lower energies. At this 
energy range ENDF/B-VII.0 estimate is much discrepant with previous evaluations. The contribution of the compound elastic scattering at $1 \mathrm{keV}$ is just as high as in case of ${ }^{232} \mathrm{Th}$, i.e. the inelastic/capture cross section uncertainty contributes to the r.s.d. in a similar way (see Fig. 2.3).

${ }^{234} \mathbf{U}$ : the r.s.d. of $[1,2]$, which is shown on the Fig. 2.4 gives increased uncertainty in the first minimum and around incident neutron energy of 10-50 keV. The r.s.d should be less optimistic than in case of ${ }^{236} \mathrm{U},{ }^{238} \mathrm{U}$ or ${ }^{232} \mathrm{Th}$, because there is no precise data on capture and no inelastic scattering data at higher energies to fix the compound contribution to the elastic scattering cross section. At the MeVenergy range the ENDF/B-VII.0 estimate is very similar to previous evaluations of JENDL-3.3 and evaluation by Maslov et al. [21], adopted for JEFF-3.1 [15]. The increased cross section uncertainty at first minimum should be discarded as for other nuclides just considered (see Fig. 2.4).

${ }^{238}$ Pu: Fig. 2.5 shows that for the incident neutron energies 1-67.4 keV the r.s.d. value for ENDF/B-VII.0 [1, 2] should be increased up to $20 \%$ because of discrepancy of ENDF/B-VII.0 with most recent evaluation by Maslov et al. [32], which is adopted for JENDL-3.3 [16]. The r.s.d of $3 \%$ at higher energy looks reasonable. Discrepancy of JENDL-3.2 data with other evaluations in no way can be perceived as a justification for the increase of the r.s.d. values in the $200 \mathrm{keV}-2 \mathrm{MeV}$ energy range, proposed in BNL covariance evaluation $[1,2]$ (see Fig. 2.5).

${ }^{240} \mathrm{Pu}$ : in that nuclide case the drop of r.s.d. in the $1^{\text {st }}$ group does not look justified. Here the r.s.d is assumed to be similar to that of ${ }^{234} \mathrm{U}$ (see Fig. 2.6).

${ }^{242}$ Pu: Fig. 2.7 shows, that in that case the ENDF/B-VII.0 (ENDF/B-VI) evaluation is compatible with most recent evaluation by Maslov et al. [33]. The drop of r.s.d. in $1^{\text {st }}$ and $2^{\text {nd }}$ groups does not look justified, as well as increase of r.s.d. in $3 \mathrm{~d}$ and $4^{\text {th }}$ groups. The r.s.d is assumed similar to that of ${ }^{234} \mathrm{U}$. The guidance comes from the ${ }^{238} \mathrm{U}$ elastic scattering analysis [23]. There is no justification, that the r.s.d of ${ }^{242} \mathrm{Pu}$ could be more optimistic than those of ${ }^{238} \mathrm{U}$ or ${ }^{232} \mathrm{Th}$ (see Fig. 2.7).

${ }^{242} \mathbf{C m}$ : in the $1^{\text {st }}$ group the uncertainty should increased up to $10 \%$, as shown on Fig. 2.8. At lower energies the discrepancy of ENDF/B-VII.0 evaluation with present and BROND estimates give estimates of r.s.d. In the group of 9-2 keV the BNL [1,2] estimate of r.s.d should be decreased. At these low energies major uncertainty comes from the compound elastic scattering cross section. The compound elastic scattering cross sections of BROND [53] and present calculations are rather close, since they produce similar estimates of the fission cross section in keV-energy range and up to $1 \mathrm{MeV}$ (see Fig. 2.8). 
${ }^{244} \mathrm{Cm}$ : JENDL-3.3 evaluation [16] is accepted for the ENDF/B-VII.0 [14] library. Decrease of r.s.d. in the fast neutron energy range from $10 \%$ to $5 \%$ and eventually $3 \%$ is justified by small discrepancy of JENDL-3.3 data at one hand an BROND and present calculation at the other hand. Evidently, in JENDL-3.3 data file the elastic cross section is obtained as a difference of the total cross section and partial neutron cross sections (see Fig. 2.9).

${ }^{235} \mathbf{U}$ : in case of fissile nuclides the contribution of the compound elastic scattering cross section is much lower than in case of even-even targets, as well as its influence on the r.s.d. values (see Fig. 2.10). The covariances of JENDL-3.3 and data file itself are adopted for BNL report [1, 2]. The discrepancy of JENDL-3.3 data with present calculation and measured data [46, 47, 54-57] scattering and systematic differences, gives guidance to increase the r.s.d. at incident neutron energies higher than $498 \mathrm{keV}$ (see Fig. 2.10).

${ }^{233} \mathrm{U}$ : ENDF/B-VII.0 and present estimates are systematically different in the energy range 1$700 \mathrm{keV}$, at higher energies both evaluations are consistent with each other and Haouat et al. [46] data within 3\% (see Fig. 2.11). The non-smooth shape of the elastic scattering cross section of ENDF/BVII.0 at $\mathrm{E}_{\mathrm{n}}<70 \mathrm{keV}$ differs very much from the present estimate. The non-smooth behavior of evaluated cross sections of JENDL-3.3 and ENDF/B-VII.0 seem to be due to normalizations to measured data on competing reactions. Our estimate is based on optical and statistical model fits of total, fission and capture cross sections. The same approach was pursued in case of ${ }^{235} \mathrm{U}$ and ${ }^{239} \mathrm{Pu}$, in both cases consistent fits were obtained. The r.s.d. values for ENDF/B-VII.0 evaluation should be fixed to 10-12\% in $1 \mathrm{keV}-1.5 \mathrm{MeV}$, while at higher energies 2-3\% value looks justified (see Fig. 2.11).

${ }^{239} \mathrm{Pu}$ : in case of ${ }^{239} \mathrm{Pu}$ target nuclide the contribution of the compound elastic scattering cross section around $1 \mathrm{keV}$ is higher than in case of ${ }^{235} \mathrm{U}$ target, as shown on Fig. 2.12. That is due to lower fission cross section of ${ }^{239} \mathrm{Pu}$ in keV energy range. The covariances of JENDL-3.3 and data file itself are adopted for the BNL report $[1,2]$. The discrepancy of JENDL-3.3 data with present calculation and measured data $[46,47,57,58,59]$ gives guidance to decrease the r.s.d., as shown on Fig. 2.12

${ }^{241} \mathrm{Pu}$ : ENDF/B-VII.0 and present estimates are systematically different in the energy range 40$1000 \mathrm{keV}$, at higher energies both evaluations are roughly consistent with each other, but non-smooth shape is a clear indication, that ENDF/B-VII.0 data were adjusted to be consistent with total and partial cross sections. That means the procedure to estimate the r.s.d. values for ENDF/B-VII.0 data file should be different from that adopted in case of ${ }^{239} \mathrm{Pu}$. Present r.s.d. estimate is fixed at $10-11 \%$ at $1-1500 \mathrm{keV}$ energy range and 2-3\% at higher energies (see Fig. 2.13). 
${ }^{243} \mathrm{Cm}$ : in ENDF/B-VII.0 data file, the evaluation by Maslov et al. [26] was adopted. In JENDL3.3 [16] basically the same evaluation is adopted, but the fission cross section was deliberately renormalized (increased by approximately $30 \%$ ) to Fursov et al. [60] data at 0.1-14.9 MeV energy range, while the elastic scattering was adjusted to be consistent with total and partial cross sections, adopted from Maslov et al. [26] evaluation. That will influence mainly the compound elastic scattering contribution, however recent surrogate measurements of ${ }^{243} \mathrm{Cm}(\mathrm{n}, \mathrm{F})$ cross section supported the data by Fomushkin et al. [61, 62], on which the evaluation by Maslov et al. [26] was based. Note, that because of high fissility of ${ }^{244} \mathrm{Cm}$ compound nuclide the influence of the uncertainty of compound elastic scattering on the lumped elastic scattering cross section would be diminished. In fact, there is no other evaluations or experimental data on elastic scattering to be compared with. Values of r.s.d are fixed at $3 \%$ in fast neutron energy range. Note, that procedure adopted to estimate the r.s.d. values for ENDF/BVII.0 data file of ${ }^{243} \mathrm{Cm}$ should be different from that adopted in case of major actinides like ${ }^{235} \mathrm{U}$ or ${ }^{239} \mathrm{Pu}$. That difference complicates severely the overall reliability of r.s.d. estimates for minor actinides (see Fig. 2.14).

${ }^{245} \mathrm{Cm}$ : in ENDF/B-VII.0 data file, the evaluation by Maslov et al. [27] was adopted. In JENDL3.3 [16] basically the same evaluation is adopted, but the fission cross section was deliberately renormalized (increased by approximately $5 \%$ ) to Fursov et al. [60] data at $14.9 \mathrm{MeV}$, the elastic scattering was adjusted to be consistent with total and partial cross sections, adopted from Maslov et al. [27] evaluation. In fact, there is no other evaluations or experimental data on elastic scattering to be compared with. Values of r.s.d are fixed at 3\% in the fast neutron energy range (see Fig. 2.15).

${ }^{237} \mathrm{~Np}$ : present calculation is compatible with ENDF/B-VII.0 [14] calculations within 2 or $3 \%$ at $\mathrm{E}_{\mathrm{n}}>100 \mathrm{keV}$ (see Fig. 2.16). At lower energies the $20 \%$ difference is observed between present calculation and ENDF/B-VII.0 [14] and JENDL-3.3 [16] evaluations. In the two latter cases the elastic scattering was adjusted to be consistent with total and partial cross sections. That is a questionable procedure, since the evaluated inelastic cross sections of ENDF/B-VII.0 and JENDL-3.3 evaluations is in severe disagreement with measured data by Kornilov et al. [63] on the inelastic scattering of neutrons, while our approach produces consistent description of $(n, f),\left(n, n^{\prime}\right)$ and $(n, \gamma)$ measured data. However, our estimate of the elastic scattering is quite consistent with the estimate for the ${ }^{241} \mathrm{Am}$ target nuclide by Maslov et al. [17]. In case of ${ }^{237} \mathrm{~Np}$ and ${ }^{241} \mathrm{Am}$ the compound elastic scattering contributions are rather similar and they should be similar, since the measured databases of competing reactions are quite similar. 
${ }^{241} \mathrm{Am}$ : there are signatures of the ENDF/B-VII.0 [14] elastic scattering adjustments to be consistent with total and partial cross sections. The JENDL-3.3 [16] compilers did the same, i.e., the elastic scattering was adjusted to be consistent with total and partial cross sections, adopted from Maslov et al. [17] evaluation, while fission cross section was slightly renormalized. In summary, r.s.d will be fixed at $10 \%$ level in $1-100 \mathrm{keV}$ energy range and 2-3\% at higher energies, which is quite similar to ${ }^{237} \mathrm{~Np}$ case (see Fig. 2.17).

${ }^{243} \mathrm{Am}$ : there are signatures of the ENDF/B-VII.0 [14] elastic scattering adjustments to attain consistency with total and partial cross sections. The JENDL-3.3 [16] compilers did the same, i.e., the elastic scattering was adjusted to be consistent with total and partial cross sections, adopted from Maslov et al. [18] evaluation, while fission cross section was slightly renormalized. In summary, r.s.d will be fixed at $20 \%$ level in $1-100 \mathrm{keV}$ energy range and $5 \%$ at higher energies. There is no reasonable explanation for the saw-tooth pattern of the r.s.d. of BNL [1, 2] estimate (see Fig. 2.18).

${ }^{242 m}$ Am: ENDF/B-VII.0 [14] and present estimates are pretty consistent in the energy range below $1 \mathrm{MeV}$, at higher energies the 10\% discrepancies are noticed in minima and maximum of the cross sections. In summary, r.s.d will be fixed at $1 \%$ level in $1-1000 \mathrm{keV}$ energy range and $10 \%$ at higher energies (see Fig. 2.19). 


\section{${ }^{232}$ Th ELASTIC CROSS SECTION}

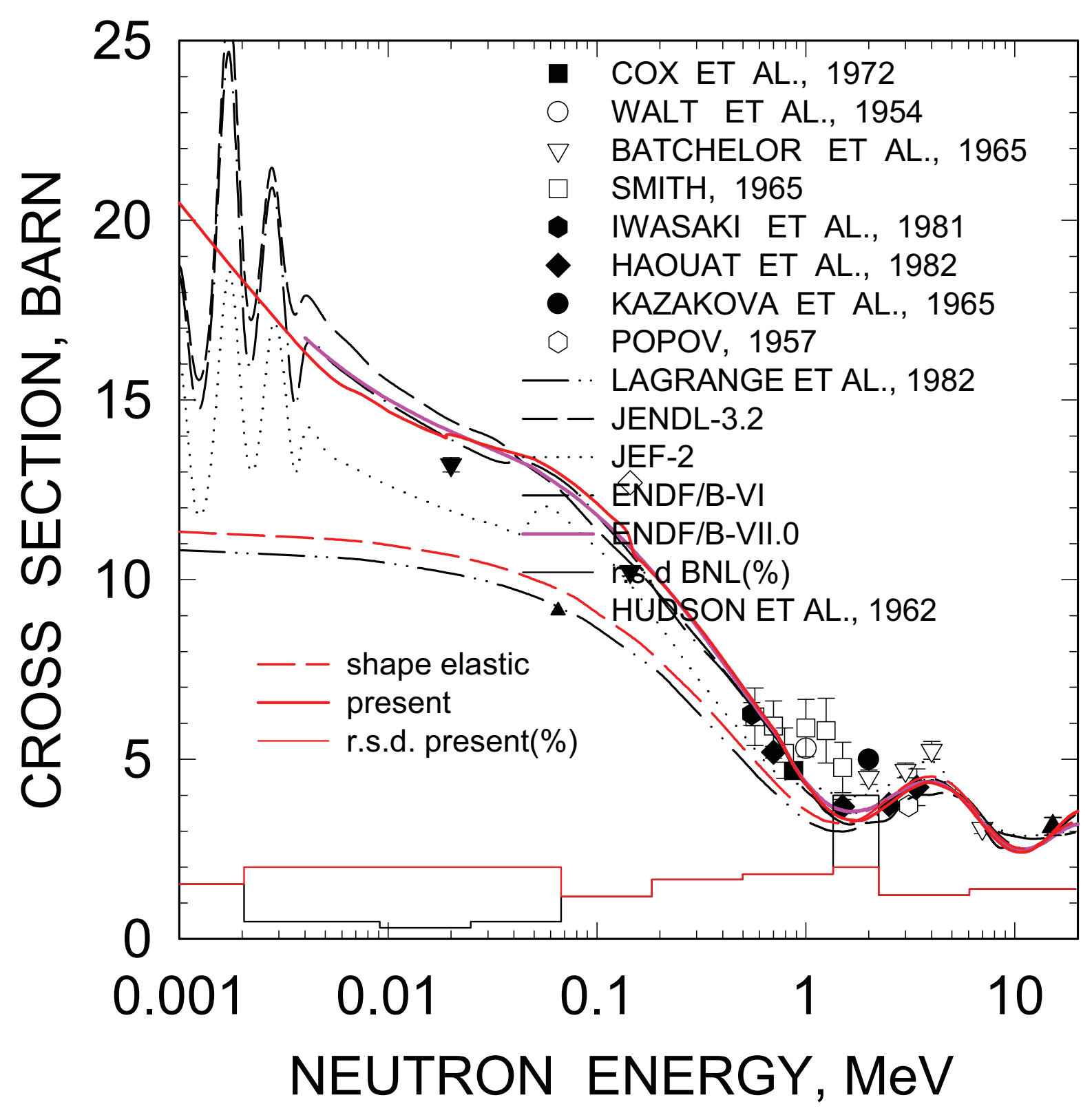




\section{${ }^{238}$ U ELASTIC CROSS SECTION}

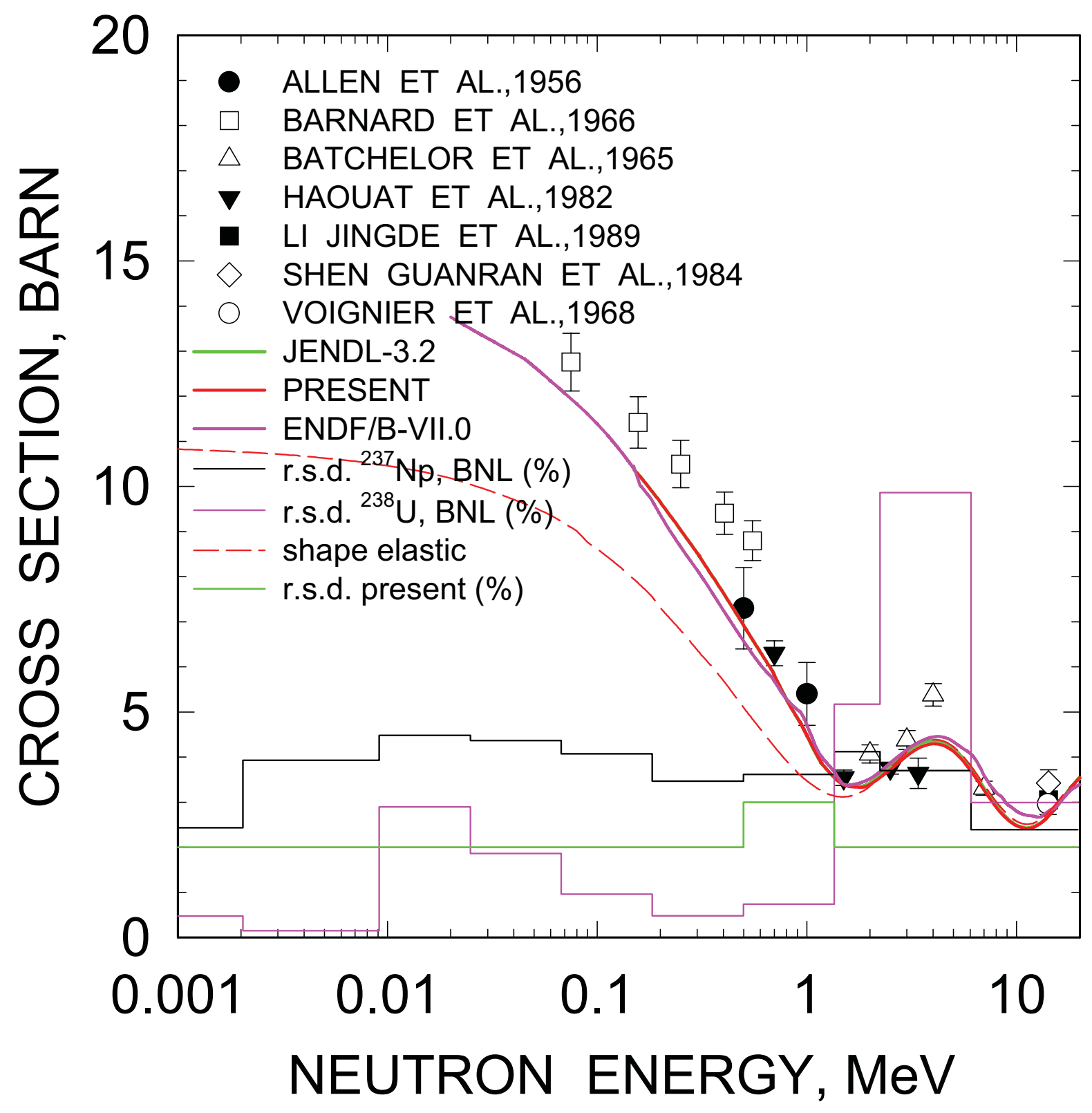




\section{${ }^{236}$ U ELASTIC CROSS SECTION}

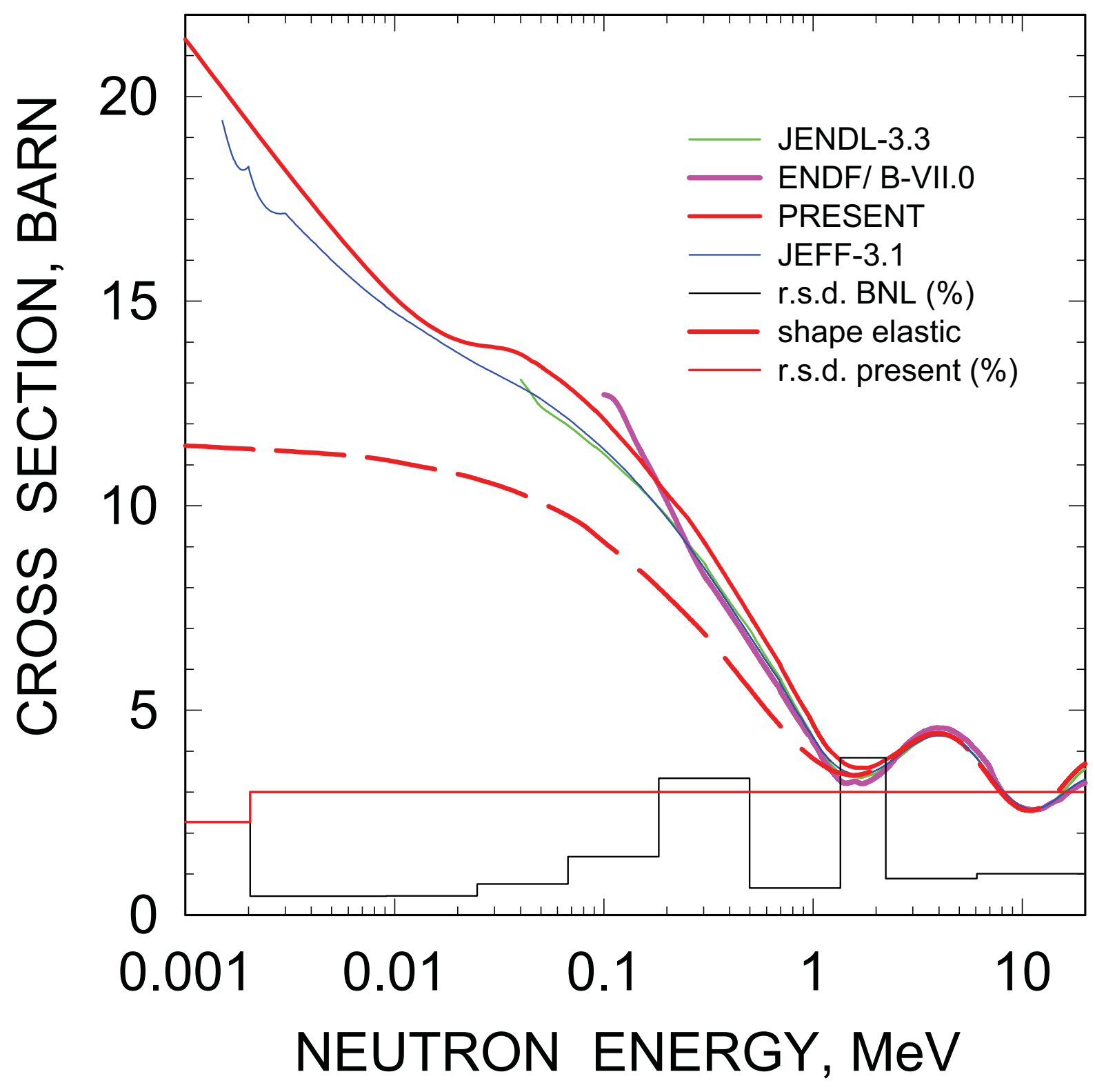




\section{${ }^{234}$ U ELASTIC CROSS SECTION}

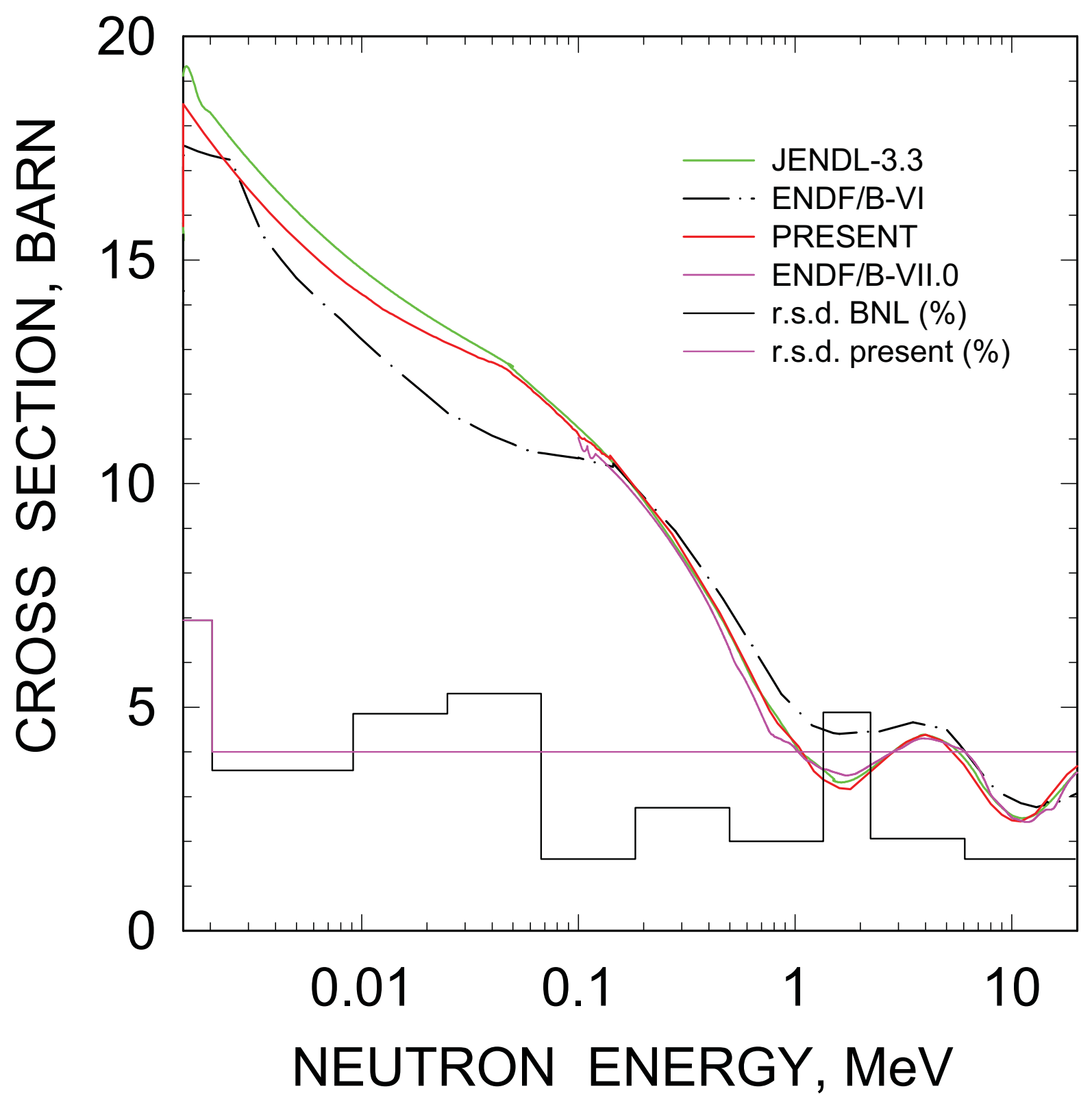




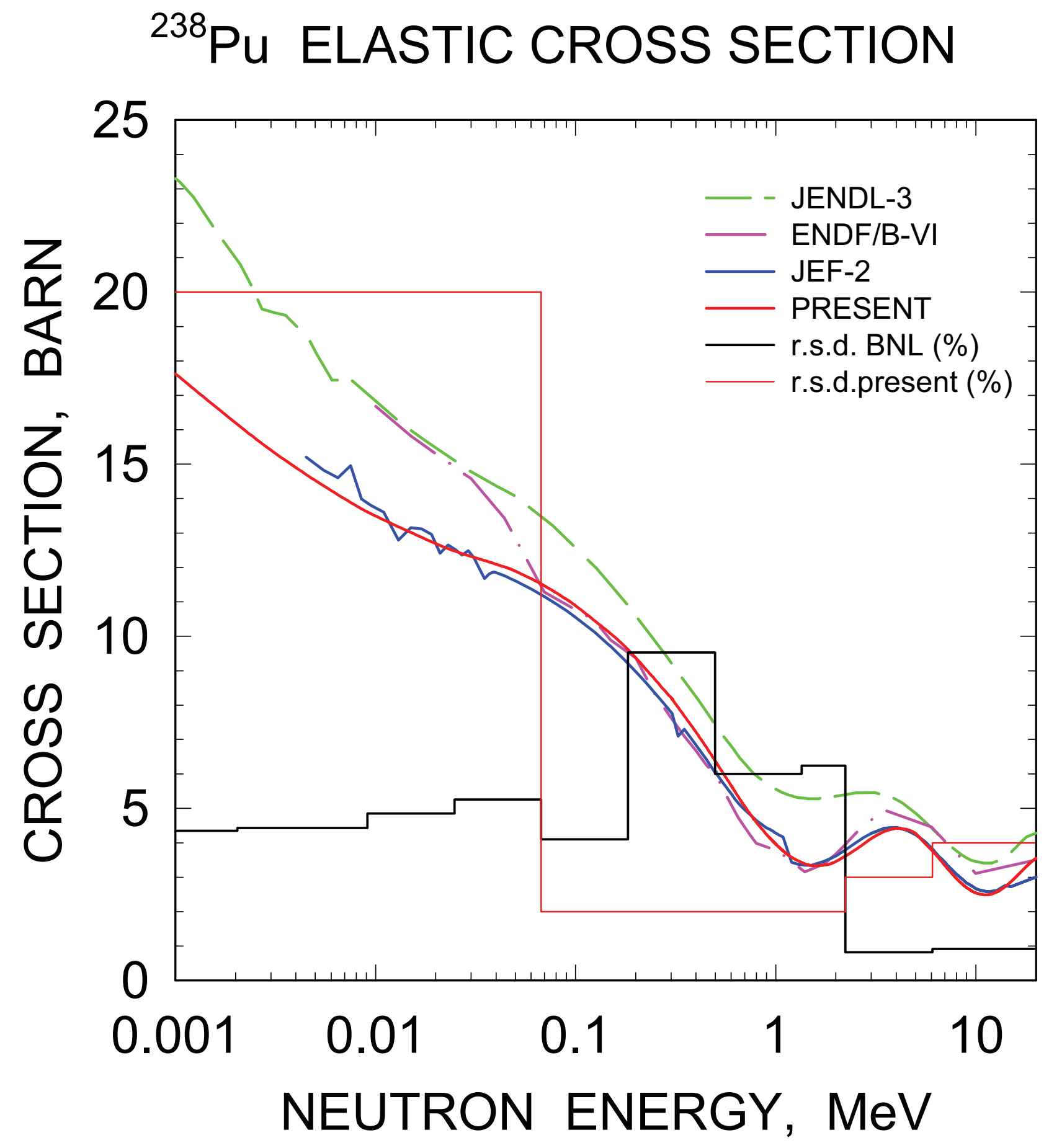




\section{${ }^{240} \mathrm{Pu}$ ELASTIC CROSS SECTION}

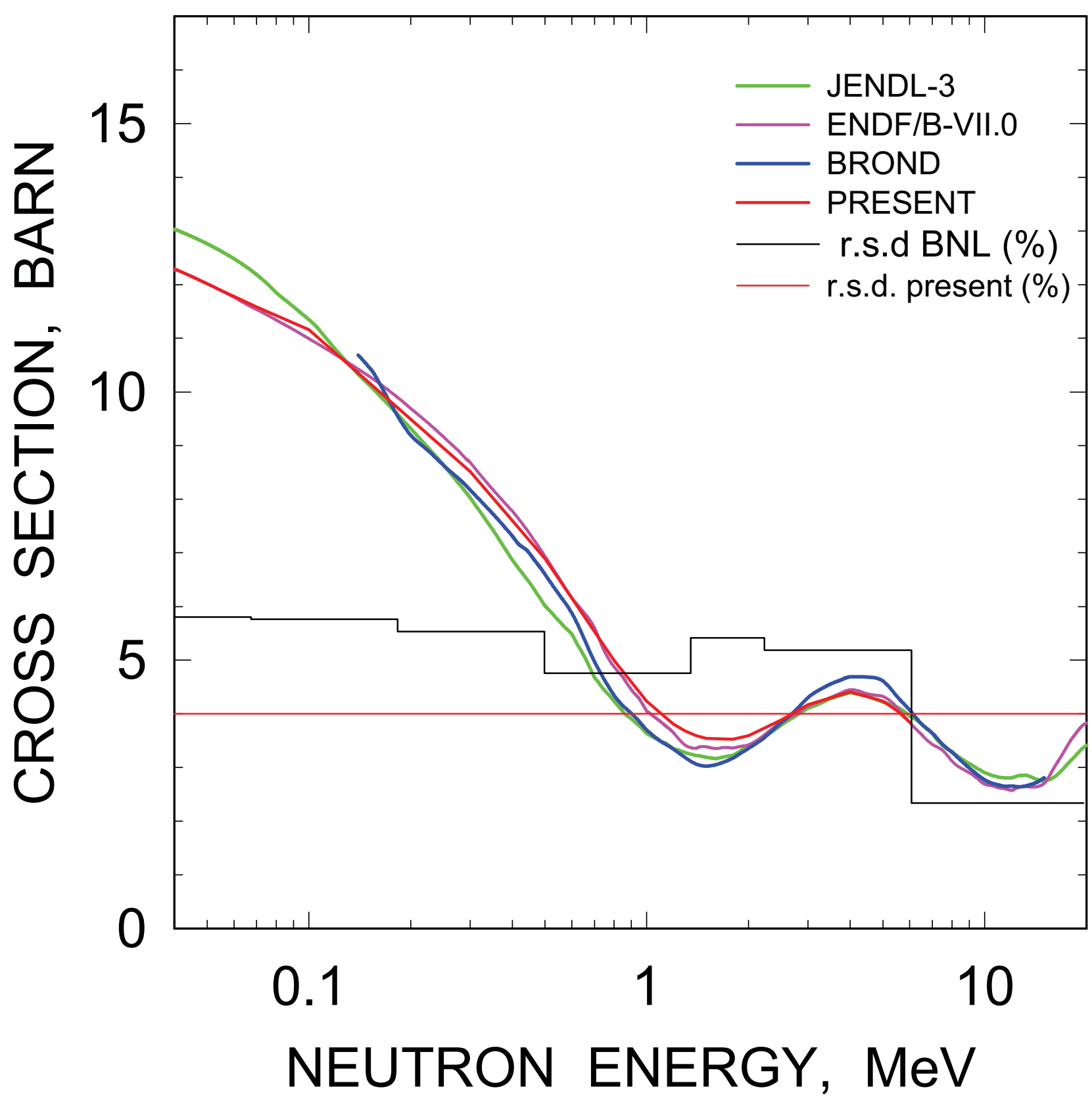


${ }^{242} \mathrm{PU}$ ELASTIC CROSS SECTION

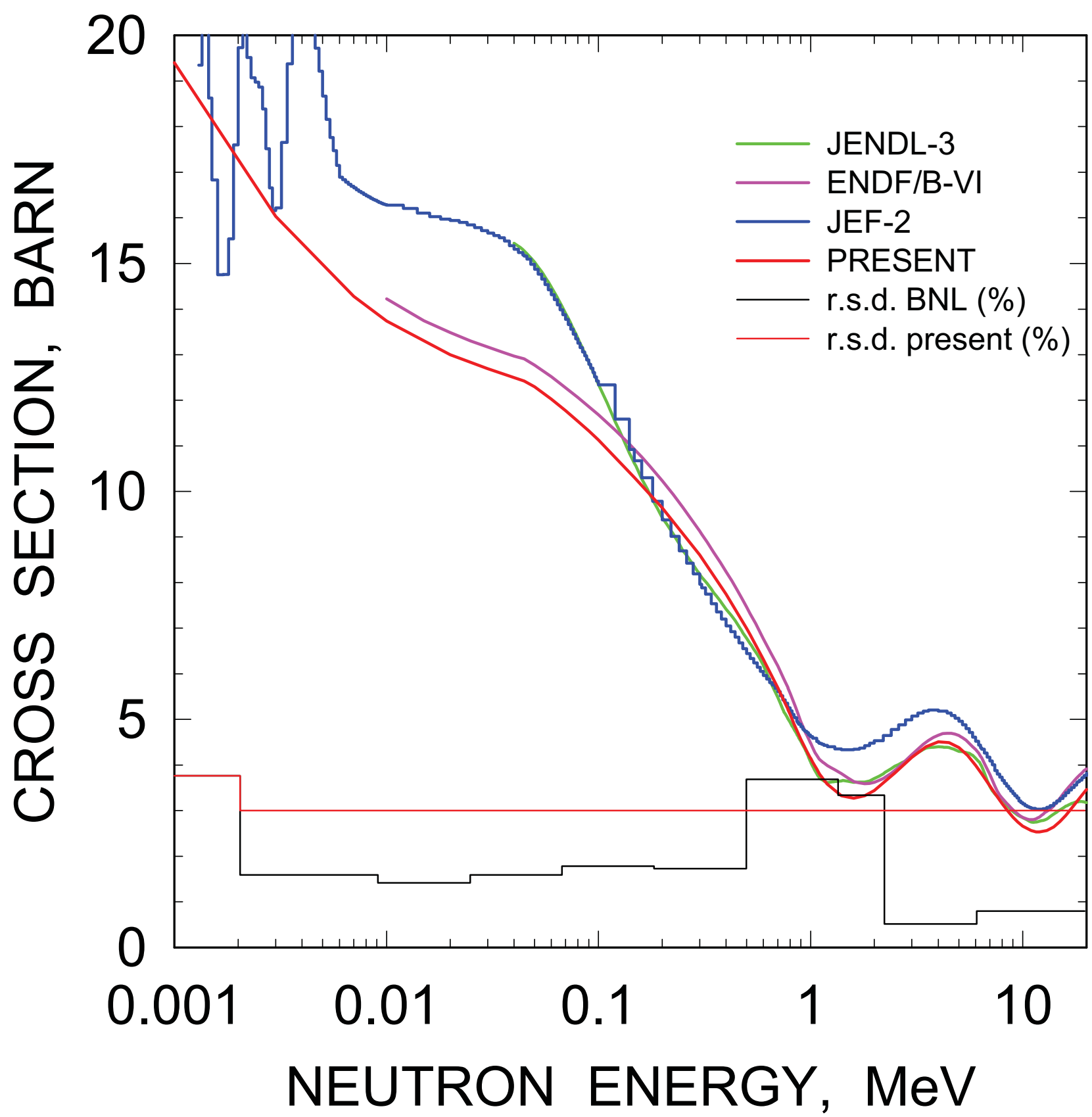




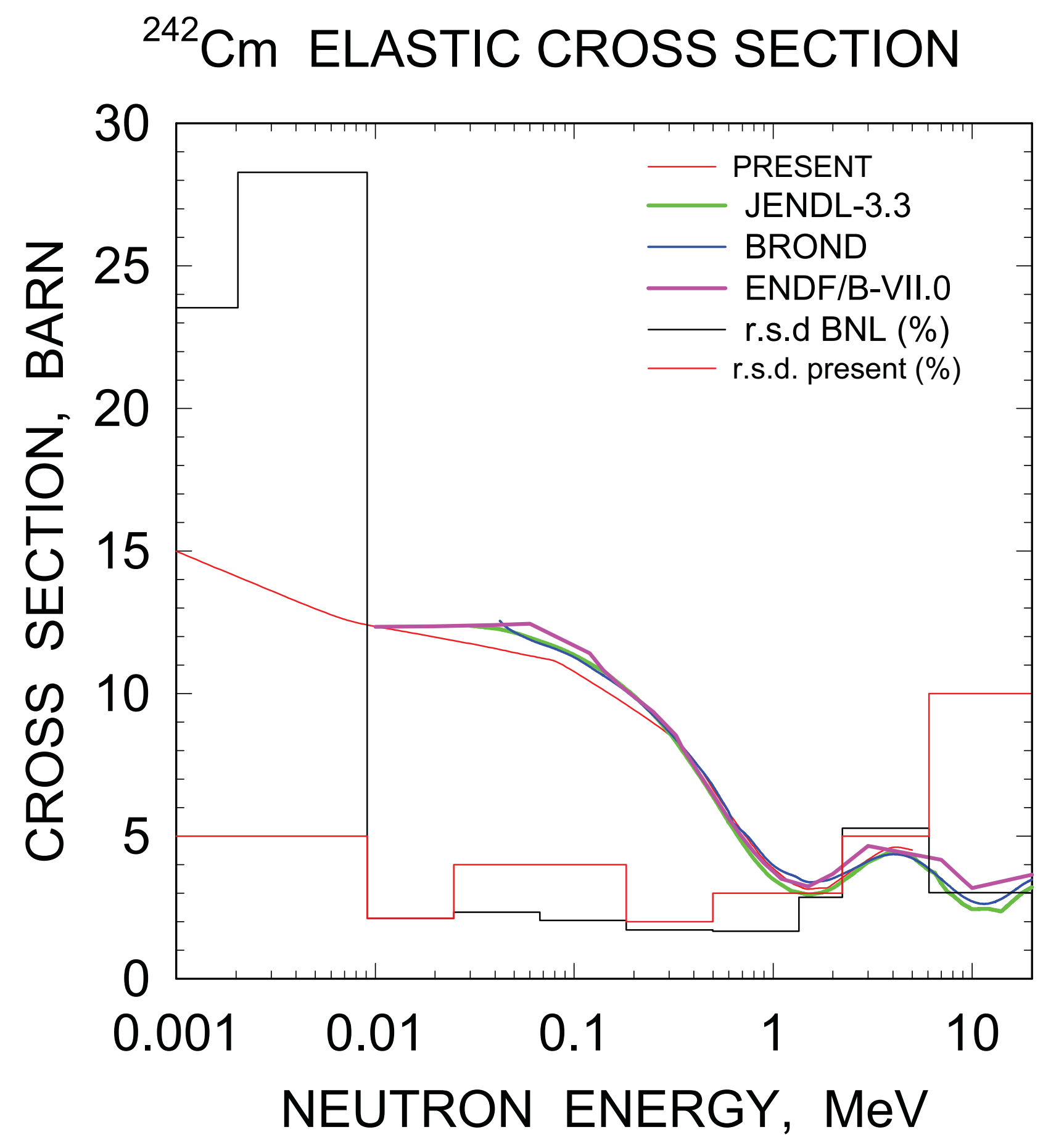




\section{${ }^{244} \mathrm{Cm}$ ELASTIC CROSS SECTION}

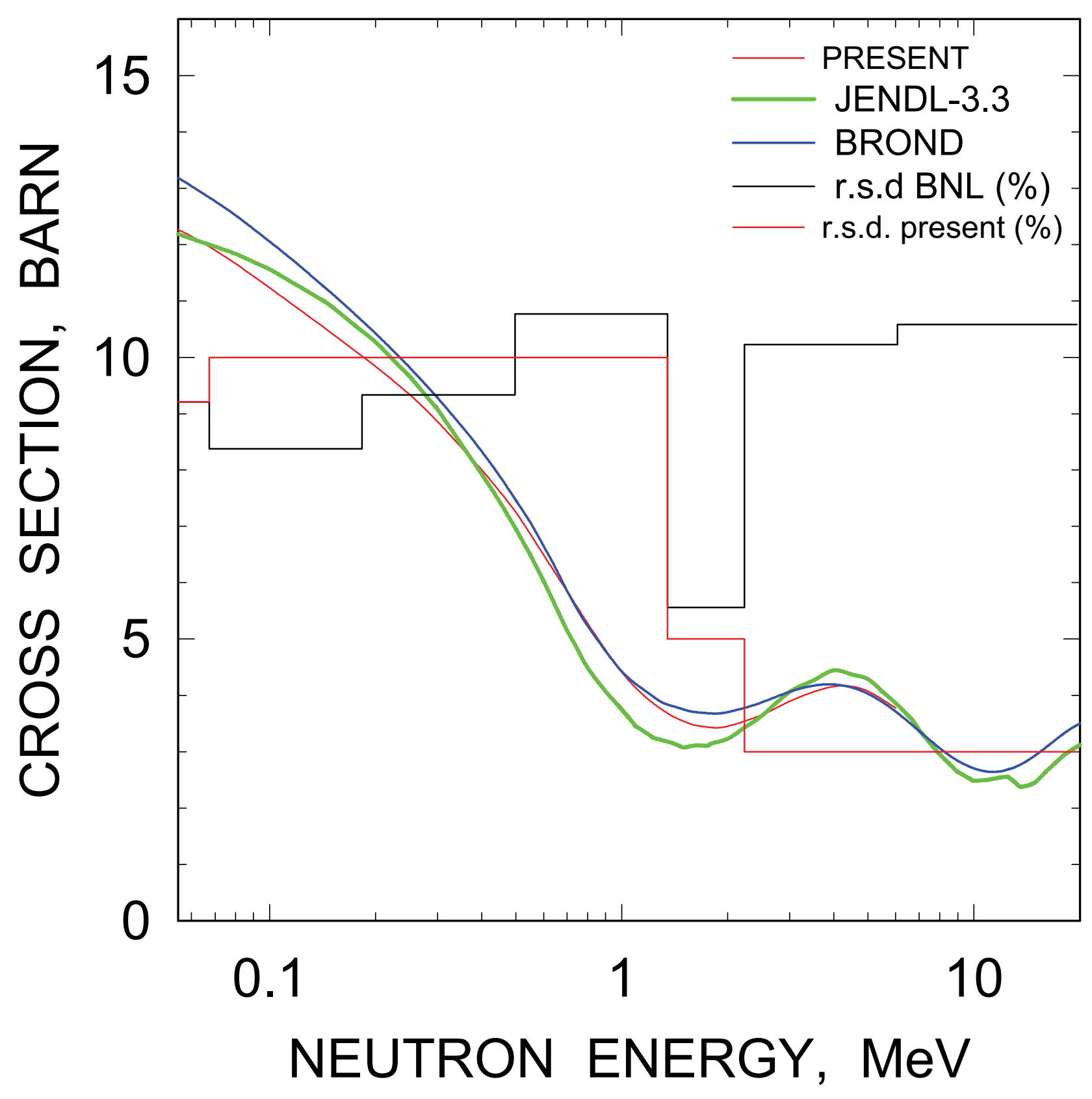




\section{${ }^{235}$ U ELASTIC CROSS SECTION}

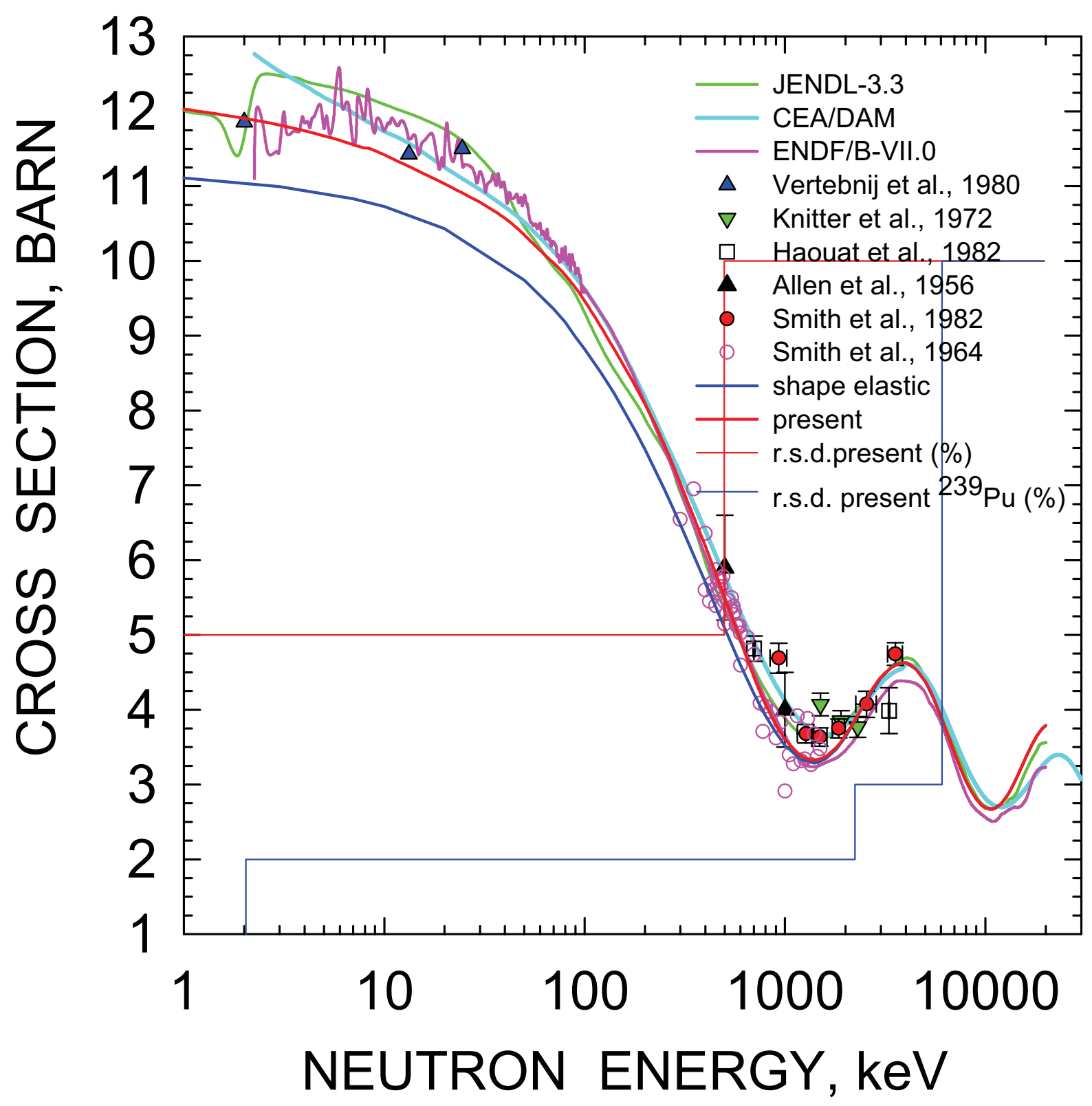




\section{${ }^{233}$ U ELASTIC CROSS SECTION}

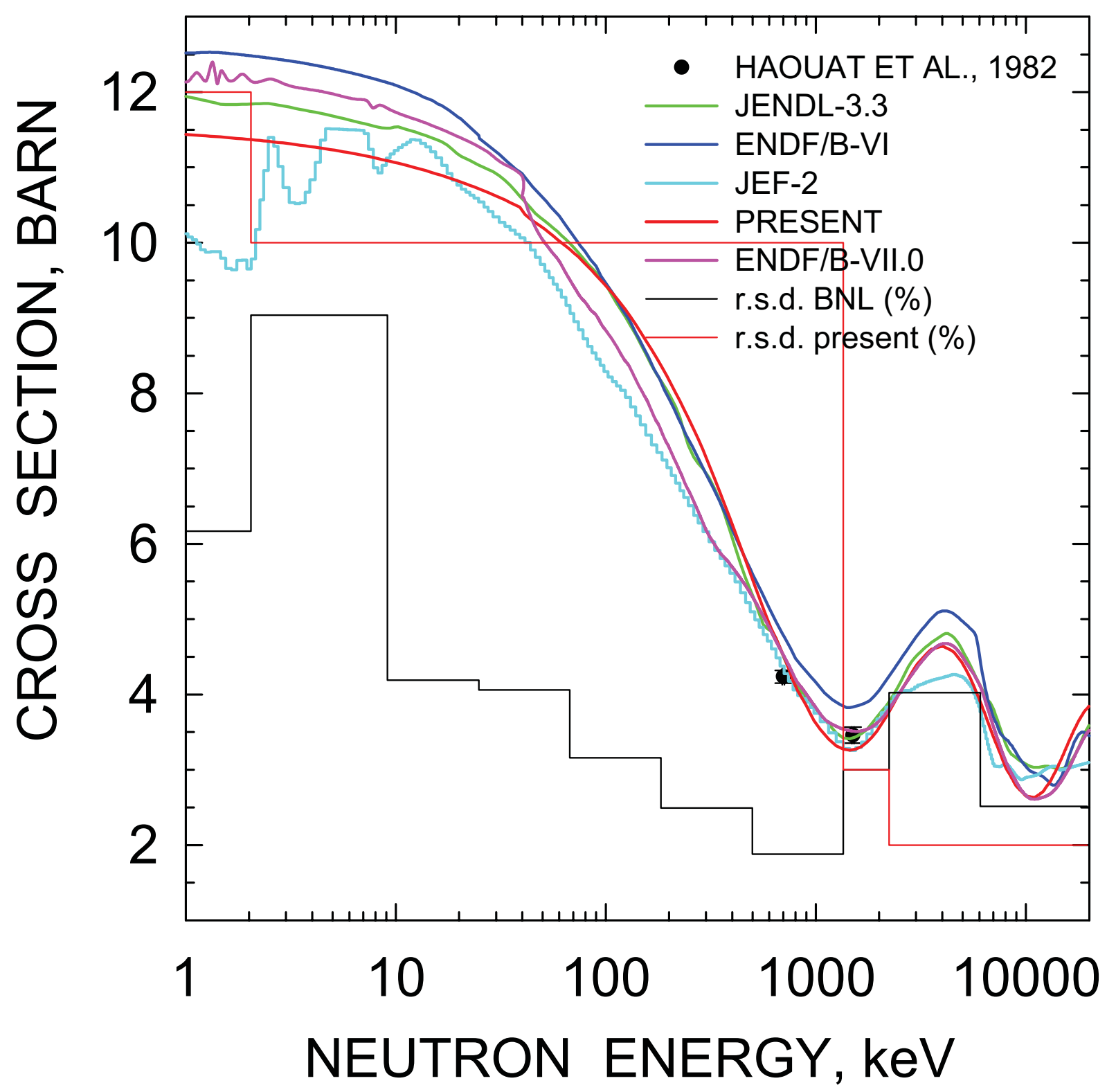




\section{${ }^{239} \mathrm{PU}$ ELASTIC CROSS SECTION}

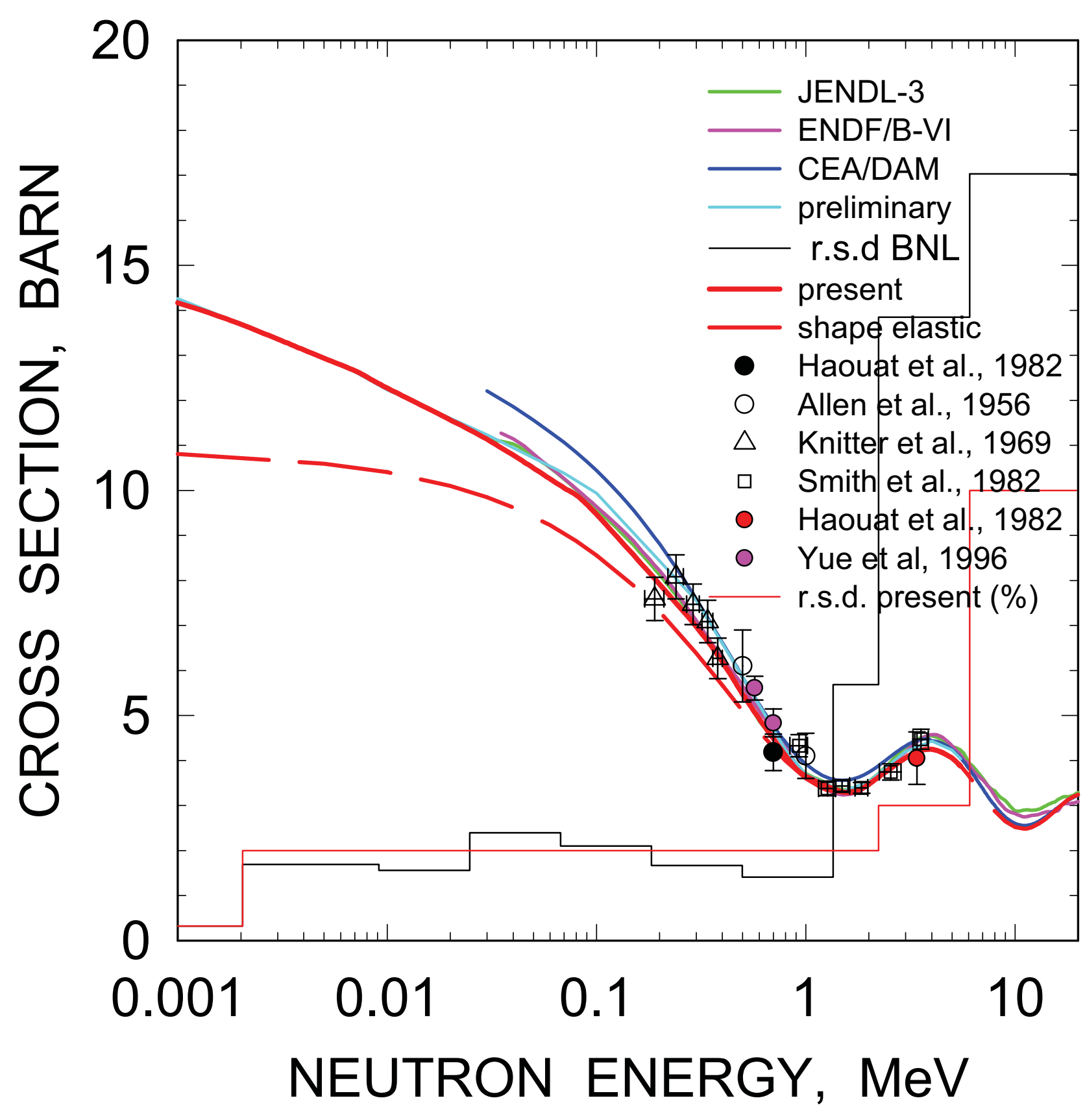




\section{${ }^{241} \mathrm{Pu}$ ELASTIC CROSS SECTION}

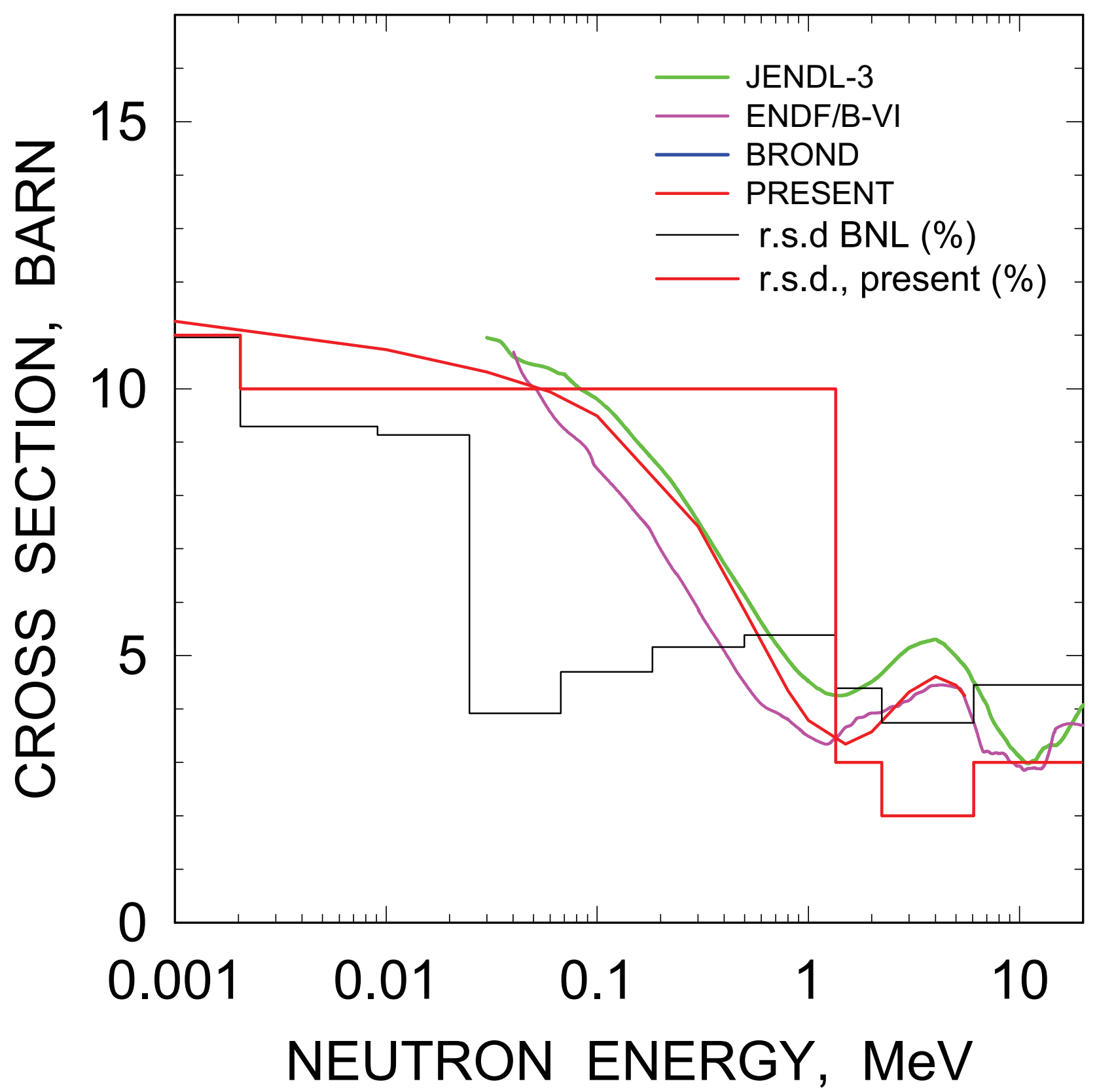


${ }^{243} \mathrm{Cm}$ ELASTIC CROSS SECTION

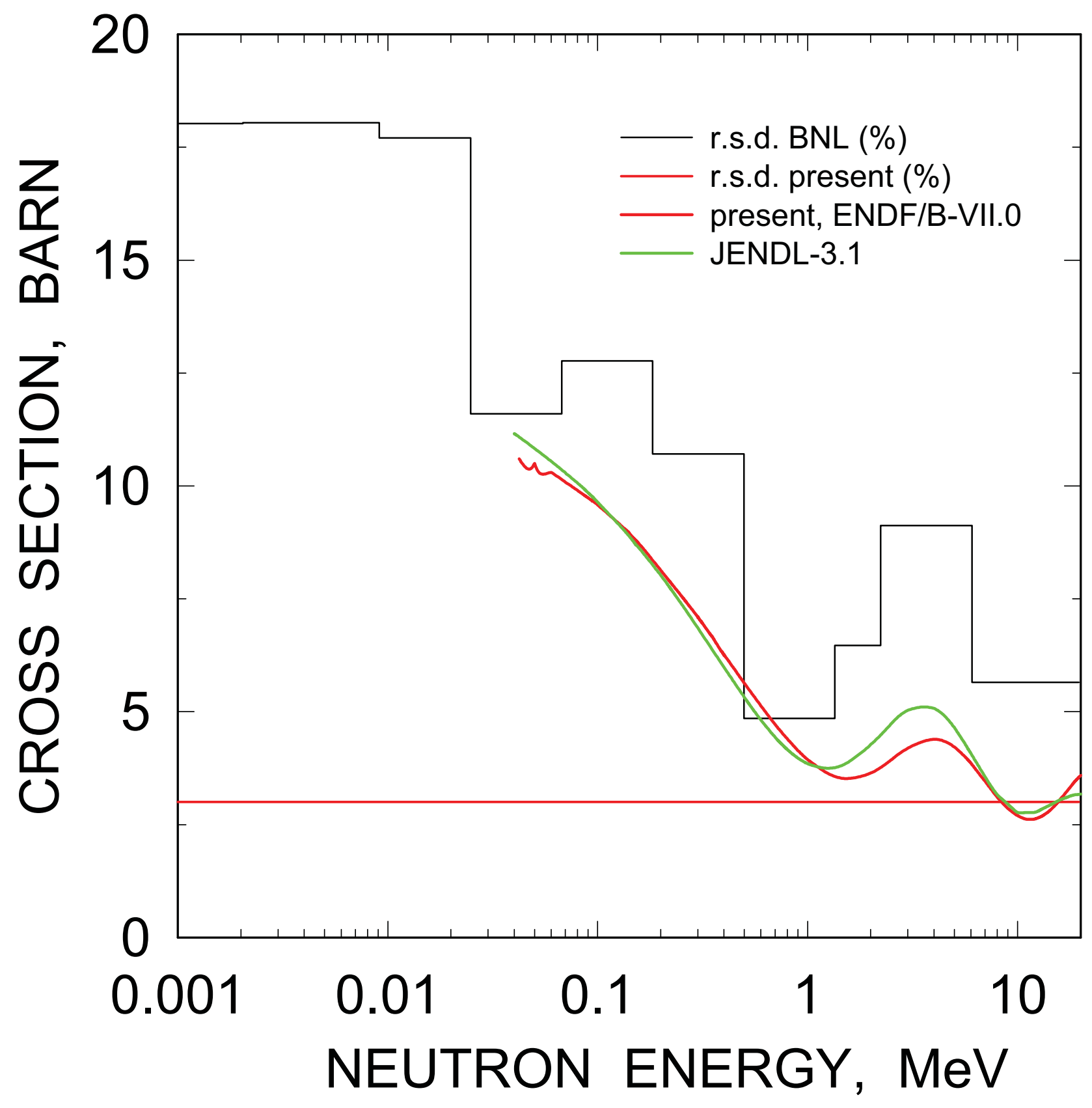




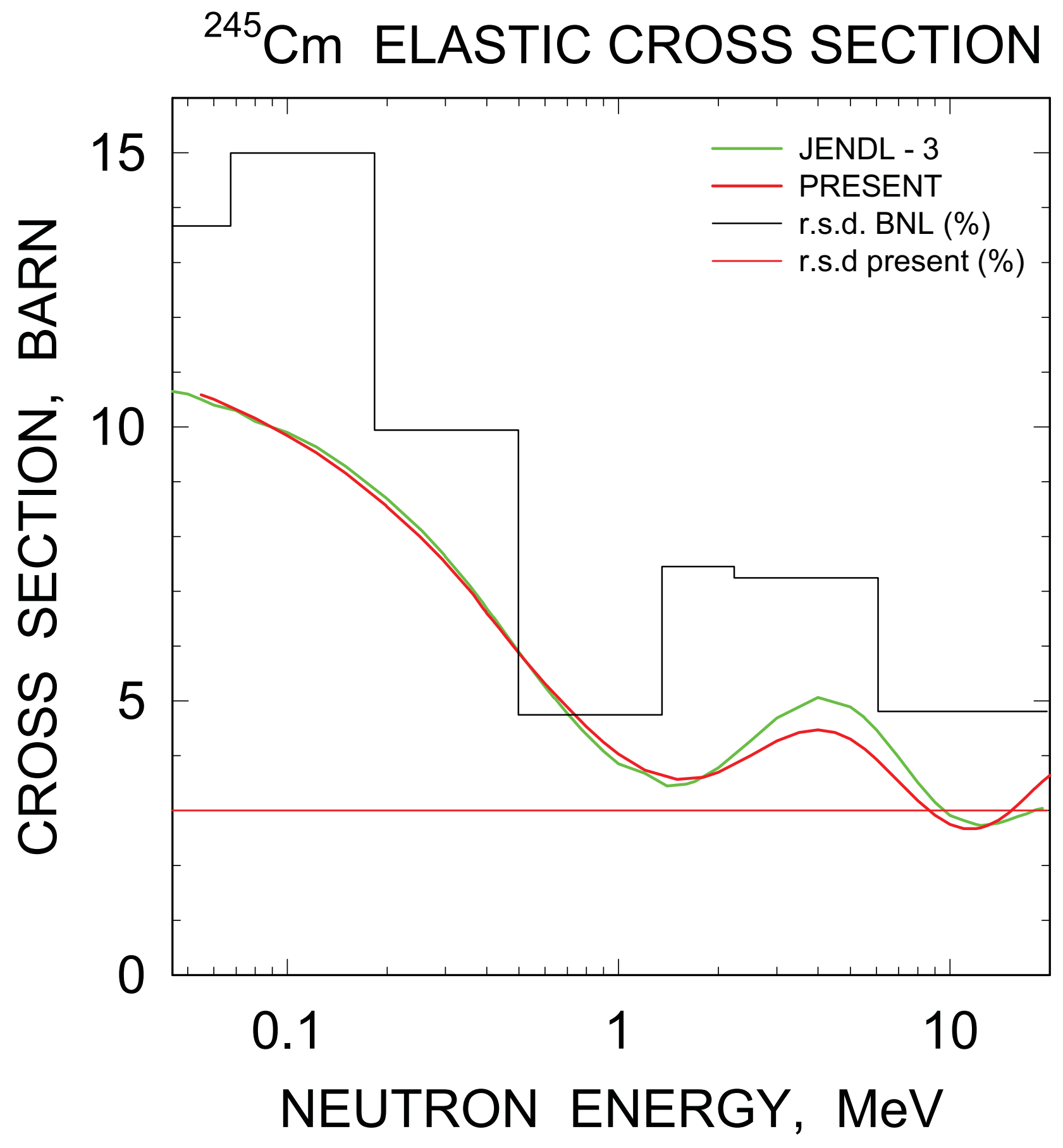




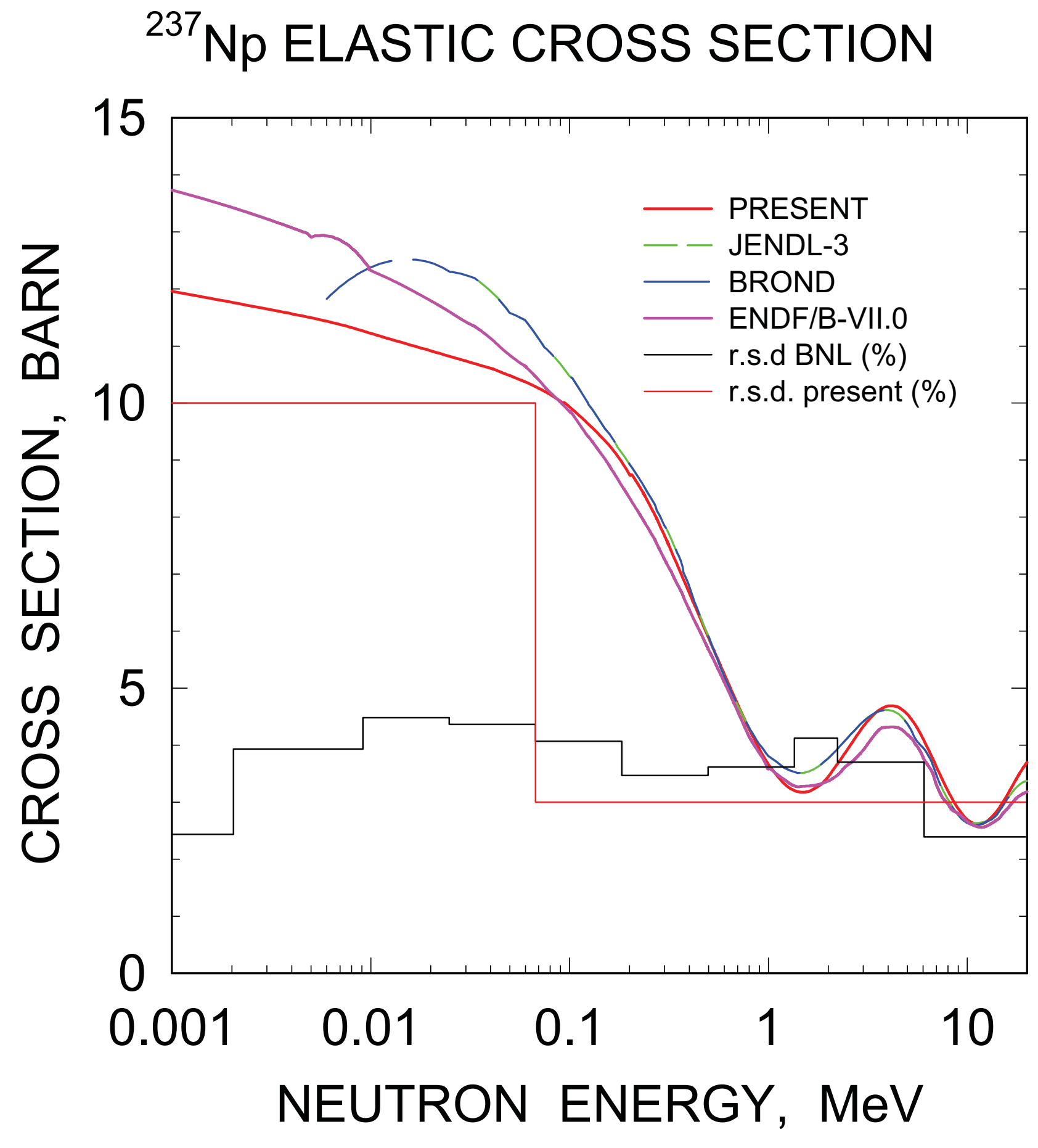


${ }^{241} \mathrm{Am}$ ELASTIC CROSS SECTION

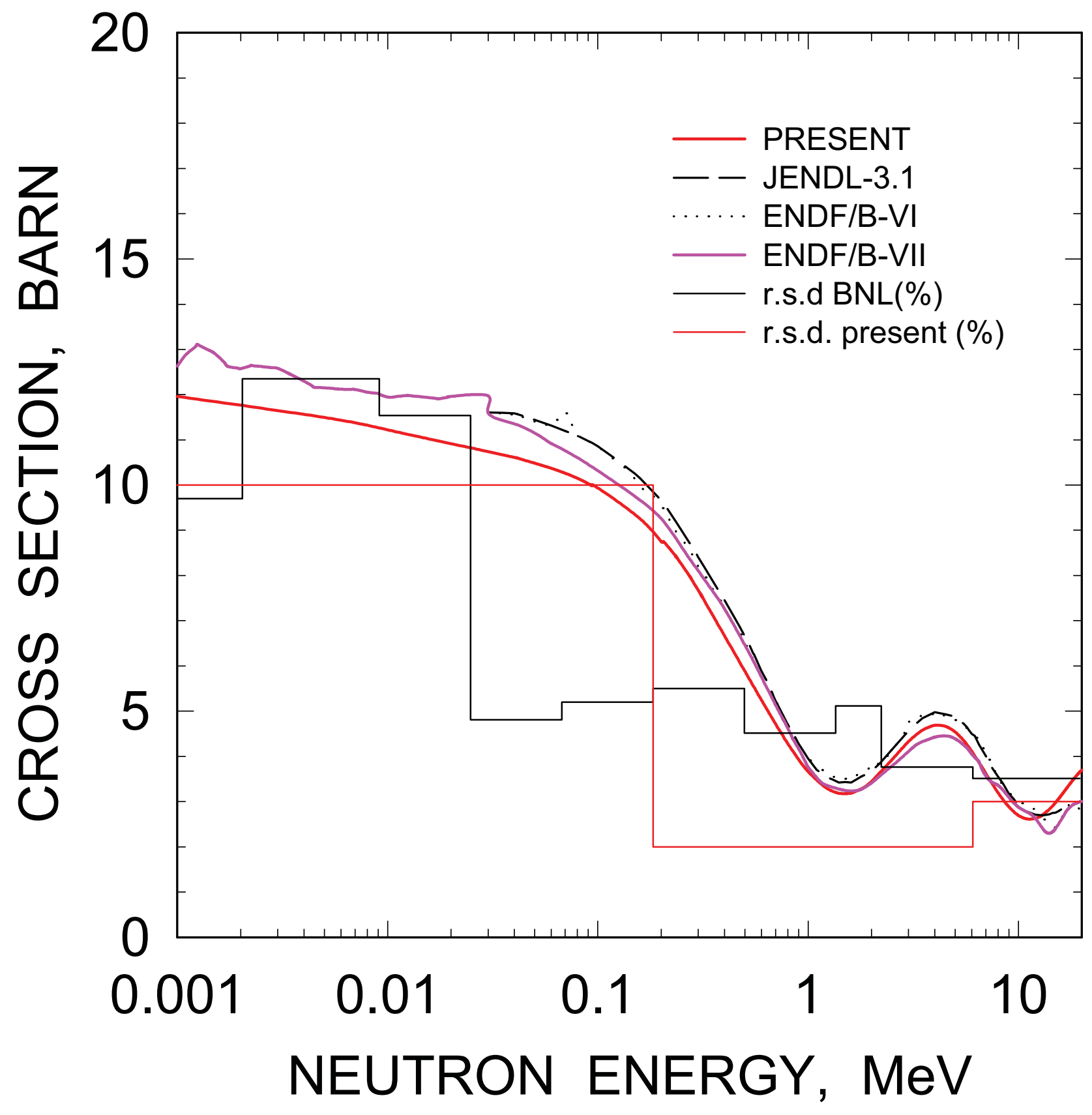




\section{${ }^{243} \mathrm{Am}$ ELASTIC CROSS SECTION}

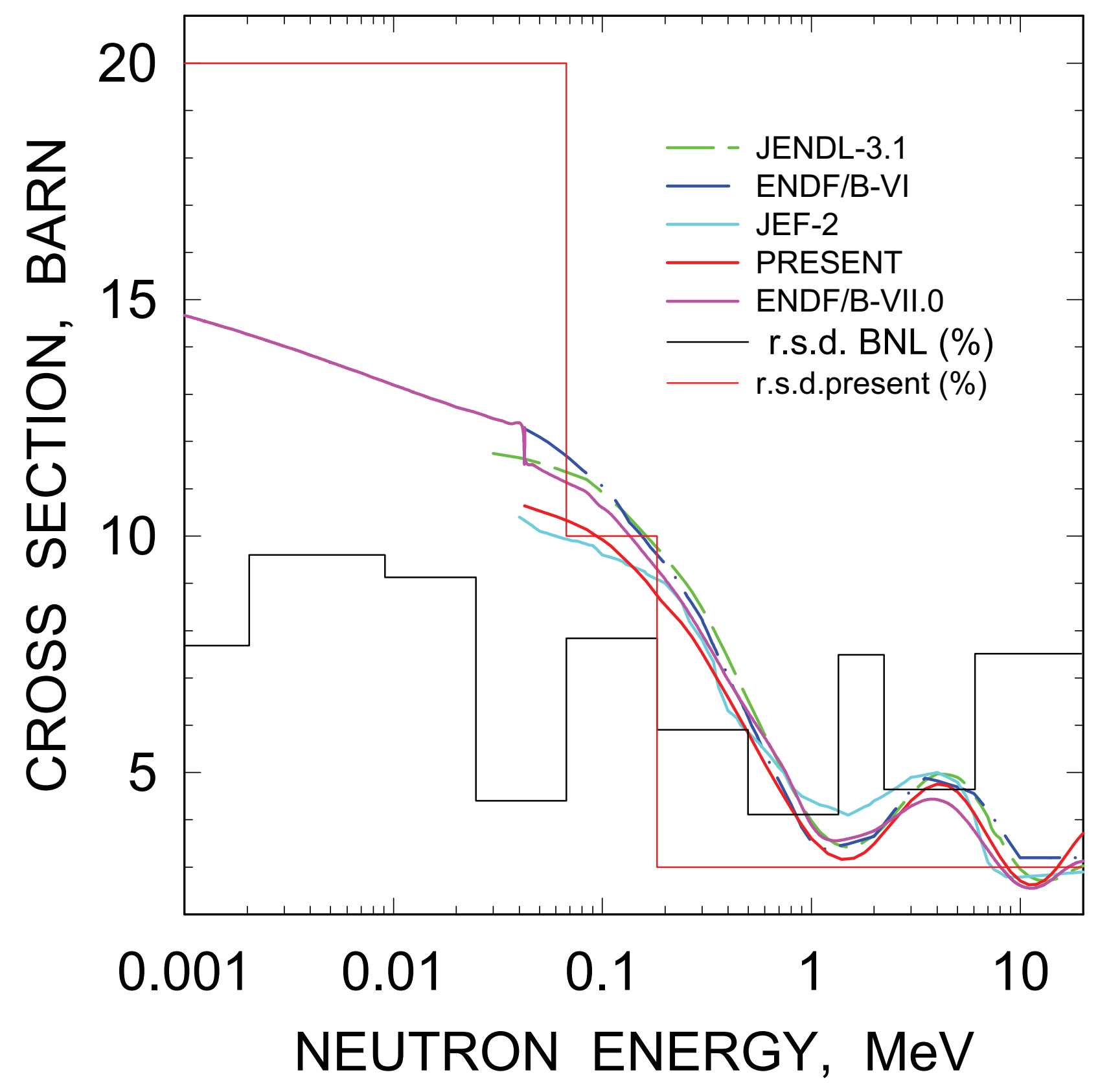




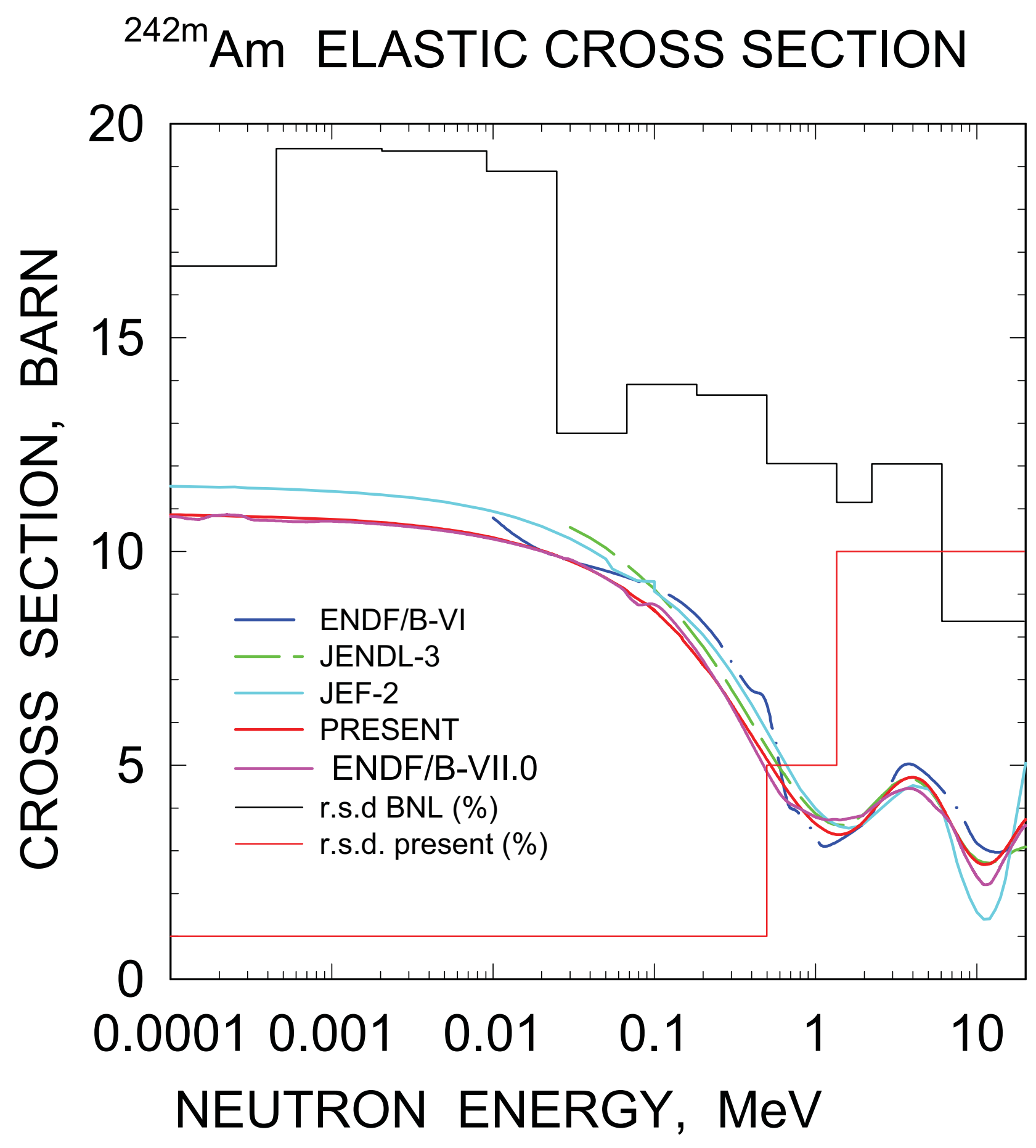




\section{Chapter 3}

\section{Fission cross sections}

${ }^{232} \mathrm{Th}$ : in fast energy range (in $1^{\text {st }}$ and $2^{\text {nd }}$ energy groups) r.s.d estimate of BNL should be increased up to $3 \%$, in accordance with the measured data [64-70] scatter (see Fig. 3.1). In other groups it looks reasonable. In our approach ${ }^{232} \mathrm{Th}(\mathrm{n}, \mathrm{F})$ fission cross section was calculated consistently with relevant $(\mathrm{n}, \mathrm{xn})$ and $(\mathrm{n}, \mathrm{f})$ reaction cross sections and prompt fission neutron spectra with proper description of the surrogate data [71, 72] on the ${ }^{231} \mathrm{Th}(\mathrm{n}, \mathrm{f})$ reaction by Maslov [4].

${ }^{238} \mathbf{U}$ : Fig. 3.2 shows, that in the fast energy range (in $1^{\text {st }}-4$ th energy groups) r.s.d estimate of BNL $[1,2]$ should be increased at least up to $1 \%$, in other cases it looks reasonable. In our approach ${ }^{238} \mathrm{U}(\mathrm{n}, \mathrm{F})$ fission cross section was calculated consistently with relevant $(\mathrm{n}, \mathrm{xn})$ and $(\mathrm{n}, \mathrm{f})$ reaction cross section [69, 73-75] data and prompt fission neutron spectra with proper description of the 2006 'surrogate data $[76,77]$ on the ${ }^{237} U(n, f)$ reaction in 2005 [5]. Note drastic discrepancies of partial fission chances contributions to the observed fission cross section of ${ }^{238} \mathrm{U}(\mathrm{n}, \mathrm{F})$ reaction for present $[11,12,13]$ and other $[14,78]$ approaches. These discrepancy would have a strong influence on the ${ }^{238} \mathrm{U}(\mathrm{n}, \mathrm{xn})$ reaction cross section uncertainty estimates.

${ }^{236} \mathrm{U}$ : ENDF/B-VII.0 evaluation and present calculations of ${ }^{236} \mathrm{U}(\mathrm{n}, \mathrm{F})$ fission cross sections are quite consistent with each other and measured data base [73, 75, 80], r.s.d are changed only slightly. Nonetheless, drastic discrepancies of partial fission chances contributions to the observed fission cross section of ${ }^{236} \mathrm{U}(\mathrm{n}, \mathrm{F})$ reaction for present and other approaches of ENDF/B-VII.0 [14] and JEFF [15] will influence substantially the ${ }^{236} \mathrm{U}(\mathrm{n}, 2 \mathrm{n})$ reaction cross section estimate (see Fig. 3.3).

${ }^{234} \mathbf{U}$ : Fig. 3.4 shows, that main discrepancies of ENDF/B-VII.0 [11] evaluation and present calculations of ${ }^{234} \mathrm{U}(\mathrm{n}, \mathrm{F})$ fission cross sections [73, 81-90], which are the same as those by Maslov et al. [21], are in $1^{\text {st }}$ and $2^{\text {nd }}$ groups, the r.s.d. values are changed only slightly. Drastic discrepancies are noticed between partial fission chances, which should influence the ${ }^{234} \mathrm{U}(\mathrm{n}, 2 \mathrm{n})$ reaction cross section.

${ }^{238} \mathrm{Pu}$ : as shown on Fig. 3.5 evaluated data file by Maslov et al. [32] describes the deep subthreshold data by Alam et al. [91] and data by Budtz-Jorgensen et al. [92] up to (n,nf) fission threshold (see Fig. 3.6). Data by Fursov et al. [60] were not available at the moment of data evaluation [32], nonetheless, they are quite compatible with the evaluated curve below and above fission threshold, except 100-500 keV energy range. The discrepancy of the evaluated curve with the measured data by Fursov et al. [60] could be attributed to the erroneously increased contribution of ${ }^{238} \mathrm{Pu}(\mathrm{n}, \mathrm{nf})$ reaction to 
the observed fission cross section ${ }^{238} \mathrm{Pu}(\mathrm{n}, \mathrm{F})$. The latter is due to erroneously increased fission probability of ${ }^{238} \mathrm{Pu}$. In 1996 it was done to decrease the discrepancy of the calculated fission cross section with the data by Budtz-Jorgensen et al. [92]. However, the final conclusion was that the data by Budtz-Jorgensen et al. [92] can not be fitted above the (n,nf) reaction threshold. As in case of ${ }^{243} \mathrm{Am}(\mathrm{n}, \mathrm{F})$ reaction (see below) the measured fission cross section data [92] are higher than neutron absorption cross section. Near the ${ }^{238} \mathrm{Pu}(\mathrm{n}, 2 \mathrm{nf})$ reaction threshold the calculated cross section is compatible with data by Ermagambetov and Smirenkin [93, 94] and newest data by Fursov et al. [60], the other data [95-97] are also shown.

New measurements of the ${ }^{238} \mathrm{Pu}(\mathrm{n}, \mathrm{F})$ reaction cross section from $10 \mathrm{keV}$ up to $14 \mathrm{MeV}$ would be rather important, moreover so that most of previous evaluations, including that adopted for ENDF/BVII.0, are higher than the newest data by Alam et al. [91] in the deep sub-threshold energy range and data by Fursov et al. [60] in the vicinity of (n,nf) reaction threshold. Values of r.s.d. should be strongly increased at low energies.

${ }^{240,242} \mathrm{Pu}$ : as shown on Figs. 3.7, 3.8, 3.9, 3.10 present calculation $\left({ }^{240} \mathrm{Pu}\right)$, evaluation $\left({ }^{242} \mathrm{Pu}\right)$ and ENDF/B-VII.0 evaluations of ${ }^{240} \mathrm{Pu}(\mathrm{n}, \mathrm{F})$ and ${ }^{242} \mathrm{Pu}(\mathrm{n}, \mathrm{F})$ fission cross sections are quite consistent, except $1^{\text {st }}$ energy group. However, the discrepancy is well within a data scatter for ${ }^{240} \mathrm{Pu}[98-104]$ and ${ }^{242} \mathrm{Pu}[99$, $103,104,105,106,107,108,109,110]$ and there is no need to change r.s.d., defined in BNL report [1, 2].

${ }^{242} \mathrm{Cm}$ : Figs. 3.11, 3.12 show that in case of ${ }^{242} \mathrm{Cm}(\mathrm{n}, \mathrm{F})$ the BNL r.s.d. [1, 2], estimated in 15 energy groups needs severe modifications, since ENDF/B-VII.0 [14] evaluation is much discrepant with the measured data at the deep sub-threshold energies [91] and up to $1 \mathrm{MeV}$ [111]. BNL [1,2] r.s.d. estimates seem to be rather optimistic in both energy ranges, especially in the former one. In case of $\mathrm{n}+{ }^{242} \mathrm{Cm}$ the ${ }^{242} \mathrm{Cm}$ (n, F) cross section shape predicted by Maslov [112] was supported by the surrogate measurements [113], presented at ND2007 [114]. The key point is the predicted over-threshold quasiresonance shape, similar to that observed in ${ }^{244} \mathrm{Cm}(\mathrm{n}, \mathrm{f})$ reaction $[60,115,116,117]$.

${ }^{244} \mathrm{Cm}$ : JENDL-3.3 evaluation is adopted for the ENDF/B-VII.0 data library. Measured subthreshold data by Maguire et al. [118] are compatible with Fomushkin et. al. [115, 116] data. Newest data by Fursov et al. [60] are systematically higher than data by Fomushkin et. al. $[115,116]$ and can not be reconciled with sub-threshold data by Maguire et al. [118] within a statistical theory calculations (see Fig. 3.13, 3.14). Present calculation fits sub-threshold data by Maguire et al. [118] and data [115, 116, 
119, 120, 121]. We will define the r.s.d based on the discrepancy of ENDF/B-VII.0 (JENDL-3.3 evaluation is adopted) evaluation with present calculation (see appropriate graph).

${ }^{235} \mathbf{U}$ : fission cross section of ${ }^{235} \mathrm{U}(\mathrm{n}, \mathrm{F})$ is a standard one. While different evaluations reproduce roughly the same database [75, 122, 123], drastic discrepancies are noticed between partial fission chances, which should influence the $(\mathrm{n}, 2 \mathrm{n})$ and $(\mathrm{n}, 3 \mathrm{n})$ reaction cross sections, as well as prompt fission neutron spectra [10, 14] (see Fig. 3.15).

${ }^{233} \mathbf{U}$ : fission cross section of ${ }^{233} \mathrm{U}(\mathrm{n}, \mathrm{F})$, measured in [124-131], in ENDF/B-VII.0 [11] data file is higher than evaluated data by Maslov et al. [22] by up to $5 \%$ in $1^{\text {st }}$ group, r.s.d. should be increased up to $5 \%$ as well, since there are a newest, still unpublished n-TOF data [132], which support the lower cross section values (see Fig. 3.16). In fact, that means the cross section shape might be different. The partial fission chances contributions in ENDF/B-VII.0 [14] and Maslov et al. [19] data files are rather similar.

${ }^{239}$ Pu: Figs. 3.17, 3.18 show that fission cross section data [88, 98, 101, 106, 124, 133, 134, 135] could be reproduced almost within errors (r.s.d.) from $1 \mathrm{keV}$ up to $20 \mathrm{MeV}$. That provides a reliable constraint for capture, inelastic and elastic scattering, and $(\mathrm{n}, 2 \mathrm{n})$ reaction cross section prediction. Values of r.s.d of JENDL-3.3 [16] look reasonable.

${ }^{241} \mathrm{Pu}$ : fission cross section data $[88,97,127,136,137,138,139,140]$ could be reproduced almost within errors (r.s.d.) from $1 \mathrm{keV}$ up to $20 \mathrm{MeV}$ (see Fig. 3.19, 3.20). That provides a reliable constraint for capture, inelastic and elastic scattering, and (n, $2 \mathrm{n})$ reaction cross section prediction. Values of r.s.d of BNL in $1^{\text {st }}, 2^{\text {nd }}$ and $3 \mathrm{~d}$ groups could be somewhat decreased.

${ }^{243} \mathrm{Cm}$ : in ENDF/B-VII.0 data file, the evaluation by Maslov et al. [26] was adopted. In JENDL3.3 [15] basically the same evaluation is adopted, but the fission cross section was deliberately renormalized (increased by approximately $20 \%$ ) to Fursov et al. [60] data at $0.1-14.9 \mathrm{MeV}$ energy range (see Fig. 3.21). Measured data base for ${ }^{243} \mathrm{Cm}(\mathrm{n}, \mathrm{f}),{ }^{245} \mathrm{Cm}(\mathrm{n}, \mathrm{f})$ and ${ }^{247} \mathrm{Cm}(\mathrm{n}, \mathrm{f})$ reaction cross sections became much more extensive after data by Fursov et al. [60] became available. Two-quasiparticle states of even fissioning nuclide ${ }^{244} \mathrm{Cm}$ might be pronounced in ${ }^{243} \mathrm{Cm}(\mathrm{n}, \mathrm{f})$ data at $E_{n}>0.05$ $\mathrm{MeV}$. That estimate of the two-quasi-particle states excitation threshold $E_{2}$ comes from the fission barrier values estimate based on cross section data in first "plateau" region. Unfortunately, at $E_{n}<0.2$ $\mathrm{MeV}$ there is no reliable data of ${ }^{243} \mathrm{Cm}(\mathrm{n}, \mathrm{f})$ reaction cross section. The four-quasi-particle states of even fissioning nuclide ${ }^{244} \mathrm{Cm}$ influence the fission cross section at $\mathrm{E}_{\mathrm{n}}=1 \sim 3 \mathrm{MeV}$. 
The bomb-shot data by Silbert [141] were used to derive the average resonance parameters. Average fission value $\left\langle\Gamma_{f}\right\rangle=0.355 \mathrm{eV}$ governs the absolute cross section value in $\mathrm{keV}$-energy range. Calculated ${ }^{243} \mathrm{Cm}(\mathrm{n}, \mathrm{F})$ cross section could be fitted to data by Fursov et al. [60], which are are much discrepant with data by Fomushkin et al. [61, 62] in the first plateau region. The shape of the data by Fursov et al. [60] could be reproduced up to (n,nf) reaction threshold, but in that case at lower energies the consistency of the calculated data with measured data by Silbert [114] will be severely deteriorated.

At excitations higher than the emissive fission threshold it is hardly possible to reproduce the shape of measured data by Fursov et al. [60], since the neutron absorption cross section is lower than the observed fission data. The fission probability of ${ }^{243} \mathrm{Cm}$, fissioning in the reaction ${ }^{243} \mathrm{Cm}(\mathrm{n}, \mathrm{nf})$, was defined using data on ${ }^{242} \mathrm{Cm}(\mathrm{n}, \mathrm{f})$ [112] (see above).

Fortunately, the ${ }^{243} \mathrm{Cm}(\mathrm{n}, \mathrm{f})$ shape predicted by Maslov et al. [26] was supported by the surrogate measurements, presented at ND2007 [114]. At present r.s.d values are severely decreased, as compared with BNL estimate.

${ }^{245} \mathrm{Cm}$ : in ENDF/B-VII.0 data file, the evaluation by Maslov et al. [27] was adopted. In JENDL3.3 basically the same evaluation is adopted, but the fission cross section was deliberately renormalized (increased by approximately $5 \%$ ) to Fursov et al. [60] data at $14.9 \mathrm{MeV}$ (see Fis. 3.22, 3.23). In case of ${ }^{245} \mathrm{Cm}(\mathrm{n}, \mathrm{F})$ reaction the measured data in the first plateau region are quite compatible (see data by Fursov et al. [60] and Fomushkin et al. [142], but discrepant with data by Moore et al. [117]. At incident neutron energies higher than $E_{n} \sim 8 \mathrm{M} \ni \mathrm{B}$ to reproduce the measured data by White and Browne [143] and Fomushkin et al. [144] is hardly possible. The reason for that are the same as in case of ${ }^{243} \mathrm{Cm}(\mathrm{n}, \mathrm{F})$ reaction - measured data at $\mathrm{E}_{n}=14 \mathrm{MeV}$ are higher than the neutron absorption cross section. The fission probability of ${ }^{245} \mathrm{Cm}$, fissioning in the reaction ${ }^{245} \mathrm{Cm}(\mathrm{n}, \mathrm{nf})$, was defined using data on ${ }^{244} \mathrm{Cm}(\mathrm{n}, \mathrm{f})$ by Fomushkin et al. $[115,116]$.

${ }^{237} \mathrm{~Np}$ : In case of ${ }^{237} \mathrm{~Np}(\mathrm{n}, \mathrm{f})$ cross section, for which there are systematic discrepancies in measured data [145-153], which were not removed by recent measurement by Tovesson et al. [153], the estimated r.s.d. is over-optimistic (see Figs. 3.24, 3.25, 3.26). That would influence the estimates of ${ }^{237} \mathrm{~Np}\left(\mathrm{n}, \mathrm{n}^{\prime}\right)$ [63] and ${ }^{237} \mathrm{~Np}(\mathrm{n}, 2 \mathrm{n})$ r.s.d $[154,155]$. The r.s.d. are increased in the first groups almost twice. Present partial chance fission cross sections are much different from those of ENDF/B-VI evaluation, unfortunately, they are not provided for the ENDF/B-VII.0 evaluation.

${ }^{241} \mathrm{Am}$ : Measured data on ${ }^{241} \mathrm{Am}(\mathrm{n}, \mathrm{F})$ [120, 156-168] cross section emerging from different experiments are scattering a lot, the systematic differences are also quite appreciable (see Figs. 3.27, 
3.28, 3.29).. Data by Dabbs et al. [157] could be easily reproduced within a statistical theory approach from $1 \mathrm{keV}$ up to $20 \mathrm{MeV}$, except the energy range in the vicinity of the (n,2nf) reaction threshold. The fission probabilities of ${ }^{241} \mathrm{Am}$ and ${ }^{240} \mathrm{Am}$ nuclides, fissioning in ${ }^{241} \mathrm{Am}(\mathrm{n}, \mathrm{nf})$ and ${ }^{241} \mathrm{Am}(\mathrm{n}, 2 \mathrm{nf})$ reactions, are defined using nucleon transfer reaction data by Britt et al [113]. The data by Prindle et al. [164] and Fomushkin et al. [120] at $\mathrm{E}_{\mathrm{n}}=14.8 \mathrm{MeV}$ are consistent with the calculated cross section. Data on the ${ }^{241} \mathrm{Am}(\mathrm{n}, 2 \mathrm{n})$ reaction cross section by Filatenkov et al. [169] are consistent with evaluation by Maslov et al. [17]. That is rather important peculiarity, which is an important evidence of the reliability of the fission chances partitioning. Recent measurement of the ${ }^{241} \mathrm{Am}(\mathrm{n}, 2 \mathrm{n})$ in the energy range of 8.8-11.4 $\mathrm{MeV}$ by Perdikakis et al. [170] favors our cross section estimate at $\mathrm{E}_{\mathrm{n}}<10 \mathrm{MeV}$ and by Vieira et al. [171] strongly support fission cross section estimate by Maslov et al. [17, 172]. The r.s.d. is increased in first groups almost twice.

${ }^{243} \mathrm{Am}$ : Measured data [173-182] on ${ }^{243} \mathrm{Am}(\mathrm{n}, \mathrm{F})$ cross section emerging from different experiments are scattering much more than in case of ${ }^{241} \mathrm{Am}(\mathrm{n}, \mathrm{F})$, the systematic differences are also much higher (see Figs. 3.30, 3.31, 3.32).. We suppose the data by Knitter et al. [174] and Fursov et al. [173], spanning the energy range of $1 \mathrm{keV}$ up to $E_{n}=7.4 \mathrm{MeV}$ are more reliable than the others. Data by Goverdovskij et al. [175] and Behrens et al. [179] predict a systematically higher cross section values. The fission probabilities of ${ }^{243} \mathrm{Am}$ and ${ }^{242} \mathrm{Am}$, fissioning in the reactions ${ }^{243} \mathrm{Am}(\mathrm{n}, \mathrm{nf})$ and ${ }^{243} \mathrm{Am}(\mathrm{n}, 2 \mathrm{nf})$ were defined by ${ }^{242 \mathrm{~m}} \mathrm{Am}(\mathrm{n}, \mathrm{f})$ и ${ }^{241} \mathrm{Am}(\mathrm{n}, \mathrm{f})$ data. The contributions of the (n,xnf) emissive fission cross sections to the observed ${ }^{243} \mathrm{Am}(\mathrm{n}, \mathrm{F})$ fission cross section predict the cross section values at $E_{n}>7.4$ $\mathrm{MeV}$, which are systematically lower than the measured data, including the data by Fomushkin et al. [176] at $E_{n}=14.5 \mathrm{MeV}$. However, the recent measurement of the energy dependence of the ratio of ${ }^{243} \mathrm{Am} /{ }^{235} \mathrm{U}$ cross sections by Laptev et al. [181] supports our theoretical estimate. The data by Laptev et al. [181], when normalized to the data by Fursov et al. [173] at $E_{n}=5-6 \mathrm{MeV}$ demonstrate nice consistency of the calculated and measured data on ${ }^{243} \mathrm{Am}(\mathrm{n}, \mathrm{F})$ in the $\mathrm{E}_{\mathrm{n}}=0.1-20 \mathrm{MeV}$ energy range. The r.s.d. is increased in first groups almost twice.

${ }^{242 \mathrm{~m}} \mathrm{Am}$ : We suppose the data by Browne et al. [182] and Fursov et al. [183], which predict a systematically lower cross section than that observed in other experiment by Dabbs et al. [184] (see Figs. 3.33, 3.34).. The energy dependence of ${ }^{242 \mathrm{~m}} \mathrm{Am}(\mathrm{n}, \mathrm{F})$ reaction cross section in the $0.1-20 \mathrm{MeV}$ energy range is stemming from the data by Browne et al. [182] and Dabbs et al. [185]. The fission probability of the ${ }^{242} \mathrm{Am}$, fissioning in the reaction ${ }^{242 \mathrm{~m}} \mathrm{Am}(\mathrm{n}, \mathrm{nf})$, is defined by the ${ }^{241} \mathrm{Am}(\mathrm{n}, \mathrm{f})$ data. The calculated cross section is consistent with data by Browne et al. [182] and Fursov et al. [183] up to $E_{n}=$ 
$10 \mathrm{MeV}$, while its energy dependence is consistent with data by Dabbs et al. [184] and Fomushkin et al. [185] at $E_{n}$ higher than the emissive fission threshold. Summarizing, we argue, that the consistent estimate of the fission probabilities of ${ }^{244} \mathrm{Am},{ }^{243} \mathrm{Am}$ and ${ }^{242} \mathrm{Am}$ nuclides produces a theoretical estimate of the ${ }^{242 \mathrm{~m}} \mathrm{Am}(\mathrm{n}, \mathrm{F})$ reaction cross section, which is different from the data by Browne et al. [182] in the same manner as in case of data by White and Browne et al. [143] on ${ }^{245} \mathrm{Cm}(\mathrm{n}, \mathrm{F})$. That is quite important observation, since both measurements were made in similar environments. The r.s.d. is increased in first groups almost twice. 


\section{${ }^{232}$ Th FISSION CROSS SECTION}

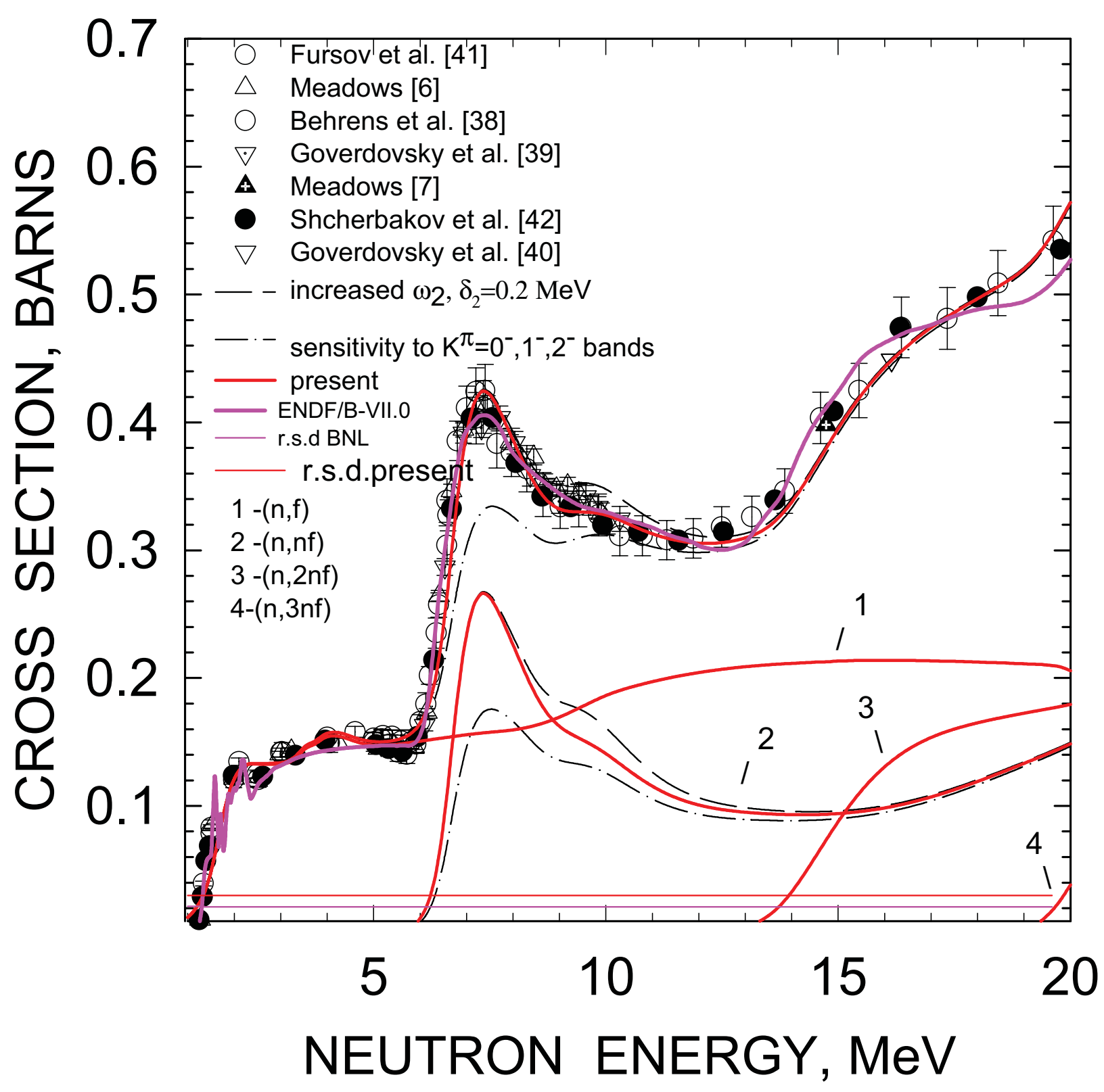




\section{${ }^{238}$ U FISSION CROSS SECTION}

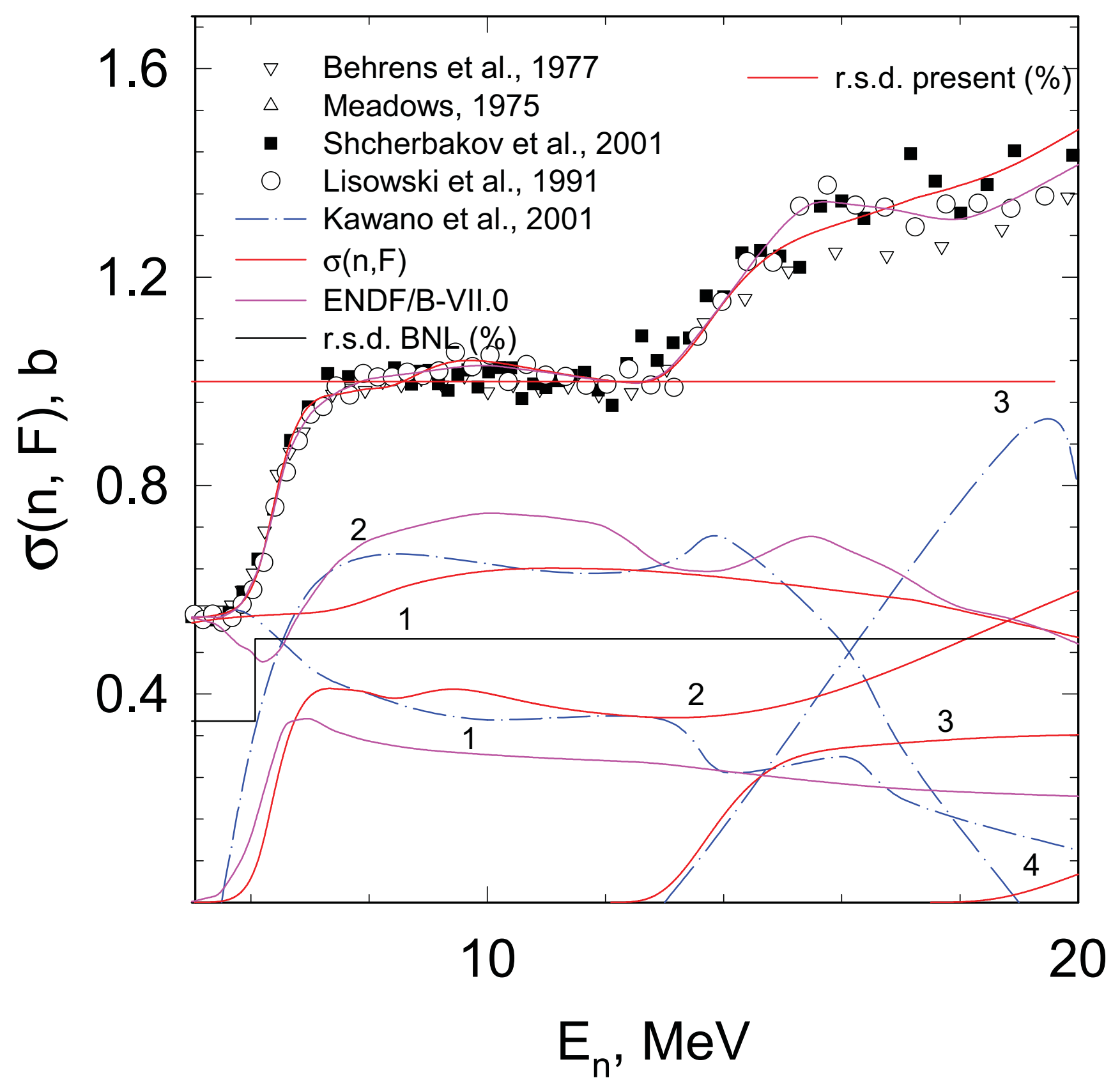




\section{${ }^{236}$ U FISSION CROSS SECTION}

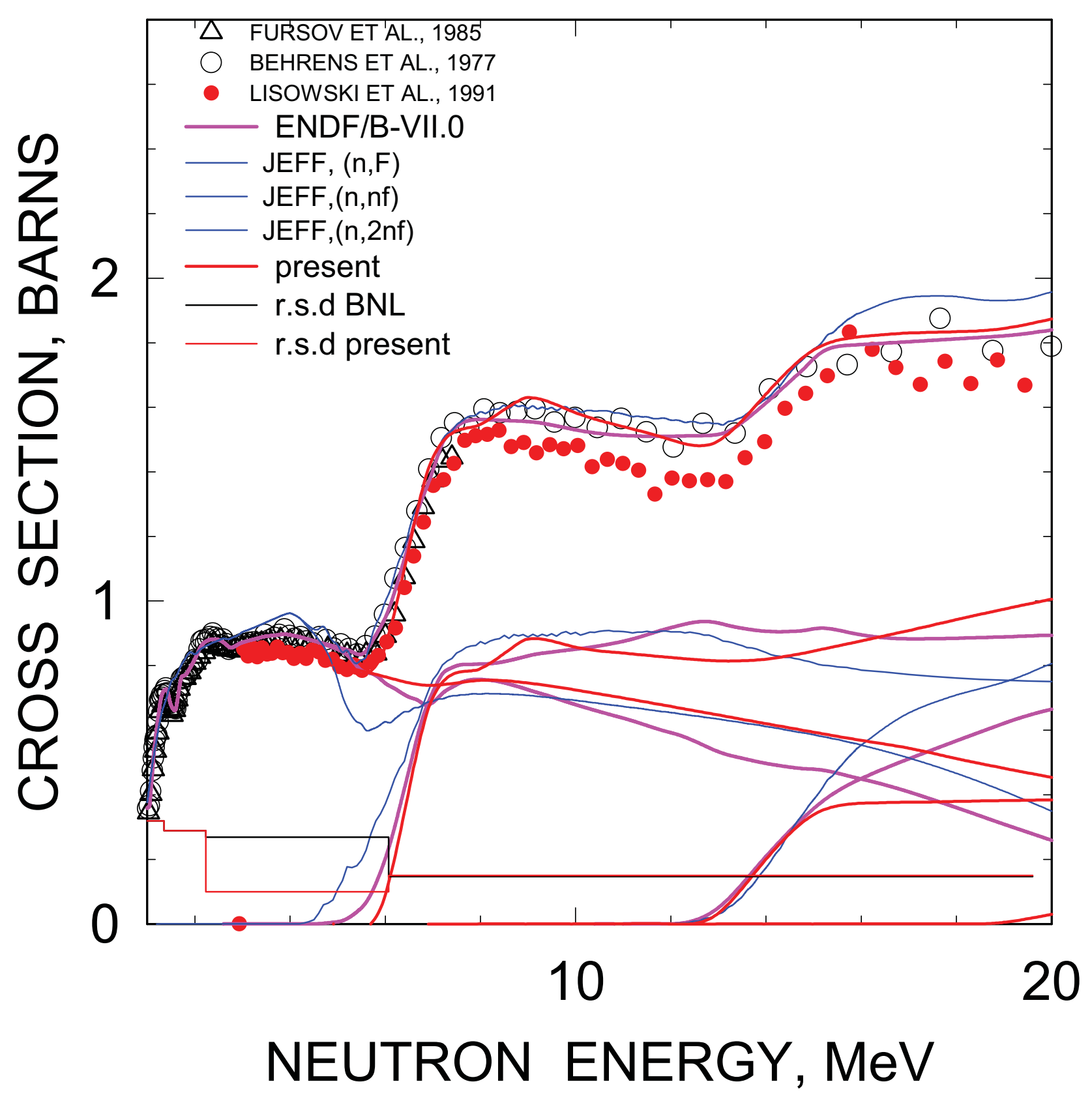




\section{${ }^{234}$ U FISSION CROSS SECTION}

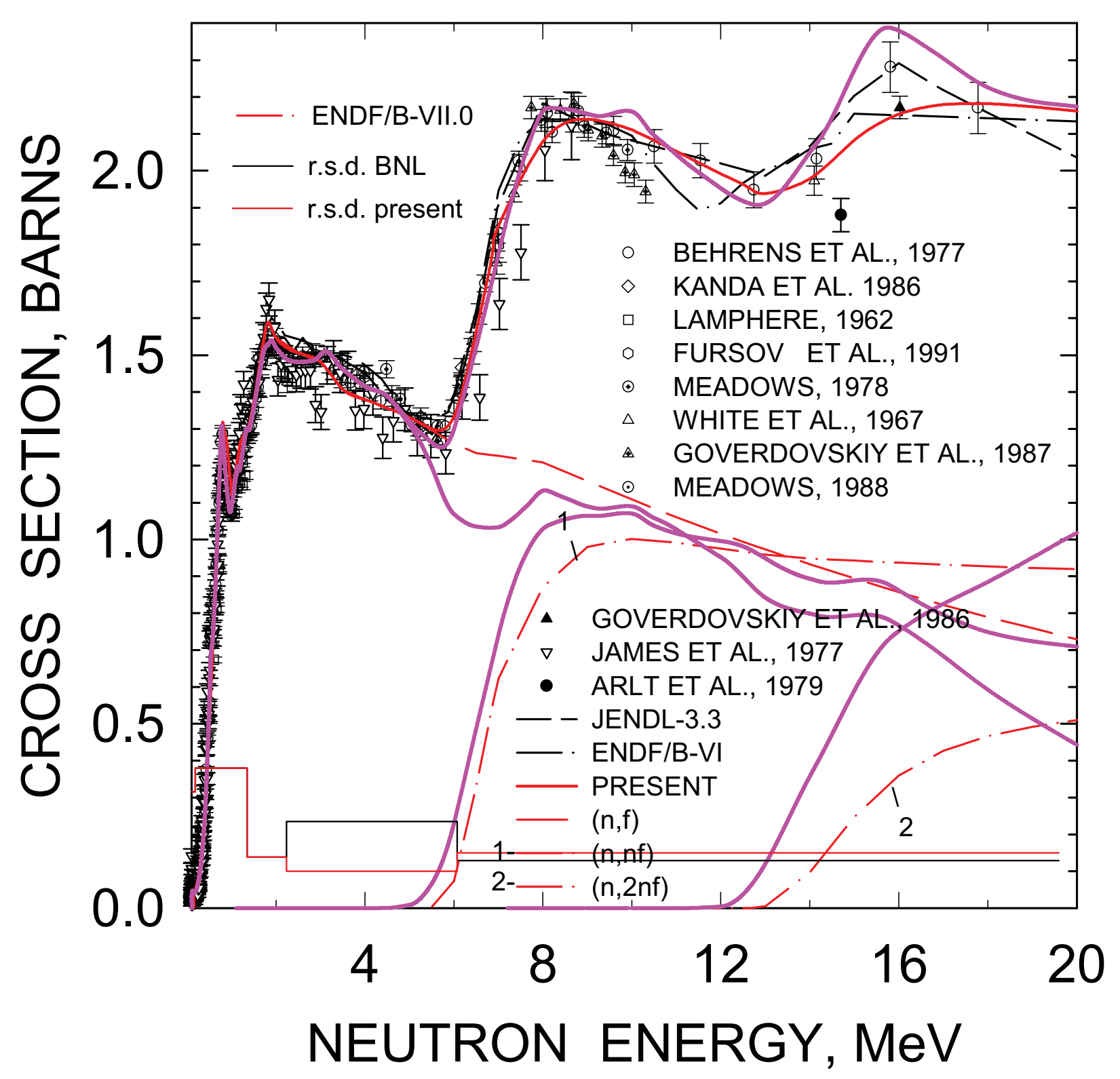




\section{${ }^{238} \mathrm{PU}$ FISSION CROSS SECTION}

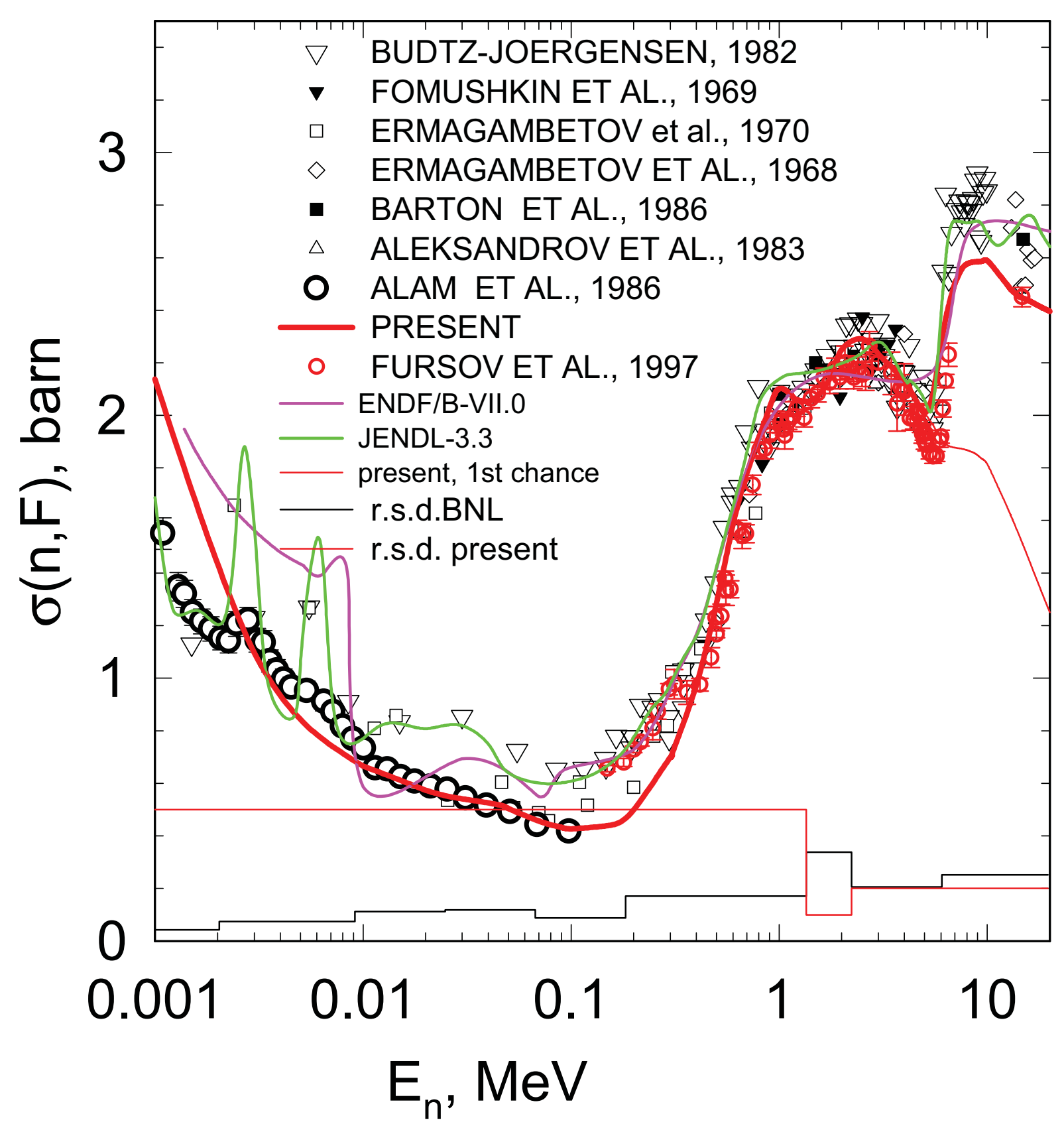




\section{${ }^{238} \mathrm{Pu}$ FISSION CROSS SECTION}

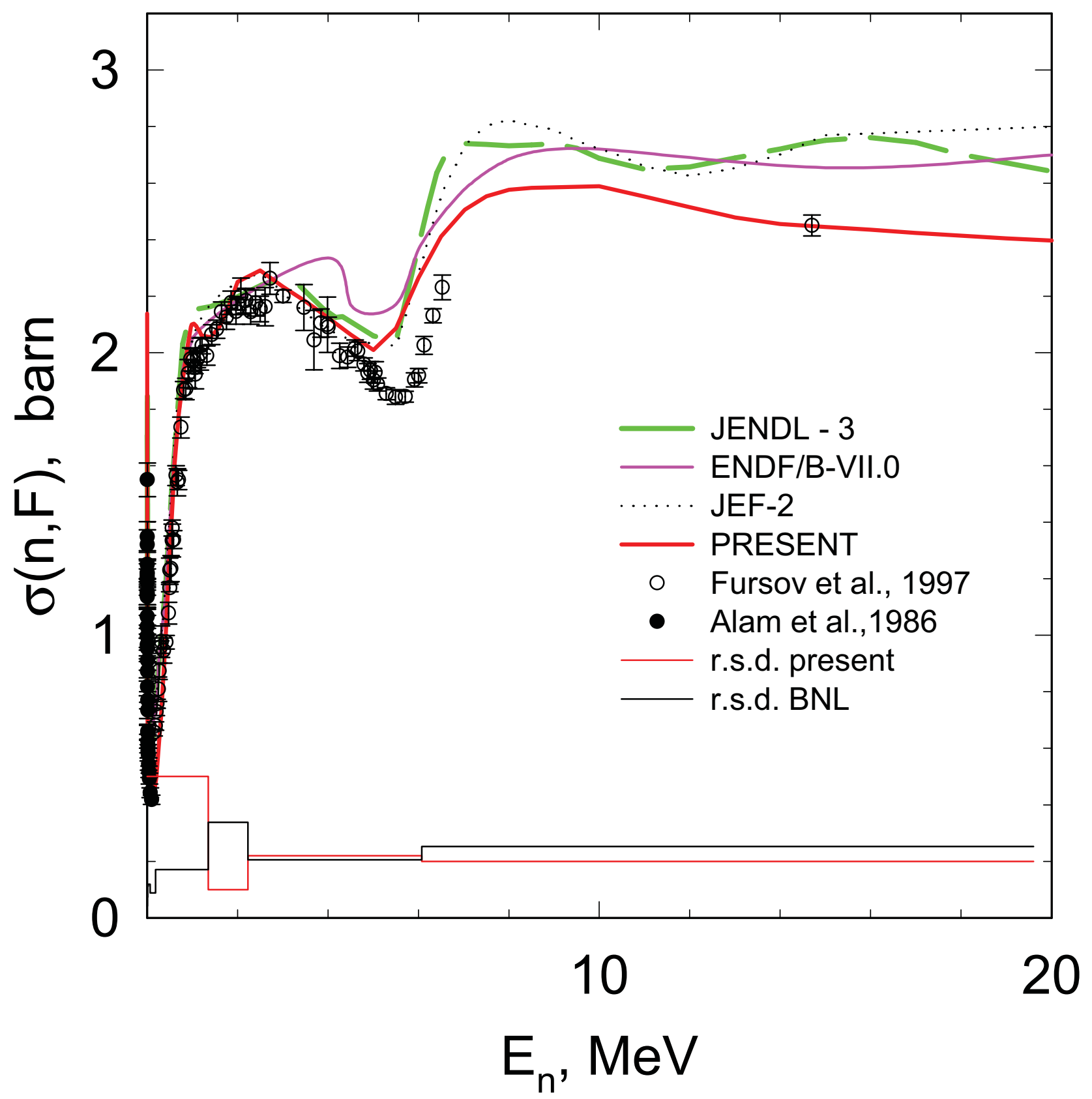




\section{${ }^{240} \mathrm{PU}$ FISSION CROSS SECTION}

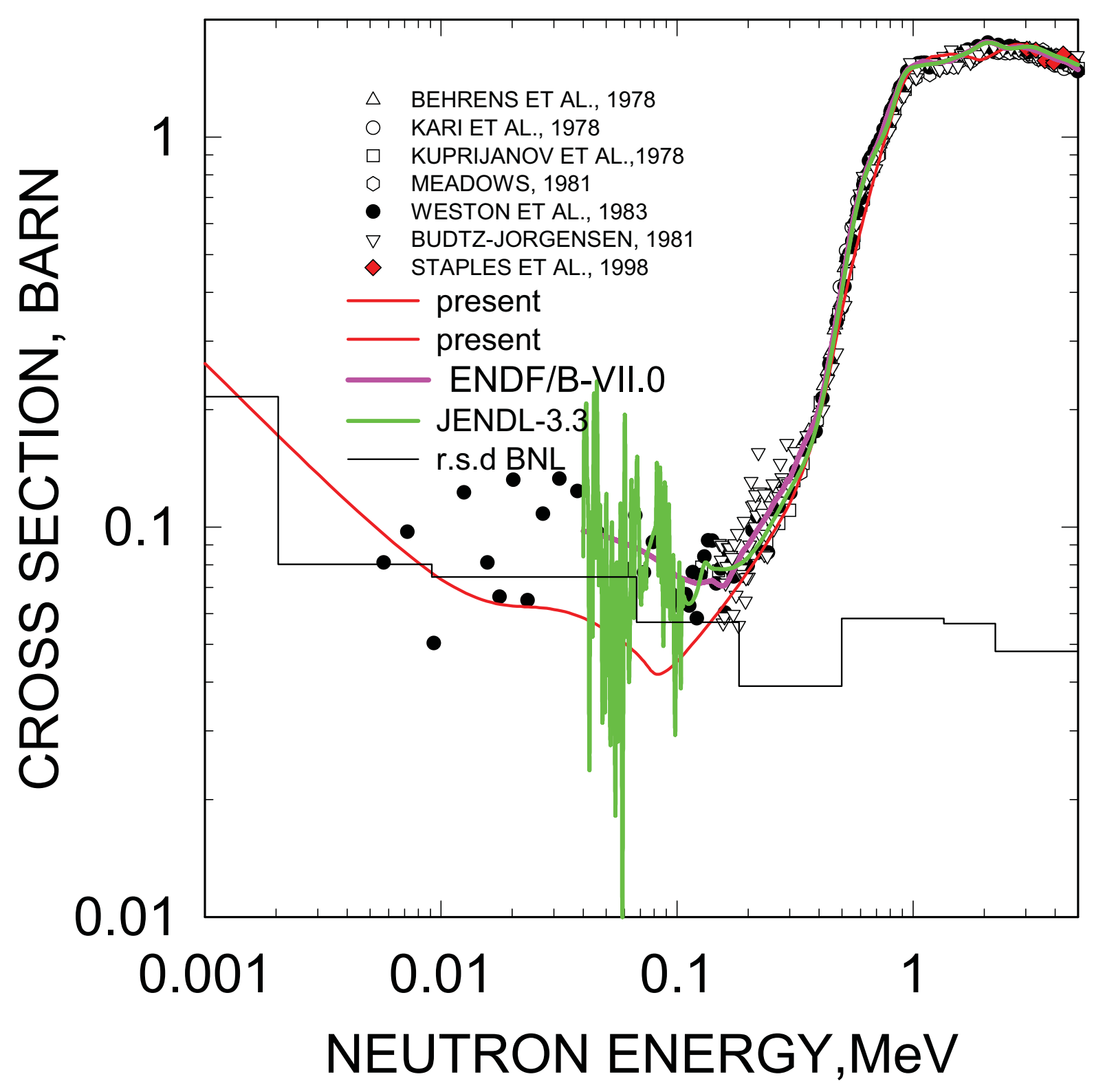




\section{${ }^{240} \mathrm{PU}$ FISSION CROSS SECTION}

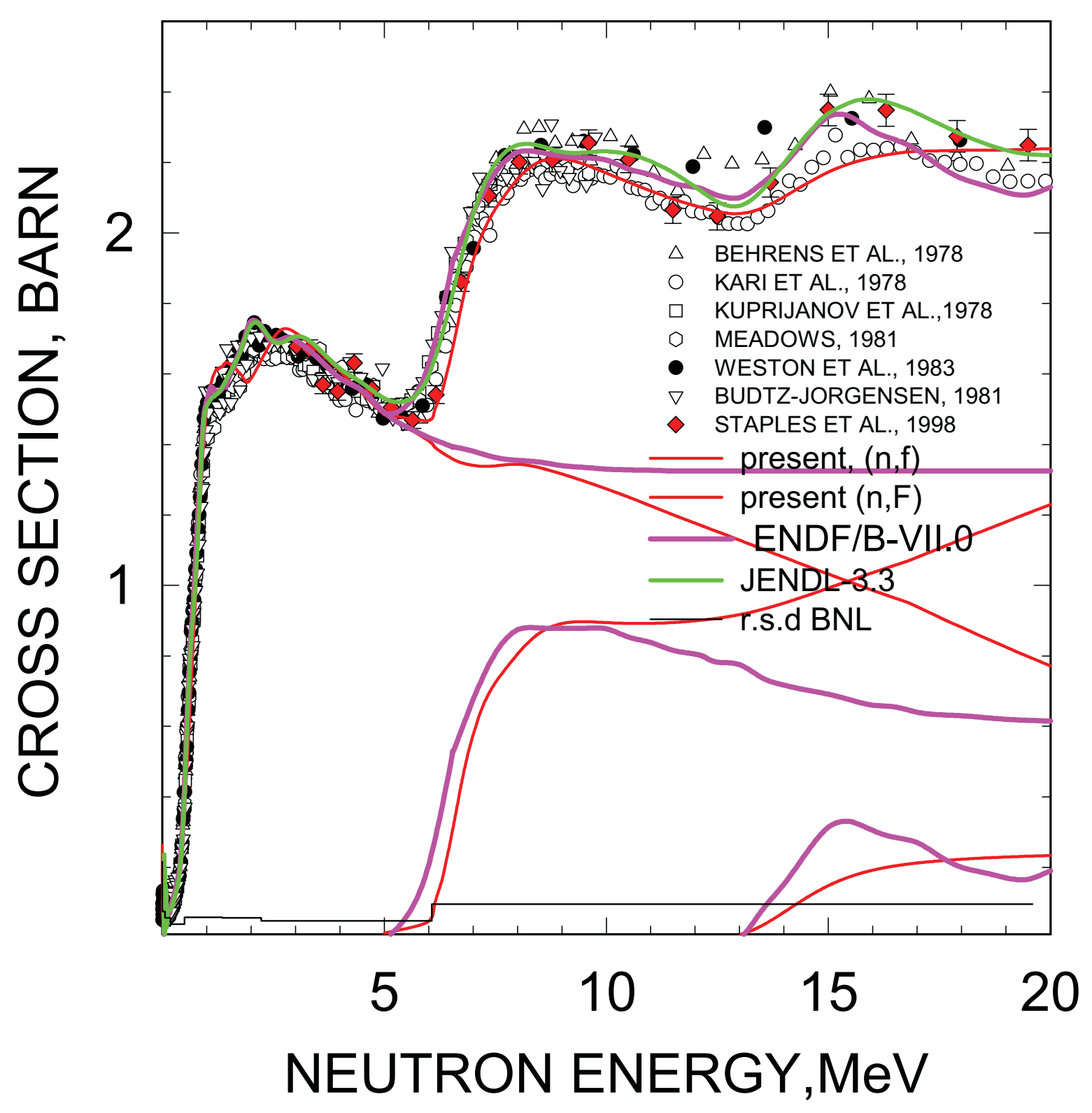




\section{${ }^{242} \mathrm{PU}$ FISSION CROSS SECTION}

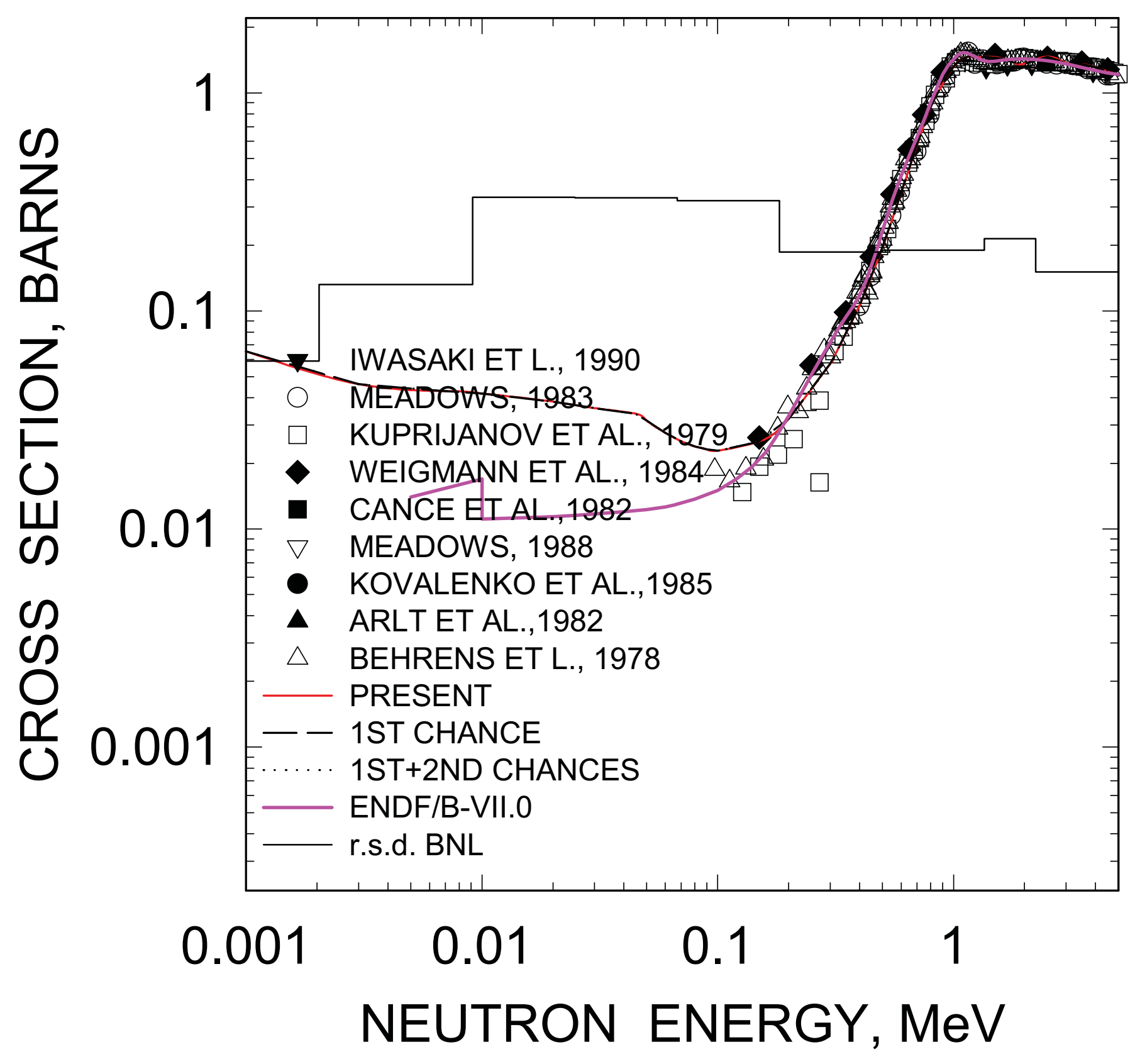




\section{${ }^{242} \mathrm{Pu}$ FISSION CROSS SECTION}

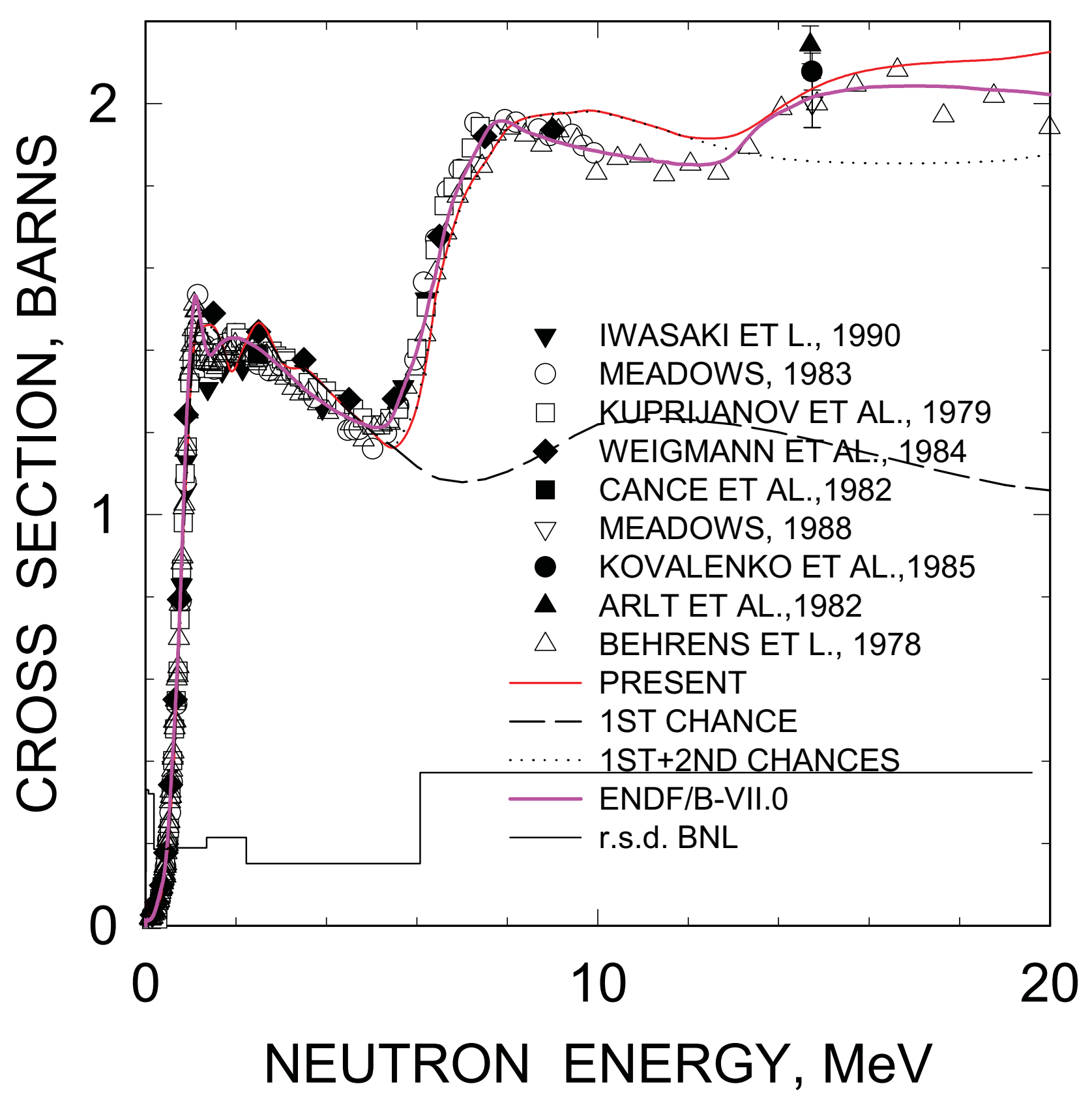




\section{${ }^{242} \mathrm{Cm}$ FISSION CROSS SECTION}

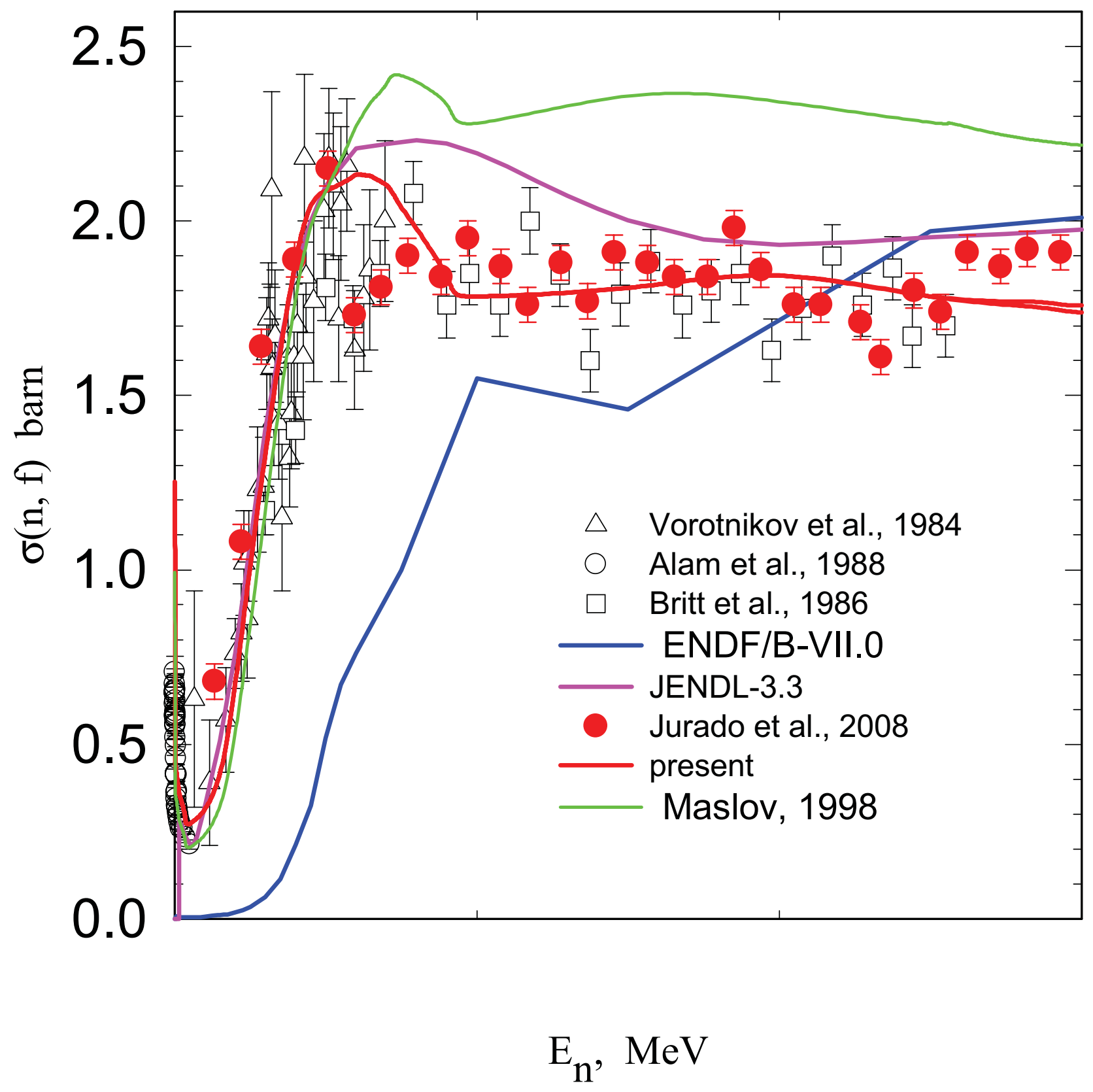




\section{${ }^{242} \mathrm{Cm}$ FISSION CROSS SECTION}

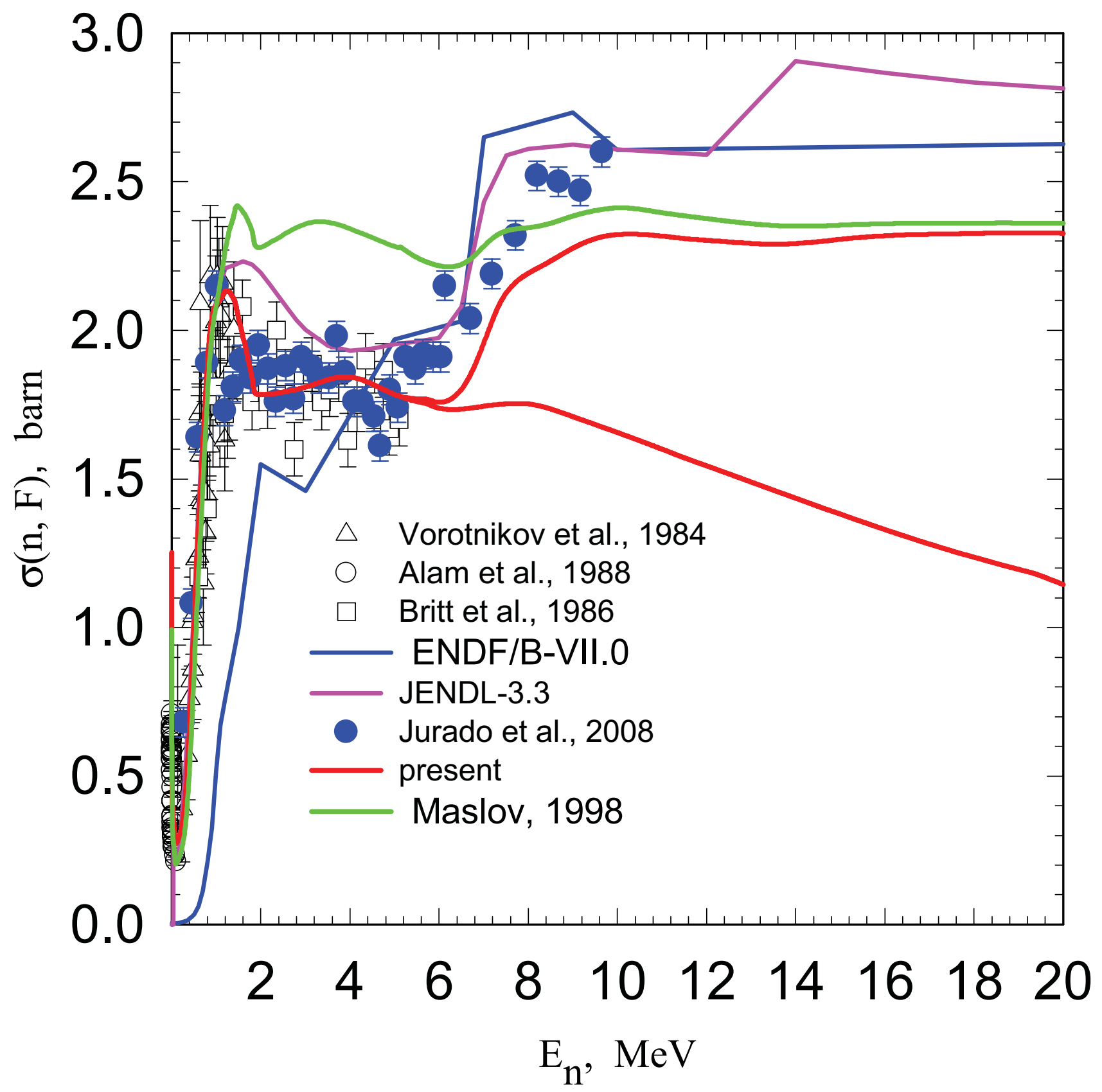




\section{${ }^{244} \mathrm{Cm}(\mathrm{n}, \mathrm{f})$}

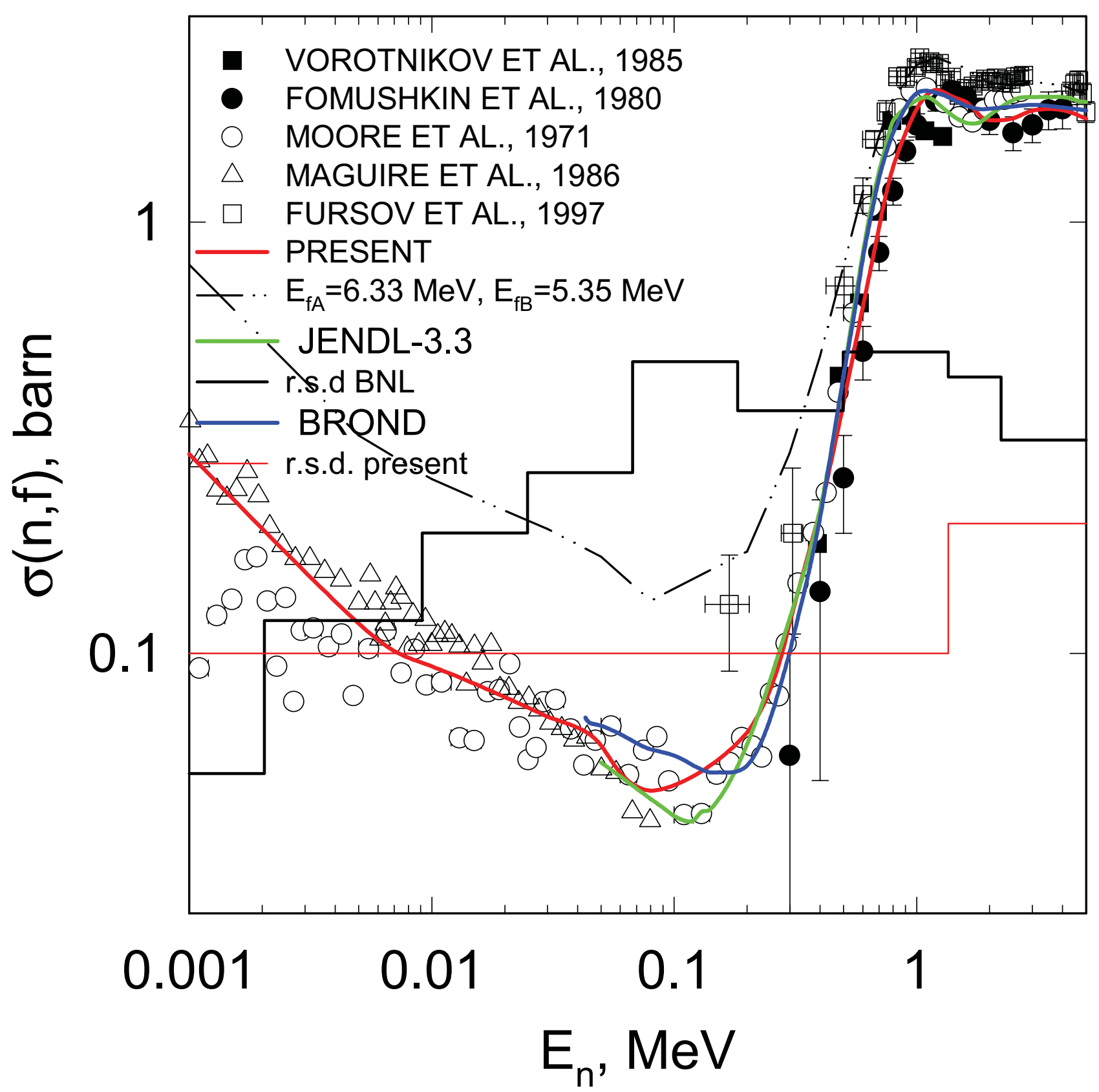




\section{${ }^{244} \mathrm{Cm}$ FISSION CROSS SECTION}

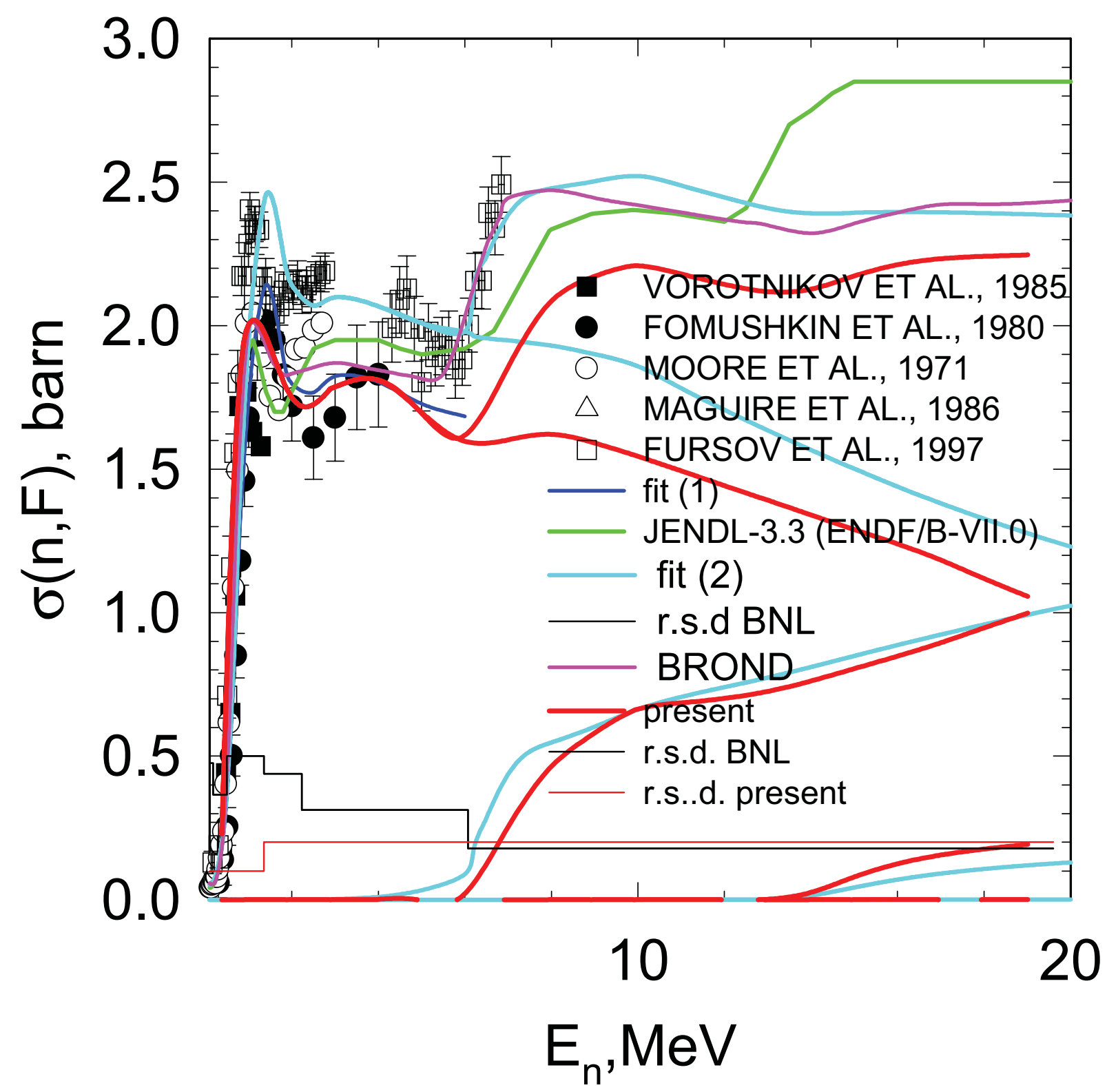




\section{${ }^{235}$ U FISSION CROSS SECTION}

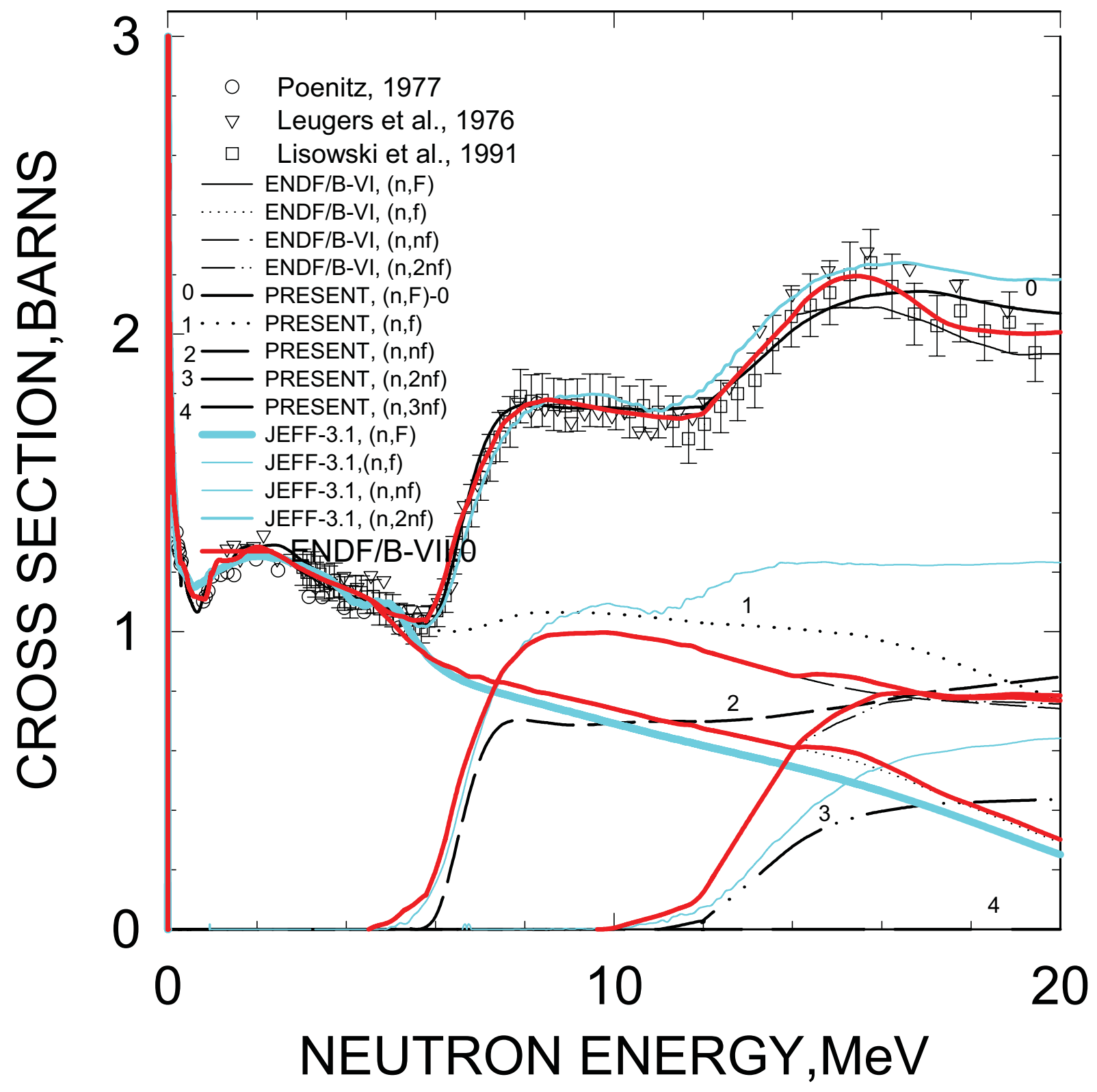




\section{${ }^{233}$ U FISSION CROSS SECTION}

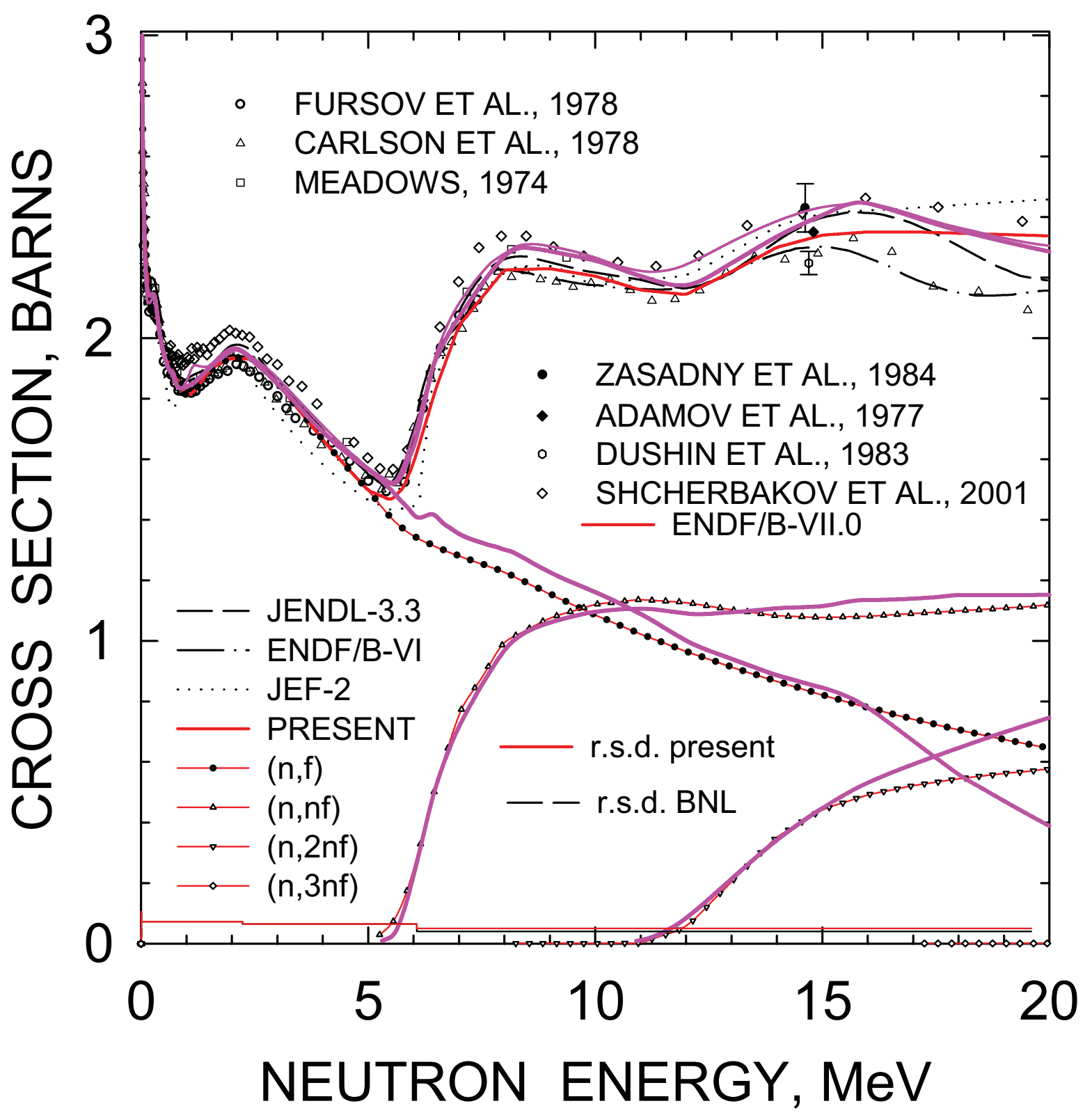




\section{${ }^{239} \mathrm{PU}$ FISSION CROSS SECTION}

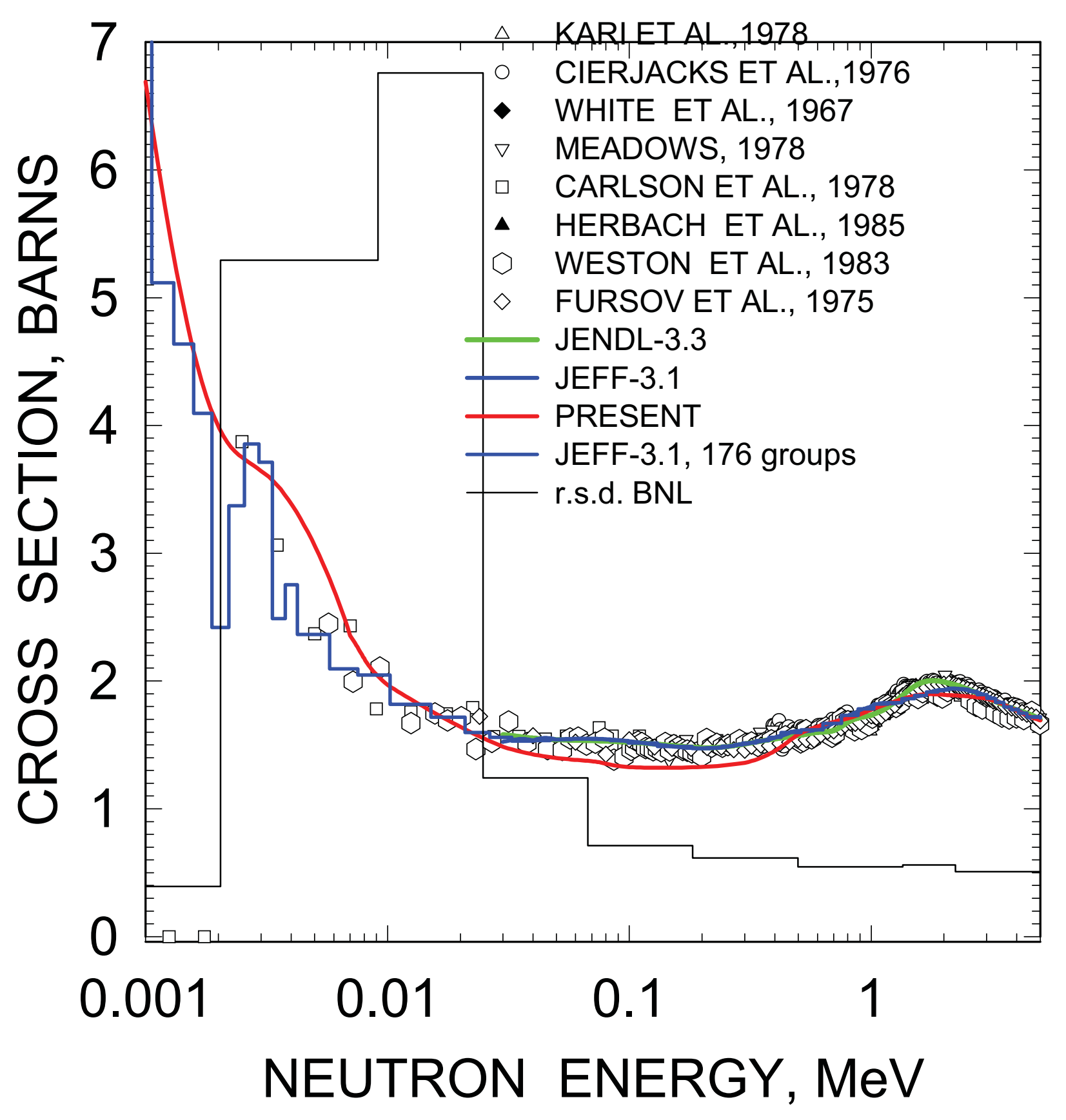




\section{${ }^{239} \mathrm{PU}$ FISSION CROSS SECTION}

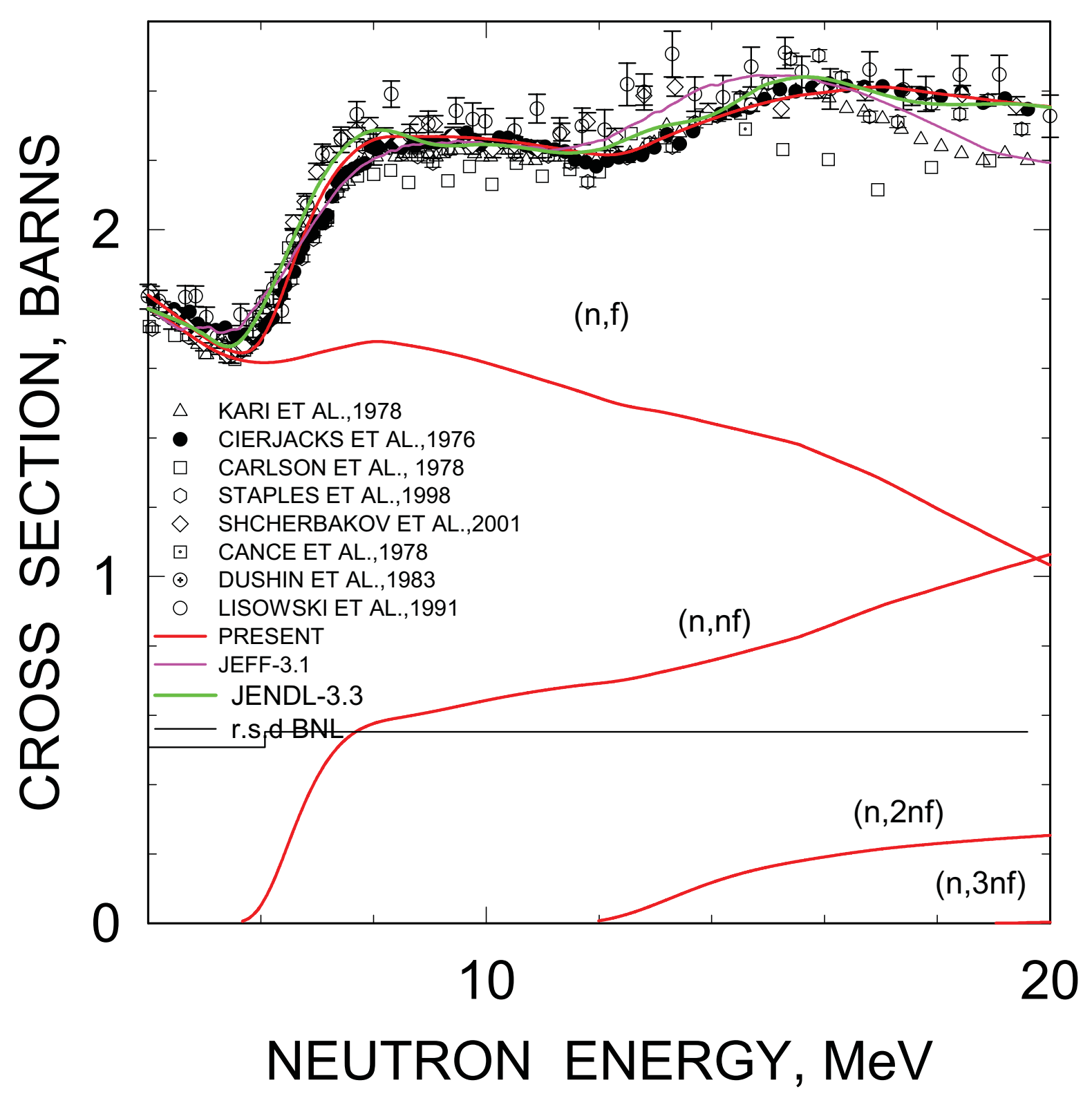




\section{${ }^{241} \mathrm{PU}$ FISSION CROSS SECTION}

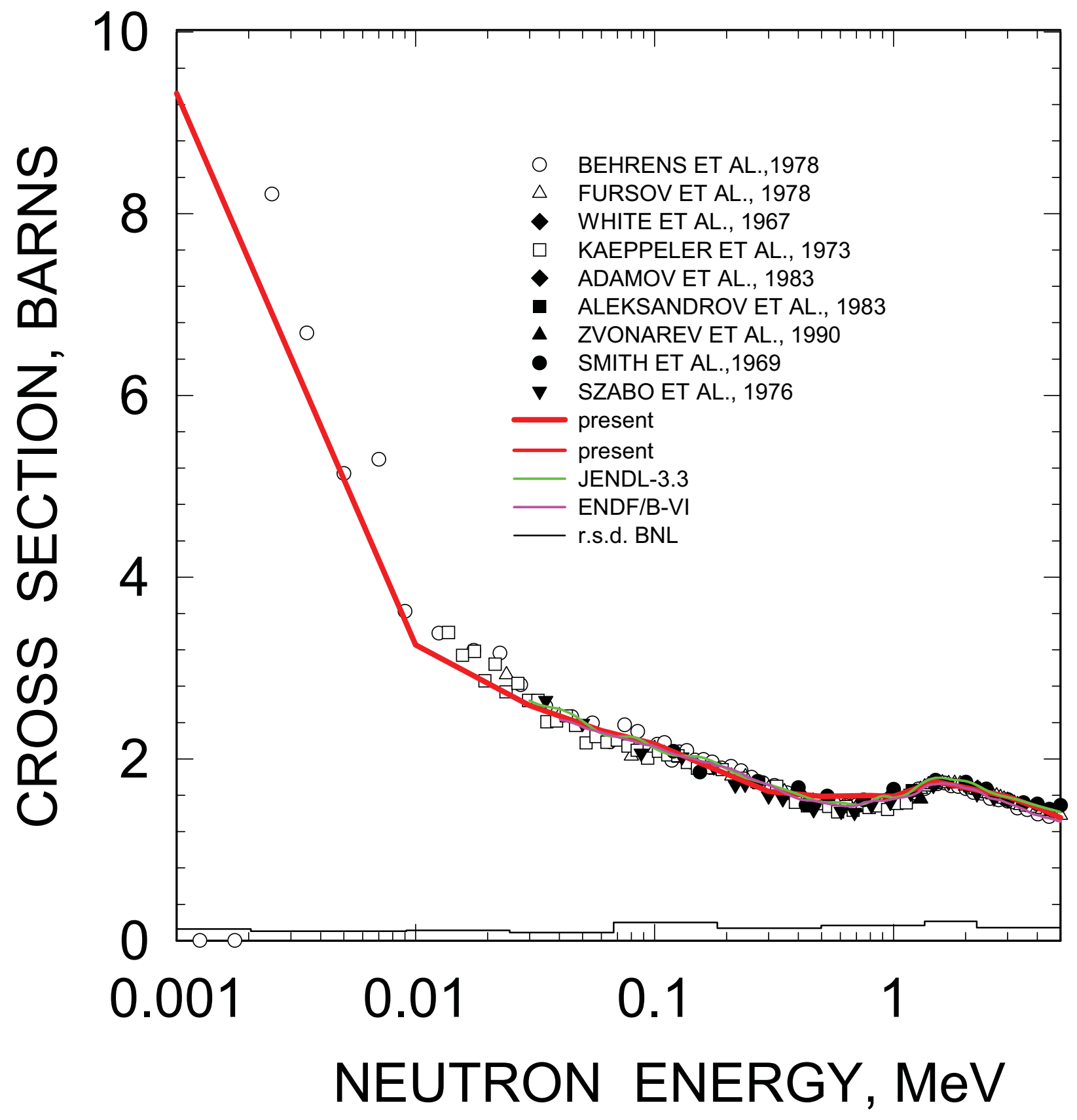




\section{${ }^{241} \mathrm{PU}$ FISSION CROSS SECTION}

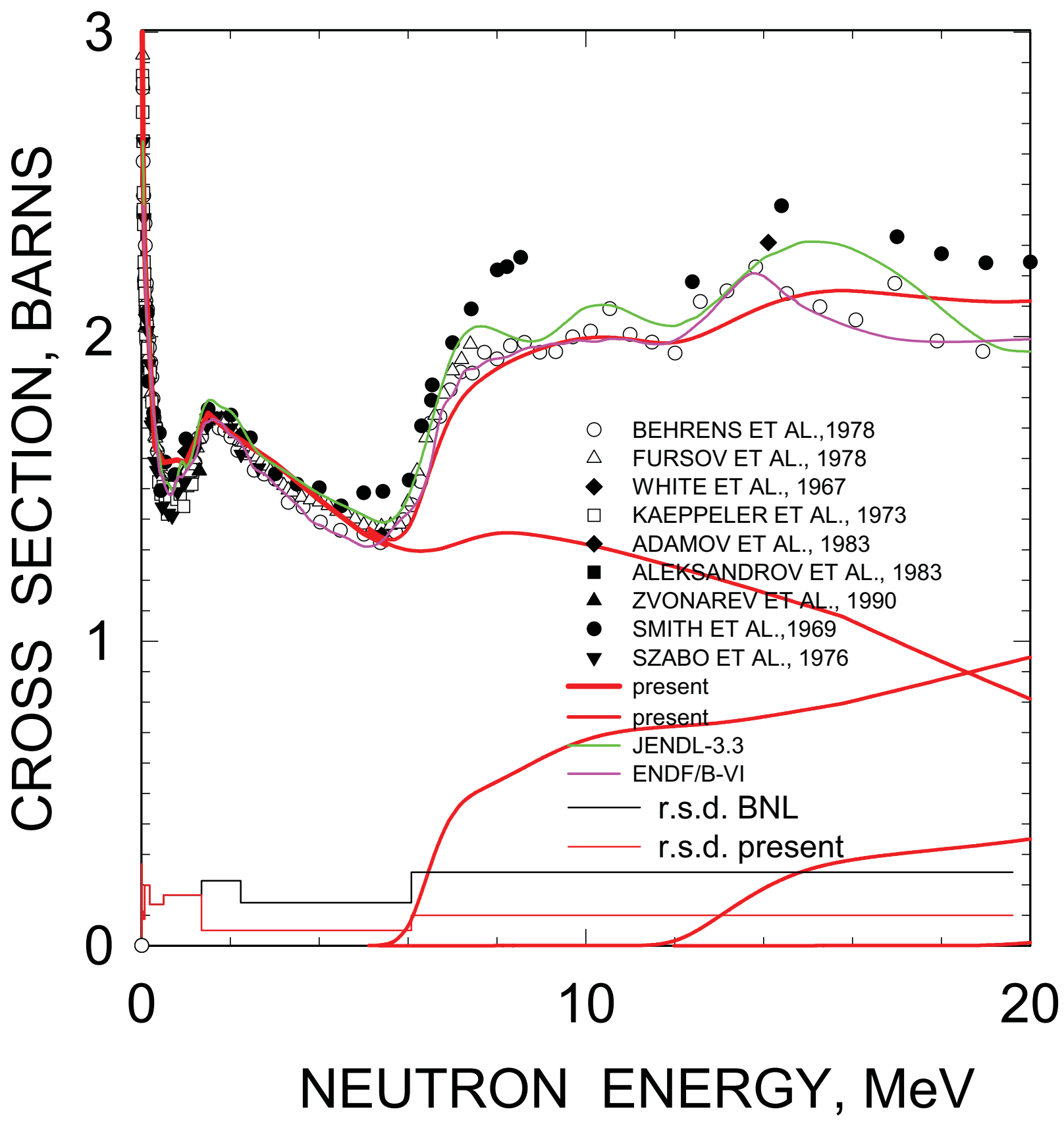




\section{${ }^{243} \mathrm{Cm}$ FISSION CROSS SECTION}

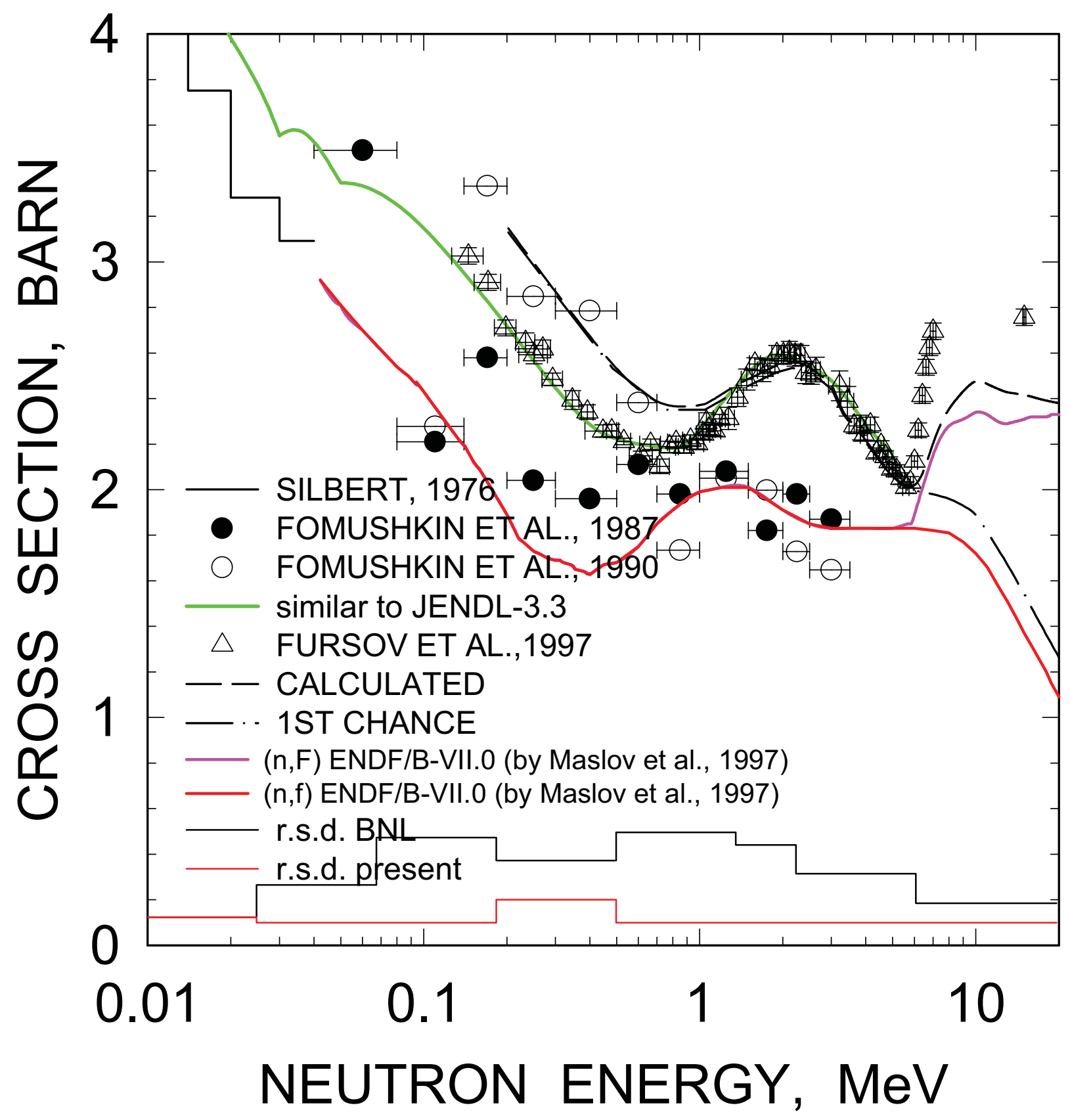




\section{${ }^{245} \mathrm{Cm}$ FISSION CROSS SECTION}

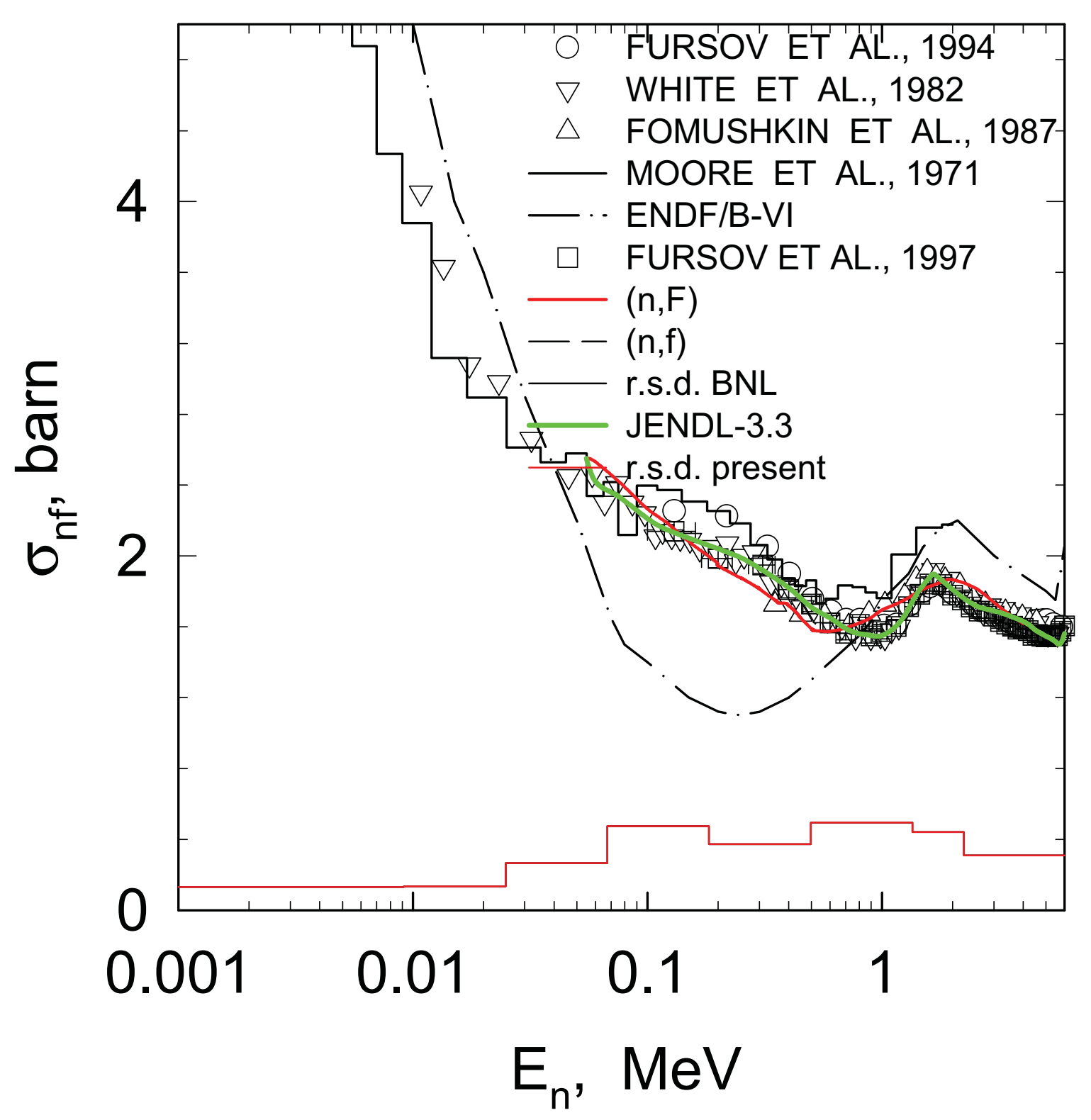




\section{${ }^{245} \mathrm{Cm}$ FISSION CROSS SECTION}

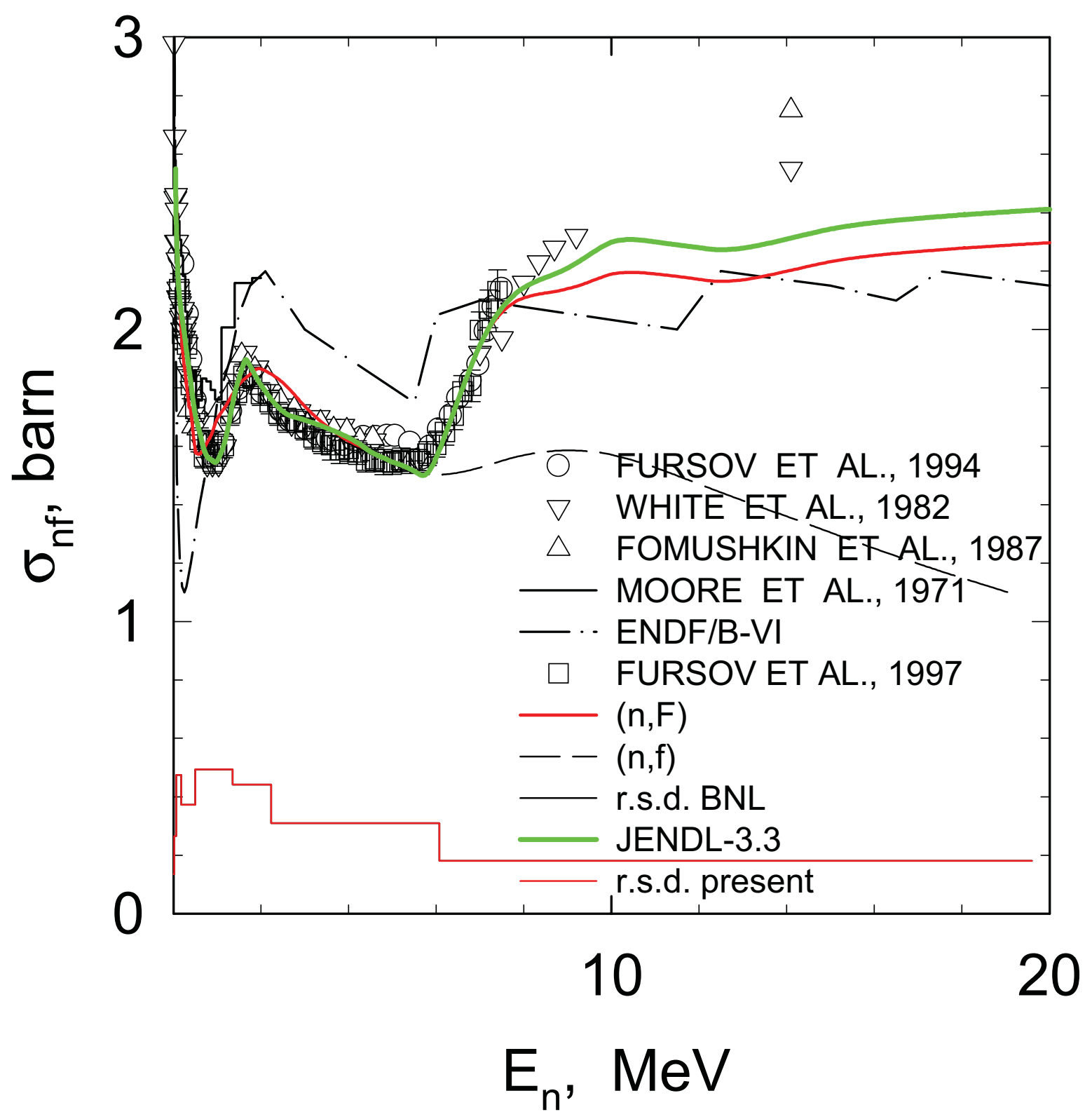




\section{${ }^{237} \mathrm{~Np}$ FISSION CROSS SECTION}

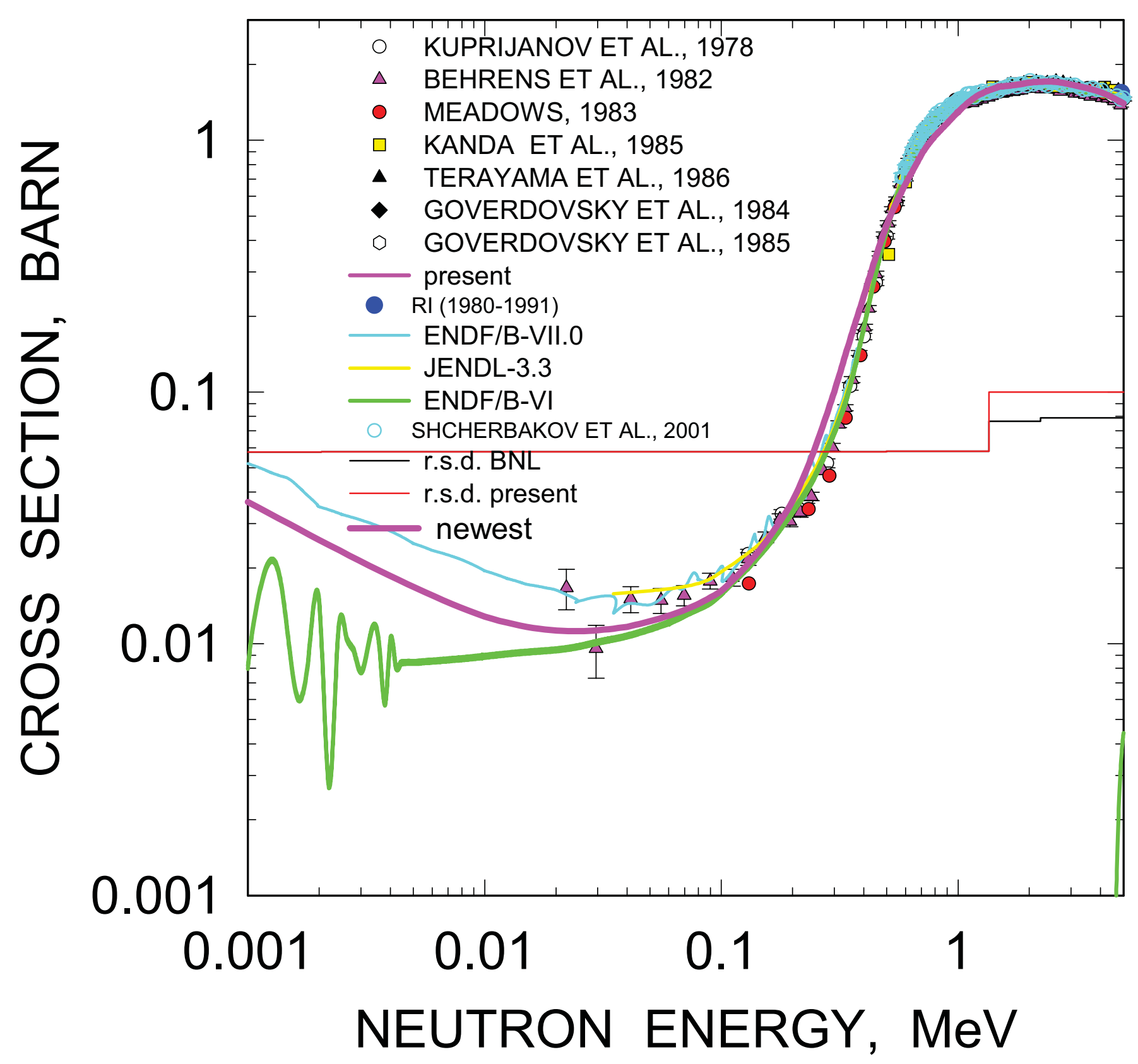




\section{${ }^{237} \mathrm{~Np}$ FISSION CROSS SECTION}

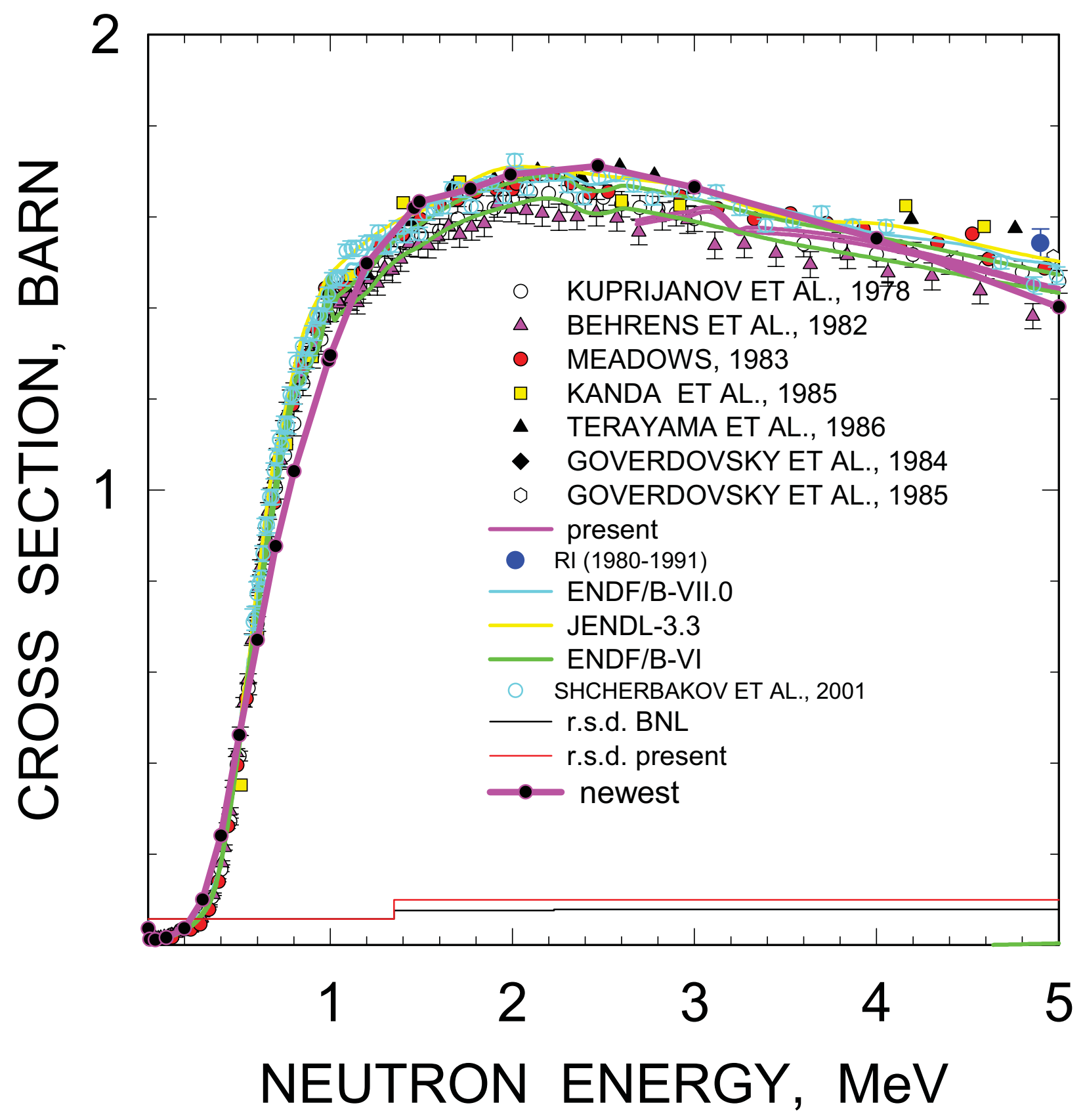




\section{${ }^{237} \mathrm{~Np}$ FISSION CROSS SECTION}

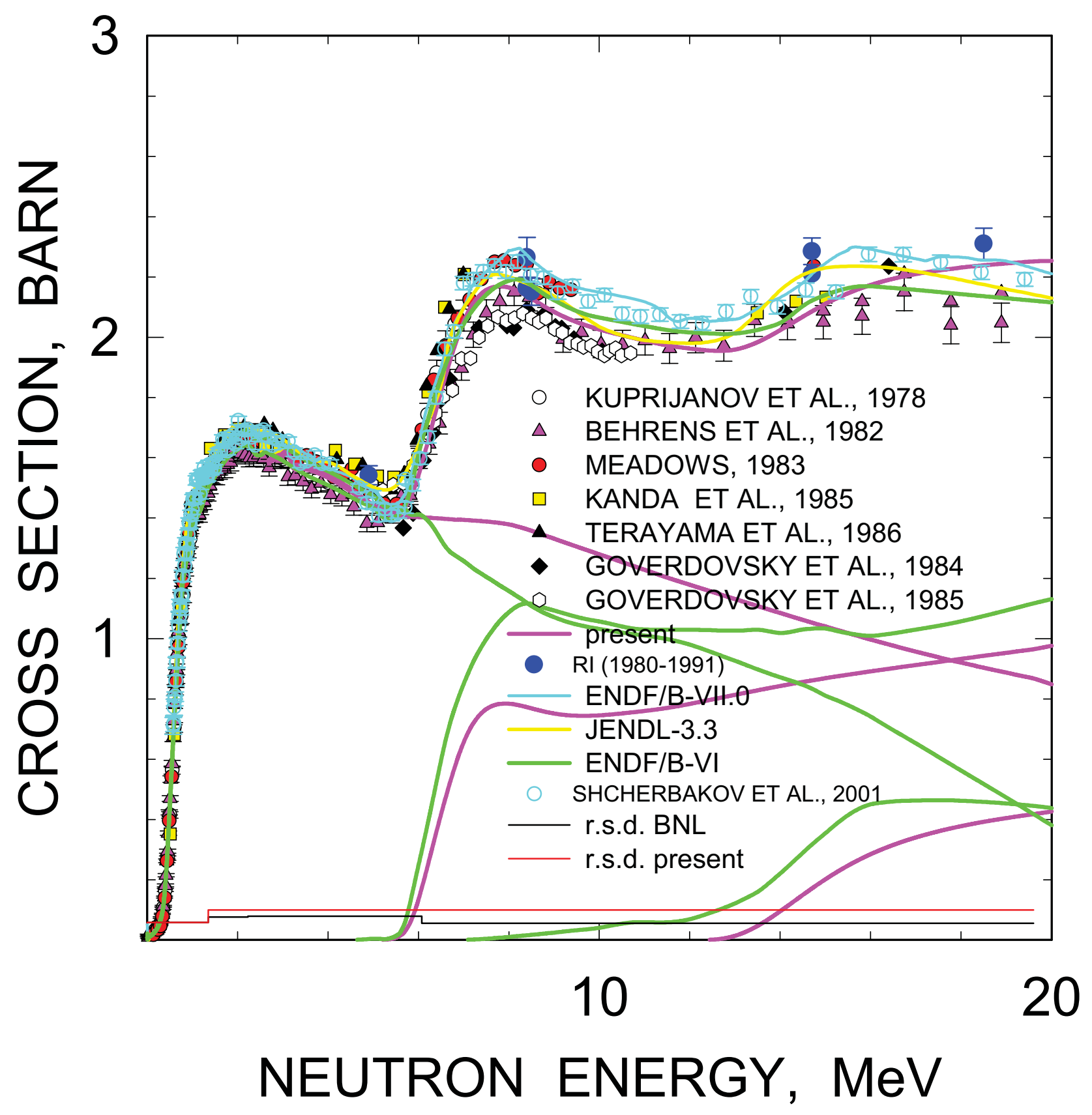




\section{${ }^{241} \mathrm{Am}$ FISSION CROSS SECTION}

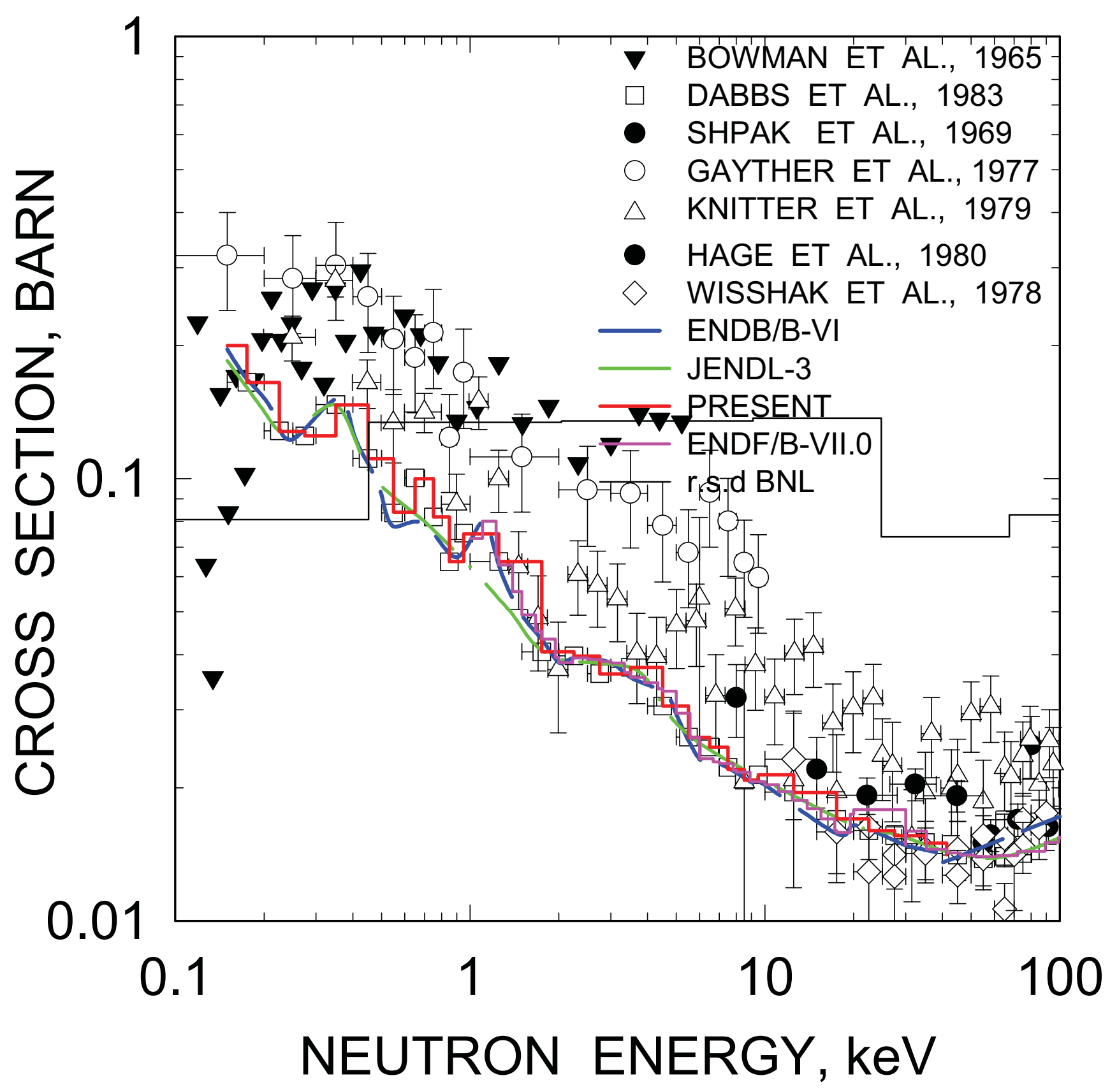




\section{${ }^{241} \mathrm{Am}$ FISSION CROSS SECTION}

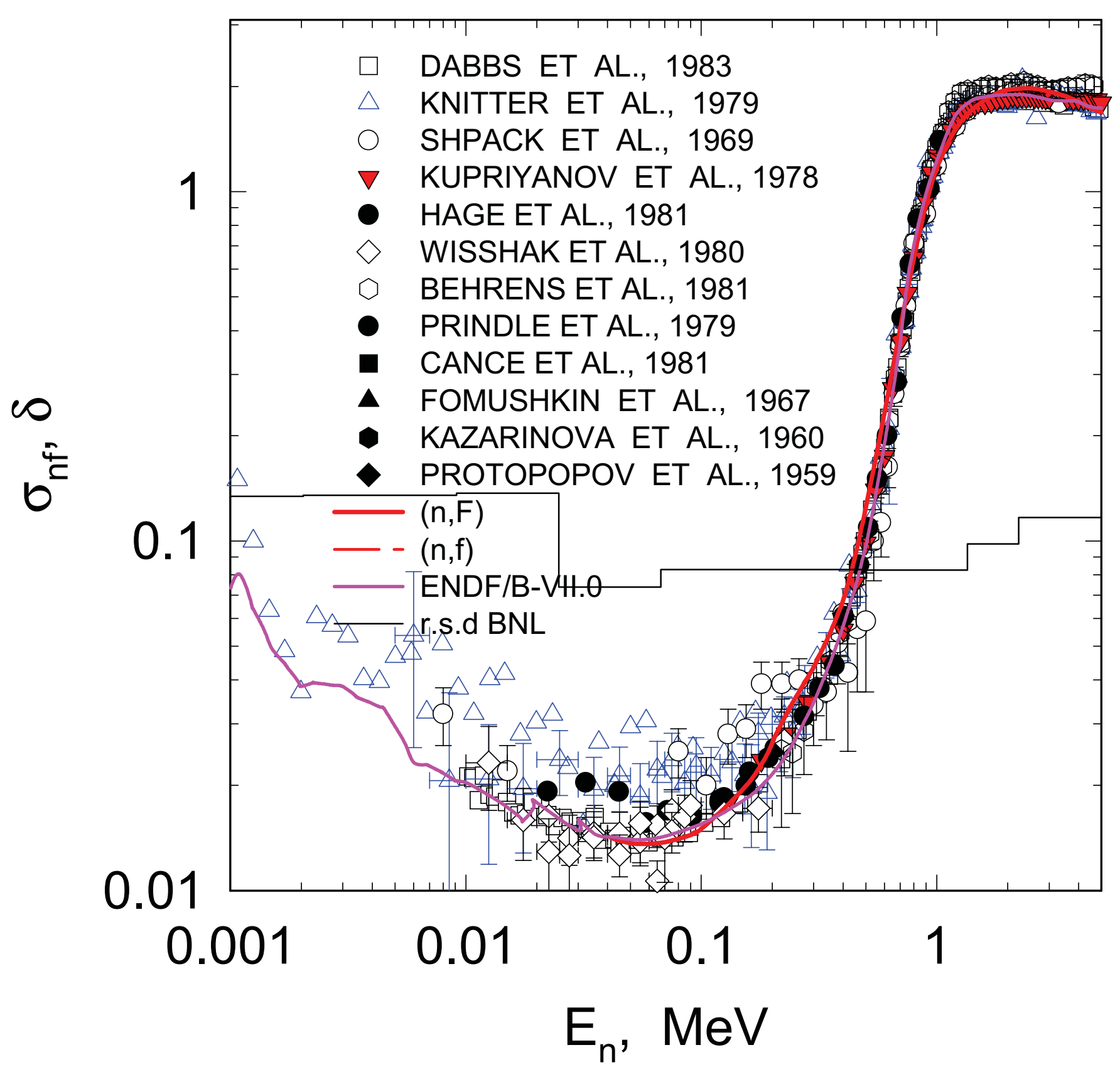




\section{${ }^{241} \mathrm{Am}$ FISSION CROSS SECTION}

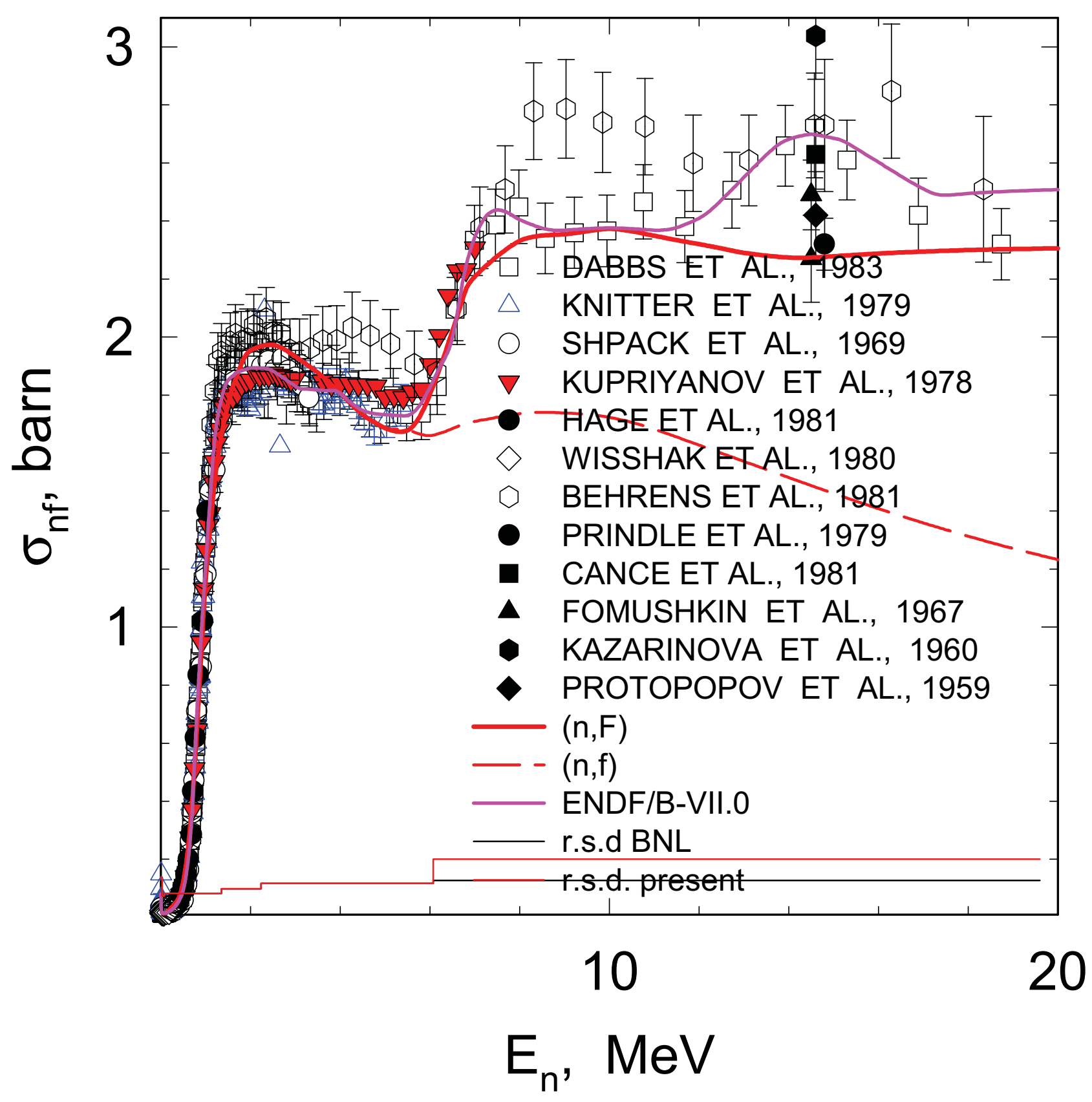




\section{${ }^{243} \mathrm{Am}$ FISSION CROSS SECTION}

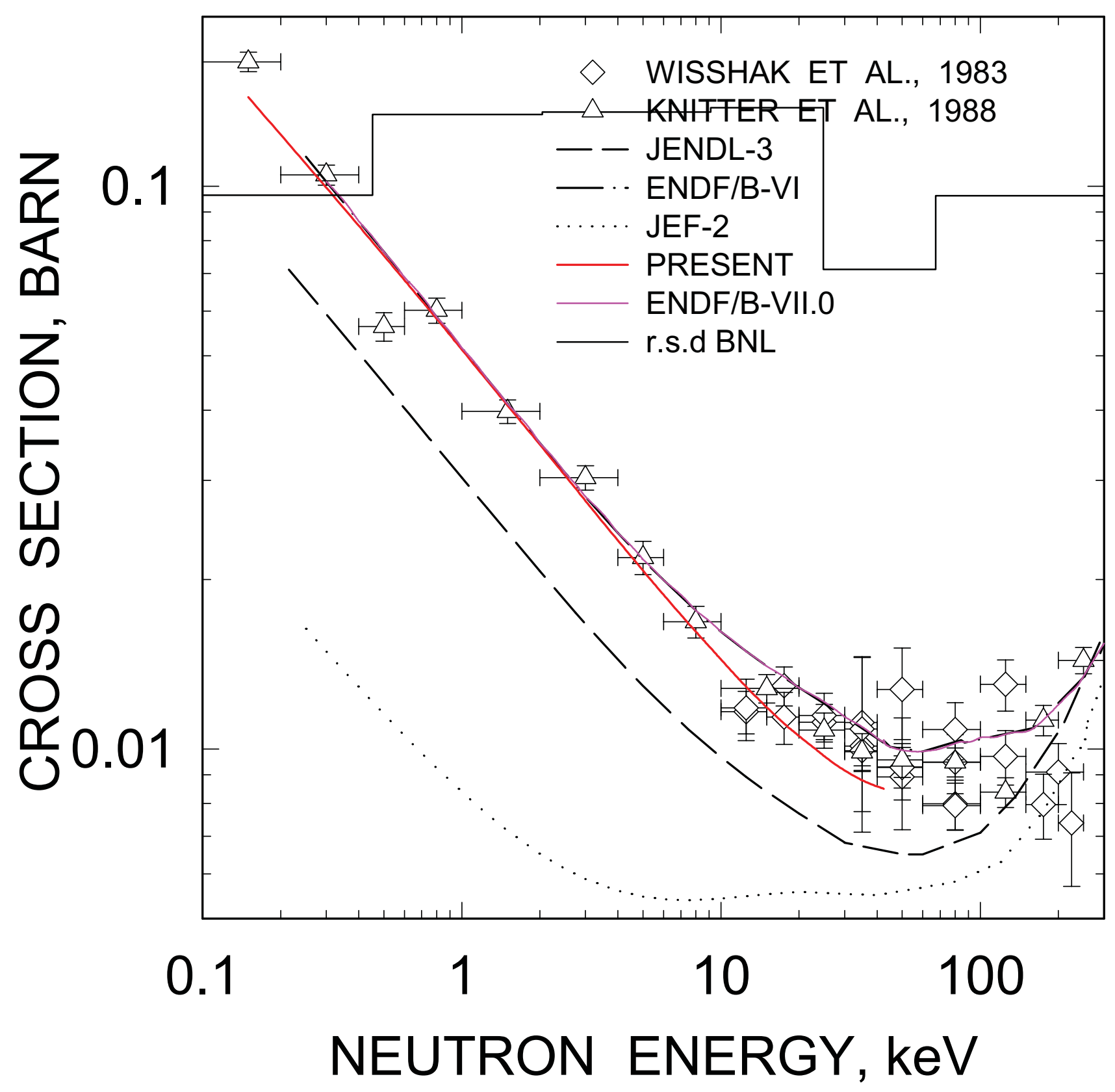




\section{${ }^{243} \mathrm{Am}$ FISSION CROSS SECTION}

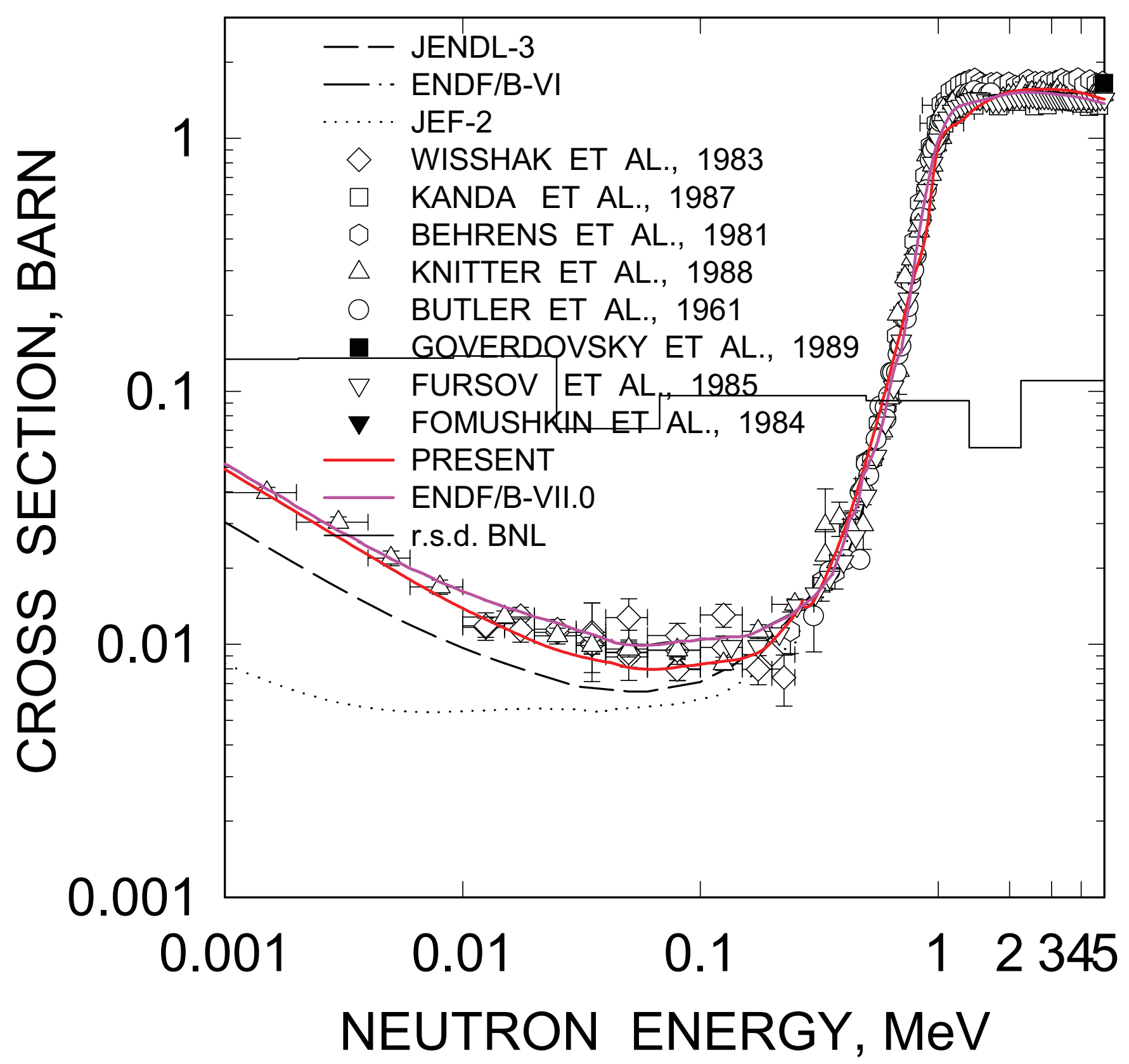




\section{${ }^{243} \mathrm{Am}$ FISSION CROSS SECTION}

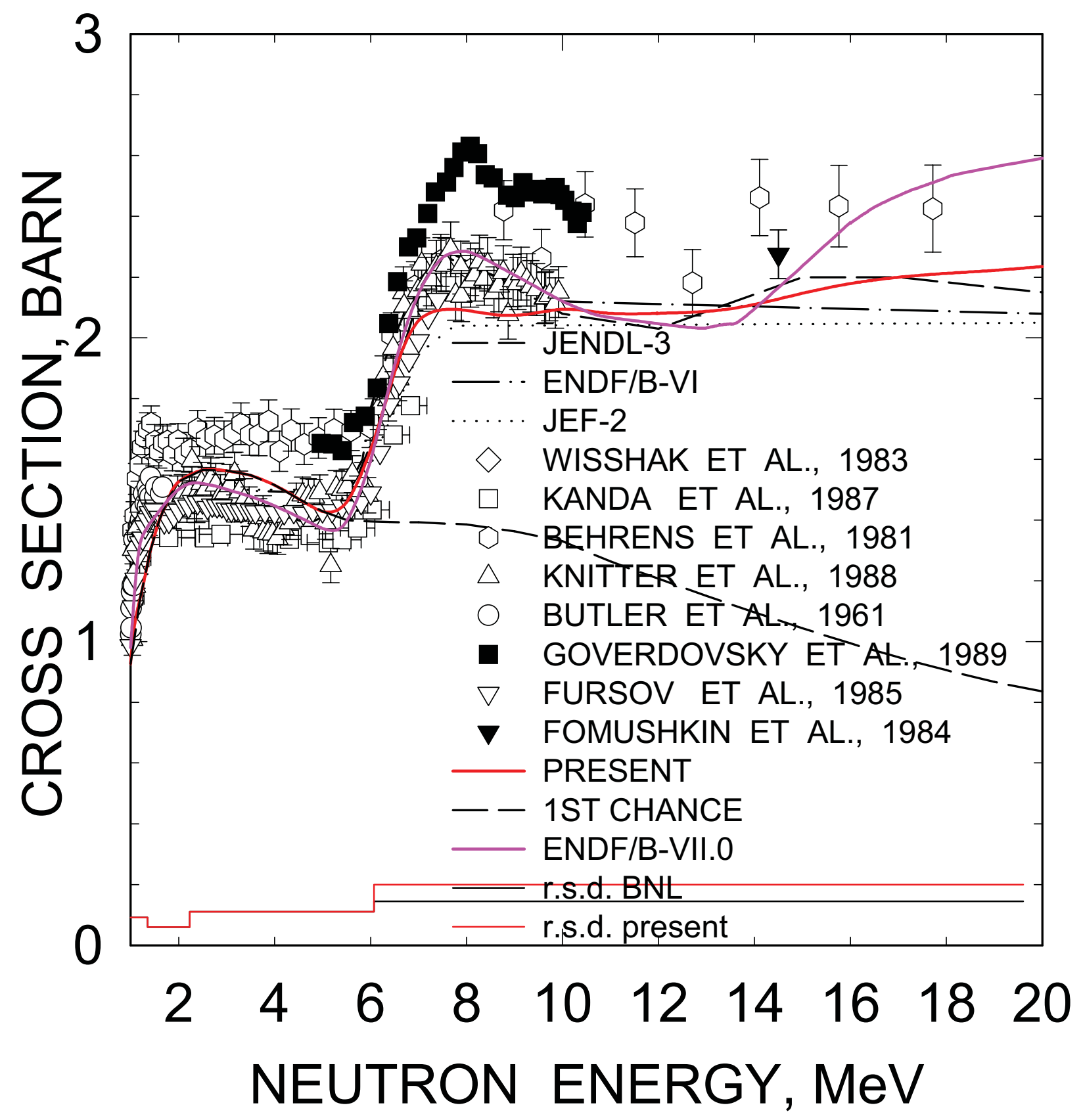




\section{${ }^{242 m}$ Am FISSION CROSS SECTION}

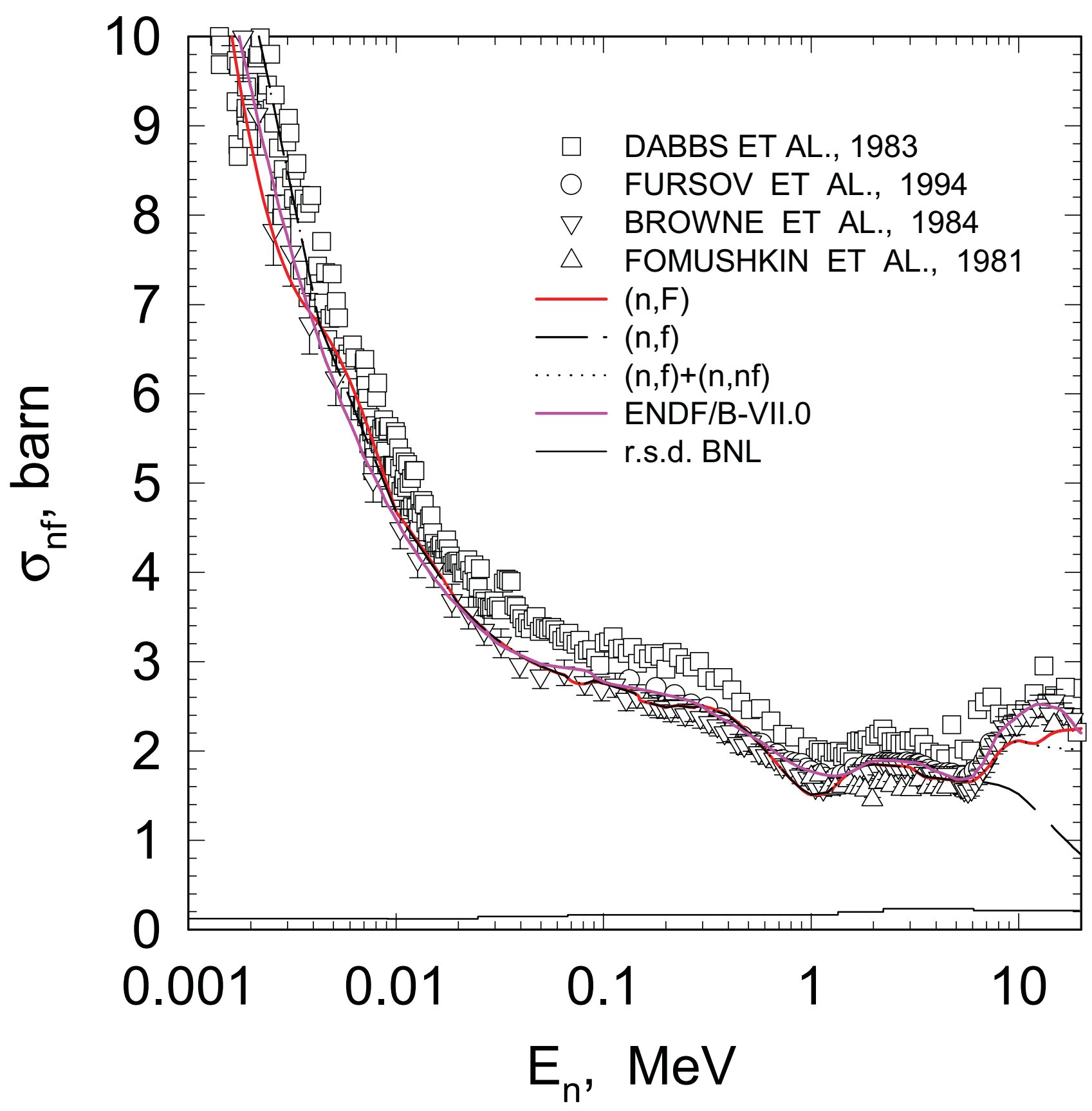




\section{${ }^{242 \mathrm{~m}} \mathrm{Am}$ FISSION CROSS SECTION}

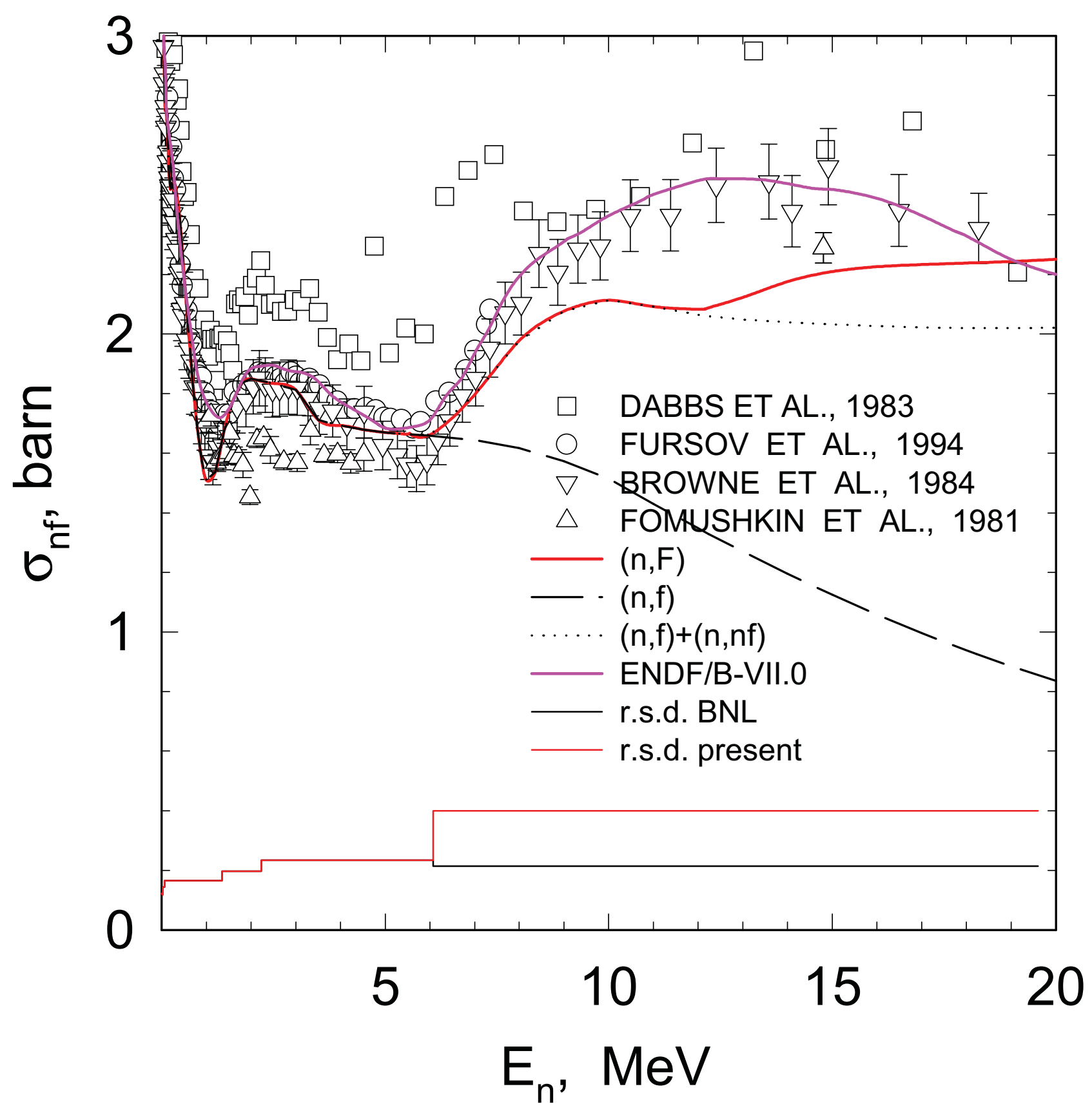




\section{Chapter 4}

\section{Inelastic scattering}

${ }^{232}$ Th: For ${ }^{232} \mathrm{Th}\left(\mathrm{n}, \mathrm{n}^{\prime}\right)$ [57, 186-188] for the first level r.s.d. estimate of ENDF/B-VII.0 seems to reflect poor fit of measured data by Fujita [188] (see Fig. 4.1). That is why it looks very pessimistic, when compared with ${ }^{238} \mathrm{U}\left(\mathrm{n}, \mathrm{n}^{\prime}\right)$ r.s.d., which is much lower, or with ${ }^{234} \mathrm{U}(\mathrm{n}, \mathrm{n}$ '), which is similar to that of ${ }^{232} \operatorname{Th}\left(n, n^{\prime}\right)$ at $E_{n}<1 \mathrm{MeV}$. The data availability for ${ }^{238} \mathrm{U}\left(\mathrm{n}, \mathrm{n}^{\prime}\right)$ and ${ }^{232} \mathrm{Th}\left(\mathrm{n}, \mathrm{n}^{\prime}\right)$ is quite similar, while for ${ }^{234} U(n, n ')$ there is no measured data. That means better fit of inelastic scattering data for discreet level and their groups, proper direct excitation of vibrational levels [6, 7, 189, 190], might lead to decrease of ${ }^{232} \mathrm{Th}\left(\mathrm{n}, \mathrm{n}\right.$ ') r.s.d. to a few percent level, claimed for ${ }^{238} \mathrm{U}(\mathrm{n}, \mathrm{n}$ ') at relevant energies. Present values of r.s.d are increased.

${ }^{238} \mathbf{U}$ : Though it is assumed that BNL fits approximately reproduces ENDF/B-VII.0 (or JENDL3.3) cross sections, it is never shown to which extent. Since in case of inelastic scattering, measured in $[57,191,192]$ the main competing channel is fission, its uncertainty much depends upon the fission competition and relative role of direct excitation of vibration levels at excitations of 0.6-1.2 MeV (for even targets). Calculations by H.Wienke et al. [193] of emissive neutron spectra demonstrated once again, that omission or weak direct excitation of these levels as in [14] is incompatible with measured data. Specifically, large value of r.s.d for the $2^{\text {nd }}$ group reflects only the approximation, involved in the evaluation procedures (proper direct excitation of vibrational levels), but not the reliability of the inelastic scattering simulation. R.s.d. values are left as they are (see Fig. 4.2).

${ }^{236} \mathbf{U}$ : The r.s.d. estimates for ${ }^{236} U\left(n, n^{\prime}\right)$ are too pessimistic, relatively over-optimistic for the $2^{\text {nd }}$ and $3^{\text {rd }}$ groups (the range where the direct excitation of vibrational levels is important, but is omitted in ENDF/B-VII.0 evaluation). Values of r.s.d are modified based on the attained level for the ${ }^{238} \mathrm{U}(\mathrm{n}, \mathrm{n}$ ') and comparison with present calculation. The latter calculation takes into account direct excitation of vibrational levels and fission competition to the compound inelastic scattering (see Fig. 4.3).

${ }^{234} \mathbf{U}$ : The r.s.d. estimates for ${ }^{234} \mathrm{U}\left(\mathrm{n}, \mathrm{n}\right.$ ') are too pessimistic, relatively over-optimistic for the $4^{\text {th }}$ group (the range where the discrete levels are murged with continuum excitation). Values of r.s.d are modified based on the attained level for the ${ }^{238} U\left(n, n^{\prime}\right)$ and comparison with Maslov et al. [21] evaluation. The latter evaluation properly includes direct excitation of vibrational levels and fission competition to the compound inelastic scattering (see Fig. 4.4). 
${ }^{238} \mathrm{Pu}$ : The r.s.d. estimates for ${ }^{238} \mathrm{Pu}\left(\mathrm{n}, \mathrm{n}^{\prime}\right)$ too optimistic (low) (note the discrepancies of evaluated cross sections with recent reliable measured fission data in these particular case) and missing of direct excitation of rotational and vibrational levels, the latter is missing also in the evaluation named present, of 1998. Values of r.s.d are severely modified (see Fig. 4.5).

${ }^{240} \mathrm{Pu}$ : The r.s.d. estimates for ${ }^{240} \mathrm{Pu}\left(\mathrm{n}, \mathrm{n}\right.$ ') too optimistic, excessively pessimistic in the $1^{\text {st }}$ group (see Fig. 4.6). Values of r.s.d are severely modified, based on comparison of ENDF/B-VII.0 evaluation with present and BROND evaluations. Note that direct excitation of vibrational levels [6, 7] is missing in all calculations.

${ }^{242} \mathrm{Pu}$ : The r.s.d. estimates for ${ }^{242} \mathrm{Pu}\left(\mathrm{n}, \mathrm{n}\right.$ ') too optimistic for $2^{\text {nd }}$ group, but excessively pessimistic for the in the $1^{\text {st }}$ group (see Fig. 4.7). Values of r.s.d are severely modified, based on comparison of ENDF/B-VII.0 evaluation with the evaluation of 1998 by Maslov et al. [33]. Note that direct excitation of vibrational levels $[6,7]$ is missing in all calculations.

${ }^{242} \mathrm{Cm}$ : The r.s.d. estimates for ${ }^{242} \mathrm{Cm}(\mathrm{n}, \mathrm{n}$ ') too optimistic (low) (note the discrepancies of evaluated cross sections with recent reliable measured fission data in sub-threshold energy range and unpublished surrogate data, presented at ND2007 [114] and missing of direct excitation of rotational and vibrational levels [6], the latter is missing also in present calculation. Values of r.s.d are severely modified (see Fig. 4.8).

${ }^{244} \mathrm{Cm}$ : The r.s.d. estimates for ${ }^{244} \mathrm{Cm}(\mathrm{n}, \mathrm{n}$ ') are too optimistic (low) (note the discrepancies of JENDL-3.3 (adopted for ENDF/B-VII.0) evaluated fission cross section with measured fission data by Fomushkin et al. $[115,116]$. We consider these data most reliable. Note missing of the direct excitation of rotational and vibrational levels $[6,7]$, the latter is missing also in present calculation. Values of r.s.d are modified (see Fig. 4.9).

${ }^{235} \mathbf{U}$ : In case of ${ }^{235} \mathrm{U}$ (n,n') the discrepancies between different evaluations and measured data $[57,191]$ are rather large (see Fig. 4.10). That discrepancy should not be reflected just in large relative standard deviation, moreover so that the JENDL-3.3 data files of ${ }^{235} \mathrm{U}$ and ${ }^{238} \mathrm{U}$ are not the best fits. In case of other nuclides, when EMPIRE-KALMAN [1,2] approach is employed, it is said only briefly about the "best fit" parameters for $\mathrm{Pu}, \mathrm{Am}$ and $\mathrm{Cm}$ targets. Values of r.s.d. seem to be similar to those of ${ }^{239} \mathrm{Pu}(\mathrm{n}, \mathrm{n}$ '), estimated in that report.

${ }^{233} \mathbf{U}$ : In case of ${ }^{233} \mathrm{U}(\mathrm{n}, \mathrm{n}$ ') [57] the discrepancies between different evaluations are extremely large at energies below $1 \mathrm{MeV}$ (see Fig. 4.11). That discrepancy should be reflected just as large relative 
standard deviation, since large cross section in ENDF/B-VII.0 is defined by large direct excitation of rotational levels. Values of r.s.d. seem to be similar to those of ${ }^{239} \mathrm{Pu}\left(\mathrm{n}, \mathrm{n}^{\prime}\right)$, estimated in that report.

${ }^{239} \mathrm{Pu}$ : In case of ${ }^{239} \mathrm{Pu}(\mathrm{n}, \mathrm{n}$ '), measured in $[194,195]$, the discrepancies between different evaluations are larger than in case of ${ }^{235} \mathrm{U}\left(\mathrm{n}, \mathrm{n}^{\prime}\right)$ (see Fig. 4.12). Our calculation provides best fits of fission, elastic scattering and capture cross sections. Present values of r.s.d. are decreased in first two groups, but increased in the remaining groups.

${ }^{241} \mathrm{Pu}$ : In case of ${ }^{241} \mathrm{Pu}\left(\mathrm{n}, \mathrm{n}^{\prime}\right)$ the discrepancies between different evaluations at energies below 1 $\mathrm{MeV}$ are even larger than in case of ${ }^{233} \mathrm{U}$ (n,n') (see Fig. 4.13). Our calculation provides best fit of fission cross section. Present values of r.s.d. are decreased in $1^{\text {st }}$ groups, but increased in the remaining groups.

${ }^{243} \mathrm{Cm}$ : in ENDF/B-VII.0 data file, the evaluation by Maslov et al. [26] is adopted. We assume r.s.d. to be similar to those of ${ }^{245} \mathrm{Cm}\left(\mathrm{n}, \mathrm{n}^{\prime}\right)$, assuming that the fission cross section is defined correctly and no further renormalizations would be required (see Fig. 4.14).

${ }^{245} \mathbf{C m}$ : in ENDF/B-VII.0 data file, the evaluation by Maslov et al. [27] is adopted. We assume r.s.d. to be similar to those of ${ }^{235} \mathrm{U}\left(\mathrm{n}, \mathrm{n}^{\prime}\right)$ and ${ }^{239} \mathrm{Pu}\left(, \mathrm{n}^{\prime}\right)$ (see Fig. 4.15).

${ }^{237} \mathrm{~Np}$ : it seems that $1.5 \mathrm{MeV}$ is a stabilization point of inelastic scattering cross section (see Fig. 4.16). We assume r.s.d to be defined by the deviation of ENDF/B-VII.0 data from present calculation. Present calculation based on the fits of fission and capture cross sections. The evaluated inelastic cross sections of ENDF/B-VII.0 and JENDL-3.3 evaluations are in severe disagreement with measured data by Kornilov et al. [63] on the inelastic scattering of neutrons with excitation of specific groups of levels, while our approach produces consistent description of $(\mathrm{n}, \mathrm{f}),\left(\mathrm{n}, \mathrm{n}^{\prime}\right)$ and $(\mathrm{n}, \gamma)$ measured data.

${ }^{241} \mathrm{Am}$ : We assume r.s.d to be defined by the deviation of ENDF/B-VII.0 data from Maslov et al. [17] evaluation. It is based on fits of total, fission and capture cross sections. R.s.d. changed in accordance with observed trends for $\mathrm{U}$ and $\mathrm{Pu}$ target nuclides (see Fig. 4.17).

${ }^{243} \mathrm{Am}$ : We assume r.s.d to be defined by the deviation of ENDF/B-VII.0 data from Maslov et al. [18] evaluation, the same values as those of ${ }^{241} A m(n, n ')$ look reasonable (see Fig. 4.18).

${ }^{242 \mathrm{~m}} \mathrm{Am}$ : The inelastic scattering cross sections of ENDF/B-VII.0 and Maslov et al. [30] evaluations differ very much in $0.5-5 \mathrm{MeV}$ energy range (see Fig. 4.19). The correlated difference of fission cross sections is much less. Obviously, the problem is with the optical potential parameters employed. That leads to the increase of r.s.d in that energy range. 


\section{${ }^{232}$ Th INELASTIC CROSS SECTION}

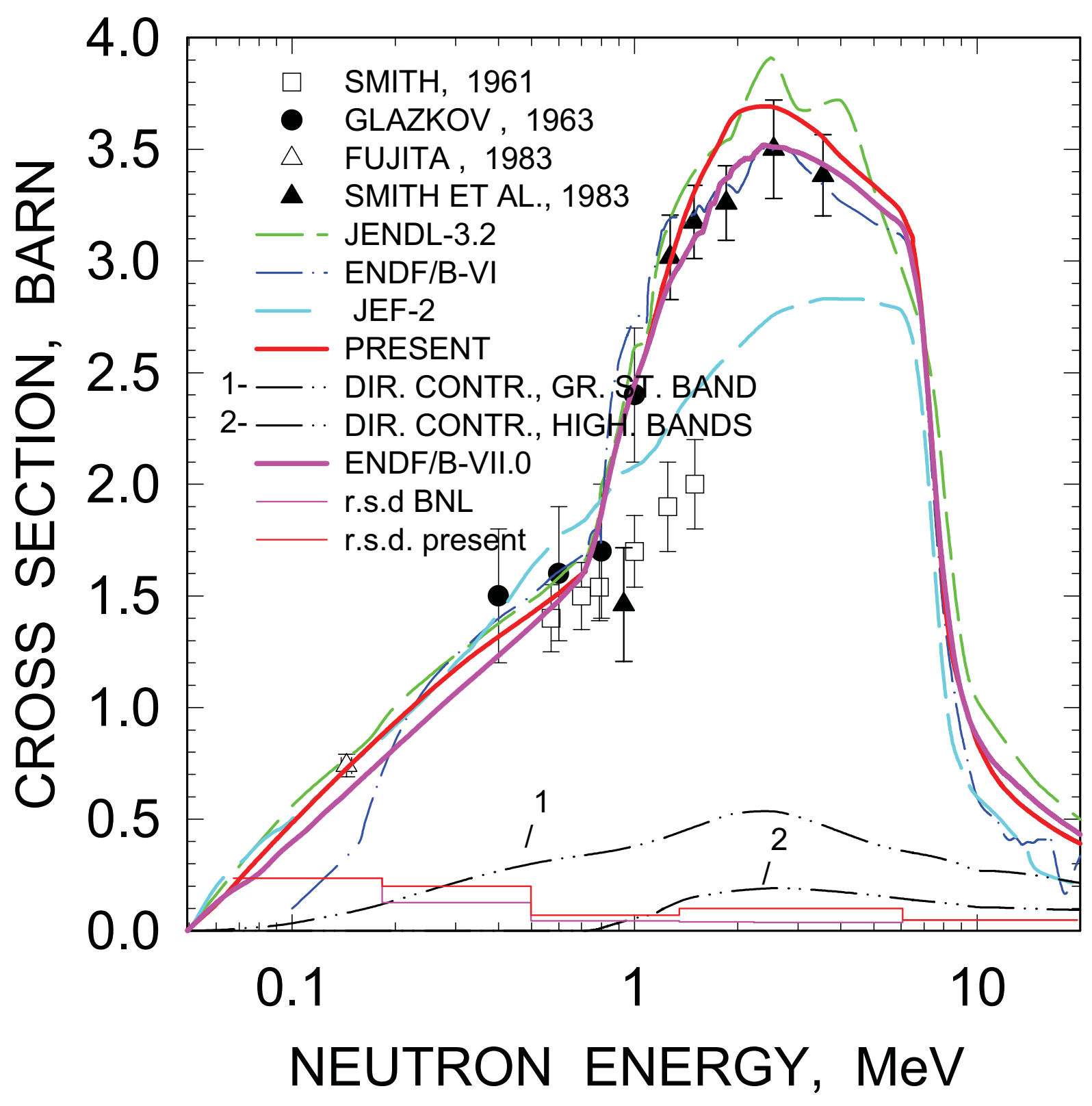




\section{${ }^{238}$ U INELASTIC CROSS SECTION}

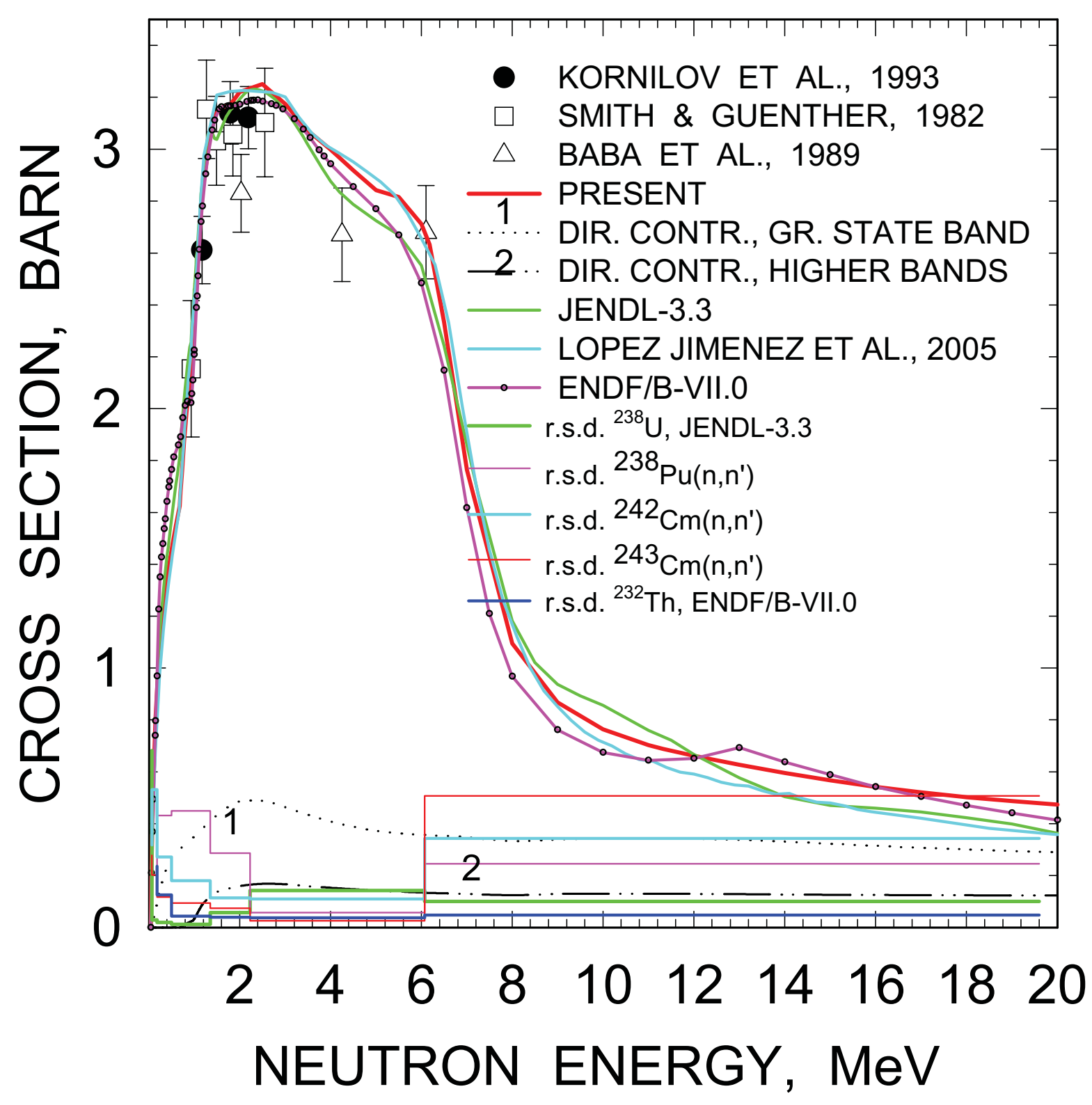




\section{${ }^{236}$ U INELASTIC CROSS SECTION}

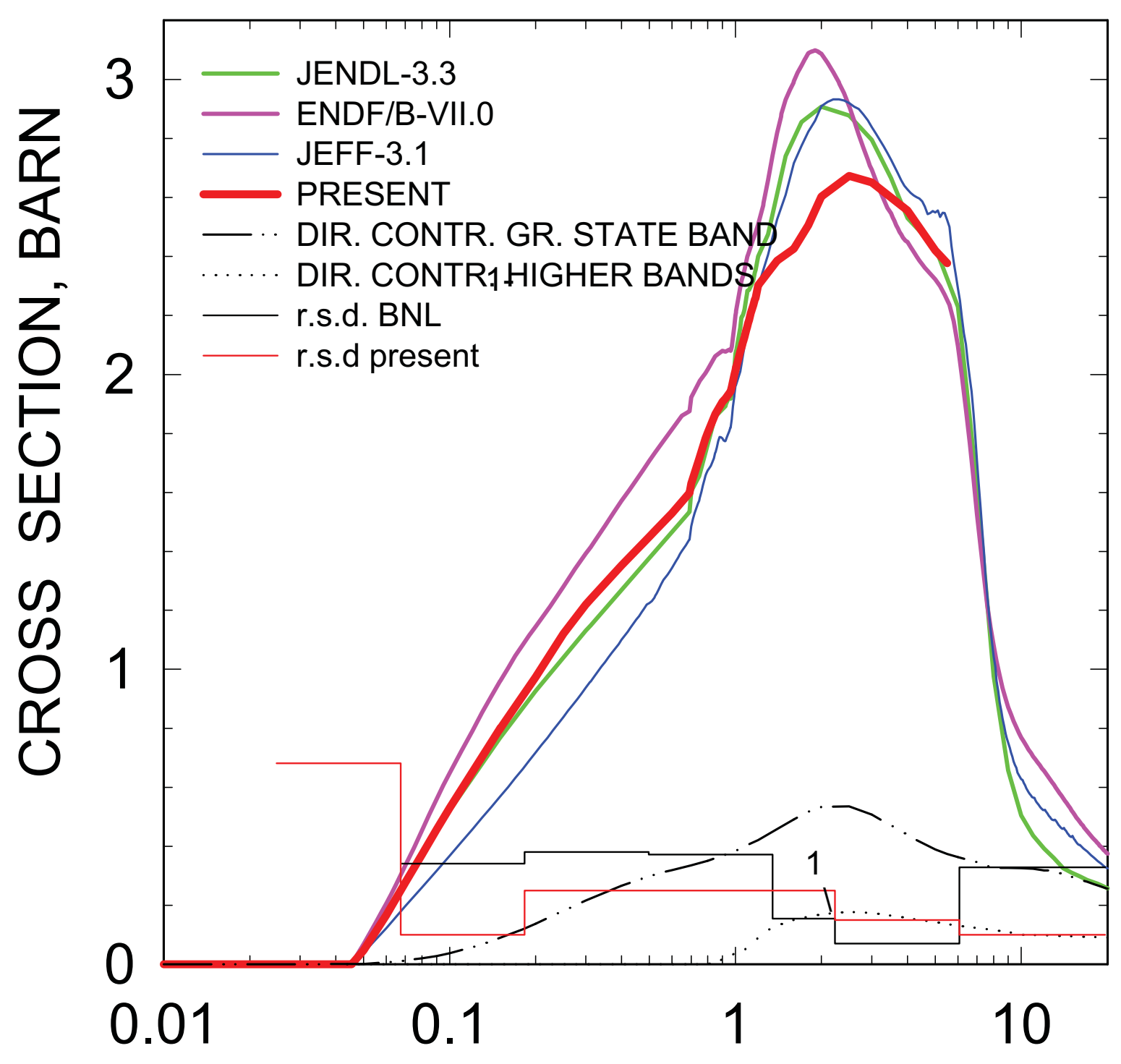

NEUTRON ENERGY, MeV 


\section{${ }^{234}$ U INELASTIC CROSS SECTION}

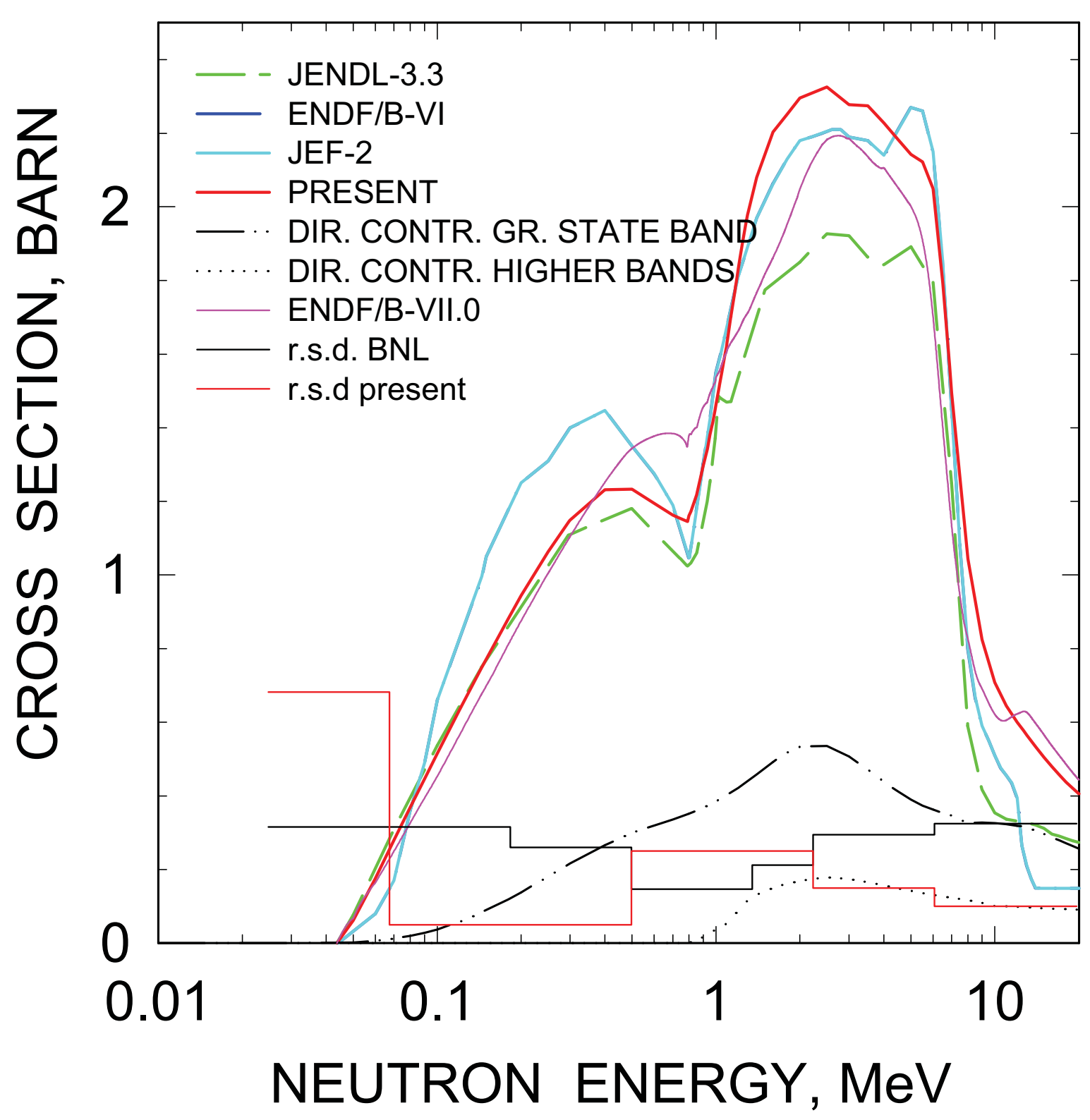




\section{${ }^{238} \mathrm{Pu}$ INELASTIC CROSS SECTION}

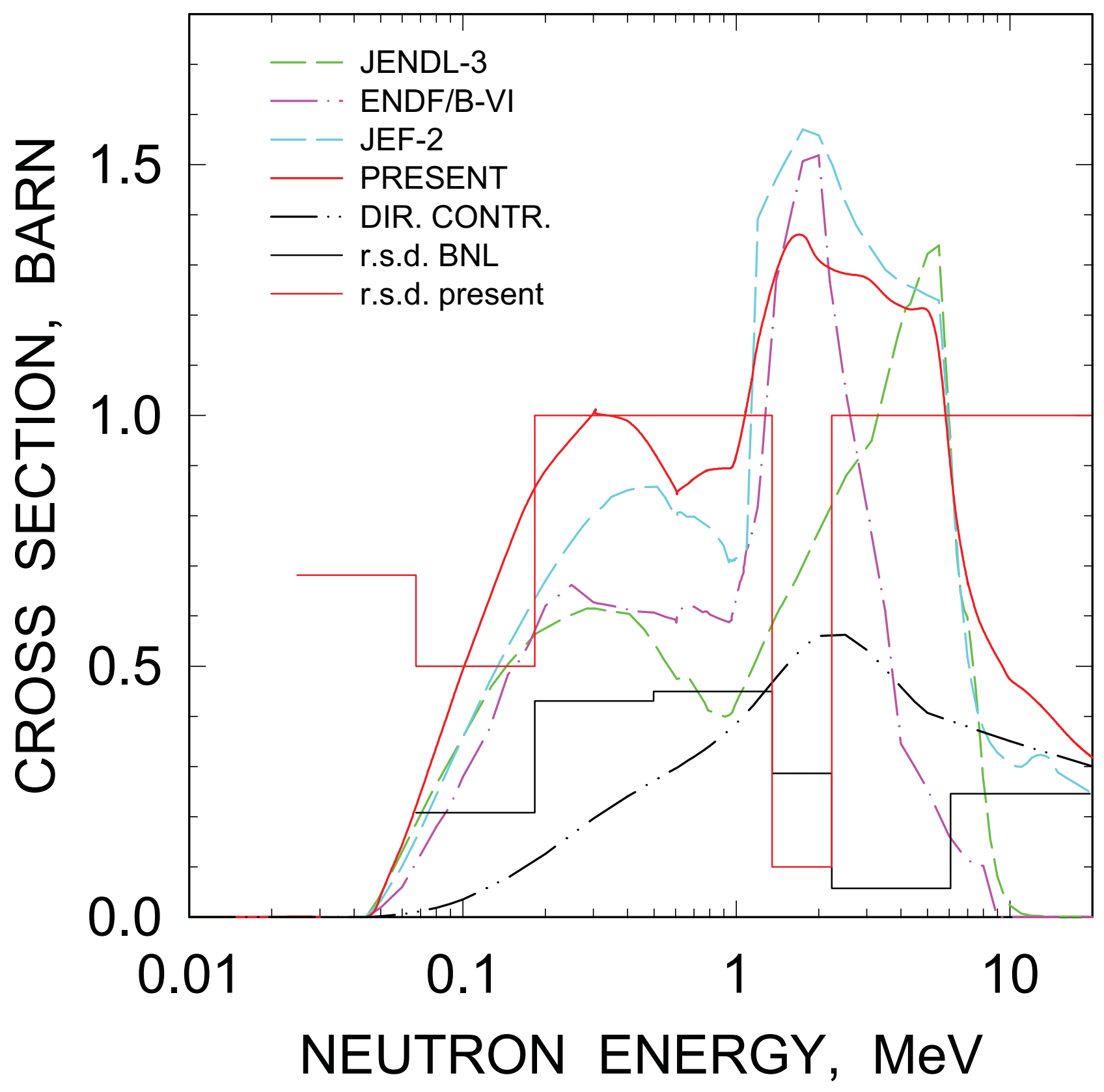




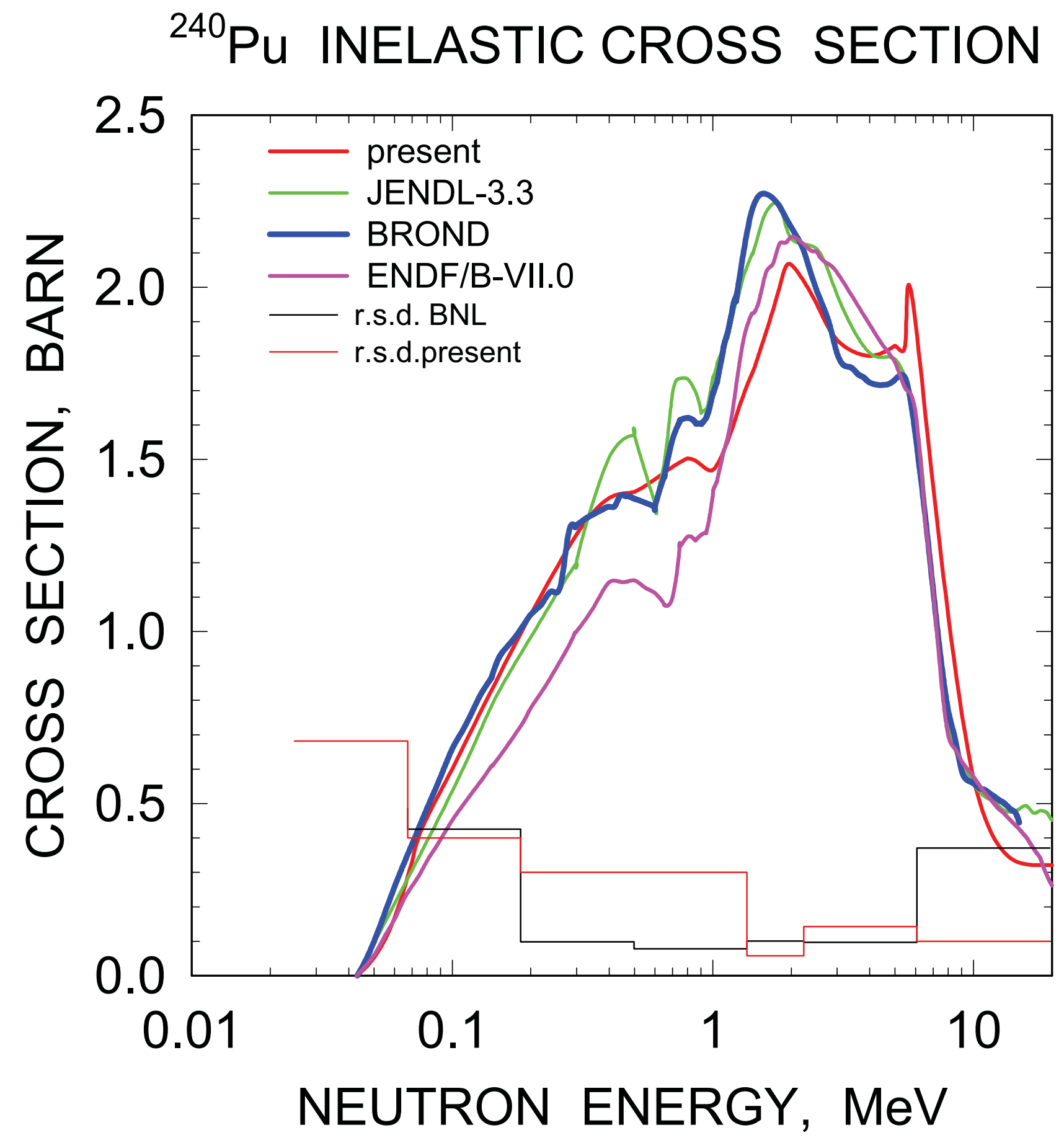




\section{${ }^{242} \mathrm{Pu}$ INELASTIC CROSS SECTION}

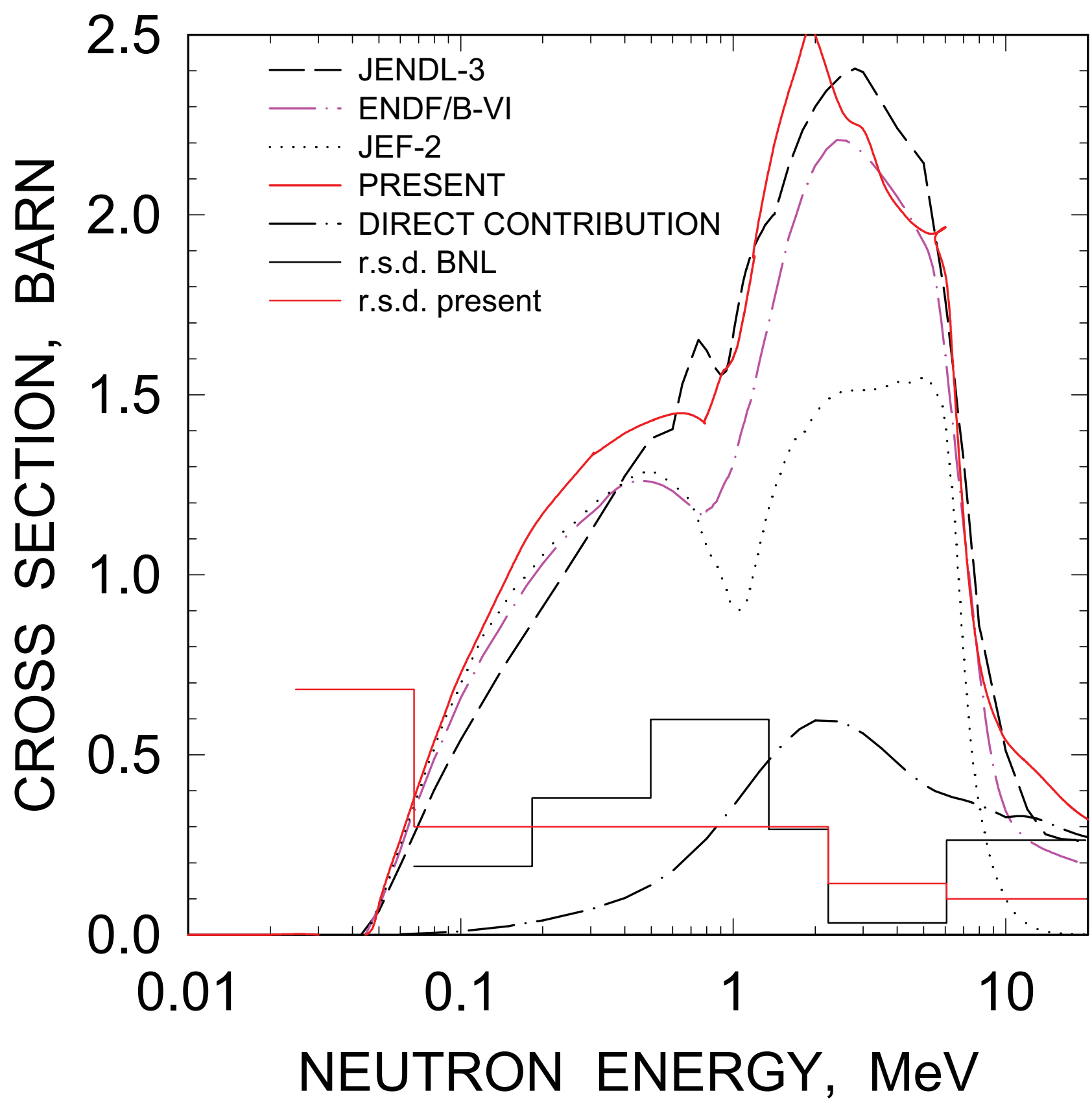




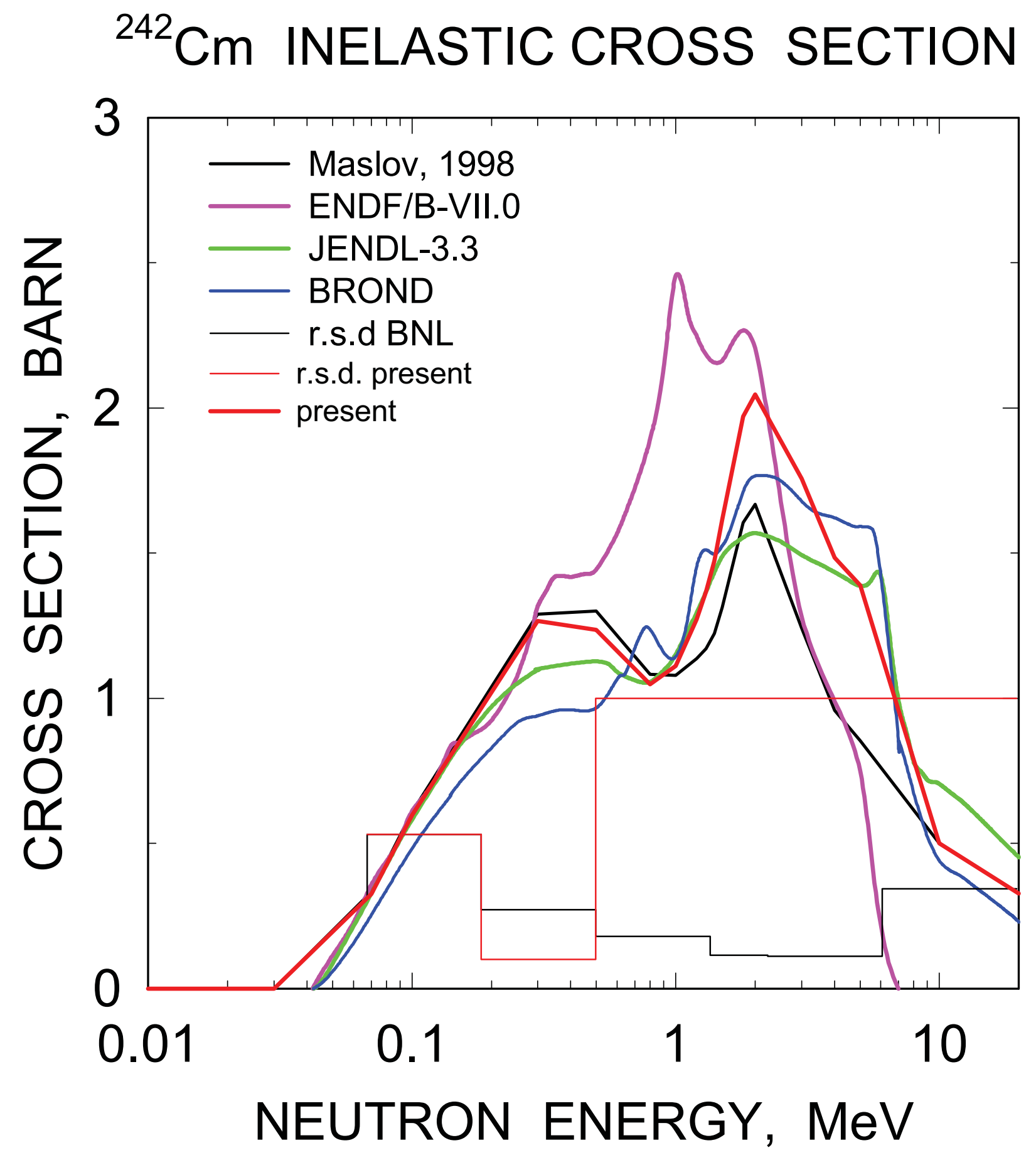




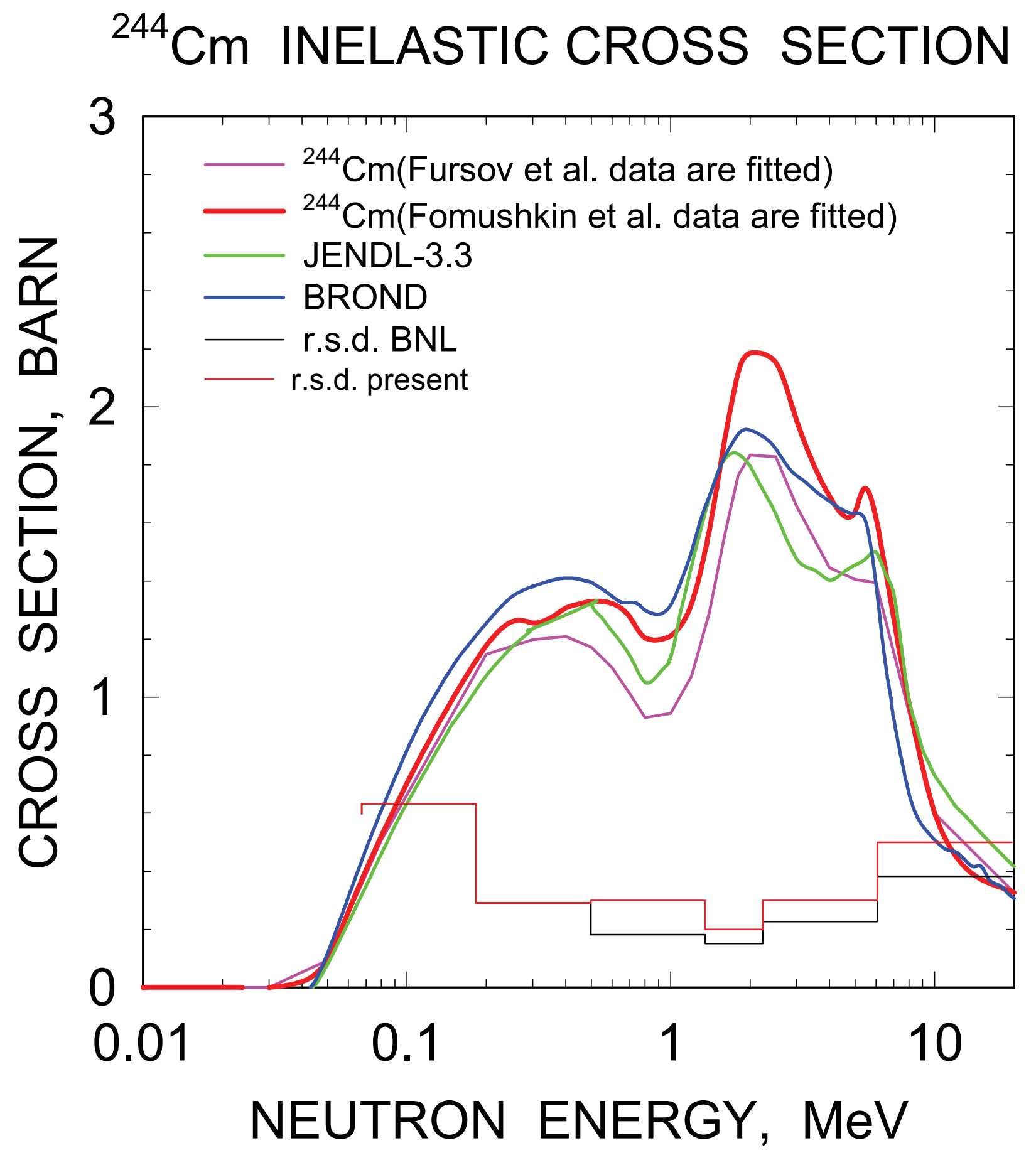




\section{${ }^{235}$ U INELASTIC CROSS SECTION}

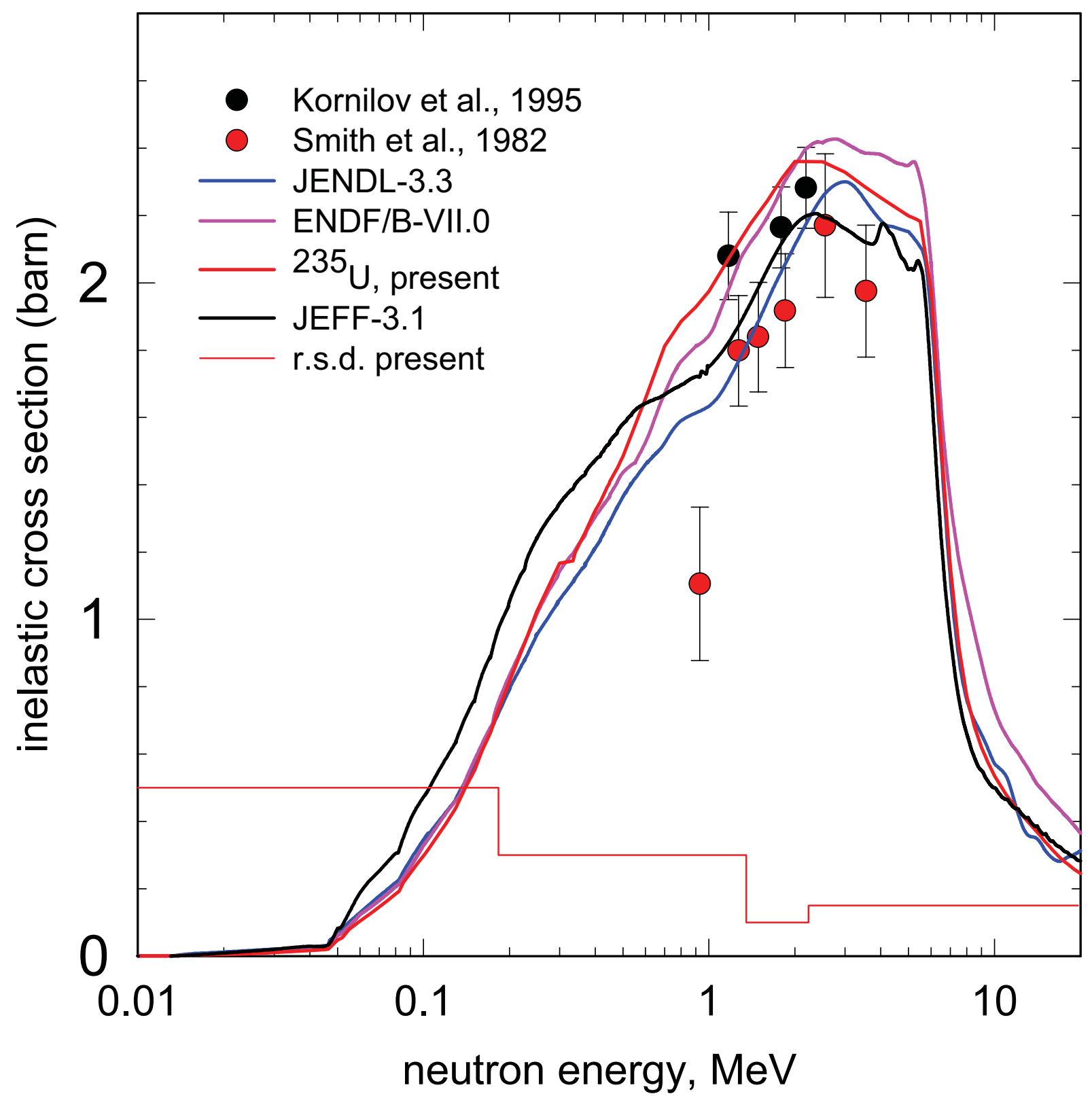




\section{${ }^{233}$ U INELASTIC CROSS SECTION}

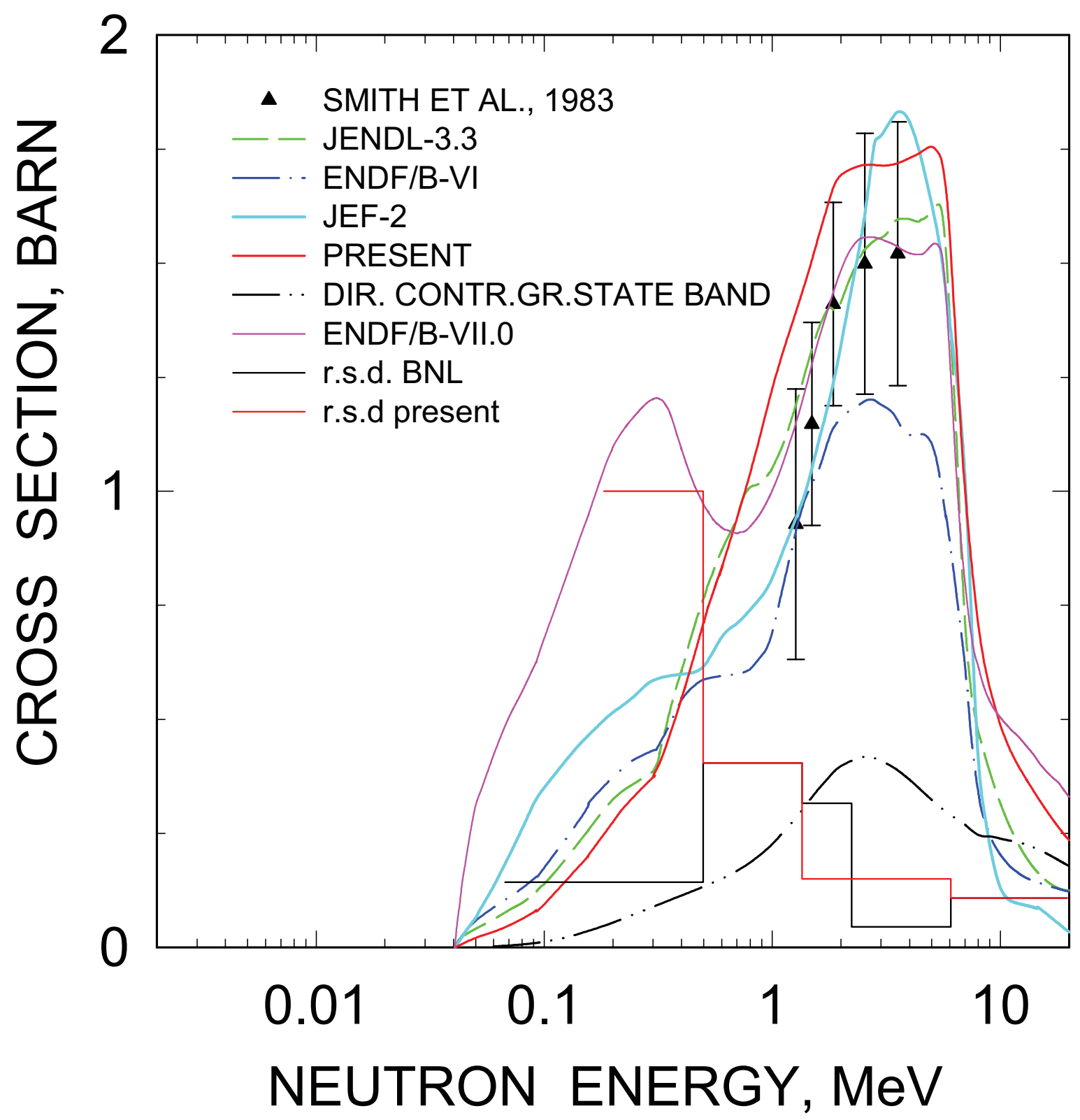




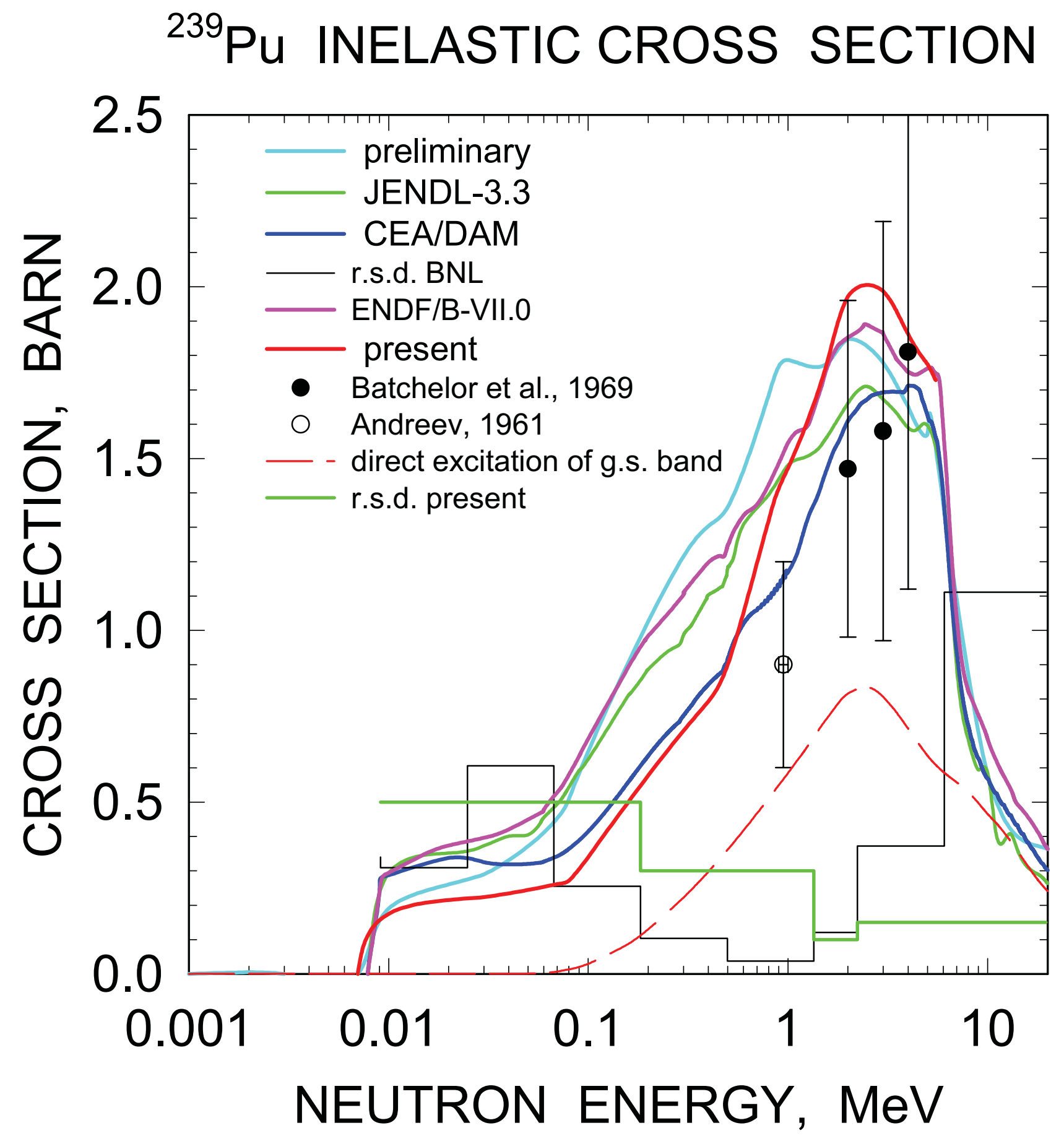




\section{${ }^{241} \mathrm{Pu}$ INELASTIC CROSS SECTION}

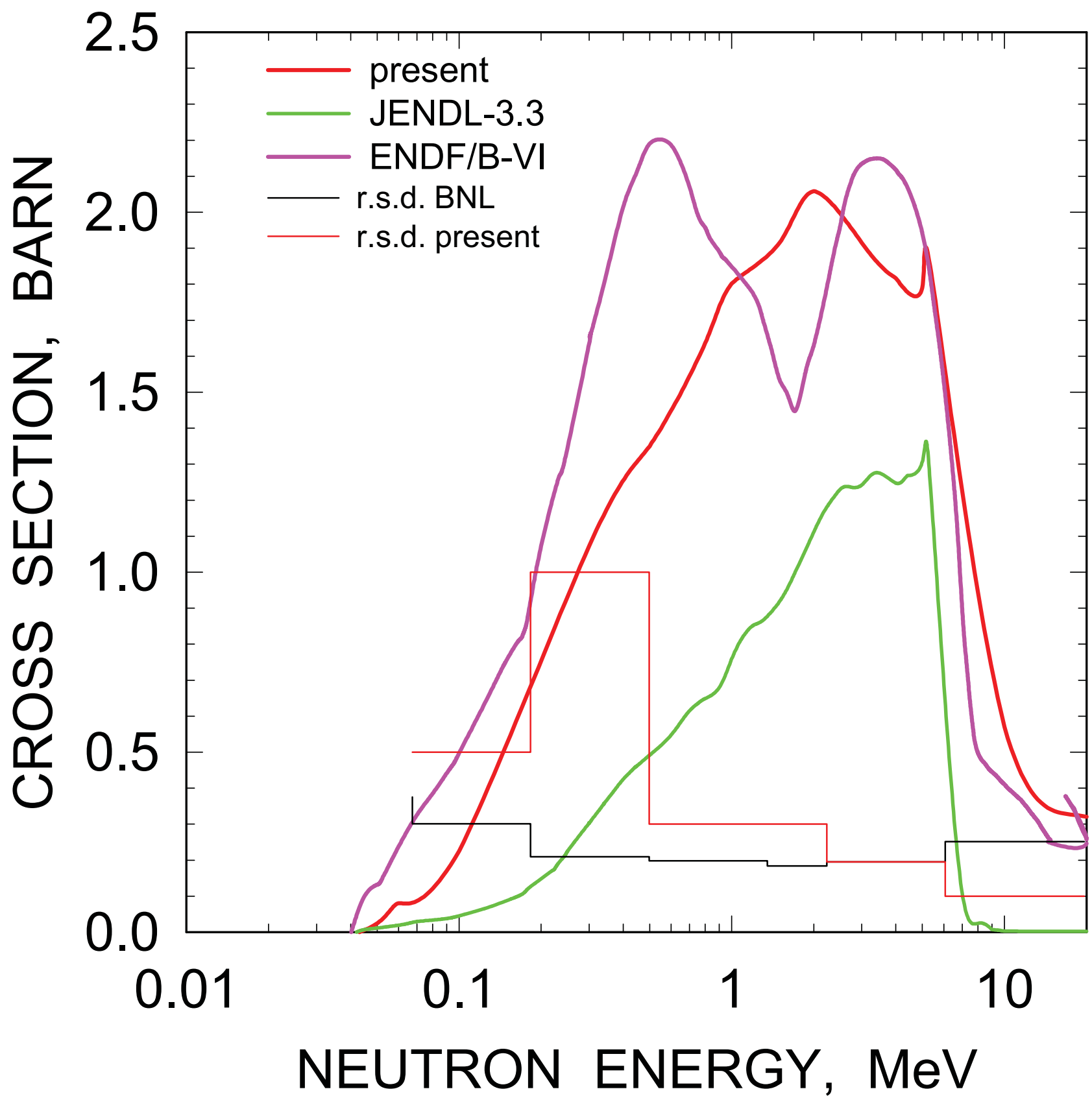


${ }^{243} \mathrm{Cm}$ INELASTIC CROSS SECTION

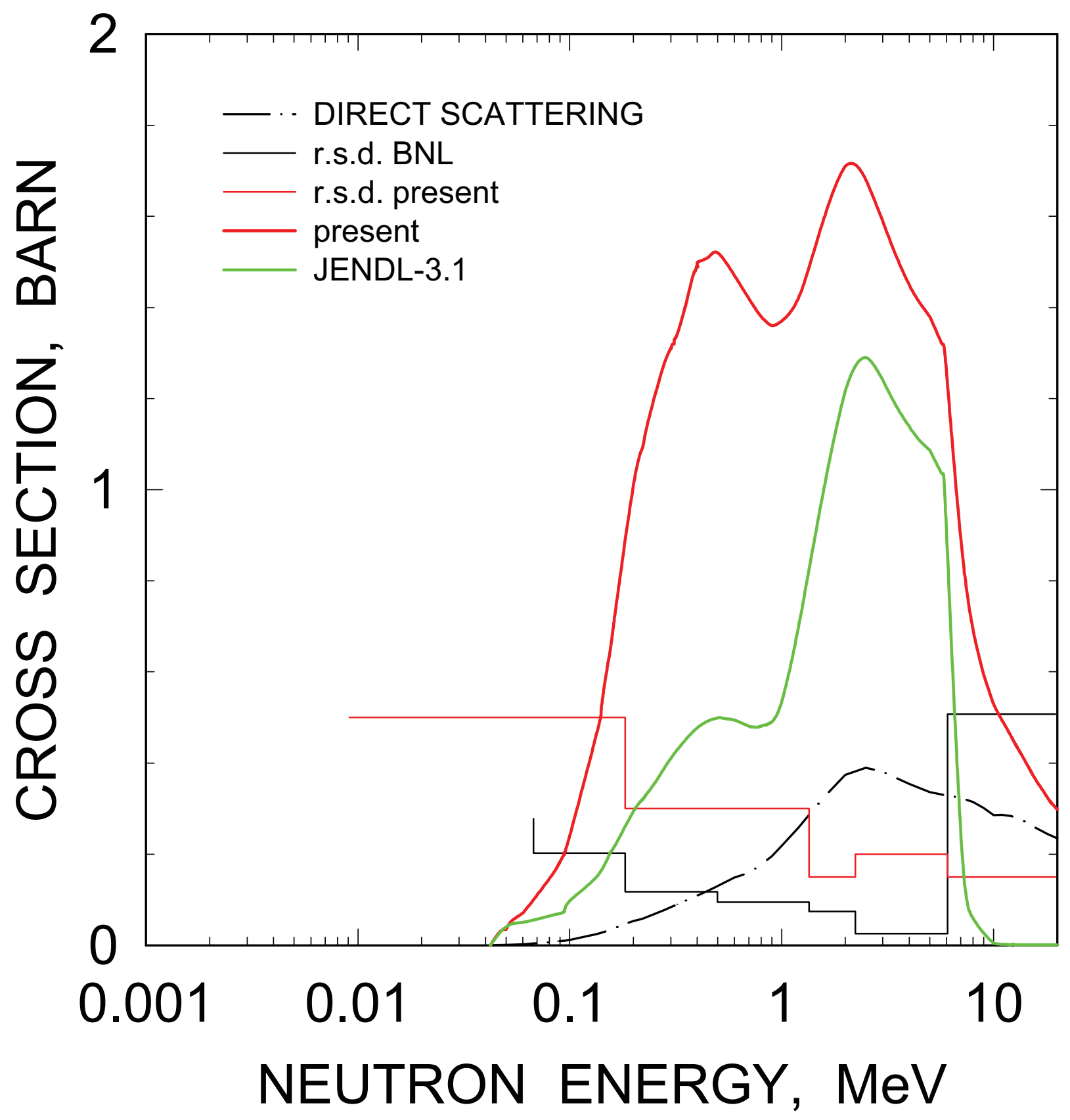




\section{${ }^{245} \mathrm{Cm}$ INELASTIC CROSS SECTION}

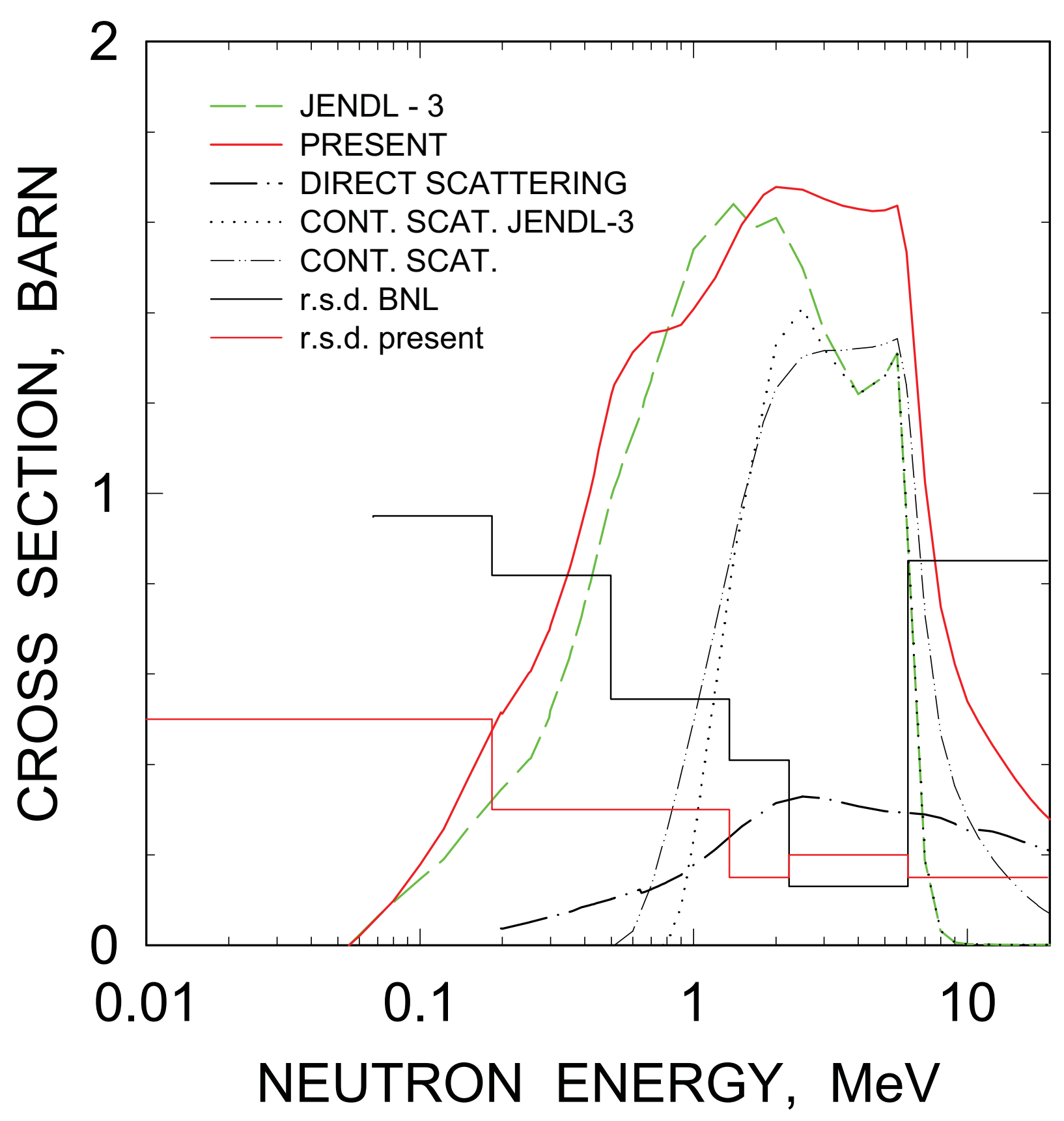




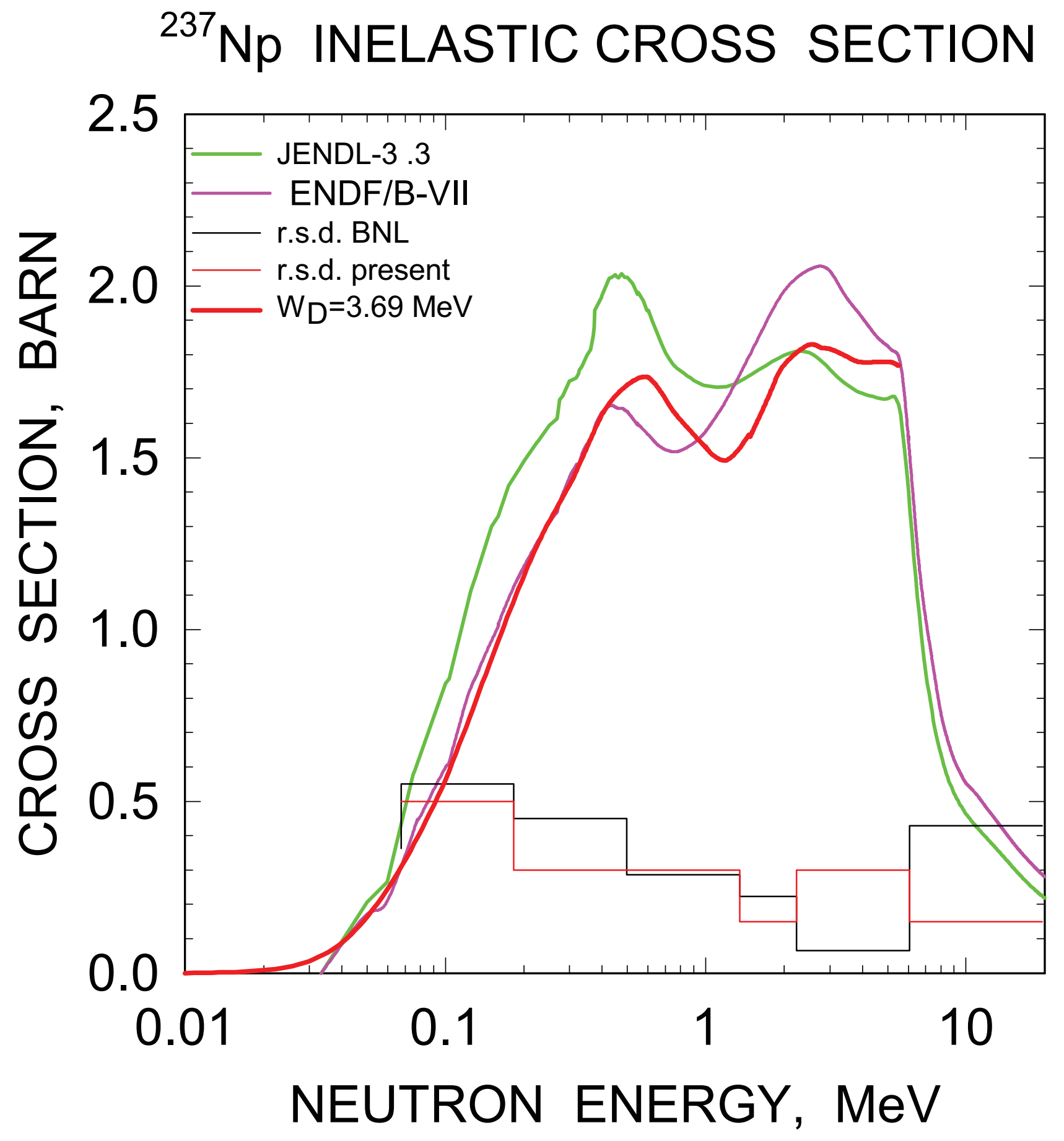


${ }^{241}$ Am INELASTIC CROSS SECTION

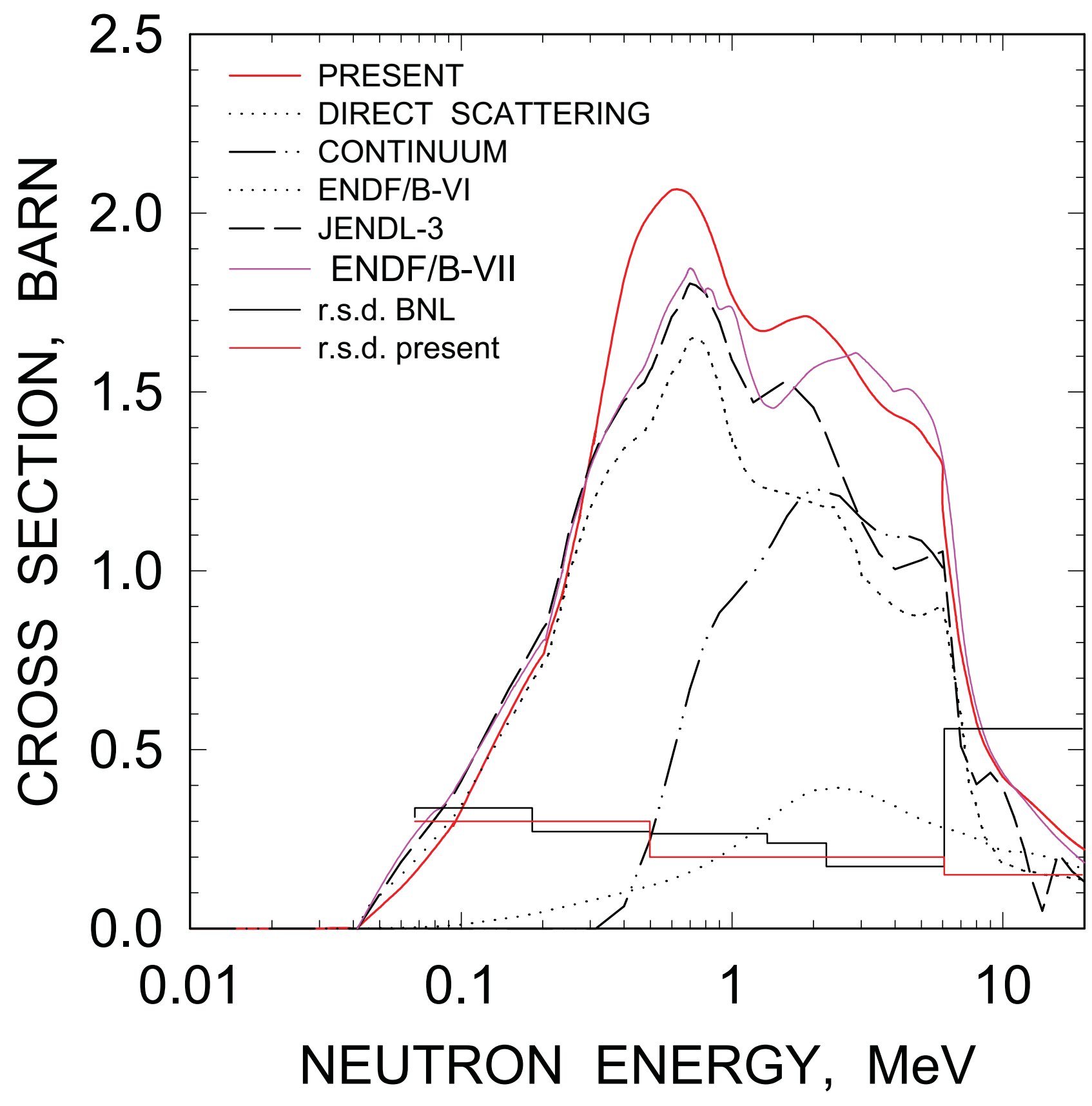




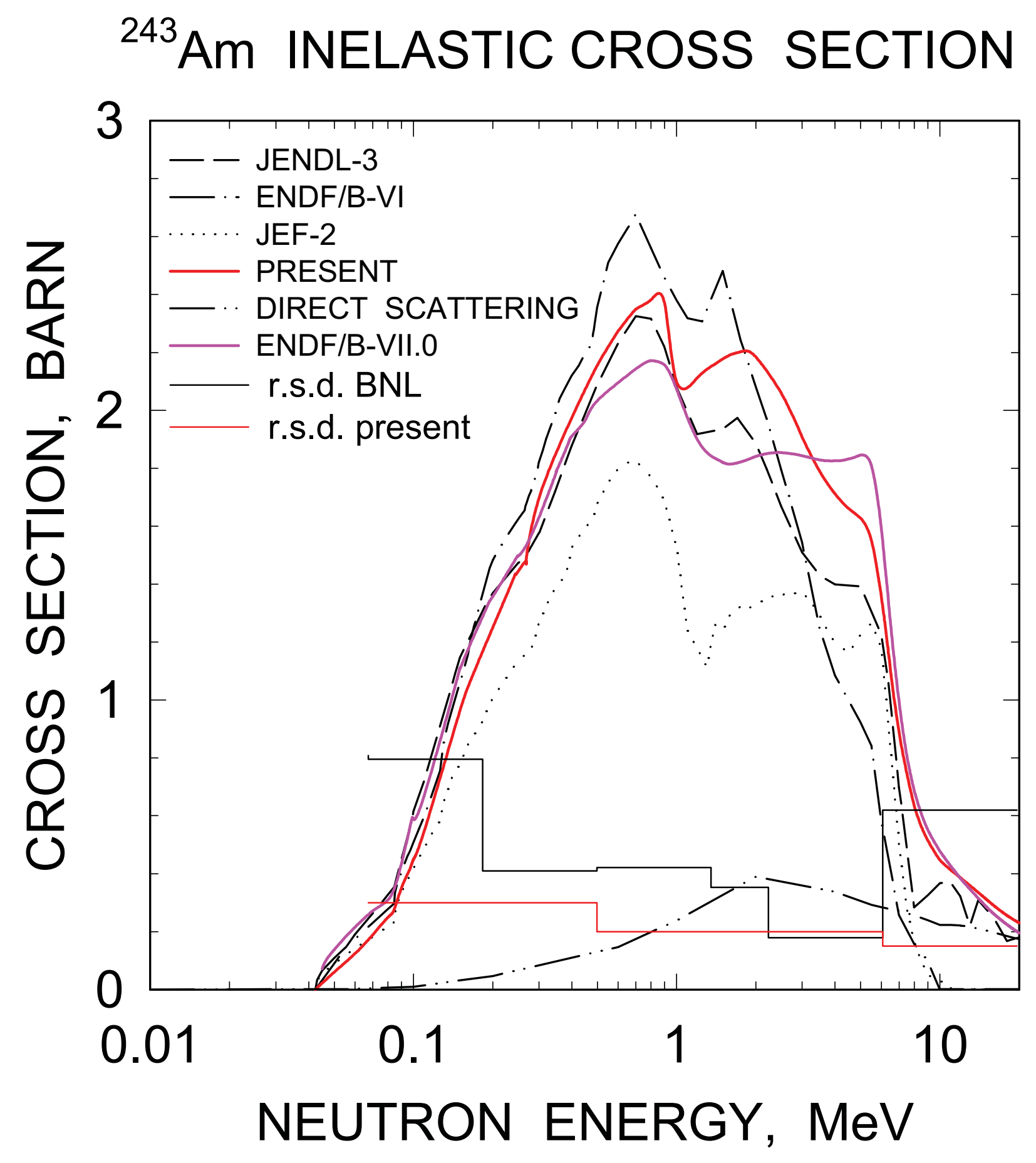




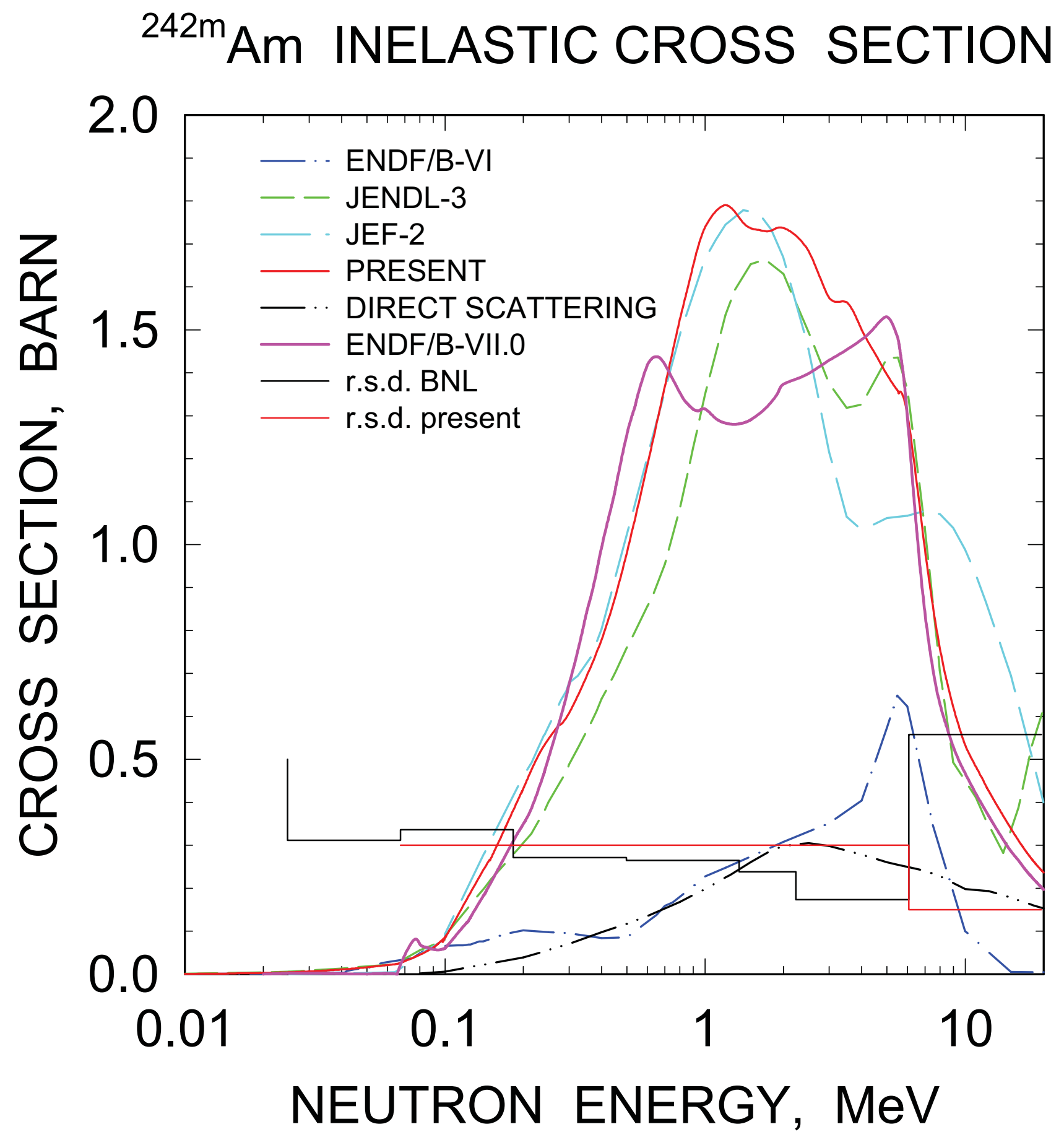




\section{Chapter 5}

\section{Capture cross sections}

${ }^{232}$ Th: In case of ${ }^{232} \mathrm{Th}(\mathrm{n}, \gamma)$ cross section, measured in [196-205], present estimate of r.s.d. for ENDF/B-VII.0 data relies on the analysis of the deficiencies of the capture data fits around $50 \mathrm{keV}$ and in the range of $800-1800 \mathrm{keV}[206,207]$ (see Figs. 5.1, 5.2).

${ }^{238} \mathbf{U}$ : As regards capture cross section, fits of capture data [208-215] in JENDL-3.3 as well as ENDF/B-VII.0 cannot be considered unambiguous, especially in the energy range of 50-1000 keV (see Fig. 5.3). In ENDF/B-VII.0 [14] integral tests the indications of ${ }^{238} \mathrm{U}$ capture under prediction in B-VII.0 by $5-10 \%$ in $50-1000 \mathrm{keV}$ are revealed. This under prediction in 200-500 keV energy range might be affected by the contribution of the $\mathrm{d}$ - and f- partial entrance neutron wave channels, as well as energy dependence of gamma-ray strength function. These effects were noted in case of ${ }^{232}$ Th capture cross section [207] and are applicable here. That means that r.s.d. in the energy range 50-1000 kev should be increased to at least $7 \%$. Only after getting a calculated ${ }^{238} \mathrm{U}$ capture cross section, which fits Kazakov et al. [215] data in hundreds keV energy range, its uncertainty could be claimed to be $3 \%$ or lower. Combining differential and integral data during the production of covariance data, but not after, implicitly or explicitly, is of the utmost importance.

${ }^{236} \mathbf{U}$ : the deviations between measured data [208, 216-219] and capture cross sections of ENDF/B-VII.0, present and our previous [220] calculations look very similar to those observed for ${ }^{238} \mathrm{U}$ target. We assume the same r.s.d. as for the ${ }^{238} \mathrm{U}(\mathrm{n}, \gamma)$ and ${ }^{232} \mathrm{Th}(\mathrm{n}, \gamma)$ cross section (see Fig. 5.4).

${ }^{234} \mathbf{U}$ : the deviations between capture cross sections of ENDF/B-VII.0 and evaluated data by Maslov et al. [21] are rather large, measured data are scarce [221]. R.s.d. for ENDF/B-VII.0 are somewhat increased to reflect these differences (see Fig. 5.5).

${ }^{238} \mathrm{Pu}$ : the deviations between capture cross sections of ENDF/B-VII.0 and evaluated data by Maslov et al. [32] are extremely large (see Fig. 5.6). It seems to be due to fission and neutron competition differences in calculation procedures. However, in second energy group the relative standard deviation (r.s.d.) is comparable to that of ${ }^{238} \mathrm{U}$ target nuclide, and in $3 \mathrm{~d}$ group it is even better. R.s.d. for ENDF/B-VII.0 should be severely increased to reflect these differences.

${ }^{240} \mathrm{Pu}$ : calculated ${ }^{240} \mathrm{Pu}(\mathrm{n}, \gamma)$ reaction cross section shape is much similar to that, observed experimentally for the ${ }^{238} \mathrm{U}(\mathrm{n}, \gamma)$ and ${ }^{232} \mathrm{Th}(\mathrm{n}, \gamma)$ reaction cross sections (see Fig. 5.7). Differences are due to fission and neutron emission competition, which depends on the $(\mathrm{Z}, \mathrm{N})$-composition of the 
compound nuclide. The first Wigner' cusp is observed around first rotation level excitation threshold, another two cusps are due to further increases in neutron and then fission competition. Decreasing trend in Weston and Todd [222] data needs to be checked experimentally. Similar cross section shape is reproduced in JENDL-3.3 data file, absolute differences are due to inherent approximations of evaluation procedures of JENDL-3.3. R.s.d. for ENDF/B-VII.0 should be severely increased at $\mathrm{E}_{\mathrm{n}}>100$ $\mathrm{keV}$ to reflect the cross section shape differences.

${ }^{242} \mathrm{Pu}$ : calculated ${ }^{242} \mathrm{Pu}(\mathrm{n}, \gamma)$ [223-225] reaction cross section shape is much similar to that, observed experimentally for the ${ }^{238} \mathrm{U}(\mathrm{n}, \gamma)$ and ${ }^{232} \mathrm{Th}(\mathrm{n}, \gamma)$ reaction cross sections (see Fig. 5.8). It resembles the shape of ${ }^{240} \mathrm{Pu}(\mathrm{n}, \gamma)$ reaction cross section, the differences above $100 \mathrm{keV}$ are due to decreased fission competition. Differences are due to fission and neutron emission competition, which depends on the (Z,N)-composition of the compound nuclide. The first Wigner' cusp is observed around first rotation level excitation threshold, another two cusps, which are more prominent, than in case of ${ }^{240} \mathrm{Pu}(\mathrm{n}, \gamma)$ reaction cross section are due to decreased fission competition. Decreasing trend in Wisshak et al. [224] data needs to be checked experimentally. Similar cross section shape is reproduced in JENDL-3.3 evaluation, absolute differences are due to inherent approximations of evaluation procedures of JENDL-3.3. R.s.d. for ENDF/B-VII.0 should be severely increased at $\mathrm{E}_{\mathrm{n}}>200 \mathrm{keV}$ to reflect the cross section absolute value and shape differences. Moreover so, that BNL estimate for ${ }^{242} \mathrm{Pu}(\mathrm{n}, \gamma)$ is better than that of ${ }^{238} \mathrm{U}(\mathrm{n}, \gamma)$ in $2^{\text {nd }}$ and $3^{\text {rd }}$ groups.

${ }^{242} \mathrm{Cm}$ : calculated ${ }^{242} \mathrm{Cm}(\mathrm{n}, \gamma)$ reaction cross section shape further demonstrates the influence of the fission competition via $(n, \gamma) /(n, f)$ and $(n, \gamma f)$ reactions. The cusps are even less pronounced than in case of ${ }^{240} \mathrm{Pu}(\mathrm{n}, \gamma)$ reaction (see Fig. 5.9). JENDL-3.3 and ENDF/B-VII.0 evaluations severely distort the cross section shape, absolute differences are due to inherent approximations of evaluation procedures of JENDL-3.3. R.s.d. for ENDF/B-VII.0 should be severely increased to reflect the cross section absolute value and shape inconsistencies with theoretical estimates, obtained with proven theoretical methods.

${ }^{244} \mathrm{Cm}$ : calculated ${ }^{244} \mathrm{Cm}(\mathrm{n}, \gamma)$ reaction cross section shape further demonstrates the influence of the fission competition via $(n, \gamma) /(n, f)$ and $(n, \gamma f)$ reactions. The cusps are more pronounced than in case of ${ }^{242} \mathrm{Cm}(\mathrm{n}, \gamma)$ reaction (see Fig. 5.10). JENDL-3.3 evaluation, adopted for ENDF/B-VII.0 data library predict rather exotic cross section shape at $\mathrm{E}_{\mathrm{n}}>1 \mathrm{MeV}$. Previous evaluations severely distort the cross section shape, absolute differences are due to inherent approximations of evaluation procedures of JENDL-3.3. R.s.d. for ENDF/B-VII.0 should be severely increased to reflect the cross section absolute value and shape inconsistencies with theoretical estimates, obtained with proven theoretical methods. 
${ }^{233} \mathbf{U},{ }^{235} \mathrm{U},{ }^{239} \mathrm{Pu}$ : capture cross sections of fissile nuclides demonstrate most vividly the influence of target spin differences, fission transition states spectroscopy and fission/gamma-emission competition on capture cross section shape and absolute values. In all cases the capture cross sections were obtained via consistent description of fission and elastic/inelastic scattering. In case of ${ }^{235} \mathrm{U}(\mathrm{n}, \gamma)$ [226-231] reasonable values of average resonance parameters support the high values of capture cross section around $10 \mathrm{keV}$ (see Fig. 5.11). In case of ${ }^{233} \mathrm{U}(\mathrm{n}, \gamma)[226,232]$ reasonable values of average resonance parameters provide a consistent description of capture data in $\mathrm{keV}$ - and $\mathrm{MeV}$-energy ranges (see Fig. 5.12). To explain the biases of ${ }^{233} \mathrm{U}(\mathrm{n}, \gamma)$ and ${ }^{235} \mathrm{U}(\mathrm{n}, \gamma)$ evaluations of ENDF/B-VII.0 relative to measured data by Weston et al. [232] and Muradyan et al. [231], respectively, robust argument should be provided. That would make possible to assess the estimates of r.s.d for capture cross sections of other fissile nuclides.

In case of ${ }^{239} \mathrm{Pu}(\mathrm{n}, \gamma)[226,228,229,233,234,235]$ the structure at $\mathrm{E}_{\mathrm{n}}$ below $5 \mathrm{keV}$ is defined by fission via $1^{+}$sub-threshold transition states (see Fig. 5.13). At $\mathrm{E}_{\mathrm{n}}$ around $100 \mathrm{keV}$ there are systematic differences in measured data trends.

R.s.d. for ${ }^{235} \mathrm{U}(\mathrm{n}, \gamma)$ reaction cross section reflects the differences of JENDL-3.3 evaluated data from measured data and present calculation and ENDF/B-VII.0 evaluation.

R.s.d. for ${ }^{233} \mathrm{U}(\mathrm{n}, \gamma)$ reaction cross section reflects the differences of ENDF/B-VII.0 evaluated data from measured data and present calculation.

R.s.d. for ${ }^{239} \mathrm{Pu}(\mathrm{n}, \gamma)$ reaction cross section reflects the differences of JENDL-3.3 evaluated data from measured data and present calculation and ENDF/B-VII.0 evaluation.

${ }^{241} \mathrm{Pu}$ : Shape of the calculated ${ }^{241} \mathrm{Pu}(\mathrm{n}, \gamma)$ capture cross section resemble more closely that of ${ }^{233} \mathrm{U}(\mathrm{n}, \gamma)$, than that of ${ }^{239} \mathrm{Pu}(\mathrm{n}, \gamma)$ (see Fig. 5.14). That is the consequence of the target spin differences, fission transition states spectroscopy and fission/gamma-emission competition. JENDL-3.3 evaluated data differ very much from both from ENDF/B-VII.0 evaluation and present calculation in $100-1000$ kev energy range. measured data and present calculation and ENDF/B-VII.0 evaluation. R.s.d. for ${ }^{241} \mathrm{Pu}(\mathrm{n}, \gamma)$ reaction cross section reflects the differences of ENDF/B-VII.0 evaluation from present calculation, which is based on fission data description.

${ }^{243} \mathrm{Cm}$ : R.s.d. for ${ }^{243} \mathrm{Cm}(\mathrm{n}, \gamma)$ reaction cross section reflects the differences of JENDL-3.1 evaluated data from data and present calculation adopted for JENDL-3.2 and ENDF/B-VII.0 evaluation (see Fig. 5.15). 
${ }^{245} \mathrm{Cm}$ : R.s.d. for ${ }^{245} \mathrm{Cm}(\mathrm{n}, \gamma)$ reaction cross section reflects the differences of JENDL-3.1 evaluated data from data and present calculation adopted for JENDL-3.2 and ENDF/B-VII.0 evaluation (see Fig. 5.16).

${ }^{237} \mathrm{~Np}$ : R.s.d. for ${ }^{237} \mathrm{~Np}(\mathrm{n}, \gamma)$ reaction cross section reflects the differences of ENDF/B-VII.0 evaluated data from measured data [208, 236-239], other evaluated data and present calculation (see Fig. 5.17).

${ }^{241}$ Am: ENDF/B-VII.0 evaluation is quite compatible with evaluation by Maslov et al. [17], though systematic differences are observed in measured data [240-242]. Some differences are observed only in 4-6 groups. R.s.d. for ${ }^{241} \mathrm{Am}(\mathrm{n}, \gamma)$ reaction cross section reflects these differences of ENDF/BVII.0 evaluated data from evaluation by Maslov et al. [17], much differing from these both early JENDL-2 evaluation was superseded by evaluation by Maslov et al. [17] (see Fig. 5.18).

${ }^{243}$ Am: ENDF/B-VII.0 evaluation is a bit less compatible with evaluation by Maslov et al. [18], than in case of ${ }^{241} \mathrm{Am}(\mathrm{n}, \gamma)$ reaction (see Fig. 5.19). Systematic differences are observed in measured data [243, 244]. Differences are observed in 4-6 groups. R.s.d. for ${ }^{243} \mathrm{Am}(\mathrm{n}, \gamma)$ reaction cross section reflects these differences of ENDF/B-VII.0 evaluated data from evaluation by Maslov et al. [18], much differing from these both early JENDL-2 evaluation was superseded by evaluation by Maslov et al. [18].

${ }^{242 m}$ Am: ENDF/B-VII.0 evaluation is much different from evaluation by Maslov et al. [30], differences are observed from $1 \mathrm{keV}$ to $20 \mathrm{MeV}$ (see Fig. 5.20). R.s.d. for ${ }^{242 \mathrm{~m}} \mathrm{Am}(\mathrm{n}, \gamma)$ reaction cross section reflects these differences of ENDF/B-VII.0 evaluated data from evaluation by Maslov et al. [30], much differing from these both early JENDL-2 evaluation was superseded by evaluation by Maslov et al. [30]. 


\section{${ }^{232} \mathrm{Th}(\mathrm{n}, \gamma)$ CROSS SECTION}

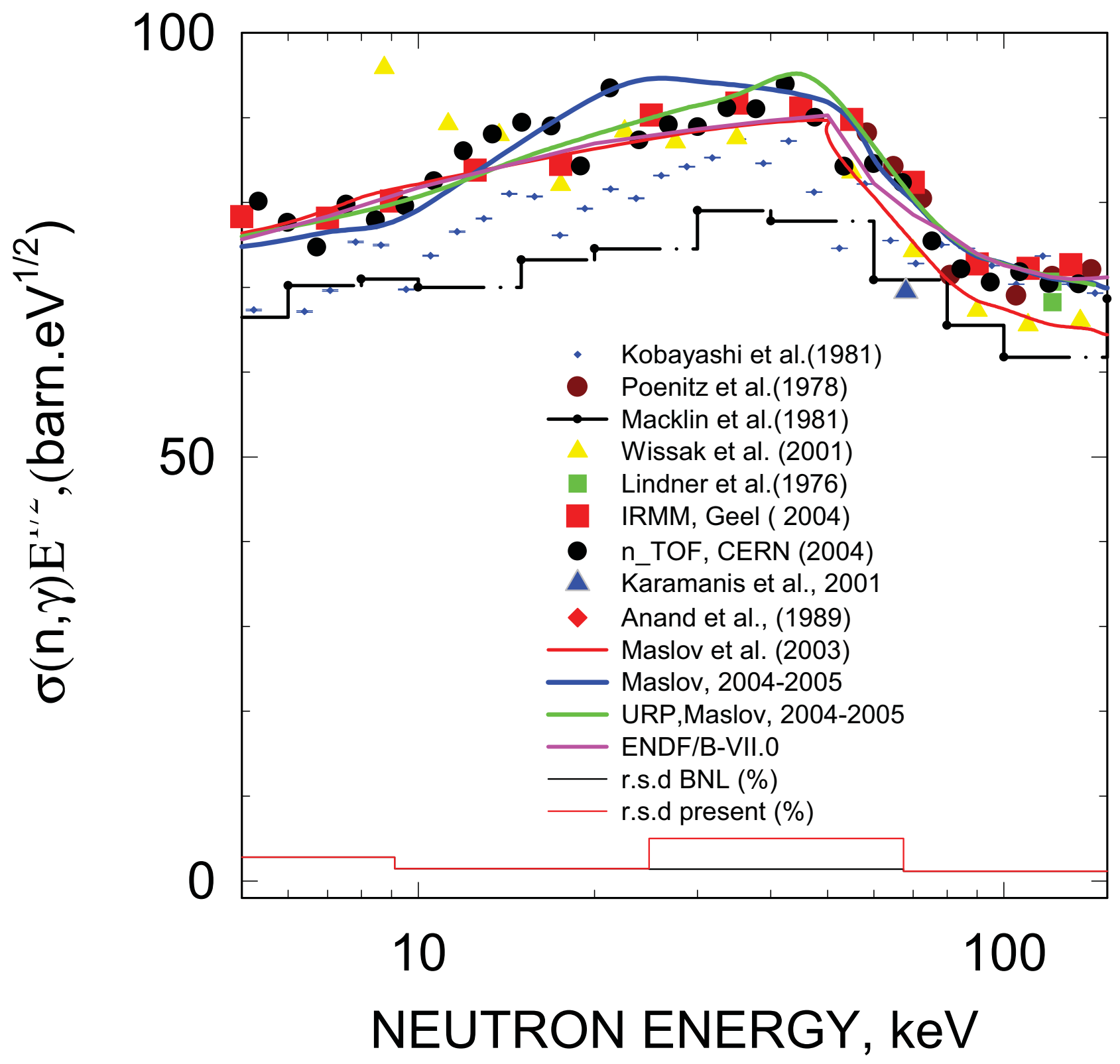




\section{${ }^{232} \mathrm{Th}(\mathrm{n}, \gamma)$ CROSS SECTION}

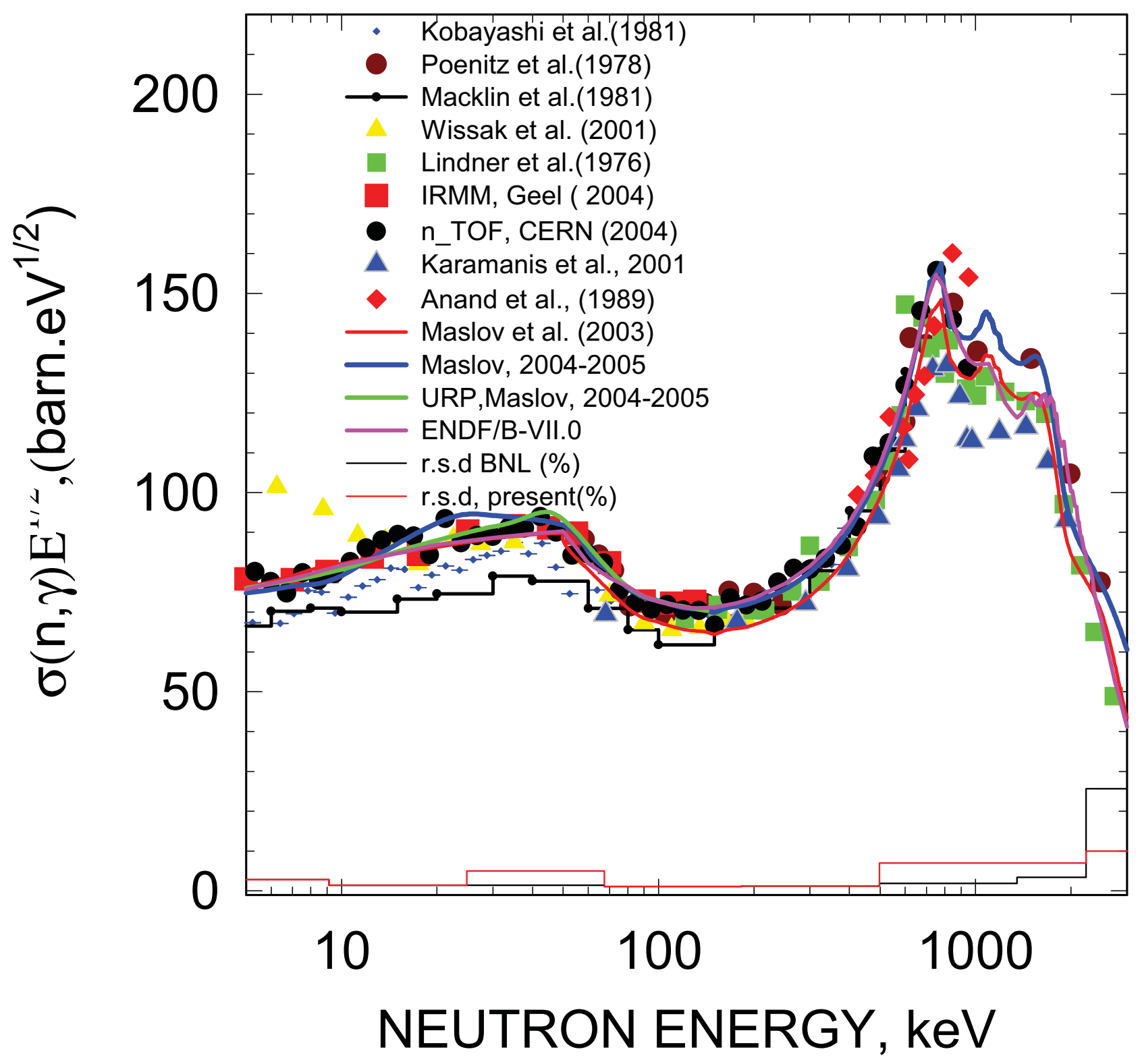




\section{${ }^{238} \mathrm{U}$ CAPTURE CROSS SECTION}

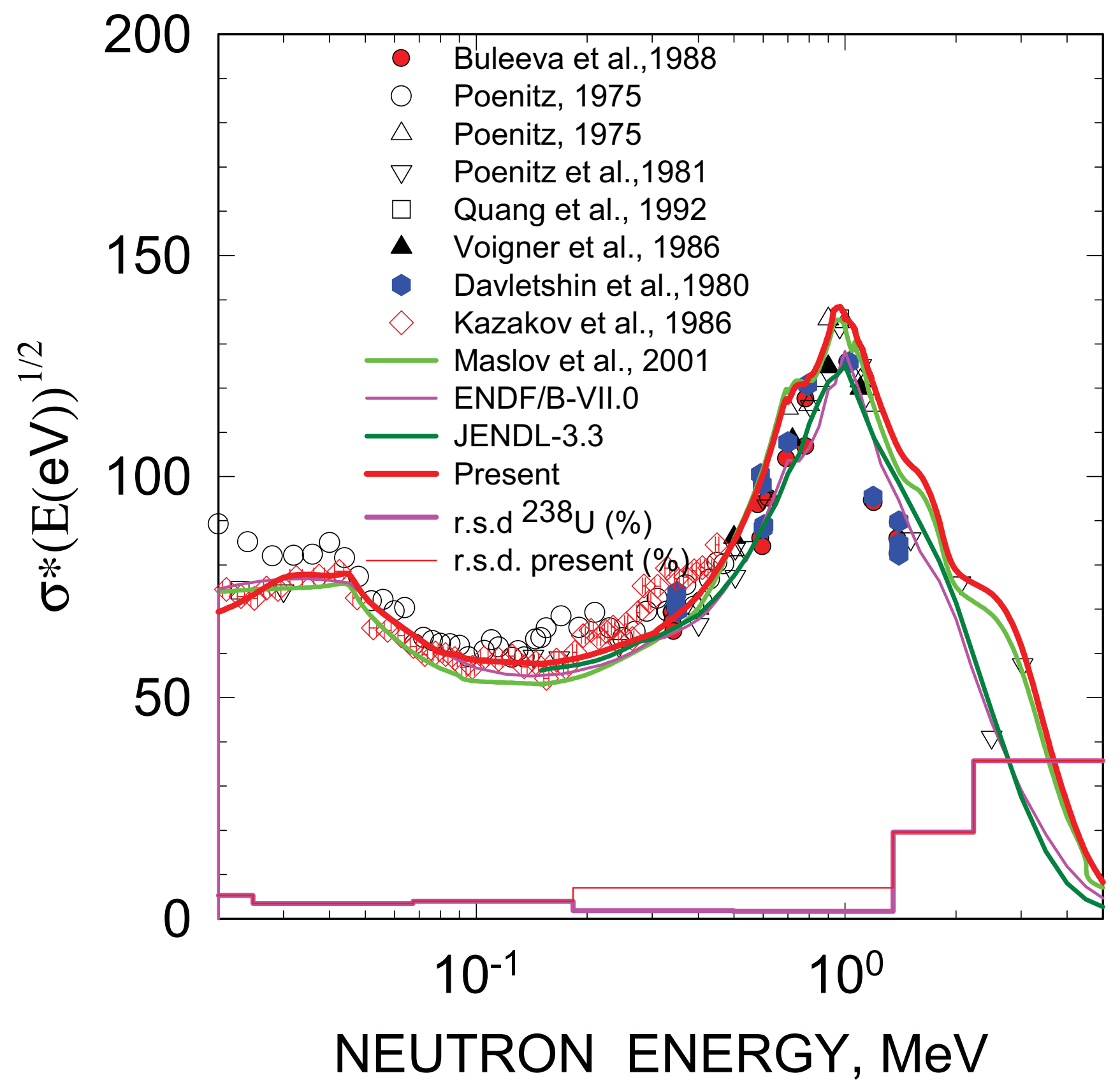




\section{${ }^{236}$ U CAPTURE CROSS SECTION}

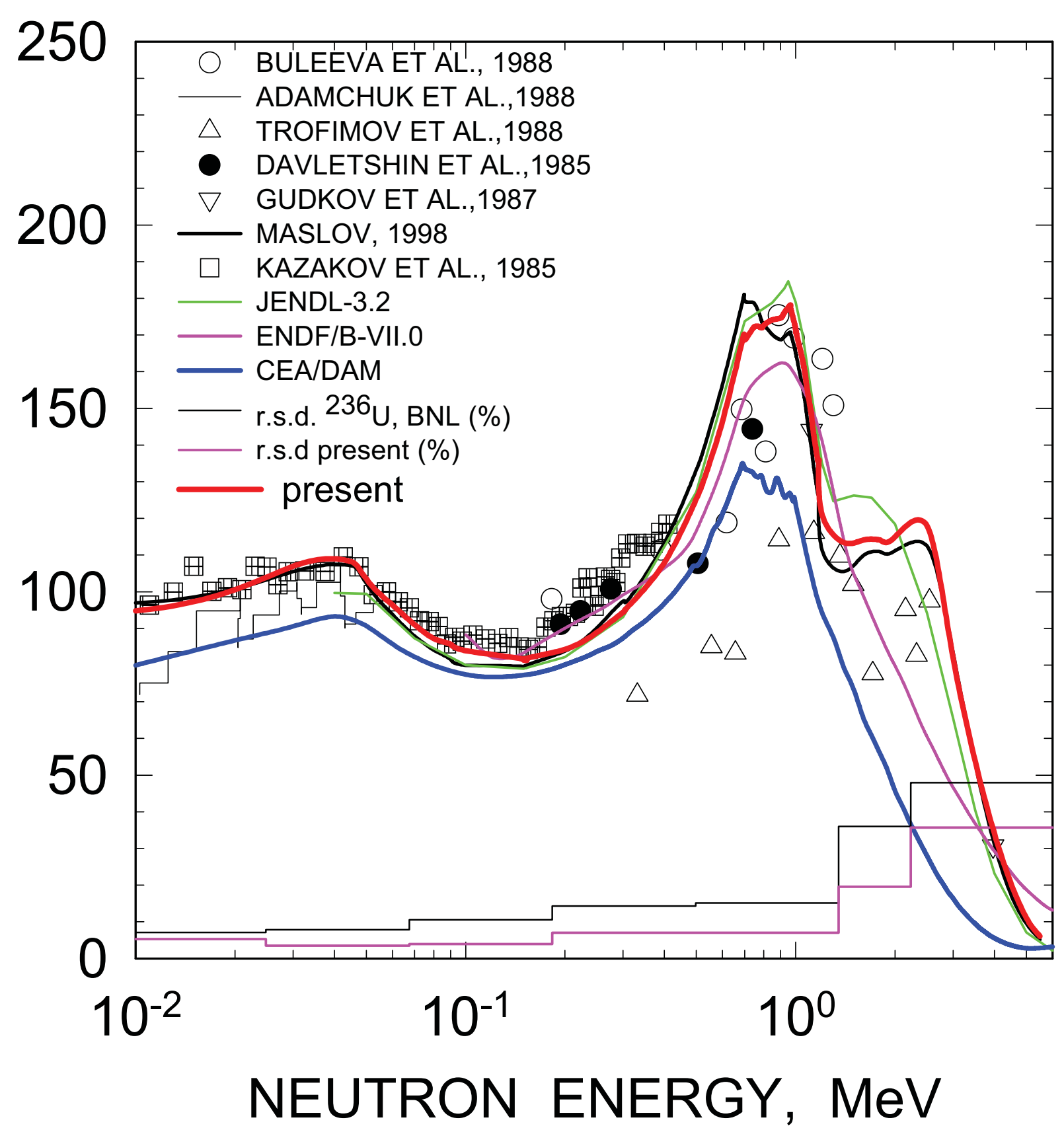




\section{${ }^{234} \mathrm{U}(n, \gamma)$ CROSS SECTION}

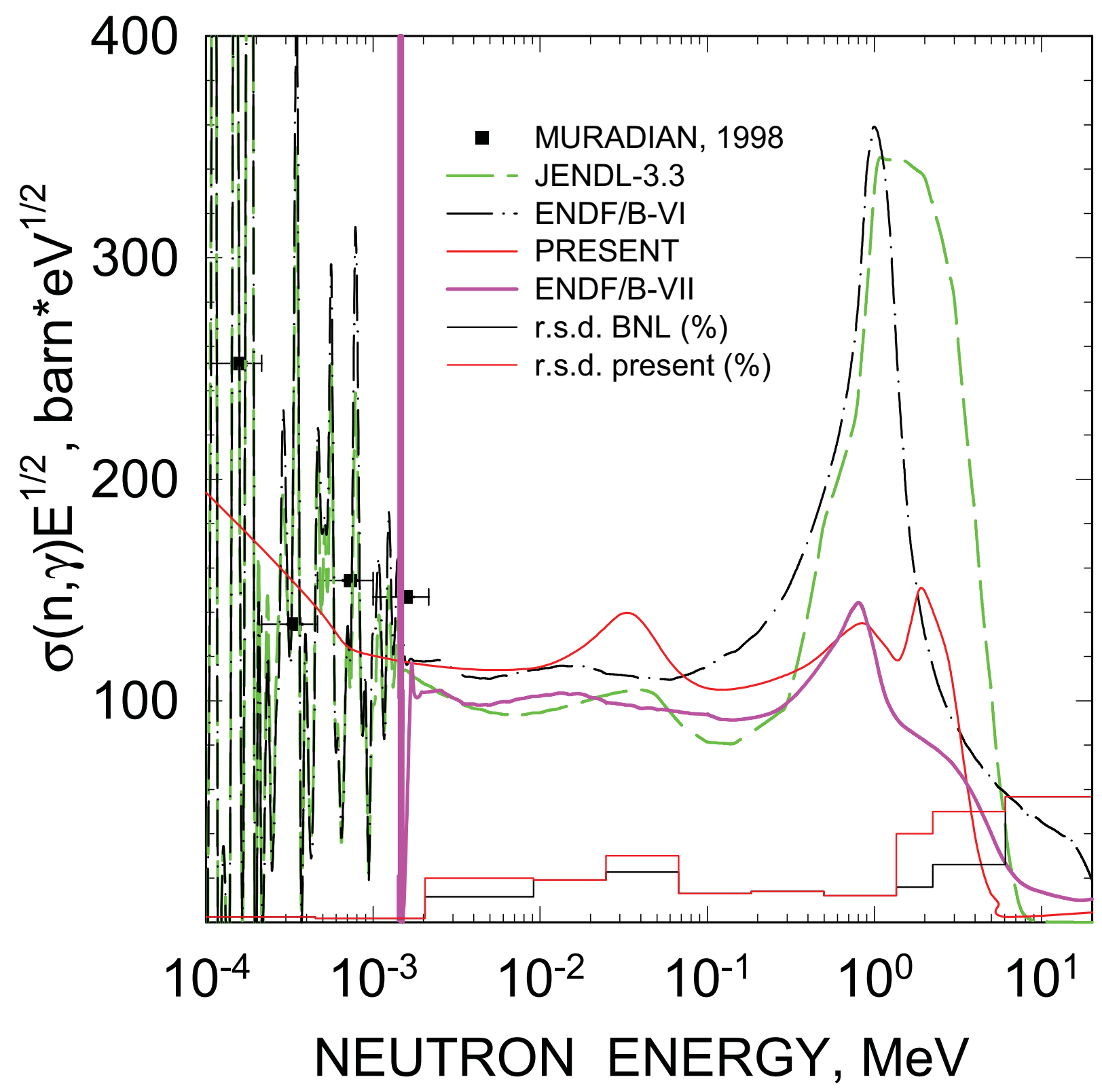




\section{${ }^{238} \mathrm{Pu}$ CAPTURE CROSS SECTION}

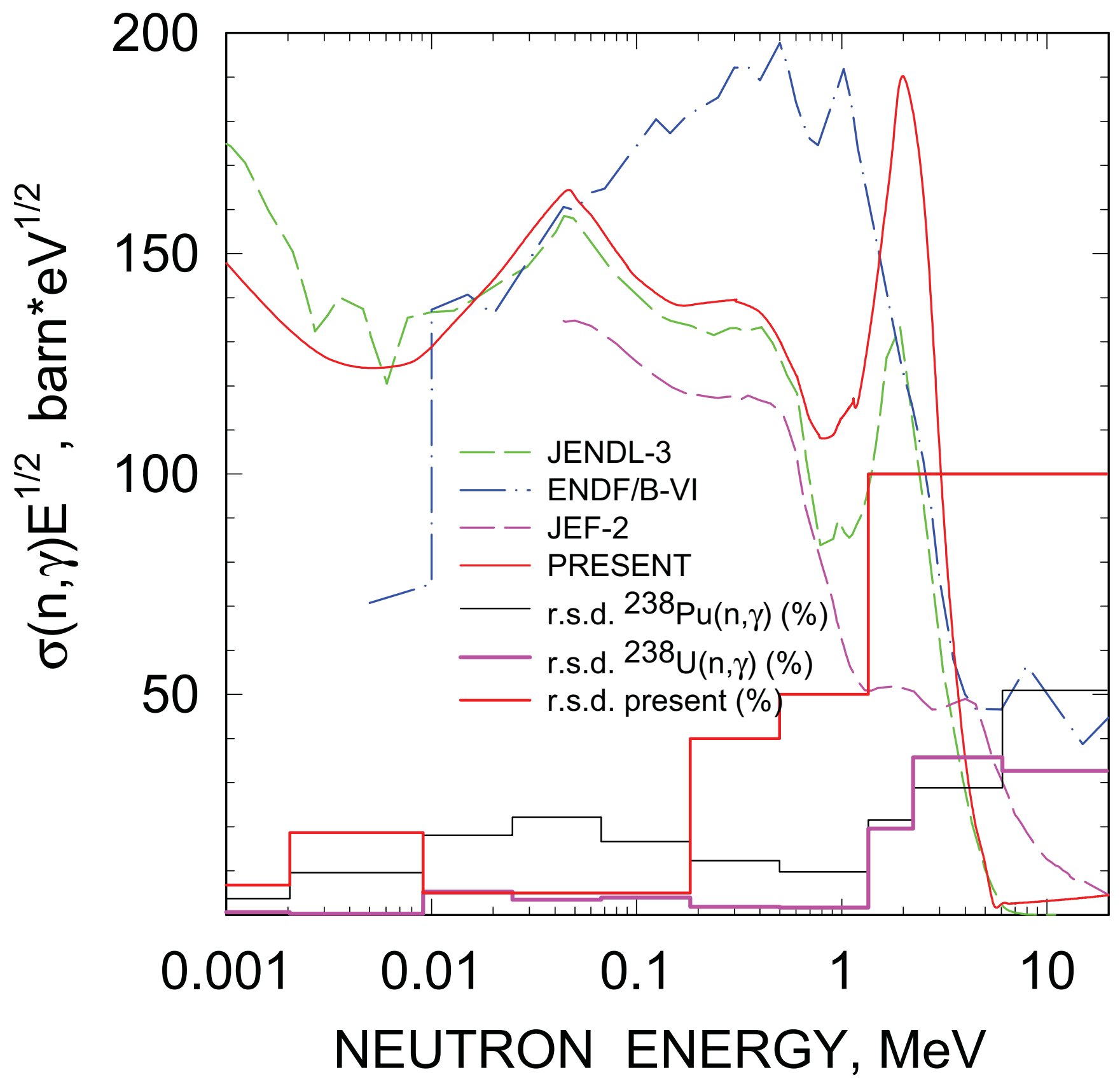


${ }^{240} \mathrm{PU}$ CAPTURE CROSS SECTION

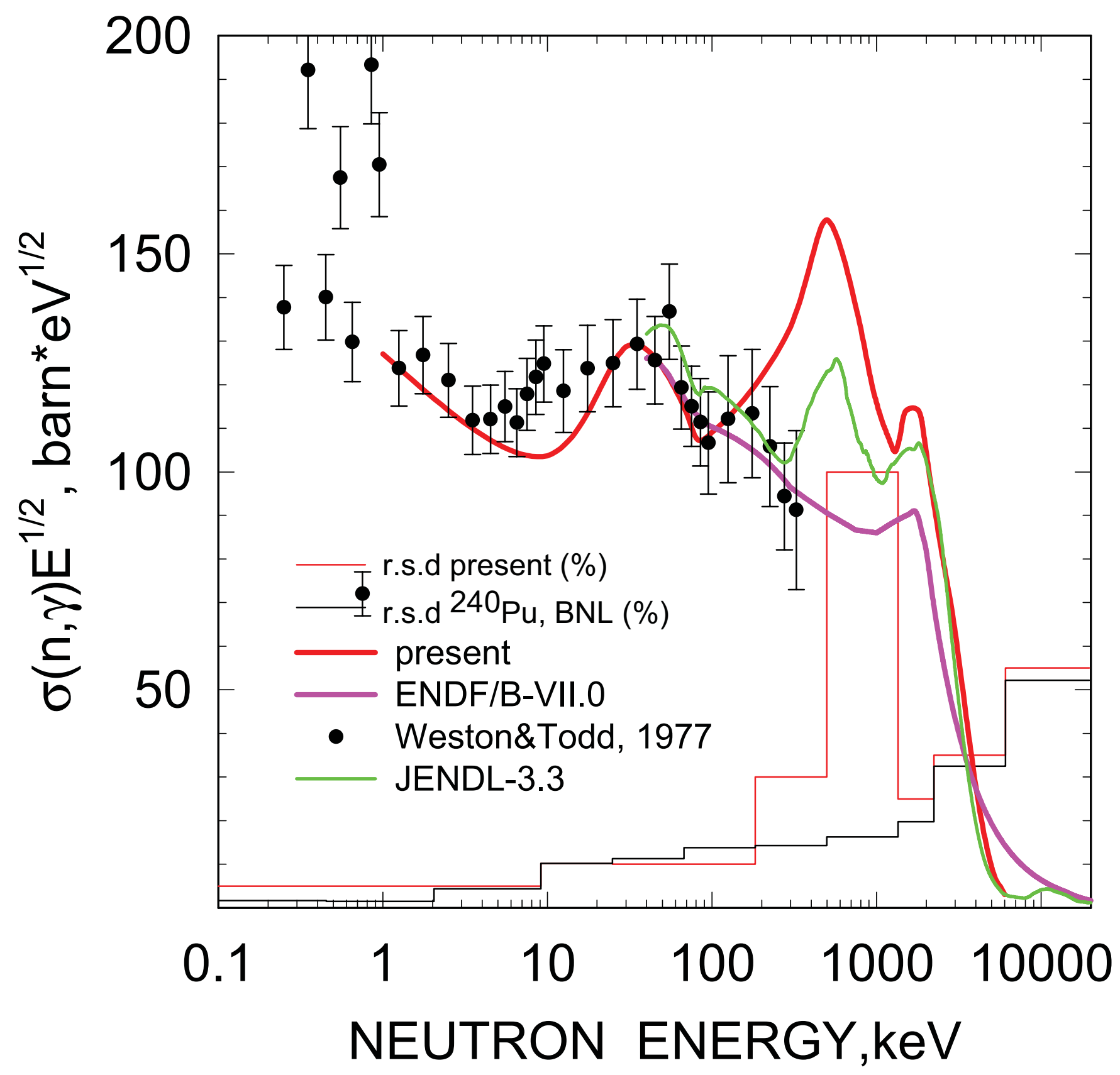




\section{${ }^{242} \mathrm{Pu}$ CAPTURE CROSS SECTION}

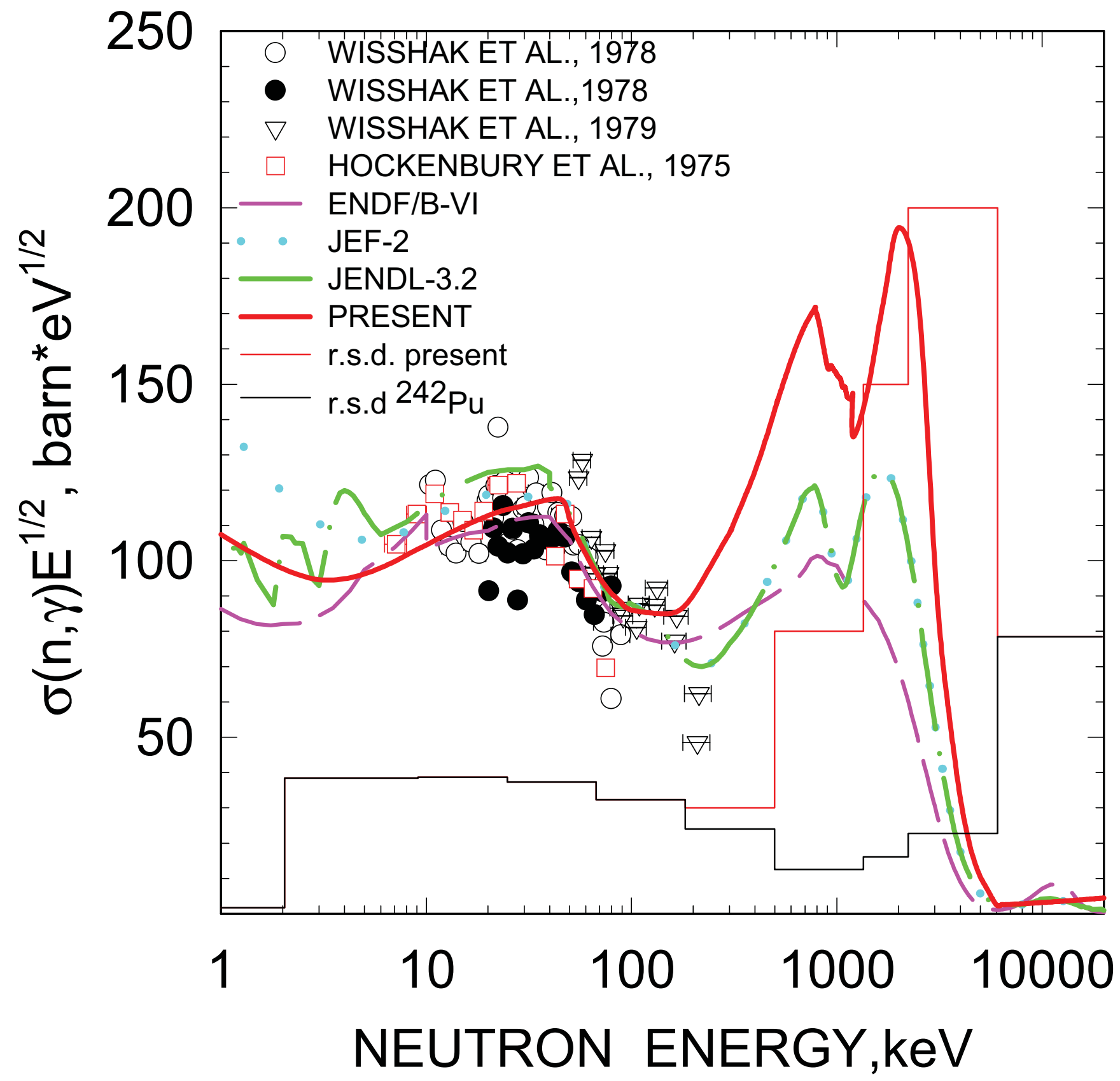




\section{${ }^{242} \mathrm{Cm}(\mathrm{n}, \gamma)$ CAPTURE CROSS SECTION}

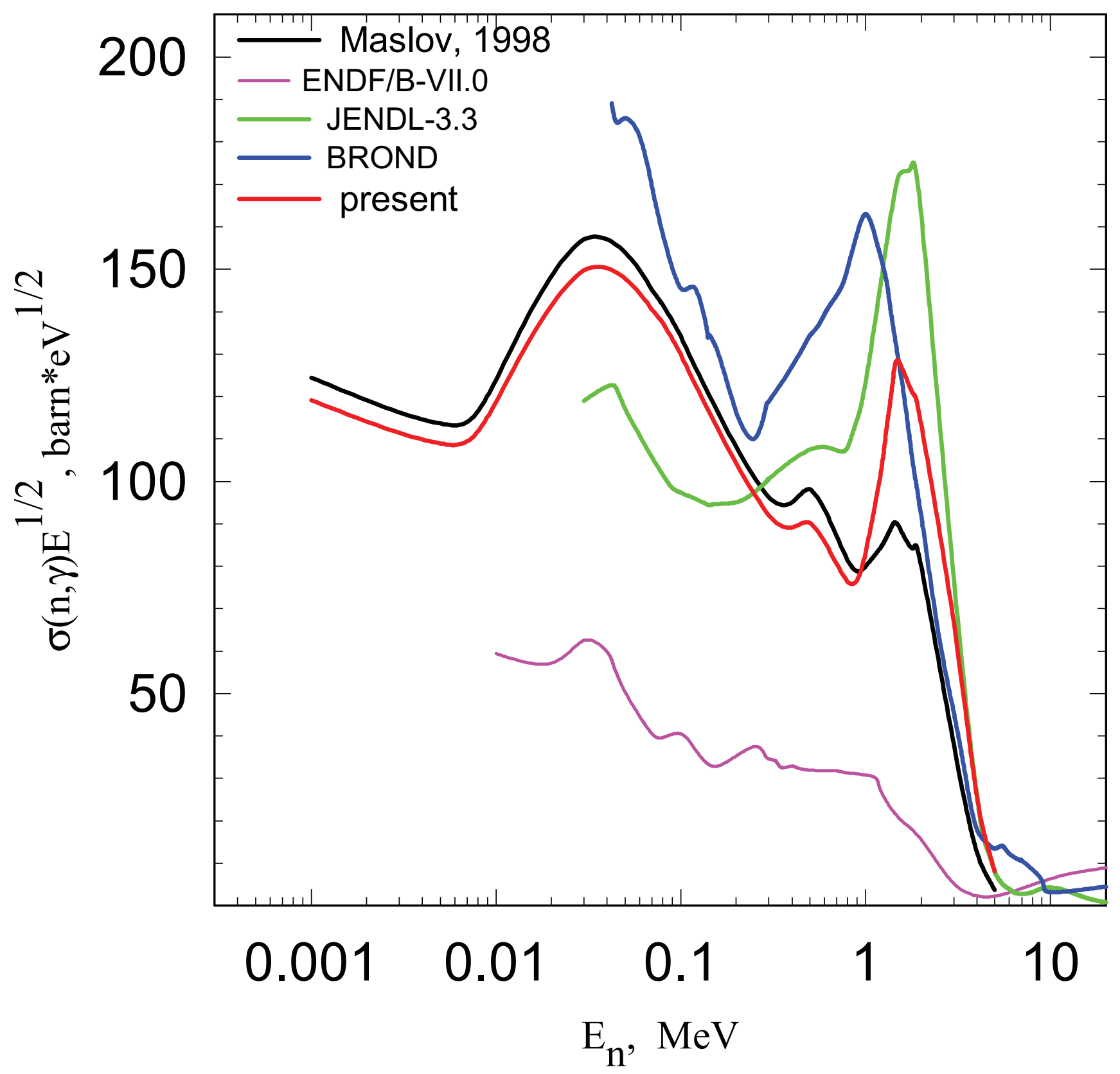


${ }^{244} \mathrm{Cm}(\mathrm{n}, \gamma)$

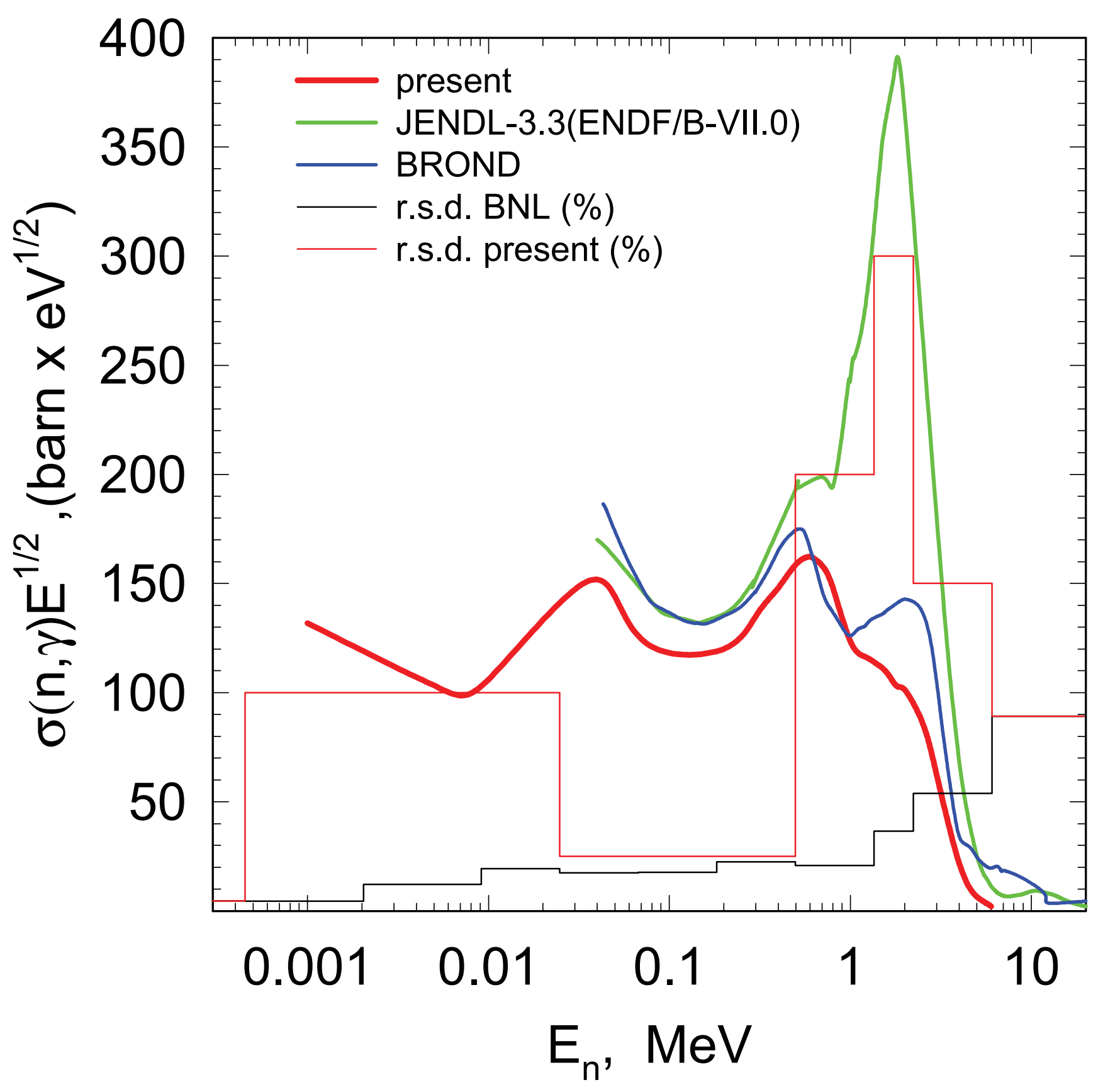




\section{${ }^{235} \mathrm{U}$ CAPTURE CROSS SECTION}

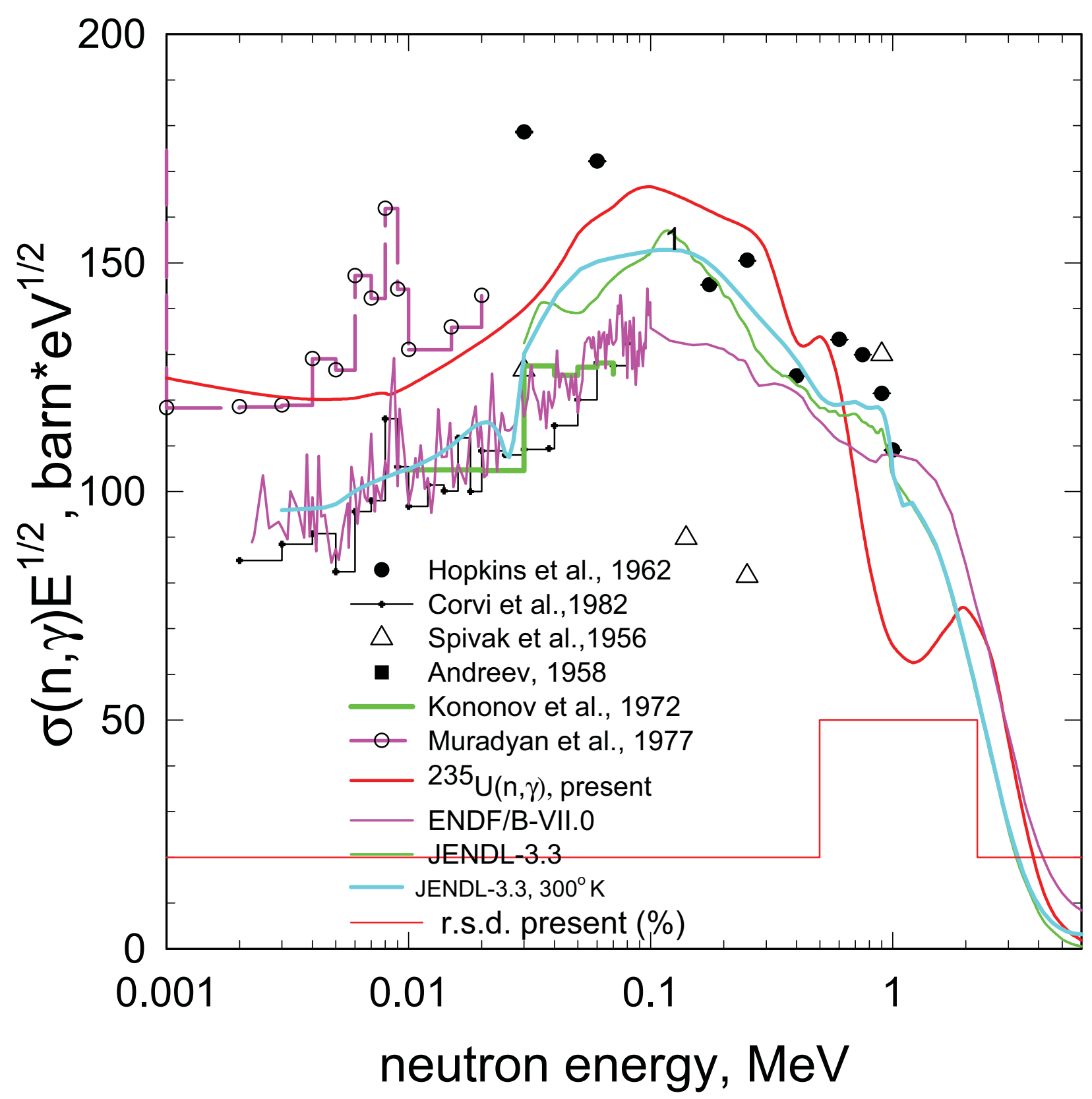




\section{${ }^{233}$ U CAPTURE CROSS SECTION}

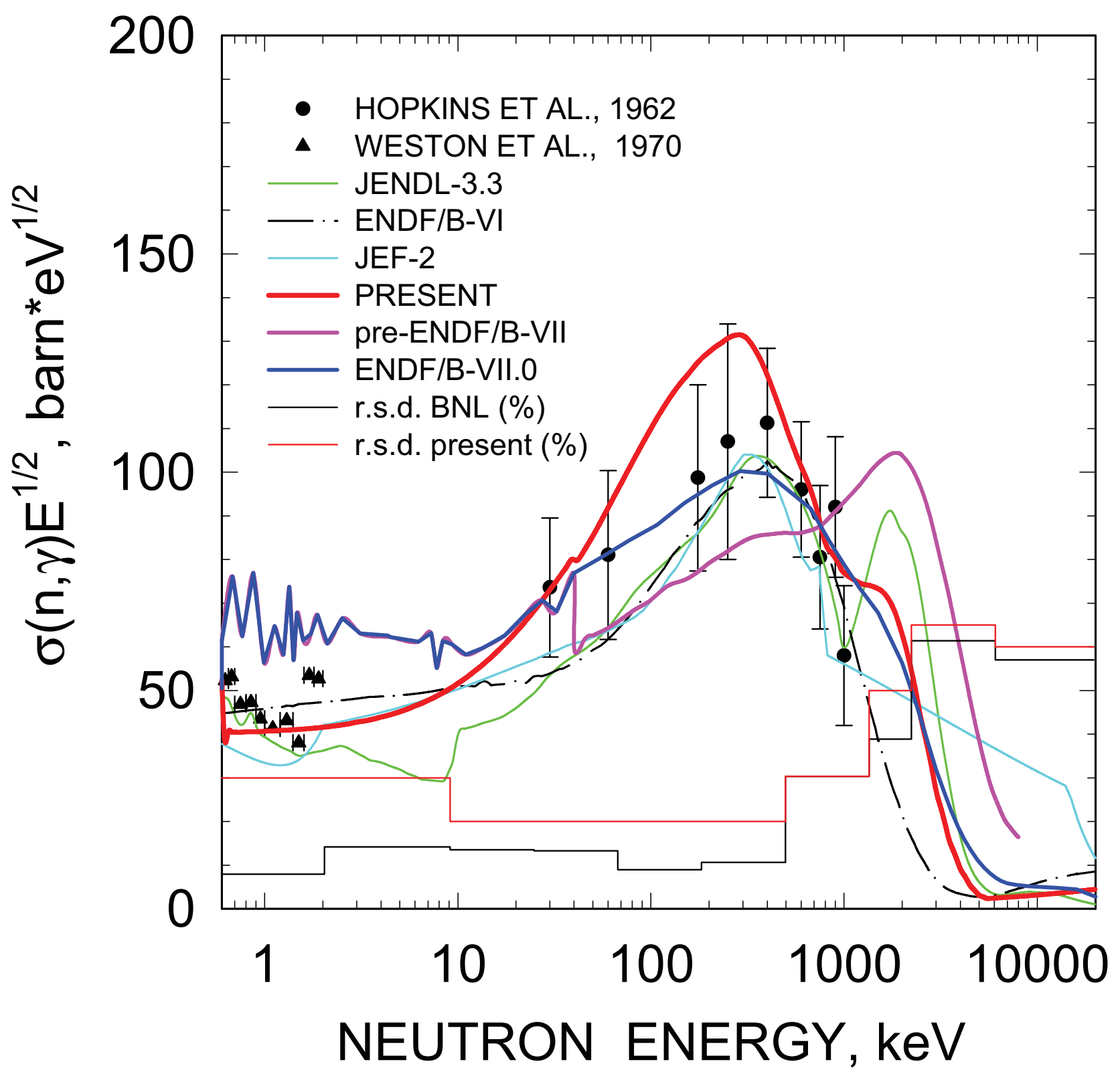




\section{${ }^{239} \mathrm{PU}$ CAPTURE CROSS SECTION}

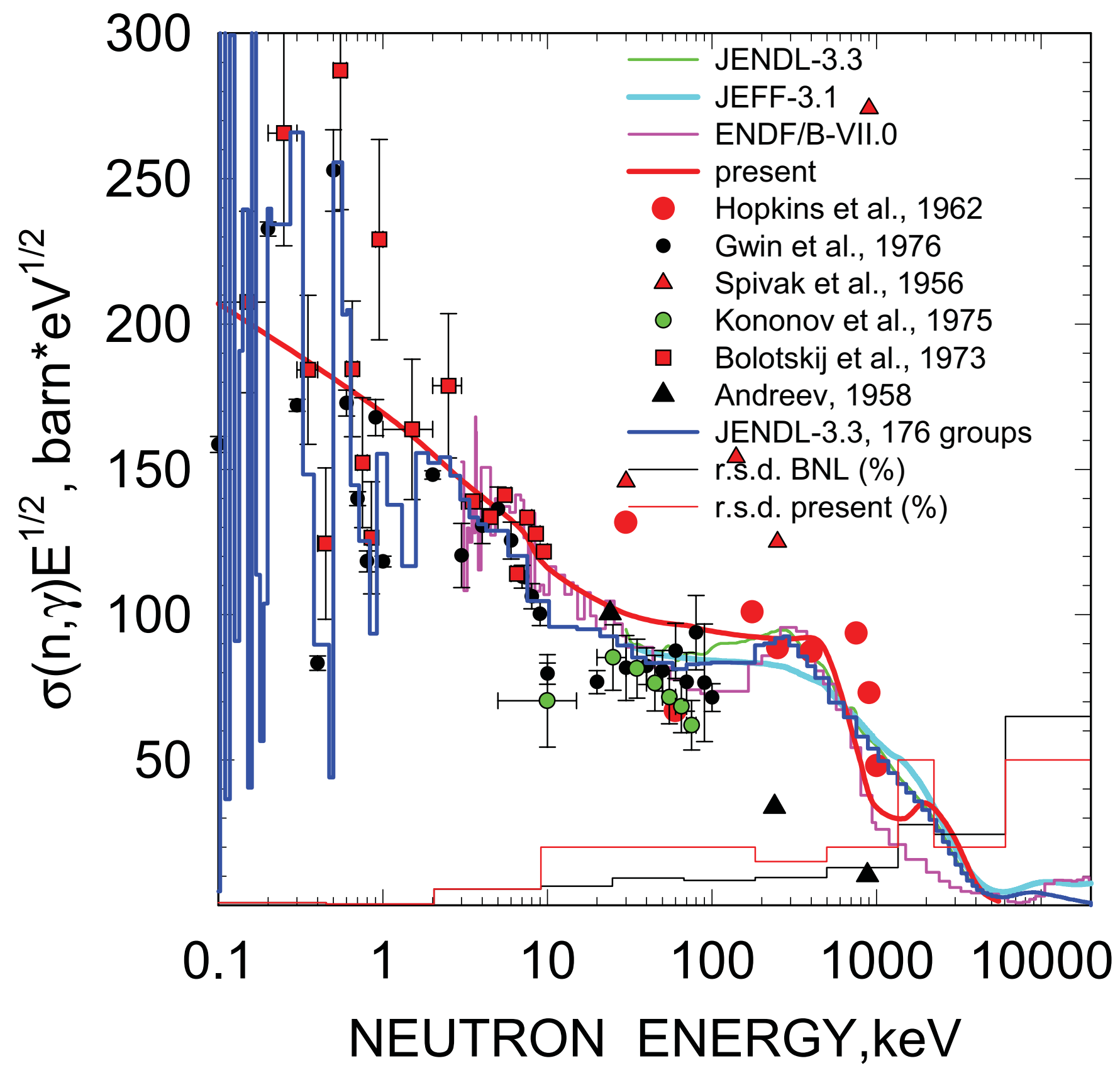


${ }^{241}$ PU CAPTURE CROSS SECTION

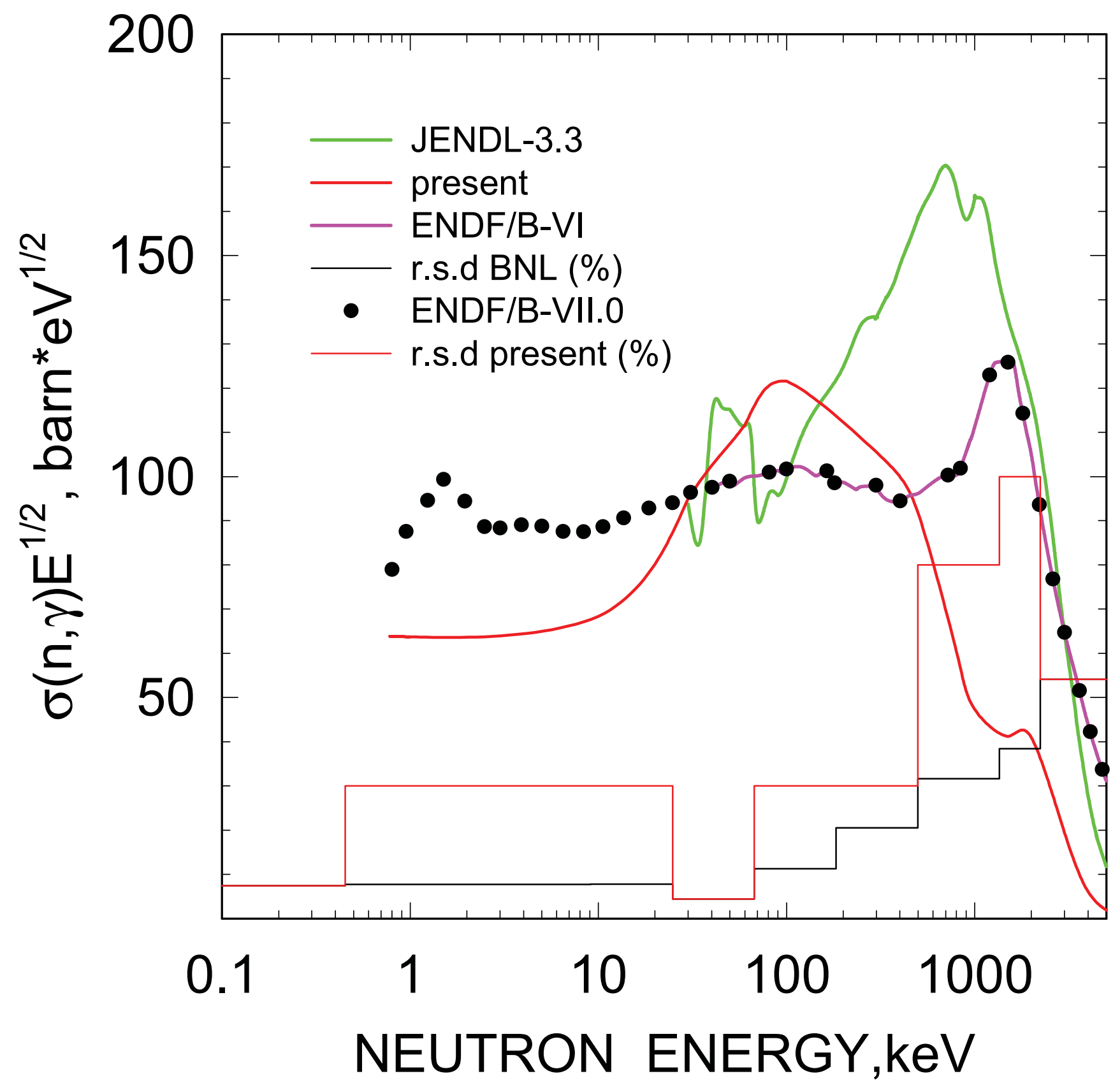


${ }^{243} \mathrm{Cm}$ CAPTURE CROSS SECTION

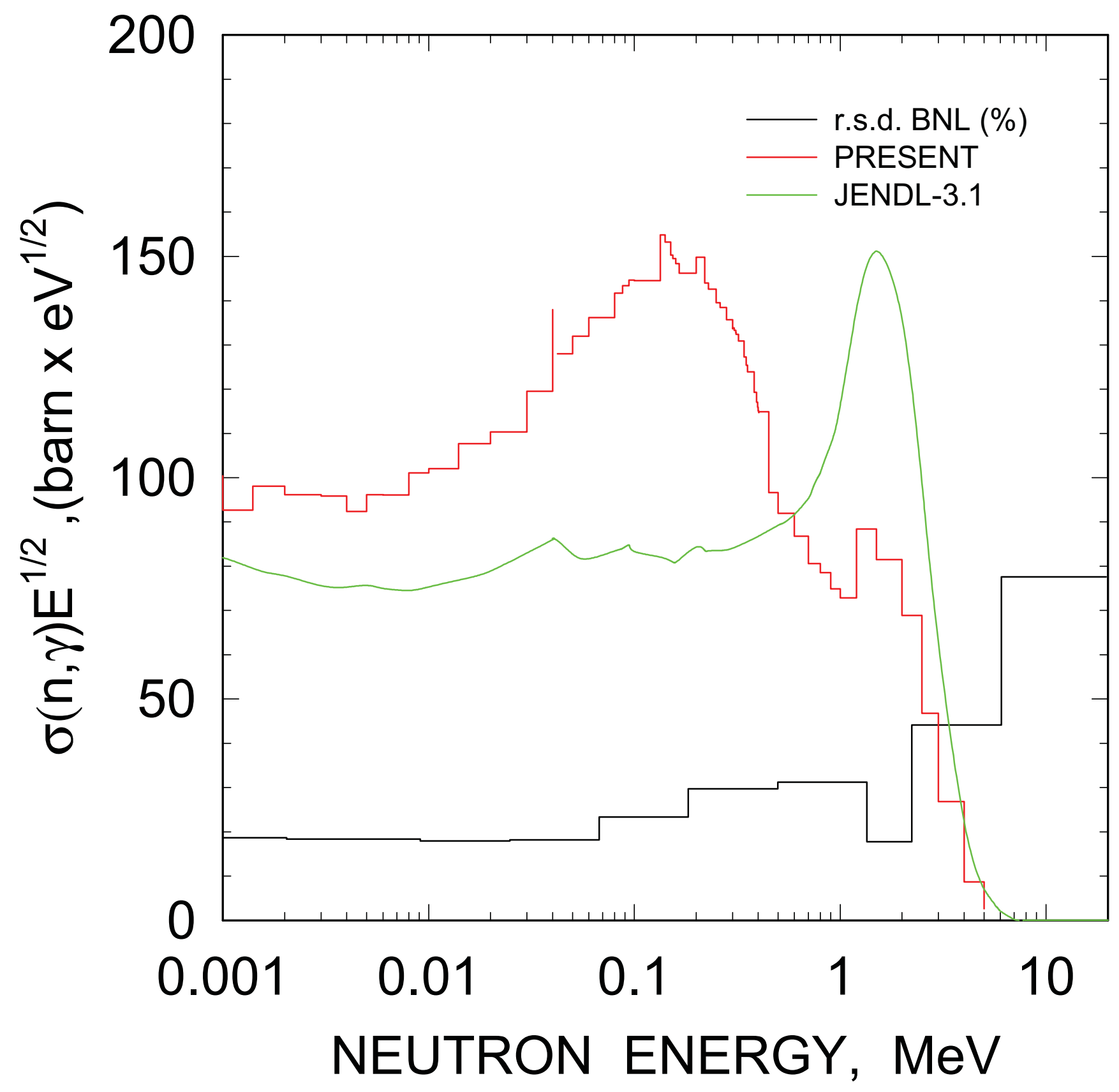




\section{${ }^{245} \mathrm{Cm}$ CAPTURE CROSS SECTION}

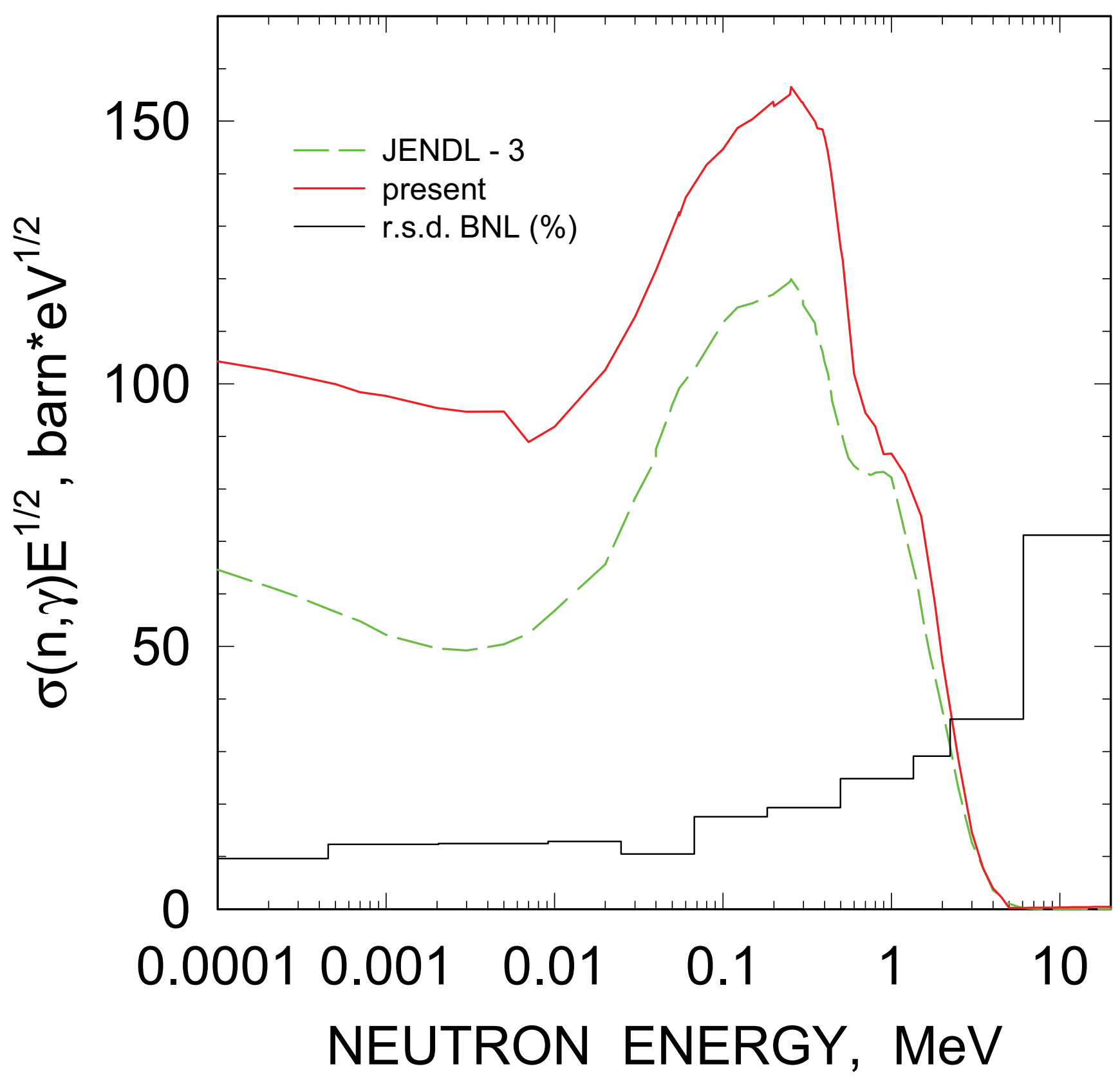




\section{${ }^{237} \mathrm{~Np}$ CAPTURE CROSS SECTION}

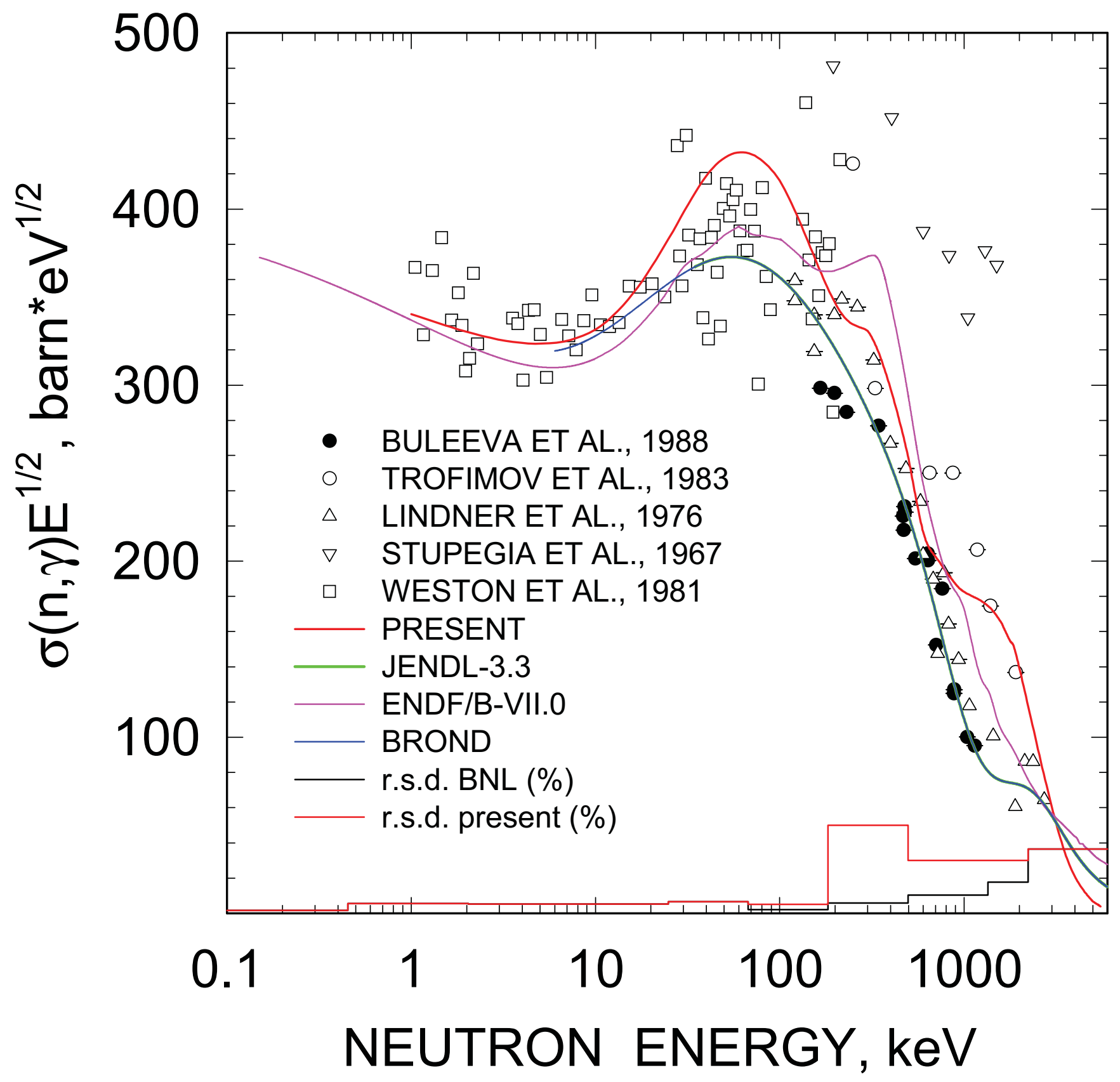




\section{${ }^{241}$ Am CAPTURE CROSS SECTION}

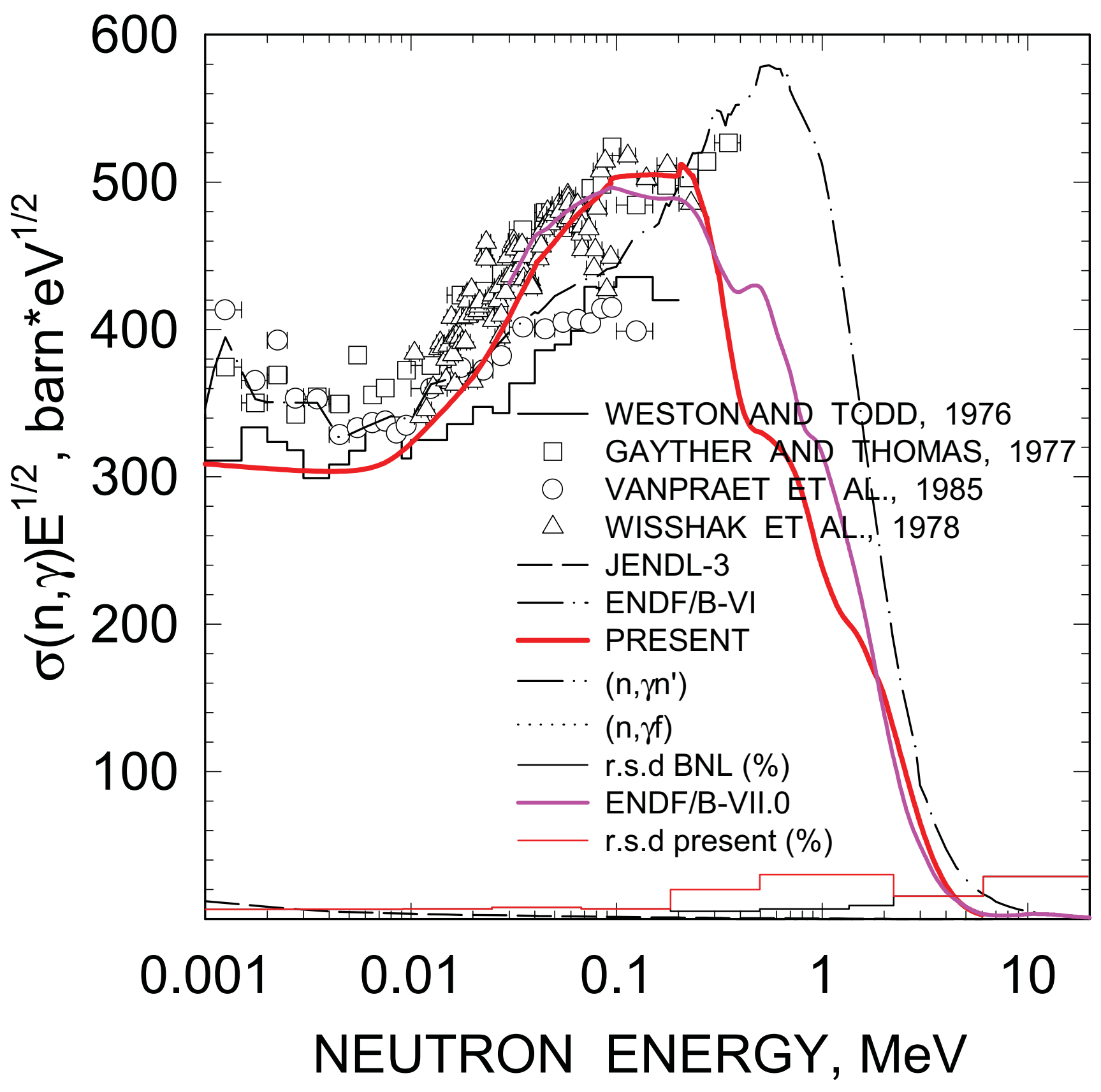




\section{${ }^{243} \mathrm{Am}$ CAPTURE CROSS SECTION}

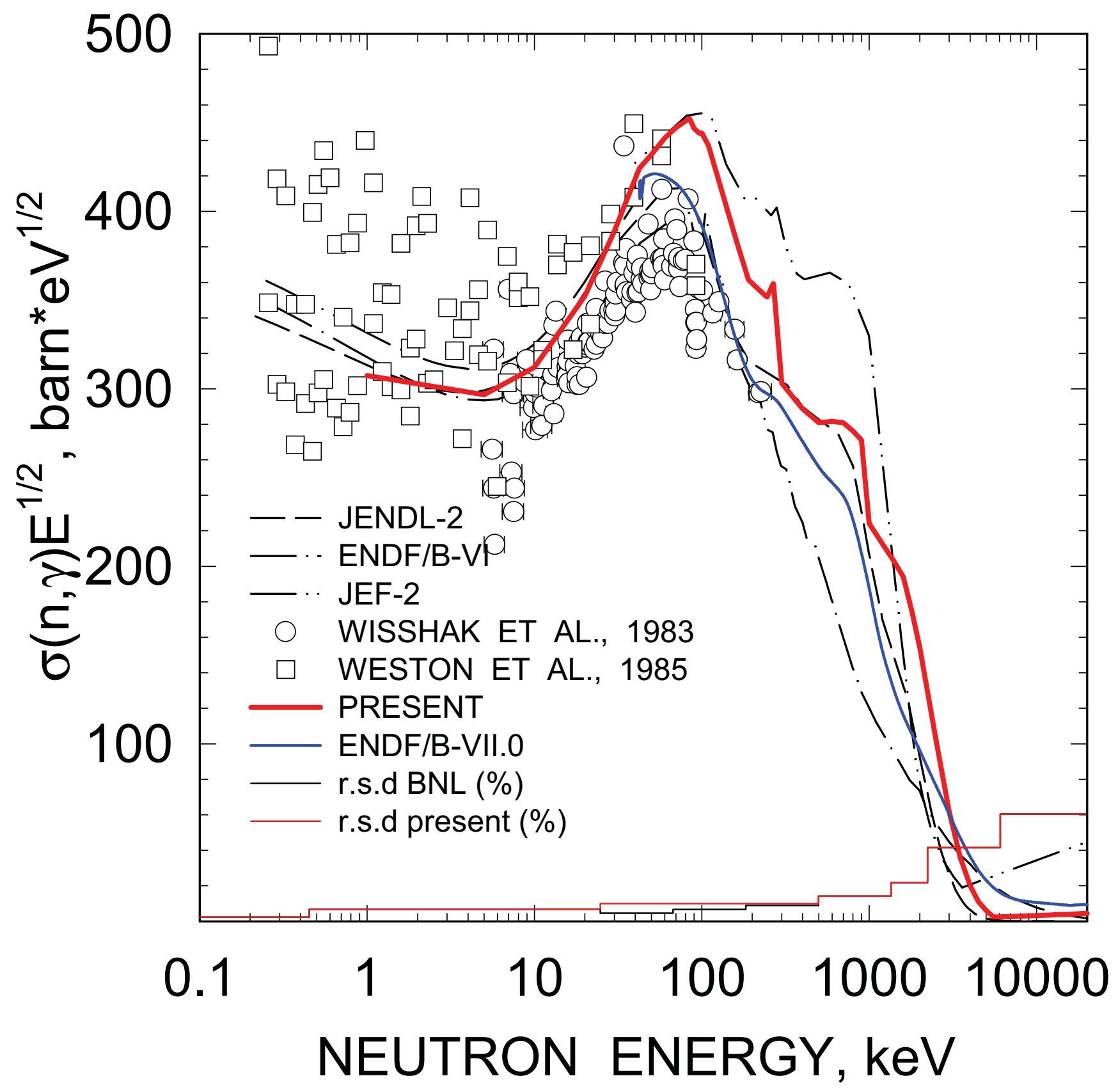




\section{${ }^{242 m}$ Am CAPTURE CROSS SECTION}

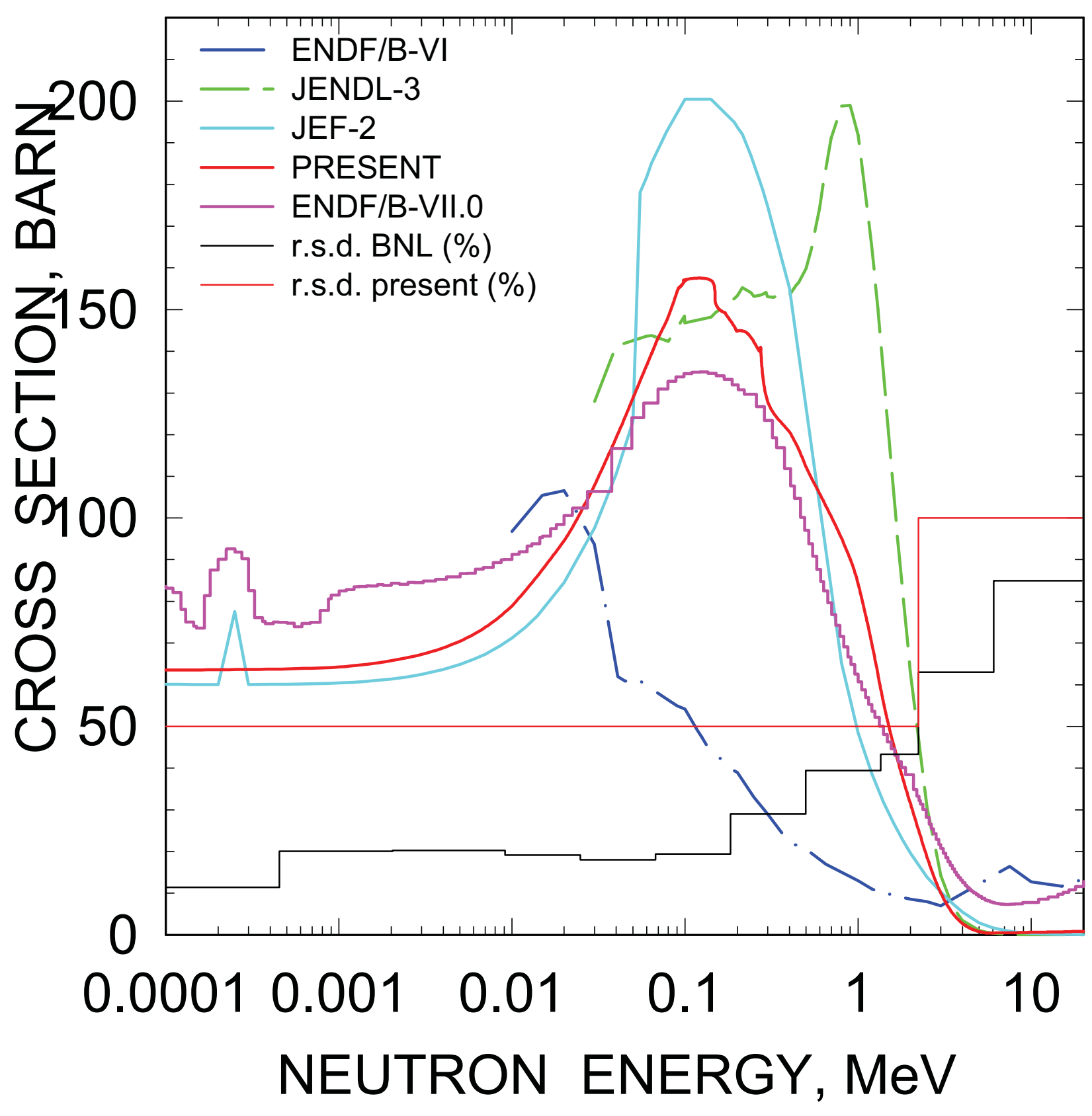




\section{Chapter 6}

\section{$(\mathbf{n}, 2 \mathrm{n})$ cross sections}

${ }^{232}$ Th: R.s.d. for ${ }^{232} \mathrm{Th}(\mathrm{n}, 2 \mathrm{n})$ reaction cross section are left unchanged, since ENDF/B-VII.0 does not differ much from newest measured data [245-256] and Maslov et al.[19] evaluation (see Fig. 6.1). Both are much differing from early JEFF and JENDL-3.3 evaluations.

${ }^{238} \mathbf{U}$ : For that nuclide covariances in BNL report were adopted from JENDL-3.3 data file. For this nuclide $(\mathrm{n}, 2 \mathrm{n})$ cross sections is much different from that of ENDF/B-VII.0 and Maslov et al. [23] data file and newest measured data $[169,257-263]$ (see Fig. 6.2). R.s.d. for ${ }^{238} \mathrm{U}(\mathrm{n}, 2 \mathrm{2n})$ reaction cross section is increased up to $30 \%$.

${ }^{236} \mathbf{U}$ : R.s.d. for ${ }^{236} \mathrm{U}(\mathrm{n}, 2 \mathrm{n})$ reaction cross section is left unchanged, since ENDF/B-VII.0 does not differ much from present calculation (see Fig. 6.3). However, both are much different from JEFF-3.1 and JENDL-3.3 evaluations.

${ }^{234} \mathbf{U}$ : R.s.d. for ${ }^{234} \mathrm{U}(\mathrm{n}, 2 \mathrm{2n})$ reaction cross section is left unchanged, since ENDF/B-VII.0 does not differ much from Maslov et al. [21] evaluation (see Fig. 6.4). However, both are much different from ENDF/B-VI and JENDL-3.3 evaluations.

${ }^{238} \mathrm{Pu}$ : R.s.d. for ${ }^{238} \mathrm{Pu}(\mathrm{n}, 2 \mathrm{n})$ reaction cross section is increased up to $100 \%$, since the ENDF/BVII.0 differ much from Maslov et al. [32] evaluation, almost by an order of magnitude. However, both are much different from JEFF and JENDL-3.1 evaluations (see Fig. 6.5).

${ }^{240} \mathrm{Pu}$ : R.s.d. for ${ }^{240} \mathrm{Pu}(\mathrm{n}, 2 \mathrm{n})$ reaction cross section is decreased down to $10 \%$, since the ENDF/B-VII.0 data, present calculation and JEFF and JENDL-3.3 evaluations are not much different from each other (see Fig. 6.6).

${ }^{242} \mathrm{Pu}$ : R.s.d. for ${ }^{242} \mathrm{Pu}(\mathrm{n}, 2 \mathrm{n})$ reaction cross section is left unchanged, it corresponds to differences of ENDF/B-VII.0 data from Maslov et al. [33] evaluation (see Fig. 6.7). Shape of the cross section in ENDF/B-VII.0 data should be updated strongly.

${ }^{242} \mathrm{Cm}$ : R.s.d. for ${ }^{242} \mathrm{Cm}(\mathrm{n}, 2 \mathrm{n})$ reaction cross should be increased 10 times, since the ENDF/BVII.0 orders of magnitude different from present calculation, which reliably predicts fission cross section. The latter is confirmed by surrogate fission data [114], presented at ND2007 conference. Both are much different from JEFF and JENDL-3.3 evaluations (see Fig. 6.8). 
${ }^{244} \mathrm{Cm}$ : R.s.d. for ${ }^{244} \mathrm{Cm}(\mathrm{n}, 2 \mathrm{n})$ reaction cross should be decreased to $30 \%$, to reflect actual differences of present calculation, which reliably predicts fission cross section, from JENDL-3.3 data, adopted for ENDF/B-VII.0 (see Fig. 6.9).

${ }^{235} \mathbf{U},{ }^{239} \mathrm{Pu}$ : For two nuclides $-{ }^{235} \mathrm{U}$ [263-265] and ${ }^{239} \mathrm{Pu}[263,265,266,267]$ - covariances in BNL report were adopted from JENDL-3.3. For these nuclides $(n, 2 n)$ cross sections are different from those of ENDF/B-VII.0 and Maslov [10, 268] calculations and measured data as well (see Figs. 6.10, 6.12). Without understanding the uncertainties of relatively well-investigated ( $n, 2 n)$ cross sections, only next to nothing could be said about poor investigated nuclides. However, it should be stated that mild consistency of different evaluations does not reflect the predictive powers of different approaches, since predicted fission chances contributions differ very much. In a number of cases, predicted r.s.d. is overconservative $\left({ }^{233} \mathrm{U}(\mathrm{n}, 2 \mathrm{n}),{ }^{234} \mathrm{U}(\mathrm{n}, 2 \mathrm{n})\right.$, for example) or over-optimistic $\left({ }^{242} \mathrm{Cm}(\mathrm{n}, 2 \mathrm{n})\right.$, for example)). R.s.d for ${ }^{235} \mathrm{U}$ and ${ }^{239} \mathrm{Pu}$ are fixed at $10 \%$ and $29 \%$ level, respectively.

${ }^{233} \mathbf{U}$ : R.s.d. for ${ }^{233} \mathrm{U}(\mathrm{n}, 2 \mathrm{n})$ reaction cross is left unchaged, it reflects the consistency between ENDF/B-VII.0 and Maslov et al. [22] evaluations, other evaluations should be severely modified (see Fig. 6.11).

${ }^{241} \mathrm{Pu}$ : R.s.d. for ${ }^{241} \mathrm{Pu}(\mathrm{n}, 2 \mathrm{n})$ reaction cross is left un-changed, it reflects the differences between present calculation and previous evaluations, which should be severely modified (see Fig. 6.13).

${ }^{245} \mathrm{Cm}$ : R.s.d. for ${ }^{245} \mathrm{Cm}(\mathrm{n}, 2 \mathrm{n})$ reaction cross section is left unchanged, since Maslov et al. [27] evaluation is adopted for JEFF, JENDL-3.3 and ENDF/B-VII.0 data libraries and there is no modern data files to compare with. However, it is much different from early JENDL evaluation (see Fig. 6.14).

${ }^{243} \mathrm{Cm}$ : R.s.d. for ${ }^{243} \mathrm{Cm}(\mathrm{n}, 2 \mathrm{n})$ reaction cross section is left unchanged, since Maslov et al. [26] evaluation is adopted for JEFF, JENDL-3.3 and ENDF/B-VII.0 data libraries and there is no modern data files to compare with (see Fig. 6.15). However, it is much different from the early JENDL evaluation.

${ }^{237} \mathrm{~Np},{ }^{241} \mathrm{Am},{ }^{243} \mathrm{Am}$ : There are a number of (n,2n) cross sections, which might be of minor importance, but they give one a confidence that the whole pipe-line is working properly, since extensive measured data are available only for ${ }^{237} \mathrm{~Np}(\mathrm{n}, 2 \mathrm{n}){ }^{2361} \mathrm{~Np}$ reaction $[269-274]$ (see Figs. 6.16, 6.17, 6.18). One of them is ${ }^{241} \mathrm{Am}(\mathrm{n}, 2 \mathrm{n})$ [275-277], its newest measurement, reported at ND2007 by Vieira et al. [171], nicely confirmed older evaluation by Maslov et al. [17], that data file afterwards was accepted for JENDL-3.3(2). As regards ${ }^{243} \mathrm{Am}(\mathrm{n}, 2 \mathrm{n})$ feeding ${ }^{242 \mathrm{~m}} \mathrm{Am}(\mathrm{J}=5)(141 \mathrm{y})$ and ${ }^{242 \mathrm{~g}} \mathrm{Am}(\mathrm{J}=1)(16 \mathrm{~h})$ there is a measurement by Gancarz [278] referred by Chadwick et al. [14]. Unfortunately, the exact reference to 
that measurement is missing. However, the quoted Gancarz [278] data point gives the yield of ${ }^{242 \mathrm{~g}} \mathrm{Am}(\mathrm{J}=1)(16 \mathrm{~h})$ at $15 \mathrm{MeV}$ as 0.2 barn. It would be quite compatible with estimate of ${ }^{243} \mathrm{Am}(\mathrm{n}, 2 \mathrm{n})^{242(\mathrm{~m}+\mathrm{g})} \mathrm{Am}$ of 0.3 barn, granted that branching ratio of $\mathrm{m} / \mathrm{g}$ or (long-lived-to-short/lived) is similar to that in ${ }^{237} \mathrm{~Np}(\mathrm{n}, 2 \mathrm{n})$ reaction. Only in that case the r.s.d. of ${ }^{243} \mathrm{Am}(\mathrm{n}, 2 \mathrm{n})$ cross section could be claimed to be equal to $30 \%$ or even to that of ${ }^{241} \mathrm{Am}(\mathrm{n}, 2 \mathrm{n})$, otherwise it should increased to $100 \%$. In ENDF/B-VII.0 there is some misunderstanding with the ${ }^{243} \mathrm{Am}(\mathrm{n}, 2 \mathrm{n})$ and ${ }^{243} \mathrm{Am}(\mathrm{n}, \mathrm{F})$ data, if Gancarz [278] measurement is activation/radiochemistry and not the mass-spectroscopy and gives the yield of ${ }^{242 \mathrm{~g}} \mathrm{Am}(\mathrm{J}=1)$. Besides all, it would be a strong constraint for the ${ }^{243} \mathrm{Am}(\mathrm{n}, \mathrm{F})$ fission cross section estimates, which are quite controversial. In case of ${ }^{243} \mathrm{Am}(\mathrm{n}, 2 \mathrm{n})$ in Maslov et al. [18] and ENDF/B-VII.0 evaluation the cross sections are very different. The problem is with the branching ratio of g.s./m.s. It should be like in case ${ }^{237} \mathrm{~Np}(\mathrm{n}, 2 \mathrm{n})$, that is quite evident, while in ENDF/B-VII.0 [14] case it is much different. Gaussian random sampling would not produce reasonable estimate of r.s.d. in that case.

We did in 1987 (Ignatyk et al. [154]) the analysis for ${ }^{237} \mathrm{~Np}\left(\mathrm{n}, 2 \mathrm{n}\right.$ ), feeding short-lived ${ }^{236} \mathrm{~Np}$ $(\mathrm{J}=1)$ with a branching ratio of long-lived( $\mathrm{J}=6)$-to-short-lived( $\mathrm{J}=1)$ at $14 \mathrm{MeV}$ of 0.35 (measured data by Myers et al. [279] fitted as well as near-threshold ${ }^{237} \mathrm{~Np}(\mathrm{n}, 2 \mathrm{n}){ }^{237} \mathrm{~Np}$ high-precision data measured by Kornilov et al. [272]. In case of ${ }^{237} \mathrm{~Np}(\mathrm{n}, 2 \mathrm{n})^{2365} \mathrm{~Np}$ reaction, where there are precise data in a threshold region, i.e. r.s.d. can not be 3 times worse than at $14 \mathrm{MeV}$ [155].

R.s.d. for ${ }^{237} \mathrm{~Np}(\mathrm{n}, 2 \mathrm{n})$ reaction cross section should be increase to $20 \%$ to reflect the differences of ENDF/B-VII.0 evaluated data from measured data and present calculation.

R.s.d. for ${ }^{241} \mathrm{Am}(\mathrm{n}, 2 \mathrm{n})$ reaction cross section reflects the differences of ENDF/B-VII.0 evaluated data from measured data and evaluation by Maslov et al. [17] and is left unchanged.

R.s.d. for ${ }^{243} \mathrm{Am}(\mathrm{n}, 2 \mathrm{n})$ reaction cross section is increased to $50 \%$ to reflect the differences of ENDF/B-VII.0 evaluated data from evaluation by Maslov et al. [18] and proper treatment of measured data in that latter evaluation.

${ }^{242 \mathrm{~m}} \mathrm{Am}$ : R.s.d. for ${ }^{242} \mathrm{Am}(\mathrm{n}, 2 \mathrm{n})$ reaction cross section reflects the differences of ENDF/B-VII.0 evaluated data from measured data and evaluation by Maslov et al. [30] and is left unchanged (see Fig. $6.19)$. 


\section{${ }^{232} \mathrm{Th}(\mathrm{n}, 2 \mathrm{n})$ CROSS SECTION}

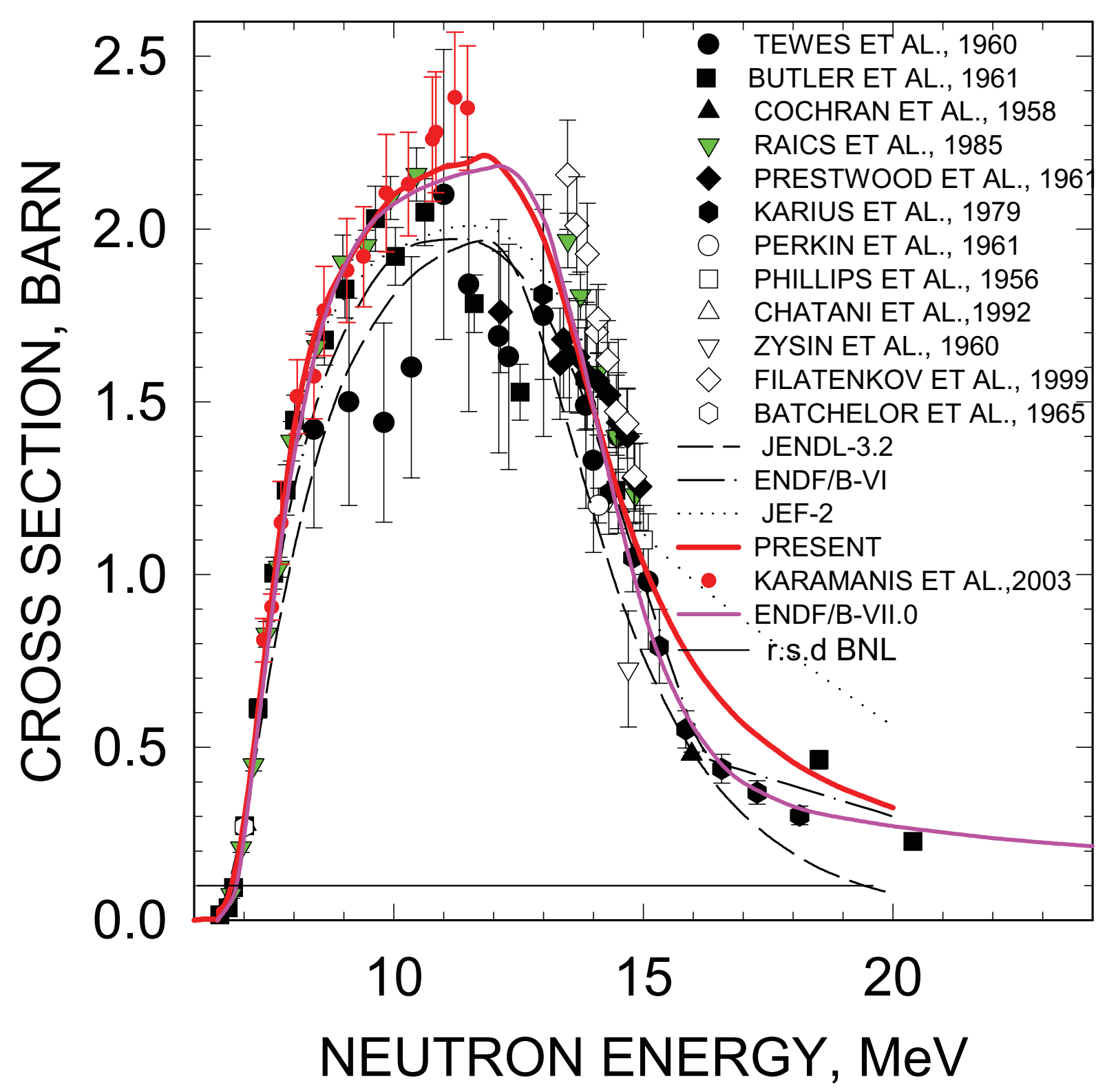




\section{${ }^{238} U(n, 2 n)$ CROSS SECTION}

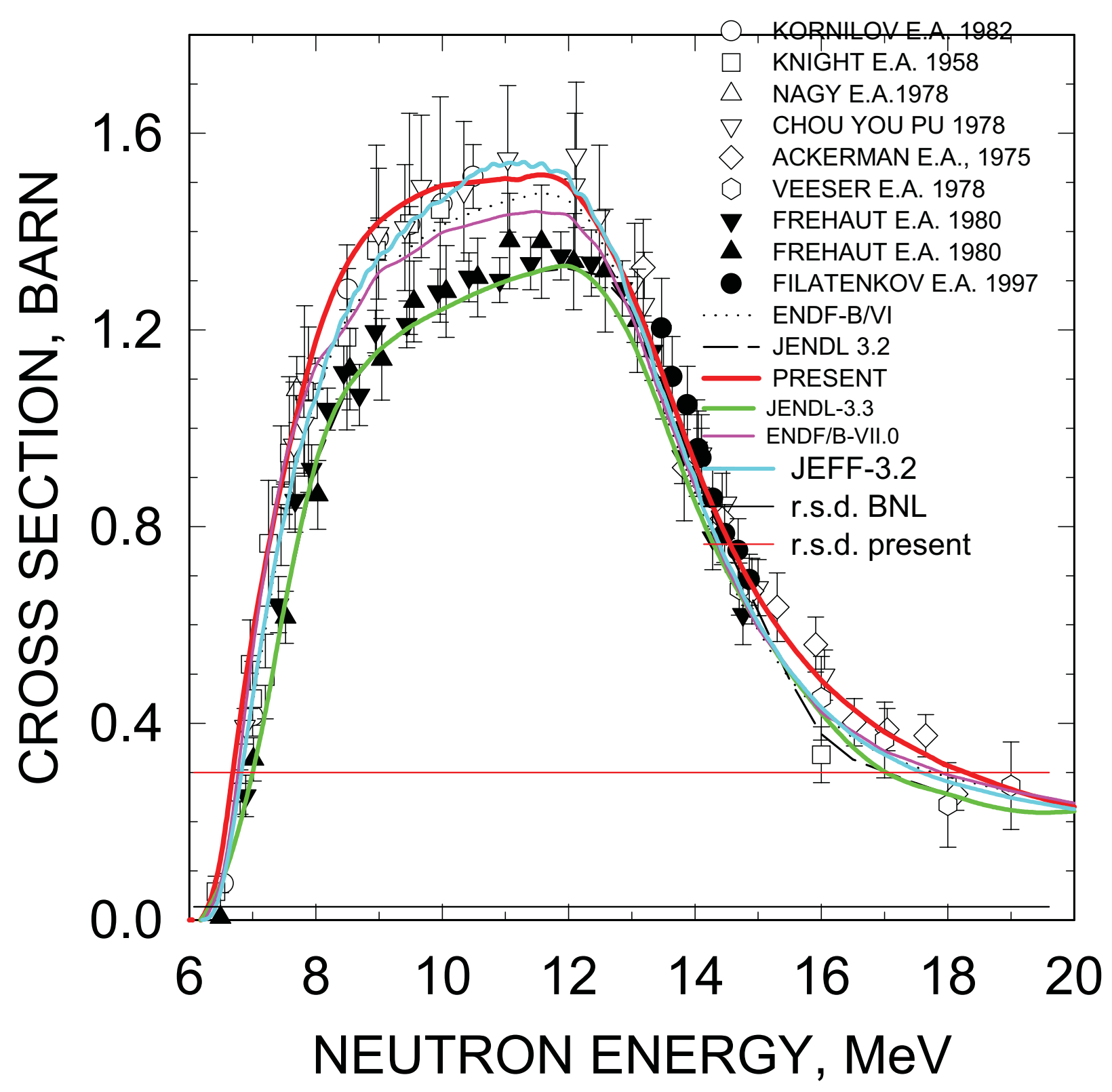


${ }^{236} U(n, 2 n)$ CROSS SECTION

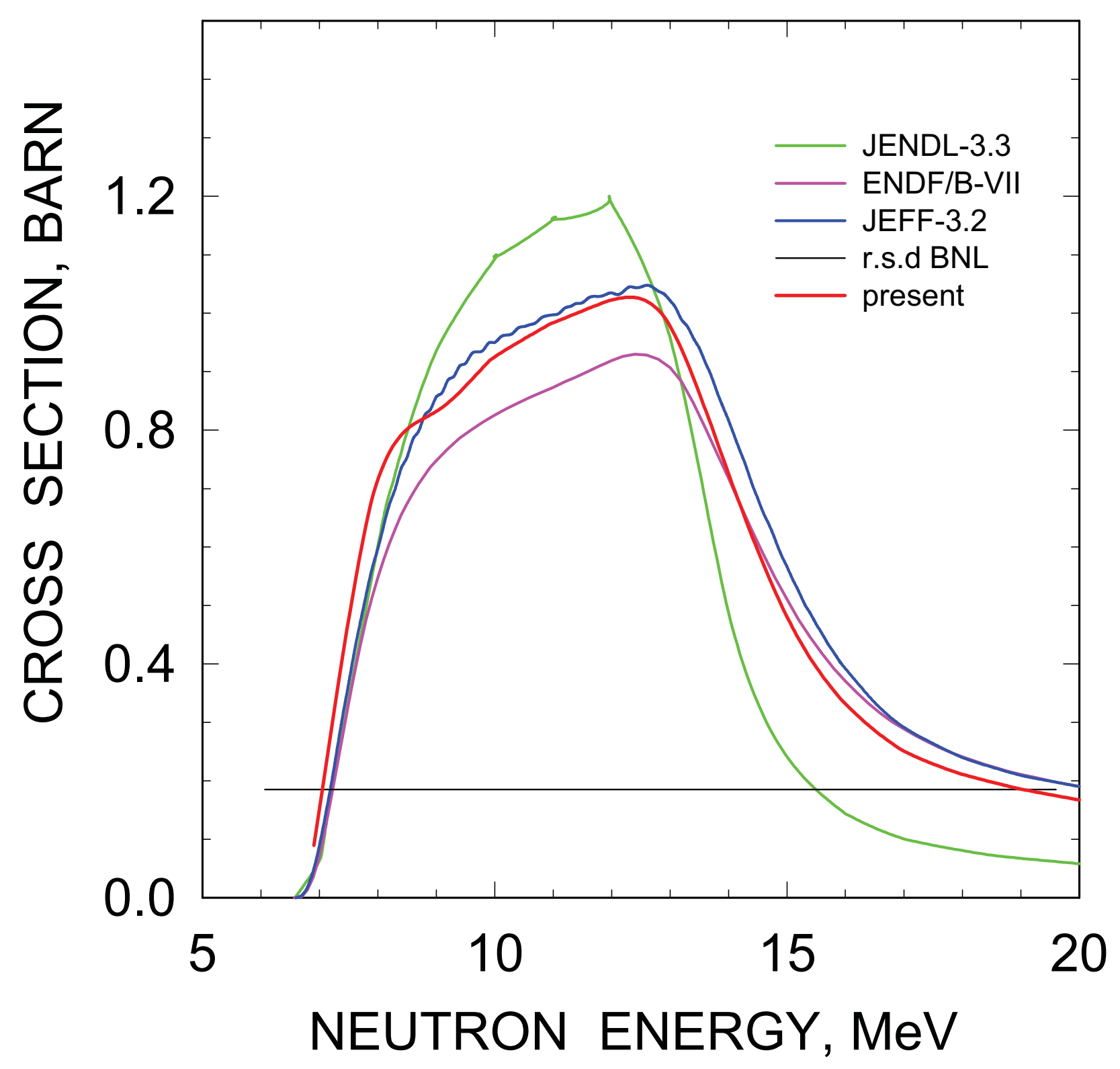


${ }^{234} U(n, 2 n)$ CROSS SECTION

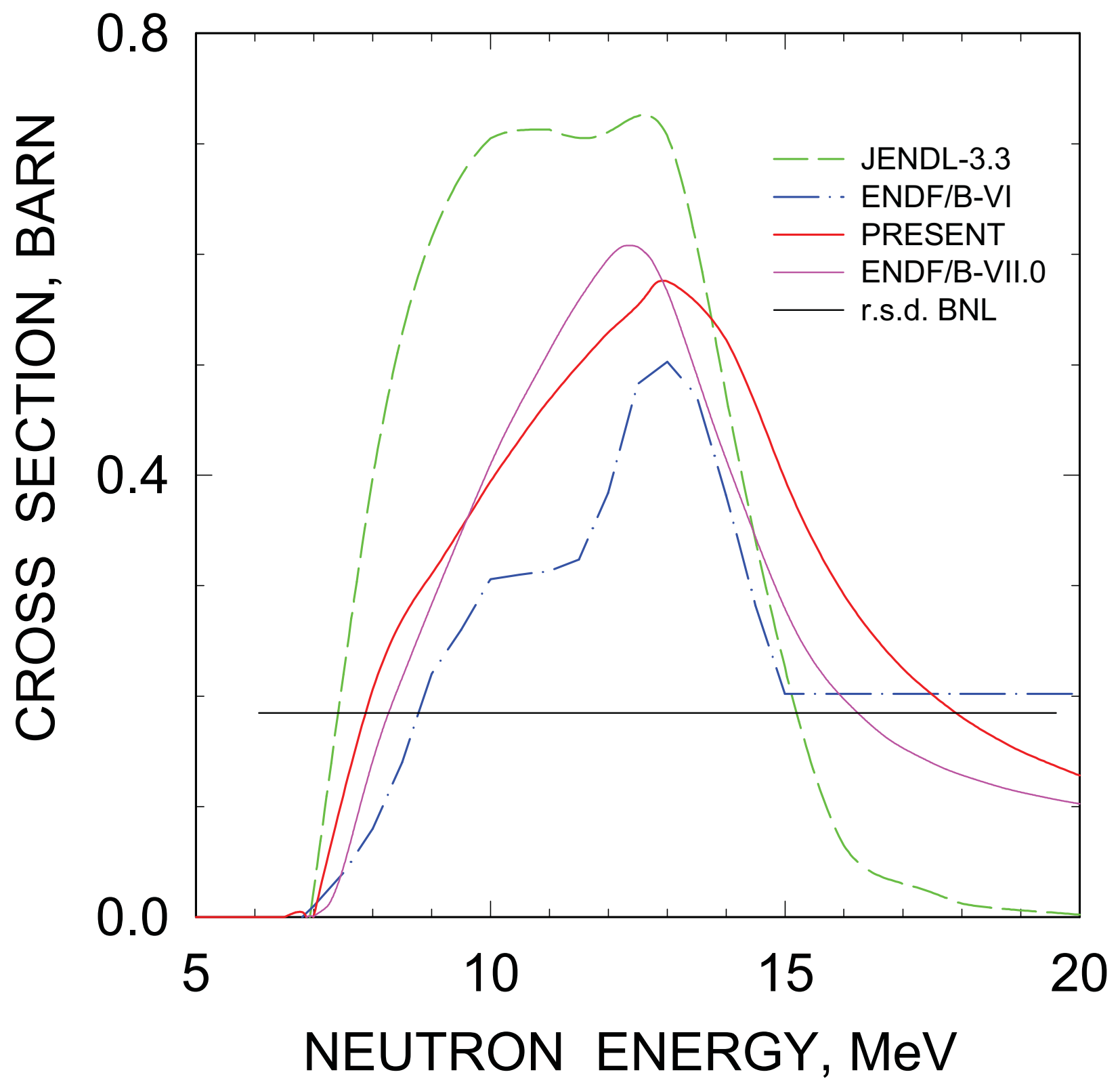




\section{${ }^{238} \mathrm{Pu}(\mathrm{n}, 2 \mathrm{n})$ CROSS SECTION}

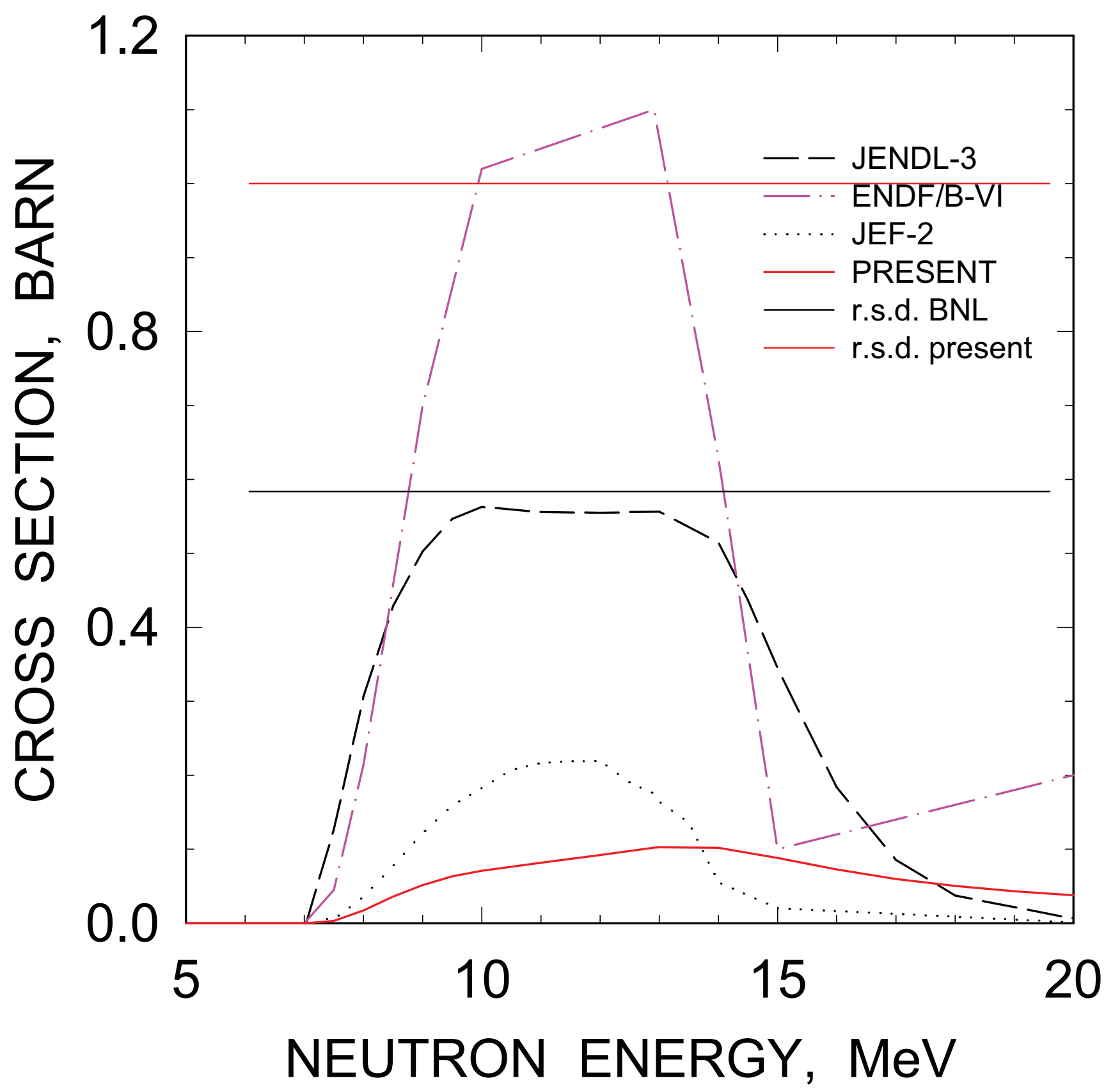


${ }^{240} \mathrm{Pu}(\mathrm{n}, 2 \mathrm{n})$ CROSS SECTION

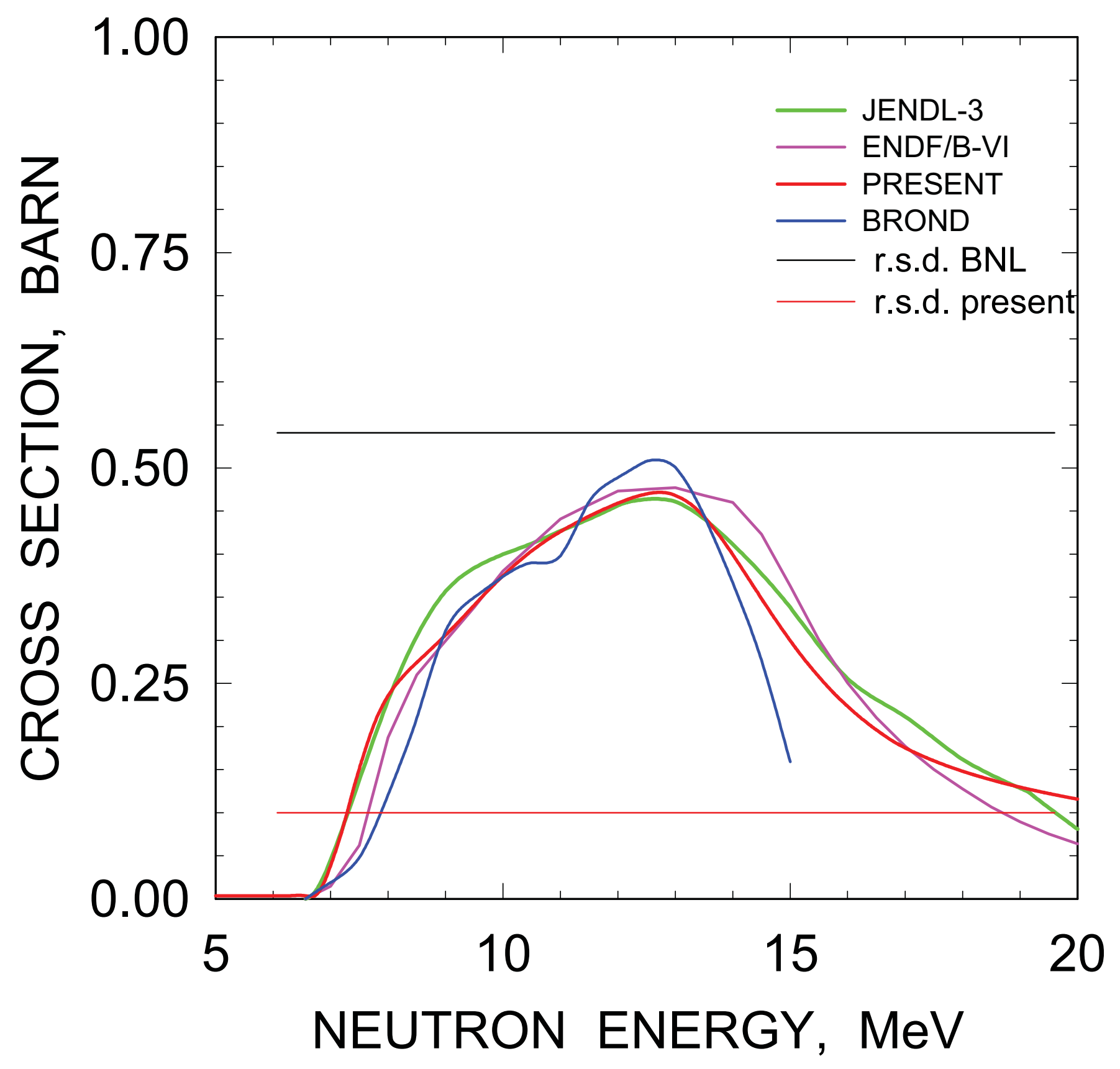


${ }^{242} \mathrm{Pu}(\mathrm{n}, 2 \mathrm{n})$ CROSS SECTION

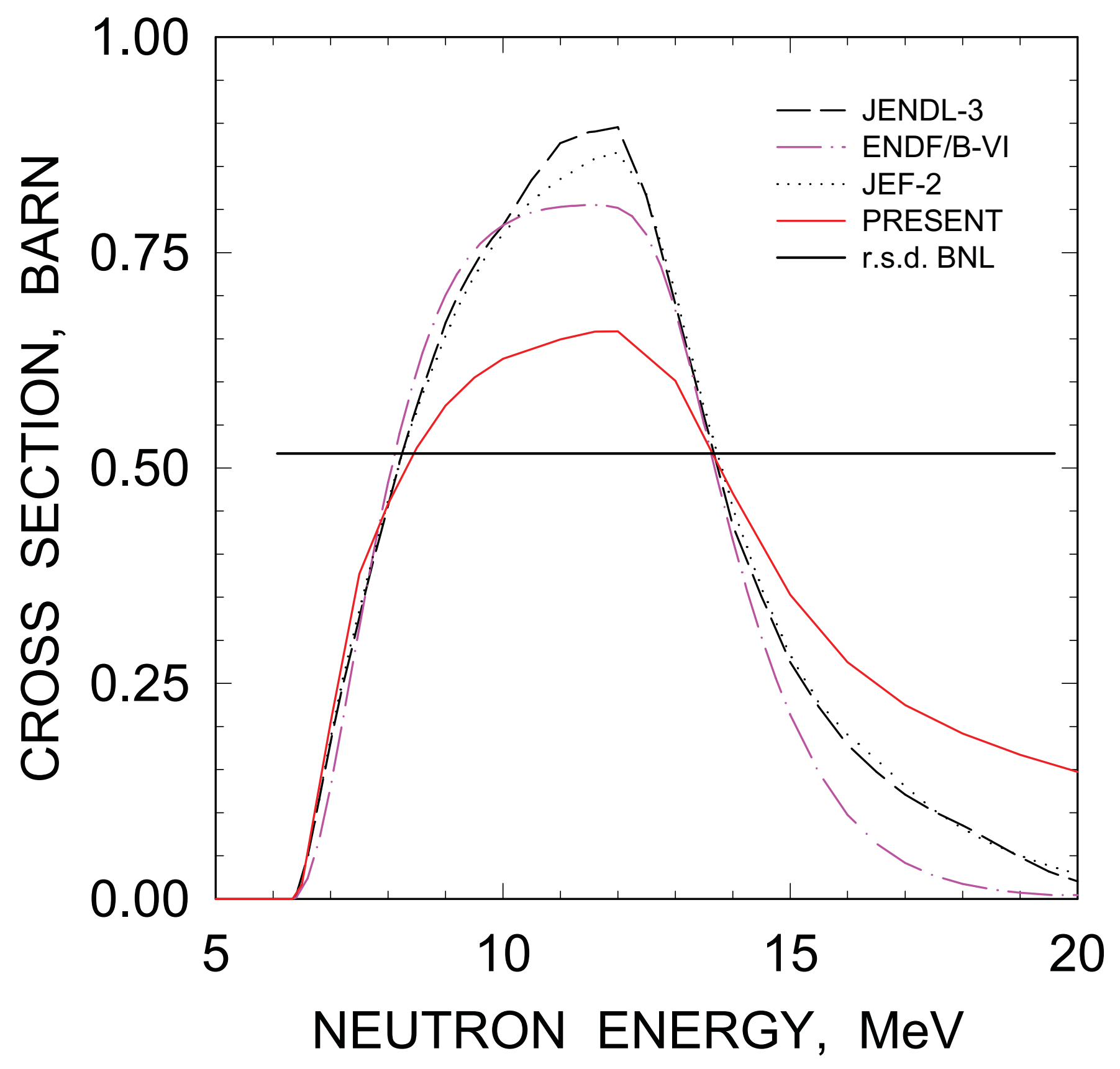


${ }^{242} \mathrm{Cm}(\mathrm{n}, 2 \mathrm{n})$ CROSS SECTION

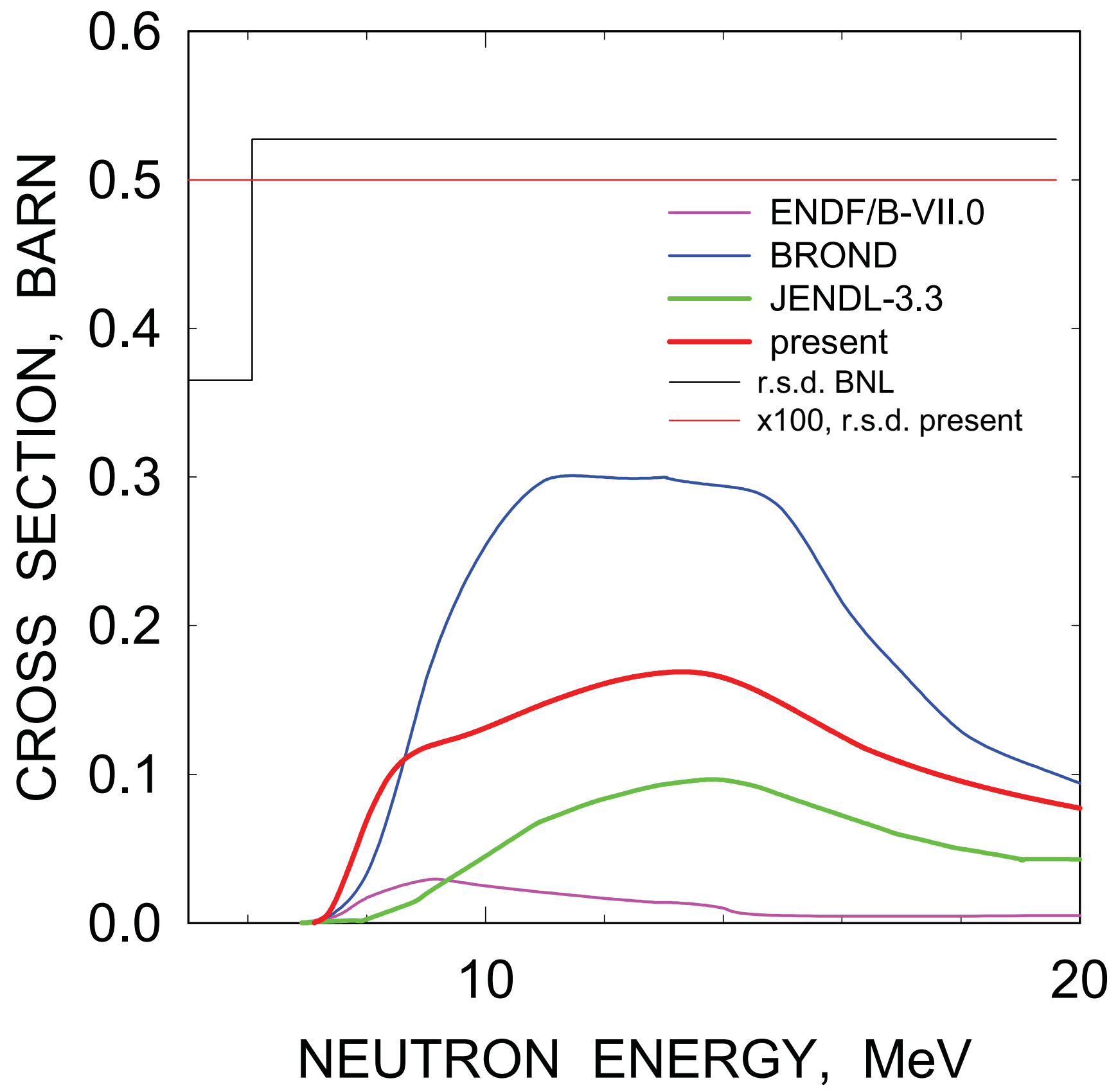


${ }^{244} \mathrm{Cm}(\mathrm{n}, 2 \mathrm{n})$ REACTION CROSS SECTION

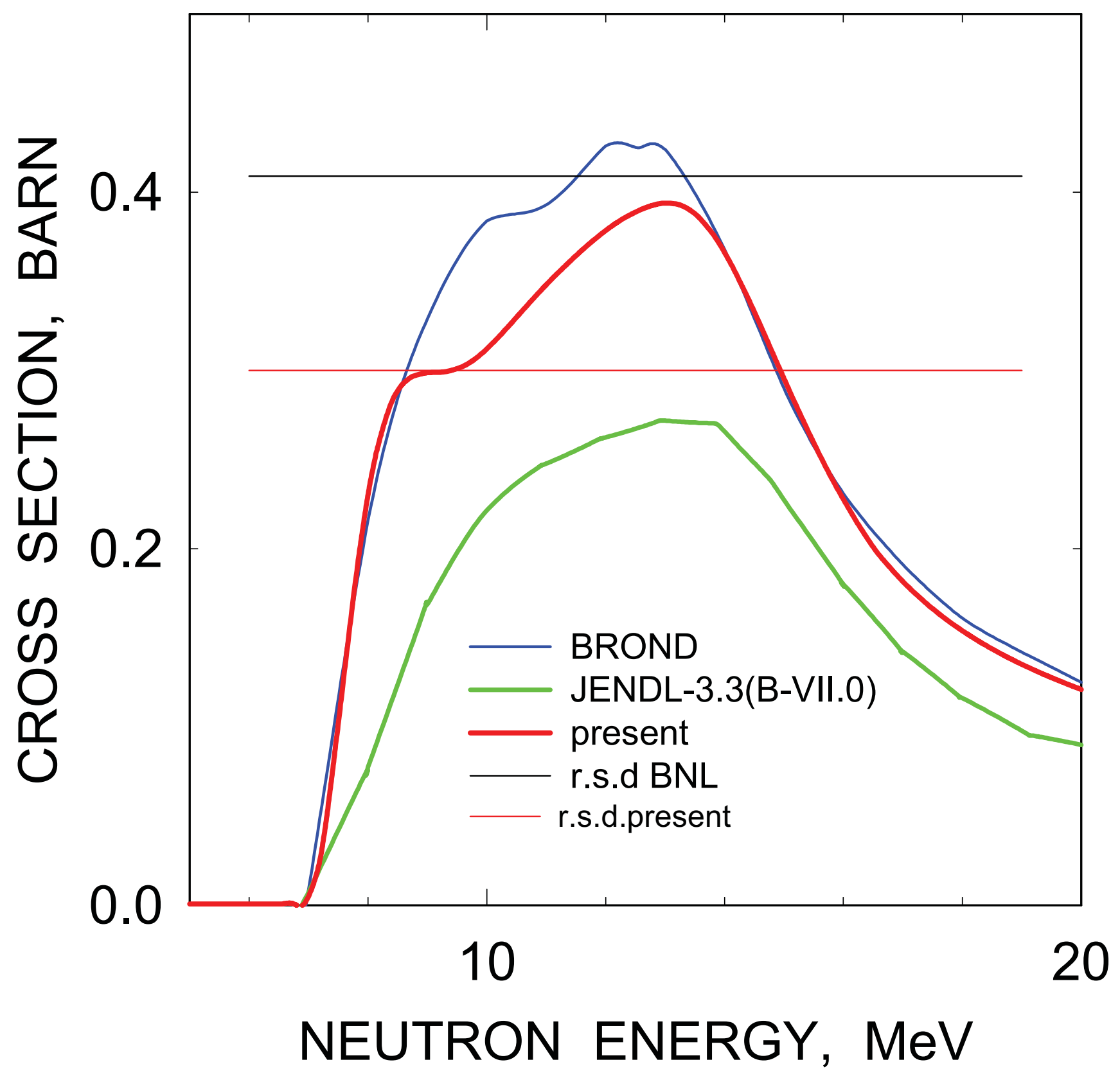




\section{${ }^{235} \mathrm{U}(\mathrm{n}, 2 \mathrm{n})$ CROSS SECTION}

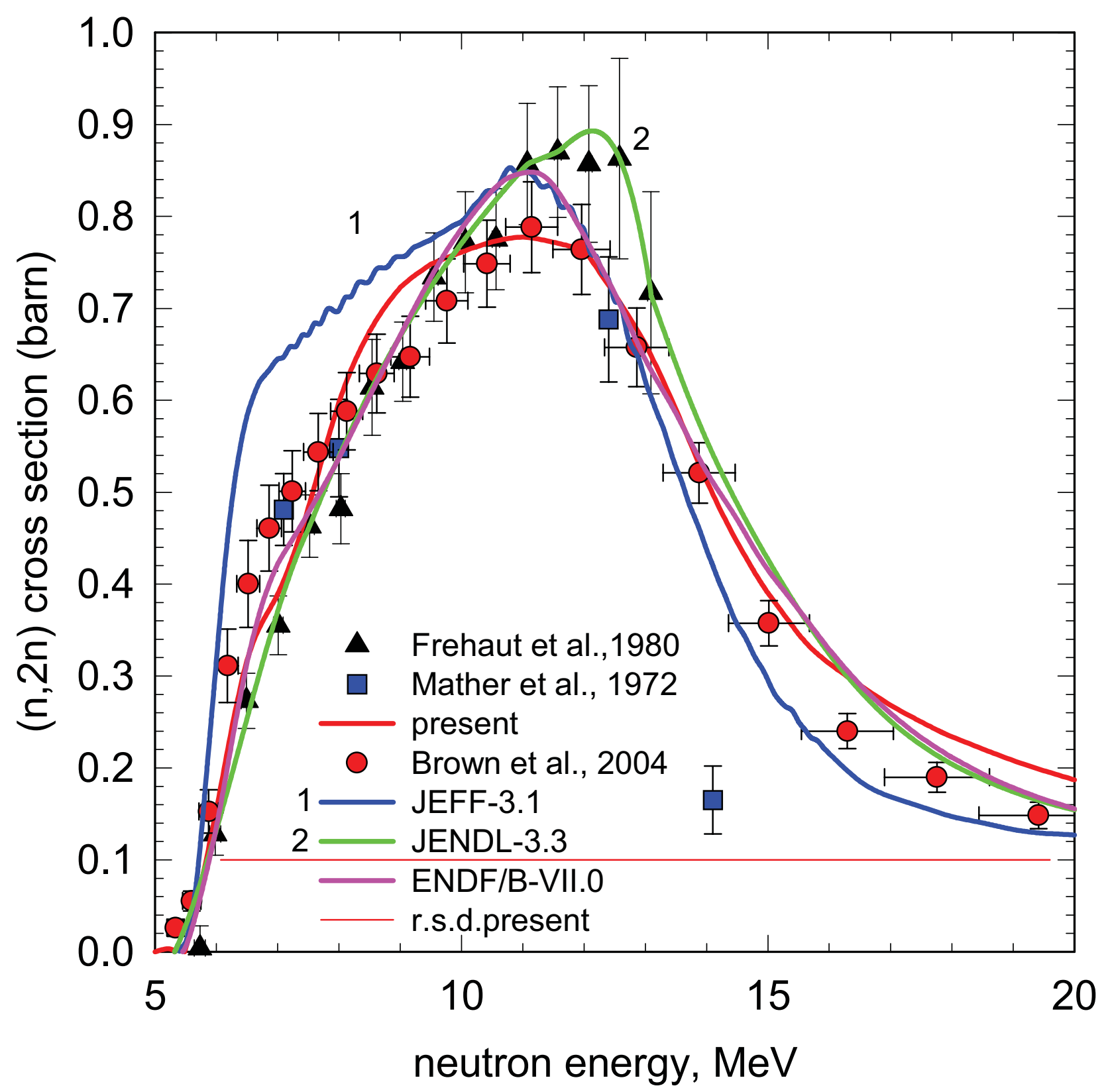




\section{${ }^{233} \mathrm{U}(\mathrm{N}, 2 \mathrm{~N})$ CROSS SECTION}

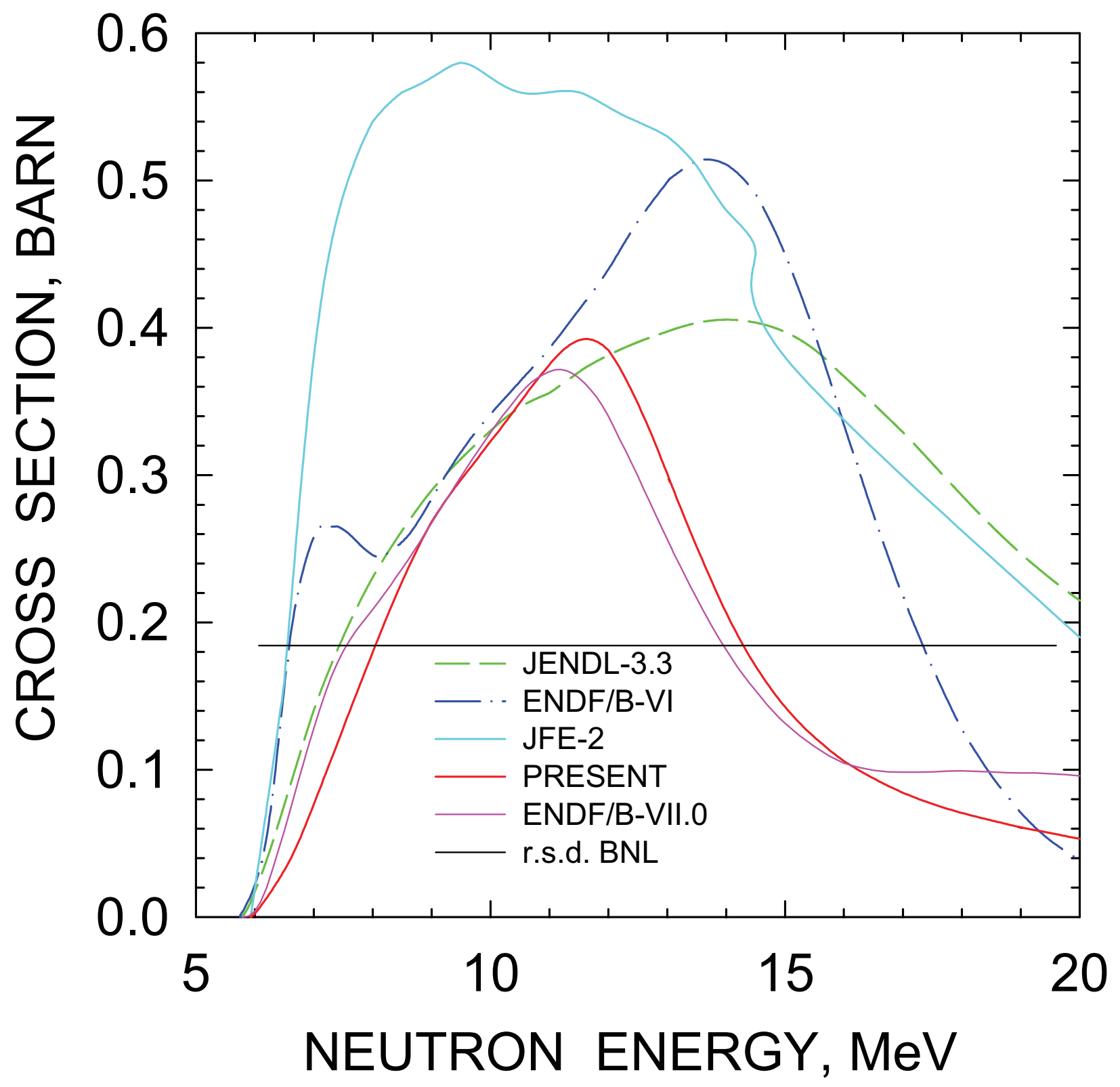




\section{${ }^{239} \mathrm{Pu}(\mathrm{n}, 2 \mathrm{n})$ CROSS SECTION}

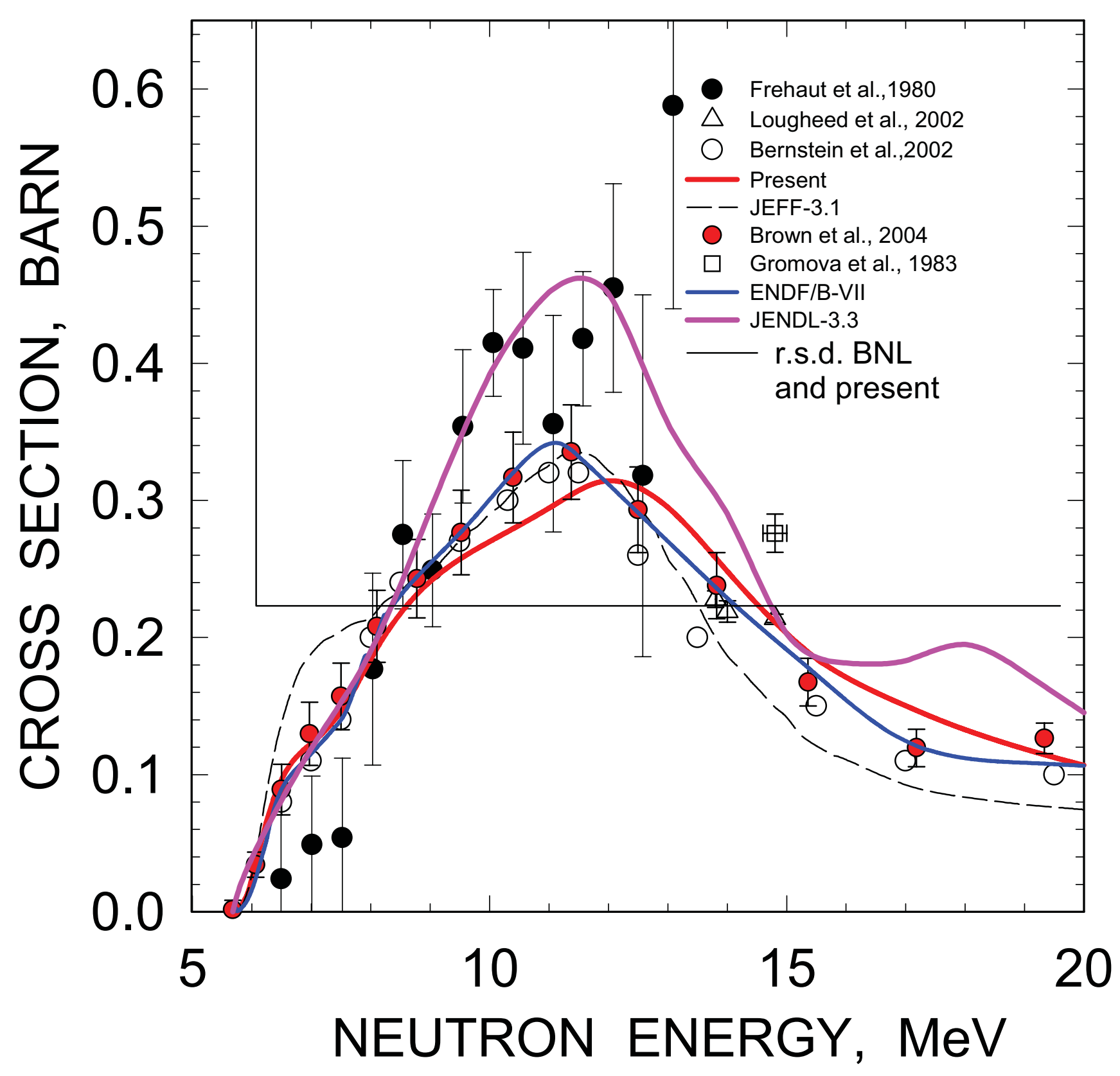


${ }^{241} \mathrm{Pu}(\mathrm{n}, 2 \mathrm{n})$ CROSS SECTION

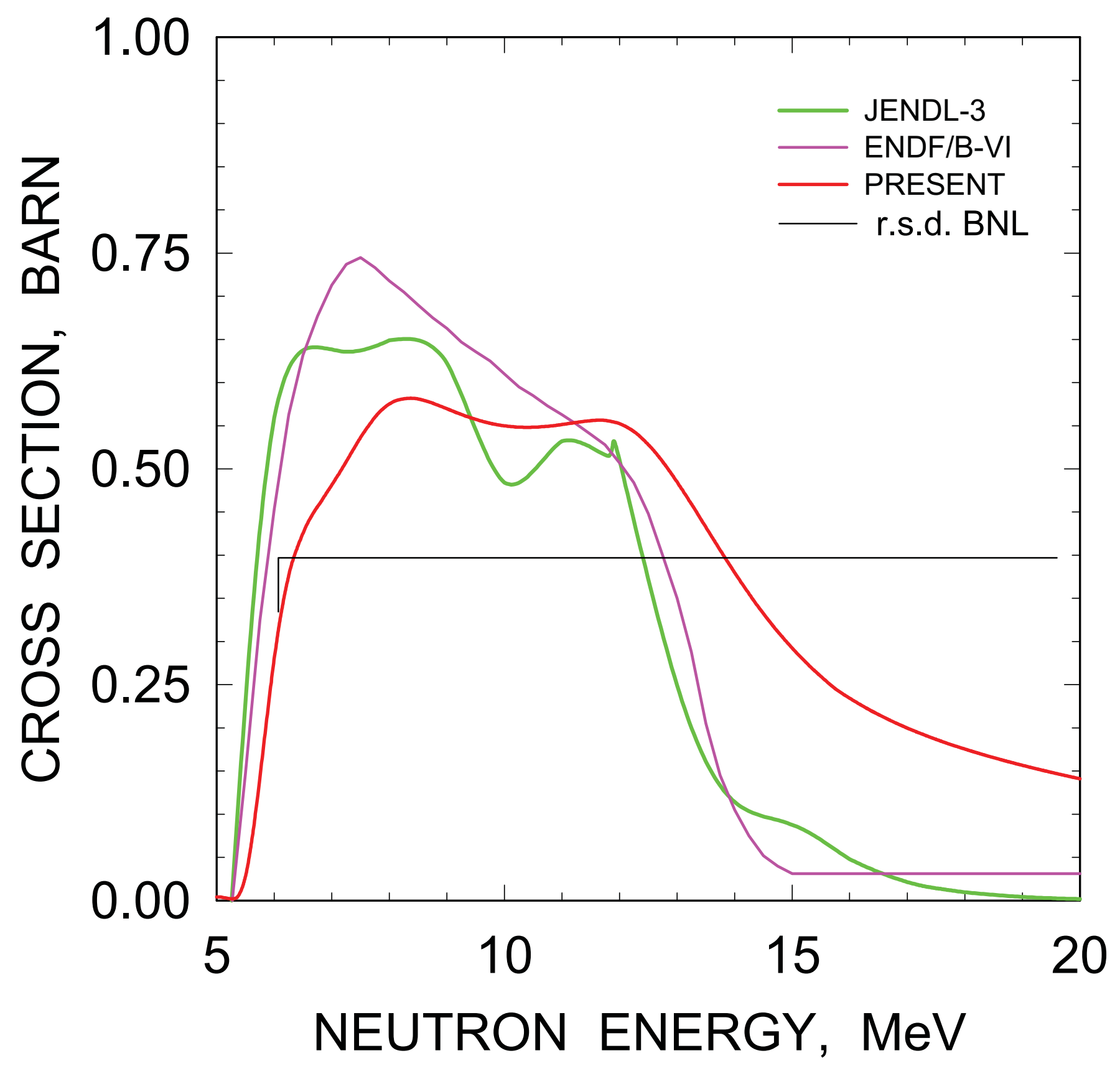


${ }^{243} \mathrm{Cm}(\mathrm{n}, 2 \mathrm{n})$ REACTION CROSS SECTION

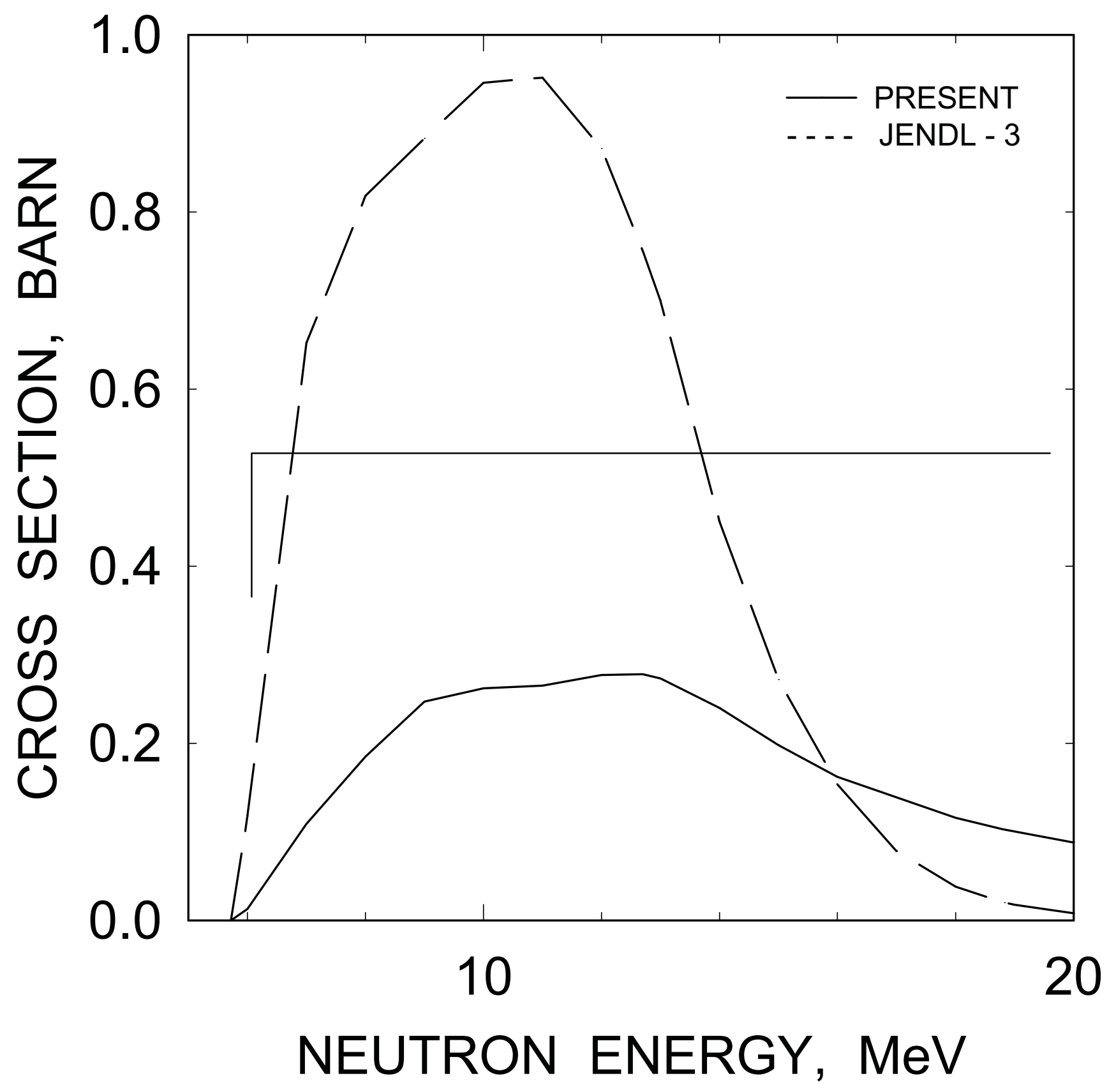




\section{${ }^{245} \mathrm{Cm}(\mathrm{n}, 2 \mathrm{n})$ CROSS SECTION}

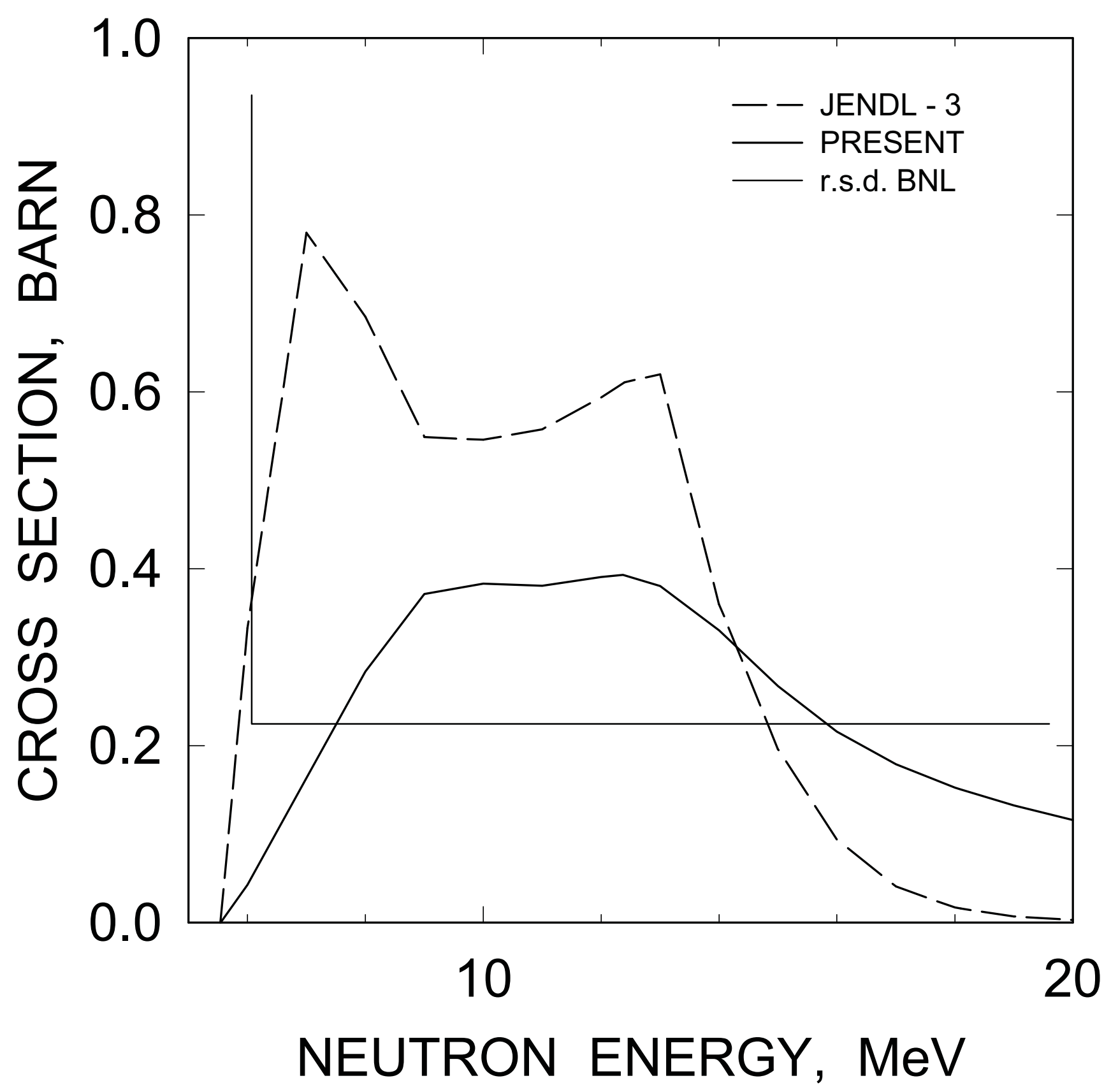




\section{${ }^{237} \mathrm{~Np}(\mathrm{n}, 2 \mathrm{n})$}

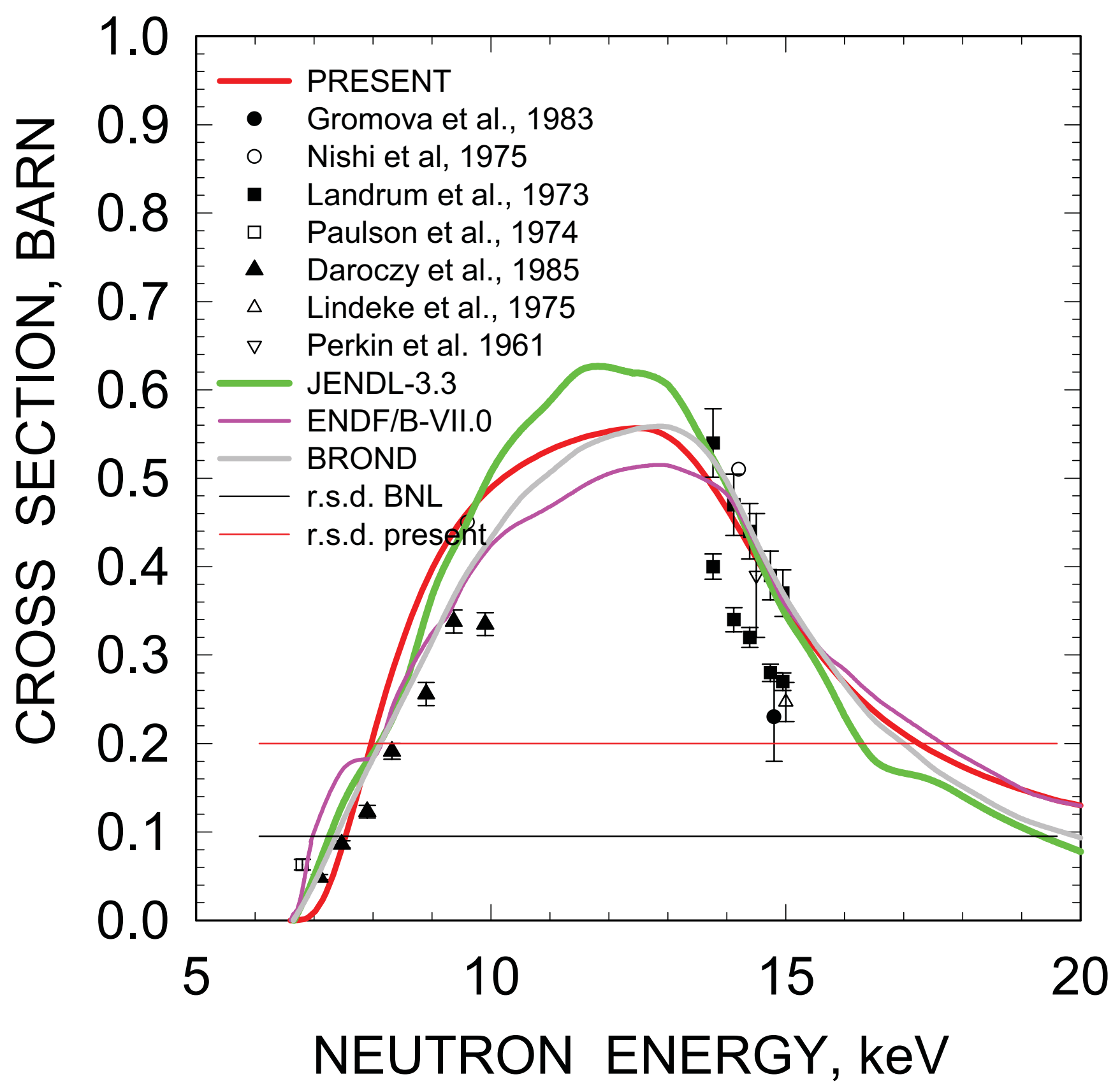


${ }^{241} \mathrm{Am}(\mathrm{n}, 2 \mathrm{2n})$ CROSS SECTION

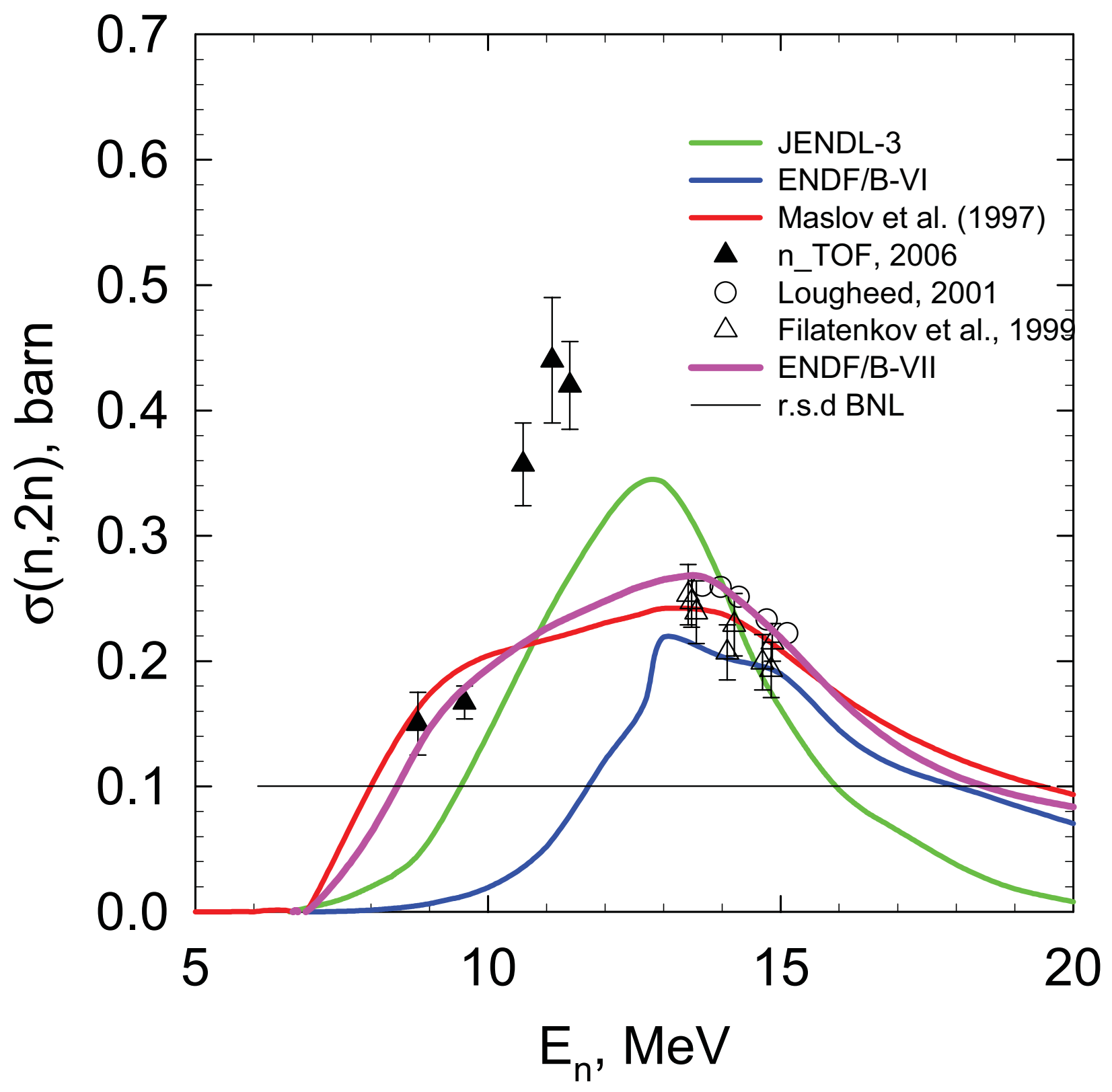


${ }^{243} \mathrm{Am}(\mathrm{n}, 2 \mathrm{n})$ CROSS SECTION

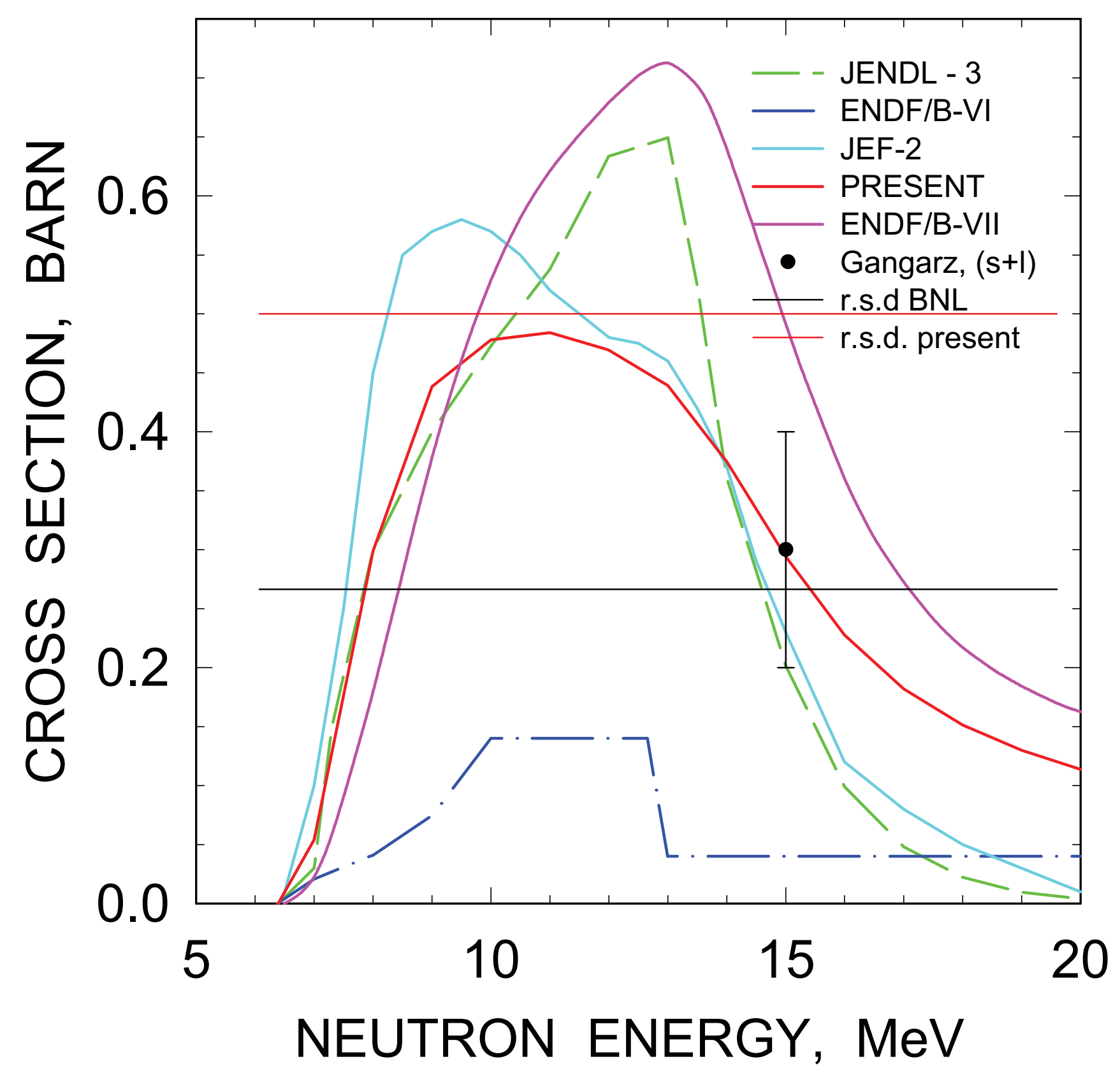




\section{Chapter 7}

\section{Prompt fission neutron multiplicities}

In some cases, described in BNL reports [1,2], the prompt fission neutron multiplicities (nubars) relative standard deviations, based on linear [280] or more complex fits of measured data are too optimistic. Present analysis would be based on the energy balance model, which takes into account the pre-fission ( $\mathrm{n}$, xnf) neutron emission in an approximate, but explicit way. The prompt neutron multiplicity $v_{\mathrm{p}}$ covariance, just as that of fission cross sections, should be strictly "correlated" with the underlying absolute values. That means both $v_{p}$ and r.s.d of $v_{p}$ for neighboring nuclides should be selfconsistent. To follow that "rule" one should interpret the variation of the slope $d v_{p} / d E$ as dependent on (Z,N)-composition of the fissioning nuclides and $E_{n}$ of the incident neutron. Since the linear approximation of $\mathrm{d} v_{\mathrm{p}} / \mathrm{dE}=$ const is often employed in evaluated data files, one should understand the nature of various violations of that simple linear behavior. One of them is encountered in case of ${ }^{232} \mathrm{Th}(\mathrm{n}, \mathrm{F})$ reaction [281-296]. Bump in $v_{\mathrm{p}}$ around $7 \mathrm{MeV}$ is due to the $(\mathrm{n}, \mathrm{nf})$ pre-fission neutrons of second-chance fission reaction. Of similar nature, but less pronounced, effect is anticipated in case of ${ }^{243} \mathrm{Am}(\mathrm{n}, \mathrm{F})$ reaction, while it is missing in case of ${ }^{238} \mathrm{U}(\mathrm{n}, \mathrm{F})[297-301]$ or ${ }^{236} \mathrm{U}(\mathrm{n}, \mathrm{F})[298,302-303]$ reactions.

The pre-equilibrium emission of the (n,nf) pre-fission neutrons of second-chance fission at higher incident neutron energies leads to general decrease of $d v_{p} / d E$, that conclusion is supported by the multiplicity data base, as opposed to Howerton [280] systematic. This effect is important for the error propagation with the incident neutron energy increase. In case of ${ }^{238,240,242} \mathrm{Pu}$ nuclides, ${ }^{240} \mathrm{Pu}$ data are adopted for the BNL covariance files [1, 2] from JENDL-3.3, the r.s.d. in first, second and some lower groups is rather low, since they are compatible with measured data by Khokhlov et al. [304]. For the ${ }^{242} \mathrm{Pu}$ nuclide r.s.d. is even lower, while the discrepancies with measured data of JENDL-3.3 evaluations, which are based on liner extrapolation from low to higher energies, tend to increases. In case of ${ }^{238} \mathrm{Pu}$ nuclide, in JENDL-3.3 Maslov et al. [32] evaluation is adopted, similar approach provides good fit in case of ${ }^{242} \mathrm{Pu}$ as well (Maslov et al. [33] ). These fits are attained by taking into account pre-equilibrium emission of the (n,nf) pre-fission neutrons of second-chance fission. The conclusion is that with increase of the incident neutron energy the r.s.d estimates for ${ }^{238,240,242} \mathrm{Pu}$ nuclides should be correlated with the measured data fits and systematic. The analysis of evaluated curves discrepancies with each other, at high energies and at lower energies, may lead to wrong estimates of r.s.d. for neighbor even nuclides. 
In case of ${ }^{242,243,244,245} \mathrm{Cm}$ nuclei, the estimate of r.s.d. for ${ }^{243} \mathrm{Cm}$ seem to be too optimistic, as compared with that of ${ }^{245} \mathrm{Cm}$. The calculated slope of $\mathrm{d} v_{\mathrm{p}} / \mathrm{dE}=0.135$ for ${ }^{243} \mathrm{Cm}$ is considerably lower than that of Howerton [280] systematic prediction. However, it is consistent with $d v_{p} / d E$ for neighboring nuclei. The Madland-Nix [305] model calculations, used in Maslov et al. [26, 27] evaluation predict non-linear shape of $v_{p}(E)$ above emissive fission threshold. The influence of pre-equilibrium pre-fission neutrons manifests in additional appreciable decrease of $\mathrm{d} v_{\mathrm{p}} / \mathrm{dE}$ above $12 \mathrm{MeV}$.

For ${ }^{238,242} \mathrm{Pu},{ }^{241,242 \mathrm{~m}, 243} \mathrm{Am},{ }^{243,245} \mathrm{Cm}$ our previous analysis (Maslov et al. [23, 24]) was based on Madland-Nix [305] model calculations with pre-equilibrium pre-fission neutron in the exit channel, new analysis, based on the refined treatment of pre-fission neutron emission and energy balance model would be of interest.

In case of ${ }^{241,242 \mathrm{~m}, 243} \mathrm{Am}$ nuclides the r.s.d. estimates also seem to be rather optimistic, having in mind data scatter and increase of the model parameter uncertainties with incident neutron energy increase.

${ }^{232}$ Th: r.s.d are increased in $1^{\text {st }}$ and $2^{\text {nd }}$ groups up to 3 and $5 \%$, respectively, to reflect the differences of ENDF/B-VII.0 evaluated data from measured data and evaluation by Maslov et al. [19] (see Fig. 7.1).

${ }^{238}$ U: r.s.d are left unchanged, since they reflect the differences of ENDF/B-VII.0 evaluated data with measured data and evaluation by Maslov et al. [23] (see Fig. 7.2).

${ }^{236} \mathbf{U}$ : r.s.d are fixed as those of ${ }^{238} \mathrm{U}$, except $1^{\text {st }}, 2^{\text {nd }}$ and $3^{\text {rd }}$ groups, where $3 \%$ values are assumed. That reflect the differences of ENDF/B-VII.0 evaluated data with measured data and previous evaluations (see Fig. 7.3).

${ }^{234} \mathbf{U}$ : r.s.d are fixed as those of ${ }^{236} \mathrm{U}$, except $1^{\text {st }}, 2^{\text {nd }}$ and $3^{\text {rd }}$ groups, where $3 \%$ values are assumed (see Fig. 7.4). That reflects the differences of ENDF/B-VII.0 evaluated data with previous evaluations of JENDL-3.3 and by Maslov et al. [21]. Data by Mather et al. [285] cover only the first chance fission energy range.

${ }^{238} \mathrm{Pu}$ : r.s.d are increased in $1^{\text {st }}$ group to $5 \%$ values, but decreased in other groups. That reflect the differences of ENDF/B-VII.0 evaluated data with evaluation by Maslov et al. [32] (see Fig. 7.5).

${ }^{240} \mathrm{Pu}$ : r.s.d are left unchanged, since they reflect the differences of ENDF/B-VII.0 evaluated data with measured data and previous evaluations (see Fig. 7.6). 
${ }^{242}$ Pu: r.s.d are increased in $1^{\text {st }}$ and $2^{\text {nd }}$ groups, where $10 \%$ and $3 \%$ values are assumed, respectively (see Fig. 7.7). That increase reflects the differences of ENDF/B-VII.0 evaluated data with measured data and previous evaluations.

${ }^{242} \mathrm{Cm}$ : r.s.d are increased roughly up to $10 \%$, to reflect the differences of ENDF/B-VII.0 evaluated data with previous evaluations (see Fig. 7.8).

${ }^{244} \mathrm{Cm}$ : r.s.d are increased roughly up to $10 \%$, to reflect the differences of ENDF/B-VII.0 evaluated data with previous evaluations (see Fig. 7.9).

${ }^{235} \mathbf{U}$ : nu-bar data [286, 306-309] are fitted with an energy balance model by Maslov et al. [10, 11], the partial contributions of (n, xnf) fission chances are distinguished (see Fig. 7.10). The perfect fit above (n, xnf) fission thresholds might be obtained by fine-tuning of nu-bars for the relevant emissive fission chances. That might be helpful for prediction of nu-bars of poorly investigated nuclides. R.s.d. values are left as they are.

${ }^{233} \mathbf{U}$ : nu-bar data [297, 310-320] is fitted with an energy balance model by Maslov et al. [10, 11, 22], the partial contributions of (n, xnf) fission chances are distinguished and compared with those of ${ }^{235} \mathrm{U}(\mathrm{n}, \mathrm{F})$ (see Fig. 7.11). R.s.d. values are left as they are.

${ }^{239}$ Pu: nu-bar data [308] are described with an energy balance model by Maslov et al. [10, 11], the partial contributions of (n, xnf) fission chances are distinguished (see Fig. 7.12). The first iteration curve is shown on the graph. The perfect fit above (n, xnf) fission thresholds might be obtained by finetuning of nu-bars for emissive fission chances. That would be helpful for fitting nu-bar of ${ }^{239} \mathrm{Pu}(\mathrm{n}, \mathrm{f})$ above emissive fission threshold by slight increase of $d v_{p} / d E$ for ${ }^{239} \mathrm{Pu}$ fissioning nuclide. R.s.d. values are left as they are.

${ }^{241}$ Pu: R.s.d. values, based on [308] data fit, are left as they are (see Fig. 7.13).

${ }^{243} \mathrm{Cm}$ : The Madland-Nix [305] model calculations, used in Maslov et al. [26] evaluation, predict non-linear shape of $v_{p}(E)$ above emissive fission threshold, similar to that, predicted for ${ }^{245} \mathrm{Cm}(\mathrm{n}, \mathrm{F})(\mathrm{see}$ Fig. 7.14). The influence of pre-equilibrium pre-fission neutrons manifests in additional appreciable decrease of $\mathrm{d} v_{\mathrm{p}} / \mathrm{dE}$ above $12 \mathrm{MeV}$. R.s.d. values are left as they are.

${ }^{245} \mathrm{Cm}$ : The Madland-Nix [305] model calculations, used in Maslov et al. [27] evaluation of measured data [304, 321-323] predict non-linear shape of $v_{\mathrm{p}}(\mathrm{E})$ above emissive fission threshold (see Fig. 7.15). The influence of pre-equilibrium pre-fission neutrons manifests in additional appreciable decrease of $\mathrm{d} v_{\mathrm{p}} / \mathrm{dE}$ above $12 \mathrm{MeV}$. R.s.d. values are left as they are. 
${ }^{237} \mathbf{N p}$ : nu-bar data [304, 306, 289, 325] are roughly reproduced with an energy balance model $[10,11]$, the partial contributions of (n, xnf) fission chances are distinguished (see Fig. 7.16). Better fit might be obtained by fine-tuning of nu-bars for emissive fission chances. R.s.d. values are increased in the first group to reflect the non-linear slope of nu-bar.

${ }^{241}$ Am: nu-bar data [304, 322, 324] is reproduced with an energy balance model by [10, 11], the partial contributions of (n, xnf) fission chances are distinguished (see Fig. 7.17). Better fit might be obtained by fine-tuning of nu-bars for emissive fission chances. Present fit it rather different from the previous evaluation by Maslov et al. [17]. R.s.d. values should be assumed equal to 3\% over the whole energy range to reflect the non-linear slope of nu-bar and data spread.

${ }^{243} \mathrm{Am}$ : nu-bar of ENDF/B-VII.0 is quite compatible with Maslov et al. evaluation [18] and measured data by Frehaut er al. [326], revealing the systematic error in Khohlov et al. [304] in ${ }^{241} \mathrm{Am}(\mathrm{n}, \mathrm{F})$ reaction as well (see Fig. 7.18). R.s.d. values are left as they are.

${ }^{242 m} \mathrm{Am}$ : nu-bar of ENDF/B-VII.0 is adopted from the evaluation by Maslov et al. evaluation [30], which is based on [321, 322, 327, 328] data description (see Fig. 7.19). R.s.d. values are left as they are. 


\section{${ }^{232} \mathrm{Th}(\mathrm{n}, \mathrm{F})$, PROMPT NEUTRON MULTIPLICIY}

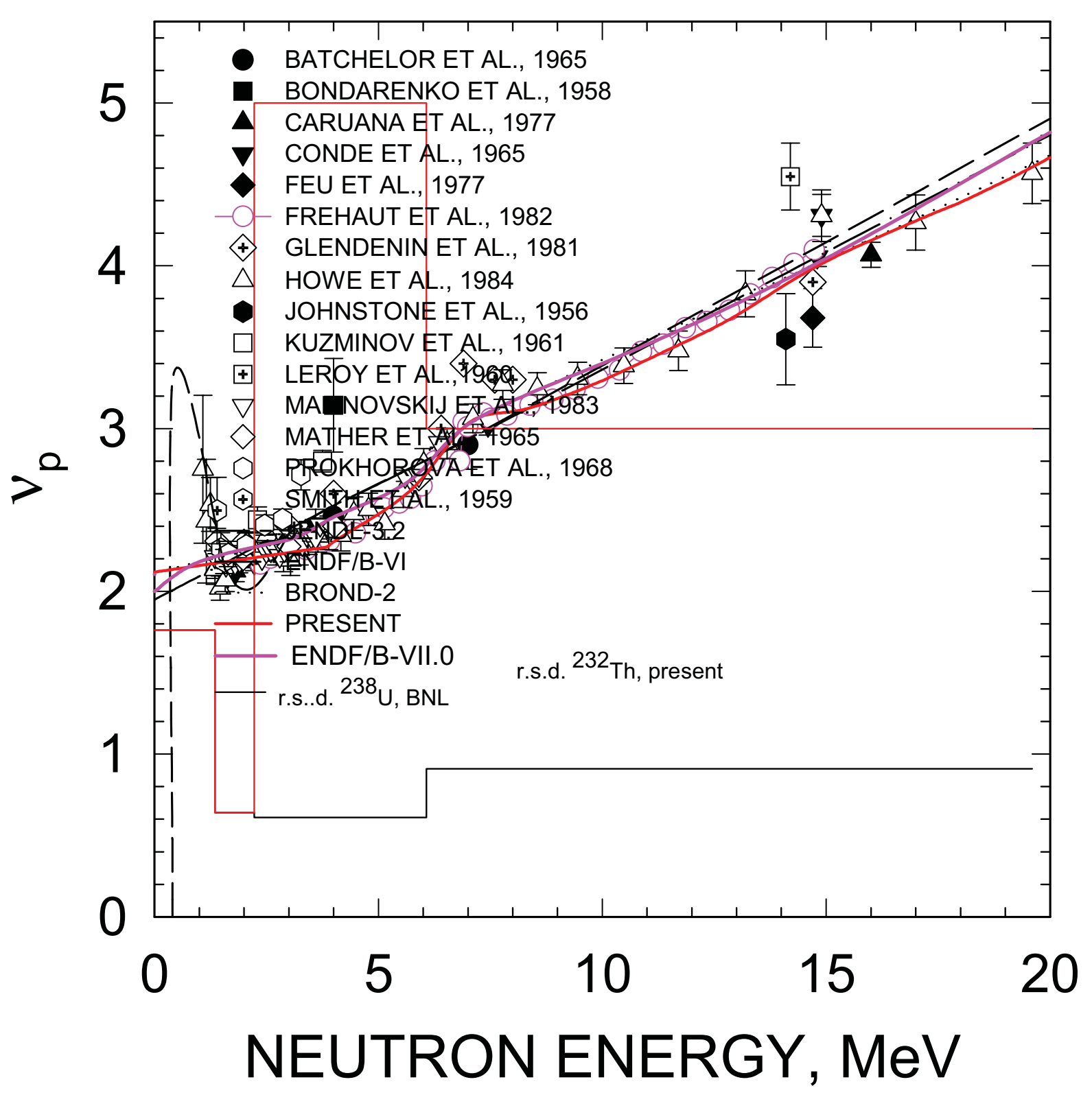


${ }^{232}$ Th(n,F) PROMPT NEUTRON MULTIPLICITY

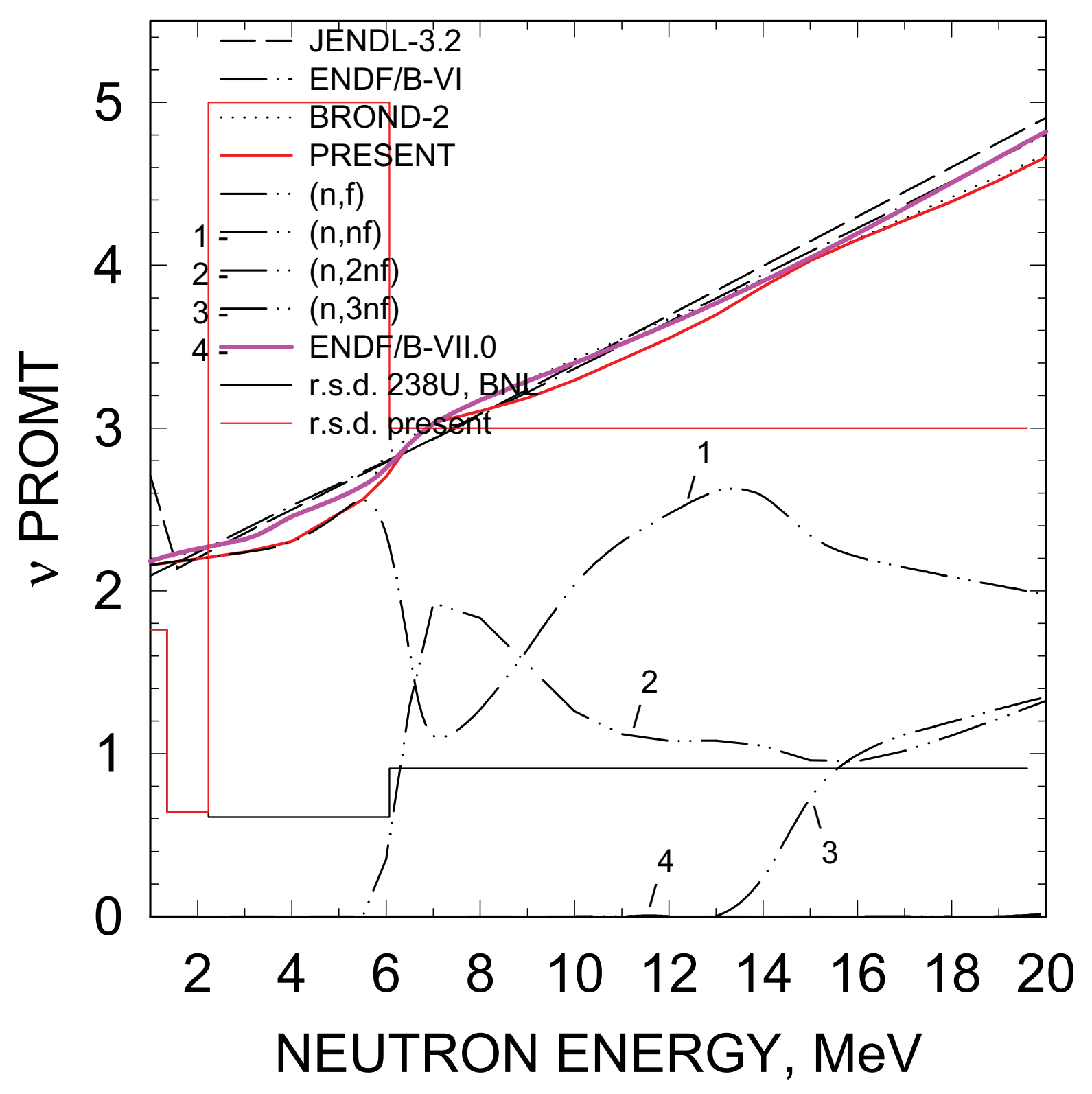




\section{${ }^{238} \mathrm{U}(\mathrm{n}, \mathrm{F})$ PROMPT NEUTRON MULTIPLICITY}

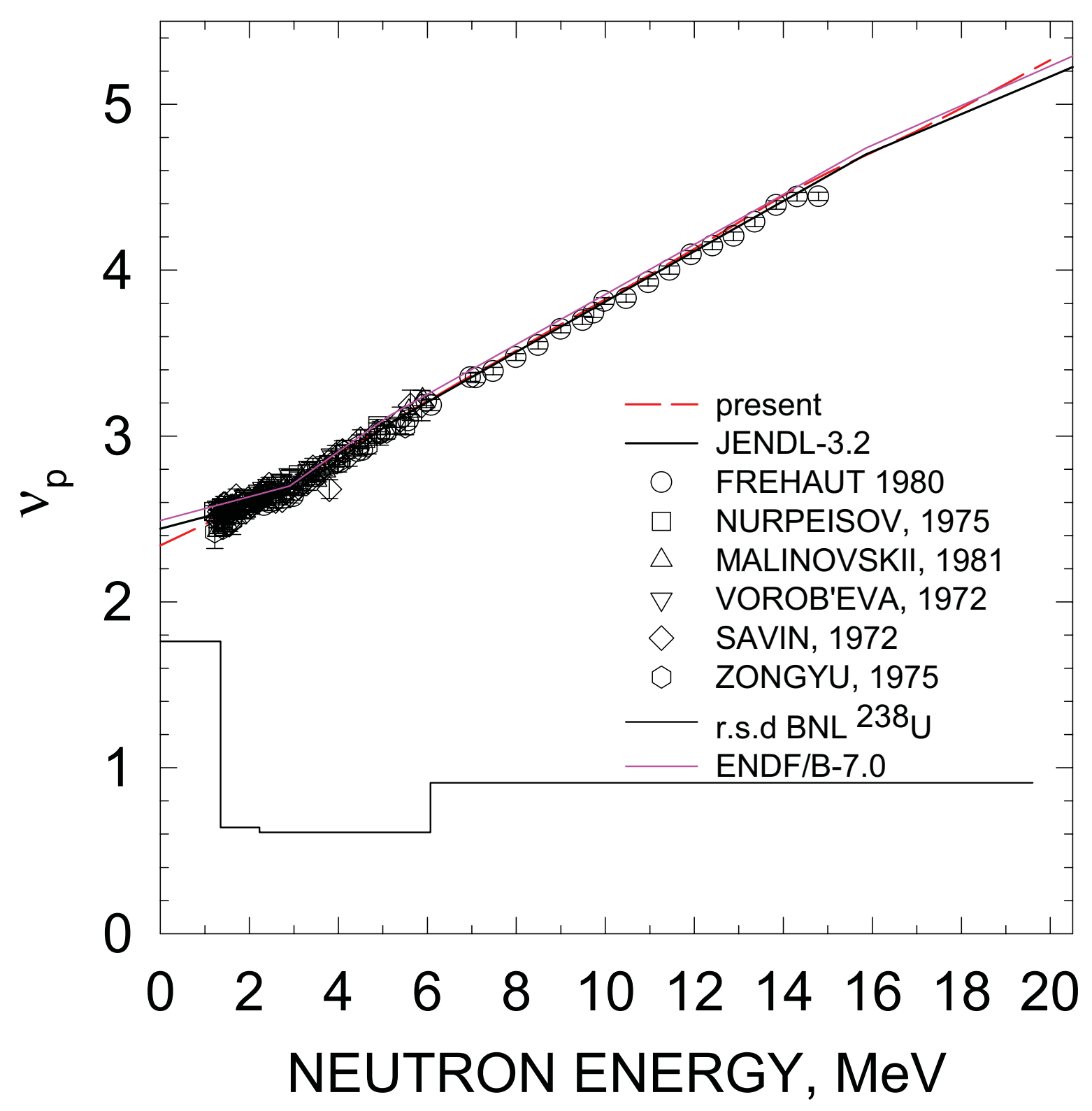




\section{${ }^{236} \mathrm{U}(\mathrm{n}, \mathrm{F})$ PROMPT NEUTRON MULTIPLICITY}

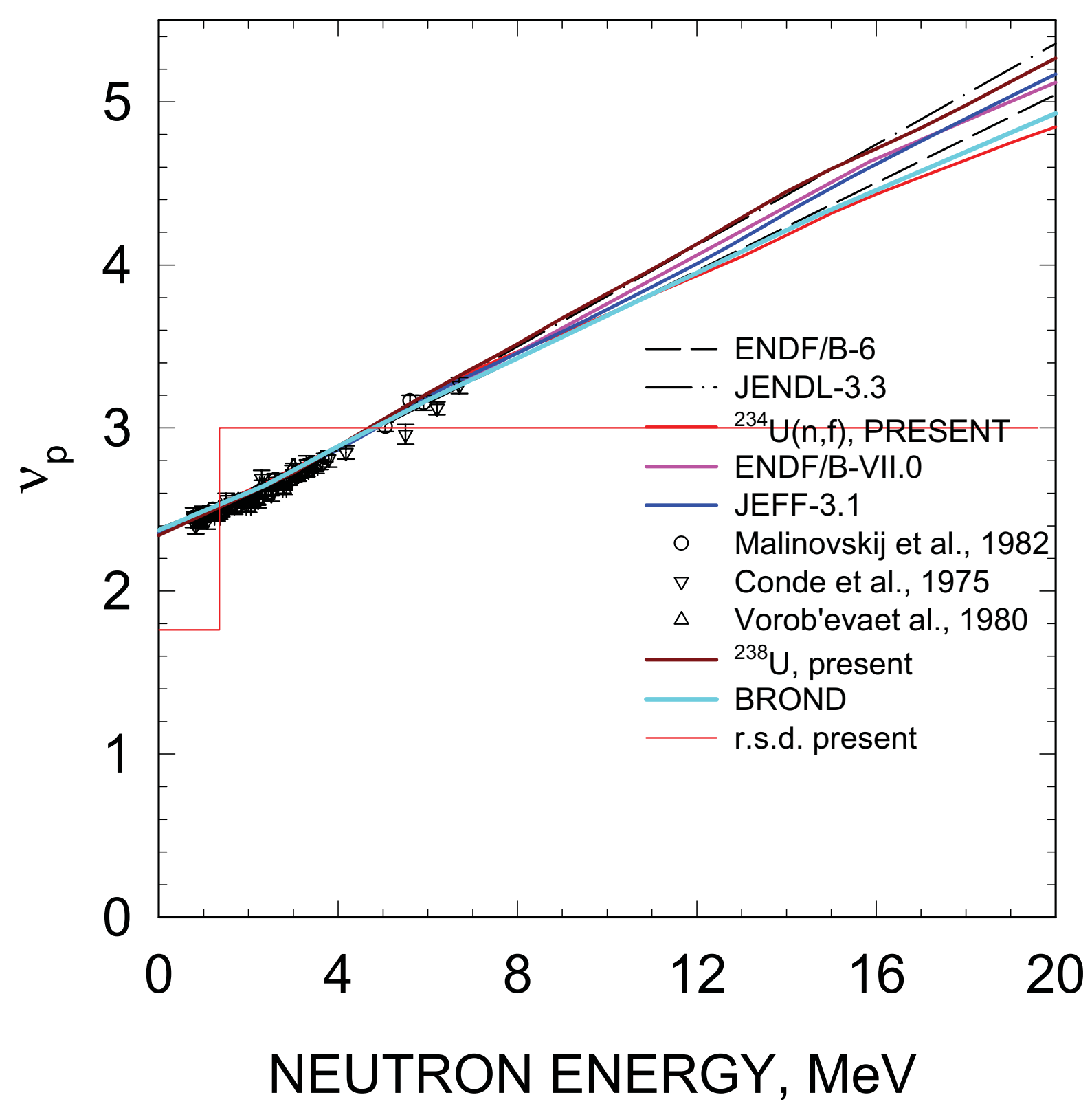




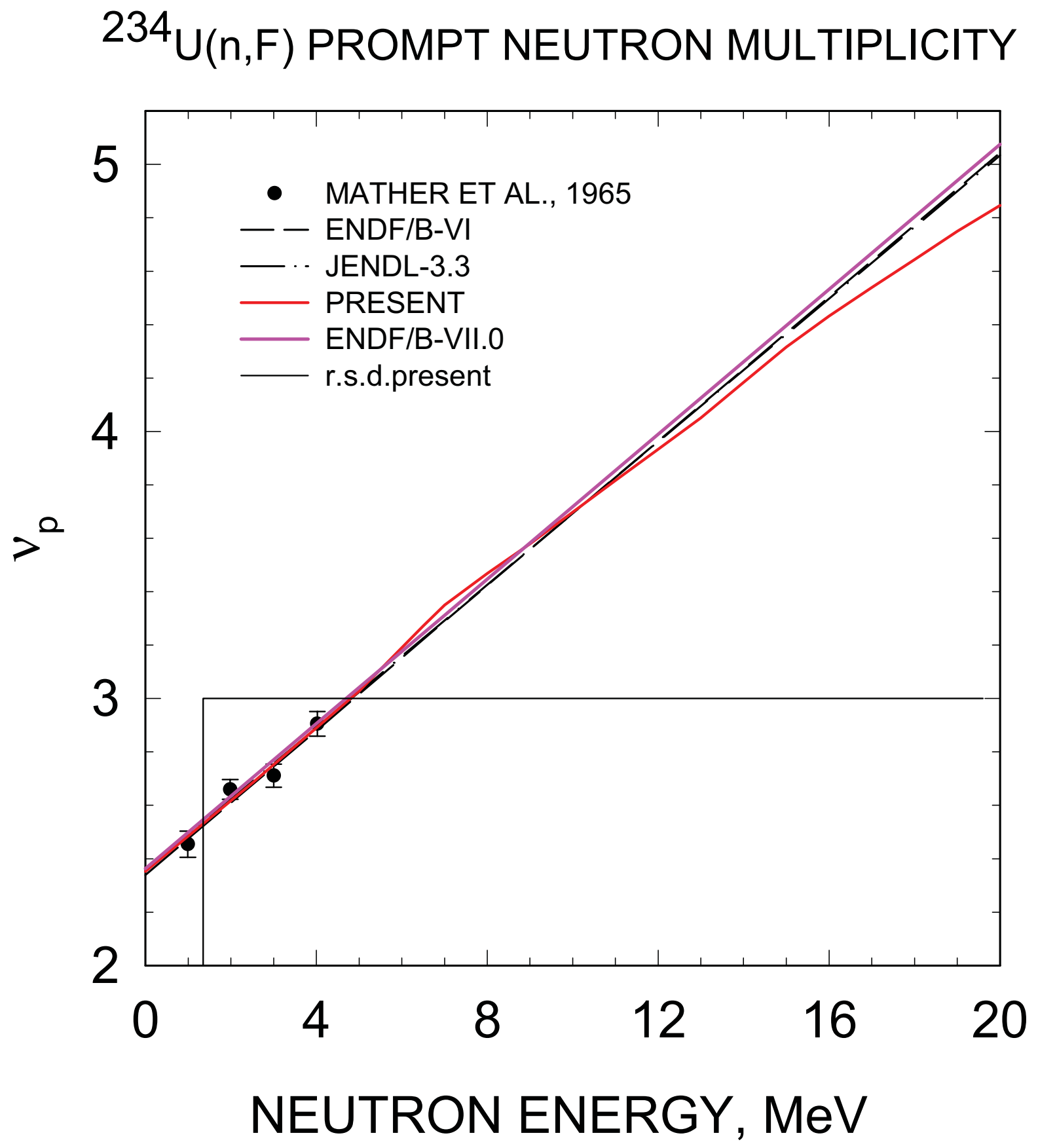


${ }^{238} \mathrm{Pu}(\mathrm{n}, \mathrm{F})$ PROMPT NEUTRON MULTIPLICITY

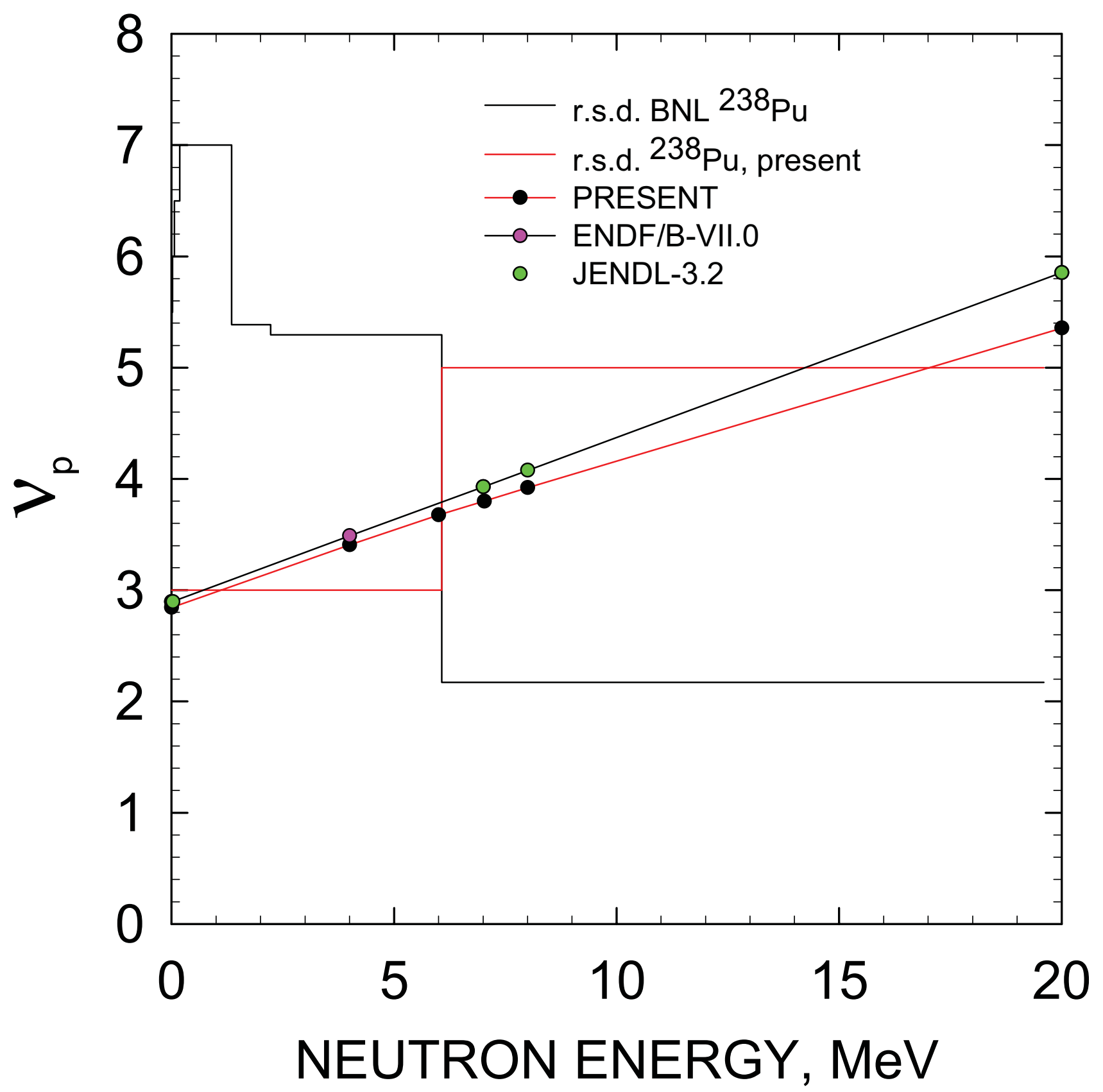


240

Pu(n,F) PROMPT NEUTRON MULTIPLICITY

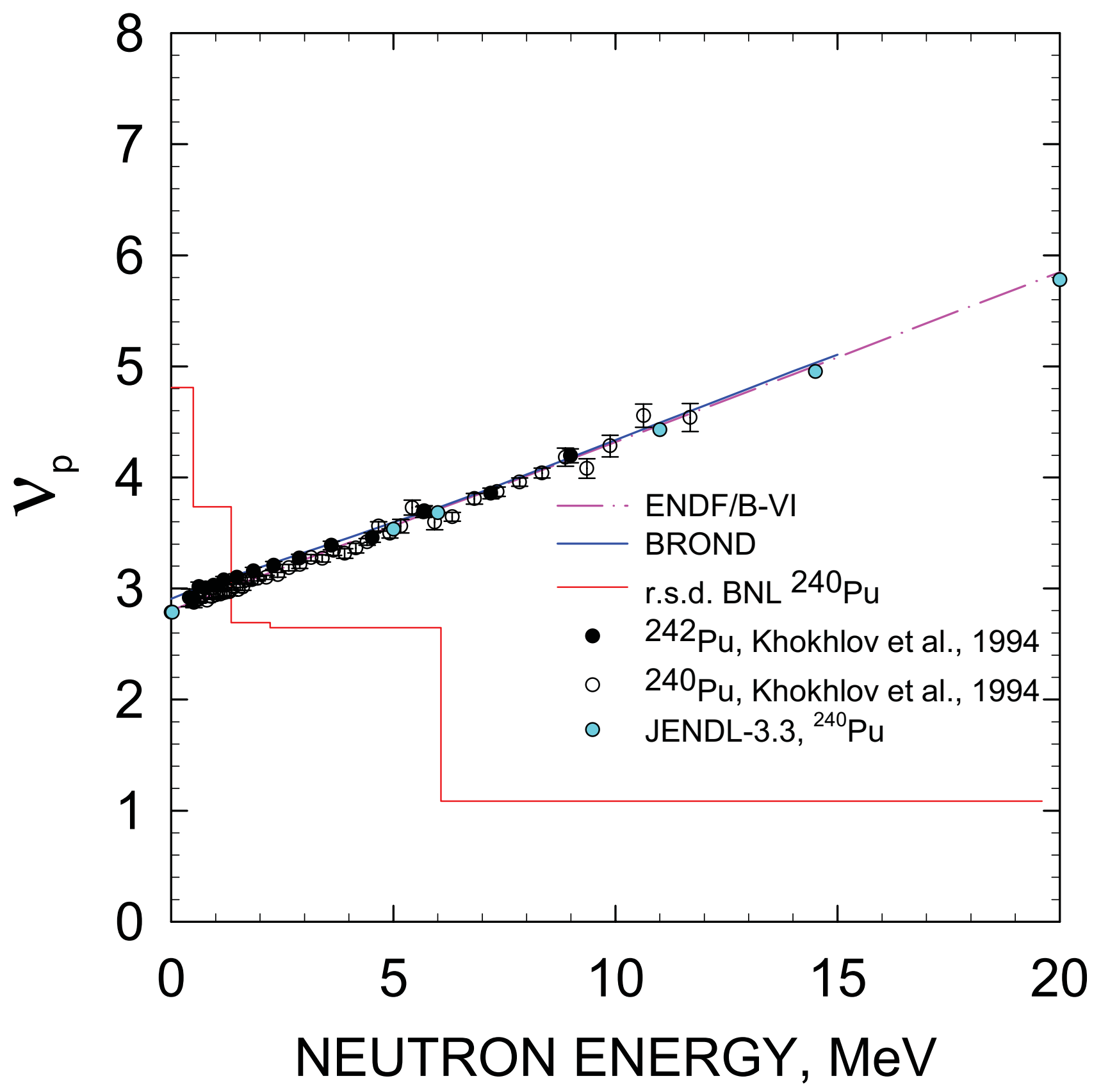




\section{${ }^{242} \mathrm{Pu}(\mathrm{n}, \mathrm{F})$ PROMPT NEUTRON MULTIPLICITY}

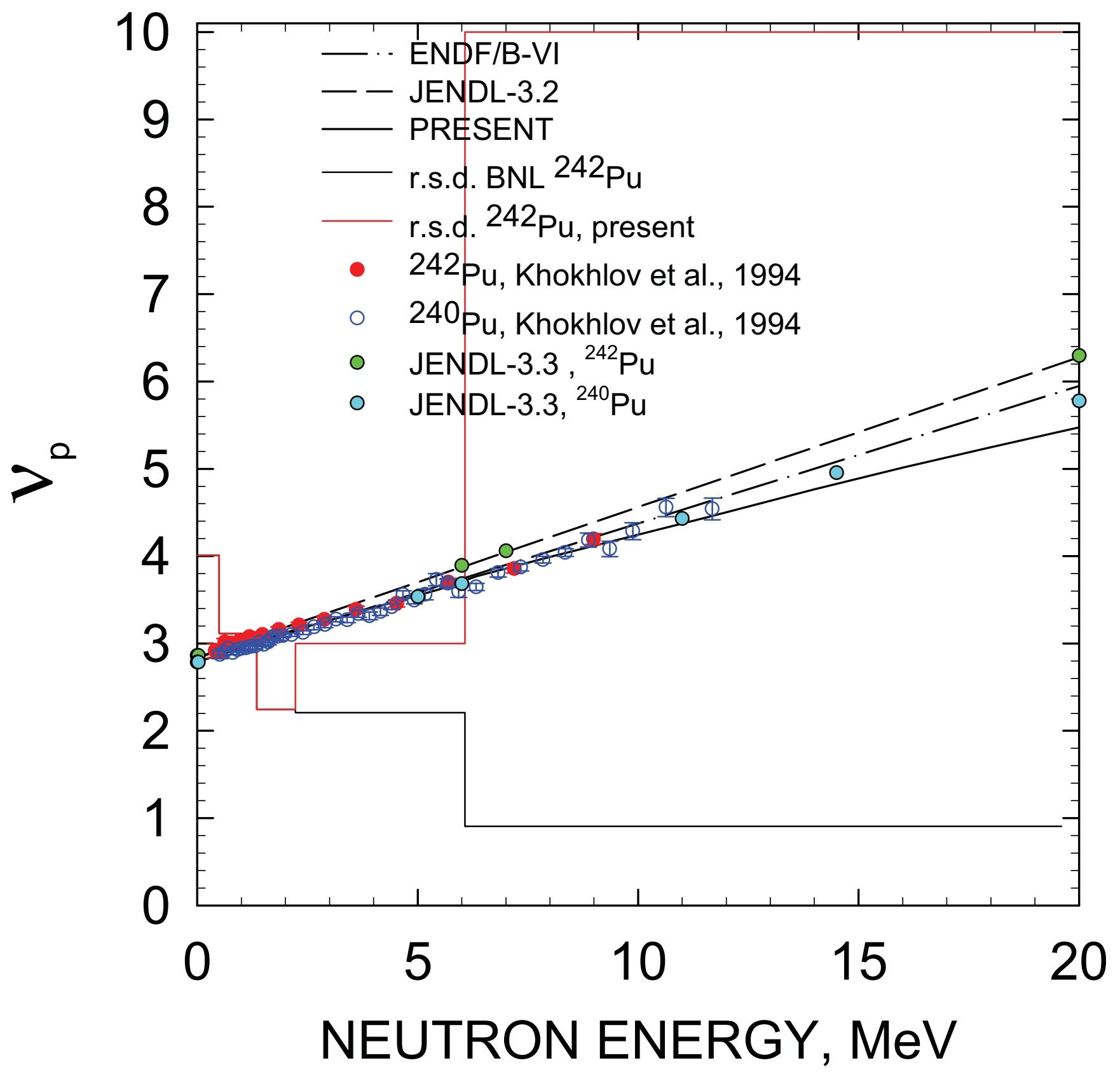




\section{${ }^{242} \mathrm{Cm}(\mathrm{n}, \mathrm{F})$ PROMPT NEUTRON MULTIPLICITY}

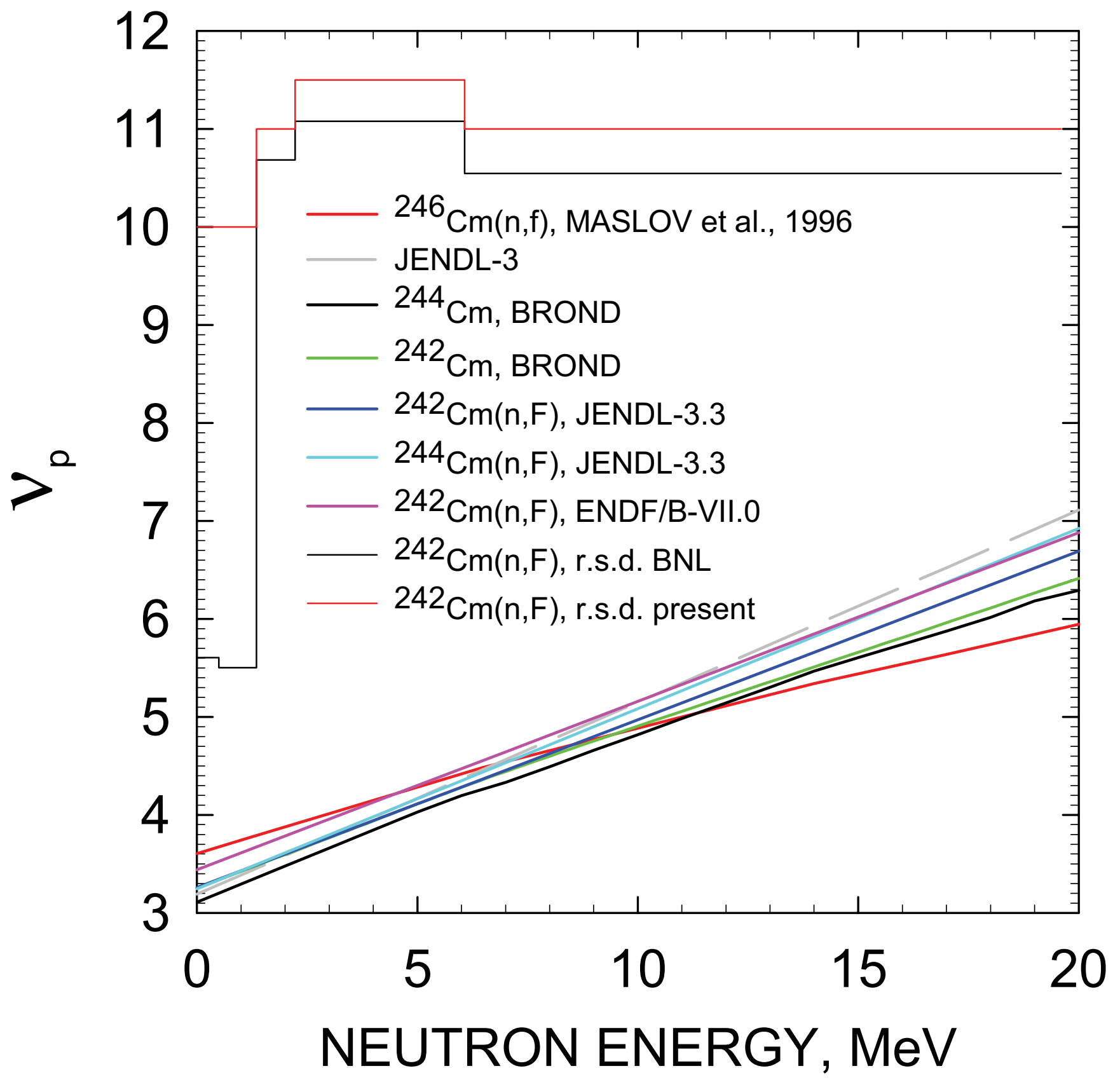




\section{${ }^{244} \mathrm{Cm}(\mathrm{n}, \mathrm{F})$ PROMPT NEUTRON MULTIPLICITY}

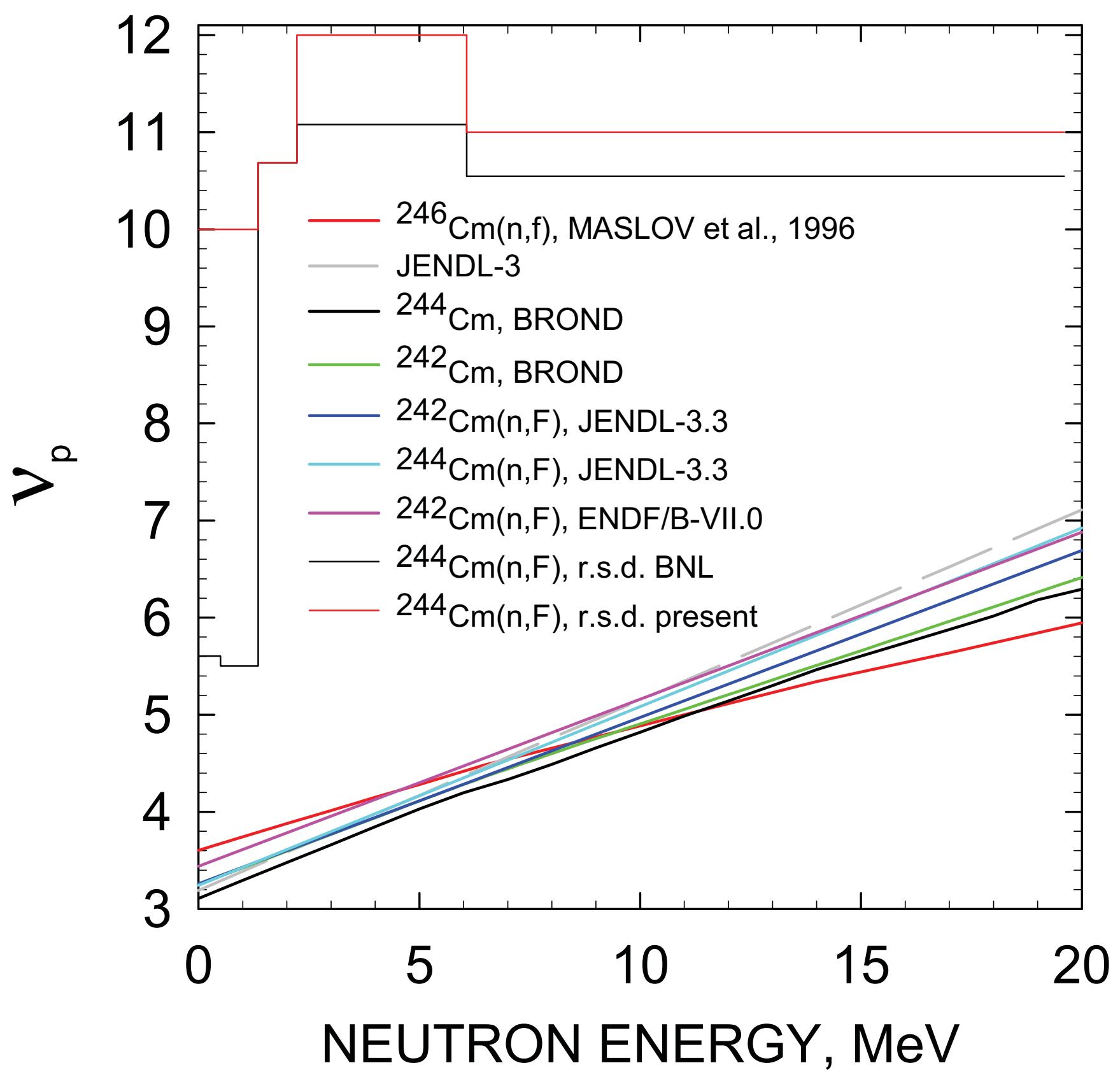




\section{${ }^{235} \mathrm{U}(\mathrm{n}, \mathrm{F})$ PROMPT NEUTRON MULTIPLICIY}

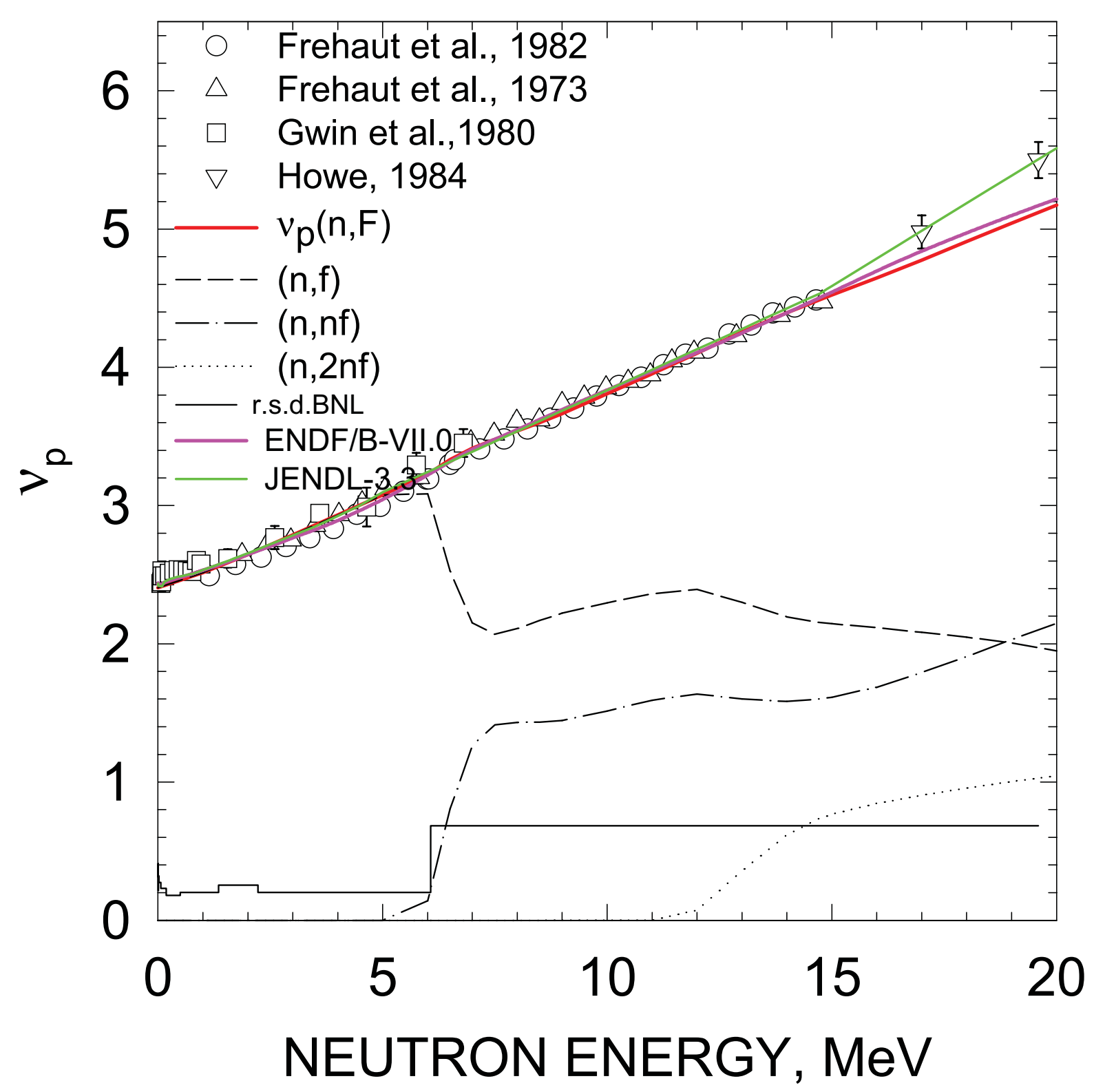




\section{${ }^{233} U(n, F)$ PROMPT NEUTRON MULTIPLICITY}

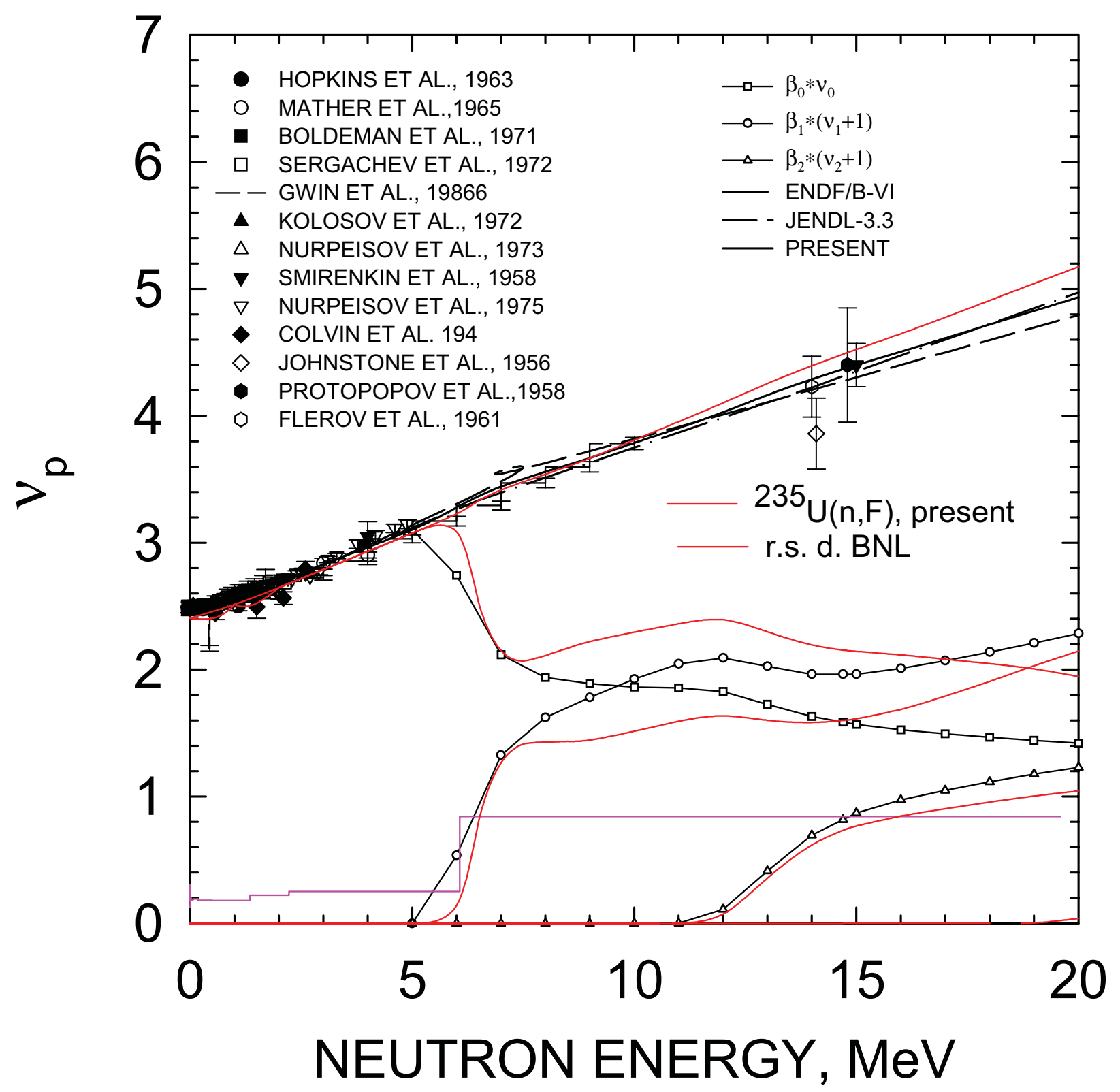


${ }^{239} \mathrm{Pu}(\mathrm{n}, \mathrm{F})$ PROMPT NEUTRON MULTIPLICIY

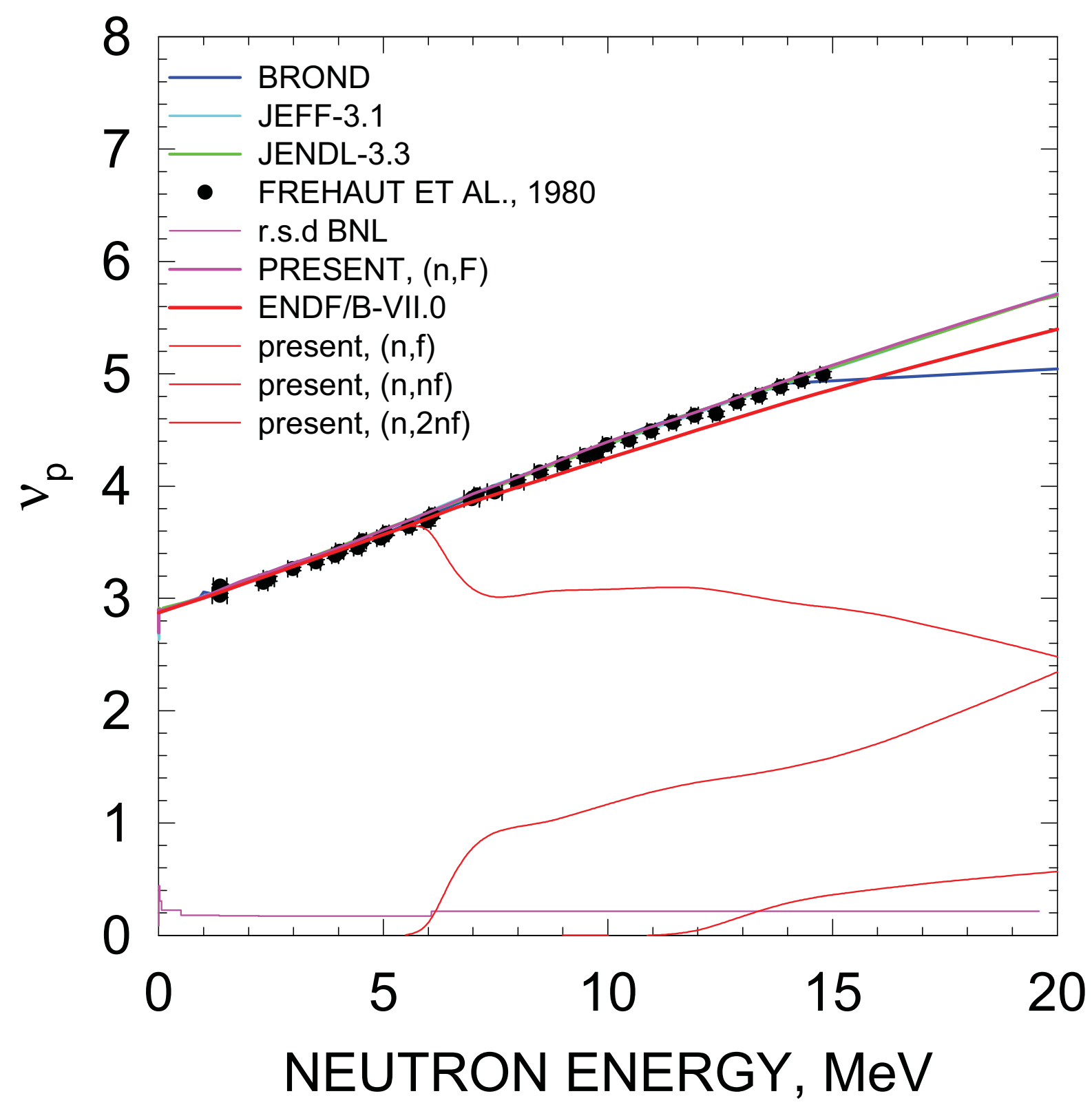


${ }^{241} \mathrm{Pu}(\mathrm{n}, \mathrm{F})$ PROMPT NEUTRON MULTIPLICIY

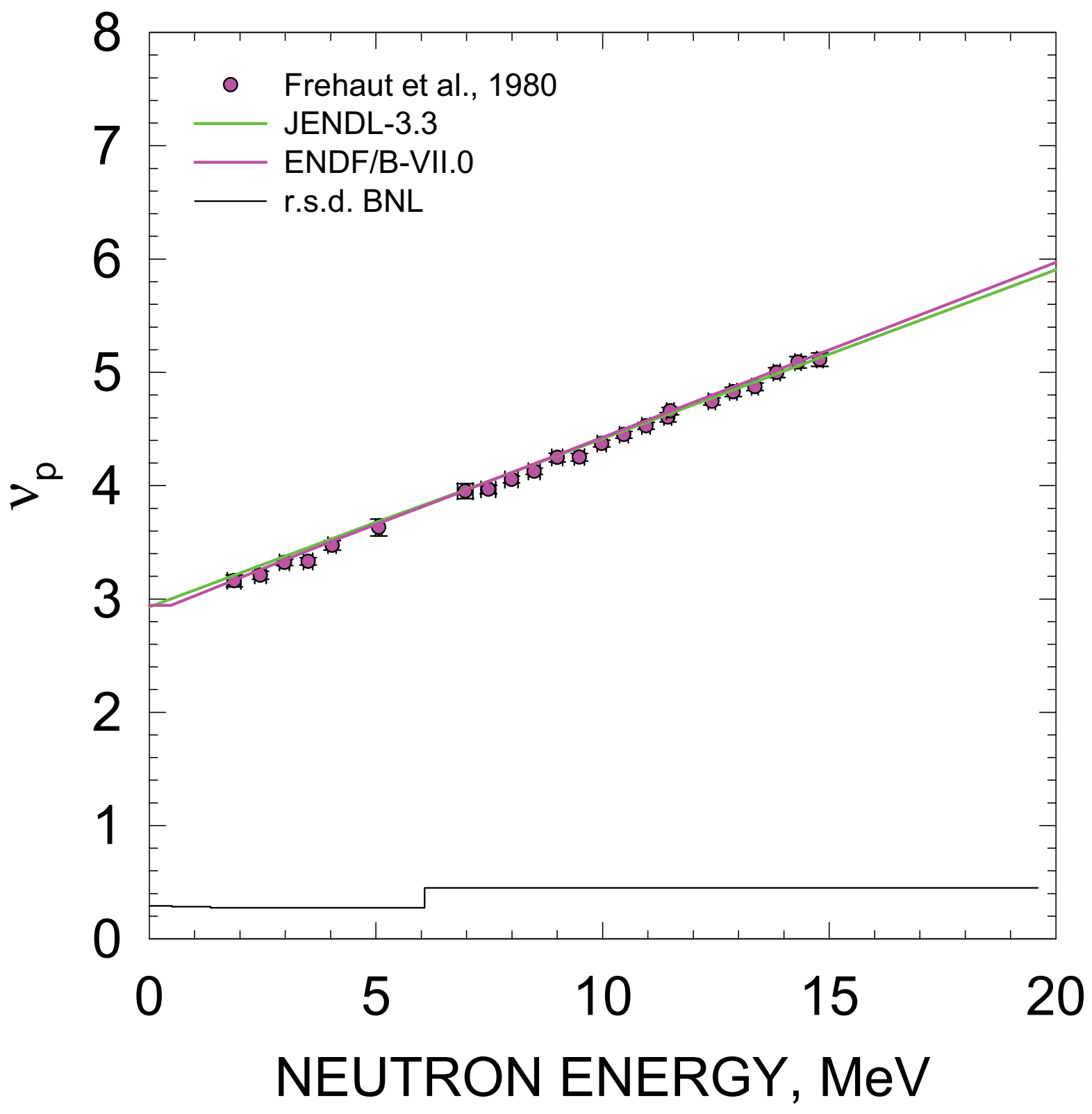


${ }^{243} \mathrm{Cm}(\mathrm{n}, \mathrm{F})$ PROMPT NEUTRON MULTIPLICITY

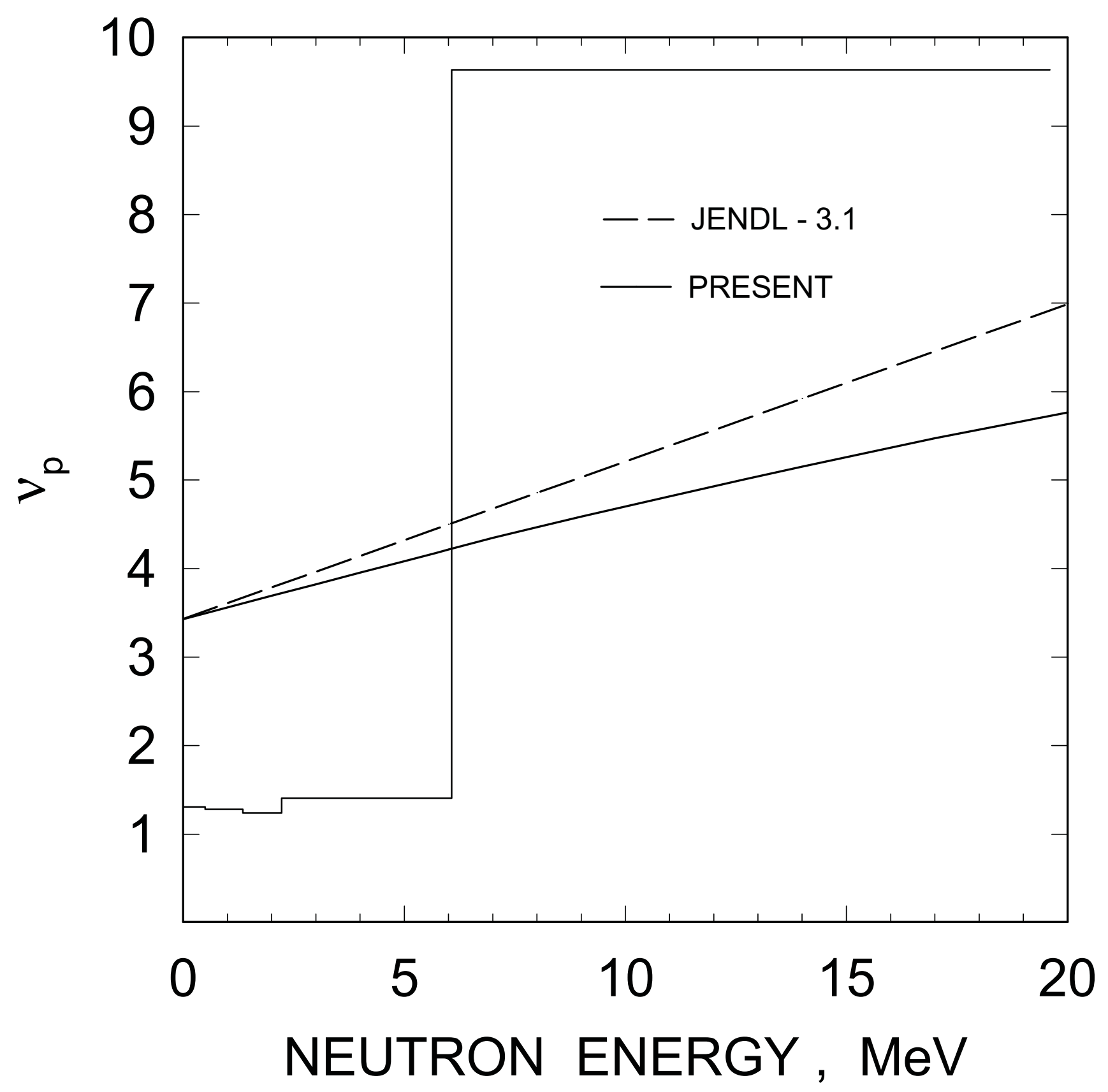


${ }^{245} \mathrm{Cm}(\mathrm{n}, \mathrm{F})$ PROMPT NEUTRON MULTIPLICITY

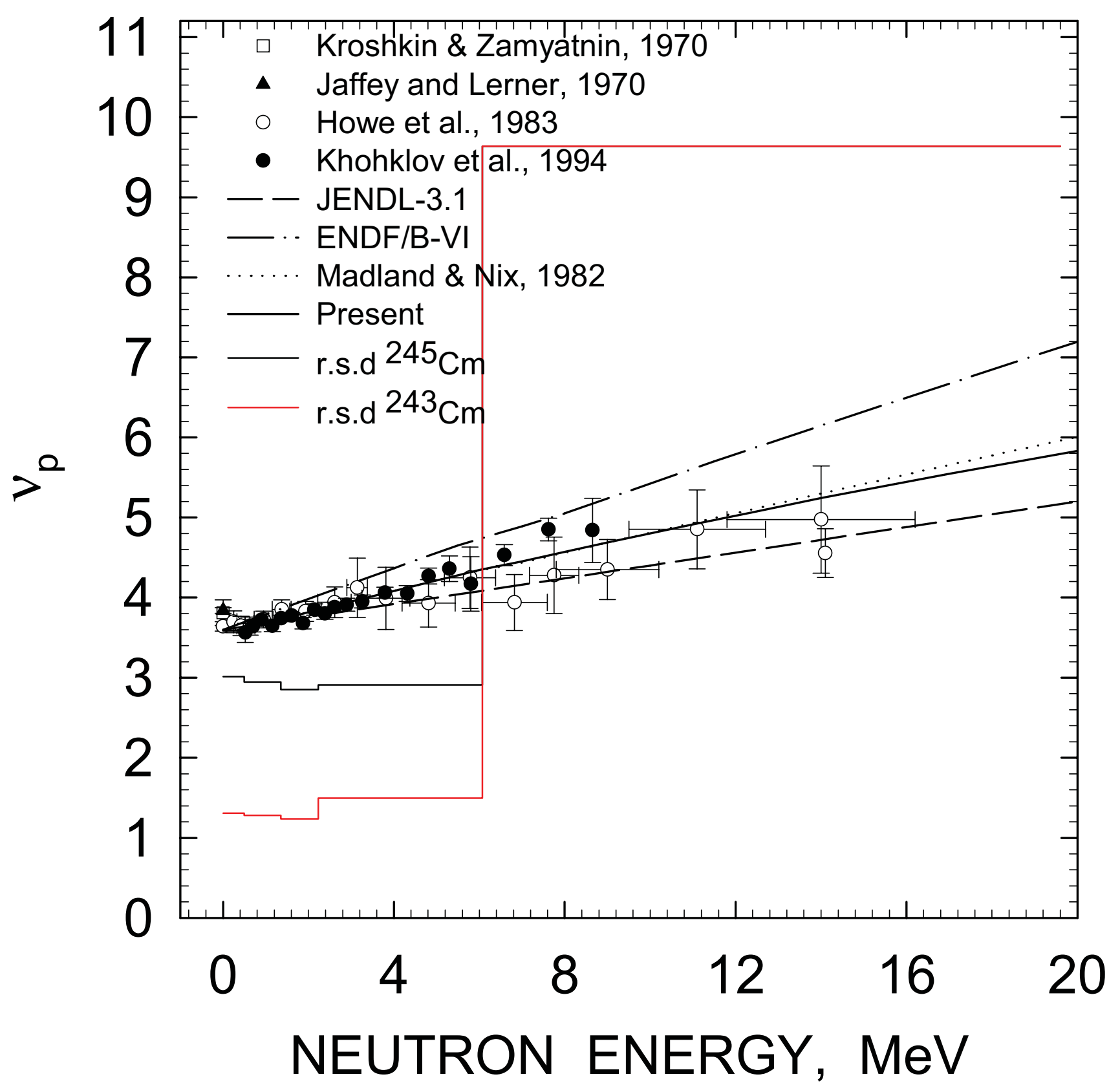




\section{${ }^{237} \mathrm{~Np}(\mathrm{n}, \mathrm{F})$ PROMPT NEUTRON MULTIPLICITY}

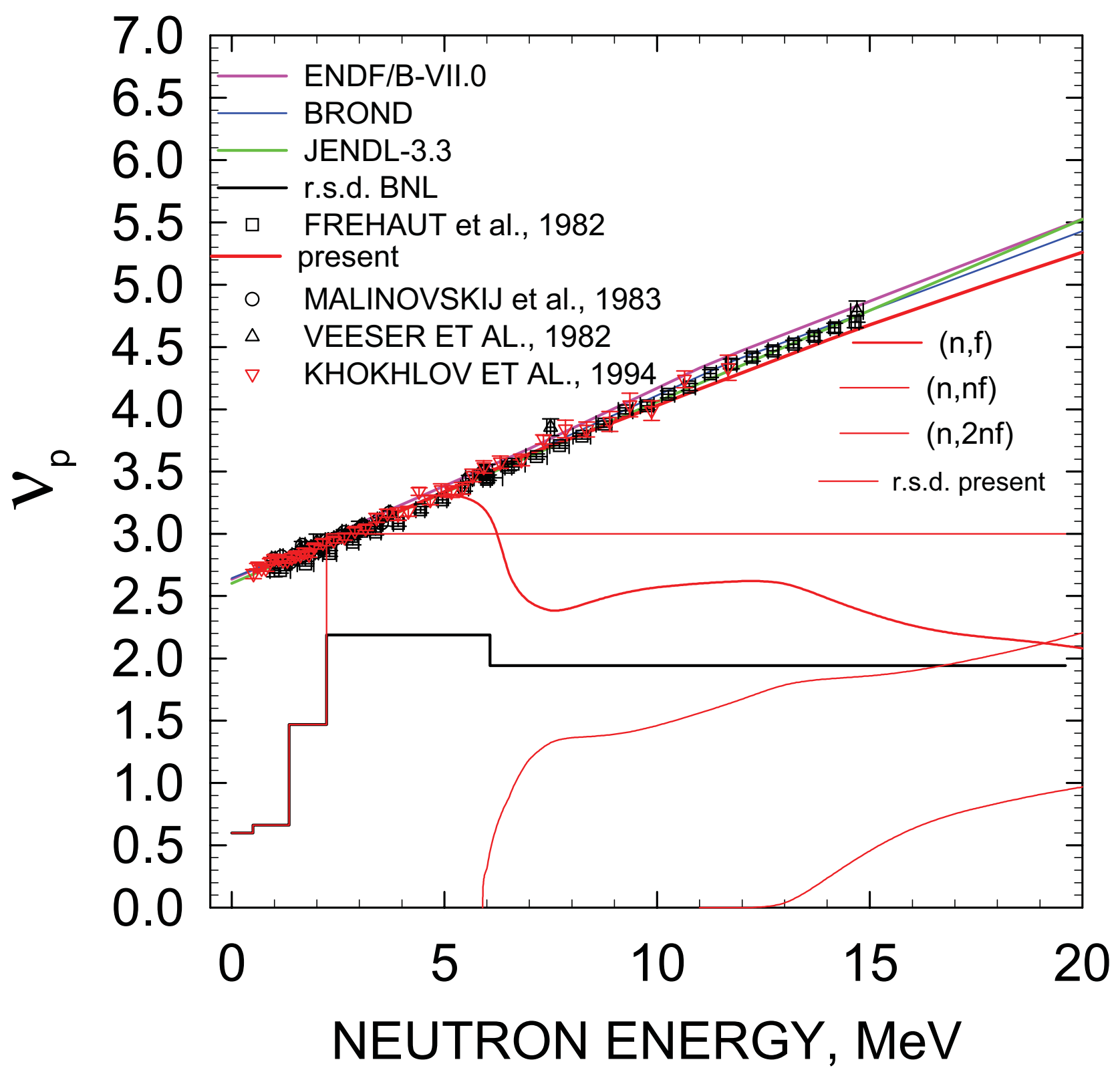




\section{${ }^{241}$ Am(n,F) PROMPT NEUTRON MULTIPLICITY}

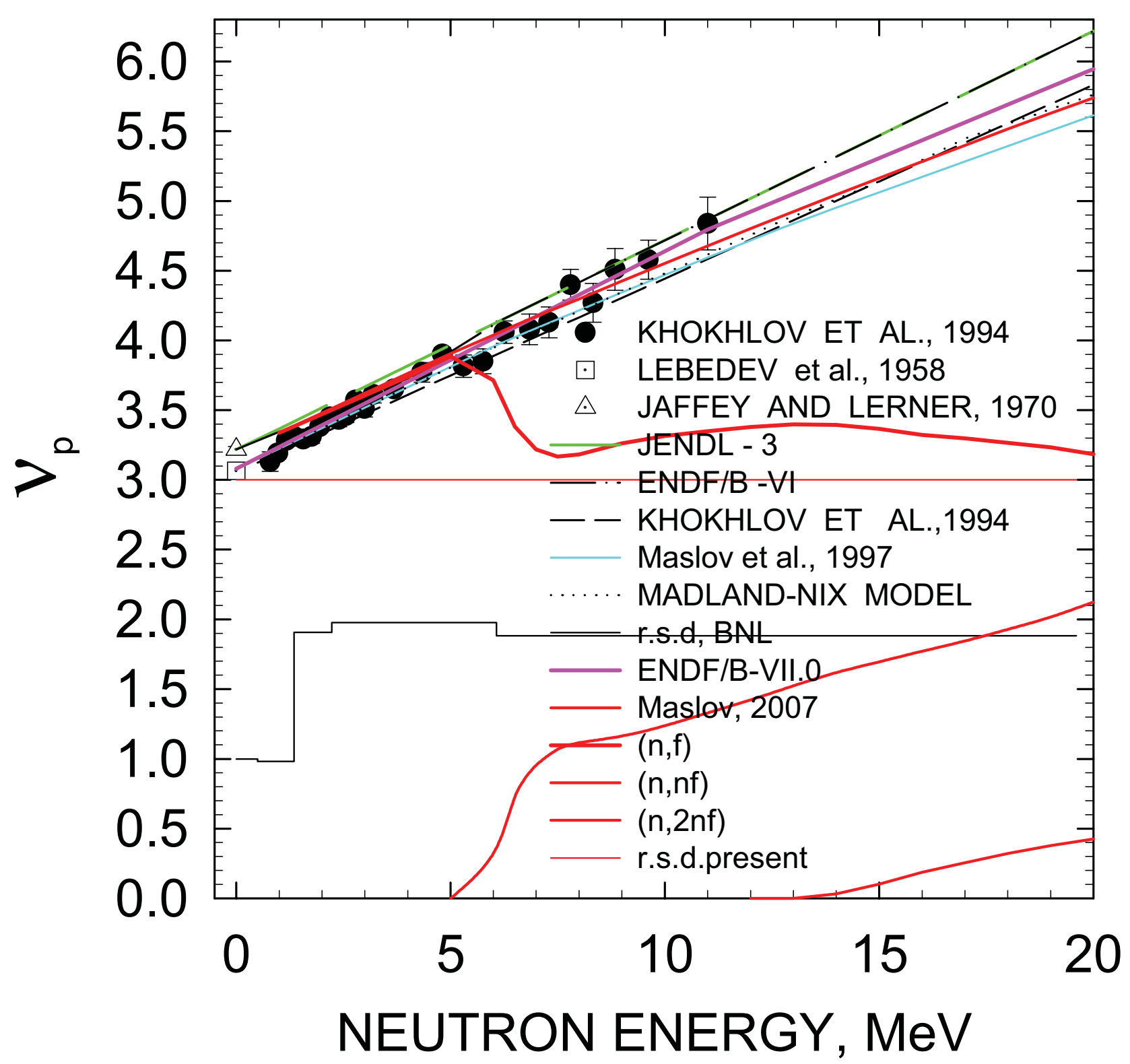




\section{${ }^{243}$ Am(n,F) PROMPT NEUTRON MULTIPLICITY}

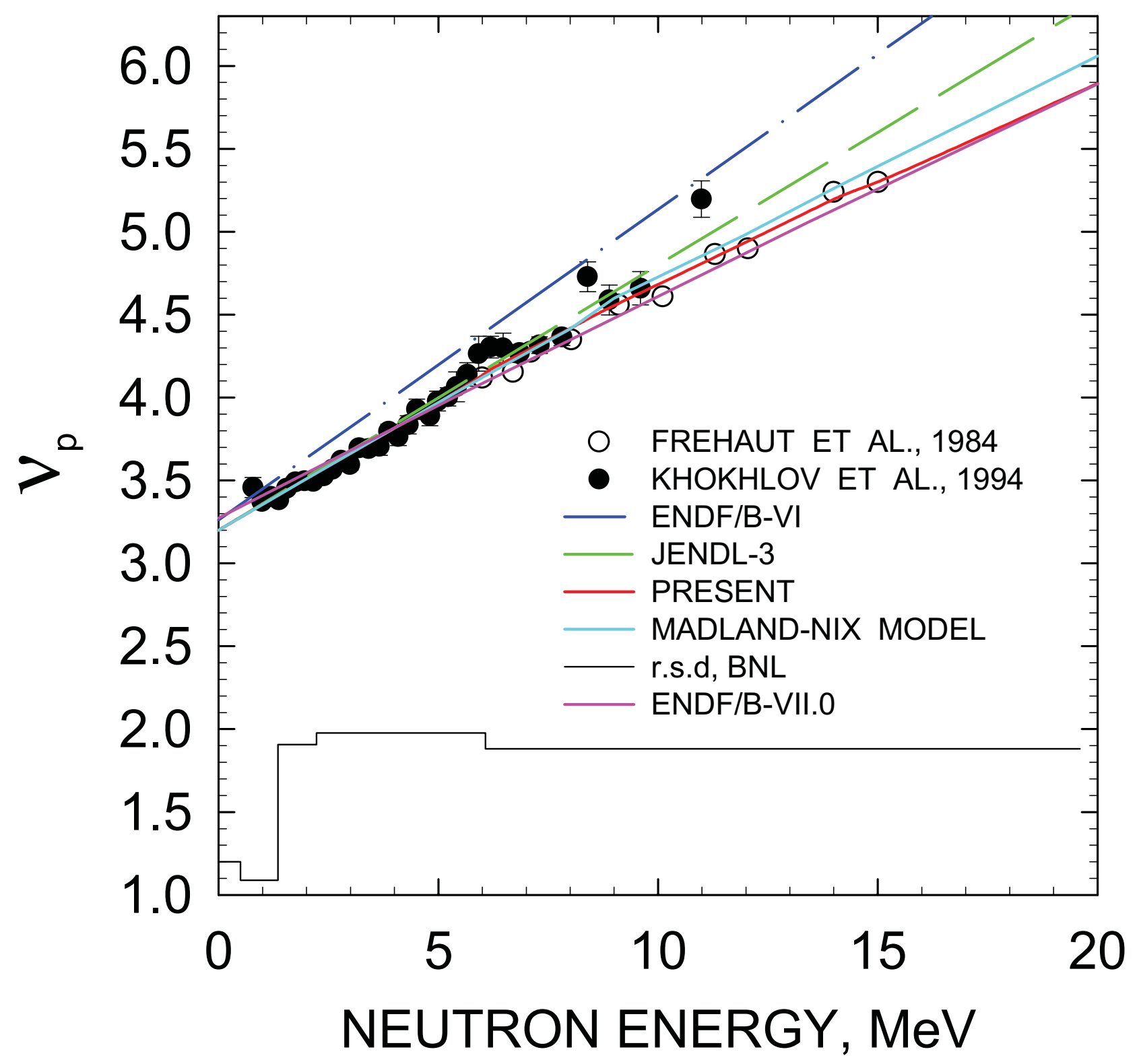


${ }^{242 m}$ Am(n,F) PROMPT NEUTRON MULTIPLICITY

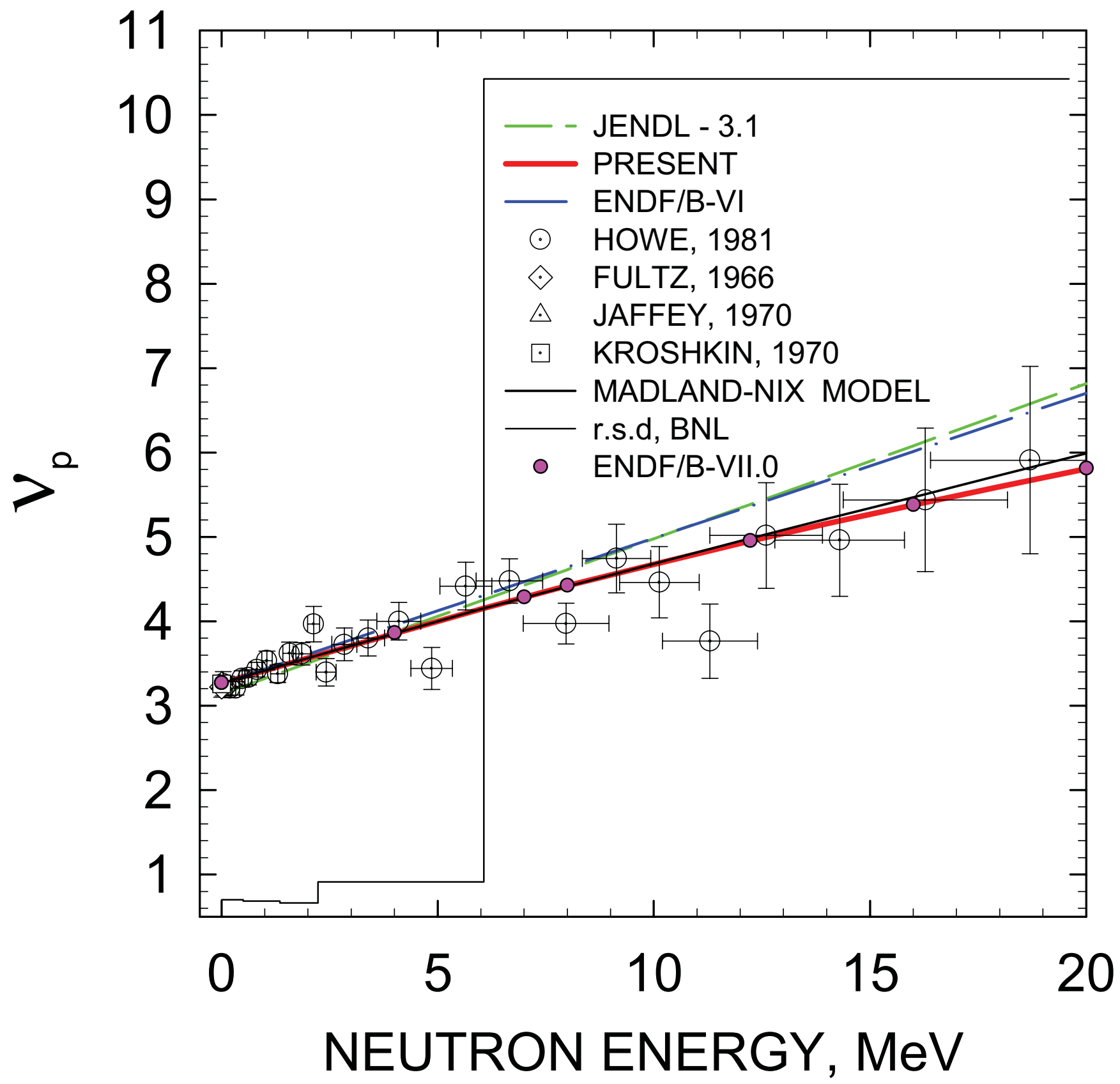




\section{Chapter 8 \\ Conclusions}

The improvements of the nuclear reaction modeling and nuclear parameter systematic, developed based on neutron data description of major actinides ${ }^{232} \mathrm{Th},{ }^{233} \mathrm{U},{ }^{235} \mathrm{U},{ }^{238} \mathrm{U}$ and ${ }^{239} \mathrm{Pu}$ is shown to provide a sound basis for critical assessment of the fission, capture, inelastic scattering, $(\mathrm{n}, \mathrm{xn})$ reaction cross sections of minor actinides. The main reasons of improvements are justified by: a) refined treatment of the spectra of collective states at equilibrium and saddle deformations; b) consistent description of $(n, F)$ as a superposition of $(n, f)$ and $(n, x n f)$ reactions, $(\mathrm{n}, \mathrm{xn})$ reaction cross sections and prompt fission neutron spectra of ${ }^{235} \mathrm{U},{ }^{238} \mathrm{U}$ and ${ }^{232} \mathrm{Th}$; c) refined treatment of the collective and intrinsic excitations influence on the level densities at equilibrium and saddle deformations; d) calculation of the exclusive neutron spectra of $(\mathrm{n}, \mathrm{xn})$ and (n,xnf) reactions. Conclusive evidence of the reliability of the approach employed comes from the confirmation of the predicted ${ }^{237} \mathrm{U}(\mathrm{n}, \mathrm{F})$ reaction cross section [7] by the surrogate measurements of the ratio of ${ }^{238} \mathrm{U}^{236} \mathrm{U}$ fission probabilities [77].

For neutron capture reactions on even-even $\mathrm{U}, \mathrm{Pu}$ and $\mathrm{Cm}$ nuclei in unresolved resonance and fast neutron energy ranges the methods, proven in case of ${ }^{232} \mathrm{Th}(\mathrm{n}, \gamma)$ and ${ }^{238} \mathrm{U}(\mathrm{n}, \gamma)$ data analysis were used. For example, calculated ${ }^{240} \mathrm{Pu}(\mathrm{n}, \gamma)$ reaction cross section shape is much similar to that, observed for the ${ }^{238} \mathrm{U}(\mathrm{n}, \gamma)$ and ${ }^{232} \mathrm{Th}(\mathrm{n}, \gamma)$ reaction cross sections. Differences are due to fission and neutron emission competition, which depends on the $(\mathrm{Z}, \mathrm{N})$-composition of the compound nucleus. The first Wigner' cusp is observed around first rotation level excitation threshold, another two cusps are due to further increases in neutron and then fission competition. Decreasing trend in Weston and Todd [222] data needs to be further checked experimentally. Similar cross section shape is reproduced in JENDL-3.3 evaluation, absolute differences are due to inherent approximations of evaluation procedures of JENDL-3.3.

For fissile targets ${ }^{239} \mathrm{Pu},{ }^{233} \mathrm{U},{ }^{235} \mathrm{U}$ capture cross sections of fissile nuclides demonstrate most vividly the influence of target spin differences, fission transition states spectroscopy and fission/gamma-emission competition on capture cross section shape and absolute values. In all cases the capture cross sections were obtained via consistent description of fission and elastic/inelastic scattering, $(\mathrm{n}, \gamma \mathrm{f})$ reaction being included. In case of ${ }^{239} \mathrm{Pu}(\mathrm{n}, \gamma)$ the structure at $\mathrm{E}_{\mathrm{n}}$ below $5 \mathrm{keV}$ is defined by fission via $1^{+}$sub-threshold transition states. At $\mathrm{E}_{\mathrm{n}}$ around $100 \mathrm{keV}$ 
there are systematic differences in measured ${ }^{239} \mathrm{Pu}(\mathrm{n}, \gamma)$ data trends. In case of ${ }^{235} \mathrm{U}(\mathrm{n}, \gamma)$ reasonable values of average resonance parameters support the high values of capture cross section around $10 \mathrm{keV}$, the measured data inconsistencies should be addressed. In case of ${ }^{233} \mathrm{U}(\mathrm{n}$, $\gamma$ ) reasonable values of average resonance parameters provide a consistent description of capture data in $\mathrm{keV}$ - and $\mathrm{MeV}$-energy ranges. To explain the biases of ${ }^{233} \mathrm{U}(\mathrm{n}, \gamma)$ and ${ }^{235} \mathrm{U}(\mathrm{n}, \gamma)$ evaluations of ENDF/B-VII.0 relative to measured data by Weston et al. [232] and Muradyan et al. [231], respectively, robust argument should be found.

Fission cross section of ${ }^{242} \mathrm{Cm}(\mathrm{n}, \mathrm{F})$ was predicted based on the sub-threshold neutron data and surrogate data at higher excitation energies. Fission cross section of ${ }^{238} \mathrm{Pu}(\mathrm{n}, \mathrm{F})$ was be predicted based on the neutron data in the non-emissive fission domain and surrogate data for ${ }^{237} \mathrm{Pu}(\mathrm{n}, \mathrm{f})$ at excitation energies higher than emissive fission threshold. The latest ${ }^{238} \mathrm{Pu}(\mathrm{n}, \mathrm{F})$ data by Fursov et al. [60] discards the previous extremely high fission cross section estimates in $\mathrm{E}_{\mathrm{n}}=6-20 \mathrm{MeV}$ range. The same problem of inconsistency we are facing for $\mathrm{Cm}$ targets, where the $(n, F)$ reaction data are higher than the modern estimates of the neutron absorption cross section.

Fission cross section fits serve as a constraint for the $(\mathrm{n}, \mathrm{xn})$ reaction prediction. One of them is ${ }^{241} \mathrm{Am}(\mathrm{n}, 2 \mathrm{n})$, its measurement, reported at ND2007 by Vieira et al. [171], nicely confirmed the older evaluation by Maslov et al. [17] of 1997, evaluated data file afterwards was accepted for JENDL-3.3. As regards ${ }^{243} \mathrm{Am}(\mathrm{n}, 2 \mathrm{n})$ reaction feeding ${ }^{242 \mathrm{~m}} \mathrm{Am}(\mathrm{J}=5)(141 \mathrm{y})$ and ${ }^{242 \mathrm{~g}} \mathrm{Am}(\mathrm{J}=1)(16$ h) there is a measurement by Gangarz referred by Chadwick et al. [14]. The quoted Gancarz data point gives the yield of ${ }^{242 \mathrm{~g}} \mathrm{Am}(\mathrm{J}=1)(16 \mathrm{~h})$ at $15 \mathrm{MeV}$ as 0.2 barn. It would be quite compatible with estimate of ${ }^{243} \mathrm{Am}(\mathrm{n}, 2 \mathrm{n})^{242(\mathrm{~m}+\mathrm{g})} \mathrm{Am}$ of 0.3 barn, granted that branching ratio of $\mathrm{m} / \mathrm{g}$ or (longlived-to-short/lived) is similar to that in ${ }^{237} \mathrm{~Np}(\mathrm{n}, 2 \mathrm{n})$ reaction. Only in that case the uncertainty of ${ }^{243} \mathrm{Am}(\mathrm{n}, 2 \mathrm{n})$ cross section could be claimed to be equal to $30 \%$ or even to that of ${ }^{241} \mathrm{Am}(\mathrm{n}, 2 \mathrm{n})$, otherwise it should increased to $100 \%$. Disentangling of the model deficiencies, when measured cross section and nubar data fits are rather poor, and model parameter uncertainties, turned out to be a major problem. Realistic assessment of the relative standard deviations is provided based on use of state-of-the-art nuclear reaction theory.

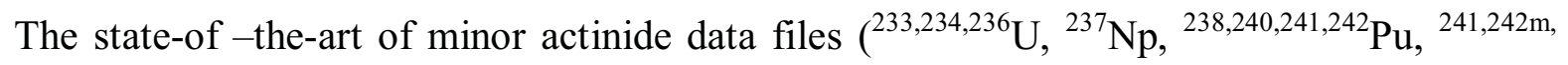
${ }^{243} \mathrm{Am},{ }^{242,243,244,245} \mathrm{Cm}$ ) dictates that their improvement based on new measured neutron data, either direct or surrogate) and advanced nuclear reaction modeling and nuclear parameter systematic will provide a sound basis for critical assessment of the fission, capture, inelastic 
scattering, $(\mathrm{n}, \mathrm{xn})$ reaction cross sections and relevant uncertainties. That will largely help to avoid substituting possible model deficiency uncertainties by enlarging the uncertainties of conventional nuclear model parameters. In a number of minor actinides the uncertainty estimation of cross sections and prompt fission neutron spectra should be preceded with the robust neutron data re-evaluation. Otherwise, in case of poorly investigated $\mathrm{Np}, \mathrm{Pu}, \mathrm{Am}, \mathrm{Cm}$ targets the artificially large cross section uncertainty estimates will be unavoidable.

The following tables summarize the possibility to use the available ENDF/B-VII.0 evaluated data files of minor actinides for the estimation of current uncertainties in evaluated nuclear data, as accomplished in [1, 2]. Sign '-' means that the uncertainties of $(n, e l)(n, f)(n, n$ ') $(n, \gamma)(n, 2 n)$ $v_{\mathrm{p}}$ are unacceptable, notwithstanding they are overoptimistic or too conservative, or evaluated data are inexplainable, sign "+" means the uncertainties of $[1,2]$ quite correspond to the actual knowledge database. In fact, a score of 5 or 4 “_“ in case of ${ }^{238} \mathrm{Pu},{ }^{242} \mathrm{Cm},{ }^{244} \mathrm{Cm}$ nuclides means the data files should be replaced. Other nuclides should be considered on a case-by-case basis, for example, ${ }^{237} \mathrm{~Np}$ with a score of five ““." needs severe modification. The prompt fission spectra representation in all data files needs severe modification, as described in $[3,10,11,12,13]$. That is inforced by the high sensitivity of the core neutronics to the prompt fission neutron spectra, as mentioned by M. Salvatores (see [329] and references therein). 
Table 8.1. Status of the uncertainty estimates for 15 minor actinides produced for Subgroup 26. Sign '_' means poor quality, sign '+' indicates good quality. The present report proposed improvements for all estimates of type '-' as well as small adjustments of estimates ' + '. It should be noted that basic ENDF/B-VII.0 evaluations for ${ }^{238} \mathrm{Pu},{ }^{242} \mathrm{Cm}$, ${ }^{244} \mathrm{Cm}$ are very poor and must be improved.

\begin{tabular}{|l|l|l|l|l|l|l|}
\hline Material & $(\mathrm{n}, \mathrm{el})$ & $(\mathrm{n}, \mathrm{f})$ & $\left(\mathrm{n}, \mathrm{n}^{\prime}\right)$ & $(\mathrm{n}, \gamma)$ & $(\mathrm{n}, 2 \mathrm{n})$ & $v_{\mathrm{p}}$ \\
\hline${ }^{233} \mathrm{U}$ & - & + & - & - & + & + \\
\hline${ }^{234} \mathrm{U}$ & - & + & - & - & + & - \\
\hline${ }^{236} \mathrm{U}$ & - & + & - & - & + & - \\
\hline${ }^{237} \mathrm{~Np}$ & - & + & - & - & - & - \\
\hline${ }^{238} \mathrm{Pu}$ & - & - & - & - & - & - \\
\hline${ }^{240} \mathrm{Pu}$ & - & + & - & - & - & + \\
\hline${ }^{241} \mathrm{Pu}$ & - & - & - & - & + & + \\
\hline${ }^{242} \mathrm{Pu}$ & - & + & - & - & + & - \\
\hline${ }^{241} \mathrm{Am}$ & - & - & + & - & + & - \\
\hline${ }^{242 \mathrm{~m}} \mathrm{Am}$ & - & - & - & - & + & + \\
\hline${ }^{243} \mathrm{Am}$ & - & - & - & + & - & + \\
\hline${ }^{242} \mathrm{Cm}$ & - & - & - & - & - & + \\
\hline${ }^{243} \mathrm{Cm}$ & - & - & - & + & + & + \\
\hline${ }^{244} \mathrm{Cm}$ & - & - & - & - & - & + \\
\hline${ }^{245} \mathrm{Cm}$ & - & + & - & + & + & + \\
\hline
\end{tabular}

Table 8.2. Status of the uncertainty estimates for the ENDF/B VII.0 evaluations of major actinides. For explation see the table above.

\begin{tabular}{|l|l|l|l|l|l|l|}
\hline Material & $(\mathrm{n}, \mathrm{el})$ & $(\mathrm{n}, \mathrm{f})$ & $(\mathrm{n}, \mathrm{n})$ & $(\mathrm{n}, \gamma)$ & $(\mathrm{n}, 2 \mathrm{n})$ & $v$ \\
\hline${ }^{232} \mathrm{Th}$ & + & + & + & - & + & - \\
\hline${ }^{235} \mathrm{U}$ & - & + & + & - & + & + \\
\hline${ }^{238} \mathrm{U}$ & - & - & + & - & - & + \\
\hline${ }^{239} \mathrm{Pu}$ & - & + & - & - & + & + \\
\hline
\end{tabular}




\section{References}

1. Rochman D., Herman M., Oblozinsky P., Mughabghab S.F., BNL Report: BNL-77407-2007-IR.

2. Rochman D., Herman M., Oblozinsky P., Mughabghab S.F., BNL Report: BNL-77407-2007-IRSuppl. 1.

3. Maslov V.M., ${ }^{235 \mathrm{~m}} \mathrm{U}$ and ${ }^{235} \mathrm{U}$ neutron-induced fission. - In: Abstracts of International Conference on Nuclear Data for Science and Technology, April 22-27, 2007, Nice, France, p.54.

4. Maslov V.M. Pairing effects in ${ }^{232}$ Th neutron-induced fission cross section. Nucl.Phys. A743 (2004) 236.

5. Maslov V. M. ${ }^{237}$ U neutron-induced fission cross section. Physical Review C 72 (2005) 044607.

6. Maslov V.M., Porodzinskij Yu. V., Baba M., Hasegawa A., Kornilov N.V., Kagalenko A.B. Neutron Scattering on ${ }^{238} \mathrm{U}$ and ${ }^{232} \mathrm{~T}$. In: Proc. of International Conference on Nuclear Data for Science and Technology, October 7-12, 2001, Tsukuba, Japan, p. 148, 2002.

7. Maslov V.M., Porodzinskij Yu. V., Baba M., Hasegawa A., Tetereva N.A. Excitation of octupole, beta- and gamma-vibration band levels of ${ }^{238} \mathrm{U}$ by inelastic neutron scattering, Nuclear Physics $\mathrm{A}$ 764 (2006) 212-245.

8. Maslov V.M., Porodzinskij Yu.V.Baba M., Hasegawa A. Neutron Capture Cross Section of ${ }^{232}$ Th, Journal of Nuclear Science and Engineering, 143 (2003) 177.

9. Maslov V. M. ${ }^{232}$ Th neutron capture cross section. Proc. of the $13^{\text {th }}$ International Seminar on Interaction of Neutrons with Nuclei, May 25-28, 2005, Dubna, Russia, p. 43.

10. Maslov V.M., Kornilov N.V., Kagalenko A. B., Tetereva N.A. Prompt fission neutron spectra of ${ }^{235} \mathrm{U}$ up above emissive fission threshold. Nucl. Phys. A760 (2005) 274.

11. Maslov V.M., Porodzinskij Yu. V., Baba M., Hasegawa A., Kornilov N. V., Kagalenko A.B., Tetereva N.A. Prompt fission neutron spectra of ${ }^{238} \mathrm{U}(\mathrm{n}, \mathrm{f})$ and ${ }^{232} \mathrm{Th}(\mathrm{n}, \mathrm{f})$ above emissive fission threshold, Phys. Rev. C69 (2004) 034607.

12. Maslov V.M., Porodzinskij Yu. V., Baba M., Hasegawa A., Kornilov N. V., Kagalenko A. B., Tetereva N.A. Prompt fission neutron spectra of ${ }^{238} \mathrm{U}(\mathrm{n}, \mathrm{f})$ above emissive fission threshold, EuroPhysics Journal A18 (2003) 93-102.

13. Maslov V.M. "Prompt fission neutrons spectra of ${ }^{238} \mathrm{U}$ ”. Physics of Atomic Nuclei, 71, 9, 2008.

14. Chadwick M.B., P. Oblozinsky, M. Herman et al., "ENDF/B-VII.0: Next generation evaluated data library for nuclear science and technology", Nucl. Data Sheets, 2006, v. 107, p. 2931-3060.

15. The JEFF-3.1 Nuclear Data Library, Edited by A. Koning, R.Forrest, M. Kellett e.a., NEA No. 6190, OECD.

16. Shibata K., Kawano T., Nakagawa T. et al., "Japanese Evaluated Nuclear Data Library Version 3 Revision-3: JENDL-3.3”, Jour. Nucl. Sci. Technol., 2002, v. 39, p. 1125-1199.

17. Maslov V.M., Porodzinskij Yu.V. e.a. Evaluation of neutron data for Americium-241.INDC(BLR)-005/G, Vienna, IAEA, 1996.

18. Maslov V.M., Porodzinskij Yu.V. e.a. Evaluation of neutron data for Americium-243.INDC(BLR)-006/G, Vienna, IAEA, 1996.

19. Maslov V.M., Porodzinskij Yu. V., Baba M., Hasegawa A., Kagalenko A. B.,. Kornilov, N.V, Tetereva N.A. Neutron Data Evaluation of ${ }^{232}$ Th. INDC(BLR)-16, IAEA, Vienna, 2003, 241 pp.

20. Maslov V.M., Porodzinskij Yu. V., Baba M., Hasegawa A., Kagalenko A. B.,. Kornilov N.V, Tetereva N.A. Neutron Data Evaluation of ${ }^{232}$ U. INDC(BLR)-15, IAEA, Vienna, 2003, 129 pp.

21. Maslov V.M., Porodzinskij Yu. V., Baba M., Hasegawa A., Kagalenko A. B.,. Kornilov N.V, Tetereva N.A. Neutron Data Evaluation of ${ }^{234}$ U. INDC(BLR)-17, IAEA, Vienna, 2003, 135 pp. 
22. Maslov V.M., Baba M., Hasegawa A., Kagalenko A. B.,. Kornilov N.V, Tetereva N.A. Neutron Data Evaluation of ${ }^{233}$ U. INDC(BLR)-18, IAEA, Vienna, 2003. 133 pp. Maslov V.M., Porodzinskij Yu. V., Baba M., Hasegawa A., Kagalenko A. B.,. Kornilov

23. N.V, Tetereva N.A. Neutron Data Evaluation of ${ }^{238}$ U. INDC(BLR)-14, IAEA, Vienna, 2003, 239 pp.

24. Maslov V.M., Baba M., Hasegawa A., Kagalenko A. B.,. Kornilov N.V, Tetereva N.A. Neutron Data Evaluation of ${ }^{231} \mathrm{~Pa}$. INDC(BLR)-19, IAEA, Vienna, 2004, $121 \mathrm{pp}$.

25. Maslov V.M., Baba M., Hasegawa A., Kagalenko A. B.,. Kornilov N.V, Tetereva N.A. Neutron Data Evaluation of ${ }^{233} \mathrm{~Pa}$. INDC(BLR)-20, IAEA, Vienna, 2004, $115 \mathrm{pp}$.

26. Maslov V.M., Porodzinskij Yu.V., Sukhovitskij E.Sh., Klepatskij A.B., Morogovskij G.B. Evaluation of Neutron Data for Curium-243. INDC(BLR)-2, 1995.

27. Maslov V.M., Porodzinskij Yu.V., Sukhovitskij E.Sh., Klepatskij A.B., Morogovskij G.B. Evaluation of Neutron Data for Curium-245. INDC(BLR)-3, 1996.

28. Maslov V.M., Porodzinskij Yu.V., Sukhovitskij E.Sh., Morogovskij G.B. Evaluation of Neutron Data for Curium-246. INDC(BLR)-4, 1996.

29. Maslov V.M., Porodzinskij Yu.V., Sukhovitskij E.Sh., Klepatskij A.B., Morogovskij G.B. and Kikuchi Y. New Evaluation of Minor Actinide Nuclides. In: Proc. International Conference on the Physics of Reactors, September 16-20,1996, Mito, Ibaraki, Japan, vol.3, p.F1.

30. Maslov V.M., Porodzinskij Yu.V., Sukhovitskij E.Sh., Morogovskij G.B. Evaluation of Neutron Data for Americium-242m. INDC(BLR)-7, 1997.

31. Maslov V.M., Porodzinskij Yu.V., Sukhovitskij E.Sh., Morogovskij G.B. Evaluation of Neutron Data for Americium-242g. INDC(BLR)-8, 1997.

32. Maslov V.M., Porodzinskij Yu.V., Sukhovitskij E.Sh., Morogovskij G.B. Evaluation of Neutron Data for Plutonium-238. INDC(BLR)-9,1997.

33. Maslov V.M., Porodzinskij Yu.V., Sukhovitskij E.Sh., Morogovskij G.B. Evaluation of Neutron Data for Plutonium-242. INDC(BLR)-10, 1997.

34. Maslov V.M., Porodzinskij Yu.V., Sukhovitskij E.Sh. Evaluation of Neutron Data for Neptunium238. INDC(BLR)-11, 1998.

35. Herman M., Mughabghab S., Oblozinsky P. et al.. In: Abstracts of International Conference on Nuclear Data for Science and Technology, April 22-27, 2007, Nice, France, p. 61.

36. Capote R., Sin M., Trkov A. In: Abstracts of International Conference on Nuclear Data for Science and Technology, April 22-27, 2007, Nice, France, p.150.

37. Lagrange Ch., NEANDC(E) 228 “L” INDC(FR) 56/L, 1982.

38. Cox S.A. and Dowling E.E., ANL-7935 (1972).

39. Walt M. and Barshall H.H., Phys. Rev. 93,1062 (1954).

40. Iwasaki T., Baba M., Hattori K. et. al., NEANDC(J)-75 (1981).

41. Hudson C.I. JR, Walker W.S., Berko S., Phys. Rev., 128,1271 (1962).

42. Batchelor R., Gilboy W.B., Towle J.H., Nuclear Physics, 65, 236 (1965).

43. Smith W., Phys. Rev.,126, 718 (1962)

44. Kazakova L.Ya., Kolesov V.E., Popov V.I. et. al., EANDC-50 (1965).

45. Popov V.I., Atomnaya Energya, 3, 498 (1957).

46. Haouat G. et. al., NEANDC(E)-196 (1978).

47. Allen R.C., Walton R.B., Perkins R.B., Olson R.A., Taschek R.F., Phys. Rev., 104, 731 (1956).

48. Barnard E., Ferguson A.T.G., McMurray W.R., Vanheerden I.J, Nucl. Phys., 80, 46 (1966).

49. Batchelor R., Gilboy W.B., Towle J.H., Nucl. Phys., 65, 236 (1965).

50. Li Jingde, Xie Daquan, Ma Gonggui et al., 86Harrog, 1, 229 (1986).

51. Shen Guanran, Cao Zhong, Wang Hui-Zhu et al., 81Grenob, 512 (1981). 
52. Voignier J., CEA-3503, 1968.

53. Bakhanovich L.A., Klepatskij A.B., Maslov V.M. et al., INDC(CCP)-366, p. 19, 1994

54. Vertebnij V.P., Gnidak N.L., Grebnev A.V. et al. Proc. $5^{\text {th }}$ All-Union Conf. Neutron Physics,Kiev, Soviet Union, September 15-19, 1980, vol. 2, 254 Atomizdat (1980).

55. Knitter H.-H., Islam M.M., Coppola M., Zitschrift fur Physik, 257, 108 (1972) 1972

56. Smith A.B. and Whalen J.F., Search for Structure in the fast neutron interaction with ${ }^{235}$ U, Nucl. Sci. Eng., 18, 126, 1964.

57. Smith A.B., Guenter P.T., McKnight R.D., Proc. Int. Conf. Nuclear Data for Science and Technology, Antwerpen, Belgium, September 6-10,1982, p. 39, K.H. Bockhoff, Ed., Holland (1982).

58. Yue G., O’Connor M., Egan J.J., Kegel G.H.R. "Neutron scattering angular distributions in ${ }^{239} \mathrm{Pu}$ at 570 and $700 \mathrm{keV}$ ". Nucl. Sci. Eng., 122, 366 (1996).

59. Knitter H.H., Coppola M. "Elastic neutron scattering measurements on ${ }^{239} \mathrm{Pu}$ in the energy range between 0.19 MeV and 0.38 MeV" Zeischrift fur Physik 228, 286 (1969).

60. Fursov B.I., Polynov V.N., Samylin B.F., Shorin V.S. Fast neutron-induced fission cross sections of some minor actinides. In: Proc. of International Conference on Nuclear Data for Science and Technology, Trieste, Italy, 19-24 May 1997, p. 488.

61. Fomushkin E.F., G.F. Novoselov, Y.I. Vinogradov et al., Atomnaya Energiya, 62, 278 (1987).

62. Fomushkin E.F., G.F. Novoselov, Y.I. Vinogradov et al., Atomnaya Energiya, 69, 258 (1990).

63. Kornilov N.V., Kagalenko A.V., Baryba V.Ya. et al., "Inelastic neutron scattering and prompt fission neutron spectra for ${ }^{237} \mathrm{~Np}$ ", Nucl. Phys. A 27, 1643 (2000).

64. J.W. Meadows, Proc. Int. Conf. on Nuclear Cross Sections for Technology, Knoxville, Tennessee, 22-26 Oct 1979, 479 (1979).

65. Meadows J.W. "the fission cross sections of ${ }^{230} \mathrm{Th},{ }^{232} \mathrm{Th},{ }^{233} \mathrm{U},{ }^{234} \mathrm{U},{ }^{236} \mathrm{U},{ }^{238} \mathrm{U},{ }^{237} \mathrm{~Np},{ }^{239} \mathrm{Pu}$ and ${ }^{242} \mathrm{Pu}$ relative to ${ }^{235} \mathrm{U}$ at $14.74 \mathrm{MeV}$ neutron energy" Ann. Nucl. Energy, 15, 421 (1988).

66. A.A. Goverdovskij, A.K. Gordjushin, Kuzminov B.D. et al., Sov. Atom. Energ., 60, 494 (1986).

67. A.A. Goverdovskij, A.K. Gordjushin, Kuzminov B.D. et al., Sov. Atom. Energ., 61, 985 (1987).

68. B.I. Fursov, E.Yu. Baranov, M.P. Klemyshev et.al., Sov. Atom. Energ., 71, 827 (1992).

69. Shcherbakov O.A., Donets A., Evdokimov A., Fomichev A., Fukahori T., Hasegawa A., Laptev A., Maslov V., Petrov G., Soloviev S., Tuboltsev Yu., Vorobyev A., Proc. International Conference on Nuclear Data for Science and Technology, October 7-12, 2001, Tsukuba, Japan, p. 230, 2002.

70. J.W. Behrens, Browne J.C., Ables E. Nucl. Sci.Eng., 81, 512 (1982).

71. Younes W. and Britt H.C. Neutron-induced fission cross sections simulated from (t,pf) results. Phys. Rev. C67 (2003) 024610.

72. Younes W. and H.C. Britt. Simulated neutron-induced fission cross sections for various $\mathrm{Pu}, \mathrm{U}$, and Th isotopes. Phys. Rev. C64 (2001) 034610.

73. Behrens J.W., Carlson G.W. Nucl. Sci. Eng., 63, 250 (1977).

74. J.W. Meadows, Nucl. Sci.Eng., 58, 255 (1975).

75. P.W. Lisowski , A. Gavron , W.E. Parker, J.L. Ullmann, S.J. Balestrini, A.D. Carlson, O.A. Wasson, N.W. Hill, Proc. Specialists'Meeting on Neutron Cross Section Standards for the Energy Region above $20 \mathrm{MeV}$, Uppsala, Sweden, May 21-23, 1991, p. 177, OECD, Paris, 1991.

76. Plettner C., Ai H., Beausang C.W. et al. Estimation of $(\mathrm{n}, \mathrm{f})$ cross sections by measuringreaction probability ratios. Phys. Rev. C71 (2005) 051602(R).

77. J.T. Burke et al., Phys. Rev. C 73, 054604 (2006).

78. T. Kawano, T. Ohsawa, M. Baba and T. Nakagawa, Phys. Rev. C 63, 034601 (2001).

79. Lopez Jimenez M.J., Morillon B., Romain P., Triple-humped fission barrier model for a new ${ }^{238} \mathrm{U}$ neutron cross sections evaluation and first validations. Ann. Nucl. Energy, 32 (2005) 195. 
80. Fursov B.I., Baranov E.Yu., Klemyshev M.P., Samylin B.F.,Smirenkin G.N., Turchin Yu.M. Atomnaya Energya, 71, 320 (1991).

81. Goverdovskiy A.A., Gordyushin A.K., Kuz'minov B.D., Mitrofanov V.F., Sergachev A.I. Atomnaya Energya, 60, 416 (1986).

82. Goverdovskij A.A., Gordyushin A.K., Kuz'minov B.D., Mitrofanov V.F., Sergachev A.I. Atomnaya Energya, 63, 60 (1987).

83. Goverdovskiy A.A., Gordyushin A.K., Kuz'minov B.D., Mitrofanov V.F., Sergachev A.I. Atomnaya Energya, 62, 190 (1987).

84. Kanda K., Imaruoka H., Yoshida K., Sato O., Hirakawa N.Radiation Effects, 93, 233 (1986).

85. Lamphere R. Nucl.Phys., 38, 561 (1962).

86. Meadows J.W. Nucl. Sci. Eng., 65, 171 (1978).

87. Meadows J.W. Ann .Nucl. Ener., 15 , 421 (1988).

88. White P.H. and Warner G.P. J. "The fission cross sections of ${ }^{233} \mathrm{U},{ }^{234} \mathrm{U},{ }^{236} \mathrm{U},{ }^{238} \mathrm{U},{ }^{237} \mathrm{~Np},{ }^{239} \mathrm{Pu}$, ${ }^{241} \mathrm{Pu}$ relative to that of ${ }^{235} \mathrm{U}$ for neutrons in the energy range 1-14 MeV", Nucl. Energy, 21, 671 (1967).

89. Arlt et al., Proc. International Conference on Nuclear Data for Science and Technology, October 712, 1979, Knoxville, USA, p. 995, 1979.

90. James G.D., Dabbs J.W.T., Harvey J.A., Hill N.W. Phys. Rev. C, 15, 2083 (1977).

91. Alam B., Block R.C., Slovacek R.E., Hoff R.W. Measurement of the Neutron-Induced Fission Cross Sections of ${ }^{242} \mathrm{Cm}$ and ${ }^{238} \mathrm{Pu}$. Nucl. Sci. Eng. 99 (1988) 267.

92. Budtz-Jòrgensen C., Knitter H.-H. and Smith D.L. In: Proc. Int. Conf. Nuclear Data for Science and Technology, Antwerpen, Belgium, September 6-10, 1982, p. 206, D/ Reidel Publishing Co., Boston (1983).

93. Ermagambetov S.B., Smirenkin G.N. JETP Letters, 9, 309 (1969).

94. Ermagambetov S.B., Smirenkin G.N. Sov. At. Energy, 25, 1364 (1969).

95. Fomushkin E.F., Gutnikova E.K. Sov. J. Nucl. Phys. 10, 529 (1970).

96. Barton D.M. and Koontz P.G. Phys. Rev., 162, 1070 (1967).

97. Aleksandrov B.M., Solovjev S.M., Soloshenkov P.S. et al. "The neutron fission cross sections for ${ }^{241} \mathrm{Am},{ }^{238} \mathrm{Pu},{ }^{240} \mathrm{Pu}$ and ${ }^{241} \mathrm{Pu} "$, Nuclear Constants, $1(50), \mathrm{p} .3,1983$ (in Russian).

98. K. Kari and S. Cierjacks, Neutron Physics and Nuclear Data for Reactors and applied purposes, Harwell, UK, p. 905, OECD, Paris, 1978.

99. Staples P., Morley K., "Neutron-induced fission cross section ratios for ${ }^{239} \mathrm{Pu},{ }^{240} \mathrm{Pu},{ }^{242} \mathrm{Pu}$ and ${ }^{242} \mathrm{Pu}$ relative to ${ }^{235} \mathrm{U}$ from $0.5 \mathrm{MeV}$ to $400 \mathrm{MeV}$ ", Nucl. Sci. Eng. 129 (1998) 149.

100.Budtz-Jòrgensen C., Knitter H.-H. "Neutron-Induced Fission crosss ection of ${ }^{240} \mathrm{Pu}$ in the energy range from $10 \mathrm{keV}$ to $10 \mathrm{MeV}$ " Nucl. Sci. Eng. 79 (1981) 380.

101.Weston L.W., Todd J.H., "Neutron fission cross section of ${ }^{239} \mathrm{Pu}$ and ${ }^{240} \mathrm{Pu}$ relative to ${ }^{235} \mathrm{U}$ ", Nucl. Sci. Eng. 84 (1983) 248.

102.Meadows J.W., "The fission cross section of plutonium-240 relative to uranium-235 from 0.35 to 9.6 MeV”, Nucl. Sci. Eng. 79 (1981) 233.

103.Kupriyanov V.M., Fursov B.I., Maslennikov B.K. et al. "The measurement of Pu-240 and Pu-242 fission cross section relative to that of U-235 in the .127-7.4 MeV neutron energy interval", Sov J. At. Energy, 46, 35 (1979).

104.Behrens J.W., Newbury R.S., Magana J.W. "Measurements of the Neutron-induced fission cross sections of ${ }^{240} \mathrm{Pu},{ }^{242} \mathrm{Pu}$, and ${ }^{244} \mathrm{Pu}$ relative to $235 \mathrm{U}$ from 0.1 to $30 \mathrm{MeV}$,, Nucl. Sci. Eng. 66, 433 (1978).

105.Iwasaki T., Wanabe F., Baba M. et al. J. Nucl. Sci. Tech.27, 885 (1990). 
106.Meadows J.W. "The fission cross section of plutonium-239 and plutonium-242 relative to uranium235 from 0.1 to $10 \mathrm{MeV”,} \mathrm{Nucl.} \mathrm{Sci.} \mathrm{Eng.} \mathrm{68,} 360$ (1978).

107.Weigmann H., Wartena J.A., Burkholz C. Nucl. Phys. A438, 333 (1985).

108. Cance M., Grenier G., "Absolute measurements of the ${ }^{240} \mathrm{Pu}(\mathrm{n}, \mathrm{f}),{ }^{242} \mathrm{Pu}(\mathrm{n}, \mathrm{f})$ and ${ }^{237} \mathrm{~Np}(\mathrm{n}, \mathrm{f})$ cross sections at $2.5 \mathrm{MeV}$ incoming neutron energy “. In:Proc. Int. Conf. Nuclear Data for Science and Technology, Antwerpen, Belgium, September 6-10,1982, p. 51, K.H. Bockhoff, Ed., Holland (1982).

109.Arlt R., Josch M., Musiol G., et al. "Absolute measurement of fission cross sections at neutron energies at about $8.5 \mathrm{MeV}$ ". Isotopenpraxis 21, 344 (1985).

110.Arlt R. et al. "Absolute determination of fission cross sections of ${ }^{233} \mathrm{U},{ }^{235} \mathrm{U},{ }^{238} \mathrm{U},{ }^{237} \mathrm{~Np},{ }^{239} \mathrm{Pu}$ and ${ }^{242} \mathrm{Pu}$ at $14.7 \mathrm{MeV}$ ", Sov J. At. Energy, 55, 656 (1984).

111.Vorotnikov P.E., Dmitriev S.V., Molchanov Yu.D. et al., "Cross section measurements for fission of ${ }^{242} \mathrm{Cm}$ induced by neutrons with energies of $0.1-1.4 \mathrm{MeV}$, performed with nanogram amounts of substance" Yadernaya Fyzika, 40 (1984) 1141.

112.Maslov V.M., "Fission Level Density and Barrier Parameters for Actinide Neutron-Induced Cross Section Calculations", INDC(BLR)-013/L, 1998, IAEA, Vienna.

113.Britt H.C., Wilhelmy J.B. Simulated (n,f) cross sections for exotic Actinide nuclei. Nucl. Sci. Eng. 72, 222 (1979).

114.B. Jurado, G. Kessedjian, M. Aiche et al., Abstracts of International Conference on Nuclear Data for Science and Technology, April 22-27, 2007, Nice, France, p.6. ; Kessedjian, M. Aiche, G. Barreau et al., Abstracts of International Conference on Nuclear Data for Science and Technology, April 22-27, 2007, Nice, France, p.186.

115.Fomushkin E.F., Novoselov G.F., Vinogradov Yu. I. Yadernaya Fyzika, 31 (1980) 39.

116.Fomushkin E.F., Novoselov G.F., Vinogradov Yu. I. Yadernaya Fyzika, 36 (1982) 582.

117.Moore M.S. and Keyworth G.A. "Analysis of the Fission and Capture Cross Sections of the Curium Isotopes”. Phys. Rev. C3 (1971) 1656.

118.Maguire Jr. H.T., Stopa C.R.S., Block R.C. et al. Neutron-Induced Fission Cross-Section Measurements of ${ }^{244} \mathrm{Cm},{ }^{246} \mathrm{Cm}$, and ${ }^{248} \mathrm{Cm}$. Nucl. Sci. Eng. 89 (1985) 293

119.Vorotnikov P.E., Kozlov L.D., Molchanov Yu.D., Shuf G.A., "The fission neutron cross sections of ${ }^{244} \mathrm{Cm}$ in energy range $0.4-1.3 \mathrm{MeV}$ " Atomnaya Energiya, 57 (1984) 61.

120.Fomushkin E.F., Gutnikova E.K., Zamyatnin Yu.S., Maslennikov B.K., et al. Cross sections and fragment angular anisotropy in fast neutron fission of some isotopes of plutonium, americium and curium", Sov. J. Nucl.Phys. 5, 689,(1967).

121.I.A.Ivanin, Yu.A.Khokhlov, V.I.In'kov, Yu.I.Vinogradov, E.F.Fomushkin, L.D.Danilin, V.N Polynov "Measurements of fission cross section for curium isotopes". Int. Conf. Nucl. Data for Sci. and Technology, Triest, Italy, 19-24 May 1997.

122.W.P. Poenitz, Nucl. Sci. Eng., 64, 894 (1977)

123.B. Leugers, S. Cerjacks et al., Proc. NEANDC/NEACRP Spec. Meeting on Fast Neutron Fission Cross Sections of ${ }^{233} \mathrm{U},{ }^{235} \mathrm{U},{ }^{238} \mathrm{U}$ and ${ }^{239} \mathrm{Pu}$. ANL, June 28-30, 1976. ANL-76-90, 1976,183.

124.G.W. Carlson and J.W. Behrens, Nucl. Sci. Eng., 66 (1978) 205.

125.M. Cance et al., Nucl. Sci. Eng. 68 (1978) 197.

126.Dushin V.N., Fomichev A.V., Kovalenko S.S. et al., Atomnaya Energiya, 55, (4), 218 (1983).

127.Fursov B.I., Kuprijanov V.M., G.N.Smirenkin.,"Fission cross section measurement for U-233 and

$\mathrm{Pu}-241$ relative to $\mathrm{U}-235$ fission cross section in the energy range 0.024-7.4 MeV" Atomnaya Energiya, 44, (3), 236, (1978).

128.Carlson G.W., Behrens J.W. Nucl. Sci. Eng., 66, 205 (1978).

129.Meadows J.W., Nucl. Sci. Eng., 54, 317 (1974). 
130.Adamov V.M., Aleksandrov B.M., Alkhazov I.D. et al., Yadernye Konstanty 24(8) (1977).

131.Zasadny K.R., Agrawal H.M., Mahdavi M., Knoll G.F."Measurement of the 14-MeV fission cross sections for ${ }^{233} \mathrm{U}$ and ${ }^{237} \mathrm{~Np}$ ". Trans. Amer. Nucl. Soc. 47, 425 (1984).

132.Calviani M., Genninni P., Colonna N. In: Proc. $4^{\text {th }}$ Workshopn on Neutron measurements, Evaluations and Aplications, October 16-18, 2007, Prague, Czech Republic., p. 15.

133.Fursov B.I., Kuprijanov V.M., Ivanov V.I. G.N.Smirenkin.,"Measurement of ${ }^{239} \mathrm{Pu}$ to ${ }^{235} \mathrm{U}$ cross section ratio for neutrons energy range 0.024-7.4 MeV" Atomnaya Energiya, 43, 261 (1977).

134.Merla K., Hausch P., Herbach C.M., et al. "Measurement of neutron-induced fission cross section ratiosat the Karlsruhe isochronous cyclotron”. In: Proc. Int. Conf. Nuclear Data for Science and Tech., Julich, Germany, 1991, p. 94.

135.S. Cerjacks, B. Leugers, et al., Proc. NEANDC/NEACRP Spec. Meeting on Fast Neutron Fission Cross Sections of ${ }^{233} \mathrm{U},{ }^{235} \mathrm{U},{ }^{238} \mathrm{U}$ and ${ }^{239} \mathrm{Pu}$. ANL, June 28-30, 1976. ANL-76-90, 1976,183.

136.Behrens J.W., Carlson G.W. "Measurement of the fission cross section of ${ }^{241} \mathrm{Pu}$ relative to ${ }^{235} \mathrm{U}$ for neutron energies from $1 \mathrm{keV}$ to $30 \mathrm{MeV}$ " Nucl. Sci. Eng., 68, 128 (1978).

137.Kaeppeler F., Pfletchinger "Measurement of the fission cross section of ${ }^{241} \mathrm{Pu}$ relative to ${ }^{235} \mathrm{U}$ " Nucl. Sci. Eng., 51124 (1973).

138.Adamov V.M., Gusev S.E., Drapchinskij L.V. et al., "Absolute measurements of fission cross sections for U-234, U-236, Pu-240, Pu-241 and Am-243 by the neutrons of Cf-252fission spectrum", Proc. 6th All-Union Conf. Neutron Physics,Kiev, Soviet Union, October 2-6, 1983, 2, 134, Atomizdat (1984).

139.Smith H.L., Smith R.K., Henkel R.L. "Neutron-induced fission of ${ }^{241}$ Pu”, Phys. Rev. 125, 1329 (1962)

140.Szabo I., Filippi G., Huet J.L., et al., "New absolute measurements of neutron-induced fission cross sections of 235U, 239Pu and $241 \mathrm{Pu}$ from $17 \mathrm{keV}$ to $1 \mathrm{MeV}$ ", Proc. Meeting on Fast Neutron Cross Sections of U-233,-235, -238 and Pu-239, Argonne, 28-30 June 1976, p. 208.

141.Silbert M.G., LA-6239-MS (1976).

142.Fomushkin E.F., G.F. Novoselov, Y.I. Vinogradov et al., Atomnaya Energiya, 63, 242 (1987)

143.White R.M., Browne J.C., In: Proc. Int. Conf. Nuclear Data for Science and Technology (NorthHolland, 1983), p.281

144.Fomushkin E.F., Novoselov G.F., Gavrilov G.F. et al. Measurement of highly active isotope fission cross sections with nuclear explosion neutrons. In: Proc. Int. Conf. On Nuclear Data for Science and Technology (Springer-Verlag, 1992), p. 439.

145.Kuprijanov V.M., Fursov B.I., Ivanov V.I. G.N.Smirenkin., 'The measurement of ${ }^{237} \mathrm{~Np} /{ }^{239} \mathrm{Pu}$ and ${ }^{241} \mathrm{Am} /{ }^{239} \mathrm{Pu}$ fission cross section ratios in the $0.13-7.0 \mathrm{MeV}$ neutron energy interval" Atomnaya Energiya, 45, 440 (1978).

146.Behrens J.W., Browne J.C., Walden J.C. "Measurement of the neutron-induced fission cross section of the ${ }^{237} \mathrm{~Np}$ relative to ${ }^{235} \mathrm{U}$ from 0.02 to $30 \mathrm{MeV}$ ”. Nucl. Sci. Eng., 80, 239 (1982).

147. Meadows J.W., "The fission cross section of ${ }^{237} \mathrm{~Np}$ relative to ${ }^{235} \mathrm{U}$ from 0.1 to $10 \mathrm{MeV}$ ". Nucl. Sci. Eng., 85, 271 (1983).

148.Kanda K., Sato O., Yoshida K. et al. "Measurement of the fast neutron induced fission crosss section", JAERI-M-85-035, 1985, p. 220.

149. Terayama H., Karino Y., Manabe F. et al. "Measurement of fast neutron-induced fission cross section of ${ }^{236} \mathrm{U},{ }^{237} \mathrm{~Np}$ and ${ }^{243} \mathrm{Am}$ relative to ${ }^{235} \mathrm{U}$ from 0.7 to $7 \mathrm{MeV}$ ", NEANDC(J)-122, 1986.

150.Goverdovskij A.A., Gordyushin A.K., Kuz'minov B.D. et al. ${ }^{، 237} \mathrm{~Np}$ to ${ }^{235} \mathrm{U}$ fission cross section ratio measurement for neutrons in the energy range 4-11 MeV" Atomnaya Energiya, 58, 137 (1985). 
151.Goverdovskij A.A., Gordyushin A.K., Kuz'minov B.D. et al. ${ }^{، 237} \mathrm{~Np}$ to ${ }^{235} \mathrm{U}$ fission cross section ratio measurement by the method of isotope impurities" Proc. $6^{\text {th }}$ All-Union Conf. on Neutron Physics, Kiev, 1983, vol.3, 115 (1983).

152.Alkhazov I.D., Ganza E.A., Drapchinskij L.V., et al. "Absolute measurements of the fission ccross sections for some heavy isotopes by the neutrons with energies 2.6, 8.4, 14.7 MeV". Proc. Of the 3d All-Union Conference on the Neutron Radiation Metrology at Reactors and Accelerators, Moscow, 1983, CNIIAtominform, 1983, vol. 2., p. 201.

153.Tovesson F. and Hill T.S., Phys. Rev. C 75, 034610 (2007).

154.Ignatyuk A.V., Kornilov N.V., Maslov V.M. "Isomer ratio and ${ }^{237} \mathrm{~Np}(\mathrm{n}, 2 \mathrm{n})$ reaction cross section" Atomnaya Energiya 63, 110 (1987).

155.Maslov V.M. “Analysis of the ${ }^{237} \mathrm{~Np}$ fission cross sections and (n,xn) reactions”. INDC(CCP)-366, p. 27, 1994 (translated from Маслов В.М. Анализ сечений деления и $(\mathrm{n}, \mathrm{xn})$ реакций для ${ }^{237} \mathrm{~Np}$.

Вопросы Атомной Науки и Техники (сер. Ядерные константы) 4 (1987) 19.).

156.Bowman J.C., Auchampaugh G.F., Fultz S.C., Hoff R.W. Phys. Rev. 166, 1216 (1968).

157.Dabbs J.W.T., Johnson C.H., Bemis Jr. C.E. Measurement of the ${ }^{241}$ Am Neutron Fission Cross Section. Nucl. Sci. Eng. 83 (1983) 22.

158.Shpack D.L., Ostapenko Yu.B., Smirenkin G.N. JETP Lett. 10, 175 (1969)

159.Gayther D.B. and Thomas B.W. Proc. 4th All-Union Conf. Neutron Physics,Kiev, Soviet Union, April 18-22, 1977, III, 3, Atomizdat (1977).

160.Wisshak K., Kappeler Nucl. Sci. Eng. 76, 148 (1980)

161.Hage W., Wisshak K., Kappeler Nucl. Sci. Eng. 78, 248 (1981)

162.Knitter H.-H., Budtz-Jorgensen C. Atomkernenergie. Kerntechnik, 3, 205 (1979).

163.Behrens J.W., Browne J.C. Measurement of the Neutron-Induced Fission Cross Sections of Americium-241 and Americium-243 Relative to Uranium-235 from 0.2 to $30 \mathrm{MeV}$. Nucl. Sci. Eng. 77 (1981) 444.

164.Prindle A.L., Sisson D.H., Nethaway D.R., Kantelo M.V., Sigg R.A. Fission of ${ }^{241}$ Am with 14.8MeV Neutrons. Phys. Rev. C20 (1979) 1824.

165.Cance M., Grenier G., CEA-N-2194, 1981

166.Protopopov A.N., Selitskij Yu.A., Solov'ev S.M. Sov. J. At. Energy 6, 36 (1959)

167.Kazarinova M.I., Zamyatnin Yu.S., Gorbachev V.M. Sov. J. At. Energy 8, 125 (1960).

168. Fomushkin E.F., Gutnikova E.K., Zamyatnin Yu.S. et al. Yadernaya Fyzika, 5, 917 (1969).

169.Filatenkov A.A., Chuvaev S.V., Aksenov V.N. et. al., Report of INDC(CCP)-402, 1997.

170.Perdikakis et al. Phys. Rev. C 73, 067601 (2006).

171.Vieira D.J., Jandel M., Bredeweg T.A. e. a. Neutron capture and (n,2n) measurements on ${ }^{241}$ Am.In: Abstracts of International Conference on Nuclear Data for Science and Technology, April 22-27, 2007, Nice, France, p.31.

172.Maslov V.M., Porodzinskij Yu.V., Sukhovitskij E.Sh., Morogovskij G.B. Neutron Data Evaluation for Americium-241-242,-242m,-243. In: Proc. International Conf. Nuclear Data for Science and Technology, May 19-24, 1997, Trieste, Italy, p. 1317.

173.Fursov B.I., Baranov E.Yu., Klemyshev M.P. et al. Sov. J. At. Energy 59, 899 (1985).

174.Knitter H.-H., Budtz-Jorgensen C. Nucl. Sci. Engng. 99, 1 (1988).

175.Goverdovskij A.A., Gordyushin A.K., Kuzminov B.D. et al. Sov. J. At. Energy 67, 524 (1990).

176.Fomushkin E.F., Novoselov G.F., Vinogradov Yu.I. et al. Yadernye Konstanty 57(3), 17 (1984).

177.Wisshak K., Kappeler Nucl. Sci. Eng. 85, 251 (1983)

178.Butler D.K. and Sjoblom R.K. Phys. Rev. 124, 1129 (1961)

179.Behrens J.W., Browne J.C. Nucl. Sci. Engng. 77, 444 (1981). 
180.Kanda K., Imaruoka H., Terayama H. et al., Journal of Nucl. Sci. Tech., 24, 423 (1987).

181.Laptev A.B., Donetz A.Yu., Dushin V.N., at al. Neutron-Induced Fission Cross Sections of ${ }^{240} \mathrm{Pu}$,

${ }^{243} \mathrm{Am}$ and ${ }^{\text {nat }} \mathrm{W}$ in the energy range 1-200 MeV. In: Proc. of the International Conference on Nuclear Data for Science and Technology, September 26 - October 1, 2004, Santa Fe, USA, p. 865.

182.Browne J.C., White R.M., Howe R.E. et al. ${ }^{242 \mathrm{~m}}$ Am Fission Cross Section. Phys. Rev. 29 (1984) 2188

183.Fursov B.I., Samylin B.F.,Smirenkin G.N., Polynov V.N., Nuclear Data for Science and Technology, Proc. of the Int. Conf., Gatlinburg, Tennessee, USA, May 9-13, 1994, v.I, p. 269.

184.Dabbs J.W. , Bemis C.E., Raman S., et al., Nucl. Sci. Engng. 84, 1 (1983).

185.Fomushkin E.F., Novoselov G.F., Vinogradov Yu.I., et al. Yad. Fyz.., 33, 620 (1981).

186.Glazkov N.P., Atomnaya Energ. 14, (4), 400, (1963).

187.Smith W., Phys. Rev, 126, 718 (1962)

188.Fujita Y., Ohsawa T., Bugger R.M. et al.,J. of Nucl. Sci. and Tech., 20, 983 (1983).

189.Маслов В.М., Породзинский Ю.В., Баба М. И Хасегава А. Рассеяние нейтронов на ядрах U и Th с возбуждением коллективных уровней ядер. Изв. Академии Наук, Серия физическая, 67 (2003) 1597.

190.Maslov V. M, Baba M., Hasegawa A., Kornilov N.V., Kagalenko A. B., Tetereva N.A. U-Th fuel cycle neutron data. In: Proc. of the International Conference on Nuclear Data for Science and Technology, September 26 - October 1, 2004, Santa Fe, USA, p. 191.

191.Kornilov N.V., Kagalenko A.B., Nucl. Sci. Eng., 120, 55 (1995).

192.Baba M. et al., J. Nucl. Sci. Technol. 27, 7, 601 (1990).

193.Wienke H. et al., In: Abstracts of International Conference on Nuclear Data for Science and Technology, April 22-27, 2007, Nice, France, p.222.

194.Batchelor R., Wyld K. "Neutron Scattering by ${ }^{235} \mathrm{U}$ and ${ }^{239} \mathrm{Pu}$ for incident neutrons of 2, 3 and 4 MeV". AWRE-0-55/69, 1969.

195.Andreev V.N. "Inelastic scattering of neutrons of the fission spectrum and neutrons with an energy of $0.9 \mathrm{MeV}$ in ${ }^{239} \mathrm{Pu}$ ". Nejtronnofizicheskie issledovaniya v USSR, 1961, No. 4, p. 287.

196.Wisshak K., Voss F., Kaeppeler F., Nucl. Sci. Eng., 137 (2001) 183.

197.Karamanis D., Petit M., Andriamonje S. et al., Nucl. Sci. Eng., 139 (2001) 282.

198.Poenitz W.P., Smith D.L., Report ANL-NDM-42, 1978.

199.Lindner M., Nagle R.J., Landrum J.H., Nucl. Sci. Eng., 59 (1976) 381.

200.Anand R.P., Jain H.M., Kailas S., et. al., Annals of Nucl. Energy, v.16(2), p.87, 1989.

201.Kobayashi K., Fujita Y., Yamamuro N., Nucl. Sci. Techn., 18 (1981) 823.

202.Macklin R.L., R.R. Winters Nucl. Sci. Eng., 78 (1981) 110.

203.Macklin R.L.,Halperin J., Nucl. Sci. and Eng., 64 (1977) 849.

204.Aerts G., Abbondanno U. and the n TOF Collaboration, Measurement of the ${ }^{232}$ Th Neutron capture cross section at the CERN n_TOF facility. Proc. of the International Conference on Nuclear Data for Science and Technology, September 26 - October 1, 2004, Santa Fe, USA, p. 1470.

205.Volev K., Kuymdjieva N., Brusegan A., Borella A., Siegler P., Janeva N., Lukyunov A., Leal L., and Schillebeeckx P. Evaluation of the ${ }^{232}$ Th neutron cross sections between $4 \mathrm{keV}$ and $140 \mathrm{keV}$. In: Proc. of the International Conference on Nuclear Data for Science and Technology, September 26 October 1, 2004, Santa Fe, USA, p. 87

206.Maslov V.M. et al., Nucl. Sci. and Eng., 143 (2003) 177.

207.V.M. Maslov, “232 Th neutron capture cross section”, Proc. of the $13^{\text {th }}$ International Seminar on Interaction of Neutrons with Nuclei, May 25-28, 2005, Dubna, Russia, 2006. 
208.Buleeva N.N., Davletshin A.N., Tipunkov O.A., et al., "Neutron radiation capture cross sections for ${ }^{236} \mathrm{U},{ }^{238} \mathrm{U}$ and ${ }^{237} \mathrm{~Np}$ measured by the activation metod". Atomnaya Energya, 65, 348 (1988).

209.Lindner M., Nagle R.J. and Landrum J.”(n,2n) cross sections for $238 \mathrm{U}$ and $237 \mathrm{~Np}$ in the region of $14 \mathrm{MeV}$ '. Nucl. Sci. Eng. 59, 381 (1976).

210.Quang E., Knoll G.F., Nucl. Sci. Eng. 110, 282 (1991).

211.Voignier J., Joly S. and Grenier G., Nucl. Sci. Eng. 93, 43 (1986).

212.Davletshin A.H., Tipunkov A.O. and Tolstikov V.A., Neutron Physics, Proc. All-Union Conference, Vol. 4, p.109, Tsniiatominform, Moscow 1975) [in Russian].

213.Poenitz W.P., Fawcett, Jr., L.R. and Smith D.L. Nucl. Sci. Eng. 78, 239 (1981).

214.Poenitz W.P., Nucl. Sci. Eng., 57, 300 (1975).

215.Kazakov L.E., Kononov V.N., Manturov G.N., et al. "Neutron capture cross section measurements for ${ }^{238} \mathrm{U}$ in the energy range from 4 to $460 \mathrm{keV}$ ", Yadernye Konstanti, 3,37 (1986).

216.Adamchuk Yu.V.,Voskanyan M.A., Muradyan G.V. et al., in: Proc. Int. Conf. on Neutron Physics, Kiev, 1987, v.2, 242 (1988).

217.Trofimov A.N. Sov. At. Energy,64, 179 (1988).

218.Davletshin A.N., Tipunkov S.V., Tikchonov C.V. et al., Atomnaya Energiya, 58, 183 (1985).

219.Gudkov A.N., Davletshin A.N., Zhivun V.N. et al., Sov. J. At. Energy 61, 956(1987)

220.Maslov V.M., Porodzinskij Yu. V., Baba M., Hasegawa A. "Actinide neutron capture cross sections" Proc. of Eleventh International Symposium on Capture Gamma-Ray Spectroscopy and Related Topics, September 2-6, Prague, 2002, pp. 757-760.

221.Muradian G.V., Furman W.I. Private communication, 1998.

222.Weston L.W. and Todd L.H., Nucl. Sci. Eng. 63, 143 (1977).

223.Wisshak K., Kappeler F. Nucl. Sci. Eng. 66, 363 (1978).

224.Wisshak K., Kappeler F. Nucl. Sci. Eng. 69, 39 (1979).

225.Hockenbury R.W., Sanislo A.J., Kaushal N.N. Proc. Conf. on Neutron Cross Sections and Technology, Washington, vol. 2, 1972, 584.

226.Hopkins, B.C. Diven, Nucl.Sci.Eng. \textbf\{12\}, 169 (1962).

227.F. Corvi et al., NEANDC(E)-232, 5 (1982)

228.B. Spivak et al., Sov. J. At. Energy $\backslash$ textbf $\{1\}, 26$ (1956).

229.V.M. Andreev, Sov. J. At. Energy \textbf $\{4\}, 247$ (1958).

230.V.M. Kononov et al., Sov. J. At. Energy \textbf\{32\}, 85 (1972).

231.G.V. Muradyan et al. In: Fourth All-Union Conf. on Neutron Physics, Kiev, 1977\}. (Moscow, 1978) vol. 3, p. 119.

232.Weston L.W., Gwin R.,.De Saussure G., Fullwood R.R., Hockenbury R.W. Nucl. Sci. Eng., 34, 1 (1968).

233.Gwin R., Silver E.G., Ingle R.W., Weaver H., Nucl. Sci. Eng., 59, 79 (1976)

234.Kononov V.N., Poletaev E.D., Prokopetz Yu.S. etal., Atomnaya energiya, 38, 81 (1975)

235.Bolotskij V.P., Petrushin V.I., Soldatov A.N., Sukhoruchkin S.I., Second All-Union Conf. on Neutron Physics, , 28 May - 1 June, 1973vol. 4., p. 49, 1973

236.Lindner M., Nagle R.J., Landrum J.H. Nucl. Sci. Eng., 59, 381 (1976).

237.Stupegia D.C., Schmidt M., Keedy C.R., Nucl. Sci. Eng., 29, 218 (1967).

238.Trofimov Yu. N., Nemilov Ju.A. Proc. $6^{\text {th }}$ All-Union Conf. on Neutron Physics, Kiev, 1983, v.2, 142 (1983).

239.Weston L.W., Todd J.H., Nucl. Sci. Eng., 79, 184 (1981).

240.Vanpraet G.,Cornelis E., Raman S., Rohr G. Nuclear Data for Basic and Applied Science, Proc. Int. Conf., Santa Fe, 1985, vol. 1, 493. 
241.Gayther D.B. and Thomas B.W. Proc. 4th All-Union Conf. Neutron Physics, Kiev, Soviet Union, April 18-22, 1977, III, 3, Atomizdat (1977).

242.Wisshak K., Kappeler Nucl. Sci. Eng. 76, 148 (1980)

243.Wisshak K., Kappeler Nucl. Sci. Eng. 85, 251 (1983)

244.Weston L.W. and Todd J.H. Nucl. Sci. Eng., 91, 444 (1985)

245.Tewes H.A., Caretto A.A., Miller A.E. et. al., Report UCRL-6028-T,1960.

246.Butler J.P., Santry D.C., Canadian Journal of Chemistry, v.39, p.89, 1961.

247.Cochran D.R.F., Henkel R.L., Preprint WASH-1013,p.34, 1958.

248.Raics P., Daroczy S., Csikai J. et. al., Phys. Rev/C, v.32, no.1, p.87, 1985; Report INDC(HUN)029/L, IAEA, 1990.

249.Prestwood R.J., Bayhurst B.P., Phys. Rev., v.121, p.1438, 1961

250.Karius H., Ackermann A., Scobel W., Journ. of Physics part G (Nuclear Physics), v.5, no.5, p.715, 1979.

251.Perkin J.L., Coleman R.F., Journal of Nuclear Energy, v.14, p.69, 1961.

252.Phillips J.A., Report of AERE-NP/R-2033, 1956.

253.Chatani H., Kimura I., Annals of Nuclear Energy, v.19, no.8, p.477, 1992.

254.Zysin Yu.A., Kovrizhnykh A.A., Lbov A.A. et. al., Journal of Atomic Energy, v.8, p.360, 1960.

255.Batchelor R.,Gilboy W.B.,Towle J.H., Nuclear Physics, v.65, p.236, 1965.

256.Karamanis D., Andriamonje S., Assimakopoulos P.A. et al. Neutron cross-section measurements in the Th-U cycle by the activation method. Nucl. Instr. and Meth. A505 (2003) 381.

257.Knight J.D., Smith R.K., Warren B. Phys. Rev., 112, 259(1958).

258.Nagy S., Flynn K.F. et al., Phys. Rev., C17, 163 (1978).

259.Kornilov N.V., Sal'nikov O.A. et al. Voprosi Atomnoi Nauki I Tehniki (VANT), ser. Yadernie konstanti, 1(45), 33 (1982)

260.Chou You-Pu, internal report HSJ-77091,7810, in chinese,EXFOR 30537

261.Ackerman A., Anders B., Borman H. Proc. Conf. Nuclear Cross Sections and Technology, Washington D.C., March 3-7, 1975, CONF-750303, Vol. 2, p.425, US National Bureau of Standards (1975).

262.Veeser L.R., Arthur E.D., Proc. Intern. Conf. on Neutron Physics and Nuclear Data, OECD, Harwell 1054 (1978).

263.Frehaut J., Bertin A., Bois R., Nucl. Sci. Eng. 74, 29 (1980).

264.D.C. Mather et al., AWRE 072/72, 1972.

265.D.A. Brown et al., LLNL Report, 2004 (in press)

266.R.W. Lougheed et al., Radiochimica Acta, 833 (2002) 833.

267.L.A. Bernstein et al., Phys. Rev. C65 (2002) 021601.

268.V.M. Maslov "Prompt fission neutron spectra of $\mathrm{U}$ and $\mathrm{Pu}$ above emissive fission threshold", Nuclear Spectroscopy, 56 ${ }^{\text {th }}$ Intern. Conf., Sarov, Russia, 2006 (in Russian); Maslov V.M. Pairing Effects in ${ }^{239} \mathrm{Pu}(\mathrm{n}, 2 \mathrm{n})$ Reaction Cross Section, Zeit. Phys. A, Hadrons \& Nuclei, 347 (1994) 211.

269.Gromova E.A., Kovalenko S.S., Nemilov Yu.A. et al. "Measurement of ${ }^{237} \mathrm{~Np}(\mathrm{n}, 2 \mathrm{n})$ reaction cross section at $14.8 \mathrm{MeV}$ neutron incident energy" Atomnaya Energiya, 54, 198 (1983).

270.Nishi T., Fujiwara I., Imanishi N. “(n,2n) cross sections for the ${ }^{237}$ Np”. NEANDC(J -42L, $20,1975$.

271.Paulson C.K., Hennelly E.J. "cross sections measurement of ${ }^{236} \mathrm{Pu}$ formation in ${ }^{238} \mathrm{Pu}$ by ${ }^{237} \mathrm{~Np}(\mathrm{n}, 2 \mathrm{n})$ reaction". Nucl. Sci. Eng. 5, 24 (1974).

272.Daroczy S., Raics P., Csikai J., Kornilov N.V. et al. "Measurement of ${ }^{237} \mathrm{~Np}(\mathrm{n}, 2 \mathrm{n}){ }^{236} \mathrm{~Np}(22.5 \mathrm{hrs})$ cross section for neutron energy between 7 and $10 \mathrm{MeV}$ ". Atomnaya Energiya, 58, 117 (1985). 
273.Lindeke K., Specht S., Born H.J. "Determination of the ${ }^{237} \mathrm{~Np}(\mathrm{n}, 2 \mathrm{n}){ }^{236} \mathrm{~Np}$ cross section at $15 \mathrm{MeV}$ neutron energy" Phys. Rev. C 12, 1507 (1975).

274.Perkin J.L., Coleman R.F. "Cross sections for the $(\mathrm{n}, 2 \mathrm{n})$ reaction of ${ }^{232} \mathrm{Th},{ }^{238} \mathrm{U}$ and ${ }^{237} \mathrm{~Np}$ with 14 MeV neutrons" Ann. Nucl. Energy, 14, 69 (1961).

275.Filatenkov A.A, Chuvaev S.V., Smith D.L., Ikeda Y., et al. In: Proc. Int. Conf. Nuclear Data for Science and Technology, Trieste, Italy, May 19-24, 1997, p. 1313.

276.Perdikakis et al. (Phys. Rev. C 73, 067601 (2006))

277.Lougheed (2001).

278. Gancarz (1983).

279.Myers W.A., Lindner M., Newburry R.S. "The isomer ratio of ${ }^{236 \mathrm{~Np}(1)} \mathrm{Np} /{ }^{236(\mathrm{~s})} \mathrm{Np}$ in the reaction $\left.{ }^{237} \mathrm{~Np}(\mathrm{n}, 2 \mathrm{n})^{236} \mathrm{~Np}\right)$ from neutrons, produced in thermonuclear devices". Journ. Inorg. Chem. 37, 637 (1975).

280.Howerton, R.J. Doya, Nucl. Sci. Eng.,46 (1971) 414.

281.Glendenin L.E., Gindler J.E., Ahmad I.,Henderson D.J., Meadows J.W. Phys. Rev. C, 22, 52 (1980).

282.Howe R.E. Nucl. Sci Eng., 86, 157 (1984).

283.Conde H., Holmberg M. Journ. AF, 29, 33 (1965).

284.Batchelor R., Gilboy W.B., Towle J.H. Nucl. Phys., 65, 236 (1965).

285.Mather D.S., Fieldhouse P., Moat A. Nucl. Phys., 66, 149 (1965).

286.Frehaut J., Bois R., Bertin A. Report of CEA-N-2196, 1981.

287.Caruana J., Boldeman J.W., Walsh R.L. Nucl. Phys. A, 285,217 (1977).

288.Prokhorova L.I., Smirenkin G.N. Sov. Nucl. Phys, 7, 579 (1968).

289.Malinovskyj V.V., Vorobjova V.G., Kuzminov B.D., Piksajkin V.M., Semjonova N.N., Valjavkin V.S., Solovjov S.M. Atomnaja Energija, 54,209 (1983).

290.Kuzminov B.D. Sov. Nucl. Phys, 4, 241 (1961).

291.Smith A.B., Nobles R.G., Cox S.A. Phys. Rev., 115, 1242(1959).

292.Bondarenko I.I., Kuzminov B.D., Kutsayeva L.S., Prokhorova L.I., Smirenkin G.N. Second UN

Conf. on the Peaceful Uses of Atomic Energy, Geneva, 15, 353, 1958, Report 2187.

293.Leroy J. Journ. de Physique (J. Phys. Radium), 21, 617 (1960.).

294.Feu C. Journ. de Physique, 38, 273 (1977).

295.Johnstone I. Report of AERE-NP/R-1912, 1956.

296.Frehaut J., NEANDC(E) 238/L (1986).

297.Nurpeisov B., Volodin K.E., Nesterov V.G., et. al.,Atomnaya Energiya, 39, 199 (1975)

298.Malinovskij V.V., Kuz'minov B.D., Vorob'jova V.G., Yadernye Konstanty, 1/50, 4, (1983)

299.Vorob'jova V.G., D'jachenko N.P., Kuz'minov B.D., Sergachjov A.I.,Yadernye Konstanty 15, 3, (1974).

300.Savin M.U., Khokhlov Yu., Paramonova I.N., Chirkin V.A., Atomnaya Energiya, 32, 408, (1972)

301.Zongyu Bao, J. CST, 9, (4), 362, (1975)

302.Conde H., Holmberg M.'Prompt nu-bar in spontaneous and neutron-induced fission of 236U and the half-life for spontaneous fission". Ann. Nucl. Energy, 25, 331 (1971).

303.Vorob'jova V.G., Kuz'minov B.D., Malinovskij V.V. et al. "Measurement of the average number of prompt fission neutrons for neutron-induced fission of ${ }^{236} \mathrm{U}$ " $5^{\text {th }}$ All-Union Conf. Neutron Physics,Kiev, Soviet Union, September 15-19, 1980, vol. 3, 95 Atomizdat (1980)..

304.Khokhlov Yu. A., Ivanin I.A., In'kov V.I., et al. "Measurements results of average neutron multiplicity from neutron induced fission of actinides in 0.5-10 MeV energy range". Proc. Int. Conf. 
Nuclear Data for Science and Technology, Gatlinburg, USA, May 9-13, 1994, p. 272, J.K. Dickens (Ed.),ANS, 1994.

305.D.C. Madland and J.R. Nix, Nucl. Sci. Eng., 81 (1982) 213.

306.J.Frehaut, R. Bois, A. Bertin, Proc. Int. Conf. Nuclear Data for Science and Technology, Antwerpen, Belgium, September 6-10, 1982, p. 78, Reidel Publ. Co., Holland, 1983.

307.J. Frehaut, M. Soleilhac, G. Mosinski, Second All-Union Conf. on Neutron Physics, Kiev, 28 May 1 June, 1973, vol. 3, p. 153.

308.Frehaut J., private communication to EXFOR (1980).

309.R. Gwin, R.R. Spencer, R.E. Ingle et al., ORNL-TM-7148, 1980

310.Boldeman J.W, Walsh R.L. J. Nucl. Energ., 25, (8), 321 (1971).

311.Flerov N.N., Talyzin V.M. J. Nucl. Energ., 17, 423 (1963).

312.Hopkins J.C.,Diven, B.C. Nucl.Phys., 48, 433 (1963).

313.Gwin R., Spencer R.R., Ingle R. Nucl. Sci. Eng., 94, 365(1986).

314.Johnstone I. AERE -NP/R-1912 (1956).

315.Kolosov N.P., Kuzminov B.D., Sergachev A.I, Surin V.M. Atomnaya Energiya, 32, (1), 83 (1972).

316.Mather D.S., Fieldhouse P., Moat A. et al. J. Nucl. Phys., 66,149 (1965).

317.Protopopov A.N., Blinov M.V. J. Nucl. Energ. 10, 65 (1959).

318.Sergachev A.I., et al. Yadernaya Fizika, 16, (3), 475 (1972).

319.Smirenkin G.N., Bondarenko I.I., Kutsaeva L.S. et al. J.Nucl. Energ. 9,155 (1959).

320.Colvin D.W. and Sowerby M.G. Harwell report, 1964, data scanned from curve in BNL-325, suppl.2, 1965.

321.Kroshkin N.I. and Zamyatnin Yu.S., Atomnaya Energiya, 29, 95 (1970).

322.Jaffey A.H., Lerner J.L., Nucl. Phys. A, 145, 1 (1970).

323.Howe R.E., White R.M., Browne J.C., Landrum J.H., Dougan R.J., Lougheed R.W., Dupzyk R.J., Nucl. Phys., A407, 193 (1983).

324.Lebedev V.I.,Kalashnikova V.I., Atomnaya Energiya 5, 176 (1958)

325.Veeser W., Phys. Rev. C 17, 385 (1978).

326.Frehaut J., Bois R., Bertin A. Report of CEA-N-2396, 1984, p. 69.

327.Howe R.E., Browne J.C., Dougan R.J., Dupzyk R.J., Landrum J.H. Nucl. Sci. Eng. 77,454 (1981).

328.Fultz S.C., Caldwell J.T., Berman B.L., et al. Phys. Rev., 152, 1046 (1966).

329. Salvatores M. Nuclear data needs for advance reactor systems. A NEA Nuclear Science Committee initiative, in: Abstracts of Interna-tional Conference on Nuclear Data for Science and Technology, April 22-27, Nice, France, p.28. 


\section{Apendix A}

In the following, numerical tables for the relative cross section uncertainties (relative standard deviations) and correlations (normalized to 1000), borrowed from $[1,2\}$ are given in a 15-group representation

Tables of cross section and certainties and covariances, borrowed from $[1,2]$

\begin{tabular}{|c|c|c|}
\hline Group no. & Energy $\operatorname{Max}(\mathrm{eV})$ & Energy Min (eV) \\
\hline 1 & $19.6 E+07$ & $6.07 \quad E+06$ \\
\hline 2 & $6.07 \quad E+06$ & $2.23 E+06$ \\
\hline 3 & $2.23 E+06$ & $1.35 \mathrm{E}+06$ \\
\hline 4 & $1.35 \mathrm{E}+06$ & $4.98 \quad E+05$ \\
\hline 5 & $4.98 E+05$ & $1.83 \mathrm{E}+05$ \\
\hline 6 & $1.83 E+05$ & $6.74 \quad E+04$ \\
\hline 7 & $6.74 \quad E+04$ & $2.48 \quad E+04$ \\
\hline 8 & $2.48 E+04$ & $9.12 \quad E+03$ \\
\hline 9 & $9.12 \mathrm{E}+03$ & $2.04 E+03$ \\
\hline 10 & $2.04 \quad E+03$ & $4.54 \quad E+02$ \\
\hline 11 & $4.54 \quad E+02$ & $2.26 \mathrm{E}+01$ \\
\hline 12 & $2.26 E+01$ & $4.00 \quad E+00$ \\
\hline 13 & $4.00 \quad E+00$ & $5.40 \mathrm{E}-01$ \\
\hline 14 & $5.40 \mathrm{E}-01$ & $1.00 \mathrm{E}-01$ \\
\hline 15 & 1.00 E-01 & $1.00 \mathrm{E}-05$ \\
\hline
\end{tabular}

$232 \mathrm{Th}(\mathrm{n}, \mathrm{el})$

group rel.s.d.

$1 \quad 1.3888 \mathrm{E}-02$

$2 \quad 1.2163 \mathrm{E}-02$

$32.0000 \mathrm{E}-02$

$4 \quad 1.7999 \mathrm{E}-02$

$5 \quad 1.6491 \mathrm{E}-02$

$61.1832 \mathrm{E}-02$

$72.0000 \mathrm{E}-02$

$82.0000 \mathrm{E}-02$

\begin{tabular}{|c|c|c|c|c|c|c|c|c|c|c|c|c|c|c|}
\hline 1000 & 189 & 74 & 74 & 102 & 101 & 0 & 0 & 0 & 0 & 0 & 0 & 0 & 0 & 0 \\
\hline 189 & 1000 & 124 & 100 & 132 & 133 & 0 & 0 & 0 & 0 & 0 & 0 & 0 & 0 & 0 \\
\hline 74 & 124 & 1000 & 290 & 217 & 164 & 0 & 0 & 0 & 0 & 0 & 0 & 0 & 0 & \\
\hline 74 & 100 & 290 & 1000 & 262 & 171 & 0 & 0 & 0 & 0 & 0 & 0 & 0 & 0 & \\
\hline 102 & 132 & 217 & 262 & 1000 & 212 & 0 & 0 & 0 & 0 & 0 & 0 & 0 & 0 & \\
\hline 101 & 133 & 164 & 171 & 212 & 1000 & 170 & 168 & 54 & 0 & 0 & 0 & 0 & 0 & \\
\hline 0 & 0 & 0 & 0 & 0 & 170 & 1000 & 991 & 322 & 0 & 0 & 0 & 0 & 0 & \\
\hline 0 & 0 & 0 & 0 & 0 & 168 & 991 & 1000 & 335 & 0 & 0 & 0 & 0 & 0 & \\
\hline 0 & 0 & 0 & 0 & 0 & 54 & 322 & 335 & 1000 & -25 & -4 & -56 & -105 & -110 & -112 \\
\hline 0 & 0 & 0 & 0 & 0 & 0 & 0 & 0 & -25 & 1000 & 5 & -64 & -118 & -124 & -126 \\
\hline 0 & 0 & 0 & 0 & 0 & 0 & 0 & 0 & -4 & 5 & 1000 & -275 & -450 & -464 & -468 \\
\hline 0 & 0 & 0 & 0 & 0 & 0 & 0 & 0 & -56 & -64 & -275 & 1000 & 505 & 496 & 492 \\
\hline 0 & 0 & 0 & 0 & 0 & 0 & 0 & 0 & -105 & -118 & -450 & 505 & 1000 & 990 & 983 \\
\hline 0 & 0 & 0 & 0 & 0 & 0 & 0 & 0 & -110 & -124 & -464 & 496 & 990 & 1000 & 999 \\
\hline 0 & 0 & 0 & 0 & 0 & 0 & 0 & 0 & -112 & -126 & -468 & 492 & 983 & 999 & 1000 \\
\hline
\end{tabular}




\begin{tabular}{|c|c|c|c|c|c|c|c|}
\hline roup & rel.s.d. & --- & -- & - & -- & -- & ---- \\
\hline 1 & $4.8492 \mathrm{E}-02$ & 1000 & 549 & 192 & 51 & 28 & 13 \\
\hline 2 & $1.0000 \mathrm{E}-01$ & 549 & 1000 & 267 & 54 & -41 & -43 \\
\hline 3 & $1.0000 \mathrm{E}-00$ & 192 & 267 & 1000 & 163 & -83 & -102 \\
\hline 4 & $7.0000 \mathrm{E}-02$ & 51 & 54 & 163 & 1000 & 149 & 15 \\
\hline 5 & $2.0000 E-01$ & 28 & -41 & -83 & 149 & 1000 & 206 \\
\hline 6 & $2.3602 \mathrm{E}-01$ & 13 & -43 & -102 & 15 & 206 & 1000 \\
\hline
\end{tabular}

$232 \operatorname{Th}(\mathrm{n}, 2 \mathrm{n})$

group rel.s.d. ---

$11.0000 \mathrm{E}-01 \quad 1000$

$232 \mathrm{Th}(\mathrm{n}, \mathrm{f})$

group rel.s.d.

$13.0000 \mathrm{E}-02$

$23.0000 \mathrm{E}-02$

$33.0000 \mathrm{E}-02$

$43.0000 \mathrm{E}-02$

$59.5167 \mathrm{E}-01$

$64.6917 \mathrm{E}-01$

$\begin{array}{rrrrrr}1000 & 983 & 980 & 960 & 16 & 8 \\ 983 & 1000 & 991 & 970 & 16 & 9 \\ 980 & 991 & 1000 & 974 & 16 & 9 \\ 960 & 970 & 974 & 1000 & 17 & 10 \\ 16 & 16 & 16 & 17 & 1000 & 217 \\ 8 & 9 & 9 & 10 & 217 & 1000\end{array}$

$232 \mathrm{Th}(\mathrm{n}$, gamma $)$

group rel.s.d.

$1 \quad 1.7397 \mathrm{E}-01$

$21.0000 \mathrm{E}-01$

$37.0000 \mathrm{E}-02$

$47.0000 \mathrm{E}-02$

$5 \quad 1.2432 \mathrm{E}-02$

$6 \quad 1.1407 \mathrm{E}-02$

$75.0000 \mathrm{E}-02$

8 1.4553E-02

9 2.7999E-02

$103.3534 \mathrm{E}-02$ 


\begin{tabular}{|c|c|c|c|c|c|c|c|c|c|c|c|c|c|c|c|c|}
\hline 11 & $2.2069 E-02$ & 0 & 0 & 0 & 0 & 0 & 0 & 0 & 0 & 0 & 0 & 1000 & 1 & 130 & 110 & 102 \\
\hline 12 & $3.2750 E-02$ & 0 & 0 & 0 & 0 & 0 & 0 & 0 & 0 & 0 & 0 & 1 & 1000 & 7 & 5 & 5 \\
\hline 13 & $1.8986 \mathrm{E}-02$ & 0 & 0 & 0 & 0 & 0 & 0 & 0 & 0 & 2 & 3 & 130 & 7 & 1000 & 902 & 838 \\
\hline 14 & $1.3095 E-02$ & 0 & 0 & 0 & 0 & 0 & 0 & 0 & 0 & 1 & 3 & 110 & 5 & 902 & 1000 & 991 \\
\hline 5 & $1.2506 \mathrm{E}-02$ & 0 & 0 & 0 & 0 & 0 & 0 & 0 & 0 & 1 & 2 & 102 & 5 & 838 & 991 & 1000 \\
\hline
\end{tabular}

$233 \mathrm{U}(\mathrm{n}, \mathrm{el})$

group rel.s.d.

$12.0000 \mathrm{E}-02$

2 2.0000E-02

1000

$1000 \quad 979 \quad 391$

3. $0000 E-02$

1. $0000 \mathrm{E}-01$

1. $0000 \mathrm{E}-01$

9791000

$-15$

193

$\begin{array}{lll}-16 & -131 & -137\end{array}$

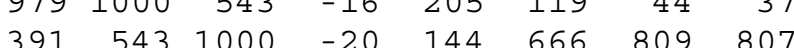

$\begin{array}{llllllll}15 & -16 & -20 & 1000 & 102 & -116 & -159 & -159\end{array}$

1. $0000 \mathrm{E}-01$

193205

$\begin{array}{llllll}144 & 102 & 1000 & 148 & 88 & 85\end{array}$

$\begin{array}{llllllll}-16 & 119 & 666 & -116 & 148 & 1000 & 785 & 784\end{array}$

1. $0000 \mathrm{E}-01$

$-131$

44

$\begin{array}{lllllll}809 & -159 & 88 & 785 & 1000 & 1000\end{array}$

1. $0000 \mathrm{E}-01$

$1.0000 \mathrm{E}-01$

$-137$

37

$807-159$

$85784 \quad 10001000$

1. $2000 \mathrm{E}-01$

0

00

0
0

0

$0 \quad 0$

$\begin{array}{lll}1000 & 317 & 332\end{array}$

$\begin{array}{lll}317 & 1000 \quad 997\end{array}$

332

$\begin{array}{lllll}1000 & 998 & 964 & 665 & 157\end{array}$

$6.0022 \mathrm{E}-02$

$5.6089 \mathrm{E}-02$

4. 1560E-02

$142.1388 \mathrm{E}-02$

$155.3372 \mathrm{E}-02$

0
0

0

0

0
0

$0 \quad 0$

$\begin{array}{lll}0 & 0 & 0\end{array}$

$\begin{array}{lllllll}340 & 996 & 998 & 1000 & 972 & 680 & 166\end{array}$

$\begin{array}{lllllll}356 & 961 & 964 & 972 & 1000 & 758 & 276\end{array}$

$\begin{array}{lllllll}276 & 658 & 665 & 680 & 758 & 1000 & 251\end{array}$

$\begin{array}{lllllrr}66 & 155 & 157 & 166 & 276 & 251 & 1000\end{array}$

\section{$233 U^{\left(n, n^{\prime}\right)}$}

group rel.s.d.

$1 \quad 1.0788 \mathrm{E}-01$

2 1.5000E-01

$31.5000 \mathrm{E}-01$

$\begin{array}{lllll}1000 & -741 & -35 & 64 & 0\end{array}$

$\begin{array}{lllll}-741 & 1000 & 43 & -95 & 0\end{array}$

4. $0461 \mathrm{E}-01$

$\begin{array}{lllll}-35 & 43 & 1000 & 980 & 0\end{array}$

5 1.0000E-00

$\begin{array}{rrrrr}64 & -95 & 980 & 1000 & 139 \\ 0 & 0 & 0 & 139 & 1000\end{array}$

$233 \mathrm{U}(\mathrm{n}, 2 \mathrm{n})$

group rel.s.d. ---

$1 \quad 1.8435 \mathrm{E}-01 \quad 1000$ 


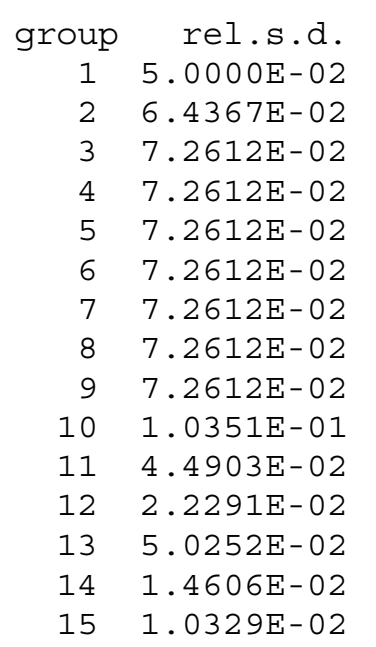

\begin{tabular}{|c|c|c|c|c|c|c|c|c|c|c|c|c|c|c|}
\hline 1000 & 795 & 291 & 291 & 291 & 291 & 291 & 291 & 291 & 3 & 0 & 0 & 0 & 0 & 0 \\
\hline 795 & 1000 & 718 & 718 & 718 & 718 & 718 & 718 & 718 & 8 & 0 & 0 & 0 & 0 & 0 \\
\hline 291 & 718 & 1000 & 1000 & 1000 & 1000 & 1000 & 1000 & 1000 & 11 & 0 & 0 & 0 & 0 & 0 \\
\hline 291 & 718 & 1000 & 1000 & 1000 & 1000 & 1000 & 1000 & 1000 & 11 & 0 & 0 & 0 & 0 & 0 \\
\hline 291 & 718 & 1000 & 1000 & 1000 & 1000 & 1000 & 1000 & 1000 & 11 & 0 & 0 & 0 & 0 & 0 \\
\hline 291 & 718 & 1000 & 1000 & 1000 & 1000 & 1000 & 1000 & 1000 & 11 & 0 & 0 & 0 & 0 & 0 \\
\hline 291 & 718 & 1000 & 1000 & 1000 & 1000 & 1000 & 1000 & 1000 & 11 & 0 & 0 & 0 & 0 & 0 \\
\hline 291 & 718 & 1000 & 1000 & 1000 & 1000 & 1000 & 1000 & 1000 & 11 & 0 & 0 & 0 & 0 & 0 \\
\hline 291 & 718 & 1000 & 1000 & 1000 & 1000 & 1000 & 1000 & 1000 & 11 & 0 & 0 & 0 & 0 & 0 \\
\hline 3 & 8 & 11 & 11 & 11 & 11 & 11 & 11 & 11 & 1000 & 17 & -3 & 1 & 1 & 1 \\
\hline 0 & 0 & 0 & 0 & 0 & 0 & 0 & 0 & 0 & 17 & 1000 & 21 & 1 & 4 & 2 \\
\hline 0 & 0 & 0 & 0 & 0 & 0 & 0 & 0 & 0 & -3 & 21 & 1000 & 30 & 55 & 51 \\
\hline 0 & 0 & 0 & 0 & 0 & 0 & 0 & 0 & 0 & 1 & 1 & 30 & 1000 & 148 & 146 \\
\hline 0 & 0 & 0 & 0 & 0 & 0 & 0 & 0 & 0 & 1 & 4 & 55 & 148 & 1000 & 948 \\
\hline 0 & 0 & 0 & 0 & 0 & 0 & 0 & 0 & 0 & 1 & 2 & 51 & 146 & 948 & 1000 \\
\hline
\end{tabular}

$233 \mathrm{U}(\mathrm{n}$, gamma $)$

\begin{tabular}{|c|c|c|c|c|c|c|c|c|c|c|c|c|c|c|c|c|}
\hline o &.$d$ & & & & & & & & & & & & & & & \\
\hline 1 & $6.0000 \mathrm{E}-01$ & 1000 & 409 & 458 & 498 & 498 & -104 & -297 & -303 & -317 & -16 & 0 & 0 & 0 & 0 & 0 \\
\hline 2 & $6.5000 \mathrm{E}-01$ & 409 & 1000 & 988 & 953 & 767 & -451 & -726 & -732 & -750 & -37 & 0 & 0 & 0 & 0 & 0 \\
\hline 3 & $5.0000 \mathrm{E}-01$ & 458 & 988 & 1000 & 988 & 839 & -405 & -712 & -719 & -740 & -36 & 0 & 0 & 0 & 0 & 0 \\
\hline 4 & $3.0000 \mathrm{E}-01$ & 498 & 953 & 988 & 1000 & 872 & -391 & -714 & -723 & -745 & -37 & 0 & 0 & 0 & 0 & 0 \\
\hline 5 & $2.0000 \mathrm{E}-01$ & 498 & 767 & 839 & 872 & 1000 & 104 & -289 & -301 & -332 & -18 & 0 & 0 & 0 & 0 & 0 \\
\hline 6 & $2.0000 \mathrm{E}-01$ & -104 & -451 & -405 & -391 & 104 & 1000 & 922 & 917 & 903 & 42 & 0 & 0 & 0 & 0 & 0 \\
\hline 7 & $2.0000 \mathrm{E}-01$ & -297 & -726 & -712 & -714 & -289 & 922 & 1000 & 1000 & 999 & 47 & 0 & 0 & 0 & 0 & 0 \\
\hline 8 & $2.0000 \mathrm{E}-01$ & -303 & -732 & -719 & -723 & -301 & 917 & 1000 & 1000 & 999 & 47 & 0 & 0 & 0 & 0 & 0 \\
\hline 9 & $3.0000 \mathrm{E}-01$ & -317 & -750 & -740 & -745 & -332 & 903 & 999 & 999 & 1000 & 48 & 0 & 0 & 0 & 0 & 0 \\
\hline 10 & $3.0000 \mathrm{E}-01$ & -16 & -37 & -36 & -37 & -18 & 42 & 47 & 47 & 48 & 1000 & 21 & 1 & 0 & 0 & 0 \\
\hline 11 & $4.2773 E-02$ & 0 & 0 & 0 & 0 & 0 & 0 & 0 & 0 & 0 & 21 & 1000 & 5 & 0 & 0 & 0 \\
\hline 12 & $3.0200 \mathrm{E}-02$ & 0 & 0 & 0 & 0 & 0 & 0 & 0 & 0 & 0 & 1 & 5 & 1000 & 40 & 14 & 0 \\
\hline 13 & $9.0560 \mathrm{E}-02$ & 0 & 0 & 0 & 0 & 0 & 0 & 0 & 0 & 0 & 0 & 0 & 40 & 1000 & 114 & -57 \\
\hline 14 & $2.5871 \mathrm{E}-02$ & 0 & 0 & 0 & 0 & 0 & 0 & 0 & 0 & 0 & 0 & 0 & 14 & 114 & 1000 & -706 \\
\hline 15 & $4.2279 E-02$ & 0 & 0 & 0 & 0 & 0 & 0 & 0 & 0 & 0 & 0 & 0 & 0 & -57 & -706 & 1000 \\
\hline
\end{tabular}

$234 \mathrm{U}(\mathrm{n}, \mathrm{el})$

group rel.s.d.

$14.0000 \mathrm{E}-02$

$24.0000 \mathrm{E}-02$

$34.0000 \mathrm{E}-02$ $\begin{array}{llllll}1000 & -244 & 181 & -20 & -188 & -75\end{array}$

$\begin{array}{llllll}-244 & 1000 & 255 & -6 & -51 & -16\end{array}$

1812551000
$25-708-289$

$\begin{array}{ccccccccr}0 & 0 & 0 & 0 & 0 & 0 & 0 & 0 & 0 \\ 0 & 0 & 0 & 0 & 0 & 0 & 0 & 0 & 0 \\ 0 & 0 & 0 & 0 & 0 & 0 & 0 & 0 & 0\end{array}$




\begin{tabular}{|c|c|c|c|c|c|c|c|c|c|c|c|c|c|c|c|c|}
\hline 4 & $4.0000 \mathrm{E}-02$ & -20 & -6 & 25 & 1000 & 125 & 33 & 0 & 0 & 0 & 0 & 0 & 0 & 0 & 0 & 0 \\
\hline 5 & $4.0000 \mathrm{E}-02$ & -188 & -51 & -708 & 125 & 1000 & 309 & 0 & 0 & 0 & 0 & 0 & 0 & 0 & 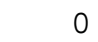 & 0 \\
\hline 6 & $4.0000 \mathrm{E}-02$ & -75 & -16 & -289 & 33 & 309 & 1000 & 929 & 925 & 898 & 0 & 0 & 0 & 0 & 0 & \\
\hline 7 & $4.0000 \mathrm{E}-02$ & 0 & 0 & 0 & 0 & 0 & 929 & 1000 & 996 & 967 & 0 & 0 & 0 & 0 & 0 & \\
\hline 8 & $4.0000 \mathrm{E}-02$ & 0 & 0 & 0 & 0 & 0 & 925 & 996 & 1000 & 972 & 0 & 0 & 0 & 0 & 0 & \\
\hline 9 & $4.0000 \mathrm{E}-02$ & 0 & 0 & 0 & 0 & 0 & 898 & 967 & 972 & 1000 & 3 & 2 & 1 & 30 & 30 & 0 \\
\hline 10 & $6.9420 \mathrm{E}-02$ & 0 & 0 & 0 & 0 & 0 & 0 & 0 & 0 & 3 & 1000 & 5 & 2 & 54 & 55 & 54 \\
\hline 1 & $2.3161 \mathrm{E}-01$ & 0 & 0 & 0 & 0 & 0 & 0 & 0 & 0 & 2 & 5 & 1000 & -5 & -25 & -13 & -11 \\
\hline 12 & $1.7123 \mathrm{E}-01$ & 0 & 0 & 0 & 0 & 0 & 0 & 0 & 0 & 1 & 2 & -5 & 1000 & 44 & 43 & 43 \\
\hline 13 & $2.3248 E-02$ & 0 & 0 & 0 & 0 & 0 & 0 & 0 & 0 & 30 & 54 & -25 & 44 & 1000 & 983 & 969 \\
\hline 14 & $2.0174 \mathrm{E}-02$ & 0 & 0 & 0 & 0 & 0 & 0 & 0 & 0 & 30 & 55 & -13 & 43 & 983 & 1000 & 998 \\
\hline 15 & $1.9753 \mathrm{E}-02$ & 0 & 0 & 0 & 0 & 0 & 0 & 0 & 0 & 30 & 54 & -11 & 43 & 969 & 998 & 1000 \\
\hline
\end{tabular}

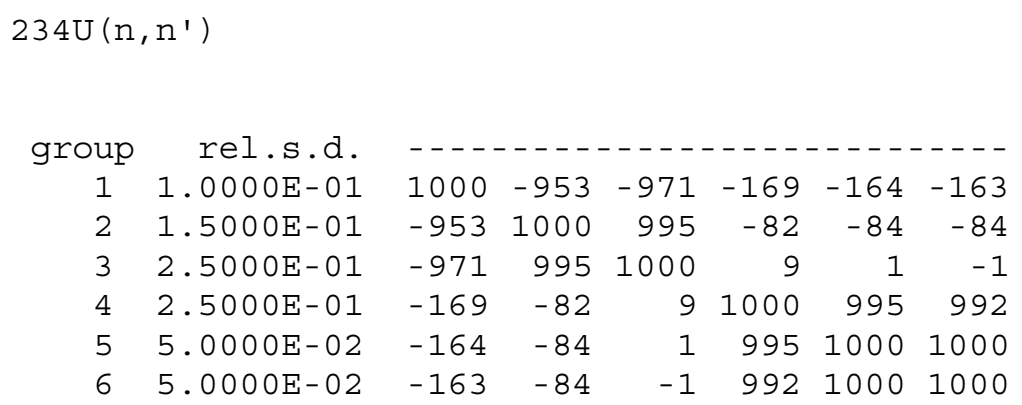

$234 \mathrm{U}(\mathrm{n}, 2 \mathrm{n})$

group rel.s.d. --.-

$1 \quad 3.4847 \mathrm{E}-01 \quad 1000$

$234 \mathrm{U}(\mathrm{n}, \mathrm{f})$

group rel.s.d.

$1 \quad 1.5000 \mathrm{E}-01$

$2 \quad 1.0000 \mathrm{E}-01$

$3 \quad 1.3834 \mathrm{E}-01$

$4 \quad 3.7974 \mathrm{E}-01$

$5 \quad 3.7974 \mathrm{E}-01$

$63.1605 \mathrm{E}-01$

$72.2840 \mathrm{E}-01$

$8 \quad 1.9411 \mathrm{E}-01$

9 1.3692E-01

$10 \quad 1.4972 \mathrm{E}-01$

$11 \quad 5.1074 \mathrm{E}-02$

\begin{tabular}{|c|c|c|c|c|c|c|c|c|c|c|c|c|c|}
\hline 1000 & 314 & 243 & 7 & 7 & 7 & 0 & 0 & 0 & 0 & 0 & 0 & 0 & 0 \\
\hline 314 & 1000 & 978 & 944 & 944 & 937 & 0 & 0 & 0 & 0 & 0 & 0 & 0 & 0 \\
\hline 243 & 978 & 1000 & 921 & 921 & 915 & 0 & 0 & 0 & 0 & 0 & 0 & 0 & 0 \\
\hline 7 & 944 & 921 & 1000 & 1000 & 993 & 0 & 0 & 0 & 0 & 0 & 0 & 0 & 0 \\
\hline 7 & 944 & 921 & 1000 & 1000 & 993 & 0 & 0 & 0 & 0 & 0 & 0 & 0 & 0 \\
\hline 7 & 937 & 915 & 993 & 993 & 1000 & 122 & 122 & 119 & 2 & 0 & 0 & 0 & 0 \\
\hline 0 & 0 & 0 & 0 & 0 & 122 & 1000 & 999 & 976 & 18 & 0 & 0 & 0 & 0 \\
\hline 0 & 0 & 0 & 0 & 0 & 122 & 999 & 1000 & 981 & 18 & 0 & 0 & 0 & 0 \\
\hline 0 & 0 & 0 & 0 & 0 & 119 & 976 & 981 & 1000 & 17 & 0 & 0 & 0 & 0 \\
\hline 0 & 0 & 0 & 0 & 0 & 2 & 18 & 18 & 17 & 1000 & 15 & 0 & 2 & 1 \\
\hline 0 & 0 & 0 & 0 & 0 & 0 & 0 & 0 & 0 & 15 & 1000 & 0 & 1 & 1 \\
\hline
\end{tabular}




\begin{tabular}{|c|c|c|c|c|c|c|c|c|c|c|c|c|c|c|c|}
\hline $1.7489 \mathrm{E}-01$ & 0 & 0 & 0 & 0 & 0 & 0 & 0 & 0 & 0 & 0 & 0 & 1000 & 51 & 18 & 17 \\
\hline $2.1849 \mathrm{E}-01$ & 0 & 0 & 0 & 0 & 0 & 0 & 0 & 0 & 0 & 2 & 1 & 51 & 1000 & 998 & 998 \\
\hline $2.4671 \mathrm{E}-01$ & 0 & 0 & 0 & 0 & 0 & 0 & 0 & 0 & 0 & 1 & 1 & 18 & 998 & 1000 & 1000 \\
\hline $2.4806 \mathrm{E}-01$ & 0 & 0 & 0 & 0 & 0 & 0 & 0 & 0 & 0 & 1 & 1 & 17 & 998 & 1000 & 1000 \\
\hline
\end{tabular}

$234 \mathrm{U}(\mathrm{n}$, gamma $)$

\begin{tabular}{|c|c|c|c|c|c|c|c|c|c|c|c|c|c|c|c|c|}
\hline & & & & & & & & & & & & & & & & \\
\hline 1 & $5.6740 \mathrm{E}-01$ & 1000 & 710 & 404 & 149 & 4 & 20 & 0 & 0 & 0 & 0 & 0 & 0 & 0 & 0 & 0 \\
\hline 2 & $5.0000 \mathrm{E}-01$ & 710 & 1000 & 784 & 304 & -42 & 29 & 0 & 0 & 0 & 0 & 0 & 0 & 0 & 0 & 0 \\
\hline 3 & $4.0000 E-01$ & 404 & 784 & 1000 & 584 & 76 & 223 & 0 & 0 & 0 & 0 & 0 & 0 & 0 & 0 & 0 \\
\hline 4 & $1.1992 \mathrm{E}-01$ & 149 & 304 & 584 & 1000 & 837 & 768 & 0 & 0 & 0 & 0 & 0 & 0 & 0 & 0 & 0 \\
\hline 5 & $1.3981 E-01$ & 4 & -42 & 76 & 837 & 1000 & 764 & 0 & 0 & 0 & 0 & 0 & 0 & 0 & 0 & 0 \\
\hline 6 & 1.2921E-01 & 20 & 29 & 223 & 768 & 764 & 1000 & 559 & 559 & 558 & 385 & 0 & 0 & 0 & 0 & 0 \\
\hline 7 & $3.0000 E-01$ & 0 & 0 & 0 & 0 & 0 & 559 & 1000 & 1000 & 998 & 688 & 0 & 0 & 0 & 0 & 0 \\
\hline 8 & $1.9156 \mathrm{E}-01$ & 0 & 0 & 0 & 0 & 0 & 559 & 1000 & 1000 & 999 & 689 & 0 & 0 & 0 & 0 & 0 \\
\hline 9 & $2.0000 E-01$ & 0 & 0 & 0 & 0 & 0 & 558 & 998 & 999 & 1000 & 696 & 0 & 0 & 0 & 0 & 0 \\
\hline 10 & $1.8562 \mathrm{E}-02$ & 0 & 0 & 0 & 0 & 0 & 385 & 688 & 689 & 696 & 1000 & 7 & 0 & 0 & 0 & 0 \\
\hline 11 & $2.4153 E-02$ & 0 & 0 & 0 & 0 & 0 & 0 & 0 & 0 & 0 & 7 & 1000 & 2 & 6 & 14 & 12 \\
\hline 12 & $1.3763 E-02$ & 0 & 0 & 0 & 0 & 0 & 0 & 0 & 0 & 0 & 0 & 2 & 1000 & 949 & 679 & 538 \\
\hline 13 & $9.3406 E-02$ & 0 & 0 & 0 & 0 & 0 & 0 & 0 & 0 & 0 & 0 & 6 & 949 & 1000 & 768 & 631 \\
\hline 14 & $3.0754 \mathrm{E}-02$ & 0 & 0 & 0 & 0 & 0 & 0 & 0 & 0 & 0 & 0 & 14 & 679 & 768 & 1000 & 981 \\
\hline 15 & $2.9278 E-02$ & 0 & 0 & 0 & 0 & 0 & 0 & 0 & 0 & 0 & 0 & 12 & 538 & 631 & 981 & 1000 \\
\hline
\end{tabular}

$235 \mathrm{U}(\mathrm{n}, \mathrm{el})$, non-diagonal terms are those of $233 \mathrm{U}$

\begin{tabular}{|c|c|c|c|c|c|c|c|c|c|c|c|c|c|c|c|c|}
\hline coup & s. & 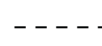 & 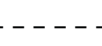 & 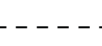 & 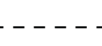 & 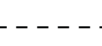 & 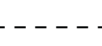 & 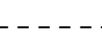 & 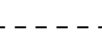 & . & & & 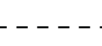 & & 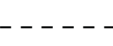 & \\
\hline 1 & $1.0000 E-01$ & 1000 & 979 & 391 & 15 & 193 & -16 & -131 & -137 & 0 & 0 & 0 & 0 & 0 & 0 & 0 \\
\hline 2 & $3.0000 E-02$ & 979 & 1000 & 543 & -16 & 205 & 119 & 44 & 37 & 0 & 0 & 0 & 0 & 0 & 0 & 0 \\
\hline 3 & $2.0000 E-02$ & 391 & 543 & 1000 & -20 & 144 & 666 & 809 & 807 & 0 & 0 & 0 & 0 & 0 & 0 & 0 \\
\hline 4 & $2.0000 E-02$ & 15 & -16 & -20 & 1000 & 102 & -116 & -159 & -159 & 0 & 0 & 0 & 0 & 0 & 0 & 0 \\
\hline 5 & $2.0000 \mathrm{E}-02$ & 193 & 205 & 144 & 102 & 1000 & 148 & 88 & 85 & 0 & 0 & 0 & 0 & 0 & 0 & 0 \\
\hline 6 & $2.0000 E-02$ & -16 & 119 & 666 & -116 & 148 & 1000 & 785 & 784 & 0 & 0 & 0 & 0 & 0 & 0 & 0 \\
\hline 7 & $2.0000 E-02$ & -131 & 44 & 809 & -159 & 88 & 785 & 1000 & 1000 & 0 & 0 & 0 & 0 & 0 & 0 & 0 \\
\hline 8 & $2.0000 E-02$ & -137 & 37 & 807 & -159 & 85 & 784 & 1000 & 1000 & 0 & 0 & 0 & 0 & 0 & 0 & 0 \\
\hline 9 & $2.0000 \mathrm{E}-02$ & 0 & 0 & 0 & 0 & 0 & 0 & 0 & 0 & 1000 & 317 & 332 & 340 & 356 & 276 & 66 \\
\hline 10 & $3.2229 E-03$ & 0 & 0 & 0 & 0 & 0 & 0 & 0 & 0 & 317 & 1000 & 997 & 996 & 961 & 658 & 155 \\
\hline 11 & $9.4190 \mathrm{E}-03$ & 0 & 0 & 0 & 0 & 0 & 0 & 0 & 0 & 332 & 997 & 1000 & 998 & 964 & 665 & 157 \\
\hline 12 & $1.8648 E-02$ & 0 & 0 & 0 & 0 & 0 & 0 & 0 & 0 & 340 & 996 & 998 & 1000 & 972 & 680 & 166 \\
\hline 13 & $3.1444 E-02$ & 0 & 0 & 0 & 0 & 0 & 0 & 0 & 0 & 356 & 961 & 964 & 972 & 1000 & 758 & 276 \\
\hline 14 & $3.4417 E-02$ & 0 & 0 & 0 & 0 & 0 & 0 & 0 & 0 & 276 & 658 & 665 & 680 & 758 & 1000 & 251 \\
\hline 15 & $6.6491 E-02$ & 0 & 0 & 0 & 0 & 0 & 0 & 0 & 0 & 66 & 155 & 157 & 166 & 276 & 251 & 1000 \\
\hline
\end{tabular}




\begin{tabular}{|c|c|c|c|c|c|c|}
\hline group & rel.s.d. & --- & ---- & ---- & ---- & --- \\
\hline 1 & $1.5000 E-01$ & 1000 & -741 & -35 & 64 & 0 \\
\hline 2 & $1.5000 E-01$ & -741 & 1000 & 43 & -95 & 0 \\
\hline 3 & $1.0000 \mathrm{E}-01$ & -35 & 43 & 1000 & 980 & 0 \\
\hline 4 & $3.0000 \mathrm{E}-01$ & 64 & -95 & 980 & 1000 & 139 \\
\hline 5 & $3.0000 \mathrm{E}-00$ & 0 & 0 & 0 & 139 & 1000 \\
\hline 6 & $5.0000 \mathrm{E}-00$ & & & & & \\
\hline 7 & $5.0000 \mathrm{E}-00$ & & & & & \\
\hline 8 & $5.0000 E-00$ & & & & & \\
\hline
\end{tabular}

$235 \mathrm{U}(\mathrm{n}, 2 \mathrm{n})$

group rel.s.d. -.-

$11.0000 \mathrm{E}-01 \quad 1000$

$235 \mathrm{U}(\mathrm{n}, \mathrm{f})$

$235 \mathrm{U}$ (n, gamma)

group rel.s.d.

$15.0000 \mathrm{E}-01$

$22.0000 \mathrm{E}-01$

$35.0000 E-01$

$4 \quad 5.0000 \mathrm{E}-01$

$52.0000 \mathrm{E}-01$

$62.0000 \mathrm{E}-01$

$72.0000 \mathrm{E}-01$

$82.0000 \mathrm{E}-01$

$92.0000 \mathrm{E}-01$

$102.0000 \mathrm{E}-01$

$110.8767 \mathrm{E}-02$

$12 \quad 2.1341 \mathrm{E}-02$

$131.7530 \mathrm{E}-01$

$142.8745 \mathrm{E}-02$

$152.1209 \mathrm{E}-02$

\begin{tabular}{|c|c|c|c|c|c|c|c|c|c|c|c|c|c|c|}
\hline 1000 & 409 & 458 & 498 & 498 & -104 & -297 & -303 & -317 & -16 & 0 & 0 & 0 & 0 & 0 \\
\hline 409 & 1000 & 988 & 953 & 767 & -451 & -726 & -732 & -750 & -37 & 0 & 0 & 0 & 0 & 0 \\
\hline 458 & 988 & 1000 & 988 & 839 & -405 & -712 & -719 & -740 & -36 & 0 & 0 & 0 & 0 & 0 \\
\hline 498 & 953 & 988 & 1000 & 872 & -391 & -714 & -723 & -745 & -37 & 0 & 0 & 0 & 0 & 0 \\
\hline 498 & 767 & 839 & 872 & 1000 & 104 & -289 & -301 & -332 & -18 & 0 & 0 & 0 & 0 & 0 \\
\hline-104 & -451 & -405 & -391 & 104 & 1000 & 922 & 917 & 903 & 42 & 0 & 0 & 0 & 0 & 0 \\
\hline-297 & -726 & -712 & -714 & -289 & 922 & 1000 & 1000 & 999 & 47 & 0 & 0 & 0 & 0 & 0 \\
\hline-303 & -732 & -719 & -723 & -301 & 917 & 1000 & 1000 & 999 & 47 & 0 & 0 & 0 & 0 & 0 \\
\hline-317 & -750 & -740 & -745 & -332 & 903 & 999 & 999 & 1000 & 48 & 0 & 0 & 0 & 0 & 0 \\
\hline-16 & -37 & -36 & -37 & -18 & 42 & 47 & 47 & 48 & 1000 & 21 & 1 & 0 & 0 & 0 \\
\hline 0 & 0 & 0 & 0 & 0 & 0 & 0 & 0 & 0 & 21 & 1000 & 5 & 0 & 0 & 0 \\
\hline 0 & 0 & 0 & 0 & 0 & 0 & 0 & 0 & 0 & 1 & 5 & 1000 & 40 & 14 & 0 \\
\hline 0 & 0 & 0 & 0 & 0 & 0 & 0 & 0 & 0 & 0 & 0 & 40 & 1000 & 114 & -57 \\
\hline 0 & 0 & 0 & 0 & 0 & 0 & 0 & 0 & 0 & 0 & 0 & 14 & 114 & 1000 & -706 \\
\hline 0 & 0 & 0 & 0 & 0 & 0 & 0 & 0 & 0 & 0 & 0 & 0 & -57 & -706 & 1000 \\
\hline
\end{tabular}

$236 \mathrm{U}(\mathrm{n}, \mathrm{el})$

group rel.s.d. 


\begin{tabular}{|c|c|c|c|c|c|c|c|c|c|c|c|c|c|c|c|c|}
\hline 1 & $3.0000 E-02$ & 1000 & 998 & 1000 & $-994-$ & -1000 & -985 & 0 & 0 & 0 & 0 & 0 & 0 & 0 & 0 & \\
\hline 2 & $3.0000 E-02$ & 998 & 1000 & 998 & -999 & -999 & -985 & 0 & 0 & 0 & 0 & 0 & 0 & 0 & 0 & \\
\hline 3 & $3.0000 E-02$ & 1000 & 998 & 1000 & $-994-$ & -1000 & -985 & 0 & 0 & 0 & 0 & 0 & 0 & 0 & 0 & \\
\hline 4 & $3.0000 E-02$ & -994 & -999 & -994 & 1000 & 996 & 982 & 0 & 0 & 0 & 0 & 0 & 0 & 0 & 0 & \\
\hline 5 & $3.0000 E-02$ & -1000 & -999 & -1000 & 996 & 1000 & 986 & 0 & 0 & 0 & 0 & 0 & 0 & 0 & 0 & \\
\hline 6 & $3.0000 E-02$ & -985 & -985 & -985 & 982 & 986 & 1000 & 168 & 168 & 75 & 0 & 0 & 0 & 0 & 0 & \\
\hline 7 & $3.0000 E-02$ & 0 & 0 & 0 & 0 & 0 & 168 & 1000 & 1000 & 449 & 0 & 0 & 0 & 0 & 0 & \\
\hline 8 & $3.0000 E-02$ & 0 & 0 & 0 & 0 & 0 & 168 & 1000 & 1000 & 449 & 0 & 0 & 0 & 0 & 0 & \\
\hline 9 & $3.0000 E-02$ & 0 & 0 & 0 & 0 & 0 & 75 & 449 & 449 & 1000 & 274 & 160 & 146 & 128 & 120 & 11 \\
\hline 0 & $2.2647 E-02$ & 0 & 0 & 0 & 0 & 0 & 0 & 0 & 0 & 274 & 1000 & 170 & 163 & 149 & 140 & 139 \\
\hline 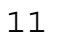 & $5.9574 \mathrm{E}-02$ & 0 & 0 & 0 & 0 & 0 & 0 & 0 & 0 & 160 & 170 & 1000 & 173 & 191 & 188 & 187 \\
\hline 12 & $2.3485 E-02$ & 0 & 0 & 0 & 0 & 0 & 0 & 0 & 0 & 146 & 163 & 173 & 1000 & 840 & 833 & 833 \\
\hline 13 & $4.7682 \mathrm{E}-02$ & 0 & 0 & 0 & 0 & 0 & 0 & 0 & 0 & 128 & 149 & 191 & 840 & 1000 & 1000 & 999 \\
\hline 14 & $4.9096 \mathrm{E}-02$ & 0 & 0 & 0 & 0 & 0 & 0 & 0 & 0 & 120 & 140 & 188 & 833 & 1000 & 1000 & 1000 \\
\hline 15 & $4.8916 E-02$ & 0 & 0 & 0 & 0 & 0 & 0 & 0 & 0 & 118 & 139 & 187 & 833 & 999 & 1000 & 1000 \\
\hline
\end{tabular}

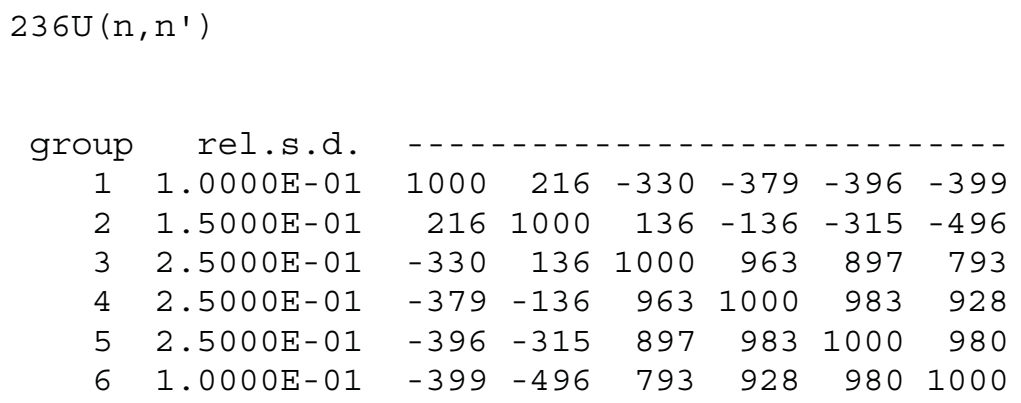

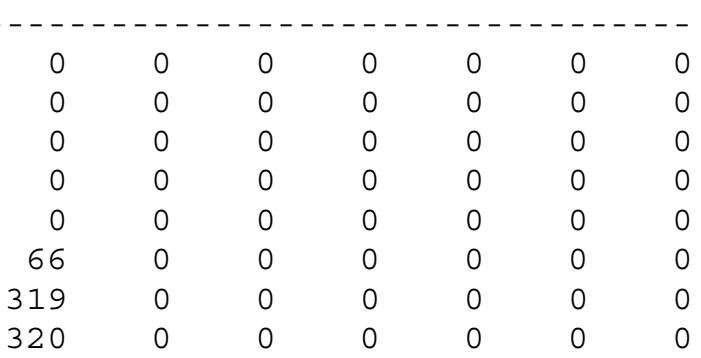




\begin{tabular}{|c|c|c|c|c|c|c|c|c|c|c|c|c|c|c|c|}
\hline $3.5008 E-02$ & 0 & 0 & 0 & 0 & 0 & 66 & 319 & 320 & 1000 & 11 & 243 & 130 & 0 & 0 & 0 \\
\hline $3.2973 E-02$ & 0 & 0 & 0 & 0 & 0 & 0 & 0 & 0 & 11 & 1000 & 899 & 767 & 0 & 0 & 0 \\
\hline $1.3702 \mathrm{E}-02$ & 0 & 0 & 0 & 0 & 0 & 0 & 0 & 0 & 243 & 899 & 1000 & 1 & 9 & 9 & 9 \\
\hline $2.5696 E-02$ & 0 & 0 & 0 & 0 & 0 & 0 & 0 & 0 & 130 & 767 & 1 & 1000 & 132 & 107 & 106 \\
\hline $1.5788 \mathrm{E}-01$ & 0 & 0 & 0 & 0 & 0 & 0 & 0 & 0 & 0 & 0 & 9 & 132 & 1000 & 999 & 999 \\
\hline $1.9584 \mathrm{E}-01$ & 0 & 0 & 0 & 0 & 0 & 0 & 0 & 0 & 0 & 0 & 9 & 107 & 999 & 1000 & 1000 \\
\hline $1.9863 E-01$ & 0 & 0 & 0 & 0 & 0 & 0 & 0 & 0 & 0 & 0 & 9 & 106 & 999 & 1000 & 1000 \\
\hline
\end{tabular}

$236 \mathrm{U}(\mathrm{n}$, gamma $)$

\begin{tabular}{|c|c|c|c|c|c|c|c|c|c|c|c|c|c|c|c|c|}
\hline 1 & $3.2677 \mathrm{~F}-01$ & 1000 & 998 & 999 & 523 & 337 & -217 & 0 & 0 & 0 & 0 & 0 & 0 & 0 & 0 & S \\
\hline 2 & $3.5693 E-01$ & 998 & 1000 & 996 & 479 & 289 & -264 & 0 & 0 & 0 & 0 & 0 & 0 & 0 & 0 & \\
\hline 3 & $1.9559 \mathrm{E}-01$ & 999 & 996 & 1000 & 560 & 378 & -175 & 0 & 0 & 0 & 0 & 0 & 0 & 0 & 0 & 0 \\
\hline 4 & $7.0000 E-02$ & 523 & 479 & 560 & 1000 & 979 & 686 & 0 & 0 & 0 & 0 & 0 & 0 & 0 & 0 & 0 \\
\hline 5 & $7.0000 \mathrm{E}-02$ & 337 & 289 & 378 & 979 & 1000 & 810 & 0 & 0 & 0 & 0 & 0 & 0 & 0 & 0 & 0 \\
\hline 6 & $3.9424 \mathrm{E}-02$ & -217 & -264 & -175 & 686 & 810 & 1000 & 271 & 271 & 269 & 0 & 0 & 0 & 0 & 0 & 0 \\
\hline 7 & $3.4607 \mathrm{E}-02$ & 0 & 0 & 0 & 0 & 0 & 271 & 1000 & 1000 & 994 & 0 & 0 & 0 & 0 & 0 & 0 \\
\hline 8 & $5.2580 E-02$ & 0 & 0 & 0 & 0 & 0 & 271 & 1000 & 1000 & 994 & 0 & 0 & 0 & 0 & 0 & 0 \\
\hline 9 & $2.9760 \mathrm{E}-03$ & 0 & 0 & 0 & 0 & 0 & 269 & 994 & 994 & 1000 & 4 & 0 & 0 & 0 & 0 & 0 \\
\hline 10 & $6.3700 \mathrm{E}-03$ & 0 & 0 & 0 & 0 & 0 & 0 & 0 & 0 & 4 & 1000 & 20 & 0 & 1 & 2 & 2 \\
\hline 11 & $8.2960 \mathrm{E}-03$ & 0 & 0 & 0 & 0 & 0 & 0 & 0 & 0 & 0 & 20 & 1000 & 1 & 18 & 42 & 42 \\
\hline 12 & 4.0519E-02 & 0 & 0 & 0 & 0 & 0 & 0 & 0 & 0 & 0 & 0 & 1 & 1000 & 327 & 271 & 254 \\
\hline 13 & $2.7286 \mathrm{E}-02$ & 0 & 0 & 0 & 0 & 0 & 0 & 0 & 0 & 0 & 1 & 18 & 327 & 1000 & 759 & 722 \\
\hline 14 & $1.9606 \mathrm{E}-02$ & 0 & 0 & 0 & 0 & 0 & 0 & 0 & 0 & 0 & 2 & 42 & 271 & 759 & 1000 & 998 \\
\hline 15 & $1.8877 E-02$ & 0 & 0 & 0 & 0 & 0 & 0 & 0 & 0 & 0 & 2 & 42 & 254 & 722 & 998 & 1000 \\
\hline
\end{tabular}

$238 \mathrm{U}(\mathrm{n}, \mathrm{el})$

group rel.s.d.

$1.0000 \mathrm{E}-02$

2 2.0000E-02

$\begin{array}{ll}2 & 2.0000 \mathrm{E}-02 \\ 3 & 2.0000 \mathrm{E}-02\end{array}$

2. $0000 \mathrm{E}-02$

2. $0000 \mathrm{E}-02$

2. $0000 \mathrm{E}-02$

$2.0000 \mathrm{E}-02$

2. $0000 \mathrm{E}-02$

2. $0000 \mathrm{E}-02$

$102.0000 \mathrm{E}-02$

$1000468 \quad 80 \quad 116$

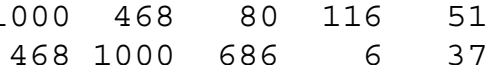

$\begin{array}{rrrrr}80 & 686 & 1000 & 156 & 44\end{array}$

$\begin{array}{lllll}116 & 6 & 156 & 1000 & 420\end{array}$

$\begin{array}{lllllll}51 & 37 & 44 & 420 & 1000 & 170 & 12\end{array}$

$\begin{array}{llllllll}-9 & 7 & 3 & 38 & 170 & 1000 & 762 & 585\end{array}$

$\begin{array}{llllllll}-2 & 3 & 1 & 9 & 12 & 762 & 1000 & 953\end{array}$

$\begin{array}{llllllll}0 & 0 & 0 & 0 & 0 & 585 & 953 & 1000\end{array}$

$\begin{array}{lllll}0 & 0 & 0 & 0 & 0 \\ 0 & 0 & 0 & 0 & 0\end{array}$

0

$\begin{array}{rrrrrrrrrr}0 & 0 & 0 & 1000 & 0 & 0 & 0 & 0 & 0 & 0 \\ 0 & 0 & 0 & 0 & 1000 & 10 & -2 & -3 & -4 & -4\end{array}$

$11 \quad 1.5274 \mathrm{E}-02$

$123.0734 \mathrm{E}-01$

$138.5536 \mathrm{E}-03$

$147.2937 \mathrm{E}-03$

$157.1430 \mathrm{E}-03$
0

0

0
0 $\begin{array}{lllll}0 & 0 & 0 & 0 & 0 \\ 0 & 0 & 0 & 0 & 0 \\ 0 & 0 & 0 & 0 & 0 \\ 0 & 0 & 0 & 0 & 0 \\ 0 & 0 & 0 & 0 & 0 \\ 0 & 0 & 0 & 0 & 0\end{array}$ 


$238 U\left(n, n^{\prime}\right)$
group rel.s.d.
$\begin{array}{ccrrrrrrr} \\ 1 & 1.0006 \mathrm{E}-01 & 1000 & 525 & 70 & 40 & -90 & -149 & -11 \\ 2 & 1.4271 \mathrm{E}-01 & 525 & 1000 & 691 & -21 & 18 & 23 & 18 \\ 3 & 5.7474 \mathrm{E}-02 & 70 & 691 & 1000 & 123 & -43 & -40 & 5 \\ 4 & 1.2202 \mathrm{E}-02 & 40 & -21 & 123 & 1000 & 47 & -106 & 73 \\ 5 & 1.9820 \mathrm{E}-02 & -90 & 18 & -43 & 47 & 1000 & 908 & 108 \\ 6 & 2.9219 \mathrm{E}-02 & -149 & 23 & -40 & -106 & 908 & 1000 & 247 \\ 7 & 6.8172 \mathrm{E}-01 & -11 & 18 & 5 & 73 & 108 & 247 & 1000\end{array}$

$238 \mathrm{U}(\mathrm{n}, 2 \mathrm{n})$

group rel.s.d. ---

$13.0000 \mathrm{E}-01 \quad 1000$

$238 \mathrm{U}(\mathrm{n}, \mathrm{f})$

group rel.s.d.

$11.0000 \mathrm{E}-02$

$21.0000 \mathrm{E}-02$

$31.0000 \mathrm{E}-02$

$4 \quad 1.0000 \mathrm{E}-02$

$53.1619 \mathrm{E}-02$

$61.0366 \mathrm{E}-01$

$71.0000 \mathrm{E}-01$

$8 \quad 1.7604 \mathrm{E}-05$

$9 \quad 1.8774 \mathrm{E}-02$

$103.8972 \mathrm{E}-04$

\begin{tabular}{|c|c|c|c|c|c|c|c|c|c|c|c|c|c|c|}
\hline 1000 & 516 & 365 & 271 & 80 & 9 & 0 & 0 & 0 & 0 & 0 & 0 & 0 & 0 & 0 \\
\hline 516 & 1000 & 555 & 416 & 123 & 14 & 0 & 0 & 0 & 0 & 0 & 0 & 0 & 0 & 0 \\
\hline 365 & 555 & 1000 & 456 & 139 & 16 & 0 & 0 & 0 & 0 & 0 & 0 & 0 & 0 & 0 \\
\hline 271 & 416 & 456 & 1000 & 229 & 23 & 0 & 0 & 0 & 0 & 0 & 0 & 0 & 0 & 0 \\
\hline 80 & 123 & 139 & 229 & 1000 & -55 & 0 & 0 & 0 & 0 & 0 & 0 & 0 & 0 & 0 \\
\hline 9 & 14 & 16 & 23 & -55 & 1000 & 0 & 0 & 0 & 0 & 0 & 0 & 0 & 0 & 0 \\
\hline 0 & 0 & 0 & 0 & 0 & 0 & 0 & 0 & 0 & 0 & 0 & 0 & 0 & 0 & 0 \\
\hline 0 & 0 & 0 & 0 & 0 & 0 & 0 & 1000 & 0 & 0 & 0 & 0 & 0 & 0 & 0 \\
\hline 0 & 0 & 0 & 0 & 0 & 0 & 0 & 0 & 1000 & 0 & 0 & 0 & 0 & 0 & 0 \\
\hline 0 & 0 & 0 & 0 & 0 & 0 & 0 & 0 & 0 & 1000 & -3 & -3 & 82 & 107 & 110 \\
\hline 0 & 0 & 0 & 0 & 0 & 0 & 0 & 0 & 0 & -3 & 1000 & -400 & -270 & -210 & -194 \\
\hline 0 & 0 & 0 & 0 & 0 & 0 & 0 & 0 & 0 & -3 & -400 & 1000 & 794 & 634 & 588 \\
\hline 0 & 0 & 0 & 0 & 0 & 0 & 0 & 0 & 0 & 82 & -270 & 794 & 1000 & 963 & 945 \\
\hline 0 & 0 & 0 & 0 & 0 & 0 & 0 & 0 & 0 & 107 & -210 & 634 & 963 & 1000 & 998 \\
\hline 0 & 0 & 0 & 0 & 0 & 0 & 0 & 0 & 0 & 110 & -194 & 588 & 945 & 998 & 1000 \\
\hline
\end{tabular}




\begin{tabular}{|c|c|c|c|c|c|c|c|c|c|c|c|c|c|c|c|c|}
\hline 1 & $3.2677 \mathrm{E}-01$ & 1000 & 28 & 0 & 0 & 0 & 0 & 0 & 0 & 0 & 0 & 0 & 0 & 0 & 0 & 0 \\
\hline 2 & $3.5693 \mathrm{E}-01$ & 28 & 1000 & 394 & 0 & 0 & 0 & 0 & 0 & 0 & 0 & 0 & 0 & 0 & 0 & 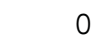 \\
\hline 3 & $1.9559 \mathrm{E}-01$ & 0 & 394 & 1000 & 4 & 0 & 0 & 0 & 0 & 0 & 0 & 0 & 0 & 0 & 0 & $c$ \\
\hline 4 & $7.0000 \mathrm{E}-02$ & 0 & 0 & 4 & 1000 & 15 & 1 & 0 & 0 & 0 & 0 & 0 & 0 & 0 & 0 & ( \\
\hline 5 & $7.0000 \mathrm{E}-02$ & 0 & 0 & 0 & 15 & 1000 & 21 & 0 & 0 & 0 & 0 & 0 & 0 & 0 & 0 & 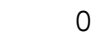 \\
\hline 6 & $3.9424 E-02$ & 0 & 0 & 0 & 1 & 21 & 1000 & 568 & -75 & 0 & 0 & 0 & 0 & 0 & 0 & \\
\hline 7 & $3.4607 \mathrm{E}-02$ & 0 & 0 & 0 & 0 & 0 & 568 & 1000 & 513 & 0 & 0 & 0 & 0 & 0 & 0 & \\
\hline 8 & $5.2580 \mathrm{E}-02$ & 0 & 0 & 0 & 0 & 0 & -75 & 513 & 1000 & 0 & 0 & 0 & 0 & 0 & 0 & \\
\hline 9 & $2.9764 E-03$ & 0 & 0 & 0 & 0 & 0 & 0 & 0 & 0 & 1000 & 0 & 0 & 0 & 0 & 0 & \\
\hline 10 & $6.3700 \mathrm{E}-03$ & 0 & 0 & 0 & 0 & 0 & 0 & 0 & 0 & 0 & 1000 & -1 & 1 & -1 & -1 & \\
\hline 11 & $8.2962 E-03$ & 0 & 0 & 0 & 0 & 0 & 0 & 0 & 0 & 0 & -1 & 1000 & 31 & 121 & 35 & \\
\hline 12 & $4.0519 E-02$ & 0 & 0 & 0 & 0 & 0 & 0 & 0 & 0 & 0 & 1 & 31 & 1000 & 356 & 312 & 30 \\
\hline 13 & $2.7286 \mathrm{E}-02$ & 0 & 0 & 0 & 0 & 0 & 0 & 0 & 0 & 0 & -1 & 121 & 356 & 1000 & 990 & 98 \\
\hline 14 & $1.9606 \mathrm{E}-02$ & 0 & 0 & 0 & 0 & 0 & 0 & 0 & 0 & 0 & -1 & 35 & 312 & 990 & 1000 & 1000 \\
\hline 15 & $1.8877 \mathrm{E}-02$ & 0 & 0 & 0 & 0 & 0 & 0 & 0 & 0 & 0 & -1 & 25 & 305 & 988 & 1000 & 100 \\
\hline
\end{tabular}

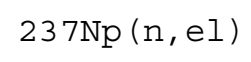




$\begin{array}{rrrrrrrrr}5 & 3.0000 \mathrm{E}-01 & -124 & 44 & 809 & 947 & 1000 & 990 & 832 \\ 6 & 5.0000 \mathrm{E}-01 & -143 & 8 & 744 & 907 & 990 & 1000 & 895 \\ 7 & 5.0000 \mathrm{E}-01 & -359 & 138 & 576 & 737 & 832 & 895 & 1000\end{array}$

$237 \mathrm{~Np}(\mathrm{n}, 2 \mathrm{n})$

group rel.s.d. ---

$12.0000 \mathrm{E}-01 \quad 1000$

$237 \mathrm{~Np}(\mathrm{n}, \mathrm{f})$

\begin{tabular}{|c|c|c|c|c|c|c|c|c|c|c|c|c|c|c|c|c|}
\hline 1 & 1 1 & 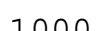 & 212 & -238 & -326 & -349 & -349 & -349 & -349 & -349 & -307 & 0 & 0 & 0 & 0 & \\
\hline 2 & 1.0000E-01 & 212 & 1000 & 853 & 764 & 733 & 733 & 733 & 733 & 733 & 645 & 0 & 0 & 0 & 0 & \\
\hline 3 & $1.0000 \mathrm{E}-01$ & -238 & 853 & 1000 & 986 & 976 & 976 & 976 & 976 & 976 & 859 & 0 & 0 & 0 & 0 & U \\
\hline 4 & $5.8154 E-02$ & -326 & 764 & 986 & 1000 & 999 & 999 & 999 & 999 & 999 & 878 & 0 & 0 & 0 & 0 & 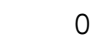 \\
\hline 5 & $5.7859 \mathrm{E}-02$ & -349 & 733 & 976 & 999 & 1000 & 1000 & 1000 & 1000 & 1000 & 879 & 0 & 0 & 0 & 0 & 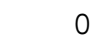 \\
\hline 6 & $5.7859 E-02$ & -349 & 733 & 976 & 999 & 1000 & 1000 & 1000 & 1000 & 1000 & 879 & 0 & 0 & 0 & 0 & 0 \\
\hline 7 & $5.7859 \mathrm{E}-02$ & -349 & 733 & 976 & 999 & 1000 & 1000 & 1000 & 1000 & 1000 & 879 & 0 & 0 & 0 & 0 & 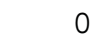 \\
\hline 8 & $5.7859 E-02$ & -349 & 733 & 976 & 999 & 1000 & 1000 & 1000 & 1000 & 1000 & 879 & 0 & 0 & 0 & 0 & 0 \\
\hline 9 & $5.7859 E-02$ & -349 & 733 & 976 & 999 & 1000 & 1000 & 1000 & 1000 & 1000 & 879 & 0 & 0 & 0 & 0 & U \\
\hline 10 & $5.7735 E-02$ & -307 & 645 & 859 & 878 & 879 & 879 & 879 & 879 & 879 & 1000 & 1 & 1 & 0 & 0 & 0 \\
\hline 11 & $7.5377 E-02$ & 0 & 0 & 0 & 0 & 0 & 0 & 0 & 0 & 0 & 1 & 1000 & 110 & 5 & 5 & 34 \\
\hline 12 & $4.6415 E-02$ & 0 & 0 & 0 & 0 & 0 & 0 & 0 & 0 & 0 & 1 & 110 & 1000 & 25 & 5 & 36 \\
\hline 13 & $5.5804 E-02$ & 0 & 0 & 0 & 0 & 0 & 0 & 0 & 0 & 0 & 0 & 5 & 25 & 1000 & 52 & 65 \\
\hline 14 & $1.4743 E-01$ & 0 & 0 & 0 & 0 & 0 & 0 & 0 & 0 & 0 & 0 & 5 & 5 & 52 & 1000 & 277 \\
\hline 15 & $4.5504 E-02$ & 0 & 0 & 0 & 0 & 0 & 0 & 0 & 0 & 0 & 0 & 34 & 36 & 65 & 277 & 1000 \\
\hline
\end{tabular}

$237 \mathrm{~Np}$ (n, gamma)

\begin{tabular}{|c|c|c|c|c|c|c|c|c|c|c|c|c|c|c|c|c|}
\hline coup & d. & & & & & & & & & -1 & & & & & & \\
\hline 1 & $4.1465 E-01$ & 1000 & 444 & 425 & 368 & 331 & -178 & -267 & -167 & 61 & 156 & 0 & 0 & 0 & 0 & 0 \\
\hline 2 & $3.6484 \mathrm{E}-01$ & 444 & 1000 & 983 & 869 & 732 & -421 & -606 & -444 & 2 & 211 & 0 & 0 & 0 & 0 & 0 \\
\hline 3 & $3.0000 \mathrm{E}-01$ & 425 & 983 & 1000 & 946 & 840 & -495 & -719 & -543 & -33 & 211 & 0 & 0 & 0 & 0 & 0 \\
\hline 4 & $3.0000 \mathrm{E}-01$ & 368 & 869 & 946 & 1000 & 962 & -588 & -859 & -669 & -81 & 207 & 0 & 0 & 0 & 0 & 0 \\
\hline 5 & $5.0000 \mathrm{E}-01$ & 331 & 732 & 840 & 962 & 1000 & -551 & -874 & -648 & -13 & 283 & 0 & 0 & 0 & 0 & 0 \\
\hline 6 & $5.0000 \mathrm{E}-02$ & -178 & -421 & -495 & -588 & -551 & 1000 & 874 & 853 & 487 & 220 & 0 & 0 & 0 & 0 & 0 \\
\hline 7 & $6.6594 \mathrm{E}-02$ & -267 & -606 & -719 & -859 & -874 & 874 & 1000 & 899 & 367 & 49 & 0 & 0 & 0 & 0 & 0 \\
\hline 8 & $5.2450 \mathrm{E}-02$ & -167 & -444 & -543 & -669 & -648 & 853 & 899 & 1000 & 737 & 476 & 0 & 0 & 0 & 0 & 0 \\
\hline 9 & $5.2484 E-02$ & 61 & 2 & -33 & -81 & -13 & 487 & 367 & 737 & 1000 & 935 & 0 & 0 & 0 & 0 & 0 \\
\hline 10 & $5.5373 E-02$ & 156 & 211 & 211 & 207 & 283 & 220 & 49 & 476 & 935 & 1000 & 1 & 0 & 0 & 0 & 0 \\
\hline 11 & $1.6955 \mathrm{E}-02$ & 0 & 0 & 0 & 0 & 0 & 0 & 0 & 0 & 0 & 1 & 1000 & 47 & 3 & 3 & 26 \\
\hline 12 & $5.5020 E-03$ & 0 & 0 & 0 & 0 & 0 & 0 & 0 & 0 & 0 & 0 & 47 & 1000 & -36 & 32 & 284 \\
\hline
\end{tabular}




\begin{tabular}{|c|c|c|c|c|c|c|c|c|c|c|c|c|c|c|c|c|}
\hline 13 & $6.9900 E-03$ & 0 & 0 & 0 & 0 & 0 & 0 & 0 & 0 & 0 & 0 & 3 & -36 & 1000 & 117 & 102 \\
\hline 14 & $2.4108 E-02$ & 0 & 0 & 0 & 0 & 0 & 0 & 0 & 0 & 0 & 0 & 3 & 32 & 117 & 1000 & 279 \\
\hline 0 & $1.5534 \mathrm{E}-02$ & 0 & 0 & 0 & 0 & 0 & 0 & 0 & 0 & 0 & 0 & 26 & 284 & 102 & 279 & 1000 \\
\hline
\end{tabular}

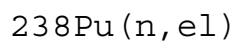

$\begin{array}{rrrrrrr}0 & 0 & 0 & 0 & 0 & 0 & 0 \\ 0 & 0 & 0 & 0 & 0 & 0 & 0 \\ 0 & 0 & 0 & 0 & 0 & 0 & 0 \\ 0 & 0 & 0 & 0 & 0 & 0 & 0 \\ 0 & 0 & 0 & 0 & 0 & 0 & 0 \\ 867 & 760 & 0 & 0 & 0 & 0 & 0 \\ 971 & 848 & 0 & 0 & 0 & 0 & 0 \\ 998 & 848 & 0 & 0 & 0 & 0 & 0 \\ 000 & 842 & 0 & 0 & 0 & 0 & 0 \\ 842 & 1000 & 112 & 9 & 19 & 19 & 19 \\ 0 & 112 & 1000 & -3 & 2 & 3 & 2 \\ 0 & 9 & -3 & 1000 & 472 & 474 & 472 \\ 0 & 19 & 2 & 472 & 1000 & 999 & 995 \\ 0 & 19 & 3 & 474 & 999 & 1000 & 999 \\ 0 & 19 & 2 & 472 & 995 & 999 & 1000\end{array}$

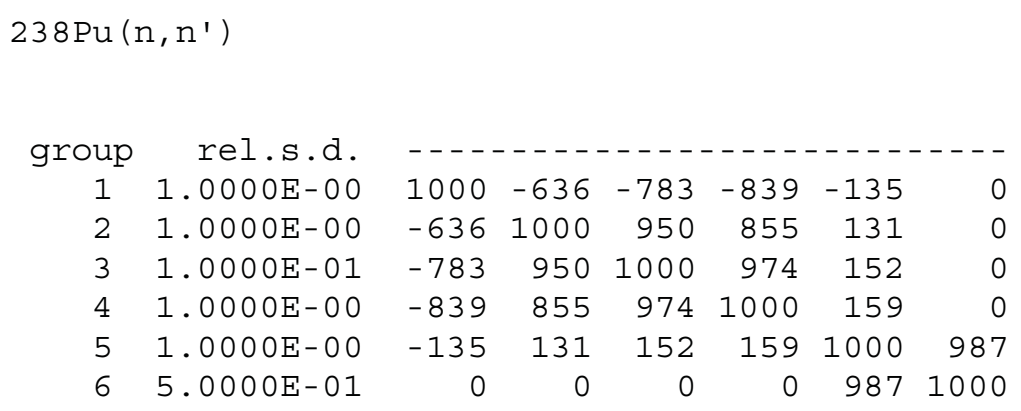




\section{$238 \mathrm{Pu}(\mathrm{n}, \mathrm{f})$}

\begin{tabular}{|c|c|c|c|c|c|c|c|c|c|c|c|c|c|c|c|c|}
\hline roup & rel.s.d. & $-\ldots$ & -- & -- & _ & $-\ldots$ & $\ldots$ & & 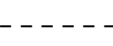 & 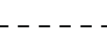 & 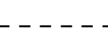 & & -- & -- & & \\
\hline 1 & $2.0000 E-01$ & 1000 & 123 & -7 & -11 & -11 & -5 & 0 & 0 & 0 & 0 & 0 & 0 & 0 & 0 & 0 \\
\hline 2 & $2.0000 E-01$ & 123 & 1000 & 930 & 605 & 605 & 258 & 0 & 0 & 0 & 0 & 0 & 0 & 0 & 0 & 0 \\
\hline 3 & $1.0000 E-01$ & -7 & 930 & 1000 & 548 & 548 & 233 & 0 & 0 & 0 & 0 & 0 & 0 & 0 & 0 & 0 \\
\hline 4 & $5.0000 E-01$ & -11 & 605 & 548 & 1000 & 1000 & 426 & 0 & 0 & 0 & 0 & 0 & 0 & 0 & 0 & 0 \\
\hline 5 & $5.0000 E-01$ & -11 & 605 & 548 & 1000 & 1000 & 426 & 0 & 0 & 0 & 0 & 0 & 0 & 0 & 0 & 0 \\
\hline 6 & $5.0000 E-01$ & -5 & 258 & 233 & 426 & 426 & 1000 & 895 & 894 & 876 & 777 & 0 & 0 & 0 & 0 & 0 \\
\hline 7 & $5.0000 E-01$ & 0 & 0 & 0 & 0 & 0 & 895 & 1000 & 999 & 980 & 870 & 0 & 0 & 0 & 0 & 0 \\
\hline 8 & $5.0000 E-01$ & 0 & 0 & 0 & 0 & 0 & 894 & 999 & 1000 & 986 & 889 & 0 & 0 & 0 & 0 & 0 \\
\hline 9 & $5.0000 E-01$ & 0 & 0 & 0 & 0 & 0 & 876 & 980 & 986 & 1000 & 949 & 0 & 0 & 0 & 0 & 0 \\
\hline 10 & $5.0000 E-01$ & 0 & 0 & 0 & 0 & 0 & 777 & 870 & 889 & 949 & 1000 & 10 & 0 & 0 & 0 & 0 \\
\hline 11 & $8.0000 E-01$ & 0 & 0 & 0 & 0 & 0 & 0 & 0 & 0 & 0 & 10 & 1000 & 1 & 36 & 9 & 4 \\
\hline 12 & $1.8975 E-01$ & 0 & 0 & 0 & 0 & 0 & 0 & 0 & 0 & 0 & 0 & 1 & 1000 & 27 & 6 & 3 \\
\hline 13 & $4.5674 E-02$ & 0 & 0 & 0 & 0 & 0 & 0 & 0 & 0 & 0 & 0 & 36 & 27 & 1000 & 545 & 529 \\
\hline 14 & $4.6265 E-02$ & 0 & 0 & 0 & 0 & 0 & 0 & 0 & 0 & 0 & 0 & 9 & 6 & 545 & 1000 & 998 \\
\hline 15 & $4.8675 E-02$ & 0 & 0 & 0 & 0 & 0 & 0 & 0 & 0 & 0 & 0 & 4 & 3 & 529 & 998 & 1000 \\
\hline
\end{tabular}

\section{$238 \mathrm{Pu}(\mathrm{n}$, gamma $)$}

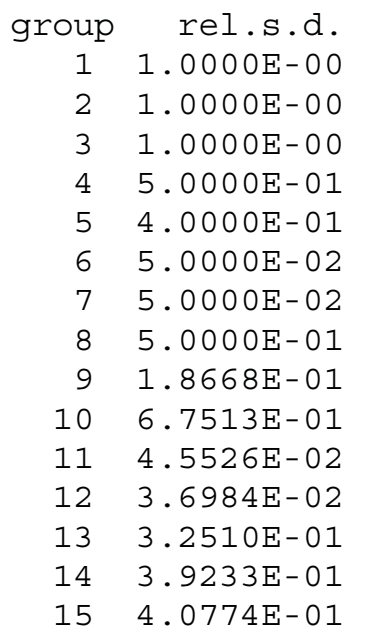

\begin{tabular}{|c|c|c|c|c|c|c|c|c|c|c|c|c|c|c|}
\hline 1000 & 630 & 624 & 278 & -161 & -19 & 0 & 0 & 0 & 0 & 0 & 0 & 0 & 0 & 0 \\
\hline 630 & 1000 & 996 & 409 & -300 & -35 & 0 & 0 & 0 & 0 & 0 & 0 & 0 & 0 & 0 \\
\hline 624 & 996 & 1000 & 478 & -228 & -27 & 0 & 0 & 0 & 0 & 0 & 0 & 0 & 0 & U \\
\hline 278 & 409 & 478 & 1000 & 738 & 87 & 0 & 0 & 0 & 0 & 0 & 0 & 0 & 0 & 0 \\
\hline-161 & -300 & -228 & 738 & 1000 & 118 & 0 & 0 & 0 & 0 & 0 & 0 & 0 & 0 & 0 \\
\hline-19 & -35 & -27 & 87 & 118 & 1000 & 988 & 987 & 982 & 866 & 0 & 0 & 0 & 0 & 0 \\
\hline 0 & 0 & 0 & 0 & 0 & 988 & 1000 & 1000 & 994 & 877 & 0 & 0 & 0 & 0 & 0 \\
\hline 0 & 0 & 0 & 0 & 0 & 987 & 1000 & 1000 & 996 & 882 & 0 & 0 & 0 & 0 & 0 \\
\hline 0 & 0 & 0 & 0 & 0 & 982 & 994 & 996 & 1000 & 911 & 0 & 0 & 0 & 0 & 0 \\
\hline 0 & 0 & 0 & 0 & 0 & 866 & 877 & 882 & 911 & 1000 & 76 & 0 & 0 & 0 & 0 \\
\hline 0 & 0 & 0 & 0 & 0 & 0 & 0 & 0 & 0 & 76 & 1000 & 1 & 2 & 6 & \\
\hline 0 & 0 & 0 & 0 & 0 & 0 & 0 & 0 & 0 & 0 & 1 & 1000 & 5 & 15 & 6 \\
\hline 0 & 0 & 0 & 0 & 0 & 0 & 0 & 0 & 0 & 0 & 2 & 5 & 1000 & 52 & 42 \\
\hline 0 & 0 & 0 & 0 & 0 & 0 & 0 & 0 & 0 & 0 & 6 & 15 & 52 & 1000 & 999 \\
\hline 0 & 0 & 0 & 0 & 0 & 0 & 0 & 0 & 0 & 0 & 3 & 6 & 42 & 999 & 1000 \\
\hline
\end{tabular}

$239 \mathrm{Pu}(\mathrm{n}, \mathrm{el})$

group rel.s.d.

1 1.0000E-01

$23.0000 E-02$

$\begin{array}{llllllll}1000 & 805 & -338 & -126 & 383 & 357 & 329 & 155\end{array}$

$\begin{array}{llllllll}805 & 1000 & -441 & -116 & 244 & 251 & 259 & 134\end{array}$ 


\begin{tabular}{|c|c|c|c|c|c|c|c|c|c|c|c|c|c|c|c|}
\hline $2.0000 E-02$ & -338 & -441 & 1000 & 458 & -262 & -223 & -177 & -76 & -3 & 0 & 0 & 0 & 0 & 0 & 0 \\
\hline $2.0000 \mathrm{E}-02$ & -126 & -116 & 458 & 1000 & 197 & 42 & -56 & -69 & -3 & 0 & 0 & 0 & 0 & 0 & 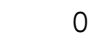 \\
\hline $2.0000 \mathrm{E}-02$ & 357 & 251 & -223 & 42 & 879 & 1000 & 905 & 385 & 16 & 0 & 0 & 0 & 0 & 0 & \\
\hline $2.0000 \mathrm{E}-02$ & 155 & 134 & -76 & -69 & 251 & 385 & 558 & 1000 & 837 & 0 & 0 & 0 & 0 & 0 & \\
\hline $2.0000 \mathrm{E}-02$ & 7 & 6 & -3 & -3 & 10 & 16 & 80 & 837 & 1000 & 0 & 0 & 0 & 0 & 0 & \\
\hline $3.2285 E-03$ & 0 & 0 & 0 & 0 & 0 & 0 & 0 & 0 & 0 & 1000 & 11 & 10 & 20 & 21 & 7 \\
\hline $1.8648 E-02$ & 0 & 0 & 0 & 0 & 0 & 0 & 0 & 0 & 0 & 10 & 17 & 1000 & 554 & 567 & 535 \\
\hline $3.1444 E-02$ & 0 & 0 & 0 & 0 & 0 & 0 & 0 & 0 & 0 & 20 & 50 & 554 & 1000 & 958 & 981 \\
\hline $3.4417 \mathrm{E}-02$ & 0 & 0 & 0 & 0 & 0 & 0 & 0 & 0 & 0 & 21 & 55 & 567 & 958 & 1000 & 936 \\
\hline $6.6491 E-02$ & 0 & 0 & 0 & 0 & 0 & 0 & 0 & 0 & 0 & 21 & 64 & 535 & 981 & 936 & 1000 \\
\hline
\end{tabular}

$239 \mathrm{Pu}\left(\mathrm{n}, \mathrm{n}^{\prime}\right)$

\begin{tabular}{|c|c|c|c|c|c|c|c|c|c|c|}
\hline oup & $r e \perp \cdot s \cdot d$. & & & & & & & & & \\
\hline 1 & $1.5000 \mathrm{E}-01$ & 1000 & 811 & -343 & -138 & 408 & 390 & 343 & 276 & 268 \\
\hline 2 & $1.5000 E-01$ & 811 & 1000 & -445 & -125 & 256 & 271 & 269 & 238 & 234 \\
\hline 3 & $1.0000 \mathrm{E}-01$ & -343 & -445 & 1000 & 475 & -284 & -250 & -189 & -135 & -129 \\
\hline 4 & $3.0000 \mathrm{E}-01$ & -138 & -125 & 475 & 1000 & 168 & 31 & -66 & -130 & -139 \\
\hline 5 & $3.0000 E-01$ & 408 & 256 & -284 & 168 & 1000 & 904 & 703 & 471 & 440 \\
\hline 6 & $5.0000 \mathrm{E}-01$ & 390 & 271 & -250 & 31 & 904 & 1000 & 923 & 737 & 709 \\
\hline 7 & $5.0000 E-01$ & 343 & 269 & -189 & -66 & 703 & 923 & 1000 & 934 & 917 \\
\hline 8 & $5.0000 E-01$ & 276 & 238 & -135 & -130 & 471 & 737 & 934 & 1000 & 999 \\
\hline 9 & $5.0000 \mathrm{E}-01$ & 268 & 234 & -129 & -139 & 440 & 709 & 917 & 999 & 1000 \\
\hline
\end{tabular}

$239 \mathrm{Pu}(\mathrm{n}, 2 \mathrm{n})$

\begin{tabular}{crrr} 
group & rel.s.d. & \multicolumn{1}{c}{$---n$} \\
1 & $2.2319 \mathrm{E}-01$ & 1000 & 299 \\
2 & $7.2530 \mathrm{E}+00$ & 299 & 1000
\end{tabular}

$239 \mathrm{Pu}(\mathrm{n}, \mathrm{f})$

group rel.s.d.

$15.5216 \mathrm{E}-03$

$25.0775 \mathrm{E}-03$

$5.6025 E-03$

5. $4610 \mathrm{E}-03$

$6.1655 E-03$

7. $1258 \mathrm{E}-03$

$\begin{array}{rrrrrrr}1000 & 791 & 684 & 677 & 585 & 489 & 233 \\ 791 & 1000 & 807 & 800 & 695 & 580 & 276 \\ 684 & 807 & 1000 & 831 & 713 & 592 & 281 \\ 677 & 800 & 831 & 1000 & 801 & 664 & 317 \\ 585 & 695 & 713 & 801 & 1000 & 692 & 325 \\ 489 & 580 & 592 & 664 & 692 & 1000 & 331\end{array}$

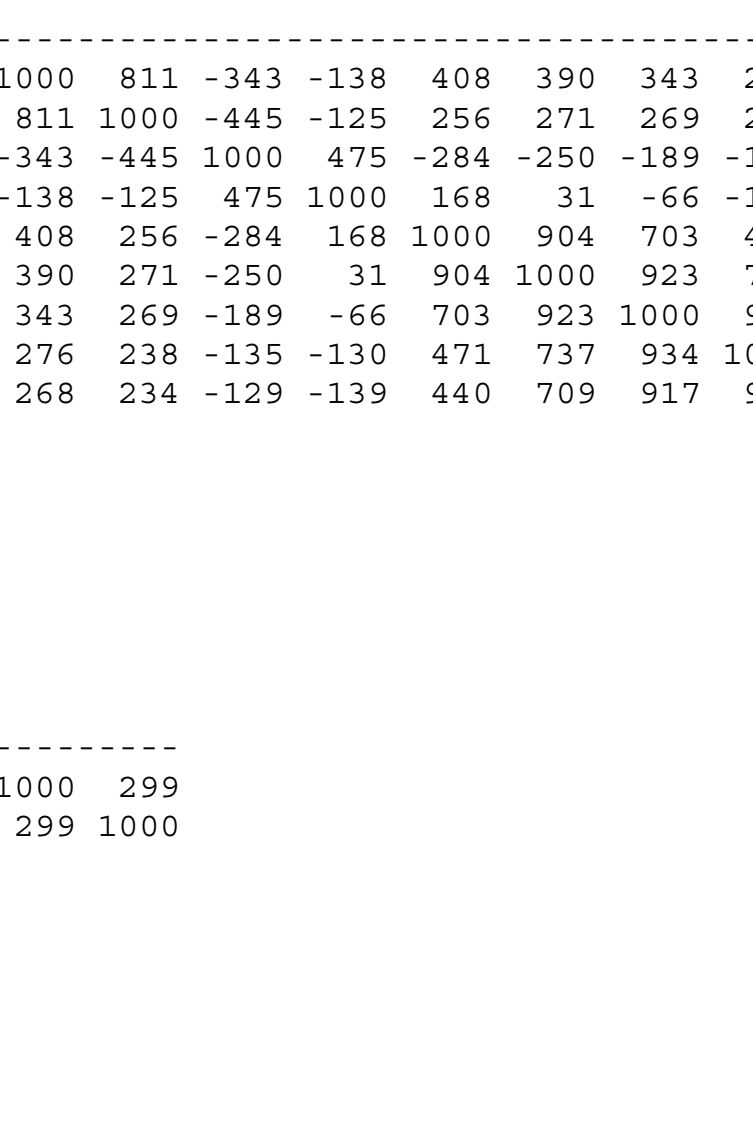

$\begin{array}{llllllll}0 & 0 & 0 & 0 & 0 & 0 & 0 & 0 \\ 0 & 0 & 0 & 0 & 0 & 0 & 0 & 0 \\ 0 & 0 & 0 & 0 & 0 & 0 & 0 & 0 \\ 0 & 0 & 0 & 0 & 0 & 0 & 0 & 0 \\ 0 & 0 & 0 & 0 & 0 & 0 & 0 & 0 \\ 0 & 0 & 0 & 0 & 0 & 0 & 0 & 0\end{array}$




\begin{tabular}{|c|c|c|c|c|c|c|c|c|c|c|c|c|c|c|c|}
\hline $1.2416 \mathrm{E}-02$ & 233 & 276 & 281 & 317 & 325 & 331 & 1000 & 816 & 740 & 0 & 0 & 0 & 0 & 0 & 0 \\
\hline $6.7595 E-02$ & 0 & 0 & 0 & 0 & 0 & 0 & 816 & 1000 & 949 & 0 & 0 & 0 & 0 & 0 & 0 \\
\hline $5.2934 \mathrm{E}-02$ & 0 & 0 & 0 & 0 & 0 & 0 & 740 & 949 & 1000 & 0 & 0 & 0 & 0 & 0 & 0 \\
\hline $3.9323 E-03$ & 0 & 0 & 0 & 0 & 0 & 0 & 0 & 0 & 0 & 1000 & -11 & 2 & -15 & 16 & 11 \\
\hline $9.9794 \mathrm{E}-03$ & 0 & 0 & 0 & 0 & 0 & 0 & 0 & 0 & 0 & -11 & 1000 & 2 & 2 & 0 & 7 \\
\hline $2.6346 \mathrm{E}-02$ & 0 & 0 & 0 & 0 & 0 & 0 & 0 & 0 & 0 & 2 & 2 & 1000 & 193 & -202 & -44 \\
\hline $2.0256 \mathrm{E}-01$ & 0 & 0 & 0 & 0 & 0 & 0 & 0 & 0 & 0 & -15 & 2 & 193 & 1000 & -942 & -35 \\
\hline $4.7989 E-02$ & 0 & 0 & 0 & 0 & 0 & 0 & 0 & 0 & 0 & 16 & 0 & -202 & -942 & 1000 & 167 \\
\hline $1.4841 E-02$ & 0 & 0 & 0 & 0 & 0 & 0 & 0 & 0 & 0 & 11 & 1 & -44 & -35 & 167 & 1000 \\
\hline
\end{tabular}

$239 \mathrm{Pu}$ (n, gamma)

\begin{tabular}{|c|c|c|c|c|c|c|c|c|c|c|c|c|c|c|c|c|}
\hline roup & el.s.d. & & & & -1 & - & -- & -- & - & -1 & -7 & -- & - & -7 & & \\
\hline 1 & $6.0000 E-01$ & 1000 & 408 & 0 & 0 & 0 & 0 & 0 & 0 & 0 & 0 & 0 & 0 & 0 & 0 & 0 \\
\hline 2 & $2.0000 E-01$ & 408 & 1000 & 820 & 659 & 162 & 35 & 23 & 0 & 0 & 0 & 0 & 0 & 0 & 0 & 0 \\
\hline 3 & $5.0000 \mathrm{E}-01$ & 0 & 820 & 1000 & 804 & 197 & 43 & 28 & 0 & 0 & 0 & 0 & 0 & 0 & 0 & 0 \\
\hline 4 & $2.0000 \mathrm{E}-01$ & 0 & 659 & 804 & 1000 & 354 & 77 & 50 & 0 & 0 & 0 & 0 & 0 & 0 & 0 & 0 \\
\hline 5 & $1.5000 \mathrm{E}-01$ & 0 & 162 & 197 & 354 & 1000 & 221 & 91 & 0 & 0 & 0 & 0 & 0 & 0 & 0 & 0 \\
\hline 6 & $2.0000 E-01$ & 0 & 35 & 43 & 77 & 221 & 1000 & 820 & 0 & 0 & 0 & 0 & 0 & 0 & 0 & 0 \\
\hline 7 & $2.0000 E-01$ & 0 & 23 & 28 & 50 & 91 & 820 & 1000 & 121 & 116 & 0 & 0 & 0 & 0 & 0 & 0 \\
\hline 8 & $2.0000 \mathrm{E}-01$ & 0 & 0 & 0 & 0 & 0 & 0 & 121 & 1000 & 986 & 0 & 0 & 0 & 0 & 0 & 0 \\
\hline 9 & $5.5706 E-02$ & 0 & 0 & 0 & 0 & 0 & 0 & 116 & 986 & 1000 & 0 & 0 & 0 & 0 & 0 & 0 \\
\hline 10 & $4.4079 E-03$ & 0 & 0 & 0 & 0 & 0 & 0 & 0 & 0 & 0 & 1000 & 0 & 1 & 1 & -1 & 1 \\
\hline 11 & $8.7665 E-03$ & 0 & 0 & 0 & 0 & 0 & 0 & 0 & 0 & 0 & 0 & 1000 & -4 & 13 & -8 & 5 \\
\hline 12 & $2.1341 E-02$ & 0 & 0 & 0 & 0 & 0 & 0 & 0 & 0 & 0 & 1 & -4 & 1000 & 65 & -87 & -13 \\
\hline 13 & $1.7530 \mathrm{E}-01$ & 0 & 0 & 0 & 0 & 0 & 0 & 0 & 0 & 0 & 1 & 13 & 65 & 1000 & -965 & -315 \\
\hline 14 & $2.8745 E-02$ & 0 & 0 & 0 & 0 & 0 & 0 & 0 & 0 & 0 & -1 & -8 & -87 & -965 & 1000 & 525 \\
\hline 15 & $2.1209 E-02$ & 0 & 0 & 0 & 0 & 0 & 0 & 0 & 0 & 0 & 1 & 5 & -13 & -315 & 525 & 1000 \\
\hline
\end{tabular}

group rel.s.d.

$14.0000 \mathrm{E}-02$

$24.0000 \mathrm{E}-02$

$34.0000 \mathrm{E}-02$

$44.0000 \mathrm{E}-02$

$54.0000 \mathrm{E}-02$

$64.0000 \mathrm{E}-02$

$74.0000 \mathrm{E}-02$

$84.0000 \mathrm{E}-02$

$94.0000 \mathrm{E}-02$

$101.2591 \mathrm{E}-02$

$11 \quad 1.6361 \mathrm{E}-02$

$123.2532 \mathrm{E}-02$

$134.8438 \mathrm{E}-03$

$144.5762 \mathrm{E}-02$

\begin{tabular}{|c|c|c|c|c|c|c|c|c|c|c|c|c|c|c|}
\hline 1000 & 917 & 442 & 427 & 816 & 638 & 243 & -23 & -86 & 0 & 0 & 0 & 0 & 0 & 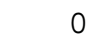 \\
\hline 917 & 1000 & 709 & 634 & 941 & 850 & 524 & 276 & 138 & 0 & 0 & 0 & 0 & 0 & 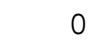 \\
\hline 442 & 709 & 1000 & 856 & 798 & 950 & 949 & 861 & 610 & 0 & 0 & 0 & 0 & 0 & \\
\hline 427 & 634 & 856 & 1000 & 844 & 906 & 901 & 787 & 548 & 0 & 0 & 0 & 0 & 0 & \\
\hline 816 & 941 & 798 & 844 & 1000 & 942 & 706 & 478 & 292 & 0 & 0 & 0 & 0 & 0 & \\
\hline 638 & 850 & 950 & 906 & 942 & 1000 & 892 & 732 & 496 & 0 & 0 & 0 & 0 & 0 & \\
\hline 243 & 524 & 949 & 901 & 706 & 892 & 1000 & 959 & 693 & 0 & 0 & 0 & 0 & 0 & \\
\hline-23 & 276 & 861 & 787 & 478 & 732 & 959 & 1000 & 744 & 0 & 0 & 0 & 0 & 0 & \\
\hline-86 & 138 & 610 & 548 & 292 & 496 & 693 & 744 & 1000 & -13 & 0 & 7 & -2 & 11 & 15 \\
\hline 0 & 0 & 0 & 0 & 0 & 0 & 0 & 0 & -13 & 1000 & 38 & 25 & 14 & 8 & \\
\hline 0 & 0 & 0 & 0 & 0 & 0 & 0 & 0 & 0 & 38 & 1000 & 49 & 16 & 24 & 26 \\
\hline 0 & 0 & 0 & 0 & 0 & 0 & 0 & 0 & 7 & 25 & 49 & 1000 & 164 & 168 & 169 \\
\hline 0 & 0 & 0 & 0 & 0 & 0 & 0 & 0 & -2 & 14 & 16 & 164 & 1000 & 988 & 986 \\
\hline 0 & 0 & 0 & 0 & 0 & 0 & 0 & 0 & 11 & 8 & 24 & 168 & 988 & 1000 & 1000 \\
\hline
\end{tabular}




\begin{tabular}{|c|c|c|c|c|c|c|c|c|}
\hline roup & rel.s.d. & 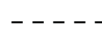 & -2 & - & & & & \\
\hline 1 & $1.0000 \mathrm{E}-01$ & 1000 & 608 & 559 & -740 & -539 & -661 & -597 \\
\hline 2 & $1.4270 \mathrm{E}-01$ & 608 & 1000 & 978 & -846 & -870 & -972 & -858 \\
\hline 3 & $5.7500 E-02$ & 559 & 978 & 1000 & -757 & -795 & -927 & -825 \\
\hline 4 & $3.0000 E-01$ & -740 & -846 & -757 & 1000 & 908 & 930 & 809 \\
\hline 5 & $3.0000 E-01$ & -539 & -870 & -795 & 908 & 1000 & 949 & 807 \\
\hline 6 & $4.0000 E-01$ & -661 & -972 & -927 & 930 & 949 & 1000 & 873 \\
\hline 7 & $6.8170 E-01$ & -597 & -858 & -825 & 809 & 807 & 873 & 1000 \\
\hline
\end{tabular}

$240 \operatorname{Pu}(n, 2 n)$

group rel.s.d. ---

$11.0000 \mathrm{E}-011000$

$240 \mathrm{Pu}(\mathrm{n}, \mathrm{f})$

\begin{tabular}{|c|c|c|c|c|c|c|c|c|c|c|c|c|c|c|c|c|}
\hline roup & eI.s.a. & & & & & & & & & & -- & - & $5-$ & -- & - & 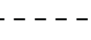 \\
\hline 1 & $9.5597 \mathrm{E}-02$ & 1000 & 741 & -204 & -344 & -337 & -577 & -594 & -594 & -205 & 0 & 0 & 0 & 0 & 0 & . \\
\hline 2 & $4.8001 E-02$ & 741 & 1000 & -374 & -594 & -582 & -941 & -962 & -962 & -331 & 0 & 0 & 0 & 0 & 0 & 0 \\
\hline 3 & $5.6532 \mathrm{E}-02$ & -204 & -374 & 1000 & 965 & 969 & 581 & 454 & 454 & 156 & 0 & 0 & 0 & 0 & 0 & 0 \\
\hline 4 & $5.8233 E-02$ & -344 & -594 & 965 & 1000 & 1000 & 774 & 672 & 672 & 231 & 0 & 0 & 0 & 0 & 0 & 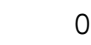 \\
\hline 5 & $3.9098 E-02$ & -337 & -582 & 969 & 1000 & 1000 & 764 & 661 & 661 & 227 & 0 & 0 & 0 & 0 & 0 & 0 \\
\hline 6 & $5.7007 E-02$ & -577 & -941 & 581 & 774 & 764 & 1000 & 989 & 989 & 341 & 0 & 0 & 0 & 0 & 0 & 0 \\
\hline 7 & $7.4510 \mathrm{E}-02$ & -594 & -962 & 454 & 672 & 661 & 989 & 1000 & 1000 & 344 & 0 & 0 & 0 & 0 & 0 & 0 \\
\hline 8 & $7.4510 \mathrm{E}-02$ & -594 & -962 & 454 & 672 & 661 & 989 & 1000 & 1000 & 344 & 0 & 0 & 0 & 0 & 0 & 0 \\
\hline 9 & $8.0144 E-02$ & -205 & -331 & 156 & 231 & 227 & 341 & 344 & 344 & 1000 & 20 & 45 & 4 & 1 & -1 & -1 \\
\hline 10 & $2.1617 E-01$ & 0 & 0 & 0 & 0 & 0 & 0 & 0 & 0 & 20 & 1000 & 357 & 24 & 6 & 16 & 18 \\
\hline 11 & $4.7157 E-02$ & 0 & 0 & 0 & 0 & 0 & 0 & 0 & 0 & 45 & 357 & 1000 & 40 & 13 & -31 & -30 \\
\hline 12 & $8.9123 E-02$ & 0 & 0 & 0 & 0 & 0 & 0 & 0 & 0 & 4 & 24 & 40 & 1000 & 8 & -21 & -21 \\
\hline 13 & 1.2186E-02 & 0 & 0 & 0 & 0 & 0 & 0 & 0 & 0 & 1 & 6 & 13 & 8 & 1000 & 559 & 478 \\
\hline 14 & $2.9756 E-01$ & 0 & 0 & 0 & 0 & 0 & 0 & 0 & 0 & -1 & 16 & -31 & -21 & 559 & 1000 & 995 \\
\hline 15 & $4.8464 E-01$ & 0 & 0 & 0 & 0 & 0 & 0 & 0 & 0 & -1 & 18 & -30 & -21 & 478 & 995 & 1000 \\
\hline
\end{tabular}




\begin{tabular}{|c|c|c|c|c|c|c|c|c|c|c|c|c|c|c|c|c|}
\hline & & & & & & & & & & & & & & & & \\
\hline 1 & $5.5000 \mathrm{E}-01$ & 1000 & 655 & 464 & 413 & 411 & 411 & 393 & 393 & 380 & 0 & 0 & 0 & 0 & 0 & 0 \\
\hline 2 & $3.5000 E-01$ & 655 & 1000 & 848 & 734 & 661 & 641 & 581 & 584 & 571 & 0 & 0 & 0 & 0 & 0 & 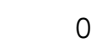 \\
\hline 3 & $2.5000 \mathrm{E}-01$ & 464 & 848 & 1000 & 971 & 917 & 904 & 836 & 838 & 814 & 0 & 0 & 0 & 0 & 0 & \\
\hline 4 & $1.0000 \mathrm{E}-00$ & 413 & 734 & 971 & 1000 & 983 & 975 & 934 & 935 & 900 & 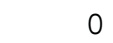 & 0 & 0 & 0 & & \\
\hline 5 & $3.0000 \mathrm{E}-01$ & 411 & 661 & 917 & 983 & 1000 & 997 & 977 & 977 & 935 & 0 & 0 & 0 & 0 & 0 & \\
\hline 6 & $1.0000 \mathrm{E}-01$ & 411 & 641 & 904 & 975 & 997 & 1000 & 972 & 970 & 930 & 0 & 0 & 0 & 0 & 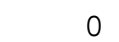 & \\
\hline 7 & $1.0000 \mathrm{E}-01$ & 393 & 581 & 836 & 934 & 977 & 972 & 1000 & 1000 & 948 & 0 & 0 & 0 & 0 & 0 & \\
\hline 8 & $1.0211 \mathrm{E}-01$ & 393 & 584 & 838 & 935 & 977 & 970 & 1000 & 1000 & 948 & 0 & 0 & 0 & 0 & 0 & \\
\hline 9 & $5.0000 \mathrm{E}-02$ & 380 & 571 & 814 & 900 & 935 & 930 & 948 & 948 & 1000 & 1 & 0 & 0 & 0 & 0 & \\
\hline 10 & $5.0000 \mathrm{E}-02$ & 0 & 0 & 0 & 0 & 0 & 0 & 0 & 0 & 1 & 1000 & 1 & $v$ & 0 & 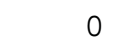 & \\
\hline 11 & $5.0000 \mathrm{E}-02$ & 0 & 0 & 0 & 0 & 0 & 0 & 0 & 0 & 0 & 1 & 1000 & 5 & 1 & 5 & \\
\hline 12 & $5.4970 \mathrm{E}-02$ & 0 & 0 & 0 & 0 & 0 & 0 & 0 & 0 & 0 & 0 & 5 & 1000 & 2 & 23 & \\
\hline 13 & $4.3621 E-03$ & 0 & 0 & 0 & 0 & 0 & 0 & 0 & 0 & 0 & 0 & 1 & 2 & 1000 & 7 & 5 \\
\hline 14 & $3.2338 E-02$ & 0 & 0 & 0 & 0 & 0 & 0 & 0 & 0 & 0 & 0 & 5 & 23 & 7 & 1000 & 96 \\
\hline 15 & $4.7875 \mathrm{E}-02$ & 0 & 0 & 0 & 0 & 0 & 0 & 0 & 0 & 0 & 0 & 5 & 25 & 58 & 962 & 100 \\
\hline
\end{tabular}

\section{$241 \mathrm{Pu}(\mathrm{n}, \mathrm{el})$}

group rel.s.d.

$13.0000 \mathrm{E}-02$

$2 \quad 2.0000 \mathrm{E}-02$

$33.0000 \mathrm{E}-02$

$4 \quad 1.0000 \mathrm{E}-01$

$5 \quad 1.0000 \mathrm{E}-01$

$6 \quad 1.0000 \mathrm{E}-01$

$7 \quad 1.0000 \mathrm{E}-01$

$8 \quad 1.0000 \mathrm{E}-01$

9 1.0000E-01

$10 \quad 1.1000 \mathrm{E}-01$

$11 \quad 1.0873 \mathrm{E}-01$

$12 \quad 1.0658 \mathrm{E}-01$

$13 \quad 1.1489 \mathrm{E}-01$

$149.9124 \mathrm{E}-02$

15 1.1318E-01

$\begin{array}{rrrrrrrrrrrrrrr}1000 & 768 & -24 & 45 & 9 & -14 & -9 & 0 & 0 & 0 & 0 & 0 & 0 & 0 & 0 \\ 768 & 1000 & 240 & -562 & -86 & 174 & 111 & 0 & 0 & 0 & 0 & 0 & 0 & 0 & 0 \\ -24 & 240 & 1000 & -411 & -253 & 88 & 86 & 0 & 0 & 0 & 0 & 0 & 0 & 0 & 0 \\ 45 & -562 & -411 & 1000 & 423 & -34 & -68 & 0 & 0 & 0 & 0 & 0 & 0 & 0 & 0 \\ 9 & -86 & -253 & 423 & 1000 & 872 & 397 & 0 & 0 & 0 & 0 & 0 & 0 & 0 & 0 \\ -14 & 174 & 88 & -34 & 872 & 1000 & 488 & 0 & 0 & 0 & 0 & 0 & 0 & 0 & 0 \\ -9 & 111 & 86 & -68 & 397 & 488 & 1000 & 870 & 857 & 0 & 0 & 0 & 0 & 0 & 0 \\ 0 & 0 & 0 & 0 & 0 & 0 & 870 & 1000 & 992 & 0 & 0 & 0 & 0 & 0 & 0 \\ 0 & 0 & 0 & 0 & 0 & 0 & 857 & 992 & 1000 & 12 & 12 & 12 & 12 & 12 & 11 \\ 0 & 0 & 0 & 0 & 0 & 0 & 0 & 0 & 12 & 1000 & 1000 & 994 & 976 & 925 & 885 \\ 0 & 0 & 0 & 0 & 0 & 0 & 0 & 0 & 12 & 1000 & 1000 & 994 & 976 & 925 & 885 \\ 0 & 0 & 0 & 0 & 0 & 0 & 0 & 0 & 12 & 994 & 994 & 1000 & 948 & 905 & 868 \\ 0 & 0 & 0 & 0 & 0 & 0 & 0 & 0 & 12 & 976 & 976 & 948 & 1000 & 957 & 912 \\ 0 & 0 & 0 & 0 & 0 & 0 & 0 & 0 & 12 & 925 & 925 & 905 & 957 & 1000 & 939 \\ 0 & 0 & 0 & 0 & 0 & 0 & 0 & 0 & 11 & 885 & 885 & 868 & 912 & 939 & 1000\end{array}$

$241 \mathrm{Pu}\left(\mathrm{n}, \mathrm{n}^{\prime}\right)$

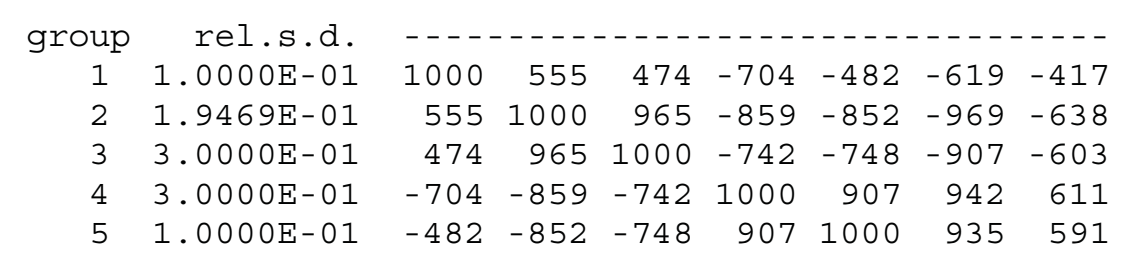




\begin{tabular}{|c|c|c|c|c|c|c|c|c|c|c|c|c|c|c|c|c|}
\hline 11 & $7.4258 \mathrm{E}-02$ & 0 & 0 & 0 & 0 & 0 & 0 & 608 & 831 & 833 & 833 & 1000 & 225 & 67 & 148 & -235 \\
\hline 12 & $8.3828 E-02$ & 0 & 0 & 0 & 0 & 0 & 0 & 0 & 0 & 0 & 0 & 225 & 1000 & 264 & 398 & -407 \\
\hline 13 & $6.3663 E-02$ & 0 & 0 & 0 & 0 & 0 & 0 & 0 & 0 & 0 & 0 & 67 & 264 & 1000 & 636 & 319 \\
\hline 4 & $6.8424 \mathrm{E}-02$ & 0 & 0 & 0 & 0 & 0 & 0 & 0 & 0 & 0 & 0 & 148 & 398 & 636 & 1000 & -6 \\
\hline 5 & $3.5907 E-02$ & 0 & 0 & 0 & 0 & 0 & 0 & 0 & 0 & 0 & 0 & -235 & -407 & 319 & -6 & 1000 \\
\hline
\end{tabular}

$242 \mathrm{Pu}(\mathrm{n}, \mathrm{el})$

group rel.s.d.

$13.0000 \mathrm{E}-02$

$23.0000 \mathrm{E}-02$

$33.0000 \mathrm{E}-02$

$43.0000 \mathrm{E}-02$

$53.0000 \mathrm{E}-02$

$63.0000 E-02$

$73.0000 \mathrm{E}-02$

$83.0000 \mathrm{E}-02$

$93.0000 \mathrm{E}-02$

$103.7640 \mathrm{E}-02$

$112.2909 \mathrm{E}-02$

$125.9371 \mathrm{E}-02$

$134.6823 \mathrm{E}-02$

$147.1901 \mathrm{E}-02$

$156.9903 \mathrm{E}-02$

$\begin{array}{rrrrrrr}1000 & 160 & 967 & 196 & -363 & 0 & 0 \\ 160 & 1000 & -2 & -351 & -141 & 0 \\ 967 & -2 & 1000 & 293 & -328 & 0 \\ 196 & -351 & 293 & 1000 & 432 & 0 & 0 \\ -363 & -141 & -328 & 432 & 1000 & 762 & 92 \\ 0 & 0 & 0 & 0 & 762 & 1000 & 121 \\ 0 & 0 & 0 & 0 & 92 & 121 & 100 \\ 0 & 0 & 0 & 0 & 0 & 0 & 993 \\ 0 & 0 & 0 & 0 & 0 & 0 & 708 \\ 0 & 0 & 0 & 0 & 0 & 0 & 0 \\ 0 & 0 & 0 & 0 & 0 & 0 & 0 \\ 0 & 0 & 0 & 0 & 0 & 0 & 0 \\ 0 & 0 & 0 & 0 & 0 & 0 \\ 0 & 0 & 0 & 0 & 0 & 0 \\ 0 & 0 & 0 & 0 & 0 & 0\end{array}$

$\begin{array}{rrrrrrrrr}0 & 0 & 0 & 0 & 0 & 0 & 0 & 0 & 0 \\ 0 & 0 & 0 & 0 & 0 & 0 & 0 & 0 & 0 \\ 0 & 0 & 0 & 0 & 0 & 0 & 0 & 0 & 0 \\ 0 & 0 & 0 & 0 & 0 & 0 & 0 & 0 & 0 \\ 92 & 0 & 0 & 0 & 0 & 0 & 0 & 0 & 0 \\ 121 & 0 & 0 & 0 & 0 & 0 & 0 & 0 & 0 \\ 1000 & 993 & 708 & 0 & 0 & 0 & 0 & 0 & 0 \\ 993 & 1000 & 711 & 0 & 0 & 0 & 0 & 0 & 0 \\ 708 & 711 & 1000 & 591 & 558 & 627 & 96 & 627 & 627 \\ 0 & 0 & 591 & 1000 & 827 & 936 & 143 & 936 & 936 \\ 0 & 0 & 558 & 827 & 1000 & 884 & 136 & 884 & 884 \\ 0 & 0 & 627 & 936 & 884 & 1000 & 169 & 998 & 998 \\ 0 & 0 & 96 & 143 & 136 & 169 & 1000 & 118 & 120 \\ 0 & 0 & 627 & 936 & 884 & 998 & 118 & 1000 & 1000 \\ 0 & 0 & 627 & 936 & 884 & 998 & 120 & 1000 & 1000\end{array}$

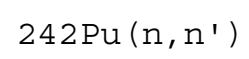


group rel.s.d.

$13.7238 \mathrm{E}-01$

2 1.5095E-01

$32.1418 \mathrm{E}-01$

$4 \quad 1.8982 \mathrm{E}-01$

$51.8630 \mathrm{E}-01$

$6 \quad 3.2071 \mathrm{E}-01$

$73.3058 E-01$

$83.3187 \mathrm{E}-01$

$9 \quad 1.3227 \mathrm{E}-01$

$105.8878 \mathrm{E}-02$

$11 \quad 1.9567 \mathrm{E}-02$

$126.4611 \mathrm{E}-02$

$137.6041 \mathrm{E}-02$

$145.2357 \mathrm{E}-02$

$155.0918 \mathrm{E}-02$

\begin{tabular}{|c|c|c|c|c|c|c|c|c|c|c|c|c|c|c|}
\hline 1000 & -366 & -37 & -32 & -16 & 0 & 0 & 0 & 0 & 0 & 0 & 0 & 0 & 0 & \\
\hline-366 & 1000 & 592 & 497 & 253 & 0 & 0 & 0 & 0 & 0 & 0 & 0 & 0 & 0 & \\
\hline-37 & 592 & 1000 & 981 & 500 & 0 & 0 & 0 & 0 & 0 & 0 & 0 & 0 & 0 & \\
\hline-32 & 497 & 981 & 1000 & 510 & 0 & 0 & 0 & 0 & 0 & 0 & 0 & 0 & 0 & \\
\hline-16 & 253 & 500 & 510 & 1000 & 860 & 103 & 0 & 0 & 0 & 0 & 0 & 0 & 0 & \\
\hline 0 & 0 & 0 & 0 & 860 & 1000 & 120 & 0 & 0 & 0 & 0 & 0 & 0 & 0 & \\
\hline 0 & 0 & 0 & 0 & 103 & 120 & 1000 & 992 & 680 & 0 & 0 & 0 & 0 & 0 & \\
\hline 0 & 0 & 0 & 0 & 0 & 0 & 992 & 1000 & 682 & 0 & 0 & 0 & 0 & 0 & \\
\hline 0 & 0 & 0 & 0 & 0 & 0 & 680 & 682 & 1000 & 0 & 0 & 0 & 0 & 0 & \\
\hline 0 & 0 & 0 & 0 & 0 & 0 & 0 & 0 & 0 & 1000 & 2 & 7 & 0 & 5 & \\
\hline 0 & 0 & 0 & 0 & 0 & 0 & 0 & 0 & 0 & 2 & 1000 & 32 & 0 & 13 & . \\
\hline 0 & 0 & 0 & 0 & 0 & 0 & 0 & 0 & 0 & 7 & 32 & 1000 & 337 & 477 & 477 \\
\hline 0 & 0 & 0 & 0 & 0 & 0 & 0 & 0 & 0 & 0 & 0 & 337 & 1000 & 708 & 70 \\
\hline 0 & 0 & 0 & 0 & 0 & 0 & 0 & 0 & 0 & 5 & 13 & 477 & 708 & 1000 & 100 \\
\hline 0 & 0 & 0 & 0 & 0 & 0 & 0 & 0 & 0 & 5 & 15 & 477 & 706 & 1000 & 1000 \\
\hline
\end{tabular}

$242 \mathrm{Pu}$ (n, gamma)

group rel.s.d.

$17.8469 \mathrm{E}-01$

$22.00000-00$

$31.5000 \mathrm{E}-00$

$48.0000 \mathrm{E}-01$

$53.0000 \mathrm{E}-01$

$63.2281 \mathrm{E}-01$

\begin{tabular}{|c|c|c|c|c|c|c|c|c|c|c|c|c|c|c|}
\hline 1000 & 369 & 230 & 42 & 0 & 0 & 0 & 0 & 0 & 0 & 0 & 0 & 0 & 0 & 0 \\
\hline 369 & 1000 & 936 & 188 & -12 & 0 & 0 & 0 & 0 & 0 & 0 & 0 & 0 & 0 & 0 \\
\hline 230 & 936 & 1000 & 345 & 9 & 0 & 0 & 0 & 0 & 0 & 0 & 0 & 0 & 0 & \\
\hline 42 & 188 & 345 & 1000 & 159 & 0 & 0 & 0 & 0 & 0 & 0 & 0 & 0 & 0 & \\
\hline 0 & -12 & 9 & 159 & 1000 & 986 & 66 & 0 & 0 & 0 & 0 & 0 & 0 & 0 & \\
\hline 0 & 0 & 0 & 0 & 986 & 1000 & 67 & 0 & 0 & 0 & 0 & 0 & 0 & 0 & \\
\hline 0 & 0 & 0 & 0 & 66 & 67 & 1000 & 998 & 997 & 0 & 0 & 0 & 0 & 0 & \\
\hline 0 & 0 & 0 & 0 & 0 & 0 & 998 & 1000 & 999 & 0 & 0 & 0 & 0 & 0 & \\
\hline 0 & 0 & 0 & 0 & 0 & 0 & 997 & 999 & 1000 & 0 & 0 & 0 & 0 & 0 & \\
\hline 0 & 0 & 0 & 0 & 0 & 0 & 0 & 0 & 0 & 1000 & 4 & 0 & 0 & 0 & \\
\hline 0 & 0 & 0 & 0 & 0 & 0 & 0 & 0 & 0 & 4 & 1000 & 12 & 0 & 10 & 1 \\
\hline 0 & 0 & 0 & 0 & 0 & 0 & 0 & 0 & 0 & 0 & 12 & 1000 & 66 & 97 & $y$ \\
\hline 0 & 0 & 0 & 0 & 0 & 0 & 0 & 0 & 0 & 0 & 0 & 66 & 1000 & 688 & 70 \\
\hline 0 & 0 & 0 & 0 & 0 & 0 & 0 & 0 & 0 & 0 & 10 & 97 & 688 & 1000 & 1000 \\
\hline 0 & 0 & 0 & 0 & 0 & 0 & 0 & 0 & 0 & 0 & 11 & 98 & 705 & 1000 & 1000 \\
\hline
\end{tabular}

$241 \mathrm{Am}(\mathrm{n}, \mathrm{el})$

group rel.s.d.

$13.0000 \mathrm{E}-02$

2 2.0000E-02

$32.0000 \mathrm{E}-02$ $\begin{array}{rrrrrrr}1000 & -57 & -244 & -61 & -6 & -7 & -9 \\ -57 & 1000 & 465 & 53 & -317 & -342 & -329 \\ -244 & 465 & 1000 & 562 & -155 & -191 & -182\end{array}$ 


$\begin{array}{rrrrrrrrrrrrrrrrr}4 & 2.0000 \mathrm{E}-02 & -61 & 53 & 562 & 1000 & 700 & 670 & 639 & 0 & 0 & 0 & 0 & 0 & 0 & 0 & 0 \\ 5 & 1.0000 \mathrm{E}-01 & -6 & -317 & -155 & 700 & 1000 & 999 & 952 & 0 & 0 & 0 & 0 & 0 & 0 & 0 & 0 \\ 6 & 1.0000 \mathrm{E}-01 & -7 & -342 & -191 & 670 & 999 & 1000 & 953 & 0 & 0 & 0 & 0 & 0 & 0 & 0 & 0 \\ 7 & 1.0000 \mathrm{E}-01 & -9 & -329 & -182 & 639 & 952 & 953 & 1000 & 302 & 299 & 127 & 0 & 0 & 0 & 0 & 0 \\ 8 & 1.0000 \mathrm{E}-01 & 0 & 0 & 0 & 0 & 0 & 0 & 302 & 1000 & 991 & 421 & 0 & 0 & 0 & 0 & 0 \\ 9 & 1.0000 \mathrm{E}-01 & 0 & 0 & 0 & 0 & 0 & 0 & 299 & 991 & 1000 & 434 & 0 & 0 & 0 & 0 & 0 \\ 10 & 1.0000 \mathrm{E}-01 & 0 & 0 & 0 & 0 & 0 & 0 & 127 & 421 & 434 & 1000 & 886 & 886 & 885 & 885 & 885 \\ 11 & 1.4527 \mathrm{E}-01 & 0 & 0 & 0 & 0 & 0 & 0 & 0 & 0 & 0 & 886 & 1000 & 1000 & 998 & 998 & 998 \\ 12 & 1.4030 \mathrm{E}-01 & 0 & 0 & 0 & 0 & 0 & 0 & 0 & 0 & 0 & 886 & 1000 & 1000 & 998 & 998 & 998 \\ 13 & 1.4204 \mathrm{E}-01 & 0 & 0 & 0 & 0 & 0 & 0 & 0 & 0 & 0 & 885 & 998 & 998 & 1000 & 996 & 996 \\ 14 & 1.3810 \mathrm{E}-01 & 0 & 0 & 0 & 0 & 0 & 0 & 0 & 0 & 0 & 885 & 998 & 998 & 996 & 1000 & 1000 \\ 15 & 1.3033 \mathrm{E}-01 & 0 & 0 & 0 & 0 & 0 & 0 & 0 & 0 & 0 & 885 & 998 & 998 & 996 & 1000 & 1000\end{array}$

$241 \mathrm{Am}\left(\mathrm{n}, \mathrm{n}^{\prime}\right)$

\begin{tabular}{|c|c|c|c|c|c|c|c|c|}
\hline & & & & & & & & \\
\hline 1 & $1.5000 \mathrm{E}-01$ & 1000 & -20 & -67 & -275 & -375 & -151 & -103 \\
\hline 2 & $2.0000 \mathrm{E}-01$ & -20 & 1000 & 953 & 889 & -305 & -798 & -718 \\
\hline 3 & $2.0000 \mathrm{E}-01$ & -67 & 953 & 1000 & 884 & -409 & -884 & -788 \\
\hline 4 & $2.0000 \mathrm{E}-01$ & -275 & 889 & 884 & 1000 & 61 & -564 & -538 \\
\hline 5 & $3.0000 \mathrm{E}-01$ & -375 & -305 & -409 & 61 & 1000 & 787 & 629 \\
\hline 6 & $3.0000 \mathrm{E}-01$ & -151 & -798 & -884 & -564 & 787 & 1000 & 855 \\
\hline 7 & $3.0000 \mathrm{E}-01$ & -103 & -718 & -788 & -538 & 629 & 855 & 1000 \\
\hline
\end{tabular}

$241 \mathrm{Am}(\mathrm{n}, 2 \mathrm{n})$

group rel.s.d. ---

$1 \quad 1.0034 \mathrm{E}-01 \quad 1000$

$241 \mathrm{Am}(\mathrm{n}, \mathrm{f})$

group rel.s.d.

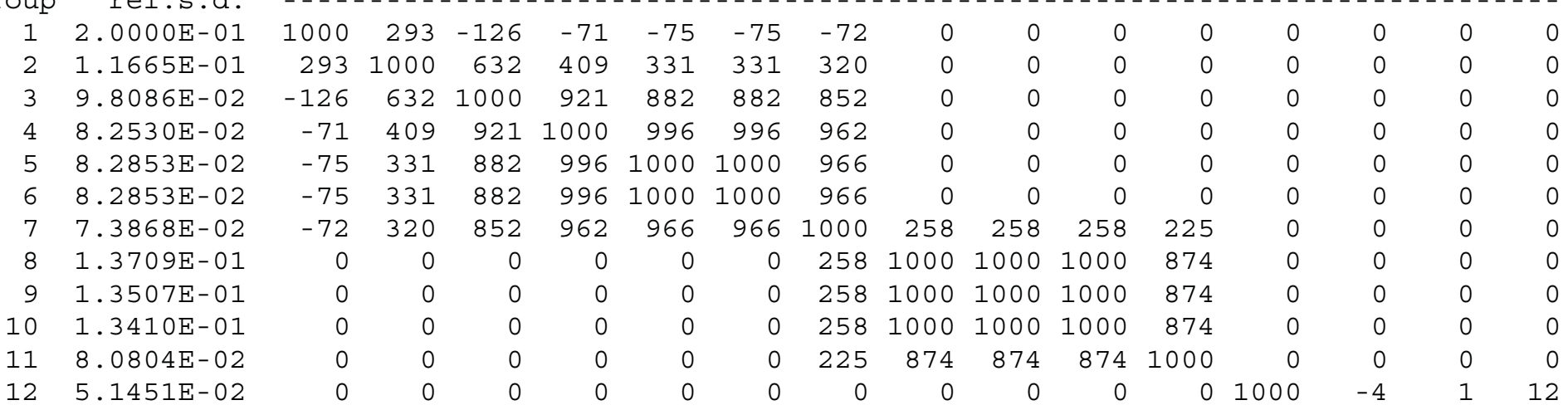




\begin{tabular}{|c|c|c|c|c|c|c|c|c|c|c|c|c|c|c|c|}
\hline $6.7239 E-02$ & 0 & 0 & 0 & 0 & 0 & 0 & 0 & 0 & 0 & 0 & 0 & -4 & 1000 & 57 & 131 \\
\hline $8.9340 \mathrm{E}-02$ & 0 & 0 & 0 & 0 & 0 & 0 & 0 & 0 & 0 & 0 & 0 & 1 & 57 & 1000 & 884 \\
\hline $3.0203 E-02$ & 0 & 0 & 0 & 0 & 0 & 0 & 0 & 0 & 0 & 0 & 0 & 12 & 131 & 884 & 10 \\
\hline
\end{tabular}

$241 \mathrm{Am}$ (n, gamma )

\begin{tabular}{|c|c|c|c|c|c|c|c|c|c|c|c|c|c|c|c|c|}
\hline coup & rel.s.d. & & & - & - & & - & - & & & -2 & -- & & $-\ldots$ & --- & 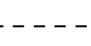 \\
\hline 1 & $2.8826 E-01$ & 1000 & 391 & 321 & 246 & 253 & 156 & 105 & 0 & 0 & 0 & 0 & 0 & 0 & 0 & 0 \\
\hline 2 & $1.5384 \mathrm{E}-01$ & 391 & 1000 & 935 & 753 & 240 & -204 & -370 & 0 & 0 & 0 & 0 & 0 & 0 & 0 & \\
\hline 3 & $3.0000 E-01$ & 321 & 935 & 1000 & 932 & 416 & -104 & -329 & 0 & 0 & 0 & 0 & 0 & 0 & 0 & \\
\hline 4 & $3.0000 E-01$ & 246 & 753 & 932 & 1000 & 618 & 100 & -148 & 0 & 0 & 0 & 0 & 0 & 0 & 0 & 0 \\
\hline 5 & $2.0000 E-01$ & 253 & 240 & 416 & 618 & 1000 & 843 & 677 & 0 & 0 & 0 & 0 & 0 & 0 & 0 & 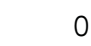 \\
\hline 6 & $6.7913 E-02$ & 156 & -204 & -104 & 100 & 843 & 1000 & 957 & 0 & 0 & 0 & 0 & 0 & 0 & 0 & 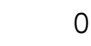 \\
\hline 7 & $7.9615 E-02$ & 105 & -370 & -329 & -148 & 677 & 957 & 1000 & 122 & 122 & 122 & 121 & 0 & 0 & 0 & 0 \\
\hline 8 & $6.8538 E-02$ & 0 & 0 & 0 & 0 & 0 & 0 & 122 & 1000 & 1000 & 1000 & 996 & 0 & 0 & 0 & 0 \\
\hline 9 & $6.6629 E-02$ & 0 & 0 & 0 & 0 & 0 & 0 & 122 & 1000 & 1000 & 1000 & 997 & 0 & 0 & 0 & 0 \\
\hline 10 & $6.5925 E-02$ & 0 & 0 & 0 & 0 & 0 & 0 & 122 & 1000 & 1000 & 1000 & 997 & 0 & 0 & 0 & 0 \\
\hline 11 & $3.6682 E-02$ & 0 & 0 & 0 & 0 & 0 & 0 & 121 & 996 & 997 & 997 & 1000 & 0 & 0 & 0 & 0 \\
\hline 12 & $1.8169 \mathrm{E}-02$ & 0 & 0 & 0 & 0 & 0 & 0 & 0 & 0 & 0 & 0 & 0 & 1000 & -157 & 0 & -1 \\
\hline 13 & $5.5364 \mathrm{E}-02$ & 0 & 0 & 0 & 0 & 0 & 0 & 0 & 0 & 0 & 0 & 0 & -157 & 1000 & 32 & 80 \\
\hline 14 & $1.2581 \mathrm{E}-02$ & 0 & 0 & 0 & 0 & 0 & 0 & 0 & 0 & 0 & 0 & 0 & 0 & 32 & 1000 & 320 \\
\hline 15 & $1.8013 \mathrm{E}-02$ & 0 & 0 & 0 & 0 & 0 & 0 & 0 & 0 & 0 & 0 & 0 & -1 & 80 & 320 & 1000 \\
\hline
\end{tabular}

$242 \mathrm{mAm}(\mathrm{n}, \mathrm{el})$

group rel.s.d.

1 1.0000E-01

2 1.0000E-01

1. $0000 E-01$

5. $0000 \mathrm{E}-02$

1. $0000 \mathrm{E}-02$

1.3909E-01

1.2761E-01

$8 \quad 1.8887 \mathrm{E}-01$

$91.9364 \mathrm{E}-01$

10 1.9423E-01

$11 \quad 1.6677 \mathrm{E}-01$

12 1.9950E-01

13 2.0611E-01

14 1.7644E-01

$152.1783 \mathrm{E}-01$

$\begin{array}{rrrrrrrrrrrrrrr}1000 & 972 & 100 & 959 & 908 & 654 & 306 & 0 & 0 & 0 & 0 & 0 & 0 & 0 & 0 \\ 972 & 1000 & 322 & 998 & 977 & 804 & 507 & 0 & 0 & 0 & 0 & 0 & 0 & 0 & 0 \\ 100 & 322 & 1000 & 367 & 490 & 797 & 952 & 0 & 0 & 0 & 0 & 0 & 0 & 0 & 0 \\ 959 & 998 & 367 & 1000 & 987 & 835 & 551 & 0 & 0 & 0 & 0 & 0 & 0 & 0 & 0 \\ 908 & 977 & 490 & 987 & 1000 & 909 & 666 & 0 & 0 & 0 & 0 & 0 & 0 & 0 & 0 \\ 654 & 804 & 797 & 835 & 909 & 1000 & 909 & 0 & 0 & 0 & 0 & 0 & 0 & 0 & 0 \\ 306 & 507 & 952 & 551 & 666 & 909 & 1000 & 153 & 138 & 136 & 20 & 0 & 0 & 0 & 0 \\ 0 & 0 & 0 & 0 & 0 & 0 & 153 & 1000 & 930 & 922 & 136 & 0 & 0 & 0 & 0 \\ 0 & 0 & 0 & 0 & 0 & 0 & 138 & 930 & 1000 & 997 & 147 & 0 & 0 & 0 & 0 \\ 0 & 0 & 0 & 0 & 0 & 0 & 136 & 922 & 997 & 1000 & 151 & 4 & 4 & 4 & 4 \\ 0 & 0 & 0 & 0 & 0 & 0 & 20 & 136 & 147 & 151 & 1000 & 989 & 987 & 921 & 984 \\ 0 & 0 & 0 & 0 & 0 & 0 & 0 & 0 & 0 & 4 & 989 & 1000 & 998 & 932 & 994 \\ 0 & 0 & 0 & 0 & 0 & 0 & 0 & 0 & 0 & 4 & 987 & 998 & 1000 & 944 & 994 \\ 0 & 0 & 0 & 0 & 0 & 0 & 0 & 0 & 0 & 4 & 921 & 932 & 944 & 1000 & 943 \\ 0 & 0 & 0 & 0 & 0 & 0 & 0 & 0 & 0 & 4 & 984 & 994 & 994 & 943 & 1000\end{array}$




\begin{tabular}{|c|c|c|c|c|c|c|c|c|c|}
\hline roup & $r e \perp$.s.d. & & - & - & & & & & \\
\hline 1 & $1.5000 \mathrm{E}-01$ & 1000 & -300 & -403 & -468 & -444 & -387 & -328 & 0 \\
\hline 2 & $3.0000 \mathrm{E}-01$ & -300 & 1000 & 960 & 874 & 691 & 399 & 207 & \\
\hline 3 & $3.0000 \mathrm{E}-01$ & -403 & 960 & 1000 & 926 & 756 & 460 & 254 & \\
\hline 4 & $3.0000 \mathrm{E}-01$ & -468 & 874 & 926 & 1000 & 938 & 754 & 576 & \\
\hline 5 & $3.0000 \mathrm{E}-01$ & -444 & 691 & 756 & 938 & 1000 & 927 & 768 & \\
\hline 6 & $3.0000 \mathrm{E}-01$ & -387 & 399 & 460 & 754 & 927 & 1000 & 913 & \\
\hline 7 & $3.0000 E-01$ & -328 & 207 & 254 & 576 & 768 & 913 & 1000 & 33 \\
\hline 8 & $3.0000 E-01$ & 0 & 0 & 0 & 0 & 0 & 0 & 332 & 100 \\
\hline
\end{tabular}

$242 \mathrm{mAm}(\mathrm{n}, 2 \mathrm{n})$

group rel.s.d.

$13.1766 \mathrm{E}-01 \quad 1000 \quad 186$

$23.7230 \mathrm{E}-01 \quad 1861000$

$242 \mathrm{mAm}(\mathrm{n}, \mathrm{f})$

group rel.s.d.

$14.0000 \mathrm{E}-01$

$2 \quad 2.3363 \mathrm{E}-01$

3 1.9701E-01

$4 \quad 1.6514 \mathrm{E}-01$

$5 \quad 1.6571 \mathrm{E}-01$

$6 \quad 1.6571 \mathrm{E}-01$

$7 \quad 1.4431 \mathrm{E}-01$

$8 \quad 1.1797 \mathrm{E}-01$

$9 \quad 1.2360 \mathrm{E}-01$

$101.2197 \mathrm{E}-01$

$111.0393 \mathrm{E}-01$

$121.0377 \mathrm{E}-01$

$136.9997 \mathrm{E}-02$

$148.8316 \mathrm{E}-02$

$158.0613 \mathrm{E}-02$
$1000 \quad 358-148$

$358-1000-645-390$

$\begin{array}{lllllll}8 & 1000 & 645 & 390 & 343 & 343 & 341\end{array}$

$\begin{array}{lllllll}-148 & 645 & 1000 & 904 & 880 & 880 & 876\end{array}$

$\begin{array}{lllllll}-82 & 390 & 904 & 1000 & 998 & 998 & 995\end{array}$

$\begin{array}{lllllll}-85 & 343 & 880 & 998 & 1000 & 1000 & 996\end{array}$

$\begin{array}{lll}-85 & 343 \quad 880\end{array}$

$\begin{array}{lll}-84 & 341 \quad 876\end{array}$

$99810001000 \quad 996$

$995996996 \quad 1000$

87100010001000

87100010001000

$8710001000 \quad 1000 \quad 92$

$1000 \quad 23$

$\begin{array}{rrrrrrrrr}0 & 0 & 0 & 0 & 23 & 1000 & 5 & 2 & 2 \\ 0 & 0 & 0 & 0 & 0 & 5 & 1000 & 159 & 149\end{array}$

$\begin{array}{rrrrrrrrr}0 & 0 & 0 & 0 & 23 & 1000 & 5 & 2 & 2 \\ 0 & 0 & 0 & 0 & 0 & 5 & 1000 & 159 & 149\end{array}$

$\begin{array}{rrrrrrrrr}0 & 0 & 0 & 0 & 0 & 5 & 1000 & 159 & 149 \\ 0 & 0 & 0 & 0 & 0 & 2 & 159 & 1000 & 979\end{array}$

1499791000

242 mAm (n, gamma )

group rel.s.d.

$11.00000-00$

$21.0000 \mathrm{E}-00$

5. $0000 \mathrm{E}-01$

$1000426 \quad 431$

$\begin{array}{llllll}426 & 431 & 370 & 349 & 378 & 320\end{array}$

$\begin{array}{lllllll}426 & 1000 & 960 & 822 & 757 & 661 & 376\end{array}$

$\begin{array}{lllllll}431 & 960 & 1000 & 939 & 897 & 830 & 551\end{array}$

5. $0000 \mathrm{E}-01$

$\begin{array}{lllllll}370 & 822 & 939 & 1000 & 994 & 928 & 655\end{array}$

5. $0000 \mathrm{E}-01$

$\begin{array}{lllllll}349 & 757 & 897 & 994 & 1000 & 949 & 701\end{array}$

$65.0000 \mathrm{E}-01$

$\begin{array}{lllllll}378 & 661 & 830 & 928 & 949 & 1000 & 881\end{array}$

$\begin{array}{llllllll}0 & 0 & 0 & 0 & 0 & 0 & 0 & 0 \\ 0 & 0 & 0 & 0 & 0 & 0 & 0 & 0 \\ 0 & 0 & 0 & 0 & 0 & 0 & 0 & 0 \\ 0 & 0 & 0 & 0 & 0 & 0 & 0 & 0 \\ 0 & 0 & 0 & 0 & 0 & 0 & 0 & 0 \\ 0 & 0 & 0 & 0 & 0 & 0 & 0 & 0\end{array}$




\begin{tabular}{|c|c|c|c|c|c|c|c|c|c|c|c|c|c|c|c|c|}
\hline 7 & $5.0000 \mathrm{E}-01$ & 320 & 376 & 551 & 655 & 701 & 881 & 1000 & 118 & 118 & 118 & 22 & 0 & 0 & 0 & 0 \\
\hline 8 & $5.0000 E-01$ & 0 & 0 & 0 & 0 & 0 & 0 & 118 & 1000 & 1000 & 999 & 187 & 0 & 0 & 0 & 0 \\
\hline 9 & $5.0000 \mathrm{E}-01$ & 0 & 0 & 0 & 0 & 0 & 0 & 118 & 1000 & 1000 & 1000 & 188 & 0 & 0 & 0 & \\
\hline 10 & $5.0000 E-01$ & 0 & 0 & 0 & 0 & 0 & 0 & 118 & 999 & 1000 & 1000 & 190 & 0 & 0 & 0 & \\
\hline 11 & $5.0000 E-01$ & 0 & 0 & 0 & 0 & 0 & 0 & 22 & 187 & 188 & 190 & 1000 & 25 & 2 & 1 & \\
\hline 12 & $1.3246 \mathrm{E}-01$ & 0 & 0 & 0 & 0 & 0 & 0 & 0 & 0 & 0 & 0 & 25 & 1000 & 47 & 5 & \\
\hline 13 & $1.3573 E-01$ & 0 & 0 & 0 & 0 & 0 & 0 & 0 & 0 & 0 & 0 & 2 & 47 & 1000 & 326 & 268 \\
\hline 14 & 1.9867E-01 & 0 & 0 & 0 & 0 & 0 & 0 & 0 & 0 & 0 & 0 & 1 & 5 & 326 & 1000 & 988 \\
\hline 15 & $1.9597 \mathrm{E}-01$ & 0 & 0 & 0 & 0 & 0 & 0 & 0 & 0 & 0 & 0 & 1 & 5 & 268 & 988 & 1000 \\
\hline
\end{tabular}

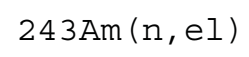


$243 \operatorname{Am}(\mathrm{n}, \mathrm{f})$

\begin{tabular}{|c|c|c|c|c|c|c|c|c|c|c|c|c|c|c|c|c|}
\hline coup & rel.s.d. & & - & --- & -1 & - & - & ---- & -- & --7 & -- & -- & ---1 & -- & -- & 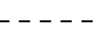 \\
\hline 1 & $2.0000 E-01$ & 1000 & 129 & 70 & -13 & -19 & -19 & -10 & 0 & 0 & 0 & 0 & 0 & 0 & 0 & 0 \\
\hline 2 & $1.1028 \mathrm{E}-01$ & 129 & 1000 & 682 & -170 & -223 & -223 & -117 & 0 & 0 & 0 & 0 & 0 & 0 & 0 & U \\
\hline 3 & $5.9739 E-02$ & 70 & 682 & 1000 & 550 & 486 & 486 & 255 & 0 & 0 & 0 & 0 & 0 & 0 & 0 & 0 \\
\hline 4 & $9.1842 \mathrm{E}-02$ & -13 & -170 & 550 & 1000 & 995 & 995 & 522 & 0 & 0 & 0 & 0 & 0 & 0 & 0 & 0 \\
\hline 5 & $9.6178 E-02$ & -19 & -223 & 486 & 995 & 1000 & 1000 & 525 & 0 & 0 & 0 & 0 & 0 & 0 & 0 & 0 \\
\hline 6 & $9.6178 E-02$ & -19 & -223 & 486 & 995 & 1000 & 1000 & 525 & 0 & 0 & 0 & 0 & 0 & 0 & 0 & 0 \\
\hline 7 & $7.1171 E-02$ & -10 & -117 & 255 & 522 & 525 & 525 & 1000 & 851 & 851 & 851 & 844 & 0 & 0 & 0 & 0 \\
\hline 8 & $1.3789 \mathrm{E}-01$ & 0 & 0 & 0 & 0 & 0 & 0 & 851 & 1000 & 1000 & 1000 & 992 & 0 & 0 & 0 & 0 \\
\hline 9 & $1.3540 E-01$ & 0 & 0 & 0 & 0 & 0 & 0 & 851 & 1000 & 1000 & 1000 & 992 & 0 & 0 & 0 & 0 \\
\hline 10 & $1.3408 E-01$ & 0 & 0 & 0 & 0 & 0 & 0 & 851 & 1000 & 1000 & 1000 & 992 & 0 & 0 & 0 & 0 \\
\hline 11 & $9.6353 \mathrm{E}-02$ & 0 & 0 & 0 & 0 & 0 & 0 & 844 & 992 & 992 & 992 & 1000 & 1 & 0 & 0 & 0 \\
\hline 12 & $5.9527 E-02$ & 0 & 0 & 0 & 0 & 0 & 0 & 0 & 0 & 0 & 0 & 1 & 1000 & 1 & 13 & 12 \\
\hline 13 & $4.8053 E-02$ & 0 & 0 & 0 & 0 & 0 & 0 & 0 & 0 & 0 & 0 & 0 & 1 & 1000 & 381 & 240 \\
\hline 14 & $2.2488 E-02$ & 0 & 0 & 0 & 0 & 0 & 0 & 0 & 0 & 0 & 0 & 0 & 13 & 381 & 1000 & 905 \\
\hline 15 & $2.1229 E-02$ & 0 & 0 & 0 & 0 & 0 & 0 & 0 & 0 & 0 & 0 & 0 & 12 & 240 & 905 & 1000 \\
\hline
\end{tabular}

243Am (n, gamma)

\begin{tabular}{|c|c|c|c|c|c|c|c|c|c|c|c|c|c|c|c|c|}
\hline roup & rel.s.d. & & - & ---- & --1 & --- & --- & --1 & - & -- & -- & - & ---- & -- & -- & - \\
\hline 1 & $6.0422 \mathrm{E}-01$ & 1000 & 353 & 246 & 128 & 145 & 147 & 72 & 0 & 0 & 0 & 0 & 0 & 0 & 0 & 0 \\
\hline 2 & $4.1502 \mathrm{E}-01$ & 353 & 1000 & 948 & 725 & 529 & -31 & -171 & 0 & 0 & 0 & 0 & 0 & 0 & 0 & 0 \\
\hline 3 & $2.1658 E-01$ & 246 & 948 & 1000 & 899 & 728 & -40 & -243 & 0 & 0 & 0 & 0 & 0 & 0 & 0 & , \\
\hline 4 & $1.4183 E-01$ & 128 & 725 & 899 & 1000 & 930 & 26 & -256 & 0 & 0 & 0 & 0 & 0 & 0 & 0 & 0 \\
\hline 5 & $1.0000 E-01$ & 145 & 529 & 728 & 930 & 1000 & 299 & -67 & 0 & 0 & 0 & 0 & 0 & 0 & 0 & 0 \\
\hline 6 & $1.0000 E-01$ & 147 & -31 & -40 & 26 & 299 & 1000 & 698 & 0 & 0 & 0 & 0 & 0 & 0 & 0 & 0 \\
\hline 7 & $1.0000 E-01$ & 72 & -171 & -243 & -256 & -67 & 698 & 1000 & 652 & 652 & 652 & 613 & 0 & 0 & 0 & 0 \\
\hline 8 & $6.7704 \mathrm{E}-02$ & 0 & 0 & 0 & 0 & 0 & 0 & 652 & 1000 & 1000 & 1000 & 939 & 0 & 0 & 0 & 0 \\
\hline 9 & $6.6441 \mathrm{E}-02$ & 0 & 0 & 0 & 0 & 0 & 0 & 652 & 1000 & 1000 & 1000 & 939 & 0 & 0 & 0 & 0 \\
\hline 10 & $6.5778 E-02$ & 0 & 0 & 0 & 0 & 0 & 0 & 652 & 1000 & 1000 & 1000 & 940 & 0 & 0 & 0 & 0 \\
\hline 11 & $2.3065 E-02$ & 0 & 0 & 0 & 0 & 0 & 0 & 613 & 939 & 939 & 940 & 1000 & 5 & 0 & 1 & 1 \\
\hline 12 & $1.7412 \mathrm{E}-02$ & 0 & 0 & 0 & 0 & 0 & 0 & 0 & 0 & 0 & 0 & 5 & 1000 & 3 & 14 & 20 \\
\hline 13 & $3.4319 \mathrm{E}-02$ & 0 & 0 & 0 & 0 & 0 & 0 & 0 & 0 & 0 & 0 & 0 & 3 & 1000 & 707 & 754 \\
\hline 14 & $3.7452 \mathrm{E}-02$ & 0 & 0 & 0 & 0 & 0 & 0 & 0 & 0 & 0 & 0 & 1 & 14 & 707 & 1000 & 942 \\
\hline 15 & $3.5761 E-02$ & 0 & 0 & 0 & 0 & 0 & 0 & 0 & 0 & 0 & 0 & 1 & 20 & 754 & 942 & 1000 \\
\hline
\end{tabular}




\begin{tabular}{|c|c|c|c|c|c|c|c|c|c|c|c|c|c|c|c|c|}
\hline roup & rel.s.d. & -- & 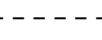 & 5 & -- & & & & 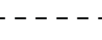 & -- & -- & $-\ldots$ & -- & & & \\
\hline 1 & $1.0000 E-01$ & 1000 & 995 & 996 & -26 & -430 & -627 & -880 & -917 & 0 & 0 & 0 & 0 & 0 & 0 & 0 \\
\hline 2 & $5.0000 \mathrm{E}-02$ & 995 & 1000 & 985 & -123 & -516 & -701 & -923 & -920 & 0 & 0 & 0 & 0 & 0 & 0 & 0 \\
\hline 3 & $3.0000 E-02$ & 996 & 985 & 1000 & 51 & -362 & -569 & -842 & -906 & 0 & 0 & 0 & 0 & 0 & 0 & 0 \\
\hline 4 & $3.0000 E-02$ & -26 & -123 & 51 & 1000 & 906 & 787 & 496 & 109 & 0 & 0 & 0 & 0 & 0 & 0 & 0 \\
\hline 5 & $2.0000 \mathrm{E}-02$ & -430 & -516 & -362 & 906 & 1000 & 973 & 805 & 463 & 0 & 0 & 0 & 0 & 0 & 0 & 0 \\
\hline 6 & $4.0000 \mathrm{E}-02$ & -627 & -701 & -569 & 787 & 973 & 1000 & 920 & 634 & 0 & 0 & 0 & 0 & 0 & 0 & 0 \\
\hline 7 & $4.0000 \mathrm{E}-02$ & -880 & -923 & -842 & 496 & 805 & 920 & 1000 & 846 & 0 & 0 & 0 & 0 & 0 & 0 & 0 \\
\hline 8 & $2.1149 E-02$ & -917 & -920 & -906 & 109 & 463 & 634 & 846 & 1000 & 359 & 358 & 225 & 0 & 0 & 0 & 0 \\
\hline 9 & $5.0000 \mathrm{E}-02$ & 0 & 0 & 0 & 0 & 0 & 0 & 0 & 359 & 1000 & 999 & 627 & 0 & 0 & 0 & 0 \\
\hline 10 & $5.0000 \mathrm{E}-02$ & 0 & 0 & 0 & 0 & 0 & 0 & 0 & 358 & 999 & 1000 & 629 & 0 & 0 & 0 & 0 \\
\hline 11 & $5.0000 \mathrm{E}-02$ & 0 & 0 & 0 & 0 & 0 & 0 & 0 & 225 & 627 & 629 & 1000 & 412 & 412 & 403 & 401 \\
\hline 12 & $1.8182 \mathrm{E}-01$ & 0 & 0 & 0 & 0 & 0 & 0 & 0 & 0 & 0 & 0 & 412 & 1000 & 986 & 968 & 963 \\
\hline 13 & $1.9871 \mathrm{E}-01$ & 0 & 0 & 0 & 0 & 0 & 0 & 0 & 0 & 0 & 0 & 412 & 986 & 1000 & 995 & 992 \\
\hline 14 & $1.9673 \mathrm{E}-01$ & 0 & 0 & 0 & 0 & 0 & 0 & 0 & 0 & 0 & 0 & 403 & 968 & 995 & 1000 & 1000 \\
\hline 15 & $1.9679 \mathrm{E}-01$ & 0 & 0 & 0 & 0 & 0 & 0 & 0 & 0 & 0 & 0 & 401 & 963 & 992 & 1000 & 1000 \\
\hline
\end{tabular}

\section{$242 \mathrm{Cm}\left(\mathrm{n}, \mathrm{n}^{\prime}\right)$}

\begin{tabular}{|c|c|c|c|c|c|c|c|c|}
\hline up & rel.s.d. & --- & 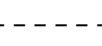 & & & $-\pi$ & $-\sigma_{-}$ & ---- \\
\hline 1 & $1.0000 \mathrm{E}-00$ & 1000 & -780 & -464 & -221 & -193 & -83 & -103 \\
\hline 2 & 1.0000E-00 & -780 & 1000 & 129 & -230 & -446 & -550 & -533 \\
\hline 3 & 1.0000E-00 & -464 & 129 & 1000 & 930 & 607 & 504 & 518 \\
\hline 4 & 1.0000E-00 & -221 & -230 & 930 & 1000 & 809 & 747 & 755 \\
\hline 5 & $1.0000 \mathrm{E}-01$ & -193 & -446 & 607 & 809 & 1000 & 991 & 993 \\
\hline 6 & $5.3151 E-01$ & -83 & -550 & 504 & 747 & 991 & 1000 & 1000 \\
\hline 7 & $3.1726 \mathrm{E}-01$ & -103 & -533 & 518 & 755 & 993 & 1000 & 1000 \\
\hline
\end{tabular}

$242 \mathrm{Cm}(\mathrm{n}, 2 \mathrm{n})$

group rel.s.d. -- -

$15.0000 \mathrm{E}-01 \quad 1000$

$242 \mathrm{Cm}(\mathrm{n}, \mathrm{f})$

\begin{tabular}{|c|c|c|c|c|c|c|c|c|c|c|c|c|c|c|c|c|}
\hline roup & . & & - & & & $5-$ & -- & -1 & -- & -- & 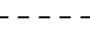 & & & & & \\
\hline 1 & $5.0000 E-01$ & 1000 & 991 & 870 & 356 & 138 & -42 & 788 & 778 & 0 & 0 & 0 & 0 & 0 & 0 & 0 \\
\hline 2 & $1.0000 \mathrm{E}-00$ & 991 & 1000 & 917 & 467 & 259 & 78 & 845 & 819 & 0 & 0 & 0 & 0 & 0 & 0 & 0 \\
\hline 3 & $1.0000 \mathrm{E}-00$ & 870 & 917 & 1000 & 743 & 551 & 318 & 837 & 807 & 0 & 0 & 0 & 0 & 0 & 0 & 0 \\
\hline 4 & $1.0000 \mathrm{E}-00$ & 356 & 467 & 743 & 1000 & 965 & 834 & 715 & 609 & 0 & 0 & 0 & 0 & 0 & 0 & 0 \\
\hline 5 & $1.0000 \mathrm{E}-00$ & 138 & 259 & 551 & 965 & 1000 & 944 & 621 & 487 & 0 & 0 & 0 & 0 & 0 & 0 & 0 \\
\hline 6 & $1.0000 \mathrm{E}-00$ & -42 & 78 & 318 & 834 & 944 & 1000 & 553 & 381 & 0 & 0 & 0 & 0 & 0 & 0 & 0 \\
\hline 7 & $1.0000 \mathrm{E}-00$ & 788 & 845 & 837 & 715 & 621 & 553 & 1000 & 871 & 0 & 0 & 0 & 0 & 0 & 0 & 0 \\
\hline 8 & $1.0000 \mathrm{E}-00$ & 778 & 819 & 807 & 609 & 487 & 381 & 871 & 1000 & 460 & 368 & 82 & 0 & 0 & 0 & 0 \\
\hline
\end{tabular}




\begin{tabular}{|c|c|c|c|c|c|c|c|c|c|c|c|c|c|c|c|}
\hline $1.0000 \mathrm{E}-00$ & 0 & 0 & 0 & 0 & 0 & 0 & 0 & 460 & 1000 & 870 & 202 & 0 & 0 & 0 & 0 \\
\hline $1.0000 \mathrm{E}-00$ & 0 & 0 & 0 & 0 & 0 & 0 & 0 & 368 & 870 & 1000 & 264 & 0 & 0 & 0 & 0 \\
\hline $1.0000 \mathrm{E}-00$ & 0 & 0 & 0 & 0 & 0 & 0 & 0 & 82 & 202 & 264 & 1000 & 1 & 8 & 4 & 3 \\
\hline $1.0000 \mathrm{E}-00$ & 0 & 0 & 0 & 0 & 0 & 0 & 0 & 0 & 0 & 0 & 1 & 1000 & 11 & 7 & 7 \\
\hline $1.0000 \mathrm{E}-00$ & 0 & 0 & 0 & 0 & 0 & 0 & 0 & 0 & 0 & 0 & 8 & 11 & 1000 & 996 & 995 \\
\hline $1.0000 \mathrm{E}-00$ & 0 & 0 & 0 & 0 & 0 & 0 & 0 & 0 & 0 & 0 & 4 & 7 & 996 & 1000 & 1000 \\
\hline $5.0000 E-01$ & 0 & 0 & 0 & 0 & 0 & 0 & 0 & 0 & 0 & 0 & 3 & 7 & 995 & 1000 & 1000 \\
\hline
\end{tabular}

$242 \mathrm{Cm}$ (n, gamma)

\begin{tabular}{|c|c|c|c|c|c|c|c|c|c|c|c|c|c|c|c|c|}
\hline 1 & $5.2782 F-01$ & 1000 & 898 & 696 & 187 & 93 & -43 & -218 & -342 & 0 & 0 & 0 & 0 & 0 & 0 & S \\
\hline 2 & $2.0000 \mathrm{E}-00$ & 898 & 1000 & 891 & 398 & 300 & 148 & -59 & -212 & 0 & 0 & 0 & 0 & 0 & 0 & \\
\hline 3 & $2.0000 \mathrm{E}-00$ & 696 & 891 & 1000 & 767 & 696 & 574 & 392 & 243 & 0 & 0 & 0 & 0 & 0 & 0 & 0 \\
\hline 4 & $2.0000 \mathrm{E}-00$ & 187 & 398 & 767 & 1000 & 994 & 965 & 890 & 807 & 0 & 0 & 0 & 0 & 0 & 0 & 0 \\
\hline 5 & $2.0000 \mathrm{E}-00$ & 93 & 300 & 696 & 994 & 1000 & 988 & 933 & 864 & 0 & 0 & 0 & 0 & 0 & 0 & 0 \\
\hline 6 & $2.0000 \mathrm{E}-00$ & -43 & 148 & 574 & 965 & 988 & 1000 & 978 & 932 & 0 & 0 & 0 & 0 & 0 & 0 & 0 \\
\hline 7 & $2.0000 \mathrm{E}-00$ & -218 & -59 & 392 & 890 & 933 & 978 & 1000 & 986 & 0 & 0 & 0 & 0 & 0 & 0 & 0 \\
\hline 8 & $2.0000 \mathrm{E}-00$ & -342 & -212 & 243 & 807 & 864 & 932 & 986 & 1000 & 59 & 56 & 12 & 0 & 0 & 0 & 0 \\
\hline 9 & $2.0000 \mathrm{E}-00$ & 0 & 0 & 0 & 0 & 0 & 0 & 0 & 59 & 1000 & 960 & 206 & 0 & 0 & 0 & 0 \\
\hline 10 & $2.0000 \mathrm{E}-00$ & 0 & 0 & 0 & 0 & 0 & 0 & 0 & 56 & 960 & 1000 & 230 & 0 & 0 & 0 & 0 \\
\hline 11 & $2.0000 \mathrm{E}-00$ & 0 & 0 & 0 & 0 & 0 & 0 & 0 & 12 & 206 & 230 & 1000 & 3 & 11 & 5 & 5 \\
\hline 12 & $2.0000 \mathrm{E}-00$ & 0 & 0 & 0 & 0 & 0 & 0 & 0 & 0 & 0 & 0 & 3 & 1000 & 29 & 21 & 20 \\
\hline 13 & $2.0000 \mathrm{E}-00$ & 0 & 0 & 0 & 0 & 0 & 0 & 0 & 0 & 0 & 0 & 11 & 29 & 1000 & 996 & 995 \\
\hline 14 & $2.0000 E-00$ & 0 & 0 & 0 & 0 & 0 & 0 & 0 & 0 & 0 & 0 & 5 & 21 & 996 & 1000 & 1000 \\
\hline 15 & $2.0000 \mathrm{E}-00$ & 0 & 0 & 0 & 0 & 0 & 0 & 0 & 0 & 0 & 0 & 5 & 20 & 995 & 1000 & 1000 \\
\hline
\end{tabular}

$243 \mathrm{Cm}(\mathrm{n}, \mathrm{el})$

\begin{tabular}{|c|c|c|c|c|c|c|c|c|c|c|c|c|c|c|c|c|}
\hline roup & el.s.d. & - & - & --- & -- & - & --- & . & 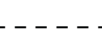 & 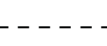 & 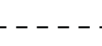 & . &.- & ---- & $\ldots$ & -- \\
\hline 1 & $3.0000 E-02$ & 1000 & 976 & 19 & 536 & 589 & 281 & 47 & 0 & 0 & 0 & 0 & 0 & 0 & 0 & 0 \\
\hline 2 & $3.0000 E-02$ & 976 & 1000 & 135 & 636 & 686 & 391 & 139 & 0 & 0 & 0 & 0 & 0 & 0 & 0 & 0 \\
\hline 3 & $3.0000 E-02$ & 19 & 135 & 1000 & 846 & 808 & 941 & 806 & 0 & 0 & 0 & 0 & 0 & 0 & 0 & 0 \\
\hline 4 & $3.0000 E-02$ & 536 & 636 & 846 & 1000 & 998 & 953 & 714 & 0 & 0 & 0 & 0 & 0 & 0 & 0 & 0 \\
\hline 5 & $3.0000 E-02$ & 589 & 686 & 808 & 998 & 1000 & 934 & 686 & 0 & 0 & 0 & 0 & 0 & 0 & 0 & 0 \\
\hline 6 & $3.0000 \mathrm{E}-02$ & 281 & 391 & 941 & 953 & 934 & 1000 & 807 & 0 & 0 & 0 & 0 & 0 & 0 & 0 & 0 \\
\hline 7 & $3.0000 E-02$ & 47 & 139 & 806 & 714 & 686 & 807 & 1000 & 558 & 558 & 557 & 545 & 0 & 0 & 0 & 0 \\
\hline 8 & $3.0000 E-02$ & 0 & 0 & 0 & 0 & 0 & 0 & 558 & 1000 & 1000 & 999 & 976 & 0 & 0 & 0 & 0 \\
\hline 9 & $3.0000 E-02$ & 0 & 0 & 0 & 0 & 0 & 0 & 558 & 1000 & 1000 & 1000 & 976 & 0 & 0 & 0 & 0 \\
\hline 10 & $3.0000 E-02$ & 0 & 0 & 0 & 0 & 0 & 0 & 557 & 999 & 1000 & 1000 & 976 & 0 & 0 & 0 & 0 \\
\hline 11 & 1.5540E-01 & 0 & 0 & 0 & 0 & 0 & 0 & 545 & 976 & 976 & 976 & 1000 & 216 & 214 & 215 & 214 \\
\hline 12 & $1.8809 E-01$ & 0 & 0 & 0 & 0 & 0 & 0 & 0 & 0 & 0 & 0 & 216 & 1000 & 988 & 989 & 984 \\
\hline 13 & $1.9530 \mathrm{E}-01$ & 0 & 0 & 0 & 0 & 0 & 0 & 0 & 0 & 0 & 0 & 214 & 988 & 1000 & 973 & 970 \\
\hline 14 & $2.4913 E-01$ & 0 & 0 & 0 & 0 & 0 & 0 & 0 & 0 & 0 & 0 & 215 & 989 & 973 & 1000 & 998 \\
\hline 15 & $2.3411 E-01$ & 0 & 0 & 0 & 0 & 0 & 0 & 0 & 0 & 0 & 0 & 214 & 984 & 970 & 998 & 1000 \\
\hline
\end{tabular}




\begin{tabular}{|c|c|c|c|c|c|c|c|c|}
\hline group & rel.s.d. & --- & --- & --- & ---- & --- & ---- & ---- \\
\hline 1 & $1.5000 \mathrm{E}-01$ & 1000 & 478 & -488 & -672 & -695 & -589 & -510 \\
\hline 2 & $2.0000 E-01$ & 478 & 1000 & 208 & 143 & 107 & 87 & 50 \\
\hline 3 & $1.5000 \mathrm{E}-01$ & -488 & 208 & 1000 & 896 & 711 & 454 & 249 \\
\hline 4 & $3.0000 \mathrm{E}-01$ & -672 & 143 & 896 & 1000 & 938 & 742 & 578 \\
\hline 5 & $3.0000 E-01$ & -695 & 107 & 711 & 938 & 1000 & 922 & 821 \\
\hline 6 & $5.0000 E-01$ & -589 & 87 & 454 & 742 & 922 & 1000 & 975 \\
\hline 7 & $5.0000 \mathrm{E}-01$ & -510 & 50 & 249 & 578 & 821 & 975 & 1000 \\
\hline
\end{tabular}

$243 \mathrm{Cm}(\mathrm{n}, 2 \mathrm{n})$

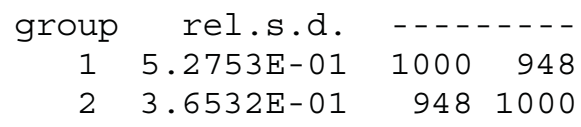

$243 \mathrm{Cm}(\mathrm{n}$, gamma $)$

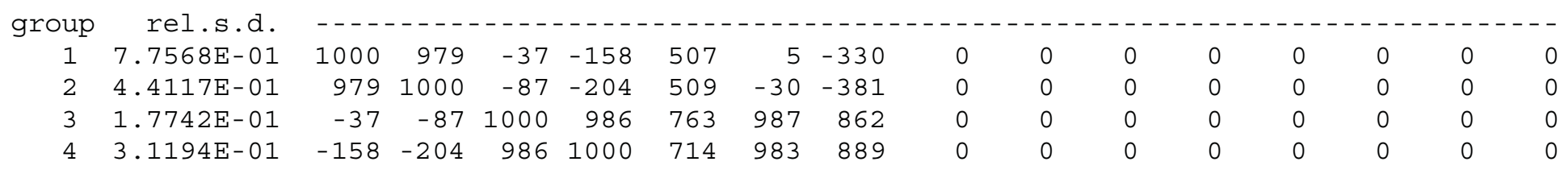




\begin{tabular}{|c|c|c|c|c|c|c|c|c|c|c|c|c|c|c|c|c|}
\hline 5 & $2.9719 E-01$ & 507 & 509 & 763 & 714 & 1000 & 828 & 483 & 0 & 0 & 0 & 0 & 0 & 0 & 0 & 0 \\
\hline 6 & $2.3358 E-01$ & 5 & -30 & 987 & 983 & 828 & 1000 & 836 & 0 & 0 & 0 & 0 & 0 & 0 & 0 & \\
\hline 7 & $1.8181 E-01$ & -330 & -381 & 862 & 889 & 483 & 836 & 1000 & 402 & 402 & 401 & 399 & 0 & 0 & 0 & \\
\hline 8 & $1.7967 E-01$ & 0 & 0 & 0 & 0 & 0 & 0 & 402 & 1000 & 999 & 997 & 992 & 0 & 0 & 0 & \\
\hline 9 & $1.8375 E-01$ & 0 & 0 & 0 & 0 & 0 & 0 & 402 & 999 & 1000 & 999 & 996 & 0 & 0 & 0 & \\
\hline 10 & $1.8701 \mathrm{E}-01$ & 0 & 0 & 0 & 0 & 0 & 0 & 401 & 997 & 999 & 1000 & 998 & 0 & 0 & 0 & \\
\hline 11 & $1.4520 \mathrm{E}-01$ & 0 & 0 & 0 & 0 & 0 & 0 & 399 & 992 & 996 & 998 & 1000 & 1 & 0 & 0 & 0 \\
\hline 12 & $5.1162 E-02$ & 0 & 0 & 0 & 0 & 0 & 0 & 0 & 0 & 0 & 0 & 1 & 1000 & 51 & 18 & 15 \\
\hline 13 & $7.9878 E-02$ & 0 & 0 & 0 & 0 & 0 & 0 & 0 & 0 & 0 & 0 & 0 & 51 & 1000 & 136 & 101 \\
\hline 14 & $1.5497 E-01$ & 0 & 0 & 0 & 0 & 0 & 0 & 0 & 0 & 0 & 0 & 0 & 18 & 136 & 1000 & 708 \\
\hline 15 & $1.6379 \mathrm{E}-01$ & 0 & 0 & 0 & 0 & 0 & 0 & 0 & 0 & 0 & 0 & 0 & 15 & 101 & 708 & 1000 \\
\hline
\end{tabular}

$244 \mathrm{Cm}(\mathrm{n}, \mathrm{el})$

\begin{tabular}{|c|c|c|c|c|c|c|c|c|c|c|c|c|c|c|c|c|}
\hline & & & & & & & & & & & & & & & & \\
\hline 1 & $3.0000 E-02$ & 1000 & 488 & 569 & 274 & 322 & 234 & 65 & 0 & 0 & 0 & 0 & 0 & 0 & 0 & 0 \\
\hline 2 & $3.00000-02$ & 488 & 1000 & 852 & 87 & 198 & 44 & -224 & 0 & 0 & 0 & 0 & 0 & 0 & 0 & \\
\hline 3 & $5.0000 E-02$ & 569 & 852 & 1000 & 594 & 680 & 551 & 213 & 0 & 0 & 0 & 0 & 0 & 0 & 0 & 0 \\
\hline 4 & $1.0000 \mathrm{E}-01$ & 274 & 87 & 594 & 1000 & 993 & 988 & 750 & 0 & 0 & 0 & 0 & 0 & 0 & 0 & 0 \\
\hline 5 & $1.0000 \mathrm{E}-01$ & 322 & 198 & 680 & 993 & 1000 & 971 & 716 & 0 & 0 & 0 & 0 & 0 & 0 & 0 & 0 \\
\hline 6 & $1.0000 \mathrm{E}-01$ & 234 & 44 & 551 & 988 & 971 & 1000 & 739 & 0 & 0 & 0 & 0 & 0 & 0 & 0 & 0 \\
\hline 7 & $9.2095 E-02$ & 65 & -224 & 213 & 750 & 716 & 739 & 1000 & 586 & 586 & 572 & 0 & 0 & 0 & 0 & 0 \\
\hline 8 & $1.4933 E-01$ & 0 & 0 & 0 & 0 & 0 & 0 & 586 & 1000 & 999 & 976 & 0 & 0 & 0 & 0 & 0 \\
\hline 9 & $1.4039 \mathrm{E}-01$ & 0 & 0 & 0 & 0 & 0 & 0 & 586 & 999 & 1000 & 975 & 0 & 0 & 0 & 0 & 0 \\
\hline 10 & $7.7188 E-02$ & 0 & 0 & 0 & 0 & 0 & 0 & 572 & 976 & 975 & 1000 & 136 & 17 & 160 & 160 & 160 \\
\hline 11 & $3.6106 \mathrm{E}-02$ & 0 & 0 & 0 & 0 & 0 & 0 & 0 & 0 & 0 & 136 & 1000 & 77 & 706 & 706 & 706 \\
\hline 12 & $7.7538 \mathrm{E}-02$ & 0 & 0 & 0 & 0 & 0 & 0 & 0 & 0 & 0 & 17 & 77 & 1000 & 5 & 26 & 28 \\
\hline 13 & $6.6248 E-02$ & 0 & 0 & 0 & 0 & 0 & 0 & 0 & 0 & 0 & 160 & 706 & 5 & 1000 & 999 & 999 \\
\hline 14 & $6.1634 \mathrm{E}-02$ & 0 & 0 & 0 & 0 & 0 & 0 & 0 & 0 & 0 & 160 & 706 & 26 & 999 & 1000 & 1000 \\
\hline 15 & $6.1192 \mathrm{E}-02$ & 0 & 0 & 0 & 0 & 0 & 0 & 0 & 0 & 0 & 160 & 706 & 28 & 999 & 1000 & 1000 \\
\hline
\end{tabular}

$244 \mathrm{Cm}\left(\mathrm{n}, \mathrm{n}^{\prime}\right)$

\begin{tabular}{|c|c|c|c|c|c|c|c|c|}
\hline roup & rel.s.d. & & & & & - & & ---- \\
\hline 1 & $5.0000 E-01$ & 1000 & -562 & -570 & -282 & -50 & 37 & -66 \\
\hline 2 & $3.0000 E-01$ & -562 & 1000 & 859 & 412 & 43 & -138 & 42 \\
\hline 3 & $2.0000 E-01$ & -570 & 859 & 1000 & 737 & 241 & 29 & 132 \\
\hline 4 & $3.0000 \mathrm{E}-01$ & -282 & 412 & 737 & 1000 & 788 & 642 & 656 \\
\hline 5 & $2.9094 E-01$ & -50 & 43 & 241 & 788 & 1000 & 976 & 973 \\
\hline 6 & $6.3307 E-01$ & 37 & -138 & 29 & 642 & 976 & 1000 & 978 \\
\hline 7 & $5.9718 E-01$ & -66 & 42 & 132 & 656 & 973 & 978 & 1000 \\
\hline
\end{tabular}

$244 \mathrm{Cm}(\mathrm{n}, 2 \mathrm{n})$

group rel.s.d. --- 
$244 \mathrm{Cm}(\mathrm{n}, \mathrm{f})$

group rel.s.d.

$12.0000 \mathrm{E}-01$

2 2.0000E-01

3 2.0000E-01

4 1.0000E-01

$51.0000 \mathrm{E}-01$

$6 \quad 1.0000 \mathrm{E}-01$

7 1.0000E-01

8 1.0000E-01

$91.00000-01$

$101.0000 \mathrm{E}-01$

$115.7020 \mathrm{E}-02$

12 1.7085E-01

13 2.1993E-01

$142.6401 \mathrm{E}-01$

$152.7178 \mathrm{E}-01$

\begin{tabular}{|c|c|c|c|c|c|c|c|c|c|c|c|c|c|c|}
\hline 1000 & 752 & 628 & 58 & 58 & 58 & 55 & 0 & 0 & 0 & 0 & 0 & 0 & 0 & 0 \\
\hline 752 & 1000 & 967 & 663 & 663 & 663 & 633 & 0 & 0 & 0 & 0 & 0 & 0 & 0 & 0 \\
\hline 628 & 967 & 1000 & 725 & 725 & 725 & 693 & 0 & 0 & 0 & 0 & 0 & 0 & 0 & 0 \\
\hline 58 & 663 & 725 & 1000 & 1000 & 1000 & 955 & 0 & 0 & 0 & 0 & 0 & 0 & 0 & , \\
\hline 58 & 663 & 725 & 1000 & 1000 & 1000 & 955 & 0 & 0 & 0 & 0 & 0 & 0 & 0 & 0 \\
\hline 58 & 663 & 725 & 1000 & 1000 & 1000 & 955 & 0 & 0 & 0 & 0 & 0 & 0 & 0 & 0 \\
\hline 55 & 633 & 693 & 955 & 955 & 955 & 1000 & 298 & 297 & 222 & 0 & 0 & 0 & 0 & \\
\hline 0 & 0 & 0 & 0 & 0 & 0 & 298 & 1000 & 997 & 745 & 0 & 0 & 0 & 0 & \\
\hline 0 & 0 & 0 & 0 & 0 & 0 & 297 & 997 & 1000 & 767 & 0 & 0 & 0 & 0 & \\
\hline 0 & 0 & 0 & 0 & 0 & 0 & 222 & 745 & 767 & 1000 & -162 & 0 & 0 & 0 & \\
\hline 0 & 0 & 0 & 0 & 0 & 0 & 0 & 0 & 0 & -162 & 1000 & 13 & 9 & 5 & \\
\hline 0 & 0 & 0 & 0 & 0 & 0 & 0 & 0 & 0 & 0 & 13 & 1000 & 42 & 20 & 18 \\
\hline 0 & 0 & 0 & 0 & 0 & 0 & 0 & 0 & 0 & 0 & 9 & 42 & 1000 & 997 & 996 \\
\hline 0 & 0 & 0 & 0 & 0 & 0 & 0 & 0 & 0 & 0 & 5 & 20 & 997 & 1000 & 1000 \\
\hline 0 & 0 & 0 & 0 & 0 & 0 & 0 & 0 & 0 & 0 & 5 & 18 & 996 & 1000 & 1000 \\
\hline
\end{tabular}

$244 \mathrm{Cm}$ (n, gamma)

\begin{tabular}{|c|c|c|c|c|c|c|c|c|c|c|c|c|c|c|c|c|}
\hline coup & rel.s & ---- & ---- & & & 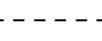 & & ---- & -- & --- & ---- & ---- & -- & ---1 & --- & --- \\
\hline 1 & $8.9189 \mathrm{E}-01$ & 1000 & 928 & 832 & 247 & 112 & -142 & -169 & 0 & 0 & 0 & 0 & 0 & 0 & 0 & 0 \\
\hline 2 & $1.5000 \mathrm{E}-00$ & 928 & 1000 & 967 & 470 & 331 & 57 & -22 & 0 & 0 & 0 & 0 & 0 & 0 & 0 & 0 \\
\hline 3 & $3.0000 \mathrm{E}-00$ & 832 & 967 & 1000 & 647 & 483 & 229 & 130 & 0 & 0 & 0 & 0 & 0 & 0 & 0 & 0 \\
\hline 4 & $2.0000 \mathrm{E}-00$ & 247 & 470 & 647 & 1000 & 946 & 870 & 732 & 0 & 0 & 0 & 0 & 0 & 0 & 0 & 0 \\
\hline 5 & $2.5000 E-01$ & 112 & 331 & 483 & 946 & 1000 & 959 & 804 & 0 & 0 & 0 & 0 & 0 & 0 & 0 & 0 \\
\hline 6 & $2.5000 \mathrm{E}-01$ & -142 & 57 & 229 & 870 & 959 & 1000 & 864 & 0 & 0 & 0 & 0 & 0 & 0 & 0 & 0 \\
\hline 7 & $2.5000 E-01$ & -169 & -22 & 130 & 732 & 804 & 864 & 1000 & 482 & 481 & 340 & 0 & 0 & 0 & 0 & 0 \\
\hline 8 & $1.0000 \mathrm{E}-00$ & 0 & 0 & 0 & 0 & 0 & 0 & 482 & 1000 & 999 & 705 & 0 & 0 & 0 & 0 & 0 \\
\hline 9 & $1.0000 \mathrm{E}-00$ & 0 & 0 & 0 & 0 & 0 & 0 & 481 & 999 & 1000 & 711 & 0 & 0 & 0 & 0 & 0 \\
\hline 10 & $1.0000 \mathrm{E}-00$ & 0 & 0 & 0 & 0 & 0 & 0 & 340 & 705 & 711 & 1000 & -366 & 0 & 0 & 0 & 0 \\
\hline 11 & $4.6026 \mathrm{E}-02$ & 0 & 0 & 0 & 0 & 0 & 0 & 0 & 0 & 0 & -366 & 1000 & 1 & 4 & 5 & 5 \\
\hline 12 & $6.6427 \mathrm{E}-02$ & 0 & 0 & 0 & 0 & 0 & 0 & 0 & 0 & 0 & 0 & 1 & 1000 & 821 & 639 & 590 \\
\hline 13 & $1.1793 \mathrm{E}-01$ & 0 & 0 & 0 & 0 & 0 & 0 & 0 & 0 & 0 & 0 & 4 & 821 & 1000 & 903 & 862 \\
\hline 14 & $1.2159 \mathrm{E}-01$ & 0 & 0 & 0 & 0 & 0 & 0 & 0 & 0 & 0 & 0 & 5 & 639 & 903 & 1000 & 996 \\
\hline 15 & $1.2506 \mathrm{E}-01$ & 0 & 0 & 0 & 0 & 0 & 0 & 0 & 0 & 0 & 0 & 5 & 590 & 862 & 996 & 1000 \\
\hline
\end{tabular}

$245 \mathrm{Cm}(\mathrm{n}, \mathrm{el})$

group rel.s.d.

$13.0000 \mathrm{E}-02$

$23.0000 \mathrm{E}-02$

$\begin{array}{lllllll}1000 & 898 & 246 & 715 & 457 & 214 & 33\end{array}$

$\begin{array}{lllllll}898 & 1000 & 541 & 903 & 690 & 479 & 128\end{array}$ 


$\begin{array}{rrrrrrrrrrrrrrrrr}3 & 3.0000 \mathrm{E}-02 & 246 & 541 & 1000 & 790 & 864 & 902 & 312 & 0 & 0 & 0 & 0 & 0 & 0 & 0 & 0 \\ 4 & 3.0000 \mathrm{E}-02 & 715 & 903 & 790 & 1000 & 933 & 808 & 258 & 0 & 0 & 0 & 0 & 0 & 0 & 0 & 0 \\ 5 & 3.0000 \mathrm{E}-02 & 457 & 690 & 864 & 933 & 1000 & 961 & 327 & 0 & 0 & 0 & 0 & 0 & 0 & 0 & 0 \\ 6 & 3.0000 \mathrm{E}-02 & 214 & 479 & 902 & 808 & 961 & 1000 & 353 & 0 & 0 & 0 & 0 & 0 & 0 & 0 & 0 \\ 7 & 3.0000 \mathrm{E}-02 & 33 & 128 & 312 & 258 & 327 & 353 & 1000 & 934 & 934 & 933 & 911 & 0 & 0 & 0 & 0 \\ 8 & 3.0000 \mathrm{E}-02 & 0 & 0 & 0 & 0 & 0 & 0 & 934 & 1000 & 1000 & 999 & 975 & 0 & 0 & 0 & 0 \\ 9 & 3.0000 \mathrm{E}-02 & 0 & 0 & 0 & 0 & 0 & 0 & 934 & 1000 & 1000 & 1000 & 976 & 0 & 0 & 0 & 0 \\ 10 & 3.0000 \mathrm{E}-02 & 0 & 0 & 0 & 0 & 0 & 0 & 933 & 999 & 1000 & 1000 & 977 & 0 & 0 & 0 & 0 \\ 11 & 5.0000 \mathrm{E}-02 & 0 & 0 & 0 & 0 & 0 & 0 & 911 & 975 & 976 & 977 & 1000 & 213 & 213 & 213 & 213 \\ 12 & 2.0251 \mathrm{E}-01 & 0 & 0 & 0 & 0 & 0 & 0 & 0 & 0 & 0 & 0 & 213 & 1000 & 999 & 999 & 999 \\ 13 & 2.1778 \mathrm{E}-01 & 0 & 0 & 0 & 0 & 0 & 0 & 0 & 0 & 0 & 0 & 213 & 999 & 1000 & 999 & 999 \\ 14 & 2.0779 \mathrm{E}-01 & 0 & 0 & 0 & 0 & 0 & 0 & 0 & 0 & 0 & 0 & 213 & 999 & 999 & 1000 & 1000 \\ 15 & 1.9438 \mathrm{E}-01 & 0 & 0 & 0 & 0 & 0 & 0 & 0 & 0 & 0 & 0 & 213 & 999 & 999 & 1000 & 1000\end{array}$

\begin{tabular}{|c|c|c|c|c|c|c|c|c|}
\hline group & rel.s.d. & ---- & ----- & ---- & ----- & ----- & ----- & ---- \\
\hline 1 & $1.5000 \mathrm{E}-01$ & 1000 & -853 & -603 & -711 & -402 & -304 & -271 \\
\hline 2 & $2.0000 \mathrm{E}-01$ & -853 & 1000 & 509 & 721 & 528 & 464 & 449 \\
\hline 3 & $1.5000 \mathrm{E}-01$ & -603 & 509 & 1000 & 861 & 362 & 121 & -44 \\
\hline 4 & $3.0000 E-01$ & -711 & 721 & 861 & 1000 & 762 & 590 & 460 \\
\hline 5 & $3.0000 \mathrm{E}-01$ & -402 & 528 & 362 & 762 & 1000 & 968 & 905 \\
\hline 6 & $5.0000 \mathrm{E}-01$ & -304 & 464 & 121 & 590 & 968 & 1000 & 982 \\
\hline 7 & $5.0000 E-01$ & -271 & 449 & -44 & 460 & 905 & 982 & 1000 \\
\hline
\end{tabular}

$245 \mathrm{Cm}(\mathrm{n}, 2 \mathrm{n})$

\begin{tabular}{crrr} 
group & rel.s.d. & \multicolumn{1}{c}{$-.-1--$} \\
1 & $2.2433 \mathrm{E}-01$ & 1000 & 165 \\
2 & $9.3532 \mathrm{E}-01$ & 165 & 1000
\end{tabular}

$245 \mathrm{Cm}(\mathrm{n}, \mathrm{f})$

\begin{tabular}{|c|c|c|c|c|c|c|c|c|c|c|c|c|c|c|c|c|}
\hline & . & & & & & & & & & & & & & & & \\
\hline 1 & $1.8111 \mathrm{E}-01$ & 1000 & 748 & 634 & 58 & 58 & 58 & 57 & 0 & 0 & 0 & 0 & 0 & 0 & 0 & 0 \\
\hline 2 & $3.0961 E-01$ & 748 & 1000 & 971 & 666 & 666 & 666 & 652 & 0 & 0 & 0 & 0 & 0 & 0 & 0 & 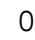 \\
\hline 3 & $4.4171 \mathrm{E}-01$ & 634 & 971 & 1000 & 720 & 720 & 720 & 706 & 0 & 0 & 0 & 0 & 0 & 0 & 0 & 0 \\
\hline 4 & $4.9428 E-01$ & 58 & 666 & 720 & 1000 & 1000 & 1000 & 980 & 0 & 0 & 0 & 0 & 0 & 0 & 0 & 0 \\
\hline 5 & $3.7220 E-01$ & 58 & 666 & 720 & 1000 & 1000 & 1000 & 980 & 0 & 0 & 0 & 0 & 0 & 0 & 0 & 0 \\
\hline 6 & $4.7447 E-01$ & 58 & 666 & 720 & 1000 & 1000 & 1000 & 980 & 0 & 0 & 0 & 0 & 0 & 0 & 0 & 0 \\
\hline 7 & $2.6531 \mathrm{E}-01$ & 57 & 652 & 706 & 980 & 980 & 980 & 1000 & 198 & 198 & 198 & 191 & 0 & 0 & 0 & 0 \\
\hline 8 & $1.3474 E-01$ & 0 & 0 & 0 & 0 & 0 & 0 & 198 & 1000 & 1000 & 1000 & 965 & 0 & 0 & 0 & 0 \\
\hline
\end{tabular}




\begin{tabular}{|c|c|c|c|c|c|c|c|c|c|c|c|c|c|c|c|c|}
\hline 9 & 1.3177E-01 & 0 & 0 & 0 & 0 & 0 & 0 & 198 & 1000 & 1000 & 1000 & 965 & 0 & 0 & 0 & 0 \\
\hline 10 & $1.3026 \mathrm{E}-01$ & 0 & 0 & 0 & 0 & 0 & 0 & 198 & 1000 & 1000 & 1000 & 965 & 0 & 0 & 0 & 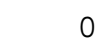 \\
\hline 11 & $8.6603 E-02$ & 0 & 0 & 0 & 0 & 0 & 0 & 191 & 965 & 965 & 965 & 1000 & 5 & 1 & 1 & 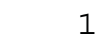 \\
\hline 12 & $3.8941 E-02$ & 0 & 0 & 0 & 0 & 0 & 0 & 0 & 0 & 0 & 0 & 5 & 1000 & 29 & 17 & 12 \\
\hline 13 & $6.2109 E-02$ & 0 & 0 & 0 & 0 & 0 & 0 & 0 & 0 & 0 & 0 & 1 & 29 & 1000 & 321 & 164 \\
\hline 14 & $5.1220 \mathrm{E}-02$ & 0 & 0 & 0 & 0 & 0 & 0 & 0 & 0 & 0 & 0 & 1 & 17 & 321 & 1000 & 773 \\
\hline 15 & $3.8175 E-02$ & 0 & 0 & 0 & 0 & 0 & 0 & 0 & 0 & 0 & 0 & 1 & 12 & 164 & 773 & 1000 \\
\hline
\end{tabular}

group rel.s.d.

$17.1207 \mathrm{E}-01$

$23.6169 \mathrm{E}-01$

$32.9122 \mathrm{E}-01$

$42.4824 \mathrm{E}-01$

$5 \quad 1.9317 \mathrm{E}-01$

$6 \quad 1.7559 \mathrm{E}-01$

$7 \quad 1.0498 \mathrm{E}-01$

$8 \quad 1.2886 \mathrm{E}-01$

9 1.2486E-01

$101.2317 \mathrm{E}-01$

$119.6045 \mathrm{E}-02$

$127.8749 \mathrm{E}-02$

$13 \quad 1.1787 \mathrm{E}-01$

$147.4618 \mathrm{E}-02$

$158.3869 \mathrm{E}-02$

\begin{tabular}{|c|c|c|c|c|c|c|c|c|c|c|c|c|c|c|}
\hline 1000 & 622 & 485 & 371 & 361 & 359 & 128 & 0 & 0 & 0 & 0 & 0 & 0 & 0 & 0 \\
\hline 622 & 1000 & 955 & 877 & 863 & 858 & 308 & 0 & 0 & 0 & 0 & 0 & 0 & 0 & 0 \\
\hline 485 & 955 & 1000 & 980 & 965 & 960 & 345 & 0 & 0 & 0 & 0 & 0 & 0 & 0 & \\
\hline 371 & 877 & 980 & 1000 & 988 & 983 & 354 & 0 & 0 & 0 & 0 & 0 & 0 & 0 & \\
\hline 361 & 863 & 965 & 988 & 1000 & 999 & 366 & 0 & 0 & 0 & 0 & 0 & 0 & 0 & \\
\hline 359 & 858 & 960 & 983 & 999 & 1000 & 367 & 0 & 0 & 0 & 0 & 0 & 0 & 0 & \\
\hline 128 & 308 & 345 & 354 & 366 & 367 & 1000 & 929 & 929 & 928 & 922 & 0 & 0 & 0 & \\
\hline 0 & 0 & 0 & 0 & 0 & 0 & 929 & 1000 & 1000 & 999 & 993 & 0 & 0 & 0 & \\
\hline 0 & 0 & 0 & 0 & 0 & 0 & 929 & 1000 & 1000 & 1000 & 994 & 0 & 0 & 0 & \\
\hline 0 & 0 & 0 & 0 & 0 & 0 & 928 & 999 & 1000 & 1000 & 994 & 0 & 0 & 0 & \\
\hline 0 & 0 & 0 & 0 & 0 & 0 & 922 & 993 & 994 & 994 & 1000 & 1 & 0 & 0 & \\
\hline 0 & 0 & 0 & 0 & 0 & 0 & 0 & 0 & 0 & 0 & 1 & 1000 & 57 & 24 & 1 \\
\hline 0 & 0 & 0 & 0 & 0 & 0 & 0 & 0 & 0 & 0 & 0 & 57 & 1000 & 136 & 7 \\
\hline 0 & 0 & 0 & 0 & 0 & 0 & 0 & 0 & 0 & 0 & 0 & 24 & 136 & 1000 & 966 \\
\hline 0 & 0 & 0 & 0 & 0 & 0 & 0 & 0 & 0 & 0 & 0 & 10 & 72 & 966 & 1000 \\
\hline
\end{tabular}




\section{Apendix B}

In the following, numerical tables for the relative uncertainty (relative standard deviation) and correlation (normalized to 1000) for nu-bar borrowed from [1,2] are given in a 15-group representation

$\begin{array}{lllll}1 & 19.6 & \mathrm{E}+06 & 6.07 & \mathrm{E}+06 \\ 2 & 6.07 & \mathrm{E}+06 & 2.23 & \mathrm{E}+06 \\ 3 & 2.23 & \mathrm{E}+06 & 1.35 & \mathrm{E}+06 \\ 4 & 1.35 & \mathrm{E}+06 & 4.98 & \mathrm{E}+05 \\ 5 & 4.98 & \mathrm{E}+05 & 1.83 & \mathrm{E}+05 \\ 6 & 1.83 & \mathrm{E}+05 & 6.74 & \mathrm{E}+04 \\ 7 & 6.74 & \mathrm{E}+04 & 2.48 & \mathrm{E}+04 \\ 8 & 2.48 & \mathrm{E}+04 & 9.12 & \mathrm{E}+03 \\ 9 & 9.12 & \mathrm{E}+03 & 2.04 & \mathrm{E}+03 \\ 10 & 2.04 & \mathrm{E}+03 & 4.54 & \mathrm{E}+02 \\ 11 & 4.54 & \mathrm{E}+02 & 2.26 & \mathrm{E}+01 \\ 12 & 2.26 & \mathrm{E}+01 & 4.00 & \mathrm{E}+00 \\ 13 & 4.00 & \mathrm{E}+00 & 5.40 & \mathrm{E}-01 \\ 14 & 5.40 & \mathrm{E}-01 & 1.00 & \mathrm{E}-01 \\ 15 & 1.00 & \mathrm{E}-01 & 1.00 & \mathrm{E}-05\end{array}$

Relative uncertainty (relative standard deviation) and correlation (normalized to 1000) for nubar for $232 \mathrm{Th}$

no-diagonal terms are those of $238 \mathrm{U}$

\begin{tabular}{|c|c|c|c|c|c|c|c|c|c|c|c|c|c|c|c|c|}
\hline 1 & & & & & & & & & & & & & & & & \\
\hline 2 & $E-02$ & 411 & 100 & 923 & 27 & 27 & & & & 27 & & 27 & & 0 & & \\
\hline 3 & $0.6402 E-02$ & 349 & 923 & 1000 & 550 & 550 & 550 & 550 & 550 & 550 & 550 & 550 & 550 & 550 & 550 & 55 \\
\hline 4 & $1.7627 \mathrm{E}-02$ & 308 & 278 & 550 & 1000 & 1000 & 1000 & 1000 & 1000 & 1000 & 1000 & 1000 & 1000 & 1000 & 1000 & 000 \\
\hline 5 & $1.7627 \mathrm{E}-02$ & 308 & 27 & 550 & 1000 & 1000 & 1000 & 1000 & 1000 & 1000 & 1000 & 1000 & 1000 & 1000 & 000 & .000 \\
\hline 6 & 1.7 & $0 \varepsilon$ & & 5 & 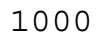 & 1000 & 0 & 10 & 0 & & 0 & 0 & 0 & & 0 & 000 \\
\hline 7 & 1.7 & 08 & 27 & 550 & 1000 & 1000 & 1000 & 10 & 1000 & 1000 & 1000 & 00 & 1000 & 0 & 1000 & 1000 \\
\hline 8 & 1.76 & 0 & 27 & 550 & 1000 & 1000 & 1000 & 1000 & 106 & 1000 & 10 & 1000 & 1000 & 1000 & 1000 & 100 \\
\hline s & 1.762 & 308 & 278 & 550 & 1000 & 1000 & 1000 & 1000 & 1000 & 1000 & 1000 & 1000 & 1000 & 1000 & 1000 & 000 \\
\hline & 1.762 & 08 & 2 & 550 & 1000 & 1000 & 1000 & 1000 & 1000 & 1000 & 1000 & 1000 & 1000 & 1000 & 1000 & 000 \\
\hline & 1.762 & 8 & & 550 & 1 & 10 & 1000 & 10 & 10 & 1 & 10 & & 0 & & 0 & 0 \\
\hline & 1.7 & 3 & & 55 & 1 & 10 & 100 & 10 & 10 & 10 & 10 & & 10 & 1 & 1( & 100 \\
\hline & .7 & & & & & 10 & & & & & & & & & & \\
\hline & .7 & & & & & & & & 10 & & 10 & & 10 & & 1000 & \\
\hline 15 & $1.7627 \mathrm{E}-02$ & 08 & 278 & 550 & 000 & 1000 & 1000 & 1000 & 1000 & 1000 & 1000 & 1000 & 1000 & 1000 & 1000 & \\
\hline
\end{tabular}

Relative uncertainty (relative standard deviation) and correlation (normalized to 1000) for nubar for $233 \mathrm{U}$

\begin{tabular}{|c|c|c|c|c|c|c|c|c|c|c|c|c|c|c|c|c|}
\hline 1 & $8.4211 \mathrm{E}-03$ & 000 & 37 & 38 & 55 & 62 & 61 & 68 & 62 & 68 & 43 & 28 & 32 & 35 & 35 & 33 \\
\hline 2 & $2.5122 \mathrm{E}-03$ & 37 & 1000 & 385 & 268 & 232 & 213 & 229 & 206 & 225 & 139 & 122 & 187 & 204 & 204 & 93 \\
\hline 3 & $2.2163 \mathrm{E}-03$ & 38 & 385 & 1000 & 347 & 309 & 267 & 278 & 246 & 270 & 166 & 160 & 61 & 4 & 284 & 69 \\
\hline 4 & $1.7977 \mathrm{E}-03$ & 55 & 268 & 347 & 1000 & 445 & 390 & 415 & 369 & 404 & 254 & 210 & 299 & 324 & 324 & U \\
\hline 5 & $1.8181 \mathrm{E}-03$ & 62 & 232 & 309 & 445 & 1000 & 465 & 457 & 412 & 451 & 282 & 212 & 280 & 305 & 305 & 8 \\
\hline 6 & $1.9268 \mathrm{E}-03$ & 61 & 213 & 267 & 390 & 465 & 1000 & 615 & 417 & 457 & 280 & 192 & 247 & 268 & 268 & 54 \\
\hline 7 & 1.83 & 68 & 229 & 278 & 415 & 457 & 615 & 1000 & 956 & 722 & 313 & 206 & 252 & 274 & 274 & 59 \\
\hline 8 & 2.0 & 62 & 206 & 246 & 369 & 412 & 417 & 956 & 1000 & 715 & 287 & 185 & 221 & 0 & 240 & 2 \\
\hline 9 & 1.84 & 68 & 225 & 270 & 404 & 451 & 457 & 2 & 715 & 1000 & 580 & 202 & 243 & 264 & 264 & \\
\hline & 3.01871 & 43 & 139 & 166 & 254 & 282 & 280 & 313 & 287 & 580 & 1000 & 820 & 145 & 158 & 158 & \\
\hline 11 & $2.4814 \mathrm{E}-03$ & 28 & 122 & 160 & 210 & 212 & 192 & 206 & 185 & 202 & 820 & 1000 & 443 & 415 & 415 & 0 \\
\hline
\end{tabular}




\begin{tabular}{|c|c|c|c|c|c|c|c|c|c|c|c|c|c|c|c|}
\hline $1.3557 E-03$ & 32 & 187 & 261 & 299 & 280 & 247 & 252 & 221 & 243 & 145 & 443 & 1000 & 919 & 919 & 891 \\
\hline $1.2690 E-03$ & 35 & 204 & 284 & 324 & 305 & 268 & 274 & 240 & 264 & 158 & 415 & 919 & 1000 & 1000 & 946 \\
\hline $1.2690 E-03$ & 35 & 204 & 284 & 324 & 305 & 268 & 74 & 240 & 264 & 158 & 15 & 919 & 1000 & 1000 & 46 \\
\hline $1.3294 E-03$ & 33 & 193 & 269 & 307 & 289 & 254 & 259 & 227 & 250 & 149 & 401 & 891 & 946 & 946 & 1000 \\
\hline
\end{tabular}

Relative uncertainty (relative standard deviation) and correlation (normalized to 1000) for nubar for $235 \mathrm{U}$

\begin{tabular}{|c|c|c|c|c|c|c|c|c|c|c|c|c|c|c|c|c|}
\hline 1 & $6.8355 E-03$ & 1000 & 132 & 80 & 74 & 67 & 50 & 41 & 35 & 54 & 51 & 23 & 0 & 0 & 0 & 0 \\
\hline 2 & $2.0161 \mathrm{E}-03$ & 132 & 1000 & 429 & 360 & 368 & 279 & 230 & 195 & 298 & 284 & 131 & 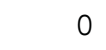 & 0 & 0 & \\
\hline 3 & $2.5371 E-03$ & 80 & 429 & 1000 & 419 & 353 & 250 & 204 & 171 & 268 & 254 & 117 & 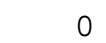 & 0 & O & \\
\hline 4 & $2.0122 \mathrm{E}-03$ & 74 & 360 & 419 & 1000 & 550 & 347 & 287 & 246 & 369 & 359 & 175 & 0 & 0 & 0 & \\
\hline 5 & $1.7967 \mathrm{E}-03$ & 67 & 368 & 353 & 550 & 1000 & 492 & 358 & 304 & 465 & 445 & 208 & 0 & 0 & 0 & \\
\hline 6 & $2.3035 E-03$ & 50 & 279 & 250 & 347 & 492 & 1000 & 319 & 268 & 385 & 370 & 164 & 0 & 0 & 0 & \\
\hline 7 & $2.7486 \mathrm{E}-03$ & 41 & 230 & 204 & 287 & 358 & 319 & 1000 & 235 & 325 & 319 & 152 & 0 & 0 & & \\
\hline 8 & $3.2002 E-03$ & 35 & 195 & 171 & 246 & 304 & 268 & 235 & 1000 & 293 & 275 & 121 & & 0 & & \\
\hline 9 & $2.1589 \mathrm{E}-03$ & 54 & 298 & 268 & 369 & 465 & 385 & 325 & 293 & 1000 & 435 & 186 & 0 & 0 & 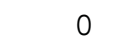 & \\
\hline 10 & $2.2034 E-03$ & 51 & 284 & 254 & 359 & 445 & 370 & 319 & 275 & 435 & 1000 & 359 & 0 & 0 & 0 & \\
\hline 11 & $4.1079 \mathrm{E}-03$ & 23 & 131 & 117 & 175 & 208 & 164 & 152 & 121 & 186 & 359 & 1000 & 58 & 53 & 53 & \\
\hline 12 & $3.1620 E-03$ & 0 & 0 & 0 & 0 & 0 & 0 & 0 & 0 & 0 & 0 & 58 & 1000 & 916 & 916 & 91 \\
\hline 13 & $3.1200 \mathrm{E}-03$ & 0 & 0 & 0 & 0 & 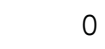 & 0 & 0 & 0 & 0 & 0 & 53 & 916 & 1000 & 1000 & 100 \\
\hline 14 & $3.1200 E-03$ & 0 & 0 & 0 & 0 & 0 & 0 & & 0 & & 0 & 53 & 916 & 1000 & 1000 & 100 \\
\hline 15 & $3.1200 \mathrm{E}-03$ & 0 & 0 & 0 & 0 & 0 & 0 & 0 & 0 & 0 & 0 & 53 & 916 & 1000 & 1000 & 100 \\
\hline
\end{tabular}

Relative uncertainty (relative standard deviation) and correlation (normalized to 1000) for nubar for $234 \mathrm{U}$

no-diagonal terms are those of $238 \mathrm{U}$

\begin{tabular}{|c|c|c|c|c|c|c|c|c|c|c|c|c|c|c|c|c|}
\hline 1 & $E-02$ & 000 & 411 & 349 & 308 & 308 & 308 & 308 & 308 & 308 & 308 & 308 & 308 & 308 & 308 & 3 \\
\hline 2 & $3.0000 \mathrm{E}-02$ & 411 & 1000 & 923 & 278 & 278 & 278 & 278 & 278 & 278 & 278 & 278 & 78 & 278 & 78 & \\
\hline 3 & -03 & 349 & 923 & 1000 & 550 & 550 & 550 & 550 & 550 & 550 & 550 & 550 & 550 & 550 & 50 & 50 \\
\hline 4 & 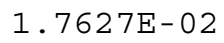 & 308 & 27 & 550 & 00 & 000 & 00 & 000 & 00 & D०० & 00 & D०० & 00 & 00 & 00 & \\
\hline 5 & $.7627 \mathrm{E}-02$ & 08 & $27 \varepsilon$ & 50 & 00 & 000 & 00 & 000 & 00 & 000 & 00 & 000 & 00 & 000 & 00 & U \\
\hline 6 & 2 & 08 & $27 \varepsilon$ & 50 & 000 & 1000 & 000 & 1000 & 00 & 000 & 00 & .000 & 00 & 000 & 00 & 0 \\
\hline 7 & .7 & 08 & 27 & 50 & 000 & 1000 & 1000 & 1000 & 1000 & 1000 & 1000 & 1000 & 1000 & .000 & 00 & \\
\hline 8 & 1.7 & 08 & $27 \varepsilon$ & 550 & 1000 & 1000 & 1000 & 1000 & 1000 & 1000 & 1000 & 1000 & 1000 & 1000 & 1000 & 0 \\
\hline 9 & 1. & & & 50 & 0 & 000 & 1000 & 000 & 0 & 1000 & 1000 & 1000 & 0 & 00 & 1000 & 00 \\
\hline & 02 & & $27 \xi$ & 0 & 1000 & 1000 & 1000 & 1000 & 1000 & 1000 & 1000 & 1000 & 1000 & 1000 & 1000 & 10 \\
\hline & .7 & ת & 27 & J & 1000 & 1000 & 1000 & 1000 & 1000 & 1000 & 1000 & 1000 & 1000 & 1000 & 1000 & 10 \\
\hline & .7 & 08 & 27 & 50 & 00 & 1000 & 1000 & 1000 & 1000 & 1000 & 1000 & 1000 & 1000 & 1000 & 1000 & 0 \\
\hline 1 & $.7627 \mathrm{E}-02$ & 08 & 27 & 50 & 1000 & 1000 & 1000 & 1000 & 1000 & 1000 & 1000 & 1000 & 1000 & 1000 & 1000 & 0 \\
\hline 14 & $1.7627 \mathrm{E}-02$ & 308 & 278 & 550 & 1000 & 1000 & 1000 & 1000 & 1000 & 1000 & 1000 & 1000 & 1000 & 1000 & 1000 & 10 \\
\hline 15 & $1.7627 \mathrm{E}-02$ & 308 & 278 & 550 & 000 & 000 & 000 & 000 & 000 & 000 & 000 & 000 & 000 & 1000 & 1000 & 100 \\
\hline
\end{tabular}

Relative uncertainty (relative standard deviation) and correlation (normalized to 1000) for nubar for $236 \mathrm{U}$

no-diagonal terms are those of $238 \mathrm{U}$

\begin{tabular}{|c|c|c|c|c|c|c|c|c|c|c|c|c|c|c|c|c|}
\hline & & & & & & & & & & & & & & & & \\
\hline 1 & $3.0000 \mathrm{E}-02$ & 1000 & 411 & 349 & 308 & 308 & 308 & 308 & 308 & 308 & 308 & 308 & 308 & 308 & 308 & \\
\hline 2 & $3.0000 \mathrm{E}-02$ & 411 & 1000 & 923 & 278 & 278 & 278 & 278 & 278 & 278 & 278 & 278 & 278 & 278 & 278 & \\
\hline 3 & $3.0000 \mathrm{E}-02$ & 349 & 923 & 1000 & 550 & 550 & 550 & 550 & 550 & 550 & 550 & 550 & 550 & 550 & 550 & \\
\hline 4 & $1.7627 \mathrm{E}-02$ & 308 & 278 & 550 & 1000 & 1000 & 1000 & 1000 & 1000 & 1000 & 1000 & 1000 & 1000 & 1000 & 1000 & 100 \\
\hline 5 & $1.7627 \mathrm{E}-02$ & 308 & 278 & 550 & 1000 & 1000 & 1000 & 1000 & 1000 & 1000 & 1000 & 1000 & 1000 & 1000 & 1000 & 100 \\
\hline 6 & $1.7627 \mathrm{E}-02$ & 308 & 278 & 550 & 1000 & 1000 & 1000 & 1000 & 1000 & 1000 & 1000 & 1000 & 1000 & 1000 & 1000 & 10 \\
\hline 7 & $1.7627 \mathrm{E}-02$ & 308 & 278 & 550 & 1000 & 1000 & 1000 & 1000 & 1000 & 1000 & 1000 & 1000 & 1000 & 1000 & 1000 & 100 \\
\hline 8 & $1.7627 \mathrm{E}-02$ & 308 & 278 & 550 & 1000 & 1000 & 1000 & 1000 & 1000 & 1000 & 1000 & 1000 & 1000 & 1000 & 1000 & 100 \\
\hline 9 & $1.7627 \mathrm{E}-02$ & 308 & 278 & 550 & 1000 & 1000 & 1000 & 1000 & 1000 & 1000 & 1000 & 1000 & 1000 & 1000 & 1000 & 10 \\
\hline
\end{tabular}




\begin{tabular}{|c|c|c|c|c|c|c|c|c|c|c|c|c|c|c|c|}
\hline 1. $7627 \mathrm{E}-02$ & 308 & 278 & 550 & 1000 & 1000 & 1000 & 1000 & 1000 & 1000 & 1000 & 1000 & 1000 & 1000 & 1000 & 1000 \\
\hline $1.7627 \mathrm{E}-02$ & 308 & 278 & 550 & 1000 & 1000 & 1000 & 1000 & 1000 & 1000 & 1000 & 1000 & 1000 & 1000 & 1000 & 1000 \\
\hline $1.7627 \mathrm{E}-02$ & 08 & 278 & 50 & 00 & 000 & 000 & 000 & 000 & 000 & 00 & 00 & 00 & 00 & 0 & \\
\hline $1.7627 \mathrm{E}-02$ & 308 & 278 & 550 & 000 & 1000 & 1000 & 1000 & 1000 & 1000 & 1000 & 000 & 1000 & 1000 & 000 & 0 \\
\hline $1.7627 \mathrm{E}-02$ & 08 & 278 & 50 & 000 & 1000 & 1000 & .000 & 1000 & 1000 & 1000 & 0 & 1000 & 1000 & 1 & 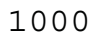 \\
\hline $1.7627 \mathrm{E}-02$ & 308 & 278 & 50 & 1000 & 1000 & 1000 & 1000 & 1000 & 1000 & 1000 & 1000 & 1000 & 1000 & 1000 & 0 \\
\hline
\end{tabular}

Relative uncertainty (relative standard deviation) and correlation (normalized to 1000) for nubar for $238 \mathrm{U}$

\begin{tabular}{|c|c|c|c|c|c|c|c|c|c|c|c|c|c|c|c|c|}
\hline & & & & & & & & & & & & & & & & \\
\hline 1 & $6 E-03$ & .000 & 411 & 349 & 308 & 308 & 308 & 308 & 308 & 308 & 308 & 308 & 308 & 308 & 308 & \\
\hline 2 & $6.1098 E-03$ & 411 & 1000 & 923 & 278 & 278 & 278 & 278 & 278 & 278 & 278 & 278 & 278 & 278 & 278 & \\
\hline 3 & $6.4020 \mathrm{E}-03$ & 349 & 923 & 1000 & 550 & 550 & 550 & 550 & 550 & 550 & 550 & 550 & 550 & 550 & 550 & \\
\hline 4 & 1.762 & 308 & 278 & 550 & 000 & 00 & 000 & 000 & 000 & 1000 & 1000 & 1000 & 1000 & 000 & 000 & 000 \\
\hline 5 & 02 & 08 & 278 & 550 & 00 & 00 & 00 & 000 & 00 & 000 & 00 & boo & 00 & 000 & 00 & 00 \\
\hline 6 & 1.7 & 08 & 278 & 550 & 00 & 000 & 00 & 1000 & 00 & boo & 00 & 000 & 00 & 000 & 00 & $0 c$ \\
\hline 7 & 1.7627 & 08 & 278 & 550 & 000 & 1000 & 000 & 1000 & 000 & 1000 & 1000 & 1000 & 1000 & 1000 & 1000 & -0 \\
\hline 8 & 1.762 & 08 & 278 & 550 & 000 & 1000 & 1000 & 1000 & 1000 & 1000 & 1000 & 1000 & 1000 & 1000 & 1000 & 06 \\
\hline 9 & 1.7 & 8 & 278 & 550 & 000 & 0 & 0 & 1000 & 1000 & 1000 & 1000 & 1000 & 1000 & 1 & 1( & 1000 \\
\hline & & 8 & 78 & 50 & 00 & 1000 & 00 & 1000 & 00 & 1000 & 1000 & 1000 & 1000 & 0 & 1000 & 100 \\
\hline & 1.7 & 08 & 278 & 550 & 00 & 1000 & 00 & 1000 & 1000 & 1000 & 1000 & 1000 & 1000 & 1000 & 1000 & 0 \\
\hline 2 & 1.7627 & 08 & 278 & 550 & 000 & 1000 & 000 & 1000 & 1000 & 1000 & 1000 & 1000 & 1000 & 1000 & 1000 & .00 \\
\hline 13 & $1.7627 \mathrm{E}-02$ & 08 & 278 & 550 & 000 & 1000 & 000 & 1000 & 1000 & 1000 & 1000 & 1000 & 1000 & 1000 & 1000 & 10 \\
\hline 14 & $1.7627 \mathrm{E}-02$ & 08 & 278 & 550 & 0 & 1000 & 0 & 1000 & 1000 & 1000 & 1000 & 1000 & 1000 & 1000 & 1000 & 100 \\
\hline 15 & $1.7627 \mathrm{E}-02$ & $0 \varepsilon$ & 278 & 550 & 0 & 1000 & 0 & 1000 & 1000 & 1000 & 1000 & 1000 & 1000 & 1000 & 1000 & 00 \\
\hline
\end{tabular}

Relative uncertainty (relative standard deviation) and correlation (normalized to 1000) for nubar for $237 \mathrm{~Np}$

\begin{tabular}{|c|c|c|c|c|c|c|c|c|c|c|c|c|c|c|c|c|}
\hline 1 & $3.0000 \mathrm{E}-02$ & 000 & 132 & 27 & 0 & 0 & 0 & 0 & 0 & 0 & 0 & 0 & 0 & 0 & 0 & \\
\hline 2 & $E-02$ & 132 & 1000 & 511 & 197 & 71 & 71 & 71 & 71 & 71 & 71 & 71 & 71 & 71 & 71 & \\
\hline 3 & $1.4704 \mathrm{E}-02$ & 27 & 511 & 1000 & 605 & 76 & 76 & 76 & 76 & 76 & 76 & 76 & 76 & 76 & 76 & \\
\hline 4 & $6.6175 E-03$ & 0 & 197 & 605 & 1000 & 818 & 818 & 818 & 818 & 818 & 818 & 818 & 818 & 818 & 818 & \\
\hline 5 & $6.0000 \mathrm{E}-03$ & 0 & 71 & 76 & 818 & 1000 & 1000 & 1000 & 1000 & 1000 & 1000 & 1000 & 1000 & 1000 & 1000 & 100 \\
\hline 6 & 6.0 & 0 & 1 & 76 & 818 & 1000 & 000 & 1000 & 1000 & 1000 & 1000 & 1000 & 1000 & 000 & & 0 \\
\hline 7 & 6.0 & 0 & 7 & 76 & 818 & 1000 & 1000 & 1000 & 1000 & 1000 & 1000 & 1000 & 1000 & 1000 & 1000 & 100 \\
\hline 8 & 6.0 & 0 & 7 & 76 & 818 & 1000 & 000 & 1000 & 1000 & 1000 & 1000 & 1000 & 1000 & 1000 & 1000 & 100 \\
\hline 9 & 6.0 & 0 & 71 & 76 & 818 & 1000 & 1000 & 1000 & 1000 & 1000 & 1000 & 1000 & 1000 & 1000 & 1000 & 100 \\
\hline 10 & 6.0 & 0 & 71 & 76 & 818 & 1000 & 1000 & 1000 & 1000 & 1000 & 1000 & 1000 & 1000 & 1000 & 1000 & 00 \\
\hline 1. & $0 E-03$ & 0 & 71 & 76 & 818 & 1000 & 1000 & 1000 & 1000 & 1000 & 1000 & 1000 & 1000 & 1000 & 1000 & 100 \\
\hline 12 & 6.0 & 0 & 71 & 76 & 818 & 1000 & 1000 & 1000 & 1000 & 1000 & 1000 & 1000 & 1000 & 1000 & 1000 & 100 \\
\hline & 6.0 & 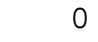 & 7 & 76 & 818 & 1000 & 1000 & 1000 & 1000 & 1000 & 1000 & 1000 & 1000 & 1000 & 1000 & 100 \\
\hline 1 & 6.0 & 0 & 71 & 76 & 818 & 1000 & & 1000 & 1000 & 1000 & 1000 & 1000 & 1000 & 1000 & 1000 & .00 \\
\hline 15 & $6.0000 \mathrm{E}-03$ & 0 & 71 & 76 & 818 & 1000 & 1000 & 1000 & 1000 & 1000 & 1000 & 1000 & 1000 & 1000 & 1000 & 100 \\
\hline
\end{tabular}

Relative uncertainty (relative standard deviation) and correlation (normalized to 1000) for nubar for $238 \mathrm{Pu}$

$\begin{array}{cr}\text { group } & \text { rel.s.d. } \\ 1 & 5.0000 \mathrm{E}-02 \\ 2 & 3.0000 \mathrm{E}-02 \\ 3 & 3.0000 \mathrm{E}-02 \\ 4 & 3.0000 \mathrm{E}-02 \\ 5 & 3.0000 \mathrm{E}-02 \\ 6 & 3.0000 \mathrm{E}-02 \\ 7 & 3.0000 \mathrm{E}-02 \\ 8 & 3.0000 \mathrm{E}-02 \\ 9 & 3.0000 \mathrm{E}-02\end{array}$

$\begin{array}{rrr}1000 & 672 & 138 \\ 672 & 1000 & 625 \\ 138 & 625 & 1000 \\ 0 & 390 & 508 \\ 0 & 303 & 309 \\ 0 & 303 & 309 \\ 0 & 303 & 309 \\ 0 & 303 & 309 \\ 0 & 303 & 309\end{array}$

$\begin{array}{rrrrrrrrrrrr}0 & 0 & 0 & 0 & 0 & 0 & 0 & 0 & 0 & 0 & 0 & 0 \\ 390 & 303 & 303 & 303 & 303 & 303 & 303 & 303 & 303 & 303 & 303 & 303 \\ 508 & 309 & 309 & 309 & 309 & 309 & 309 & 309 & 309 & 309 & 309 & 309 \\ 1000 & 975 & 975 & 975 & 975 & 975 & 975 & 975 & 975 & 975 & 975 & 975 \\ 975 & 1000 & 1000 & 1000 & 1000 & 1000 & 1000 & 1000 & 1000 & 1000 & 1000 & 1000 \\ 975 & 1000 & 1000 & 1000 & 1000 & 1000 & 1000 & 1000 & 1000 & 1000 & 1000 & 1000 \\ 975 & 1000 & 1000 & 1000 & 1000 & 1000 & 1000 & 1000 & 1000 & 1000 & 1000 & 1000 \\ 975 & 1000 & 1000 & 1000 & 1000 & 1000 & 1000 & 1000 & 1000 & 1000 & 1000 & 1000 \\ 975 & 1000 & 1000 & 1000 & 1000 & 1000 & 1000 & 1000 & 1000 & 1000 & 1000 & 1000\end{array}$


$10 \quad 3.0000 \mathrm{E}-02$

$113.0000 \mathrm{E}-02$

$123.0000 E-02$

$133.0000 \mathrm{E}-02$

$143.0000 \mathrm{E}-02$

$153.0000 \mathrm{E}-02$

$\begin{array}{lll}0 & 303 & 309 \\ 0 & 303 & 309 \\ 0 & 303 & 309 \\ 0 & 303 & 309 \\ 0 & 303 & 309 \\ 0 & 303 & 309\end{array}$

$9751000 \quad 1000 \quad 1000 \quad 1000 \quad 1000 \quad 1000 \quad 1000 \quad 10001000 \quad 10001000$ $9751000100010001000 \quad 1000 \quad 1000 \quad 1000 \quad 10001000 \quad 10001000$ $9751000100010001000 \quad 1000 \quad 10001000 \quad 1000100010001000$ $9751000100010001000 \quad 10001000 \quad 1000 \quad 10001000 \quad 10001000$ $\begin{array}{lllllllllllll}975 & 1000 & 1000 & 1000 & 1000 & 1000 & 1000 & 1000 & 1000 & 1000 & 1000 & 1000\end{array}$ 97510001000100010001000100010001000100010001000

Relative uncertainty (relative standard deviation) and correlation (normalized to 1000) for nubar for $239 \mathrm{Pu}$

\begin{tabular}{|c|c|c|c|c|c|c|c|c|c|c|c|c|c|c|c|c|}
\hline & & & & & & & & & & & & & & & & \\
\hline 1 & $2.1524 \mathrm{E}-03$ & 1000 & 740 & 513 & 334 & 217 & 217 & 79 & 26 & 26 & 26 & 21 & 25 & 21 & 35 & 35 \\
\hline 2 & $1.7031 \mathrm{E}-03$ & 740 & 1000 & 914 & 588 & 382 & 382 & 134 & 41 & 41 & 41 & 34 & 42 & 35 & 58 & 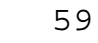 \\
\hline 3 & $1.7340 \mathrm{E}-03$ & 513 & 914 & 1000 & 640 & 415 & 415 & 143 & 42 & 42 & 42 & 36 & 45 & 37 & 61 & 3 \\
\hline 4 & $1.7900 \mathrm{E}-03$ & 334 & 588 & 640 & 1000 & 550 & 550 & 185 & 51 & 51 & 52 & 29 & 36 & 29 & 48 & \\
\hline 5 & $2.2400 \mathrm{E}-03$ & 217 & 382 & 415 & 550 & 1000 & 1000 & 303 & 58 & 58 & 58 & 18 & 22 & 18 & 31 & \\
\hline 6 & $2.2400 \mathrm{E}-03$ & 217 & 382 & 415 & 550 & 1000 & 1000 & 303 & 58 & 58 & 58 & 18 & 22 & 18 & 31 & \\
\hline 7 & $3.0540 \mathrm{E}-03$ & 79 & 134 & 143 & 185 & 303 & 303 & 1000 & 969 & 969 & 969 & 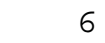 & 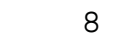 & 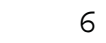 & 11 & \\
\hline 8 & $4.3980 E-03$ & 26 & 41 & 42 & 51 & 58 & 58 & 969 & 1000 & 1000 & 1000 & 2 & 2 & 2 & 3 & \\
\hline 9 & $4.3980 \mathrm{E}-03$ & 26 & 41 & 42 & 51 & 58 & 58 & 969 & 1000 & 1000 & 1000 & 2 & 2 & 2 & 3 & \\
\hline 10 & $4.3509 E-03$ & 26 & 41 & 42 & 52 & 58 & 58 & 969 & 1000 & 1000 & 1000 & 6 & 5 & 4 & 5 & \\
\hline 11 & $1.5633 \mathrm{E}-03$ & 21 & 34 & 36 & 29 & 18 & 18 & 6 & 2 & 2 & 6 & 1000 & 730 & 447 & 521 & 485 \\
\hline 12 & $1.3122 \mathrm{E}-03$ & 25 & 42 & 45 & 36 & 22 & 22 & 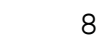 & 2 & 2 & 5 & 730 & 1000 & 585 & 640 & 59 \\
\hline 13 & $1.2082 \mathrm{E}-03$ & 21 & 35 & 37 & 29 & 18 & 18 & 6 & 2 & 2 & 4 & 447 & 585 & 1000 & 531 & 49 \\
\hline 14 & $9.1368 \mathrm{E}-04$ & 35 & 58 & 61 & 48 & 31 & 31 & 11 & 3 & 3 & 5 & 521 & 640 & 531 & 1000 & 81 \\
\hline 15 & $8.5168 \mathrm{E}-04$ & 35 & 59 & 63 & 49 & 31 & 31 & 11 & 3 & 3 & 5 & 485 & 595 & 492 & 819 & 100 \\
\hline
\end{tabular}

Relative uncertainty (relative standard deviation) and correlation (normalized to 1000) for nubar for $240 \mathrm{Pu}$

\begin{tabular}{|c|c|c|c|c|c|c|c|c|c|c|c|c|c|c|c|c|}
\hline 1 & $.0857 \mathrm{E}-02$ & 000 & 672 & 138 & 0 & 0 & 0 & 0 & 0 & 0 & 0 & 0 & 0 & 0 & 0 & \\
\hline 2 & $79 E-02$ & 672 & 1000 & 625 & 390 & 303 & 303 & 303 & 303 & 303 & 303 & 303 & 303 & 303 & 3 & \\
\hline 3 & $26 \mathrm{E}-02$ & 138 & 625 & 1000 & 508 & 309 & 309 & 309 & 309 & 309 & 309 & 309 & 09 & & 309 & \\
\hline 4 & $.7373 E-02$ & 0 & 390 & 508 & 1000 & 975 & 975 & 975 & 975 & 975 & 975 & 975 & 975 & 975 & 975 & \\
\hline 5 & $4.8100 \mathrm{E}-02$ & 0 & 303 & 309 & 975 & 1000 & 1000 & 1000 & 1000 & 1000 & 1000 & 1000 & 1000 & 1000 & 1000 & 10 \\
\hline 6 & 4.8 & 0 & 303 & 309 & 975 & 1000 & 1000 & 1000 & 1000 & 1000 & 1000 & 1000 & 1000 & 1000 & 1000 & 10 \\
\hline 7 & $4 . \varepsilon$ & 0 & 303 & 309 & 975 & 1000 & 1000 & 000 & 1000 & 000 & 1000 & 1000 & 1000 & 000 & 000 & 00 \\
\hline 8 & 4. & 0 & 303 & 09 & 975 & 1000 & 1000 & 1000 & 1000 & 1000 & 1000 & 1000 & 1000 & 1000 & 1000 & 100 \\
\hline 9 &.$\varepsilon$ & 0 & 303 & 309 & 975 & 1000 & 1000 & 1000 & 1000 & 1000 & 1000 & 1000 & 1000 & 1000 & 1000 & 100 \\
\hline 0 & $4.8100 \mathrm{E}-02$ & 0 & 303 & 309 & 975 & 1000 & 1000 & 1000 & 1000 & 1000 & 1000 & 1000 & 1000 & 1000 & 1000 & 100 \\
\hline 11 & $4.8100 \mathrm{E}-02$ & 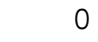 & 303 & 309 & 975 & 1000 & 1000 & 1000 & 1000 & 1000 & 1000 & 1000 & 1000 & 1000 & 1000 & 100 \\
\hline 12 & $4.8100 \mathrm{E}-02$ & 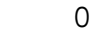 & 303 & 309 & 975 & 1000 & 1000 & 1000 & 1000 & 1000 & 1000 & 1000 & 1000 & 1000 & 1000 & 100 \\
\hline 7 & 4.81 & 0 & 303 & 309 & 975 & 1000 & 1000 & 1000 & 1000 & 1000 & 1000 & 1000 & 1000 & 1000 & 1000 & 100 \\
\hline & . & 0 & 30 & 309 & 975 & 1000 & 1000 & 1000 & 1000 & 1000 & 1000 & 1000 & 0 & 1000 & 1000 & 100 \\
\hline$x$ & $.8100 \mathrm{E}-02$ & 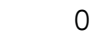 & 303 & 309 & 975 & 1000 & 000 & 1000 & 1000 & 1000 & 1000 & 1000 & 000 & 1000 & .000 & \\
\hline
\end{tabular}

Relative uncertainty (relative standard deviation) and correlation (normalized to 1000) for nubar for $241 \mathrm{Pu}$

group rel.s.d.

$14.4976 \mathrm{E}-03$

$22.7245 \mathrm{E}-03$

$32.7345 \mathrm{E}-03$

$42.8414 \mathrm{E}-03$

$52.9154 \mathrm{E}-03$

$62.9154 \mathrm{E}-03$

$72.9154 \mathrm{E}-03$

$82.9154 \mathrm{E}-03$

$92.9154 \mathrm{E}-03$

\begin{tabular}{|c|c|c|c|c|c|c|c|c|c|c|c|c|c|c|}
\hline 000 & 581 & 531 & 358 & 288 & 288 & 288 & 288 & 288 & 288 & 288 & 288 & 288 & 288 & 288 \\
\hline 581 & 1000 & 998 & 968 & 946 & 946 & 946 & 946 & 946 & 946 & & & & & 946 \\
\hline 31 & 998 & 000 & 98 & & 964 & & 96 & & & & & & & 64 \\
\hline 5 & 968 & 981 & 1000 & 99 & 99 & 99 & 99 & 9 & 9 & 9 & & & & 9 \\
\hline 88 & 946 & 64 & 997 & 000 & مחمח & 000 & 1000 & م & 0 & 0 & b & & 9 & 95 \\
\hline 8 & 94 & 9 & 99 & 0 & 10 & 1000 & 000 & & & 0 & & & & 9 \\
\hline 80 & 16 & 964 & 99 & 0 & 0 & 1000 & مिم0 & 70 & م & 000 & 70 & 100 & 9 & 99 \\
\hline 8 & & 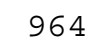 & 99 & 100 & 1000 & 1000 & 1000 & & 10 & 1000 & & & & 99 \\
\hline 88 & 46 & 64 & 997 & 1000 & 1000 & 1000 & 1000 & 1000 & 1000 & 1000 & 1000 & 100 & 999 & 9 \\
\hline
\end{tabular}




$\begin{array}{ll}10 & 2.9154 \mathrm{E}-03 \\ 11 & 2.9154 \mathrm{E}-03 \\ 12 & 2.9154 \mathrm{E}-03 \\ 13 & 2.9146 \mathrm{E}-03 \\ 14 & 2.9154 \mathrm{E}-03 \\ 15 & 2.9154 \mathrm{E}-03\end{array}$

$288946 \quad 964$

$288946 \quad 964$

$288946 \quad 964$

$288946 \quad 964$

$288946 \quad 964$

$288946 \quad 964$
$997100010001000 \quad 1000 \quad 1000 \quad 1000 \quad 1000 \quad 10001000$

$9971000100010001000 \quad 1000 \quad 1000 \quad 1000 \quad 10001000$

$99710001000 \quad 1000 \quad 1000 \quad 1000 \quad 1000 \quad 1000 \quad 10001000$

999

999999

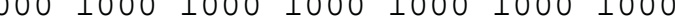

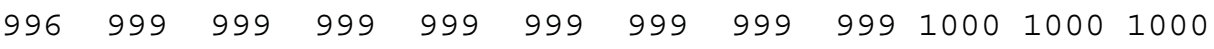
$99699999999999999999 \quad 999 \quad 999 \quad 999100010001000$

Relative uncertainty (relative standard deviation) and correlation (normalized to 1000) for nubar for $242 \mathrm{Pu}$

\begin{tabular}{|c|c|c|c|c|c|c|c|c|c|c|c|c|c|c|c|c|}
\hline 1 & $1.0000 \mathrm{E}-01$ & 000 & 672 & 138 & 0 & 0 & 0 & 0 & 0 & 0 & 0 & 0 & 0 & 0 & 0 & \\
\hline 2 & $E-02$ & 672 & 1000 & 625 & 390 & 303 & 303 & 303 & 303 & 303 & 303 & 303 & 303 & 303 & 303 & \\
\hline 3 & $39 E-02$ & 138 & 625 & 1000 & 508 & 309 & 309 & 309 & 309 & 309 & 309 & 309 & 309 & 309 & 309 & \\
\hline 4 & $3.1144 \mathrm{E}-02$ & 0 & 390 & 508 & 1000 & 975 & 975 & 975 & 975 & 975 & 975 & 975 & 975 & 975 & 975 & 97 \\
\hline 5 & $4.0083 E-02$ & 0 & 303 & 309 & 975 & 1000 & 1000 & 1000 & 1000 & 1000 & 1000 & 1000 & 1000 & 1000 & 1000 & 100 \\
\hline 6 & 4.0 & 0 & 303 & 309 & 975 & 1000 & 000 & 1000 & 000 & 1000 & 1000 & 1000 & 1000 & 1000 & 1000 & 100 \\
\hline 7 & 4.0 & 0 & 303 & 30 & 975 & 1000 & 000 & 1000 & .000 & 1000 & 1000 & 1000 & 1000 & 1000 & 000 & 100 \\
\hline 8 & $3 E-02$ & 0 & 303 & 309 & 975 & 1000 & 1000 & 1000 & 1000 & 1000 & 1000 & 1000 & 1000 & 1000 & 1000 & 100 \\
\hline 9 & $33 E-02$ & 0 & 303 & 309 & 975 & 1000 & 1000 & 1000 & 1000 & 1000 & 1000 & 1000 & 1000 & 1000 & 1000 & 100 \\
\hline 10 & 4.00 & 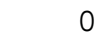 & 303 & 309 & 975 & 1000 & 1000 & 1000 & 1000 & 1000 & 1000 & 1000 & 1000 & 1000 & 1000 & 100 \\
\hline 11 & 4.0 & 0 & 303 & 09 & 975 & 1000 & 1000 & 1000 & 1000 & 1000 & 1000 & 1000 & 1000 & 1000 & 1000 & 100 \\
\hline & 4.0 & 0 & 303 & 309 & 975 & 1000 & 1000 & 1000 & 1000 & 1000 & 1000 & 1000 & 1000 & 1000 & 1000 & 100 \\
\hline & & 0 & 30 & & $9^{7}$ & 1000 & 0 & 10 & 1000 & 10 & 1000 & 1000 & 1000 & 1000 & 1000 & 100 \\
\hline 1 & & 0 & 303 & & 975 & 1000 & 1000 & 1000 & 1000 & 1000 & 1000 & 1000 & 1000 & 1000 & 1000 & .00 \\
\hline 15 & $4.0083 E-02$ & 0 & 303 & 309 & 975 & 1000 & 1000 & 1000 & 1000 & 1000 & 1000 & 1000 & 1000 & 1000 & 1000 & 00 \\
\hline
\end{tabular}

Relative uncertainty (relative standard deviation) and correlation (normalized to 1000) for nubar for $241 \mathrm{Am}$

\begin{tabular}{|c|c|c|c|c|c|c|c|c|c|c|c|c|c|c|c|c|}
\hline & & & & & & & & & & & & & & & & \\
\hline 1 & $.0000 \mathrm{E}-02$ & 000 & 132 & 27 & 0 & 0 & 0 & 0 & 0 & 0 & 0 & 0 & 0 & 0 & 0 & \\
\hline 2 & $E-02$ & 132 & 1000 & 511 & 197 & 71 & 71 & 71 & 71 & 71 & 71 & 71 & 71 & 71 & 71 & \\
\hline 3 & $00 \mathrm{E}-02$ & 27 & 511 & 1000 & 605 & 76 & 76 & 76 & 76 & 76 & 76 & 76 & 76 & 76 & 76 & \\
\hline 4 & $.0000 \mathrm{E}-03$ & 0 & 197 & 605 & 1000 & 818 & 818 & 818 & 818 & 818 & 818 & 818 & 818 & 818 & 818 & 0. \\
\hline 5 & $3.0000 \mathrm{E}-02$ & 0 & 71 & 76 & 818 & 1000 & 1000 & 1000 & 1000 & 1000 & 1000 & 1000 & 1000 & 1000 & 00 & 100 \\
\hline 6 & 3.000 & 0 & 71 & 76 & 818 & 1000 & 1000 & 1000 & 1000 & 1000 & 1000 & 000 & 1000 & 000 & 1000 & 0 \\
\hline 7 & . & 0 & 71 & 76 & 818 & 1000 & 1000 & 1000 & 1000 & 1000 & 1000 & 1000 & 1000 & 1000 & 1000 & 100 \\
\hline 8 & . & 0 & 71 & 7 & 818 & 1000 & 1000 & 1000 & 1000 & 1000 & 1000 & 1000 & 1000 & 1000 & 1000 & 100 \\
\hline 0 & -02 & 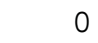 & 7 & 76 & 818 & 1000 & 1000 & 1000 & 1000 & 1000 & 1000 & 1000 & 1000 & 1000 & 1000 & 100 \\
\hline 10 & $3.0000 \mathrm{E}-02$ & 0 & 71 & 76 & 818 & 1000 & 1000 & 1000 & 1000 & 1000 & 1000 & 1000 & 1000 & 1000 & 1000 & 100 \\
\hline 11 & $3.0000 \mathrm{E}-02$ & 0 & 71 & 76 & 818 & 1000 & 1000 & 1000 & 1000 & 1000 & 1000 & 1000 & 1000 & 1000 & 1000 & 100 \\
\hline 12 & $3.0000 \mathrm{E}-02$ & 0 & 71 & 76 & 818 & 1000 & 1000 & 1000 & 1000 & 1000 & 1000 & 1000 & 1000 & 1000 & 1000 & 100 \\
\hline 13 & 3. & 0 & 7 & 7 & 8 & 1000 & 1000 & 1000 & 1000 & 1000 & 1000 & 1000 & 1000 & 1000 & 1000 & 100 \\
\hline & 3. & 0 & 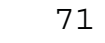 & & 8 & 1000 & 1000 & 1000 & 1000 & 1000 & 1000 & 1000 & 1000 & 1000 & 1000 & 100 \\
\hline 15 & $0 \mathrm{E}-02$ & 0 & 71 & 76 & 818 & 1000 & 1000 & 1000 & 1000 & 1000 & 1000 & 1000 & 1000 & 1000 & 1000 & 100 \\
\hline
\end{tabular}

Relative uncertainty (relative standard deviation) and correlation (normalized to 1000) for nubar for $242 \mathrm{mAm}$

\begin{tabular}{|c|c|c|c|c|c|c|c|c|c|c|c|c|c|c|c|c|}
\hline & & & & & & & & & & & & & & & & \\
\hline 1 & $1.0428 E-01$ & 1000 & 581 & 531 & 358 & 288 & 288 & 288 & 288 & 288 & 288 & 288 & 288 & 288 & 288 & 288 \\
\hline 2 & $9.1295 E-03$ & 581 & 1000 & 998 & 968 & 946 & 946 & 946 & 946 & 946 & 946 & 946 & 946 & 946 & 946 & \\
\hline 3 & $6.6162 E-03$ & 531 & 998 & 1000 & 981 & 964 & 964 & 964 & 964 & 964 & 964 & 964 & 964 & 964 & 964 & \\
\hline 4 & $6.8430 E-03$ & 358 & 968 & 981 & 1000 & 997 & 997 & 997 & 997 & 997 & 997 & 997 & 997 & 997 & 996 & \\
\hline 5 & $6.9995 E-03$ & 288 & 946 & 964 & 997 & 1000 & 1000 & 1000 & 1000 & 1000 & 1000 & 1000 & 1000 & 1000 & 999 & \\
\hline 6 & $6.9995 E-03$ & 288 & 946 & 964 & 997 & 1000 & 1000 & 1000 & 1000 & 1000 & 1000 & 1000 & 1000 & 1000 & 999 & 99 \\
\hline 7 & $6.9995 E-03$ & 288 & 946 & 964 & 997 & 1000 & 1000 & 1000 & 1000 & 1000 & 1000 & 1000 & 1000 & 1000 & 999 & 9 \\
\hline 8 & $6.9995 E-03$ & 288 & 946 & 964 & 997 & 1000 & 1000 & 1000 & 1000 & 1000 & 1000 & 1000 & 1000 & 1000 & 999 & 9. \\
\hline 9 & $6.9995 E-03$ & 288 & 946 & 964 & 997 & 1000 & 1000 & 1000 & 1000 & 1000 & 1000 & 1000 & 1000 & 1000 & 999 & 99 \\
\hline
\end{tabular}




$\begin{array}{ll}10 & 6.9995 E-03 \\ 11 & 6.9995 E-03 \\ 12 & 6.9995 E-03 \\ 13 & 6.9965 E-03 \\ 14 & 6.9995 E-03 \\ 15 & 6.9995 E-03\end{array}$

$\begin{array}{lll}288 & 946 & 964 \\ 288 & 946 & 964 \\ 288 & 946 & 964 \\ 288 & 946 & 964 \\ 288 & 946 & 964 \\ 288 & 946 & 964\end{array}$

$9971000100010001000 \quad 1000 \quad 1000 \quad 1000 \quad 10001000$ $997100010001000100010001000 \quad 1000 \quad 10001000$ 997100010001000100010001000100010001000 999999 999999

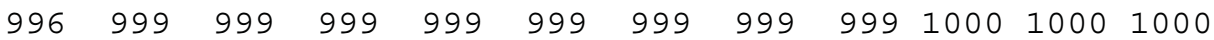

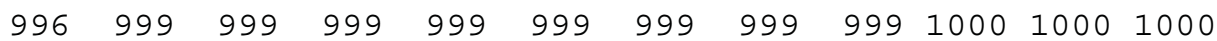

Relative uncertainty (relative standard deviation) and correlation (normalized to 1000) for nubar for $243 \mathrm{Am}$

\begin{tabular}{|c|c|c|c|c|c|c|c|c|c|c|c|c|c|c|c|c|}
\hline & & & & & & & & & & & & & & & & \\
\hline 1 & $1.8823 \mathrm{E}-02$ & 1000 & 132 & 27 & 0 & 0 & 0 & 0 & 0 & 0 & 0 & 0 & 0 & 0 & 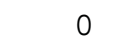 & \\
\hline 2 & $1.9772 \mathrm{E}-02$ & 132 & 1000 & 511 & 197 & 71 & 71 & 71 & 71 & 71 & 71 & 71 & 71 & 71 & 71 & \\
\hline 3 & $1.9067 \mathrm{E}-02$ & 27 & 511 & 1000 & 605 & 76 & 76 & 76 & 76 & 76 & 76 & 76 & 76 & 76 & 76 & \\
\hline 4 & $1.0880 \mathrm{E}-02$ & 0 & 197 & 605 & 1000 & 818 & 818 & 818 & 818 & 818 & 818 & 818 & 818 & 818 & 818 & 8 \\
\hline 5 & 1.2 & 0 & 71 & 76 & 818 & 1000 & 000 & 1000 & boo & 1000 & 00 & 1000 & 00 & 000 & 00 & 100 \\
\hline 6 & 1.2 & 0 & 71 & 76 & 818 & 1000 & 000 & 1000 & 1000 & 1000 & 1000 & 1000 & 00 & 00 & 00 & $0 c$ \\
\hline 7 & $1.2000 \mathrm{E}-02$ & 0 & 71 & 76 & 818 & 1000 & 1000 & 1000 & 1000 & 1000 & 1000 & 1000 & 1000 & 1000 & 1000 & 100 \\
\hline 8 & $1.2000 \mathrm{E}-02$ & 0 & 71 & 76 & 818 & 1000 & 1000 & 1000 & 1000 & 1000 & 1000 & 1000 & 1000 & 1000 & 1000 & 100 \\
\hline 9 & 1.2000 & 0 & 71 & 76 & 818 & 1000 & 1000 & 1000 & 1000 & 1000 & 1000 & 1000 & 1000 & 1000 & 1000 & 100 \\
\hline & 1.2 & 0 & 1 & 76 & 818 & 1000 & 1000 & 1000 & 1000 & 1000 & 1000 & 1000 & 1000 & 1000 & 1000 & 100 \\
\hline 1 & 1.2 & 0 & 71 & 76 & 818 & 1000 & 1000 & 1000 & 1000 & 1000 & 1000 & 1000 & 1000 & 1000 & 1000 & 100 \\
\hline 12 & $1.2000 \mathrm{E}-02$ & 0 & 71 & 76 & 818 & 1000 & 1000 & 1000 & 1000 & 1000 & 1000 & 1000 & 1000 & 1000 & 1000 & 100 \\
\hline 13 & $1.2000 \mathrm{E}-02$ & 0 & 71 & 76 & 818 & 1000 & 1000 & 1000 & 1000 & 1000 & 1000 & 1000 & 1000 & 1000 & 1000 & 100 \\
\hline 14 & $1.2000 \mathrm{E}-02$ & 0 & 71 & 76 & 818 & 1000 & 1000 & 1000 & 1000 & 1000 & 1000 & 1000 & 1000 & 1000 & 1000 & 100 \\
\hline 15 & $1.2000 \mathrm{E}-02$ & 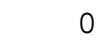 & 71 & 76 & 818 & 1000 & 1000 & 1000 & 1000 & 1000 & 1000 & 1000 & 1000 & 1000 & 1000 & 100 \\
\hline
\end{tabular}

Relative uncertainty (relative standard deviation) and correlation (normalized to 1000) for nubar for $242 \mathrm{Cm}$

\begin{tabular}{|c|c|c|c|c|c|c|c|c|c|c|c|c|c|c|c|c|}
\hline 1 & $.1000 \mathrm{E}-01$ & 000 & 132 & 27 & 0 & 0 & 0 & 0 & 0 & 0 & 0 & 0 & 0 & 0 & 0 & \\
\hline 2 & $.1500 \mathrm{E}-01$ & 132 & 1000 & 511 & 197 & 71 & 71 & 71 & 71 & 71 & 71 & 71 & 71 & 71 & 71 & \\
\hline 3 & $.1000 \mathrm{E}-01$ & 27 & 511 & 1000 & 605 & 76 & 76 & 76 & 76 & 76 & 76 & 76 & 76 & 76 & 76 & \\
\hline 4 & $1.0000 \mathrm{E}-01$ & 0 & 197 & 605 & 1000 & 818 & 818 & 818 & 818 & 818 & 818 & 818 & 818 & 818 & 818 & 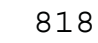 \\
\hline 5 & $1.0000 \mathrm{E}-01$ & 0 & 71 & 76 & 818 & 1000 & 1000 & 1000 & 1000 & 1000 & 1000 & 1000 & 1000 & 1000 & 1000 & 100 \\
\hline 6 & $1.0000 \mathrm{E}-01$ & 0 & 71 & 76 & 818 & 1000 & 1000 & 1000 & 1000 & 1000 & 1000 & 1000 & 1000 & 1000 & 1000 & 100 \\
\hline 7 & 1.0 & 0 & 71 & 76 & 818 & 1000 & 1000 & 1000 & 1000 & 000 & 1000 & 000 & 1000 & 000 & 00 & .00 \\
\hline 8 & 1.0 & 0 & 71 & 7 & 818 & 1000 & 1000 & 1000 & 1000 & 1000 & 1000 & 1000 & 1000 & 1000 & 1000 & 100 \\
\hline 9 & 1.0 & 0 & 7 & 7 & 818 & 1000 & 1000 & 1000 & 1000 & 1000 & 1000 & 1000 & 1000 & 1000 & 1000 & 100 \\
\hline 10 & $1.0000 \mathrm{E}-01$ & . & 71 & 76 & 818 & 1000 & 1000 & 1000 & 1000 & 1000 & 1000 & 1000 & 1000 & 1000 & 1000 & 100 \\
\hline 11 & $1.0000 \mathrm{E}-01$ & 0 & 71 & 76 & 818 & 1000 & 1000 & 1000 & 1000 & 1000 & 1000 & 1000 & 1000 & 1000 & 1000 & 100 \\
\hline 12 & $1.0000 \mathrm{E}-01$ & 0 & 71 & 76 & 818 & 1000 & 1000 & 1000 & 1000 & 1000 & 1000 & 1000 & 1000 & 1000 & 1000 & 100 \\
\hline 13 & 1.000 & 0 & 71 & 7 & 818 & 1000 & 1000 & 1000 & 1000 & 1000 & 1000 & 1000 & 1000 & 1000 & 1000 & 100 \\
\hline 1 & .0 & 0 & $7 \perp$ & 7 & 818 & 1000 & 1000 & 1000 & 1000 & 1000 & 1000 & 1000 & 1000 & 1000 & 1000 & 100 \\
\hline 13 & $1.0000 \mathrm{E}-01$ & 0 & 71 & 76 & 818 & 1000 & 1000 & 1000 & 1000 & 1000 & 1000 & 1000 & 1000 & 1000 & 1000 & .04 \\
\hline
\end{tabular}

Relative uncertainty (relative standard deviation) and correlation (normalized to 1000) for nubar for $243 \mathrm{Cm}$

\begin{tabular}{|c|c|c|c|c|c|c|c|c|c|c|c|c|c|c|c|c|}
\hline & & & & & & & & & & & & & & & & \\
\hline 1 & $9.6361 \mathrm{E}-02$ & 1000 & 581 & 531 & 358 & 288 & 288 & 288 & 288 & 288 & 288 & 288 & 288 & 288 & 288 & 2 \\
\hline 2 & $1.4075 \mathrm{E}-02$ & 581 & 1000 & 998 & 968 & 946 & 946 & 946 & 946 & 946 & 946 & 946 & 946 & 946 & 946 & \\
\hline 3 & $1.2378 \mathrm{E}-02$ & 531 & 998 & 1000 & 981 & 964 & 964 & 964 & 964 & 964 & 964 & 964 & 964 & 964 & 964 & \\
\hline 4 & $1.2802 \mathrm{E}-02$ & 358 & 968 & 981 & 1000 & 997 & 997 & 997 & 997 & 997 & 997 & 997 & 997 & 997 & 996 & \\
\hline 5 & $1.3095 E-02$ & 288 & 946 & 964 & 997 & 1000 & 1000 & 1000 & 1000 & 1000 & 1000 & 1000 & 1000 & 1000 & 999 & \\
\hline 6 & $1.3095 E-02$ & 288 & 946 & 964 & 997 & 1000 & 1000 & 1000 & 1000 & 1000 & 1000 & 1000 & 1000 & 1000 & 999 & \\
\hline 7 & $1.3095 E-02$ & 288 & 946 & 964 & 997 & 1000 & 1000 & 1000 & 1000 & 1000 & 1000 & 1000 & 1000 & 1000 & 999 & \\
\hline 8 & $1.3095 E-02$ & 288 & 946 & 964 & 997 & 1000 & 1000 & 1000 & 1000 & 1000 & 1000 & 1000 & 1000 & 1000 & 999 & \\
\hline 9 & $1.3095 E-02$ & 288 & 946 & 964 & 997 & 1000 & 1000 & 1000 & 1000 & 1000 & 1000 & 1000 & 1000 & 1000 & 999 & \\
\hline
\end{tabular}




\begin{tabular}{|c|c|c|c|c|c|c|c|c|c|c|c|c|c|c|c|}
\hline 1.3095E-02 & 288 & 946 & 964 & 997 & 1000 & 1000 & 1000 & 1000 & 1000 & 1000 & 1000 & 1000 & 1000 & 999 & 999 \\
\hline 1.3095E-02 & 288 & 946 & 964 & 997 & 1000 & 1000 & 1000 & 1000 & 1000 & 1000 & 1000 & 1000 & 1000 & 999 & 999 \\
\hline 1.3095E-02 & 88 & 946 & 64 & 997 & 1000 & 1000 & 1000 & 000 & 1000 & 1000 & 1000 & 000 & 1000 & 99 & ( \\
\hline $1.3089 E-02$ & 88 & 946 & 964 & 997 & 1000 & 1000 & 1000 & 1000 & 1000 & 1000 & 1000 & 1000 & 1000 & 000 & \\
\hline $1.3095 E-02$ & 288 & 946 & 964 & 996 & 99 & 999 & 999 & 999 & 999 & 999 & 999 & 999 & 1000 & 1000 & \\
\hline 1.3095E-02 & 288 & 946 & 964 & 996 & 999 & 999 & 999 & 999 & 999 & 999 & 999 & 999 & 1000 & 1000 & 000 \\
\hline
\end{tabular}

Relative uncertainty (relative standard deviation) and correlation (normalized to 1000) for nubar for $244 \mathrm{Cm}$

\begin{tabular}{|c|c|c|c|c|c|c|c|c|c|c|c|c|c|c|c|c|}
\hline & & & & & & & & & & & & & & & & \\
\hline 1 & $1.1000 \mathrm{E}-01$ & 1000 & 132 & 27 & 0 & 0 & 0 & 0 & 0 & 0 & 0 & 0 & 0 & 0 & 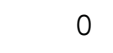 & \\
\hline 2 & $1.2000 \mathrm{E}-01$ & 132 & 1000 & 511 & 197 & 71 & 71 & 71 & 71 & 71 & 71 & 71 & 71 & 71 & 71 & \\
\hline 3 & $1.0000 \mathrm{E}-01$ & 27 & 511 & 1000 & 605 & 76 & 76 & 76 & 76 & 76 & 76 & 76 & 76 & 76 & 76 & \\
\hline 4 & $1.0000 \mathrm{E}-01$ & 0 & 197 & 605 & 1000 & 818 & 818 & 818 & 818 & 818 & 818 & 818 & 818 & 818 & 818 & 8 \\
\hline 5 & 1.0 & 0 & 71 & 76 & 818 & 1000 & 000 & 1000 & 000 & 1000 & 00 & 1000 & 00 & 000 & 00 & 100 \\
\hline 6 & 1.0 & 0 & 71 & 76 & 818 & 1000 & 000 & 1000 & 1000 & 1000 & 1000 & 1000 & 00 & 1000 & 00 & $0 c$ \\
\hline 7 & $1.0000 \mathrm{E}-01$ & 0 & 71 & 76 & 818 & 1000 & 1000 & 1000 & 1000 & 1000 & 1000 & 1000 & 1000 & 1000 & 1000 & 100 \\
\hline 8 & $1.0000 \mathrm{E}-01$ & 0 & 71 & 76 & 818 & 1000 & 1000 & 1000 & 1000 & 1000 & 1000 & 1000 & 1000 & 1000 & 1000 & 100 \\
\hline 9 & 1.0 & 0 & 71 & 76 & 818 & 1000 & 1000 & 1000 & 1000 & 1000 & 1000 & 1000 & 1000 & 1000 & 1000 & 100 \\
\hline & 1 & 0 & 77 & 76 & 818 & 1000 & 1000 & 1000 & 1000 & 1000 & 1000 & 1000 & 1000 & 1000 & 1000 & 100 \\
\hline 7 & 1.0 & 0 & 71 & 76 & 818 & 1000 & 1000 & 1000 & 1000 & 1000 & 1000 & 1000 & 1000 & 1000 & 1000 & 100 \\
\hline 12 & 1.0 & 0 & 71 & 76 & 818 & 1000 & 1000 & 1000 & 1000 & 1000 & 1000 & 1000 & 1000 & 1000 & 1000 & 100 \\
\hline 13 & $1.0000 \mathrm{E}-01$ & 0 & 71 & 76 & 818 & 1000 & 1000 & 1000 & 1000 & 1000 & 1000 & 1000 & 1000 & 1000 & 1000 & 100 \\
\hline 14 & $1.0000 \mathrm{E}-01$ & 0 & 71 & 76 & 818 & 1000 & 1000 & 1000 & 1000 & 1000 & 1000 & 1000 & 1000 & 1000 & 1000 & 100 \\
\hline 15 & $1.0000 \mathrm{E}-01$ & 0 & 71 & 76 & 818 & 1000 & 1000 & 1000 & 1000 & 1000 & 1000 & 1000 & 1000 & 1000 & 1000 & 100 \\
\hline
\end{tabular}

Relative uncertainty (relative standard deviation) and correlation (normalized to 1000) for nubar for $245 \mathrm{Cm}$

\begin{tabular}{|c|c|c|c|c|c|c|c|c|c|c|c|c|c|c|c|c|}
\hline & & & & & & & & & & & & & & & & \\
\hline 1 & $.6361 \mathrm{E}-02$ & 1000 & 581 & 531 & 358 & 288 & 288 & 288 & 288 & 288 & 288 & 288 & 288 & 288 & 288 & \\
\hline 2 & $9088 \mathrm{E}-02$ & 581 & 1000 & 998 & 968 & 946 & 946 & 946 & 946 & 946 & 946 & 946 & 946 & 946 & 6 & \\
\hline 3 & $8496 \mathrm{E}-02$ & 531 & 998 & 000 & 981 & 964 & 64 & 964 & 964 & 964 & 4 & 964 & 4 & 64 & & \\
\hline 4 & $9473 E-02$ & 358 & 968 & 981 & 1000 & 997 & 997 & 997 & 997 & 997 & 997 & 997 & 997 & 997 & & \\
\hline 5 & -02 & 288 & 946 & 964 & 997 & .000 & 1000 & .000 & 1000 & .000 & 1000 & .000 & 1000 & 000 & 9 & \\
\hline 6 & 3.0 & 288 & 946 & 964 & 997 & 000 & 1000 & 000 & 1000 & 000 & 1000 & .000 & 1000 & .000 & & \\
\hline 7 & 3.0 & 88 & 946 & 64 & 997 & 000 & 1000 & 000 & 1000 & 00 & 1000 & & 00 & 00 & 9 & \\
\hline 8 & 3.0 & 38 & 9 & 964 & 997 & D०० & 1000 & 000 & 1000 & 1000 & 1000 & 1000 & 1000 & 1000 & 9 & \\
\hline 9 & 3.0 & 88 & 94 & 964 & 997 & 1000 & 1000 & 1000 & 1000 & 1000 & 1000 & 1000 & 1000 & 1000 & 9 & \\
\hline 0 & $E-02$ & 88 & 4 & 64 & 997 & 1000 & 1000 & 1000 & 1000 & 1000 & 1000 & 1000 & 1000 & 1000 & 9 & \\
\hline & -02 & 88 & 946 & 64 & 97 & 1000 & 1000 & 1000 & 1000 & 1000 & 1000 & 1000 & 1000 & 1000 & 9 & \\
\hline 2 & $3.0147 E-02$ & 288 & 946 & 964 & 997 & 1000 & 1000 & 1000 & 1000 & 1000 & 1000 & 1000 & 1000 & 1000 & 999 & \\
\hline 13 & 3.0 & 288 & 946 & 64 & 997 & 1000 & 1000 & 1000 & 1000 & 1000 & 1000 & 1000 & 1000 & 1000 & 000 & 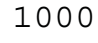 \\
\hline.+ & $\Xi-02$ & 288 & 946 & 64 & 996 & 999 & 999 & 999 & 999 & 999 & 999 & 999 & 999 & 1000 & o 0 & \\
\hline 15 & $3.0147 \mathrm{E}-02$ & 288 & 946 & 64 & 996 & 999 & 999 & 999 & 999 & 999 & 999 & 999 & 999 & 1000 & 1000 & \\
\hline
\end{tabular}

